\title{
Collected Papers
}

\section{in Avian Paleontology \\ Honoring the 90th Birthday of Alexander Wetmore}




\title{
SERIAL PUBLIGATIONS OF THE SMITHSONIAN INSTITUTION
}

The emphasis upon publications as a means of diffusing knowledge was expressed by the first Secretary of the Smithsonian Institution. In his formal plan for the Institution, Joseph Henry articulated a program that included the following statement: "It is proposed to publish a series of reports, giving an account of the new discoveries in science, and of the changes made from year to year in all branches of knowledge." This keynote of basic research has been adhered to over the years in the issuance of thousands of titles in serial publications under the Smithsonian imprint, commencing with Smithsonian Contributions to Knowledge in 1848 and continuing with the following active series:

\author{
Smithsonian Annals of Flight \\ Smithsonian Contributions to Anthropology \\ Smithsonian Contributions to Astrophysics \\ Smithsonian Contributions to Botany \\ Smithsonian Contributions to the Earth Sciences \\ Smithsonian Contributions to Paleobiology \\ Smithsonian Contributions to Zoology \\ Smithsonian Studies in History and Technology
}

In these series, the Institution publishes original articles and monographs dealing with the research and collections of its several museums and offices and of professional colleagues at other institutions of learning. These papers report newly acquired facts, synoptic interpretations of data, or original theory in specialized fields. These publications are distributed by mailing lists to libraries, laboratories, and other interested institutions and specialists throughout the world. Individual copies may be obtained from the Smithsonian Institution Press as long as stocks are available.

S. Dillon Ripley

Secretary

Smithsonian Institution 


\title{
Collected Papers in Avian Paleontology \\ Honoring the 90th Birthday of Alexander Wetmore
}

\author{
Storrs L. Olson \\ EDITOR
}

ISSUED

IAAY 211976

SMITHSONIAN INSTITUTION PRESS

City of Washington

1976 
Olson, Storrs L., editor. Collected Papers in Avian Paleontology Honoring the 90th Birthday of Alexander Wetmore. Smithsonian Contributions to Paleobiology, number 27, 211 pages, 91 figures, 38 tables, 1976.-Eighteen papers covering diverse aspects of avian paleontology-from the earliest known bird to extinct species found in Indian middens-are collected here to honor the 90 th birthday of Alexander Wetmore. These are preceded by an appraisal of the current state of avian paleontology and of Alexander Wetmore's influence on it, including a bibliography of his publications in this field. John H. Ostrom analyzes the hypothetical steps in the origin of flight between Archaeopteryx and modern birds. Philip D. Gingerich confirms that Ichthyornis and Hesperornis did indeed bear teeth, that the palate in Hesperornis is paleognathous, and that these Cretaceous toothed birds appear to occupy a position intermediate between dinosaurs and modern birds. Larry D. Martin and James Tate, Jr. describe the skeleton of the Cretaceous diving bird Baptornis advenus and conclude that the Baptornithidae belong in the Hesperornithiformes, but are less specialized than Hesperornis. Pierce Brodkorb describes the first known Cretaceous land bird as forming a new order possibly ancestral to the Coraciiformes and Piciformes. E. N. Kurochkin summarizes the distribution and paleoecology of the Paleogene birds of Asia, with particular emphasis on the evolution of the gruiform families Eogruidae and Ergilornithidae. Pat Vickers Rich and David J. Bohaska describe the earliest known owl from Paleocene deposits in Colorado. Alan Feduccia transfers the Eocene genus Neanis from the Passeriformes to the Piciformes and he and Larry D. Martin go on to refer this and four other genera to a new family of Piciformes, concluding that these were the dominant perching land birds of the Eocene of North America. Storrs L. Olson describes a new species of Todidae from the Oligocene of Wyoming and refers the genus Protornis from the Oligocene of Switzerland to the Momotidae, concluding that the New World Coraciiformes originated in the Old World. Charles T. Collins describes two new species of the Eo-Oligocene genus Aegialornis and presents evidence that the Aegialornithidae should be referred to the Caprimulgiformes rather than to the Apodiformes, although they might be ancestral to the swifts. In the following paper he shows that the earliest known true swifts (Apodidae) are three nominal forms from the Lower Miocene of France which prove to be but a single species of Cypseloides, a modern genus belonging to a primitive subfamily now restricted to the New World. Stuart L. Warter describes a new osprey from the Miocene of California to provide the earliest certain occurrence of the family Pandionidae and he treats functional aspects of the evolution of the wing in Pandion. Hildegarde Howard describes a new species of flightless mancalline auk, also from the Miocene of California, which is temporally and morphologically intermediate between Praemancalla lagunensis and the species of Mancalla. Robert W. Storer analyzes Pleistocene fossils of pied-billed grebes, synonymizing Podilymbus magnus Shufeldt with modern $P$. podiceps and describing a new species from peninsular Florida. Kenneth E. Campbell, Jr., lists 53 species of birds, including new species of Buteo and Oreopholus, from a Pleistocene deposit in southwestern Ecuador and compares this with a fauna of similar age from northwestern Peru, both of which indicate more humid conditions in the past. Oscar Arredondo summarizes aspects of the morphology, evolution, and ecology of the gigantic owls, eagles, and vultures recently discovered in Pleistocene deposits in Cuba. Joel Cracraft analyzes variation in the moas of New Zealand, reduces the number of species recognized to 13 , and suggests that several "species pairs" represent examples of sexual size dimorphism. G. Victor Morejohn reports remains of the extinct flightless duck Chendytes lawi, previously known only from Pleistocene deposits, from Indian middens in northern California and concludes that the species became extinct through human agency less than 3800 years ago.

Official pUblication dATE is handstamped in a limited number of initial copies and is recorded in the Institution's annual report, Smithsonian Year. SI Press Number 6137. Series Cover Design: The trilobite Phacops rana Green.

Library of Congress Cataloging in Publication Data

Main entry under title:

Collected papers in avian paleontology honoring the 90th birthday of Alexander Wetmore.

(Smithsonian contributions to paleobiology ; no. 27)

Contents: Ostrom, J. H. Some hypothetical anatomical stages in the evolution of avian flight-

Gingerich, P. D. Evolutionary significance of the Mesozoic toothed birds.-Martin, L. D. and

Tate, J., Jr. The skeleton of Baptornis advenus (Aves: Hesperornithiformes). [etc.]

Supt. of Docs. No.: SI 1.30:27

1. Birds, Fossil-Addresses, essays, lectures. I. Wetmore, Alexander, 1886- II. Olson, Storrs L.

III. Series: Smithsonian Institution. Smithsonian contributions to paleobiology ; no. 27.

QE701.S56 no. 27 [QE871] 560'8s [568'.2] 75-619322 


\section{Contents}

Preface

Page
$\mathrm{v}$
vii
$\mathrm{xi}$
$\mathrm{xvii}$
$\mathrm{xxv}$

Some Hypothetical Anatomical Stages in the Evolution of Avian FLIGHT, by John $\mathrm{H}$. Ostrom $\quad \ldots \ldots \ldots \ldots \ldots$

Evolutionary Significance of the Mesozorc Toothed Birds, by Philip

D. Gingerich $\ldots \ldots \quad \ldots \ldots \quad \ldots \ldots \ldots$

The Skeleton of Baptornis advenus (Aves: Hesperornithiformes), by

Larry D. Martin and James Tate, Jr. . . . . . . . . . . . .

Discovery of a Cretaceous Bird, Apparently Ancestral to the Orders

Coracilformes and Piciformes (Aves: Carinatae), by Pierce Brodkorb

A Survey of the Paleogene Birds of Asia, by E. N. Kurochkin

The World's Oldest Owl: A New Strigiform from the Paleocene of

Southwestern Colorado, by Pat Vickers Rich and David J. Bohaska

Neanis schucherti Restudied: Another Eocene Piciform Bird, by Alan

Feduccia $\ldots \ldots \quad \ldots \ldots \ldots \ldots \ldots \ldots \ldots$

The Eocene Zygodactyl Birds of North America (Aves: Piciformes),

by Alan Feduccia and Larry D. Martin .... .... ...

Oligocene fossils Bearing on the Origins of the Todidae and the

Momotidae (Aves: Coracilformes), by Storrs L. Olson ... ...

Two New Species of Aegialornis from France, with Comments on the

Ordinal Affinities of the Aegialornithidae, by Charles T. Collins

A Review of the Lower Miocene Swifts (Aves: Apodidae), by Charles

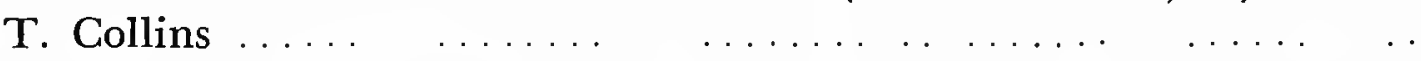

A New Osprey from the Mrocene of California (Falconiformes: Pandionidae), by Stuart L. Warter .... . . . . . . . .

A New Species of Fuightless Auk from the Miocene of California (Alcidae: Mancallinae), by Hildegarde Howard .........

The Pleistocene Pied-billed Grebes (Aves: Podicipedidae), by Robert W. Storer

The Late Pleistocene Avifauna of La Carolina, Southwestern

ECUADOR, by Kenneth E. Campbell, Jr.

The Great Predatory Birds of the Pleistocene of Cuba, by Oscar Arredondo, translated and amended by Storrs L. Olson ....... 169

The Species of Moas (Aves: Dinornithidae), by Joel Cracraft . . . . . . 189

Evidence of the Survival to Recent Times of the Extinct Flightless Duck Chendytes lawi Miller, by G. Victor Morejohn 



\section{Preface}

Had contributions for this volume been sought from the associates and friends of Alexander Wetmore in all fields of ornithology, their number would have been much too great to permit the timely appearance of this festschrift, for the endeavor was conceived barely in time for its proper execution. It was decided, therefore, to limit the scope of this work to avian paleontology-a study which has been particularly dear to Alex Wetmore for three score years. That this collection could be assembled and set before the press in less than a year is a tribute not only to the eagerness of the contributors to honor their esteemed colleague in his 90 th year, but also to the fact that there is currently an extensive and active interest in the study of fossil birds-a fact that must be particularly gratifying to Dr. Wetmore, who for so many years strived to keep such an interest alive. The editor is particularly indebted to Dorsey Dunn and Joanne Williams, who typed and retyped manuscripts with great patience and care, and Anne Curtis, who assisted in preparing numerous illustrations. He also wishes to express his appreciation for the fine cooperation of the contributors; their combined efforts have here produced what is certain to be a landmark in paleornithology. 


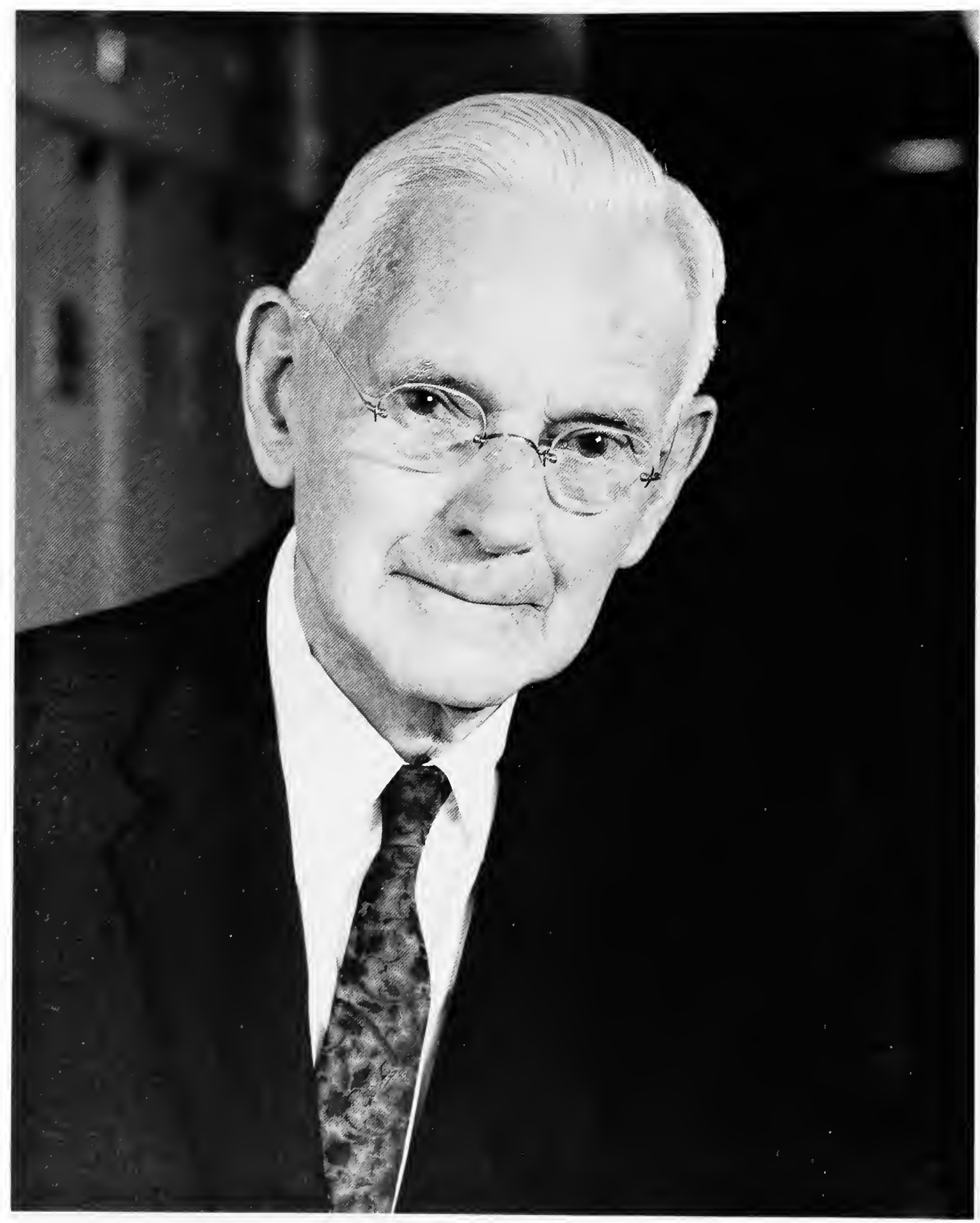

Alexander Wetmore 


\title{
Appreciations
}

\author{
S. Dillon Ripley \\ SECRETARY, \\ SMITHSONIAN INSTITUTION
}

Alexander Wetmore is so familiar a figure to scientists as the dean of American ornithology that it is difficult to realize that he has been directly associated with the Smithsonian Institution as an administrator since 1924. His first responsibilities were in connection with the National Zoological Park, of which he became Superintendent in 1924. Subsequently, Dr. Wetmore became Assistant Secretary for Science of the Institution and Director of the Museum of Natural History in 1925, and continued as Assistant Secretary until 1945, when he was elected by the Regents to serve as the sixth Secretary, succeeding Dr. Charles G. Abbot, who retired in that year.

Throughout this period, and after his own retirement from administrative responsibilities in 1952, Dr. Wetmore has continued an extraordinarily active career in ornithology. In addition to his many duties with the Smithsonian, he also served as Home Secretary of the National Academy of Sciences from 1951 to 1955 and has been for many years a Trustee and Vice-Chairman of the Research Committee of the National Geographic Society.

Throughout this career his publications on birds have continued in depth and in great volume. Following his retirement he has continued his monographic studies on the birds of Panama, which have culminated in the publication of three volumes of "The Birds of the Republic of Panama" (Smithsonian Miscellaneous Collections, volume 150), with a fourth part in preparation. Even now, Dr. Wetmore's work is not completed and he continues to be a productive scientist in the laboratory of the Division of Birds.

In addition to the many research publications on fossil material specializing in birds, Dr. Wetmore is known today as one of the most outstanding systematic specialists. His renowned arrangement of the sequence of higher taxa of birds, "A Classification for the Birds of the World" (Smithsonian Miscellaneous Collections, $139(11): 1-37,1960)$, still stands virtually unchallenged. $\mathrm{He}$ is a winner of the Brewster Medal of the American Ornithologists' Union, and recently, in May 1975, of the Hubbard Medal of the National Geographic Society.

The amount of materials contributed by him to the collections of the National Museum is monumental. Indeed, present-day ornithologists would be staggered to think of the production of research and study material deposited by Dr. Wetmore in the National Collection: some 26,058 skins from North America, Puerto Rico, Hispaniola, the Hawaiian Islands, Uruguay, Paraguay, Argentina, Chile, Venezuela, and Central America, with more than half, some 14,291, from Panama alone. Of skeletal and anatomical specimens, Dr. Wetmore has prepared and contributed 4363, an enormously important increment to the anatomy collections in Washington. The majority of these are from North America and Puerto Rico, but nearly 1000 are from Central and South America and 540 from Panama 
alone. Of eggs, Dr. Wetmore has collected 201 clutches from North, Central, and South America. In this day and age when the collecting of birds has become markedly diminished due to the general knowledge of specimens in existing museums, as well as the varying directions taken in present-day studies in environment and ecology which tend to preclude such collecting, Dr. Wetmore's collections seem large in retrospect; but they form part of the fundamental resource on which present and future work will depend. The very magnitude of these collections would tend to make further collecting in most areas where he has worked superfluous. So today the specialist in taxonomic studies can be grateful for the efforts of meticulous collectors such as Dr. Wetmore, whose work has laid out in depth representative material. Thus, only highly specific additional collecting need be done in the future in areas where Wetmore's work has given us the foundation of our knowledge.

The number of species and subspecies described by Dr. Wetmore is equally impressive. Over the years since 1914 he has described as new to science some 189 species and subspecies of recent birds. Many of these, in fact most, are from Central and northern South America, but much of Dr. Wetmore's most significant early field work was done in the Caribbean, particularly in Puerto Rico, Hispaniola, and adjacent islands in the Greater Antilles. In addition, through the initiative of the late Dr. Casey Wood, Wetmore worked on and described a number of species from the Fiji Islands, as well as forms from other islands of the Pacific. His monographic revisions of a number of species of northern Central and North American birds, as well as Argentinian and southern South American birds, have produced many novelties for science. A great deal of his work was done in revising the avifauna of Venezuela with the late W. H. Phelps, Sr., with whom he co-authored a number of new species and subspecies.

At least one of Dr. Wetmore's discoveries, the population of Chilean Pintail found in the vicinity of Bogotá, Colombia, has subsequently gone extinct, due presumably to hunting pressure. Many of the environments in which he worked in Colombia and adjacent parts of northern South America are already so radically changed that one wonders whether additional forms may not have gone extinct as well. It is a sadness of our time that the development of tropical regions of the world, with the consequent destruction of forests and unique habitats, particularly in South and Central America, has been so rapid that many forms of the accompanying avifauna may never be seen again in life. In a spirit of prescience, Alexander Wetmore was an early supporter of the Pan-American Section of the International Council for Bird Preservation, having joined T. Gilbert Pearson, Robert Cushman Murphy, Marshall McLean, William Vogt, and Hoyes Lloyd in helping to set up the original organization with Latin American colleagues.

Many of his admirers have named numbers of new birds after our beloved former Secretary, among them a long-billed rail of the Venezuelan coast, Rallus wetmorei, which I have recently considered in my own ornithological work. Including Rallus wetmorei, some 16 modern species and subspecies of birds have been named in honor of Alexander Wetmore, as well as 4 mammals, 7 reptiles and amphibians, 2 fishes, 9 insects, 5 molluscs, a sponge, a cactus, a glacier, and a canopy bridge in the Bayano River forest in Panama. Truly the incessant and intensive zeal which he has single-mindedly given to the study of birds over the years, often at very considerable personal expenditure in time and energy, will mark the career of Alexander Wetmore as one of the most memorable in the entire history of American ornithology. 


\section{Jean Delacour \\ DIRECTOR EMERITUS, \\ NATURAL HISTORY MUSEUM OF LOS ANGELES COUNTY}

I had been corresponding with Alexander Wetmore for several years before I had a chance to meet him. This I did in Washington, D.C., in the spring of 1926. Referring to a visit I made to the National Zoological Park at that time, I wrote as follows:

.. . the National Zoological Park is managed by the Assistant Secretary of the Smithsonian Institution, Dr. Alexander Wetmore, one of the youngest and most accomplished naturalists in the United States. Notwithstanding his heavy administrative obligations, Dr. Wetmore finds enough time for study in descriptive ornithology and technical work, and observations of birds in freedom and in captivity, all with remarkable results. I visited the Zoo under his kind guidance. ... (L'Oiseau, 7(1926):205).

Dr. Wetmore himself published in the same issue of that periodical (pages 324-325), a report of the first breeding in captivity at the National Zoo of the Blue Snow Goose, with several photographic plates. He was, therefore, awarded a special medal by the Société Nationale d'Acclimatation de France. Dr. Wetmore was Director of the National Zoo for two years, and before he exchanged that function for the Assistant Secretaryship he was responsible for choosing as his successor, Dr. William Mann, who was an outstanding Zoo director for many years.

The welcome given me by Dr. Wetmore in 1926 remains vivid in my memory, and my mother and I visited Washington under his cordial and competent guidance. Later on, we had many opportunities of getting together at meetings and congresses, as we have had many interests in common. We met in Europe and in America frequently, working together for bird preservation since the inception of the International Council for Bird Preservation. We saw even more of each other after 1940, when I came to live in the United States.

We are now among the few ornithologists of our generation still alive. We sadly miss many of our old friends, particularly Frank Chapman, Tom Barbour, Robert Cushman Murphy, James Chapin and T. Gilbert Pearson, to list only a few who worked with us on different projects. It is to me a very special comfort to know that Alex still is here, looking and acting and writing much as he always has, and I wish him all the happiness he deserves. As past Secretary of the Smithsonian Institution he joins the ranks of those others who have seemed over the years almost immortal; thus his continuing research for many years seems assured. 



\title{
Alexander Wetmore and the Study of Fossil Birds
}

\author{
Storrs L. Olson
}

In most general discussions of paleontology or ornithology, the subject of fossil birds is almost invariably treated with a predictable uniformity. Mention is made of Archaeopteryx and the Cretaceous toothed birds, and occasionally some of the large Tertiary predators like Diatryma and Phorusrhacos. This is accompanied by a statement explaining that bird bones are fragile and seldom preserved, thus accounting for what is alleged to be a meager and uninformative fossil record for the entire class. Through frequent repetition, this myth has gained such general acceptance that the uninformed find it difficult to conceive of an avian paleontologist being able to find enough to keep himself occupied.

Yet for 60 years Alexander Wetmore has produced a steady stream of papers on fossil birds. With over 150 such entries and nearly as many new fossil taxa to his credit, he can without reservation be said to have contributed more to this field than any other single person. One cannot help but be humbled to think that this is but a fraction of his total scientific output.

Bringing together this collection of papers in avian paleontology to honor Alexander Wetmore's 90th birthday on 18 June 1976 provides not only an opportunity to review his influence on paleornithology over the past six decades, but also offers a chance to begin dispelling the fiction that fossil birds are rare and provide little information on avian evolution.

Wetmore's most intensive work on fossil birds took place in the period after the waning of excitement over the spectacular 19th century discoveries of Mesozoic birds, but before most of the renewed modern interest in avian paleontology had been sparked. For many years Wetmore was virtually the only person anywhere who was engaged in research on fossil birds, with the notable exception of the California school of Loye and Alden Miller and Hildegarde Howard. Thus it was natural that bird fossils from all parts of the United States and from areas of the world as diverse as Inner Mongolia, Java, St. Helena, Hawaii, and Bermuda, passed through Wetmore's hands continually. To this day, the cabinets in his office hold a rich trove of undescribed treasures from a wide array of horizons and localities.

For many years, Wetmore has assiduously maintained an extensive card catalog of references from which he prepared three separate editions of a checklist of fossil birds of North America. He also endeavored to keep his colleagues abreast of current developments in avian paleontology through numerous addresses, lectures, and entertaining synoptic papers-all the while maintaining a consistently high level of production of basic detailed descriptions and diagnoses of new forms.

Wetmore's first paper on fossil birds involved removing the large Miocene bird described by R. W. Shufeldt as Palaeochenoides miocaenus from the Anseriformes to the Pelecaniformes. Shufeldt, whom Wetmore knew well, was in no way 
pleased by this, but Wetmore's action was quite correct. Specimens possibly representing two new species of Palaeochenoides have recently come to the National Museum and it now appears that these may provide a breakthrough in our understanding of these huge, enigmatic scabirds. Wetmore's recognition of the true affinities of Palaeochenoides marked the first step toward this understanding. Shufeldt, it might be noted, was a singular eccentric who, although making many contributions to avian paleontology, repeatedly made serious errors in identification. The process of re-evaluating Shufeldt's taxa, begun by Wetmore and others, has continued up to the present, as seen, for example, in the papers on Eocene Piciformes elsewhere in this volume.

The first new bird Wetmore described from osteological remains was a new genus and species of large flightless rail, Nesotrochis debooyi, found in Indian middens in the Virgin Islands. That such deposits may still be of interest to avian paleontologists is clearly demonstrated by Morejohn in the final paper of the present volume. In recent years two new species of Nesotrochis have been described from Cuba and Hispaniola; despite this, the genus remains so distinctive that there is not yet a good clue as to its affinities within the Rallidae.

Wetmore continued to draw notice to the extinct Pleistocene birds of the West Indies, analyzing fossil avifaunas from Puerto Rico, Haiti, Cuba, and the Bahamas. Among the most notable of his discoveries was the giant barn owl, Tyto ostologa, of Haiti, which he correctly diagnosed from a small fragment of tarsometatarsus. He later described a similar species, $T$. pollens, along with two new large eagles, from the Bahamas. As late as 1959, Brodkorb, in dedicating to him a new fossil species of crow from New Providence Island, remarked that Alexander Wetmore was "responsible for all previous knowledge of fossil birds of the West Indies." Since then, there have been many additional discoveries of avian fossils in the Antilles, the most remarkable of which are certainly the gigantic raptors of Cuba brought to light through the labors of Oscar Arredondo (summarized in this volume). Among the material from the same deposits that yielded Tyto ostologa, a new rail and a new falcon have recently been found. There is every reason to believe that the fossil resources of the Greater Antilles will continue to produce surprises, while as far as avian paleontology is concerned, the Lesser Antilles are terra incognita.

Perhaps the greatest proportion of Wetmore's paleontological efforts concerned the identification and description of Tertiary birds from North America, especially those of the Eocene, Oligocene, and Miocene terrestrial deposits of the western states and the marine Miocene of the cast coast. In these areas he has laid the groundwork for all future researches.

Some of the most exciting recent finds of fossil birds are from the extensive lower Eocene deposits of the Green River Formation, for these often yield complete, articulated skeletons, as for example a particularly fine specimen of primitive frigatebird now under study by the writer. Feduccia and Martin in this volume discuss the significance of the Green River Piciformes, which are now coming to light with remarkable rapidity since Brodkorb's recognition of the first species in 1970. But perhaps the most astonishing of developments in Green River paleornithology are the tremendous deposits of flamingo bones discovered by Paul $O$. McGrew and now under study by him and Alan Feduccia. Here too, Wetmore's past contributions have played a part, for he described this flamingo in 1926 as a new genus of recurvirostrid, Presbyomis. This case of mistaken identity is understandable in view of Feduccia's further investigations, which 
have disclosed some extraordinary similarities between the skeletons of recurvirostrids and flamingos, particularly those of the lower Eocene forms. This is further confirmed by an undescribed flamingo of Bridgerian age in the National Museum which is even more similar to recurvirostrids than is Presbyornis. These discoveries now appear to be leading to a reappraisal of the affinities of both the flamingos and the shorebirds.

Wetmore's several contributions on Eocene owls resulted in his erecting a new family, the Protostrigidae, the importance of which is only now becoming apparent. The fossil record of owls is particularly good and we now know that the order extends back at least as far as the Paleocene (see Rich and Bohaska's paper in this volume). Much unstudied material of fossil owls is to be found in various museums, which, along with the revision of the many forms already known, should provide an especially fruitful area of inquiry for avian paleontologists in the future. Of Wetmore's Eocene birds, perhaps the most provocative is Neocathartes grallator, a long-legged vulture that was based on a nearly complete skeleton.

Wetmore's contributions once provided just about all that was known of the birds from the extensive Oligocene deposits of western North America. These are now producing new and extremely interesting fossil birds almost annually (e.g., Olson's paper in this volume). One of the predominant groups of birds in the North American Oligocene was the gruiform family that Wetmore named the Bathornithidae. Wetmore himself offered more than one interpretation of the possible relationships of this group and Cracraft has recently proposed others. It seems certain that the final word has not been said on this matter, but the importance of the Bathornithidae is undisputed. Once again, it was Wetmore's pioneering work on the group that has made possible all subsequent investigations. It now appears that the Oligocene limpkins (Aramidae) described by Wetmore will soon be augmented by a new genus, known from much of a skeleton collected in Wyoming by Dr. R. J. Emry of the National Museum. Oligocene raptors described by Wetmore include two forms inseparable from the modern genus Buteo, and an intriguing species, Palaeoplancus sternbergi, which was made the type of a new subfamily of Accipitridae.

For Wetmore, some of the most interesting fossil deposits were those closest to home-the Miocene marine beds of the Chesapeake Group. Most of what we know of the birds of these deposits is to be found in Wetmore's publications, including the description of a diminutive gannet, Microsula avita, which is now known to be relatively common in these beds. In the past few years many new specimens, some of them highly significant, have come to the National Museum from this area, although these are as yet undescribed. As abundant as this material is, it is far overshadowed by the tremendous collections of Miocene and Pliocene age that have recently been acquired from a phosphate mine in North Carolina and which this writer has had the privilege of studying in collaboration with Dr. Wetmore. This is probably the largest deposit of Tertiary birds in existence and thousands of fossils of more than 50 species have so far been recovered. These collections, along with those from Bone Valley, Florida, being studied by Brodkorb, and those from the Pacific coast, which are constantly productive (see the contributions by Howard and Warter in this volume), provide a solid basis for making unprecedented gains in our knowledge of evolution in the Alcidae, Procellariidae, Diomedeidae, Gaviidae, Sulidae, Phalacrocoracidae, and other families of marine birds. 


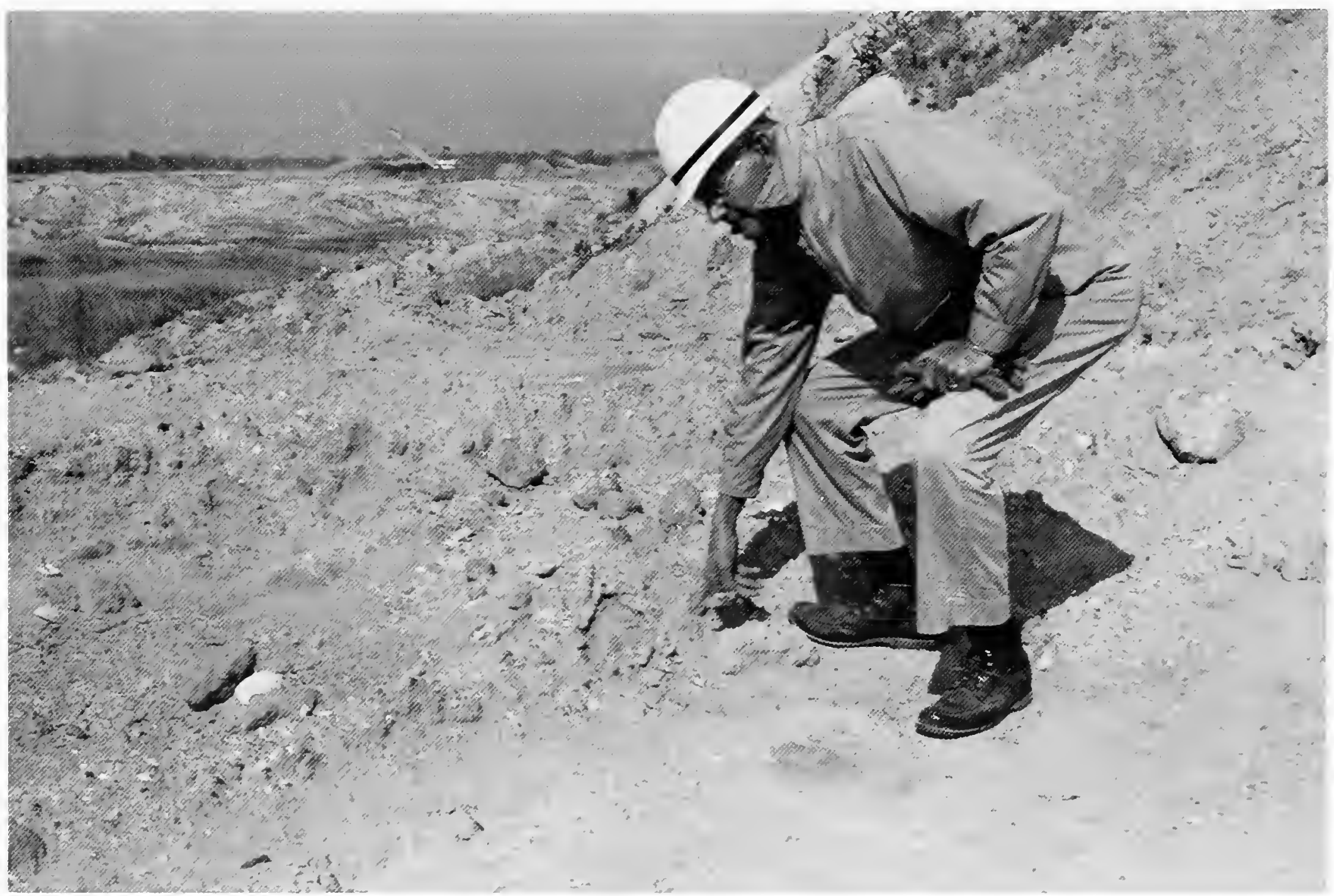

Dr. Wetmore on a Smithsonian collecting trip to the Lee Creek phosphate mine, Aurora, North Carolina, 26 April 1972.

In 1931, Wetmore published a large paper on the Pleistocene avifauna of Florida in which it was shown that several birds, such as the California condor and the huge vulture Teratornis, then known only from the west, particularly from the tarpits at Rancho la Brea, were also present in Florida. This opened up a very fertile area of investigation and in succeeding years the studies of Brodkorb and others have continued to be a source of new information on the rich Pleistocene avifauna of Florida (e.g., Storer's paper herein). In his many years of involvement in paleornithology, Wetmore has repeatedly been called upon to identify material from Pleistocene caves and from Indian middens, a task which as often as not holds few rewards but which nevertheless he pursued with alacrity. From such studies he published numerous notes showing that the distribution of many modern North American species was once much different than at present, as indicated, for example, by Canada Jays, Magpies, and Sharptailed Grouse in Virginia, and Spruce Grouse in Virginia and Georgia. The sum of these observations has proved to be a significant contribution to our knowledge of the effects of Pleistocene climatic changes on avian distribution.

When the Central Asiatic Expeditions of the American Museum of Natural History discovered fossil birds in the Eocene of Inner Mongolia, it was to Wetmore that the specimens were sent for study. The most abundant material was that of the crane-like bird which Wetmore named Eogrus aeola, assigning it to 
a new family, Eogruidae. Recently, the significance of these birds as the probable ancestors of the peculiar two-toed running birds of the family Ergilornithidae has been demonstrated (see Kurochkin's paper herein) and provides one of the most interesting examples of an evolutionary lineage in the avian fossil record.

Oceanic islands are of particular interest to the avian paleontologist because of the rapid extinction of species after the introduction of exotic predators by man. Most such introductions occurred before the era of scientific exploration and thus many insular species can be known only from the study of fossil or subfossil remains. Here Wetmore has likewise made numerous contributions. In 1943 he described an extinct goose from the island of Hawaii. This turned out to be but a small indication of what was to come, for in the past few years the Bishop Museum has forwarded to him for examination numerous fossils from Molokai and Maui, which comprise one of the most extraordinary avifaunas ever uncovered, some of the species being so anomalous as to be quite beyond the wildest imaginations of the most whimsical fantasizer. From Pleistocene deposits on Bermuda, Wetmore described a crane and a duck, leaving to Brodkorb the naming of five new rails from these and other deposits on the island (as yet undescribed). From St. Helena, in the South Atlantic Ocean, Wetmore named a new rail to provide a first step in the elucidation of the extensive fossil avifauna of that island, which this writer has recently had the opportunity to expand.

We have touched on but a few of Alexander Wetmore's contributions to avian paleontology and their importance to present and future research. It should by now be clear that, contrary to persistent belief, fossil birds are not uncommon, and in the following pages it should be equally evident that there is much to be gained from their study.

At last there is some light being shed on the study of Cretaceous land birds (see Brodkorb's paper herein), an area that had hitherto been a void. The renowned Pleistocene tarpits at Rancho la Brea, California, long erroneously held to be the only really productive source of avian fossils, now find a rival in similar deposits in South America which portend a new era of discovery on that continent (see Campbell's paper in the present volume). Although these many new finds are of paramount importance, the avian paleontologist has also inherited a rich source of information in the fossils that have been made known previously. Re-examination of the much discussed but widely misunderstood Mesozoic birds, such as the Jurassic Archaeopteryx and the Cretaceous toothed divers, has generated exciting new ideas and controversy, all of which can only lead to a better understanding of avian evolution (see the papers by Ostrom, Gingerich, and Martin and Tate in this volume). Long-neglected fossil birds, such as those from the vast Tertiary collections of France and from the wealth of material in the New Zealand Quaternary, are coming under scrutiny once again, and in the light of modern concepts find a better place in the evolutionary scheme (see papers herein by Collins and Cracraft). It would seem, therefore, that avian paleontology is truly experiencing a renaissance.

In 1932, Joseph Grinnell ( $A u k, 49: 9-13)$ in pondering the latest edition of the American Ornithologists' Union's Checklist of North American Birds, to which Wetmore contributed the portion on fossils, attempted to make some inferences about future lists and the number of species they might contain. Concerning the fossil list he queried, "And what about the number and relative acumen of future students in avian paleontology: Will they be more numerous and more 
alert than heretofore or will the attractions in this field wane in the face of the ascending allurements for bright minds of bio-physics, bio-chemistry and cosmic mathematics? These questions are more or less baffling of answer." Forty-five years later, the answers are apparent. We offer the present volume as testimony to the fact that avian paleontology has quite enough allure of its own to attract numerous and perspicacious practitioners, and that the materials they study allow of significant advances not only in the knowledge of birds, but of biology and paleontology as a whole. The discipline that Alexander Wetmore nurtured for sixty years is expanding and vigorous and reaping the benefits of his devotion. 


\section{Publications in Avian Paleontology by Alexander Wetmore}

1917

1. The Relationships of the Fossil Bird Palaeochenöides miocaenus. Journal of Geology, 25(6): 555-557, 1 figure.

\section{8}

2. Bones of Birds Collected by Theodoor de Booy from Kitchen Midden Deposits in the Islands of St. Thomas and St. Croix. Proceedings of the United States National Museum, 54(2245):513-522, plate 82. (21 November) ${ }^{1}$

\section{0}

3. Five New Species of Birds from Cave Deposits in Porto Rico. Proceedings of the Biological Society of Washington, 33:77-82, plates 2-3. (30 December)

1922

4. A Fossil Owl from the Bridger Eocene. Proceedings of the Academy of Natural Sciences of Philadelphia, 73(3):455-458, 2 figures. (6 April)

5. Bird Remains from the Caves of Porto Rico. Bulletin of the American Museum of Natural History, 46(4):297-333, 25 figures.

6. Remains of Birds from Caves in the Republic of Haiti. Smithsonian Miscellaneous Collections, 74(4):1-4, 2 figures. (17 October)

1923

7. An Additional Record for the Extinct Porto Rican Quail-Dove. $A u k, 40(2): 324$.

8. Avian Fossils from the Miocene and Pliocene of Nebraska. Bulletin of the American Museum of Natural History, 48(12):483-507, 20 figures. (3 December)

1924

9. Fossil Birds from Southeastern Arizona. Proceedings of the United States National Museum, 64(5):1-18, 9 figures. (15 January)

1925

10. The Systematic Position of Palaeospiza bella Allen, with Observations on Other Fossil Birds. Bulletin of the Museum of Comparative Zoology, 67(2):183-193, 4 figures, plates 1-4. (May)

11. Another Record for the Genus Corvus in St. Croix. Auk, 42(3):446.

1926

12. Descriptions of Additional Fossil Birds from the Miocene of Nebraska. American Museum Novitates, 211:1-5, 6 figures. (11 March)

13. Fossil Birds from the Green River Deposits of Eastern Utah. Annals of the Carnegie Museum, 16(3-4):391-402, plates 36-37. (10 April)

\footnotetext{
${ }^{1}$ Exact dates of publication, when known, are included for papers in which new taxa are proposed.
} 
14. Description of a Fossil Hawk from the Miocene of Nebraska. Annals of the Carnegie Museum, 16(3-4):403-408, plate 38. (10 April)

15. Observations on Fossil Birds Described from the Miocene of Maryland. $A u k, 43(4): 462-468$.

16. The Fossil Birds of North America. Natural History, 26(5):525-526.

17. [Abstract of] A. Wetmore, Descriptions of Additional Fossil Birds from the Miocene of Nebraska. Biological Abstracts, 1(1):201.

18. An Additional Record for the Fossil Hawk Urubitinga enecta. American Museum Novitates, 241:1-3, 3 figures.

19. Present Status of the Check-list of Fossil Birds for North America. Auk, 44(2):179-183.

20. Fossil Birds from the Oligocene of Colorado. Proceedings of the Colorado Museum of Natural History, 7(2):1-13, 23 figures. (15 July)

21. [On Cygnus paloregonus from Nampa, Idaho.] Page 267 in O. P. Hay, The Pleistocene of the Western Region of North America and Its Vertebrated Animals. Carnegie Institution of Washington Publication, 322B.

22. A Record of the Ruffed Grouse from the Pleistocene of Maryland. $A u k, 44(4): 561$.

23. The Birds of Porto Rico and the Virgin Islands: Colymbiformes to Columbiformes. Pages 245-406 of part 3 in volume 9 of New York Academy of Sciences, Scientific Survey of Porto Rico and the Virgin Islands. 1 map, 16 figures, plates 55-61. The Birds of Porto Rico and the Virgin Islands: Psittaciformes to Passeriformes. Pages 407-598 of part 4 in volume 9 of New York Academy of Sciences, Scientific Survey of Porto Rico and the Virgin Islands. 3 figures, plates 62-65. [Includes discussion and figures of fossil species.]

1928

24. Bones of Birds from the Ciego Montero Deposit of Cuba. American Museum Novitates, 301:1-5, 2 figures.

25. Additional Specimens of Fossil Birds from the Upper Tertiary Deposits of Nebraska. American Museum Novitates, 302:1-5, 2 figures.

26. The Tibio-tarsus of the Fossil Hawk Buteo typhoius. Condor, 30(2):149-150, figures 58-61.

27. The Systematic Position of the Fossil Bird Cyphornis magnus. (Contributions to Canadian Palaeontology, Geological Series Number 48). Canada Department of Mines, Geological Survey Bulletin, 49:1-4, 1 figure. (15 March)

28. Prehistoric Ornithology in North America. Journal of the Washington Academy of Sciences, 18(6):145-158.

29. The Short-tailed Albatross in Oregon. Condor, 30(3):191.

30. [List of Aves.] Page 3 in G. G. Simpson, Pleistocene Mammals from a Cave in Citrus County, Florida. American Museum Novitates, 328.

31. [Abstract of] J. F. van Bemmelen, Animaux disparus. Biological Abstracts, 3(1-3):390.

32. [Abstract of] W. v. Szeliga-Mierzeyewski, Der diluviale Kernbeisser (Loxia coccothraustes L.) aus Starunia in Polen (Anatomie und Histologic). Biological Abstracts, 3(1-3):1012.

33. Birds of the Past in North America. Pages 377-389 in Smithsonian Report for 1928. 11 plates. Washington, Government Printing Office.

34. The Fossil Birds of the A. O. U. Check-list. Condor, 32(1):12-14, 1 table.

35. [and H. T. Martin.] A Fossil Crane from the Pliocene of Kansas. Condor, 32(1):62-63, figures 23-25. (20 January)

36. [Abstract of] G. Archey. On a Moa Skeleton from Amodes Bay and some Moa Bones from Karamu. Biological Abstracts, 4(1):287-288.

37. The Age of the Supposed Cretaceous Birds from New Jersey. Auk, 47(2):186-188.

38. [Abstract of] M. D. d. Saez, Las Aves Corredoras Fósiles del Santacru Cense [sic]. Biological Abstracts, 4(3):992. 
39. Two Fossil Birds from the Miocene of Nebraska. Condor, 32(3):152-154, figures 51-56. (15 May)

40. Fossil Bird Remains from the Temblor Formation near Bakersfield, California. Proceedings of the California Acadeny of Sciences, series 4, 19(8):85-93, 7 figures. (15 July)

41. The Supposed Plumage of the Eocene Diatryma. Auk, 47(4):579-580.

\section{1}

42. [and B. H. Swales.] The Birds of Haiti and the Dominican Republic. United States National Museum Bulletin, 155:1-483, 2 figures, 26 plates. [Includes discussion of fossils.]

43. The California Condor in New Mexico. Condor, 33(2):76-77.

44. The Avifauna of the Pleistocene in Florida. Smithsonian Miscellaneous Collections, 85(2): $1-41,16$ figures, 6 plates. (13 April)

45. Two Primitive Rails from the Eocene of Colorado and Wyoming. Condor, 33(3):107-109, figures 21-29. (15 May)

46. [Report on Birds Found in a Limestone Urn at Chichen Itzá.] Page 189 in volume 1 of E. H. Morris, J. Charlot, and A. A. Morris, The Temple of the Warriors at Chichen Itzá, Yucatan. Carnegie Institution of Washington Publication, 406.

47. The Pleistocene Avifauna of Florida. Pages 479-483 in Proceedings of the VIIth International Ornithological Congress at Amsterdam 1930.

48. The Fossil Birds of North America. Pages $401-472$ in Check-list of North American Birds. Fourth edition. Lancaster, Pennsylvania: American Ornithologists' Union.

49. Bones of the Great Horned Owl from the Carlsbad Cavern. Condor, 33(6):248-249.

50. Record of an Unknown Woodpecker from the Lower Pliocene. Condor, 33(6):255-256.

\section{2}

51. Additional Records of Birds from Cavern Deposits in New Mexico. Condor, 34(3):141-142.

52. The Former Occurrence of the Mississippi Kite in Ohio. Wilson Bulletin, 44(2):118.

\section{3}

53. [and H. Friedmann.] The California Condor in Texas. Condor, 35(1):37-38.

54. A Fossil Gallinaceous Bird from the Lower Miocene of Nebraska. Condor, 35(2):64-65. (17 March)

55. Status of the Genus Geranoaëtus. Auk, 50(2):212.

56. A Second Specimen of the Fossil Bird Bathornis veredus, Auk, 50(2):213-214.

57. Fossil Bird Remains from the Eocene of Wyoming. Condor, 35(3):115-118, figure 22 (15 May)

58. Bird Remains from the Oliocene Deposits of Torrington, Wyoming. Bulletin of the Museum of Comparative Zoology, 75(7):297-311, 19 figures. (October)

59. Development of Our Knowledge of Fossil Birds. Pages 231-239 in Fifty Years' Progress of American Ornithology 1883-1933. Lancaster, Pennsylvania: American Ornithologists' Union.

60. The Status of Minerva antiqua, Aquila ferox, and Aquila lydekkeri as Fossil Birds. Anerican Museum Novitates, 680:1-4, 1 figure. (4 December)

61. An Oligocene Eagle from Wyoming. Smithsonian Miscellaneous Collections, 87(19):1-9, 19 figures. (26 December)

62. Pliocene Bird Remains from Idaho. Smithsonian Miscellaneous Collections, 87(20):1-12, 8 figures. (27 December)

1934

63. [and E. C. Case.] A New Fossil Hawk from the Oligocene Beds of South Dakota. Contributions from the Museum of Paleontology, University of Michigan, 4(8):129-132, 1 plate. (15 January)

64. A Fossil Quail from Nebraska. Condor, 36(1):30, figure 5. (15 January)

65. [Review of] K. Lambrecht, Handbuch der Palaeornithologie. $A u k$, 51(2):261-263.

66. Fossil Birds from Mongolia and China. American Museum Novitates, 711:1-16, 6 figures. (7 April)

67. The Types of the Fossil Mammals Described as Aquila antiqua and Aquila ferox. Journal of Mammalogy, 15(3):251. 
68. On the Genera Oligocorax and Miocorax. Auk, 52(1):75-76.

69. The Mexican Turkey Vulture in the United States. Condor, 37(3):176.

70. The Common Loon in the Florida Keys. $A u k, 52(3): 300$.

71. Pre-Columbian Bird Remains from Venezuela. $A u k, 52(3): 328-329$.

72. A Record of the Trumpeter Swan from the Late Pleistocene of Illinois. Wilson Bulletin, $47(3): 237$.

73. Aves (Birds). Pages 275-277 in C. B. Schultz and E. B. Howard, The Fauna of Burnet Cave, Guadalupe Mountains, New Mexico. Proceedings of the Academy of Natural Sciences of Philadelphia, 87:273-298.

74. The Range of the Sharp-tailed Grouse in New Mexico. Condor, 38(2):90.

75. How Old Are Our Birds? Bird-Lore, 38(5):321-326, 7 figures.

76. Two New Species of Hawks from the Miocene of Nebraska. Proceedings of the United States National Museum, 84(3003):73-78, figures 13-14. (3 November)

1937

77. The Eared Grebe and Other Birds from the Pliocene of Kansas. Condor, 39(1):40.

78. Ancient Records of Birds from the Island of St. Groix with Obscrvations on Extinct and Living Birds of Puerto Rico. Journal of Agriculture of the University of Puerto Rico, 21(1):5-16, 1 plate. (January)

79. The Systematic Position of Bubo leptosteus Marsh. Condor, 39(2):84-85, figure 23.

80. Bird Remains from Cave Deposits on Great Exuma Island in the Bahamas. Bulletin of the Museum of Comparative Zoology, 80(12):427-441, 16 figures, 1 plate. (October)

81. The Tibiotarsus of the Fossil Bird Bathornis veredus. Condor, 39(6):256-257, figure 70.

82. A Record of the Fossil Grebe, Colymbus parvus, from the Pliocene of California, with Remarks on Other American Fossils of This Family. Proceedings of the California Academy of Sciences, series 4, 23(13):195-201, 15 figures.

\section{8}

83. A Miocene Booby and Other Records from the Calvert Formation of Maryland. Proceedings of the United States National Museum, 85(3030):21-25, figures 2-3. (14 January)

84. Another Fossil Owl from the Eocene of Wyoming. Proceedings of the United States National Museum, 85(3031):27-29, figures 4-5. (17 January)

85. Bird Remains from the West Indies. $A u k, 55(1): 51-55$.

86. A Fossil Duck from the Eocene of Utah. Journal of Paleontology, 12(3):280-283, 5 figures. (4 May)

\section{9}

87. A Pleistocene Egg from Nevada. Condor, 41(3):98-99, figure 29.

88. [On Marsh's Discovery of Toothed Birds.] Page 48 in C. Schuchert, Biographical Memoir of Othniel Charles Marsh. National Academy of Sciences of the United States of America Biographical Memoirs, 20(1):1-78.

\section{0}

89. Fossil Bird Remains from Tertiary Deposits in the United States. Journal of Morphology, $66(1): 25-37,14$ figures. (2 January)

90. A Check-list of the Fossil Birds of North America. Smithsonian Miscellaneous Collections, 99(4):1-81.

91. Avian Remains from the Pleistocene of Central Java. Journal of Paleontology, 14(5):447450,7 figures. (1 September)

\section{1}

92. An Unknown Loon from the Miocene Fossil Beds of Maryland. $A u k, 58(4): 567$. 
93. Two New Fossil Birds from the Oligocene of South Dakota. Smithsonian Miscellaneous Collections, 101(14):1-6, 13 figures. (11 May)

\section{3}

94. Evidence for the Former Occurrence of the Ivory-billed Woodpecker in Ohio. Wilson Bulletin, 55(1):55.

95. Remains of a Swan from the Miocene of Arizona. Condor, 45(3):120.

96. Fossil Birds from the Tertiary Deposits of Florida. Proceedings of the New England Zoological Club, 32:59-68, plates 11-12. (23 June)

97. The Little Brown Crane in Ohio. Wilson Bulletin, 55(2):127.

98. The Occurrence of Feather Impressions in the Miocene Deposits of Maryland. $A u k, 60(3)$ : 440-441.

99. [Review of] L. Miller and I. DeMay, The Fossil Birds of California. Auk, 60(3):458-459.

100. An Extinct Goose from the Island of Hawaii. Condor, 45(4):146-148, figure 39. (23 July)

101. A Second Specimen of the Fossil Guillemot, Miocepphus. Auk, 60(4):604.

102. Two More Fossil Hawks from the Miocene of Nebraska. Condor, 45(6):229-231, figures 62-63. (8 December)

\section{4}

103. A New Terrestrial Vulture from the Upper Eocene Deposits of Wyoming. Annals of the Carnegie Museum, 30:57-69, 10 figures, 5 plates. (24 May)

104. Remains of Birds from the Rexroad Fauna of the Upper Pliocene of Kansas. University of Kansas Science Bulletin, 30(pt. 1, no. 9):89-105, 19 figures. (15 May)

\section{5}

105. A Further Record for the Double-crested Cormorant from the Pleistocene of Florida. Auk, $62(3): 459$.

106. Record of the Turkey from the Pleistocene of Indiana. Wilson Bulletin, 57(3):204.

107. From My Cave Notebooks. Bulletin of the National Speleological Society, 7:1-5.

\section{8}

108. A Pleistocene Record for Mergus merganser in Illinois. Wilson Bulletin, 60(4):240.

\section{9}

109. Archaeopteryx. Pages 260-262 in volume 2 of Encyclopaedia Britannica. 2 figures.

110. Diatryma. Page 324 in volume 7 of Encyclopaedia Britannica.

111. Hesperornis. Pages 530-531 in volume 11 of Encyclopaedia Britannica.

112. Ichthyornis. Page 58A in volume 12 of Encyclopaedia Britannica.

113. Odontornithes. Page 707 in volume 16 of Encyclopaedia Britannica.

114. Phororhacos. Pages 778-779 in volume 17 of Encyclopaedia Britannica. I figure.

115. The Pied-billed Grebe in Ancient Deposits in Mexico. Condor, 51(3):150.

\section{0}

116. A Correction in the Generic Name for Eocathartes grallator. Auk, 67(2):235. (28 April)

\section{1}

117. The Original Description of the Fossil Bird Cryptornis antiquus. Condor, 53(3):153.

118. A Revised Classification for the Birds of the World. Smithsonian Miscellaneous Collections, 117(4):3. (1 November) 
1952

119. Presidential Address. Recent Additions to Our Knowledge of Prehistoric Birds 1933-1949. Pages 51-74 in Proceedings of the Xth International Ornithological Congress Uppsala June 1950.

120. A Record for the Black-capped Petrel, Pterodroma hasitata, in Martinique. $A u k, 69(4): 460$.

1955

121. The Genus Lophodytes in the Pleistocene of Florida. Condor, 57(3):189.

122. A Supposed Record of a Fossil Cormorant. Condor, 57(6):371.

123. Paleontology. Pages 44-56 in A. Wolfson, editor, Recent Studies in Avian Biology. Urbana: University of Illinois Press.

\section{6}

124. A Check-list of the Fossil and Prehistoric Birds of North America and the West Indies. Smithsonian Miscellaneous Collections, 131(5):1-105.

125. A Fossil Guan from the Oligocene of South Dakota. Condor, 58(3):234-235, 1 figure. (23 May)

126. Footprint of a Bird from the Miocene of Louisiana. Condor, 58(5):389-390, 1 figure.

127. The Muscovy Duck in the Pleistocene of Panamá. Wilson Bulletin, 68(4):327.

1957

128. A Fossil Rail from the Pliocene of Arizona. Condor, 59(4):267-268, 1 figure. (23 July)

\section{8}

129. Miscellaneous Notes on Fossil Birds. Smithsonian Miscellaneous Collections, 135(8):1-11, 5 plates. (26 June)

130. Birds of the Pleistocene in North America. Smithsonian Miscellaneous Collections, 138(4): 1-24.

131. Notes on Certain Grouse of the Pleistocene. Wilson Bulletin, 71(2):178-182, 1 table, 4 figures.

1960

132. A Classification for the Birds of the World. Smithsonian Miscellaneous Collections, 139(11): 4. (23 June)

133. Pleistocene Birds in Bermuda. Smithsonian Miscellaneous Collections, 140(2):1-11, 3 plates. (7 July)

134. [and K. C. Parkes.] Archaeornithes. Pages 510-511 in volume 1 of McGraw-Hill Encyclopedia of Science and Technology.

135. Aves Fossils. Pages 694-695 in volume 1 of McGraw-Hill Encyclopedia of Science and Technology. 1 figure.

136. [and K. C. Parkes.] Diatrymiformes. Page 104 in volume 4 of McGraw-Hill Encyclopedia of Science and Technology. 1 figure.

137. [and K. C. Parkes.] Dinornithiformes. Page 108 in volume 4 of McGraw.Hill Encyclopedia of Science and Technology.

138. Hesperornis. Pages 426-427 in volume 6 of McGraw-Hill Encyclopedia of Science and Technology.

139. Ichthyornithes. Page 8 in volume 7 of McGraw-Hill Encyclopedia of Science and Tech. nology. 
140. Notes on Fossil and Subfossil Birds. Smithsonian Miscellaneous Collections, 145(2):1-17, 2 figures. (26 June)

141. Birds. Pages 92, 95 in J. E. Guilday, The Pleistocene Local Fauna of the Natural Chimneys, Augusta County, Virginia. Annals of the Carnegie Museum, 36(9):87-122.

142. Ice Age Birds in Virginia. Raven, 33(4):3.

\section{3}

143. An Extinct Rail from the Island of St. Helena. !bis, 103b(3):379-381, plate 9. (1 September)

\section{4}

144. [List of Aves.] Page 134 in J. E. Guilday, P. S. Martin, and A. D. McCrady, New Paris No. 4: A Pleistocene Cave Deposit in Bedford County, Pennsylvania. Bulletin of the National Speleological Society, 26(4):121-194.

\section{5}

145. [Aves.] Pages 71-72 in volume 1 of L. S. B. Leakey, Olduvai Gorge 1951-61. Cambridge: University Press.

\section{7}

146. Pleistocene Aves from Ladds, Georgia. Bulletin of the Georgia Academy of Science, 25(3): 151-153, 1 figure.

147. Re-creating Madagascar's Giant Extinct Bird. National Geographic, 132(4):488-493, 7 figures.

\section{8}

148. [With C. E. Ray, D. H. Dunkle, and P. Drez.] Fossil Vertebrates from the Marine Pleistocene of Southeastern Virginia. Smithsonian Miscellaneous Collections, 153(3):1-25, 2 figures, 2 plates.

149. Archaeopteryx. Pages 284-285 in volume 2 of Encyclopaedia Britannica, 2 figures.

150. Diatryma. Page 370 in volume 7 of Encyclopaedia Britannica.

151. Hesperornis. Pages $461-462$ in volume 11 of Encyclopaedia Britannica.

152. Ichthyornis. Page 1055 in volume 11 of Encyclopaedia Britannica.

153. Phororhacos. Page 911 in volume 17 of Encyclopaedia Britannica. 1 figure.

\section{2}

154. [Review of] G. G. Simpson, A Review of the Pre-Pliocene Penguins of New Zealand. Quarterly Review of Biology, 47(1)78-79.

155. A Pleistocene Record for the White-winged Scoter in Maryland. Auk, 90(4):910-911. 



\section{Index to Fossil Avian Taxa Described by Alexander Wetmore}

The status of a number of these taxa has changed since their original description and therefore only an alphabetical arrangement is attempted here. Species are listed in the genera in which they were originally described. Taxa marked with an asterisk are preoccupied and no longer available. Following each name is the publication number (from the preceding bibliography) and page in which the name was proposed.

Superfamilies, Families, and Subfamilies

Bathornithidae, 58:301

Bathornithinae, 20:13

Cladornithes, 132:4

Cyphornithidae, 27:4

Eleutherornithidae, 118:3

*Eocathartidae, 103:69

*Eocathartoidea, 103:69

Eogruidae, 65:30

Aphanocrex, 143:379

Aramornis, 12:1

Badistornis, 89:30

Baeopteryx, 133:6

Bathornis, 20:11

Calohierax, 80:428

*Eocathartes, 103:58

Eocrex, 45:107

Eogrus, 65:3

Eonessa, 85:280

Gaviella, 89:28

Geochen, 100:146

Geranoides, 57:115

abavus, Presbychen, 40:92 aeola, Eogrus, 65:30

ales, Geranoaetus, 14:403

anaticula, Eonessa, 85:280

antecessor, Plegadornis, 140:1

antecursor, Buteo, 58:298

anthonyi, Gallinago, 3:78

aramiellus, Gnotornis, 93:1

aramus, Badistornis, 89:30

atavus, Palaeastur, 102:230

autochthones, Ara, 78:12

avita, Sula, 83:22
Eonessinae, 85:280

Gaviellinae, 89:30

Geranoididae, 57:115

Nautilornithinae, 13:394

Neocathartidae, 116:235

Neocathartoidea, 116:235

Palaeoplancinae, 61:4

Palaeospizidae, 10:190

\section{GENERA AND SubGenERA}

Gnotornis, 93:1

Microsula, 83:25

Miocepphus, 89:35

Nautilornis, 13:392

Neocathartes, 106:235

Nesotrochis, 2:516

Palaealectoris, 39:152

Palaeastur, 102:230

Palaeocrex, 20:9

Palaeogyps, 20:5

Palaeonossax, 125:234

Palaeoplancus, 61:1

Palaeorallus, 45:108

\section{SPECIES}

avus, Nautilornis, 13:392 brodkorbi, Promilio, 129:4 bunkeri, Nettion, 104:92

calobates, Rhegminornis 96:61

cavatica, Tyto, 3:80

celeripes, Bathornis, 58:302

concinna, Gavia, 89:25

conterminus, Geranoaetus, $8: 487$

contortus, Geranoaetus, 8:492
Palaeotringinae, 90:57

*Plegadornithidae, 140:3

* Plegadornithoidea, 140:3

Presbyornithidae, 13:396

Protostrigidae, 60:4

Rhegminornithidae, 96:60

Telecrecinae, 65:14

Palaeostruthus, 10:192

Paractiornis, 39:153

Phasmagyps, 20:30

*Plegadornis, 140:1

Presbychen, 40:92

Presbyornis, 13:396

Promilio, 129:3

Protostrix, 60:3

Rhegminornis, 96:61

Telecrex, 65:13

Titanohierax, 80:430

cooki, Cyrtonyx, 64:30

cursor, Bathornis, 58:310

debooyi, Nesotrochis, 2:516

effera, Proictinia, 8:504

enecta, Urubitinga, 8:500

epileus, Promilio, 129:4

eversa, Dendrocygna, 9:3

fax, Palaeocrex, 20:9

fratercula, Conuropsis, 12:3 geographics, Bathornis, 93:3 gloveralleni, Titanohierax, 79:431 
grallator, Eocathartes,

103:58

grangeri, Buteo, 63:129

grangeri, Telecrex, 65:13

halieus, Pelecanus, 62:3

hesternus, Micropalama, 9:11

hibbardi, Colinus, 104:96

howardae, Palaeoborus, 75:73

inceptor, Puffinus, 40:86

incertus, Palaealectoris,

39:152

jepseni, Geranoides, 57:115

larua, Oreopeleia, 3:79

latebrosus, Polyborus, 3:77

latipes, Baeopteryx, 133:6

longurio, Aramornis, 12:1

mcclungi, Miocepphus, 89:35

micula, Chloroenas, 9:13

mimica, Protostrix, 84:27 minuscula, Branta, 9:6 nannodes, Grus, 35:62

ostologa, Tyto, 6:2 pachyscelus, Anas, 133:2 palaeodytes, Gavia, 96:64 patritus, Phasmagyps, 20:3 perpusillus, Paractiornis, 39: 153 pervetus, Presbyornis, 13:396 phengites, Ortalis, 8:487 phillipsi, Rallus, 128:267 podarces, Aphanocrex, 143:379 pollens, Tyto, 80:436 prenticei, Rallus, 104:99 pressa, Chen, 62:9 primus, Eocrex, 45:107 proavitus, Nautilornis, 13:394 prodromus, Palaeogyps, 20:5 pumilus, Corvus, 3:81 quadratus, Calohierax, 80:429

ramenta, Falco, 76:75

rhuax, Geochen, 100:146

saurodosis, Minerva, 4:455

senectus, Palaeonossax, $125: 234$

sternbergi, Palaeoplancus, 61:1

tantala, Ortalis, 54:64 titan, Leptotilos, 91:447 tridens, Meleagris, 44:33 troxelli, Palaeorallus, 45:108 typhoius, Buteo, 8:489 vagabundus, Moris, 40:89 yeredus, Bathornis, 20:11 vetustus, Neophrontops, 102:229 


\title{
Collected Papers in Avian Paleontology
}

\author{
Some Hypothetical Anatomical Stages \\ in the Evolution of Avian Flight
}

\author{
John H. Ostrom
}

\begin{abstract}
The five known skeletal specimens of Archaeopteryx provide the only presently available anatomical evidence pertaining to the earliest stages in the evolution of the avian flight apparatus. This evidence, together with the osteology of modern birds, makes possible the reconstruction of some hypothetical anatomical stages that must have occurred during the course of avian evolution. It is postulated that one of the most critical components of the flight apparatus is the coracoid. Evolutionary changes in coracoid morphology elevated the actions of the principal humeral extensor (M. coracobrachialis) and forearm flexor (M. biceps), and as a consequence, caused deflection of the course of the $M$. supracoracoideus, converting it from a humeral depressor to a wing elevator. These changes appear to have been related to predation and feeding activities in the earliest birds, rather than to early stages of flight. Subsequently, additional changes in the forelimb components provided for restricted elbow and wrist movements, compact folding of the forelimb, and more stable support of the remiges. These last changes appear to have taken place after the acquisition of incipient flight capability.
\end{abstract}

\section{Introduction}

One of the most remarkable of all animal adaptations is that of flight, which perhaps has reached

John H. Ostrom, Department of Geology and Geophysics and the Peabody Museum of Natural History, Yale University, New Haven, Connecticut 06520. its zenith among vertebrates in the diverse kinds of flight displayed by modern birds. Strangely enough, there have been only a few investigations or speculations about the origins of avian flight, but perhaps that stems from the clear logic (Bock, 1965, 1969) of the currently favored arboreal theory of flight origins (Marsh, 1880). The purpose of this paper, however, is not to explore that particular question, which I have already reviewed elsewhere (Ostrom, 1974), but rather it is to present purely theoretical reconstructions of some of the anatomical stages that must have occurred during the course of evolution of the avian flight apparatus, and to discuss the implications thereof.

Reconstruction of such hypothetical evolutionary stages is speculative to be sure, but it is a fruitful exercise in this instance because we know the nature of the starting point, the almost non-bird Archaeopteryx (Figure 1), as well as the "end point," the highly perfected flight apparatus of modern birds. A few authors (Heptonstall, 1970; Yalden, 1970) have investigated the possible flight capabilities of Archaeopteryx, but apparently no one has examined in any detail the anatomical changes that clearly must have occurred in the flight apparatus between the Archaeopteryx stage and that of modern birds. In the absence of any recognized intermediate stages within the avian fossil record, consideration of these necessary anatomical changes assumes major significance, since they may very well provide the only possible clues about early selective factors that led to the develop- 


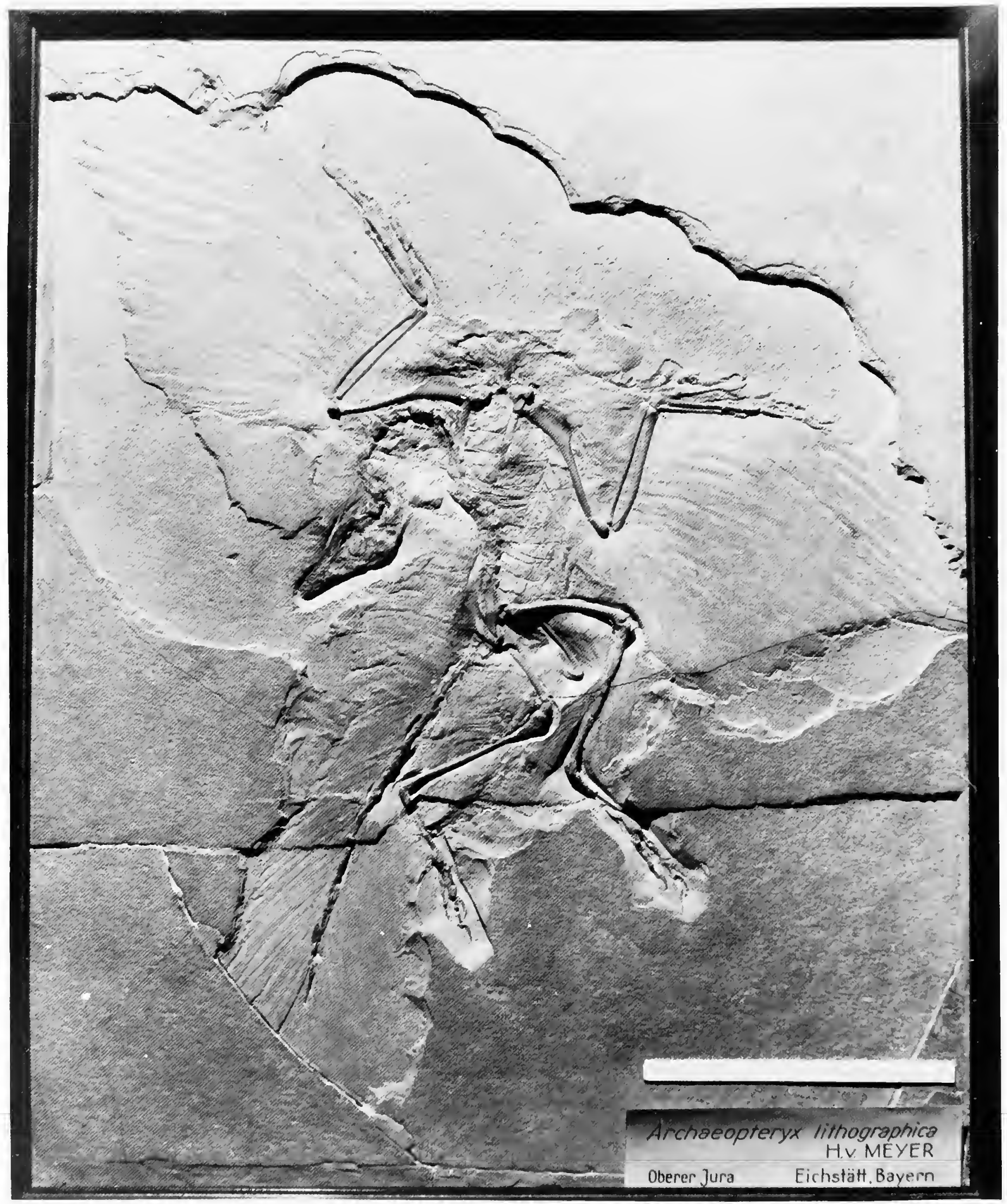

Figure 1.-The Berlin specimen of Archneopteryx lithographica found in 1877 near Eichstätt, Germany, in the Late Jurassic Solnhofen Limestoncs. Preservation of feather impressions, showing remarkably fine structural details, established these as the remains of a true bird, despite the fact that the skeletal anatomy is more like that of theropod dinosaurs than that of modern birds. (The scale is $100 \mathrm{~mm}$ long.) 
ment of powered avian flight. Conceivably, such considerations might even shed light on the actual beginnings of flight.

A premise that is critical for the remarks that follow is that the several specimens of Archaeopteryx represent an extremely primitive stage in the evolution of birds (Ostrom, 1973, 1975). (I also believe that Archaeopteryx represents a preflight stage [Ostrom, 1974], but not everyone concurs with such an interpretation.) Some authors (de Beer, 1954; Swinton, 1960, 1964) have maintained that Archaeopteryx was not in the main lineage of avian evolution, but so far not one single bit of evidence has been found, either in the known specimens of Archaeopteryx or elsewhere, to support such a contention. Indeed, as Simpson (1946) observed, Archaeopteryx is anatomically intermediate between reptiles and modern birds, and regardless of whether it is directly ancestral to modern carinates, it is entirely reasonable to assume that the early main-line ancestry of birds included an anatomical stage comparable, if not identical, to that of Archaeopteryx. Thus, any consideration of the evolution of avian flight must start with Archaeopteryx.

ACKNowLEDGMENTs.-I gratefully acknowledge the assistance and courtesies of A. J. Charig of the British Museum (Natural History), London; $H$. Jaeger of the Humboldt Museum für Naturkunde, East Berlin; T. Kress of the Solenhofer ActienVerein, Solnhofen, Bavaria; C. O. van Regteren Altena of Teyler's Stichting, Haarlem; and P. Wellnhofer of Bayerische Staatssammlung für Paläontologie und historische Geologie, Munich, who granted me the privilege of studying the specimens of Archaeopteryx in their care. I am also indebted to Walter Bock, who read an early version of the manuscript and offered valuable suggestions and criticisms. These studies were funded by grants from the Frank M. Chapman Memorial Fund of the American Museum of Natural History, and the John T. Doneghy Fund of the Yale Peabody Museum.

\section{Flight Apparatus of Modern Birds}

By way of introduction to this section, certain generalized comparisons among higher vertebrates may be useful. In modern quadrupedal reptiles, the proximal components of both the fore and hind limbs extend laterally from the hip and shoulder joints (sprawling posture), which are situated well below the level of the vertebral column. In quadrupedal mammals, both appendages are normally positioned in near-parasagittal orientation (upright posture) articulating with hip and shoulder sockets that are close to the level of the vertebral column. In birds, the hip and shoulder sockets are both elevated and lie in or near the plane of the vertebrae. But birds are peculiar in that the hind limb projects downward in a nearly parasagittal orientation, whereas the forelimb extends out laterally from the body. These contrasting limb orientations in birds obviously are correlated with the different limb movements in the two modes of avian locomotion: terrestrial locomotion by means of alternating (or synchronous) longitudinal limb excursion in the hind quarters, and powered flight by means of complex, but chiefly synchronous (nonalternating) dorsoventral transverse movements of the forelimbs.

The avian skeleton includes a number of specializations that are directly or indirectly involved with powered flight: (1) The trunk region is quite rigid due to fusion or restricted articular freedom of the thoracic vertebrae, the solid bony connection between the vertebral column and the sternum, by full ossification of the ventral (sternal) as well as the dorsal ribs, and the development of uncinate processes on the dorsal ribs. (2) Fixation of the shoulder joints by means of elongation of the coracoids which have developed solid bony articulations with a fully ossified sternum; fusion of the clavicles into a single median strut, the furcula, which appears to function as a spring-like spacer maintaining proper transverse spacing of the shoulder joints. (3) Complete ossification and enlargement of the sternum and the development of a deep and robust sternal keel. (4) Modification of the forelimb skeleton into a rigid but collapsible airfoil support in which the shoulder joint permits humeral movements in nearly all directions (including limited long-axis humeral rotation), but the elbow and wrist joints are restricted so as to confine forearm flexion and extension chiefly to the plane of the wing, wrist movements being limited to flexion and extension in the wing plane only; fusion of some carpals and metacarpals to provide a solid platform for the attachment of the primary remiges; and reduction of the manus to 
digits I, II and III, with II and III united into a relatively rigid structure. Elsewhere (Ostrom, in press), I have given reasons for discounting the suggestion by some authors (Holmgren, 1955) that the remaining digits of the hand are II, III and IV. (5) The caudal vertebrae are reduced in number and coalesced into a short pygostyle, providing a firmer and more readily controlable base of attachment for the tail feathers. (6) Of particular importance is the great development of the coracoids and furcula, which are constructed so as to prevent the shoulder sockets from being pulled downward or squeezed toward the midline by the powerful contractions of the flight muscles that originate on the sternum.

In addition to these skeletal specializations, the pectoral and forelimb musculature of carinates have also been highly modified from the primitive tetrapod condition, to the extent that in some instances homologies are very much in doubt. Fortunately, the establishment of homologies is not critical for the theoretical reconstructions and interpretations that follow here. The flight musculature of modern carinates has been studied and described by many authorities, among them Stresemann (1933), Sy (1936), Fisher (1946), Hudson and Lanzillotti (1955), Berger (1960), and George and Berger (1966). From these studies, we may classify the flight muscles in six broadly functional categories as follows: (I) those that fix or adjust the pectoral girdle and the shoulder socket; (2) those that power the wing, producing the propulsive down stroke; (3) those producing the recovery stroke of the wing; (4) the flexors, for folding the wing; (5) the extensors, for unfolding the wing, and (6) the muscles that produce minor adjustments of the wing components, including the remiges. Some thoracic and appendicular muscles are involved in two or more of these actions. The following tabulation summarizes the principal muscles in each of these generalized categories. In the discussion that follows, the emphasis will be on those muscles that are concerned with the power and recovery strokes of the wing, not because other muscles are less important, but because these are more conspicuously involved in the evolutionary changes that occurred between Archaeopteryx and later birds.

\section{Shoulder JOINT Fixors AND Adjustors}

Rhomboideus superficialis Rhomboideus profundus

Serratus superficialis anterior

Serratus superficialis posterior Serratus profundus Sternocoracoideus

\section{FLIGHT MUSCLES}

Pectoralis superficialis

\section{Wing Recovery Muscles}

Supracoracoideus Deltoideus major posterior

Coracobrachialis anterior Deltoideus minor

Deltoideus major anterior

\section{WING FOLDERS}

Latissimus dorsi anterior Latissimus dorsi posterior Scapulohumeralis anterior Scapulohumeralis posterior Coracobrachialis posterior Subcoracoideus

Biceps brachii Brachialis Flexor carpi ulnaris Flexor digitorum sublimis Flexor digitorum profundus Supinator

Subscapularis

\section{WING UNFOLDERS}

Coracobrachialis anterior Deltoideus major anterior

Triceps brachii Deltoideus major posterior

Extensor metacarpi radialis Deltoideus minor

Extensor digitorum communis

\section{Wing Adjustors}

Serratus superficialis

Pronator sublimis metapatagialis

Pronator profundus

Pectoralis propatagialis longus

Pectoralis propatagialis brevis

Cucullaris propatagialis

Propatagialis longus

Propatagialis brevis

Expansor secundariorum

Entepicondylo-ulnaris

Flexor carpi ulnaris

Ulnimetacarpalis ventralis

Extensor metacarpi radialis Supinator

Extensor digitorum communis Extensor carpi ulnaris

Powered avian flight is produced by synchronous down strokes of the wing caused by contraction of the large ventral muscle complex, the M. pectoralis. This complex usually consists of three or four distinct muscles, the $M$. pectoralis thoracica, or pectoralis superficialis, being the largest and most important. The other pectoralis muscles typically are small slips that function to tense the protopatagium, thus belonging to the last category listed above. The $M$. pectoralis superficialis originates extensively on the posterior and lateroventral surfaces of the sternum, the ventral half of the entire length of the carina, the entire posterolateral 
surface of the clavicle and the anterior margin of the sterno-coracoclavicular membrane. The pectoralis tendon inserts broadly on the ventral surface over most of the length of the deltopectoral crest (crista lateralis humeri) of the humerus. This muscle provides nearly all the force for flight and is the largest of all avian muscles, averaging more than 15 percent of total body weight among all flying birds (Hartman, 1961; Greenwalt, 1962). Two osseous features reflect the size and functional importance of this muscle: the very large sternum and its carina, and the long and prominent deltopectoral crest of the humerus.

Wing elevation (recovery stroke) is accomplished by the combined actions of several muscles: the M. supracoracoideus, M. coracobrachialis anterior and $\mathrm{Mm}$. deltoideus major and minor. Of these, the supracoracoideus is by far the most important. The coracobrachialis, by virtue of its origin on the anterodorsal extremity of the coracoid (the acrocoracoid) anterior and dorsal to the glenoid fossa, provides some lifting of the humerus, but its chief action is to extend or pull the humerus forward, thereby unfolding the wing. Typically, it is the smallest "elevator" muscle. The M. deltoideus major usually consists of a pars anterior and pars posterior. The pars anterior arises from a small area on the dorsal side of the scapula adjacent to the glenoid. The pars posterior originates on the dorsal end of the clavicle and the anterodorsal surface of the scapula. Accordingly, these fibers tend to elevate the humerus and draw it forward. The M. deltoideus minor also originates on the anterodorsal apex of the scapula, above, medial, and slightly anterior to the glenoid, hence also acting to elevate the humerus.

The largest humeral abductor, as noted above, is the M. supracoracoideus, also termed the pectoralis secundus or pectoralis minor (Figure 2). This muscle arises by extensive attachment on the dorsal parts of the sternal carina, the anterolateral surfaces of the sternum, the ventro-anteromedial surface of the coracoid and the lateral part of the coracoclavicular membrane. Its fibers converge dorsally, attaching to a narrow tendon that passes backward through an osseous canal, the foramen triosseum, between the dorsal extremities of the coracoid and clavicle and the anterior extremity of the scapula. From there, the tendon turns downward to insert on the dorsal surface of the hu-

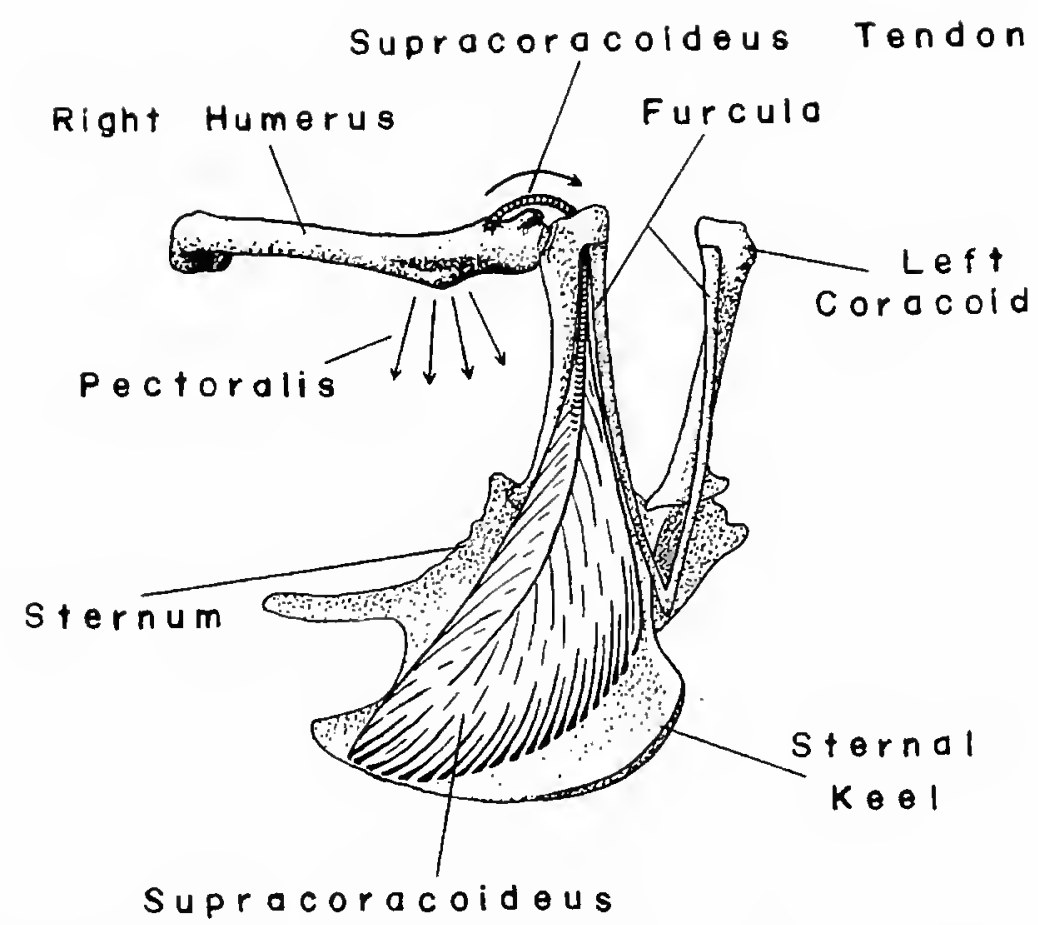

Figure 2.-Anterolateral view of the pectoral girdle and sternum of Columbia livia to show the general relationships of the $M$. supracoracoideus. The upper arrow indicates the course and action of the supracoracoideus tendon from the insertion toward the triosseal canal. The lower arrows indicate the location and action of the $M$. pectoralis, which has been removed in this drawing. (After Fig. III.1, George and Berger, 1966.)

merus between the head and the deltopectoral crest. The fact that the triosseal canal is situated above the insertion point when the humerus is depressed allows this ventrally placed muscle to elevate rather than depress the humerus.

Figures 2 and 3 illustrate the structure of the triosseal canal and its relationship to the supracoracoideus muscle. Of particular importance is the very prominent dorsal process of the coracoid (the acrocoracoid) that extends well above and anterior to the glenoid. The medial side of this process forms the lateral wall of the triosseal canal and is the primary structural reason for the deflected course of the supracoracoideus tendon. Medially, the dorsal extremity of the clavicle articulates with the upper medial surface of the acrocoracoid, forming the dorsomedial roof of the triosseal canal. A further factor of importance is that two important muscles arise from the upper anterior surface of the acrocoracoid, the M. coracobrachialis anterior and the M. biceps brachii. As noted earlier, the coracobrachialis anterior is a primary extensor of the humerus and the biceps is equally important as the principal flexor of the 
a

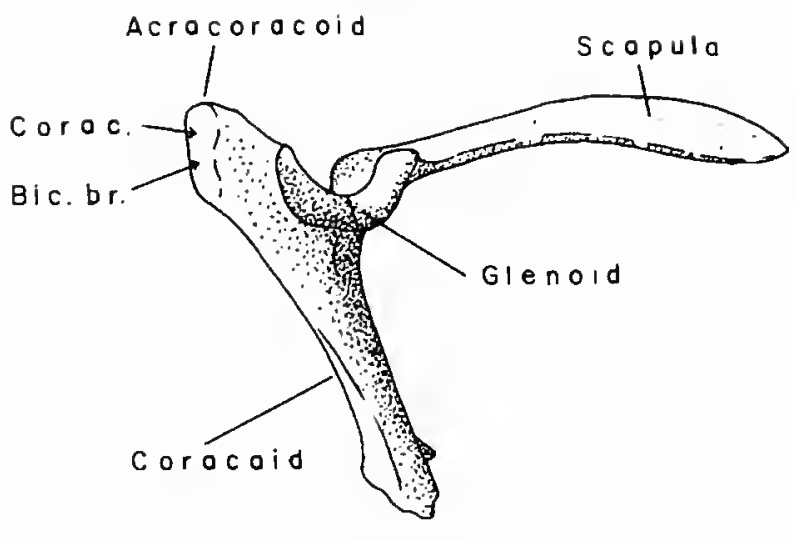

$\mathrm{b}$

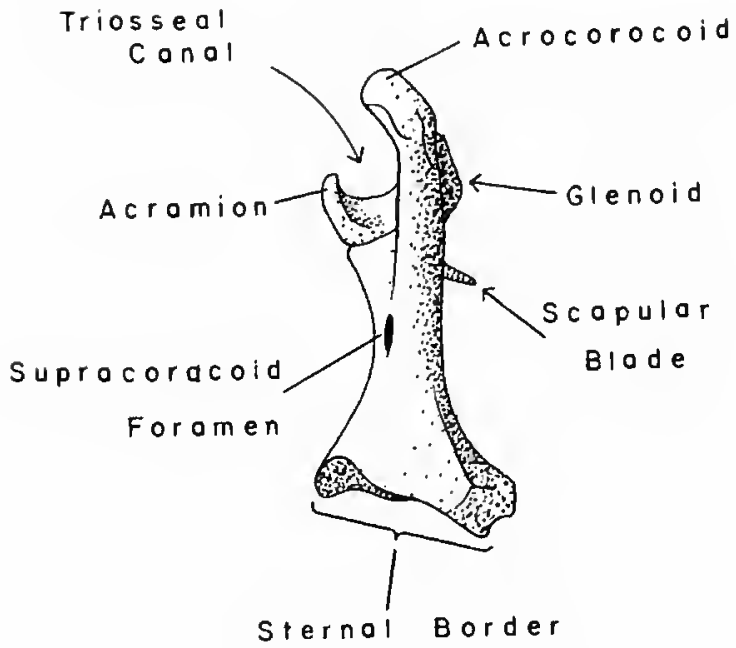

$\mathrm{c}$

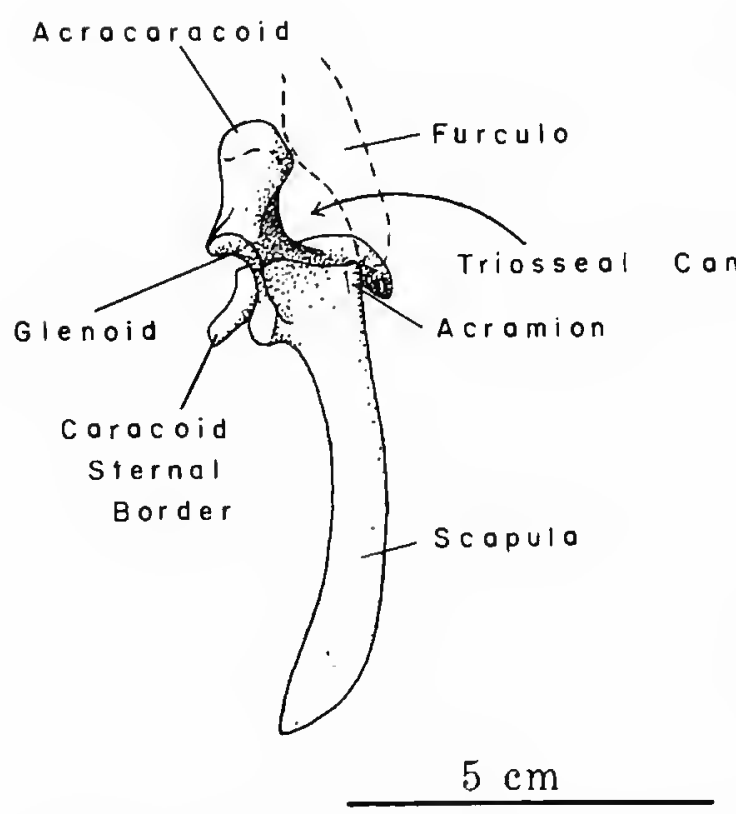

d

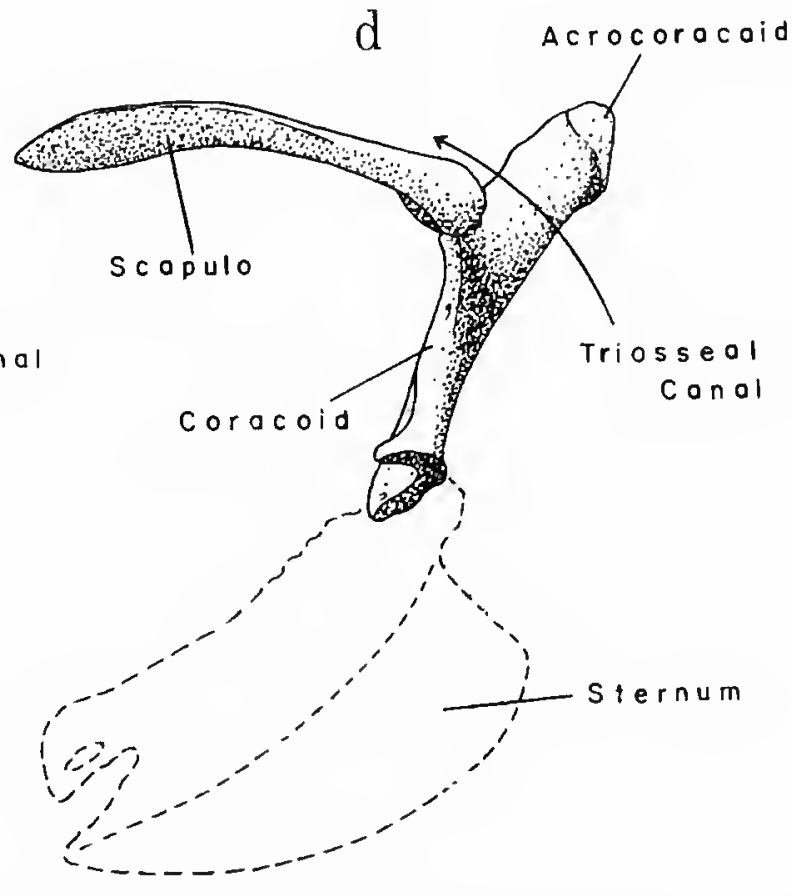

Figure 3.-Four views of the left scapulo-coracoid of Cathartes aura to show the nature of the triosseal canal, which is responsible for the reversed action of the M. supracoracoideus in modern carinates: $a$, lateral view; $b$, anterior view; $c$, dorsal view; $d$, medial view. (Bic. br. $=$ the site of origin of the M. biceps brachii; Corac. = the site of origin of the M. coracobrachialis anterior.

forearm. It is safe to assume that the elevated positions of these origins at the apex of the acrocoracoid have functional significance.

Without concerning ourselves with homologies, or the proper name for the avian "supracoracoideus," the action of that muscle in modern carinates emerges as extremely important for reconstructing some of the details of avian evolution. By the nature of its location and architecture, it is clear that at some carlier stage in the evolution of birds the antecedent of this muscle must have acted to depress the arm. Therefore, its action has been completely reversed, probably as a consequence of the development of the pulley-like arrangement of the triosseal canal and its interposition between the points of origin and insertion. The avian wing is elevated chiefly by this ventral muscle, rather than by dorsal muscles as we would expect, and as is the case in bats.

The fact that virtually all muscles in all organ- 
isms follow the most direct route between the points of origin and insertion argues strongly against the possibility that the insertion of the supracoracoideus gradually migrated to the dorsal side of the humerus, without prior or concurrent deflection of the fibers or tendon leading to that insertion. Even if the insertion had shifted to a dorsal position on the humerus, contraction of the muscle would still depress, as well as rotate, the humerus-unless the fibers approached the humerus from above. Consequently, the most logical explanation of the peculiar organization and action of the modern avian supracoracoideus would seem to be that its path was altered during the course of avian evolution. Modern carinates, together with the specimens of Archaeopteryx, establish that these postulated changes resulted from drastic changes in the shape of the coracoid and that these changes occurred subsequent to the Archaeopteryx stage.

\section{"Flight" Apparatus of Archaeopteryx}

The portion of the skeleton of Archaeopteryx that can be equated with the flight apparatus of modern carinates displays a number of important features:

1. There appears to be little or no loss of flexibility in the trunk region, either by vertebral fusion or by restriction of vertebral articular freedom. Although fully ossified gastralia are present, there is no evidence of ossification of either sternal ribs or the sternum. Also, there are no uncinate processes on the dorsal ribs.

2. The pectoral arch does not appear to have been as rigidly fixed as in modern birds. The coracoids are short, subquadrangular, not strut-like, and had only cartilaginous or membranous contact with the sternum. The clavicles, however, were fused and fully ossified into a robust furcula, but the nature of its contacts with the scapulocoracoid are not known.

3. Contrary to de Beer's (1954) interpretation, no sternum is preserved in any of the presently known specimens of Archaeopteryx (Ostrom, in press). This indicates that the sternum was almost certainly cartilaginous and probably lacked a keel. It may even have been membranous. Furthermore, the space anterior to the gastralia is quite short, a clear indication that the sternum, whether ossified or not, could not have been enlarged, as it is in all modern carinates.

4. The forelimb is elongated, but it does not possess any of the skeletal specializations of modern carinates that are usually equated with avian flight. The deltopectoral crest of the humerus is comparable to that of small theropod dinosaurs and is longer and more elevated above the shaft than is typical of most carinates. The elbow and wrist joints are unmodified, the carpals and metacarpals are not fused and digits I, II, and III are separate and unfused. The London and Berlin specimens clearly show that the forelimbs bore large, remex-like feathers, but it is uncertain whether these feathers were attached directly to the forelimb skeleton as in modern birds and as would seem to be required of true "flight" feathers. Despite exceptional preservation of several of the specimens, none shows anything that can reasonably be interpreted as quill nodes on the ulna. This is negative evidence only, but a further indication that the "flight" feathers were not firmly attached to the skeleton is the fact that imprints of the "primaries" of both wings in the London specimen are preserved with only slight disarrayment, yet the left hand is disarticulated and the right hand is missing altogether.

5. The long reptilian tail of Archaeopteryx bore feathers, but there is no indication in any of the specimens that the caudal series was undergoing reduction or fusion into a pygostyle. On account of the feathers, we can conclude that the tail may have functioned as an aerodynamic, rather than an inertial, stabilizer, but this should not be construed as proof of flight capability in Archaeopteryx.

The more important of the above conditions in Archaeopteryx are the nonavian form of the coracoid, the absence of an ossified sternum, the unfused carpometacarpus and the unfused digits of the manus. As Figures 4 and 5 show, the coracoid of Archaeopteryx is not elongated, and clearly did not serve as a strong, anticompressive brace against the sternum. It appears to have been fused with the scapula and its sternal border, although not as robust as the scapular margin, is well defined, but thin. The glenoid segment is stout, a relatively large supracoracoid foramen is present and a very prominent lateral process occurs just anterior to and below the glenoid. This last feature, some- 

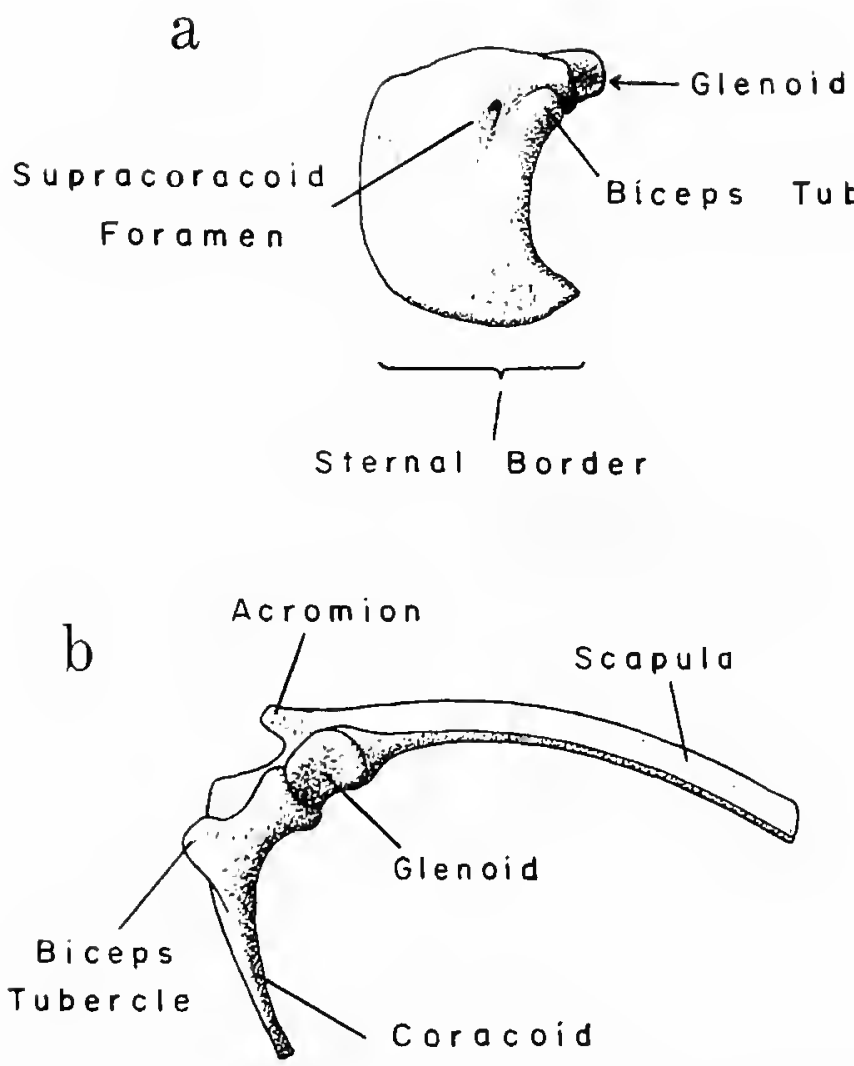

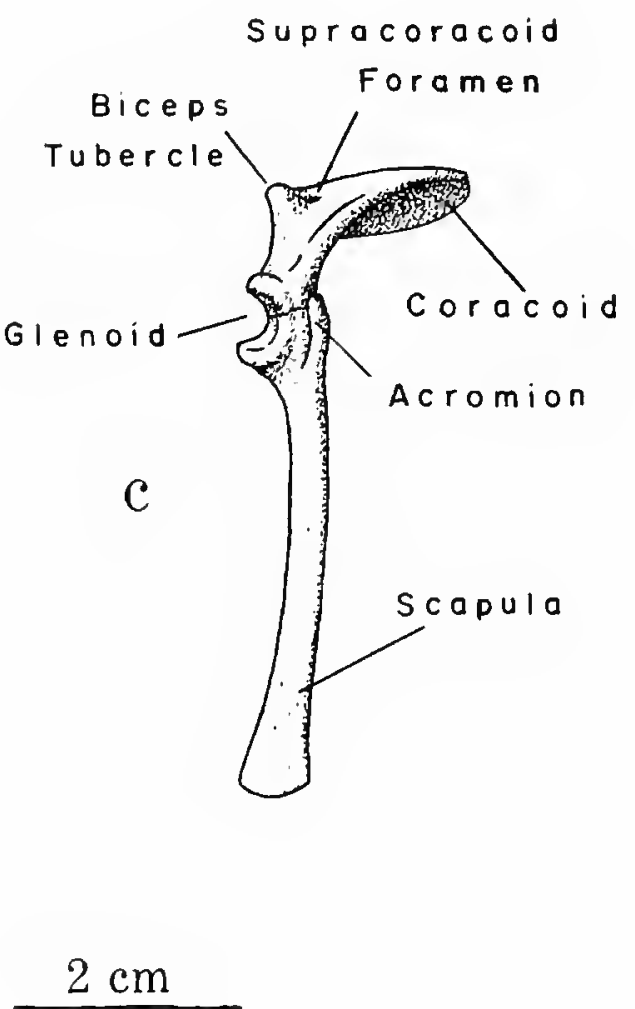

$2 \mathrm{~cm}$

Figure 4.-Three views of the pectoral girdle of Archaeopteryx as reconstructed from the London, Berlin, and Maxberg specimens: $a$, anterior view of the left coracoid; $b$, lateral view of the left scapulo-coracoid; $c$, dorsal view of the left scapulo-coracoid.

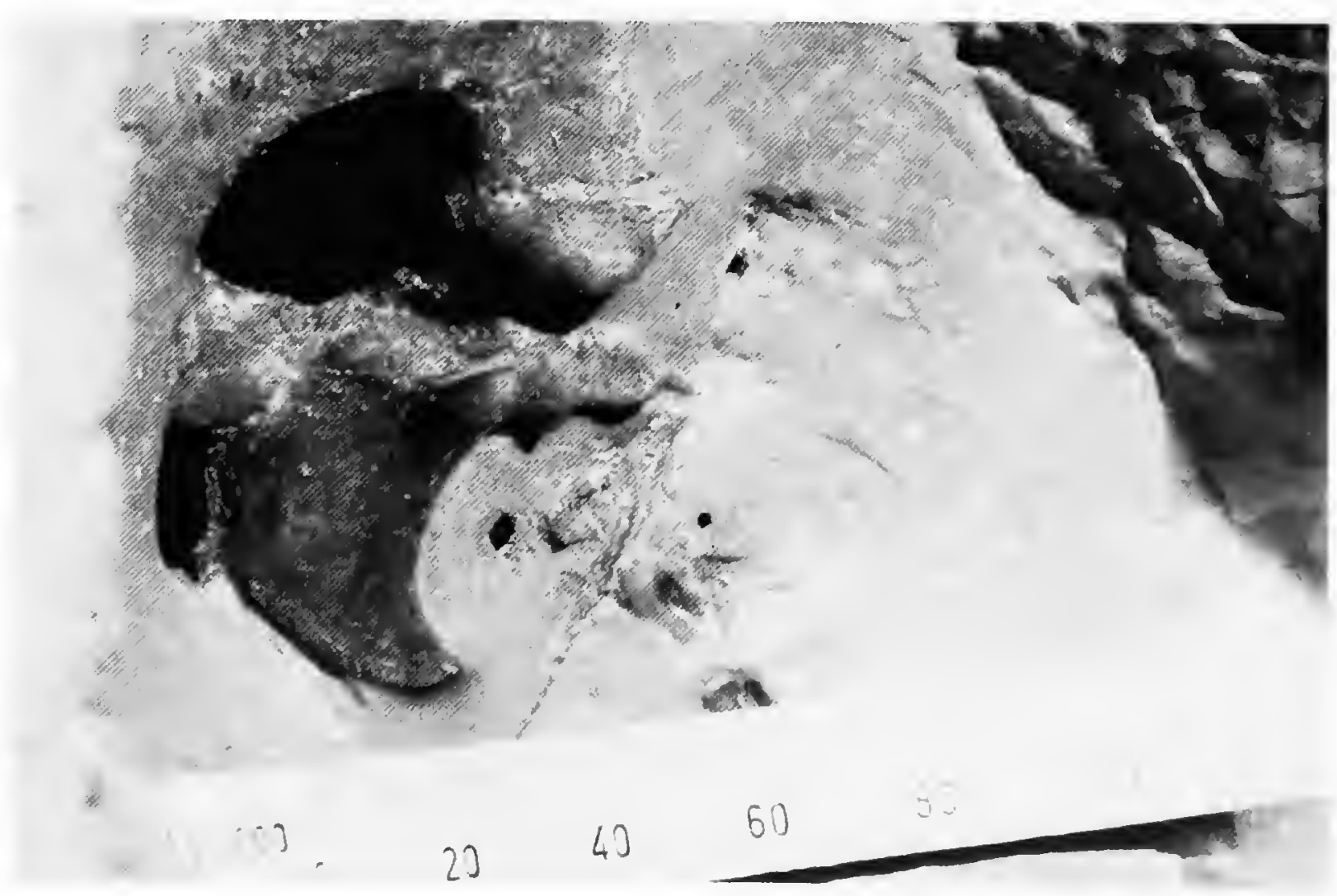

Figure 5.-Left coracoid and glenoid of the London specimen of Archaeopteryx, as seen in anterior view from the underside of the main slab. (The smallest divisions on the scale equal $0.5 \mathrm{~mm}$.) 
times referred to as the biceps tubercle (Walker, 1972), is of special significance because it appears to be the precursor of the avian acrocoracoid. Contrary to Bakker and Galton's (1974) interpretation, the glenoid does not face downward, but is directed laterally (Figures 4 and 5) more or less as in modern carinates (Figure 3).

\section{The Transition from Archaeopteryx to Modern Birds}

\section{Changes in the Pectoral Girdle}

Before attempting to reconstruct hypothetical transitional stages in the evolution of the pectoral arch between Archaeopteryx and modern birds, it may be useful to review certain facts. First, the coracoid of all lower tetrapods, including birds, has certain constant relationships with other elements of the trunk. It occupies a position between the scapula (with which it usually forms the shoulder socket) and the sternum, regardless of whether the latter is ossified or cartilaginous. Thus, at least two regions of the coracoid, the sternal border and the scapular border, are unmistakable reference points no matter what the shape or size of the coracoid. Similarly, the glenoid portion is always recognizable.

The second consideration is the role of the coracoid in forelimb biomechanics of lower tetrapods. Chief among the various muscles that attach to the coracoid (most of which insert on the humerus) is the biceps, the principal flexor of the antebrachium. (A structural and functional analog, the $M$. coracoradialis proprius, is present in amphibians.) The biceps passes between the coracoid and the internal proximal surfaces of the radius and ulna. Even in mammals, where the coracoid is no longer present as a separate bone, the major forearm flexor (which also happens to be termed the biceps) originates on the presumed relict of the coracoid, the coracoid process of the scapula.

The final consideration is that the location of the flexor origin relative to the glenoid fossa determines the approximate path of forearm flexion. Thus, for any given position of the humerus, the approximate orientation of the plane of forearm flexion can be determined from those two points. For example: the biceps brachii of lizards originates on a small area adjacent to the sternal border of the coracoid, anterior and ventral to the glenoid. With the humerus positioned in a horizontal transverse position, the biceps flexes the forearm anteroventrally toward the midline. But with the humerus extended forward, forearm flexion is down and backward. In birds, the site of origin of the biceps on the anterolateral surface of the acrocoracoid is situated in front of and above the glenoid; consequently, forearm flexion is restricted to a forward movement (Figure 6).

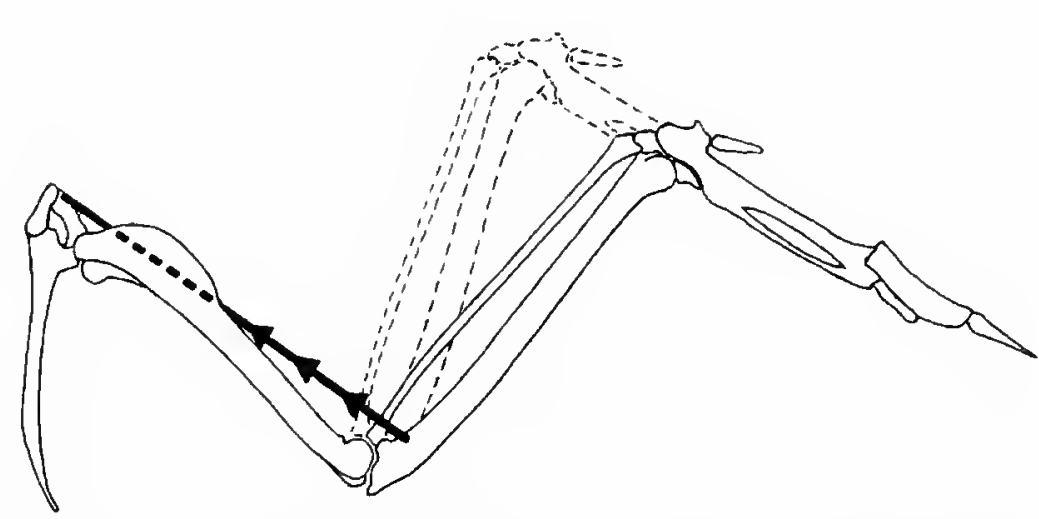

FiguRE 6.-Dorsal aspect of the wing, skeleton and pectoral girdle of Corous brachyrhynchos, showing the location and action of the M. biceps brachii (heavy arrow), the chief flexor of the forearm in modern birds.

If, as seems reasonable, we accept the so-called biceps tubercle of Archaeopteryx as the homolog of the acrocoracoid of modern birds and the probable site of origin of the chief flexor of the forearm (whatever we call it), we can reconstruct the general nature of forearm flexion in Archaeopteryx. Although the precise orientation of the scapulocoracoid in Archaeopteryx cannot be established from any of the presently known specimens, there can be little doubt that the biceps tubercle was situated well below and anterior to the glenoid (Figure $4 b$ ). Consequently, there must necessarily have been a major downward component in forearm flexion, regardless of whether the humerus was extended, retracted, or even adducted.

Transformation of the avian coracoid from the condition in Archaeopteryx to that of modern birds involved two major changes: the dorsoventral elongation of the main body of the coracoid and the raising of the site of origin of the $M$. biceps brachii by anterodorsal prolongation of the acrocoracoid. Elongation of the coracoid increased the distance between the glenoid and the sternum, pre- 


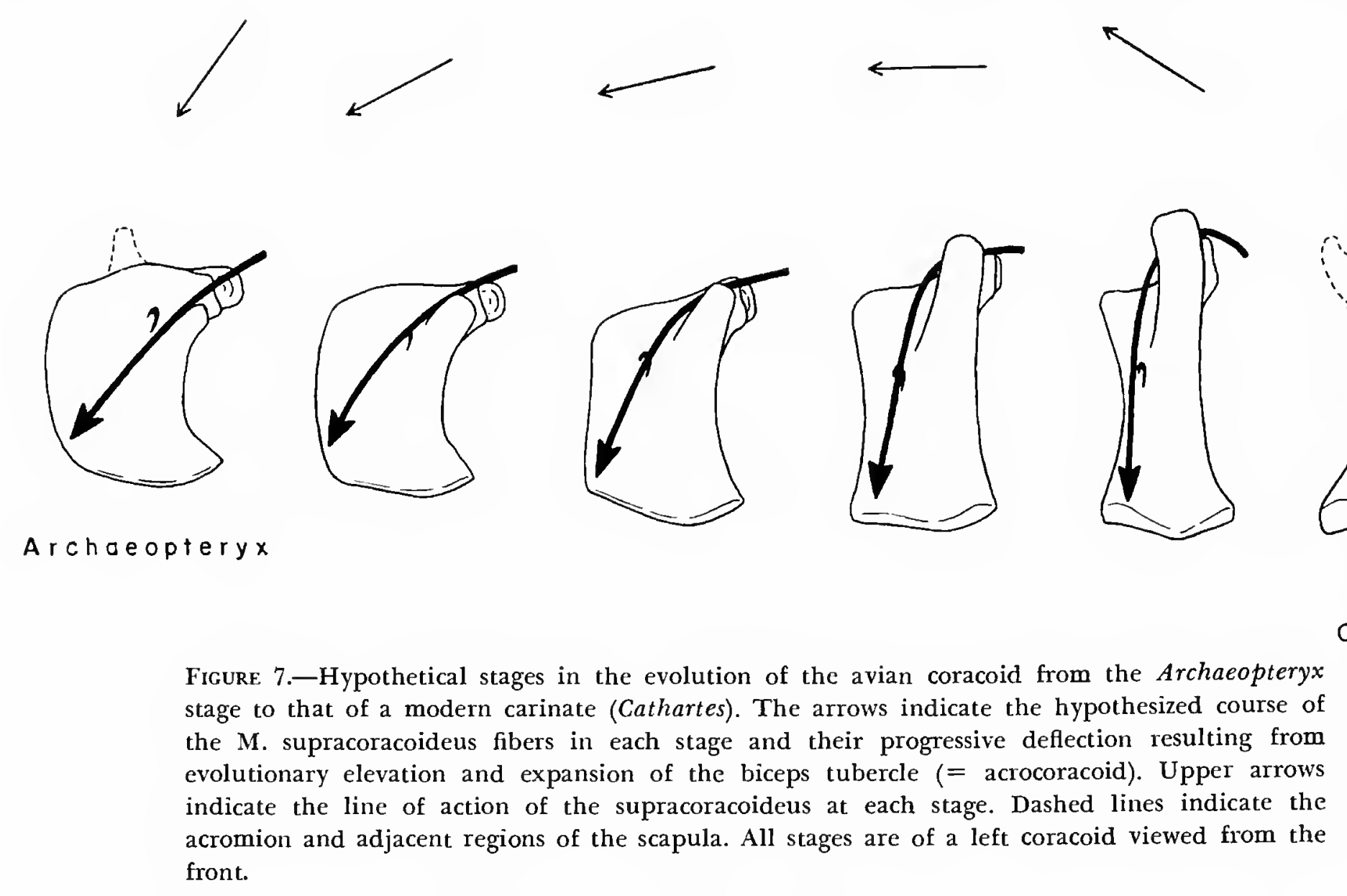

FIGURE 7.-Hypothetical stages in the evolution of the avian coracoid from the Archaeopteryx stage to that of a modern carinate (Cathartes). The arrows indicate the hypothesized course of the M. supracoracoideus fibers in each stage and their progressive deflection resulting from evolutionary elevation and expansion of the biceps tubercle ( $=$ acrocoracoid). Upper arrows indicate the line of action of the supracoracoideus at each stage. Dashed lines indicate the front.

sumably increasing the range of dorsoventral humeral excursion. This in turn may have been correlated with the anteroposterior elongation of the sternum, the development of the sternal keel, and the enlargement of the ventral adductor musclesthe $M$. pectoralis. Increased force of forelimb adduction, for whatever biological role, required strengthening of the coracoid into a strong, anticompressive strut between the shoulder socket and the enlarged muscle origins on the sternum.

Because the supracoracoideus of lower tetrapods originates ventral and anterior to the glenoid, and because it also has a ventral origin close to the sternal border in modern birds, the primitive site of origin of this muscle in Archaeopteryx probably was in a similar position-ventral and somewhat medial to the biceps tubercle. If so, then any upward expansion of the biceps tubercle would have impinged against the supracoracoideus tendon, gradually deflecting its course medially around the base of the expanding "protoacrocoracoid." Once the base of this process reached the level of the glenoid, the then-deflected supracoracoideus would have pulled the humerus anteromedially, rather than downward. Continued expansion and elevation of the acrocoracoid would have resulted in further deflection of the supracoracoideus. The action of this muscle almost certainly was not reversed abruptly, but probably changed gradually from that of a humeral adductor, to an anteroventral extensor, to a forward extensor, to an antero-dorsal extensor and finally becoming an abductor of the humerus. Figure 7 illustrates how this transformation may have taken place.

If the above reconstruction is even approximately correct, it is clear that one of the major factors in the evolution of avian flight structures was the upward expansion of the acrocoracoid. This conclusion is established beyond any doubt by the presently reversed action of the supracoracoideus in modern birds. The critical question is: What brought about the upward expansion of the acrocoracoid? There appear to be several possibilities: (1) elevation of the anterior part of the glenoid and rotation of the shoulder socket to face directly laterally, thereby permitting unrestricted transverse (up and down) movements of the forelimb; (2) provision of an enlarged buttress at the level of the glenoid for the furcula to brace against, thereby insuring proper transverse separation of the shoulder sockets; (3) raising of the levels of humeral extension and forearm flexion by elevat- 


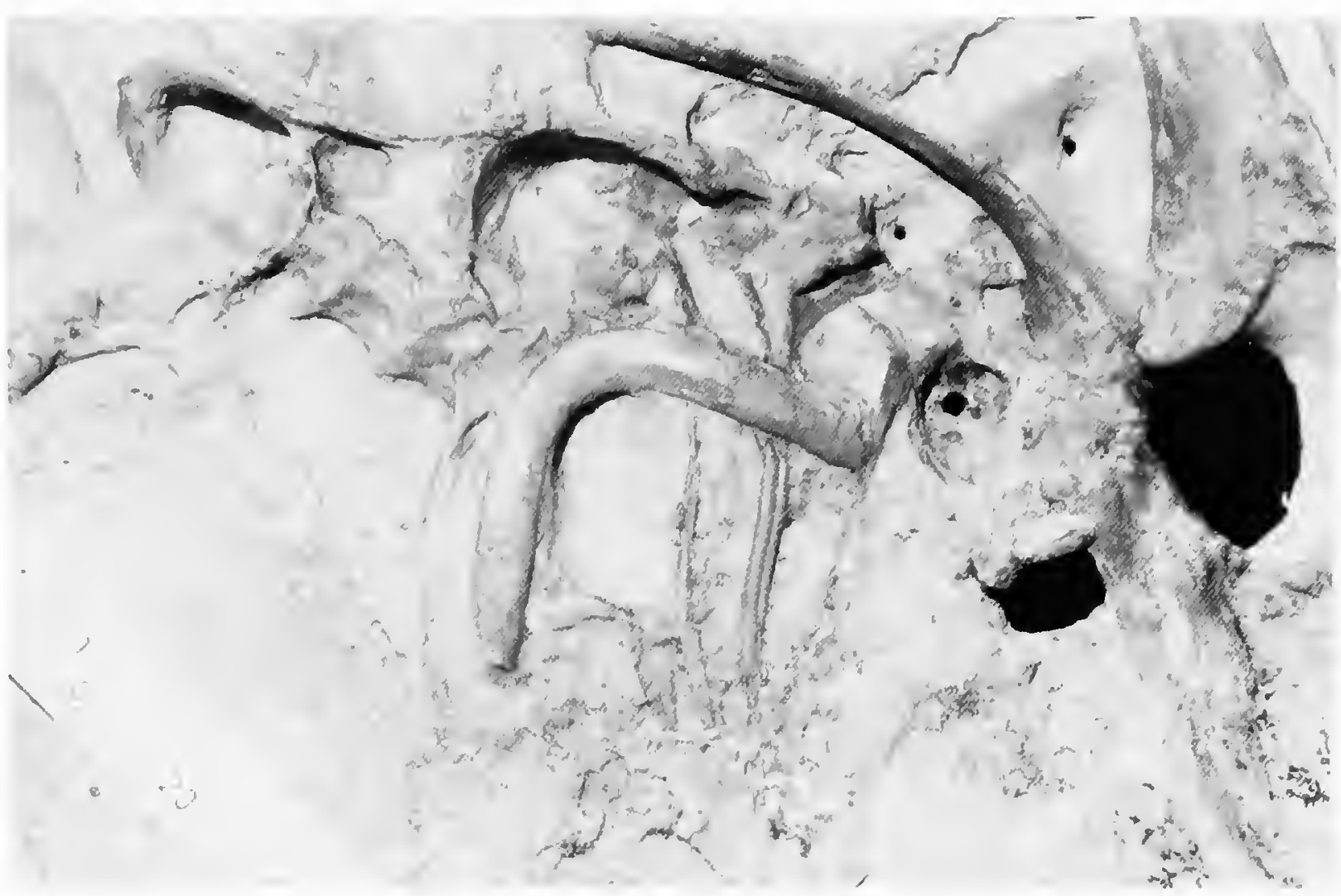

Figure 8.-The furcula of Archaeopteryx as preserved in the London specimen. The exposed surface is probably the anterior surface. (The smallest divisions on the scale equal $0.5 \mathrm{~mm}$.)

ing the sites of origin of the coracobrachialis and biceps. In all probability, none of these factors acted alone, and other less obvious factors may have been involved as well.

Whether enlargement of the pectoral adductor muscles and the elongation of the coracoids into robust struts occurred before, after, or concurrently with upward expansion of the acrocoracoid cannot be determined in the absence of intermediate stages in the avian fossil record. Whatever the sequence, the upward growth of the acrocoracoid would have progressively deflected the action of the supracoracoideus. It also brought about significant changes in other forelimb movements, especially in elevating the range of humeral extension and increasingly confining it to the craniad sector. As a direct consequence, the level of forearm flexion was also elevated to a nearly horizontal fore-aft plane more or less perpendicular to the transverse, up and down, humeral movements produced by the enlarged pectoral muscles.

Considering these three possibilities, it appears that the glenoid in Archaeopteryx already faced laterally and slightly forward (Figure 4b,c) not ventrolaterally, as Bakker and Galton (1974) claim. The coracoid portion of the glenoid also seems to have been elevated. Yet, the biceps tubercle was still small and located well below the glenoid. Also, as was noted earlier, a robust furcula is present in Archaeopteryx (as seen in the London [Figure 8] and Maxberg specimens), and although the nature of its articulations with the other elements of the pectoral girdle is not clear, there does not appear to have been any special structure of the coracoid that might have served to buttress it, since, as already noted, the biceps tubercle is not elevated. This, of course, raises the question of the function of the furcula in Archaeopteryx. Did it serve as a transverse spacer between the shoulder sockets? If so, it would appear to have been related to some activity other than powered flight-perhaps predation. Since both the M. coracobrachialis anterior and the $M$. biceps brachii arise from the upper anterior surface of the acrocoracoid in all modern carinates, then by virtue of their positions above and in front of the glenoid, these muscles, respectively, pull the humerus forward and up, and flex the forearm forward and inward toward the midline. In Archaeopteryx, the humerus apparently could not be extended forward and upward above the level of the shoulder because no part of the coracoid was situated above 
and in front of the glenoid (Figures 4 and 9). Thus, of the three possibilities suggested above, the evolutionary expansion of the avian acrocoracoid would seem to have been most critically linked with the actions of the coracobrachialis and biceps muscles. There appears to have been some selective advantage in raising the level or attitude of forelimb extension and forearm flexion.

So far, I have given little attention to the scapula. This is because the scapula of Archaeopteryx already had acquired a form remarkably similar to that of modern birds, being very long, narrow and strap-like. Its principal distinctions from the condition in most modern birds are its fusion to the coracoid, the form of the acromion, and the shape of the distal extremity, which is rectangular or slightly flared in Archaeopteryx rather than tapered. The fact that the acromion is more prominent and robust than in most modern birds suggests that the $M$. deltoideus was perhaps a more
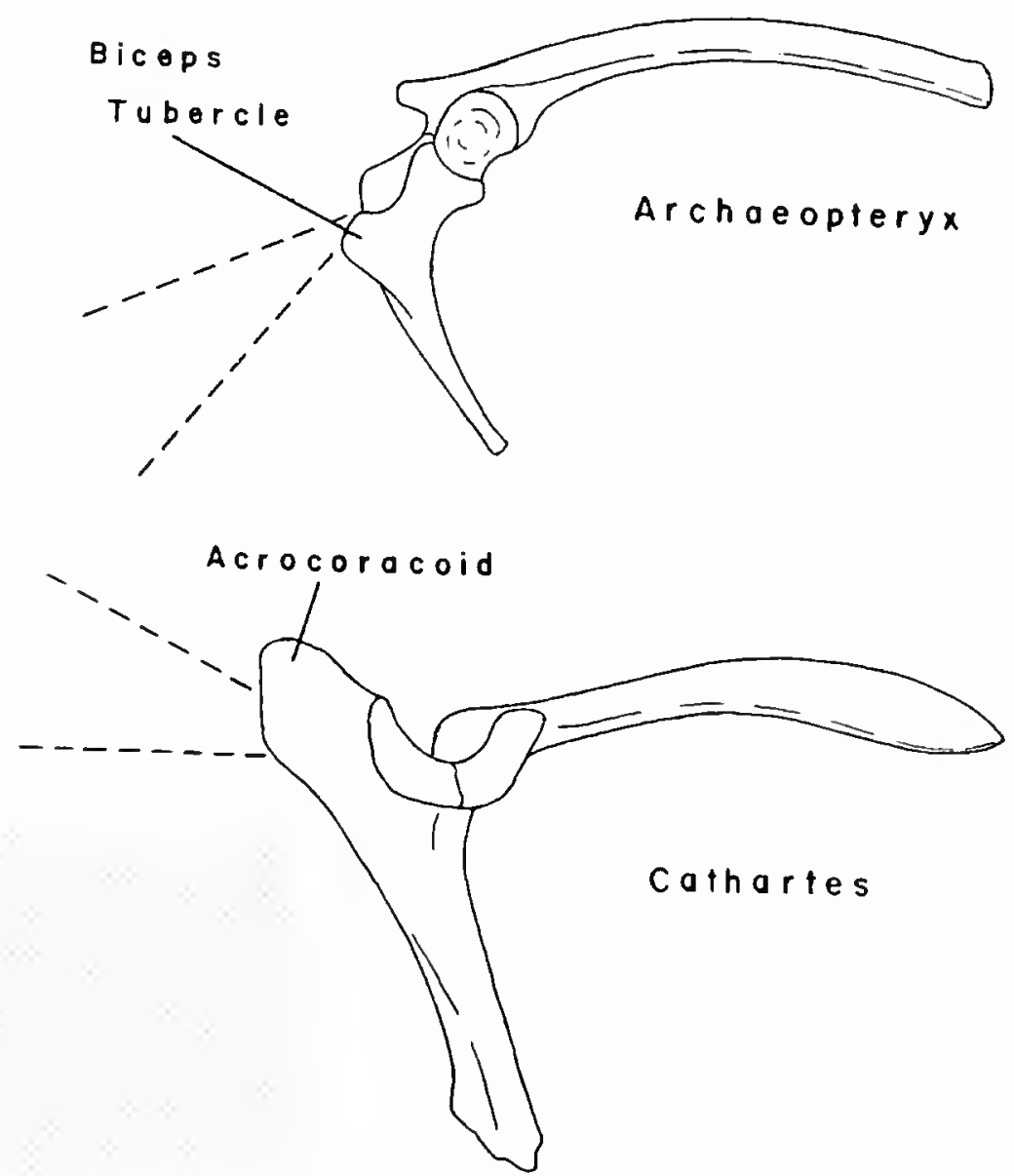

Figure 9.-Comparison of lateral views of the pectoral arch of Archaeopteryx and a modern carinate (Cathartes) to show the respective positions of the biceps tubercle and the acrocoracoid relative to the glenoid. The broken lines define the approximate dorsoventral range of humeral extension and forearm flexion possible in each as a result of contractions by the muscle that originated on those two processes. important humeral elevator at the Archaeopteryx stage of avian evolution. This would be consistent with the conclusion reached above that the supracoracoideus of Archaeopteryx could not have elevated the humerus (as was noted by Walker, 1972), but rather must have been a lateral adductor. If the deltoideus, however, was more important as a humeral elevator at the Archaeopteryx stage than it is in modern carinates, then it would appear that the force of the recovery stroke must have continued to decline in birds succeeding Archaeopteryx, until complete deflection of the supracoracoideus was accomplished. This implies that there probably was no tendency at the Archaeopteryx stage, or immediately afterward, toward powered flight.

It should also be noted here that the stout acromion in Archaeopteryx may not have had anything to do with the deltoideus muscles, but might have served as a buttress for the stout furcula. This cannot be established on the basis of present specimens, however.

The narrow form of the scapula, as compared with the broad, triangular form in all other tetrapods except theropod dinosaurs, suggests that the musculature that inserted or originated on the scapular blade-and particularly on its dorsal surface-was greatly reduced. This certainly is true of modern birds in which the $M$. rhomboideus and M. scapulohumeralis (the largest dorsal shoulder muscles) are of relatively small size. The fact that this narrow scapular form occurs only in obligate bipeds (birds, Archaeopteryx, and theropod dinosaurs), but not in facultative bipeds (such as nonhuman primates, kangaroos, or ornithopod dinosaurs), or in any quadrupedal animal is highly suggestive. It indicates that strong stabilization of the pectoral arch by muscles connecting the scapular blade with the vertebral column and dorsal ribs, and powerful abduction of the limb by large muscles extending between the humerus and the scapular blade, were unnecessary in obligate bipeds in which the forelimb was no longer involved in weight support.

\section{Changes in the Forelimb}

Comparison of the forelimb skeleton of Archaeopleryx with that of modern birds reveals several major differences, the most conspicuous of which 


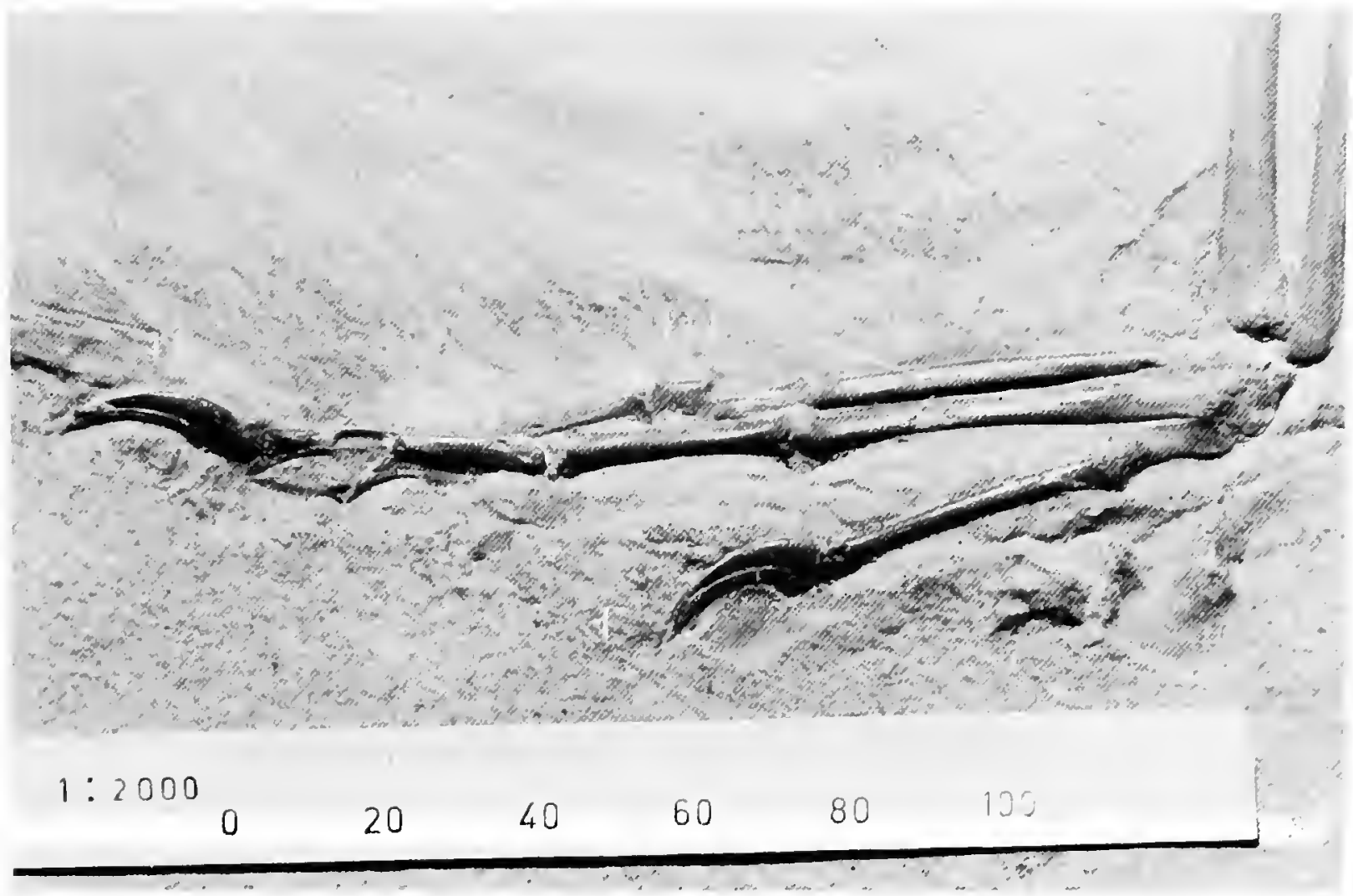

Figure 10.-The right manus and carpus of the Berlin specimen of Archaeopteryx, seen in dorsal aspect. Notice the separated fingers and the unfused metacarpus and carpus, as well as the extent of lateral flexion. (The smallest divisions on the scale equal $0.5 \mathrm{~mm}$. Roman numerals identify the digits.)

occur in the hand and wrist. Figure 10 shows the right hand and wrist of the Berlin specimen of Archaeopteryx with its unfused metacarpus and three separated fingers. The same construction is present in the other three specimens in which the hands are preserved. This construction is in sharp contrast to the united metacarpus and manus of modern birds (Figure 11). It is obvious that phalanges have been lost or co-ossified in at least the external finger (digit III) of modern birds, but the most interesting changes have taken place in the metacarpus and wrist. Figure 12 illustrates the carpus and metacarpus as they are preserved in the Berlin (Figure 12a) and Eichstätt (Figure $12 b)$ specimens, compared with the same elements of a modern carinate, Cathartes aura (Figure $12 c, d)$. The first metacarpal is considerably shorter than the other two (Figure 10), as it is in modern forms, but it does not appear to be co-ossified with metacarpal II, nor are the second and third metacarpals fused. The carpus consists of only three elements, a large distal carpal with a distinctive semicircular proximal profile, and two smaller bones, which probably represent the radiale (sca- pholunar) and the ulnare (cuneiform). Although neither of the last two elements resemble modern bird carpals, two features in Archaeopteryx do preview specialized conditions of the modern avian carpometacarpus. These are the large Iunate distal carpal that is closely articulated with the first and second metacarpals (Figure 12a,b), and the internal expansion at the base of metacarpal I. There can be little doubt that the lunate carpal of $\mathrm{Arch}$ aeopteryx, by fusion with the two metacarpals, became the pulley-like trochlea of the carinate carpometacarpus. The proximal internal expansion at the base of the first metacarpal in Archaeopteryx is almost certainly the precursor of the large extensor process (processus metacarpalis I) of the modern carpometacarpus. In Figure 13, I have attempted to show how the modern avian carpometacarpus probably evolved from the condition in Archaeopteryx.

Reconstructing the above intermediate stages is far simpler than trying to account for the conditions that brought about such changes. The second digit clearly was the dominant finger and ultimately became the main supporting structure of 


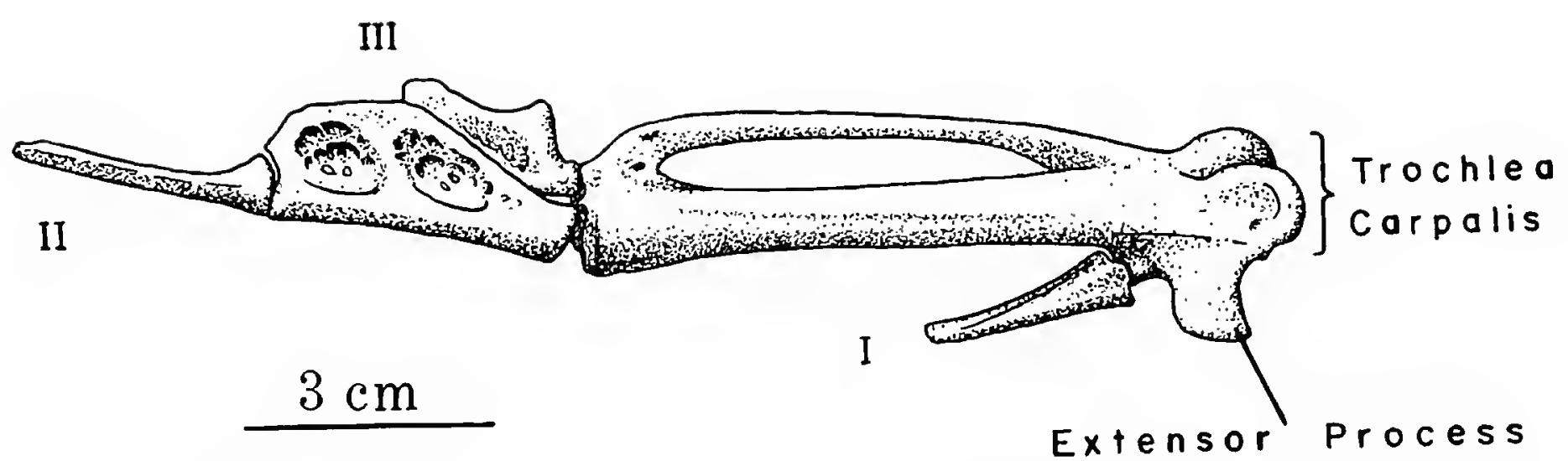

Figure 11.-The right manus and carpometacarpus of Cathartes aura in dorsal aspect, for comparison with Figure 10. (Roman numerals identify the digits.)

the primary remiges. The third or outermost finger gradually was reduced and metacarpal III was modified into a posterior (external) brace against metacarpal II. These changes could well have come about in connection with flight and the attachment of the primaries to the second metacarpal, presumably bracing it against lift forces that would tend to rotate the second digit and metacarpal upward. Fusion of the lunate carpal to the metacarpus, and its expansion into the pulleylike trochlea, increased the degree of flexion possible at the wrist, but at the same time reduced wrist mobility to the plane of the metacarpus and the wing. The prominent extensor process of the modern carpometacarpus is the point of insertion of the largest muscle of the avian forearm, the $M$. extensor metacarpus radialis, the action of which extends or unfolds the hand (Figure 14).

In the discussion that follows, it is essential to distinguish between two very different kinds of flexing movements at the wrist: that in which the extremity is flexed toward the ulnar or external side of the forearm (termed lateral flexion here) and that in which the hand and metacarpus are "flexed" inward toward the radial side of the forearm. This last movement might be termed "medial flexion," but for the sake of clarity it is designated here as "hyperextension." These terms differ from the usual terminology applied by ornithologists (which by convention is in terms of a laterally extended wing), but hopefully they will be clear to all readers. The term extension is used here in the sense of straightening the wrist, and where necessary for clarity, it will be specified as extension from the laterally flexed or the hyperextended condition.

In the Berlin and Eichstätt specimens of Archaeopteryx, the hands are flexed laterally toward the ulna at about 80 degrees to the radius and ulna. Close examination of the wrist in each case (Figure 12a,b), and especially of the morphology of the lunate carpal and the external aspect of the ulnar extremity, reveals that in both specimens the wrists are fully flexed. Notice that the internal condyle or condylus metacarpalis does not extend proximally along the outer surface of the ulnar shaft as it does in modern birds. For contrast, Figure $12 c$ shows the much greater maximum degree of lateral flexion (hyperflexion) possible in the modern bird wrist. Also conspicuous in modern birds is the elongated extensor process of the carpometacarpus, which greatly increases the leverage of the principal extensor of the hand.

It is tempting to relate these features to some aspect of flight; for example, the need for adjusting or changing the surface area of the airfoil by improved efficiency and precision of extension and flexion at the wrist. Once flight capability had been achieved, increased leverage for the $M$. extensor metacarpus radialis would reduce the amount of energy required to counteract the force of the airstream that tends to flex or fold the wing extremity laterally. On the other hand, during the power stroke, lift forces tend to open or extend the wing extremities. Another possibility is that the extensor process grew larger in conjunction with the development of wrist hyperflexion, which in turn was made possible by gradual expansion of 

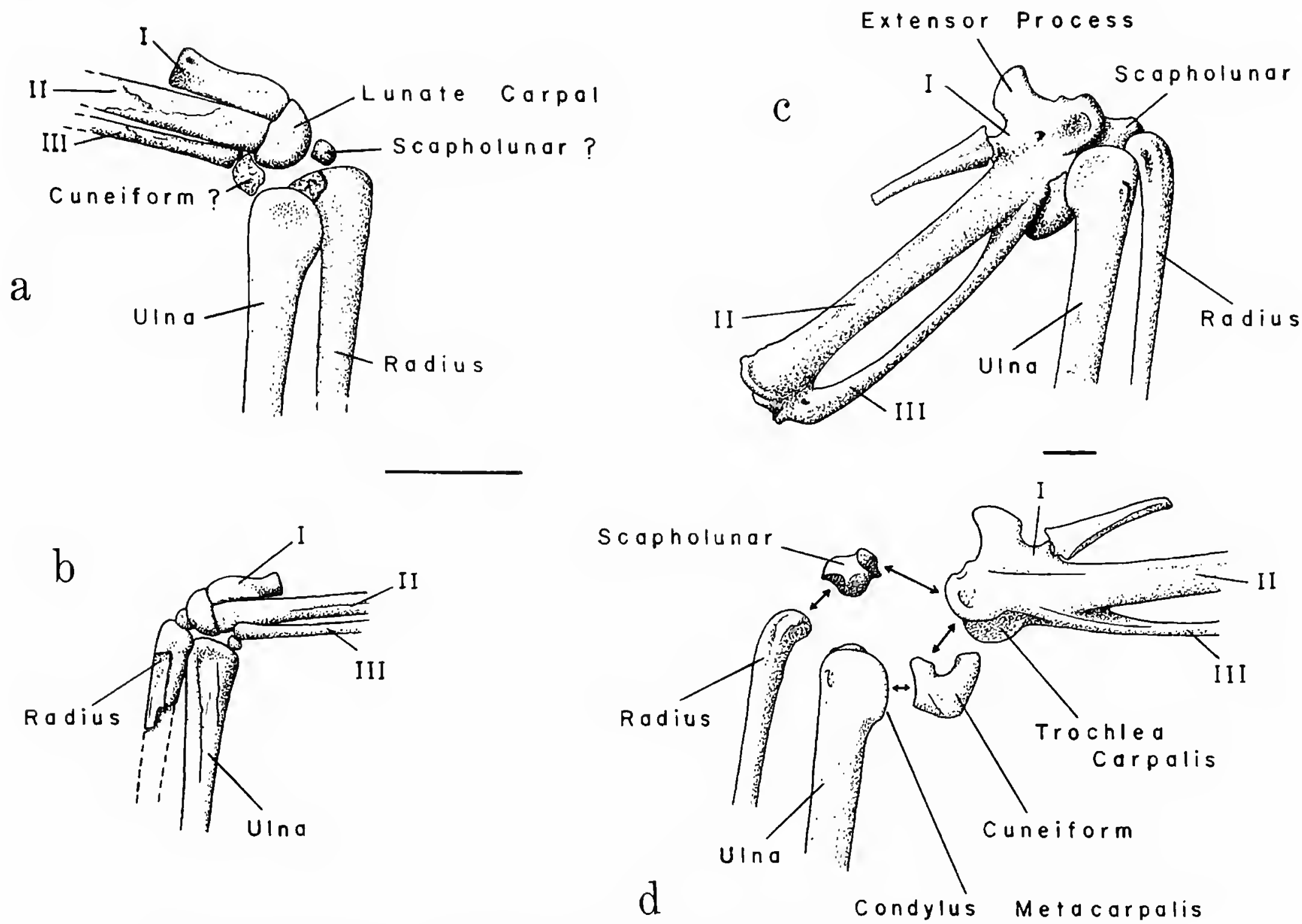

Figure 12.-The wrists of Archaeopteryx ( $a$ and $b$ ) and Cathartes aura $(c$ and $d$ ) as viewed from above: $a$, left wrist of the Berlin specimen; $b$, right wrist of the recently recognized Eichstätt specimen ( $b$ and $c$ are preserved flexed laterally, toward the ulnar side of the forearm, to the maximum degree possible); $c$, left wrist of Cathartes drawn in the same laterally hyperflexed position to show the greater degree of flexion possible in modern carinates; $d$, "exploded" dorsal view of the right wrist of Cathartes, flexed to the same degree as $b$, to show the specialized facets of the wrist elements, arrows indicating complementary articular facets. Notice in particular the lengths of the external portions of the condylus metacarpalis of the ulna and also the trochlea carpalis of the carpometacarpus, as compared with the corresponding regions in Archaeopteryx. Also notice the large extensor process of the carpometacarpus compared with the modest expansion on metacarpal I of Archaeopteryx. The phalanges have been omitted from digit $I$ in $a$ and $b$. (Roman numerals identify the metacarpals; the horizontal lines equal $10 \mathrm{~mm}$ ).

the trochlea carpalis of the carpometacarpus and elongation of the condylus metacarpalis of the ulna. A critical point here, however, is that extreme hyperflexion of the manus has no obvious "flight" advantage, but it clearly is advantageous for compact folding of the forelimb extremities to protect the airfoil when not in use. Under these circumstances, it would appear that the increased extension leverage that was provided by a larger extensor process on the carpometacarpus was not related to the first explanation above, but probably was advantageous for quick unfolding of a hyperflexed wing. This interpretation is reinforced when it is considered in conjunction with the unique linkage between the modern avian elbow and wrist that automatically synchronizes flexion (or extension) at those two joints. As first observed by Coues (1871) and Headley (1895), and confirmed by Fisher's (1957) experiments, the radius of birds functions as a "connecting rod" between 

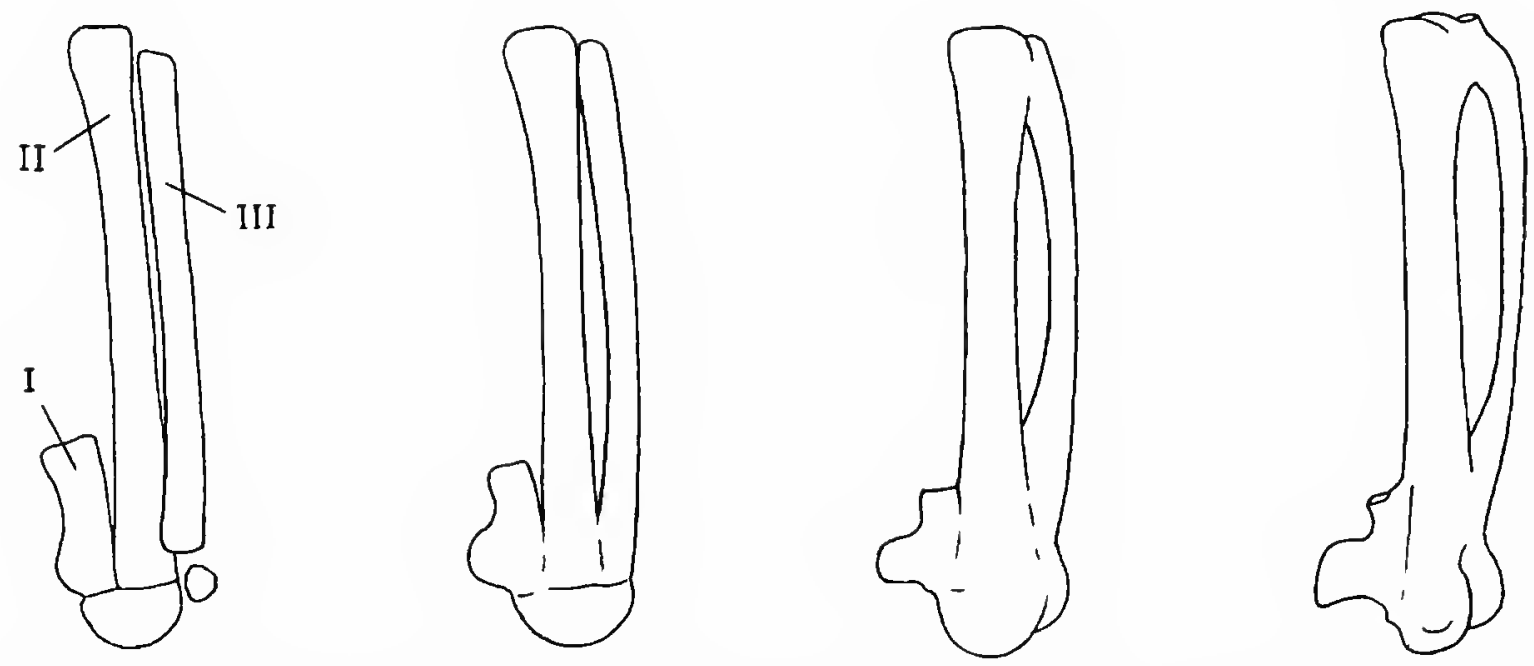

Figure 13.-Hypothetical stages in the evolution of the avian carpometacarpus from the Archaeopteryx stage to that of modern carinates.

the elbow and wrist. Because of the greater length of the radial versus the ulnar condyle of the humerus, the radius slides distally along its axis when the elbow is flexed by the M. biceps, thereby pushing against the carpus and metacarpus and forcing the wing extremity to flex. Extension of the wrist and elbow are similarly linked. In fact, because of the "connecting rod" action of the radius, and the increased leverage of the $\mathrm{M}$. extensor metacarpus radialis provided by the enlarged extensor process, it is possible for that muscle to function as the primary unfolder of the entire wing, not just of the hand. Although smaller than the M. triceps brachii, the forearm extensor, the $M$. extensor metacarpus radialis of most carinates has far better leverage than the triceps (which inserts on the olecranon) for extending the wing extremity.

It is not possible to establish which, if either, of the above possibilities was the decisive factor in the evolution of the modern avian wrist, but the specimens of Archaeopteryx seem to provide a clue. All four of the specimens in which the hand is preserved show what appears to be a maximum degree (about $80^{\circ}$ ) of flexion of the hands toward the ulnar side of the forearm. In other words, the hand could not be hyperflexed or folded back tightly against the forearm as in modern birds. Also, the extensor process is only very weakly developed in these specimens. The nature of the articular surfaces in the wrists of the Berlin and Eichstätt specimens, however, indicates that the hands almost certainly could have been hyperextended medially, or bent toward the radial side of the forearm, to about the same degree that they are preserved flexed laterally toward the ulna, perhaps even more so. This last is important, because medial hyperextension of the hand is not possible in modern birds. In fact, the manus cannot even be fully extended to align parallel with the radius and ulna. From this, the most probable conclusion is that the extensor process is most important for recovery (extension) of the avian manus from a folded or laterally hyperflexed condition. If it had developed for enhancing medial hyperextension it is difficult to understand why this process was retained, even enlarged, while at the same time

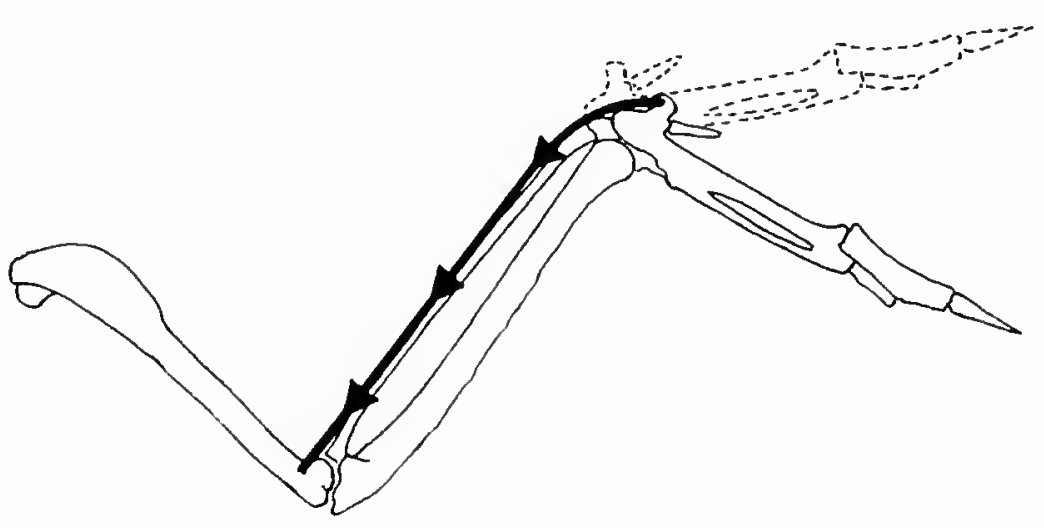

Ficure 14.-Dorsal view of the wing skeleton of Corous brachyrhynchos to show the position and action of the $M$. extensor metacarpus radialis (heavy arrow), the chief extensor of the hand. 
the capacity for medial hyperextension of the hand was being reduced and ultimately eliminated.

The rest of the forelimb appears to have been altered in much less conspicuous ways during the transition from Archaeopteryx to modern birds, yet those changes that can be recognized may have significant implications. In the ulna, the most obvious changes involved the external expansion and elongation of the condylus metacarpalis (Figure 12), the articular facet of which permits hyperflexion of the manus laterally. Less obvious is the apparent lack of direct attachment of the secondary remiges to the ulna, or of the primaries to the metacarpus, as is indicated by the absence of quill nodes. These conditions are lacking in the specimens of Archaeopteryx, but are well developed in a variety of modern carinates.

The humerus of Archaeopteryx, although very bird-like, is much simpler than that of modern carinates. There is a long and well-defined del topectoral crest, but as can be seen in Figure 15, this crest projects farther from the shaft than is characteristic of most later birds. More important, though, are the features that are missing from the humerus of Archaeopteryx. There is no sign of either the external or internal tuberosity, nor is

\section{ARCHAEOPTERYX}
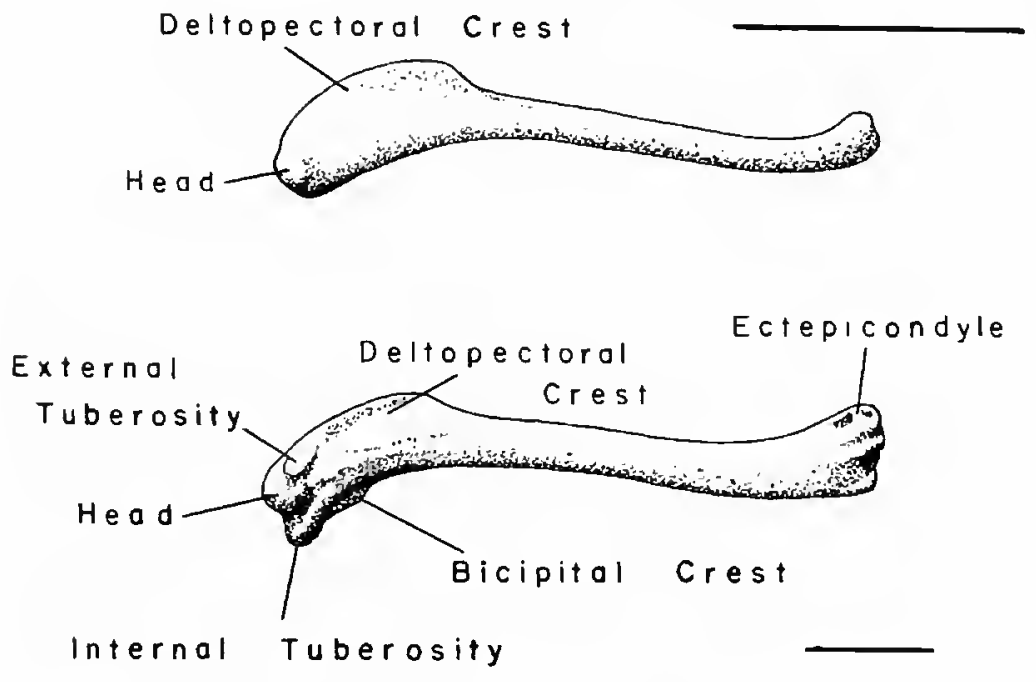

CATHARTES

Figure 15.-Comparison of the humeri of Archaeopteryx and a modern carinate (Cathartes), as viewed in dorsal aspect. Humeri are drawn to unit length for easy comparison, the relative sizes of each being indicated by the horizontal scale lines which equal $3 \mathrm{~cm}$. The humerus of Archaeopteryx is devoid of most of the tubercles and crests that are well developed in most modern birds. Most of these features are the sites of attachment of muscles that act to fold the wing. there a bicipital crest. Distally, the ectepicondyle is also absent, or at least there is no detectable tubercle preserved in presently known specimens. In view of the other related features of the distal segments of the forelimb of Archaeopteryx, the absence of these processes seems to have special significance, because in modern carinates they play a direct part in the compact folding of the wing.

The internal tuberosity (tuberculum mediale) is the site of insertion of the three principal humeral retractors (the M. subscapularis, M. subcoracoideus, and M. coracobrachialis posterior). The external tuberosity (tuberculum laterale) is the site of insertion of the M. supracoracoideus which, in addition to elevating the wing, also rotates the entire folded wing dorsally toward the midline in modern birds. In Archaeopteryx, however, this muscle must have been a humeral depressor, as has been emphasized above. The bicipital crest (crista medialis) of modern birds is the area of insertion of the M. scapulohumeralis posterior, which draws the humerus back against the body. The implications of these conditions are obvious: in the absence of all specialized features of the humerus, ulna, and carpometacarpus that in modern birds are directly related to the folding of the wing, we are forced to conclude that Archaeopteryx was unable to fold the forelimb back against the body as in modern birds. Add to this the absence in Archaeopteryx of an ectepicondyle, which is the site of origin of the $M$. extensor metacarpus radialis, and also the weak development of the extensor process of metacarpal I, which is the site of insertion of this same muscle in later birds. These conditions indicate that powerful or rapid extension of the manus was unlikely, and probably not necessary, because the wrists of Archaeopteryx clearly show that lateral hyperflexion of the manus was not possible. On the other hand, a high degree of medial hyperextension was retained, perhaps as a critical action for prey catching or feeding activities.

\section{Discussion}

It would appear that the acquisition of obligate bipedal posture and locomotion in some preArchaeopteryx stage of avian evolution was responsible in large part for the ultimate development of powered avian flight. An early consequence was the narrowing of the scapula. Strong stabiliza- 
tion of the scapula and shoulder joint, and powerful abduction of the forelimb became less critical than in obligate or occasional quadrupeds (whether of sprawling or upright posture), where antagonistic and synergistic interaction of dorsal abductors and ventral adductors are necessary for precise dynamic control of limb movements and positions under weight-bearing conditions. By the Archaeopteryx stage, forelimb abduction may have been accomplished solely by the action of a reduced remnant of the $M$. deltoideus that presumably originated on the prominent acromion.

With the assumption of upright, obligate bipedal posture and the release of the forelimbs from a weight-supporting role, new forelimb functions became possible. At the Archaeopteryx stage these functions apparently involved laterally elevated movements of the forelimb (as indicated by the outward facing glenoid), anteroventral extension of the humerus (as indicated by the anteriorly facing surface of the coracoid below the level of the glenoid-the only available site of origin for humeral extensors), and powerful anteroventral flexion of the forearm toward the midline (as indicated by the prominent biceps tubercle below and anterior to the glenoid-the most probable site of origin of the forearm flexor). The hands were capable of nearly 180 degrees of lateral flexion and medial hyperextension, as noted above. The capacity for extreme hyperextension at the wrist (not possible in modern birds), coupled with the evidence for strong flexion of the forearm toward the sagittal plane, appears to be especially significant. Perhaps even more significant is the evidence that the forelimb of Archaeopteryx probably could not have been raised above the level of the glenoid when in the anteriorly extended position, simply because no part of the shoulder girdle was situated above and anterior to the glenoid. The strong anterior extensor (M. coracobrachialis anterior) and forearm flexor (M. biceps brachii) of modern birds have their present actions only because of the elevated positions of their origins on the acrocoracoid. The evolutionary upward expansion of the acrocoracoid would seem to have been linked causally with the actions of those two muscles and most especially with that of the humeral extensor. Selection apparently favored the elevation of forearm and hand activities.

As observed above, it is tempting to equate such changes with some aspect of flight. For example, these changes might permit alterations in the surface area of the "wing" by means of flexion or extension of distal components more or less in the plane of the "wing." Notice, however, that these capabilities apparently were not yet available in Archaeopteryx, where wrist and elbow movements were not restricted. Another possibility is that elevation of forelimb extension and forearm and hand flexion and extension ostensibly might improve the aerodynamic qualities of an incipient "wing" by making possible a positive angle of attack (where the leading edge of the airfoil is above the trailing edge, relative to the airflow or flight path). A positive angle of wing attack is essential for all forms of flight, whether powered or passive, because without it there can be no lift. That being true, then there is a critical flaw in attributing the above anatomical changes between Archaeopteryx and modern birds to aerodynamic adaptations. The flaw is that there can be no lift, and thus no aerodynamic selective advantage in raising the attitude of a potential airfoil until after the smallest degree of a positive angle of attack has been acquired.

An aerodynamic explanation of the anatomical changes noted above is also weakened by the absence of an ossified sternum in all specimens of Archaeopteryx. The absence of a sternum strongly suggests that the "flight" muscles of Archaeopteryx were not of unusual size, a conclusion that is substantiated by the short space available for the sternum in front of the ossified gastralia, as well as by the short nonstrut-like form of the coracoid. If all these assessments are correct, then some biological role other than flight must have been involved in the initial and early phases of the upward expansion of the biceps tubercle into the future acrocoracoid.

Aside from making lift possible, the only other obvious consequence of raising the level of forelimb extension and flexion is to place the hands and their activities directly in front of and above the animal. Two activities immediately come to mind: climbing and prey-catching. Various authors (Bock, 1965, 1969; de Beer, 1954; Swinton, 1960) have interpreted Archaeopteryx as being an arboreal animal. I have argued that there is no compelling evidence for this (Ostrom, 1974), and instead, the skeletal anatomy of Archaeopteryx appears to have been adapted for ground-dwelling activities. 
Even if Archaeopteryx were arboreal, however, a possibility that I do not deny, then it acquired its climbing skills prior to elevation of the acrocoracoid and the capacity of elevated forelimb extension, and after the acquisition of obligate bipedal posture.

Obviously the same is true of prey-catching and feeding activities of Archaeopteryx. If Archaeopteryx were insectivorous, as seems almost certain, it clearly must have been proficient at catching insects, whether it did so with its mouth by quick darting movements of the head on the long flexible neck, or by grasping them in the hands or snaring them beneath the forelimb plumage. Considering the general absence of flight-related skeletal structures in the forelimb and pectoral girdle, it does not seem unreasonable to conclude that the forelimbs of this obligatory bipedal predator must have taken part in prey-catching activities.

If the forelimbs of Archaeopteryx were used to catch prey, and if the original advantages behind the enlargement of the contour feathers of the forelimb was to enhance insect-catching skills (Ostrom, 1974), there would be very real selective advantages in any changes that increased the scope of forelimb movements, especially if we think in terms of leaping or flying insects.

At this point it is not possible to identify the exact activities or selective advantages that promoted the upward expansion of the acrocoracoid, but it seems clear that these were related to upward extension of the arms and hands. It also appears that flight was not a factor in these first modifications. It was perhaps only coincidental that once a certain degree of upward enlargement of the acrocoracoid had been accomplished, the action of the coracobrachialis anterior would have been supplemented by the newly deflected supracoracoideus acting as an anterodorsal extensor of the humerus.

The various specialized features of the modern avian forelimb skeleton mentioned above (reduced fingers, fused carpometacarpus, novel tubercles and crests on the humerus) seem best explained as flight-related adaptations that appeared subsequent to the dorsal expansion of the acrocoracoid and the resultant ability to raise the attitude of the extended forelimb, thereby achieving at least a minimal positive angle of attack. Fusion of the metacarpus would solidify the structural support of the primary flight feathers and brace the second metacarpal against long-axis rotation resulting from lift forces. Phalangeal reduction may have been correlated with changing the function of the manus to that of an airfoil and the reduction of the primitive prey-grasping role of the long, separated fingers. Fusion of the distal carpal to the metacarpus reduced the amount of abductionadduction possible at the wrist, but at the same time facilitated precise flexion-extension of the manus in the plane of the wing, essentially perpendicular to the powerful adductive actions of the enlarged pectoral muscles. The capacity for medial hyperextension of the manus was reduced and ultimately lost, presumably as the primitive avian hand became less and less involved with prey-catching and feeding activities and was increasingly adapted for flight-related functions. Later stages presumably involved development of structures related to compact folding of the wing and rapid unfolding - the various tubercles of the humerus noted above, the capacity for lateral hyperflexion of the manus, and the enlarged extensor process of the carpometacarpus.

\section{Summary}

The existence of several specimens of Archaeopteryx, the oldest known fossil remains that are universally accepted as avian, provides important anatomical details of an extremely early stage in bird evolution. Despite impressions of what appear to have been modern-type "flight" feathers attached to the forelimb (but possibly not attached to the forelimb skeleton), the five presently known specimens of Archaeopteryx show almost no osteological features that compare with the skeletal adaptations of the modern avian flight apparatus. The only exception is the furcula, preserved in the two largest specimens.

Assuming that Archaeopteryx is in fact an ancestral bird, and in the absence of any known intermediate structural stages in the avian fossil record between Archaeopteryx (of Late Jurassic age) and the essentially modern birds of Late Cretaceous and Early Tertiary ages, we can postulate only the most obvious structural changes that occurred during the evolution of the avian flight mechanism. From the Archaeopteryx stage, the 
following sequence of developments seems probable, with the first two possibly taking place concurrently or, less probably, in reversed order: (1) Upward expansion of the biceps tubercle, thereby raising the sites of origin of the $M$. biceps and $M$. coracobrachialis and thus the level of humeral extension and forearm flexion-possibly in connection with prey-catching or feeding activities, or perhaps to facilitate quadrupedal climbing. A direct consequence of the expansion of the acrocoracoid was the conversion of the M. supracoracoideus from a humeral adductor to a humeral elevator. (2) Enlargement of the pectoral muscles for more powerful arm adduction, accompanied by enlargement and ossification of the sternum, and elongation and strengthening of the coracoids to immobilize the shoulder joints. (3) Attachment of the remiges to the ulna and the second digit to resist feather deflection during the wing down- stroke. (4) Fusion of carpals and metacarpals into a united carpometacarpus for firmer fixation of the primaries, modification of the trochlea carpalis to permit only planar flexion and extension at the wrist, and loss of phalanges from all three fingers. (5) Loss of medial hyperextension of the hand and development of the capacity for compact folding of the wing, due to elongation of the condylus metacarpalis of the ulna and various tubercles on the humerus. This was associated with enlargement of the extensor process of the carpometacarpus to provide leverage for rapid unfolding of the wing.

The occurrence of other changes in the musculoskeletal system that affected the flight apparatus cannot be determined in the above sequence, but powered flight, as opposed to either gliding or flapping leaps, almost certainly could not have occurred before the first three of the above stages had been completed.

\section{Literature Cited}

Bakker, R. T., and P. M. Galton.

1974. Dinosaur Monophyly and a New Class of Vertebrates. Nature, 248:168-172.

de Beer, G.

1954. Archaeopteryx lithographica. xi +64 pages, 9 figures, 15 plates. London: British Museum (Natural History).

Berger, A. J

1960. The Musculature. Chapter 8 in A. J. Marshall, editor, Biology and Comparative Physiology of Birds, Volume 1. 9 figures. New York: Academic Press.

Bock, W. J.

1965. The Role of Adaptive Mechanisms in the Origin of Higher Lcvels of Organization. Systematic Zoology, 14(4):272-287, 6 figures.

1969. The Origin and Radiation of Birds. Annals of the New York Academy of Sciences, 167(1):147-155.

Coucs, E.

1871. On the Mechanism of Flexion and Extension in Bird's Wings. Proceedings of the American Association for the Advancement of Science, 20:278-284, 2 figures.

Fisher, H. I.

1946. Adaptations and Comparative Anatomy of the Locomotor Apparatus of New World Vultures. American Midland Naturalist, 35(3):545-727, 28 figures, 13 plates.

1957. Bony Mechanisms of Automatic Flexion and Extension in the Pigeon's Wing. Science, 126:446, 1 figure.
George, J. C., and A. J. Berger

1966. Avian Myology. xii +500 pages, 248 figures. New York: Academic Press.

Greenewalt, C. H.

1962. Dimensional Relationships for Flying Animals. Smithsonian Miscellaneous Collections, 144(2):1-46, 17 figures.

Hartman, F. A.

1961. Locomotor Mcchanisms of Birds. Smithsonian Miscellaneous Collections, 143(1):1-91, 7 figures, 5 tables.

Hcadley, F. W.

1895. The Structure and Life of Birds. $\mathrm{xx}+412$ pages, 78 figures. New York: MacMillan.

Heptonstall, W. B.

1970. Quantitative Assessment of the Flight of Archaeopteryx. Nature, 228:185-186, 2 figures.

Holmgren, $\mathrm{N}$.

1955. Studies on the Phylogeny of Birds. Acta Zoologica, 36:243-328, 37 figures.

Hudson, G. E., and P. J. Lanzillotti

1955. Gross Anatomy of the Wing Muscles in the Family Corvidae. American Midland Naturalist, 53:1-44, 35 figures.

Marsh, O. C.

1880. Odontomithes: A Monograph on the Extinct Toothed Birds of North America. xv + 201 pages, 40 figures, 34 plates. Volume 7 of Report of the Geological Exploration of the Fortieth Parallel. (Professional Papers of the Enginecr Department, United States Army, No. 18.) Washington, D.C. 


\section{Ostrom, J. H.}

1973. The Ancestry of Birds. Nature, 242:136.

1974. Archaeopteryx and the Origin of Flight. Quarterly Review of Biology, 49:27-47, 10 figures.

1975. The Origin of Birds. Pages 55-57 in volume 3 of F. A. Donath, editor, Annual Review of Earth and Planetary Sciences. 9 figures. Palo Alto: Annual Reviews Inc.

In press. Archaeopteryx and the Origin of Birds. Linnean Society Biological Journal.

Simpson, G. G.

1946. Fossil Penguins. Bulletin of the American Museum of Natural History, 87:1-100, 33 figures.

Stresemann, E.

1933. Aves. Number 2 of volume 7 in W. Kükenthal and T. Krumbach, editors, Handbuch der Zoologie. Berlin: W. Gruyter.
Swinton, W. E.

1960. The Origin of Birds. Chapter 1 in volume 1 in A. J. Marshall, editor, Biology and Comparative Physiology of Birds. New York: Academic Press.

1964. Origin of Birds. Pages 559-562, in A. L. Thomson, editor, $A$ New Dictionary of Birds. 1 figure. London: Nelson.

Sy, M.

1936. Funktionall-anatomische Untersuchungen am Vogelfügel. Journal für Ornithologie, 84:199-296, 52 figures.

Walker, A. D.

1972. New Light on the Origin of Birds and Crocodiles. Nature, 237:257-263, 9 figures.

Yalden, D. W.

1970. The Flying Ability of Archaeopteryx. Ibis, 113: 349-356, 4 figures. 



\title{
Evolutionary Significance of the Mesozoic Toothed Birds
}

\author{
Philip D. Gingerich
}

\begin{abstract}
Well-preserved fossils of the Mesozoic toothed birds Archaeopteryx, Hesperornis, and Ichthyornis, and of the bird-like dinosaur Compsognathus, discovered in the 19th century, indicated to early evolutionary biologists that dinosaurs and birds were closely related, and that birds in all probability evolved from a dinosaur similar to Compsognathus. The modern ratites, sharing some distinctive similarities with Hesperornis, were regarded as survivors of a primitive initial radiation of birds. Several workers have subsequently challenged the idea that the Cretaceous birds Ichthyornis and Hesperornis had teeth or that they bore any similarity to the ratites. After careful study of the actual fossil specimens of Hesperornis, it is clear that this Cretaceous bird had toothed jaws and a palaeognathous palate, the latter condition being shared with ratites and certain dinosaurs. These and other characters place Hesperornis, like Archaeopteryx, in a position morphologically, as well as temporally, intermediate between dinosaurs and typical birds. The few significant features uniting the living ratites and tinamous all appear to be primitive characteristics, suggesting that ratites and tinamous are either survivors of an early radiation of birds, or are possibly a more recently derived artificial group in which primitive characters have reappeared secondarily through neoteny.
\end{abstract}

\section{Introduction}

The discovery of fossil birds with teeth was one of the most dramatic events in 19th century paleontology. In 1861 a partial skeleton of the

Philip D. Gingerich, Museum of Paleontology, The University of Michigan, Ann Arbor, Michigan 48104. feathered Archaeopteryx was discovered in the Jurassic deposits of Bavaria. In the next 16 years, skeletons of Ichthyornis and Hesperornis were discovered in the Cretaceous of North America and a more complete skeleton of Archaeopteryx was found in Germany. Surprisingly, the jaws of each of these birds bore reptile-like teeth. Being discovered only a few years after publication of The Origin of Species, toothed birds were much discussed in connection with Darwin's evolutionary hypothesis.

As spectacular as the original discoveries were, it is remarkable in retrospect how little detailed study was made of the actual specimens until relatively recently. The history of the original discoveries of toothed birds, the initial recognition of their evolutionary significance, and their subsequent fate are reviewed here. The whole provides an interesting historical comment on the treatment of intermediate forms that do not conform to preconceived archetypical categorizations.

AcKNOWLEDGMENTs.-I should like to acknowledge here the encouragement Dr. Wetmore gave to continued study of the Yale collection of Mesozoic birds when work was initiated on Hesperornis several years ago. My study of Hesperornis began, curiously enough, as a tutorial with K. S. Thomson on kinesis and jaw mechanics in fishes. Expanding the range of comparisons, the Mesozoic bird material at Yale was examined to determine the form of kinesis of primitive birds. When no simple answer was forthcoming, J. H. Ostrom authorized Peter Whybrow to undertake further preparation of the original specimens. Thus I am particularly indebted to Professors Thomson and Ostrom and to Mr. Whybrow for their assistance and encouragement. 
In addition, Drs. C. C. Black, T. H. Eaton, and L. D. Martin permitted an extended loan of the University of Kansas skull of Hesperornis. Drs. C. E. Ray, Nicholas Hotton III, and Mr. Robert Purdy allowed me to borrow the cranial material of Hesperornis in the National Museum of Natural History. Drs. W. J. Bock, Pierce Brodkorb, Peter Dodson, J. T. Gregory, Hildegard Howard, P. V. Rich, and M. V. Walker have all assisted one way or another as well.

I also thank Mrs. Gladys Newton for typing the manuscript, and $\mathrm{Mr}$. Karoly Kutasi for printing the illustrations. Margaret Egan read the manuscript and her comments have improved the paper considerably.

\section{Mesozoic Birds with Teeth}

It is now generally admitted by biologists who have made a study of the vertebrates, that Birds have come down to us through the Dinosaurs, and the close affinity of the latter with recent Struthious Birds will hardly be questioned. The case amounts almost to a demonstration, if we compare, with Dinosaurs, their contemporaries, the Mesozoic Birds. The classes of Birds and Reptiles, as now living, are separated by a gulf so profound that a few years since it was cited by the opponents of evolution as the most important break in the animal series, and one which that doctrine could not bridge over. Since then, as Huxley has clearly shown, this gap has been virtually filled by the discovery of bird-like Reptiles and reptilian Birds. Compsognathus and Archaeopteryx of the Old World, and Ichthyornis and Hesperornis of the New, are the stepping stones by which the evolutionist of to-day leads the doubting brother across the shallow remnant of the gulf, once thought impassable. (O. C. Marsh, 1877:352).

In 1859, perhaps the gravest deficiency of Darwin's hypothesis of evolutionary descent was the rarity of intermediate forms in the geological record. Intermediate forms linking species into graded chains or linking major groups of animals to a common ancestor were at that time poorly known. Evidence remedying this deficiency was supplied in a most spectacular way by the discovery of several intermediate forms linking birds to a reptilian origin. Interestingly, each discovery of itself was insufficient to overcome archetypical categorizations of birds and reptiles, and a truly evolutionary view of both classes was necessary in order to interpret literally the clear evidence for bird-reptile relationships offered by the skeletons of Compsognathus, Archaeopteryx, and Icthyornis.
J. A. Wagner (1861) described a remarkably complete skeleton of a very small new dinosaur, Compsognathus longipes, from the Jurassic lithographic limestone of Solenhofen, Germany. In the same year $H$. von Meyer (1861) first published a notice on the skeleton of a bird from the same deposit, which he named Archaeopteryx lithographica. Having a dinosaurian skeleton, Compsognathus was clearly a variant of the "Reptile type." On the other hand, Archaeopteryx, with its distinct impressions of feathers, was from the beginning regarded as a variant of the "Bird type." Influenced at least in part by Darwin's dynamic view of evolution, T. H. Huxley was able to overcome his contemporaries' fixed categorizations, even of groups as large as reptiles and birds, and he found in Compsognathus a bird-like dinosaur, and in Archaeopteryx the most reptilian of birds. Thus, Huxley (1868) confirmed the Darwinian expectation of intermediate forms linking birds and reptiles in the fossil record. Although the actual common ancestor of living reptiles and birds had not been found, Huxley judged from their morphology that late Jurassic birds and reptiles were clearly much more closely related than their living descendants seemed to suggest. This closer similarity of the early forms was itself strong evidence favoring Darwin's dynamic view of evolutionary descent, as opposed to the then-prevailing view that living "reptiles" and "birds" were static groups persisting through time within some predetermined bounds.

There was, however, a limit to the intermediate position even Huxley would accept for Archaeopteryx. Thus, of the single skeleton of Archaeopteryx then known, he wrote "unfortunately the skull is lost" (Huxley, I868:70), making no mention of an earlier paper by Sir Jolın Evans (1865) describing a premaxilla with four teeth preserved among the other bones of the specimen. Evans' note (1865:421) quotes a letter from von Meyer himself concerning the apparent association of a toothed premaxilla with Archaeopteryx:

Teeth of this sort I do not know in the lithographic stone .... From this it would appear that the jaw really belongs to the Archacopteryx. An arming of the jaw with teeth would contradict the view of the Archacopteryx being a bird or an embryonic form of bird. But after all, I do not belicve that God formed his creatures after the systems devised by our philosophical wisdom. Of the classes of birds and reptiles as we define them, the Creator knows nothing, and just as little 
of a prototype, or of a constant embryonic condition of the bird, which might be recognized in the Archacopteryx. The Archaeopteryx is of its kind just as perfect a creature as other creatures, and if we are not able to include this fossil animal in our system, our short-sightedness is alone to blame.

The presence of teeth in the bird Archaeopteryx was apparently too reptilian a characteristic for even Huxley to accept.

O. C. Marsh was the first to discover the unequivocal presence of teeth in primitive birds, though he too was at the outset apparently unable to accept the evidence. In September 1872, Professor Mudge of Kansas presented Marsh with some fossils from the Cretaceous Niobrara Chalk, the formation from which Marsh had earlier described the headless skeleton of a large, flightless, diving bird as Hesperornis regalis. Marsh studied Mudge's new fossils and in October published a note describing the postcranial skeleton as a new form of smaller volant bird, Ichthyornis dispar (Marsh, 1872a). A month later he published another note (Marsh, 1872b) on the jaws of a new small "reptile," Colonosaurus mudgei, found in association with the remains of Ichthyornis. In the same month that Colonosaurus was described (November, 1872), Marsh's assistant T. H. Russell discovered a nearly perfect skeleton of Hesperornis, again in the Niobrara Chalk. This new skeleton included a skull with associated toothed jaws (Figure 1). Immediately after the discovery of this skeleton of Hesperornis, Marsh published a short paper in February 1873 stating that the toothed jaws of "Colonosaurus" actually belonged to Ichthyornis. Of Ichthyornis dispar, Marsh (1873: 162) wrote:

When the remains of this species were first described, the portions of lower jaws found with them were regarded by the writer as reptilian; the possibility of their forming part of the same skeleton, although considered at the time, was not deemed sufficiently strong to be placed on record. On subsequently removing the surrounding shale, the skull and additional portions of both jaws were brought to light, so that there cannot now be a reasonable doubt that all are parts of the same bird.

Although no mention was then made of the toothed jaws of Hesperornis, that discovery probably provided Marsh with the necessary corroboration for him to accept the previously evident association of toothed jaws with Ichthyornis. Two years after the toothed jaws of Hesperornis were first described by Marsh (1875), the Berlin specimen of Archaeopteryx was found about 10 miles from the original Solenhofen discovery, and its feathers, reptilian skeleton, and toothed jaws left no doubt about the reptilian ancestry of birds.

Beyond their importance in dramatically filling a gap in the fossil evidence of evolution originally available to Darwin, the three early avian fossils Archaeopteryx, Ichthyornis, and Hesperornis are of interest for another reason. Huxley (1868:74) originally interpreted the great similarity of Compsognathus as indicating a dinosaurian (more specifically, coelurosaurian) origin of birds:

Surely there is nothing very wild or illegitimate in the hypothesis that the phylum of the Class Aves has its foot in the Dinosaurian reptiles-that these, passing through a series of such modifications as are exhibited in one of their phases by Compsognathus, have given rise to the Ratitae-while the Carinatae are still further modifications and differentiations of these last,...

Similarly, Marsh (1880:189) saw in the skull of Hesperornis certain resemblances to the "Ratitae," a group he regarded as being survivors of an evolutionary stage intermediate between reptiles and the true "ornithic type."

Three principal ideas have come out of the early work of Huxley and Marsh: (1) that ratites are survivors of a primitive stock of birds, (2) that Hesperornis was similar to ratites, and (3) that Hesperornis and Ichthyornis actually possessed jaws with teeth. All three of these views have been challenged in the century since their first publication by Huxley and Marsh. Disagreement with these ideas has come in part from authorities urging caution in attempting any interpretation at all, but in most cases a strong contrary interpretation has been offered, usually without critical examination of even the evidence available to Huxley and Marsh. Advocating ratites as a derived group of birds, reconstructing Hesperornis with a "neognathous" skull, and denying the presence of teeth in Icthyornis or Hesperornis have a common effect - to deny the primitiveness and the reptilian characters of the best known Cretaceous birds and to maintain a wide gulf between birds and reptiles. This common effect of so many studies by postDarwinian evolutionary biologists can only be ascribed to a deep-seated typological conception of "birds" and "reptiles"- an interesting comment on the pervasiveness of typological thinking. 


\section{The Skull of Hesperornis}

Our knowledge of the structure of the skull in Hesperornis is based almost entirely on three specimens: (1) that found by Marsh and Russell in 1872, now in the Yale Peabody Museum (YPM 1206) (Figure 1); (2) the premaxillae and mandibles of a skull in the National Museum of Nitural History, Smithsonian Institution (USNMI 4978); and (3) a nearly complete but crushed skull in the collections of the University of Kansas (KU 2987) (Figures 2 and 3). The first of these skulls was described and illustrated in some detail by Marsh (1880:5-12, plates 1,2), and a brief description of the last two was published by Lucas (1903), who illustrated the quadrate and pterygoid of the Kansas specimen and the lacrimal of the National Museum specimen. The Yale and National Museum specimens are very nearly the same size and both have been identified as Hesperornis regalis by virtually all workers. The Kansas specimen, on the other hand, is slightly smiller than the other two and was placed by Lucas (1903) in a new ge. nus, Hargeria, having as its type the species Hesperornis gracilis Marsh. After extensive comparison of the three skulls, I agree with Gregory (1952) that all three are of the same genus, Hesperornis. It remains an open question whether more than a single species should be recognized.

The Yale skull was only partly removed from the enclosing rock by Marsh, and those portions that were freed for study were subsequently remounted on the original slab for display purposes. Consequently, the specimen was not really available for examination until relatively recently, when it was removed from public exhibition.

The Yale skull is in many respects the best one for study, because its components were scattered before fossilization and are now disarticulated and very little crushed (except for the braincase). The major portion of the Yale skull is illustrated here as it was mounted for exhibition (Figure 1). The braincase and some smaller fragments were completely removed from the rock by Marsh and it is not certain that their positions as shown in Figure 1 are those in which they were found. The pre-

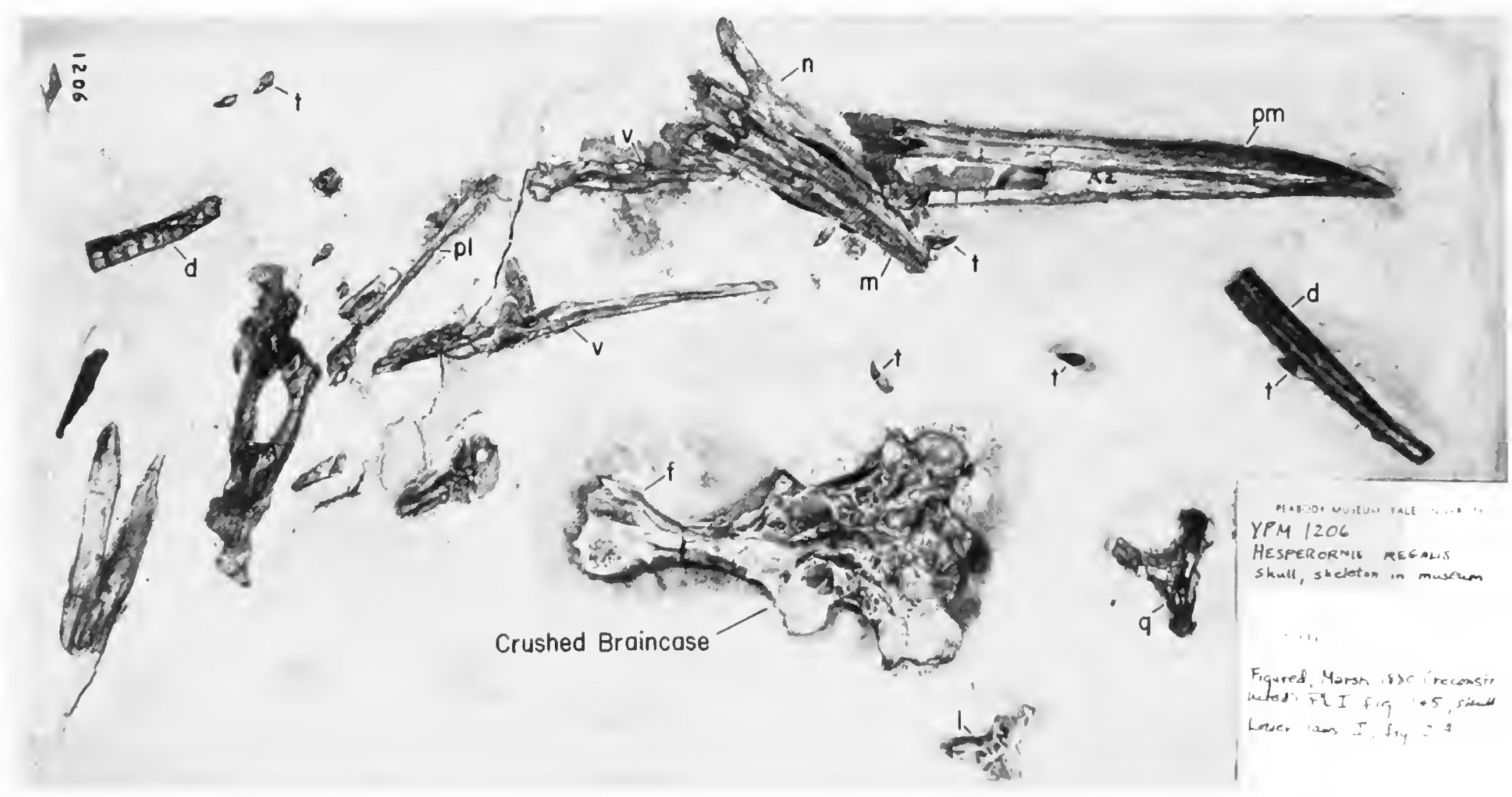

FIGUR! 1.-The Yale skull of Hesperornis regalis Marsh (YPM 1206), showing the individual disarticulated bones well preserved. Premaxilla, nasal, maxilla, and vomers are illustrated in the position in which they were fonnd-all have subsequently been removed and cleance for study. $\langle\mathrm{d}=$ dentary, $\mathrm{f}=$ frontal, $\mathrm{l}=$ lacrimal, $\mathrm{m}=$ maxilla, $\mathrm{n}=$ nasal, $\mathrm{pl}=$ palatine, $\mathrm{pm}=$ pre maxilla, $\varphi=$ (fuadrate, $\mathrm{l}=$ tooth, $v=$ vomer.) Nete presence of teeth in dentary, as illustrated by Marsh (1880, pl. l). (Approximately onc-half natural size.) 
maxilla, maxilla, nasal, vomers, and palatine, however, were never removed and thus retain their original orientation as buried. It should be noted that Marsh had the nasal and maxilla exposed from both sides of the slab, but they were never completely removed. All of the important pieces of the Yale skull were carefully removed from their matrix in 1971 by Mr. Peter Whybrow, and they can now be studied freely and articulated.

The cranium of the University of Kansas skull of Hesperornis is also in a slab of Niobrara chalk, but unlike the Yale specimen, it was preserved in articulation and both the braincase and the maxillary portion of the skull have suffered considerable crushing. Furthermore, Lucas (1903) reported that the specimen was preserved with the skull doubled backwards against the pelvis, and that portions of both the dorsal and the sternal ribs were crushed into the palate. It is possible to identify most of the bones preserved in this specimen, but the maxillae are conspicuously lacking-whether they are crushed beyond recognition into the palate or lost entirely cannot be determined.

In addition to the portions illustrated in Figure 2, the Kansas specimen includes most of the lower jaws, a complete left quadrate, and a complete left pterygoid, which have been fully prepared and can be articulated with each other and also with the left palatine preserved with the main part of the cranium. The quadrate and pterygoid were illustrated by Lucas (1903, figs. 1,2; the left pterygoid is incorrectly identified as a right pterygoid), and they are illustrated here in articulation (Figure 3). The complicated S-shaped surface of the left pterygoid ("Apl" in Figure 3) articulates with the S-shaped proximal end of the palatine ("Apt" in Figure 2).

The principal contribution of the USNM specimen to our understanding of the skull morphology of Hesperornis is furnished by the nearly complete left lacrimal (illustrated by Lucas, 1903, fig. 3).

By studying all three specimens it is possible to reconstruct the major features of the morphology of the rostrum, the palate, and the mandible (Figure 4). The reconstruction has been discussed elsewhere (Gingerich, 1973), but some additional notes are added here. These notes and the illustrations of the Yale and Kansas specimens (Figures 1-3) are preliminary to a more definitive description of this important material. They are intended to provide additional documentation of the remarkable completeness of the preserved specimens and to answer, in part, some questions raised by several skeptical colleagues.

The length of the reconstructed skull was determined from the Yale specimen (YPM 1206). The dorsal surface of the braincase in this specimen is crushed forward, but without affecting the length from the occipital condyle to the anterior end of the frontals. The overlapping articulation between the nasal and the frontal is outlined on the surface of the frontal, and the two can be fitted together as in life. The nasal-premaxillary articulation is preserved in both of the elements and these too can be fitted together accurately. As neither frontals, nasals, premaxillae, nor the base of the braincase appear in any way distorted in length, a total length of $26-27 \mathrm{~cm}$ is estimated for this skull.

Regarding the possibilities of cranial kinesis, little can be added to my previous discussion (Gingerich, 1973) except perhaps to add a more cautionary note. Rhynchokinesis in Hesperornis is almost certainly ruled out by the complete ring of bone formed by the premaxillae and nasals around the external narial opening. Some slight prokinetic movement might have been possible if the premaxillae and nasals were capable of being lifted off the frontals, although I know of no modern bird with such thick bone in the region of bending, and the complex interdigitation of the nasal and lacrimal in Hesperornis would likewise limit prokinetic movement. The quadrates were clearly streptostylic, which appears to have been correlated with a unique form of maxillokinesis whereby the maxillae were able to slide anteroposteriorly on rails formed by the nasal-premaxillary subnarial bars (Gingerich, 1973). While I am reluctant to postulate a form of kinetic motion so distinctive from that of any other animal, the preserved osteology of the rostrum in Hesperornis is unique and its adaptations were clearly different from those of any known vertebrate. Maxillokinesis appears to explain several unique features of the known fossil material.

One of the most curious features of the upper jaw of Hesperornis is the fact that the premaxilla bore a horny sheath as in modern birds (indicated by the vascular nature of the underlying bone), while the teeth were confined to the maxillae 


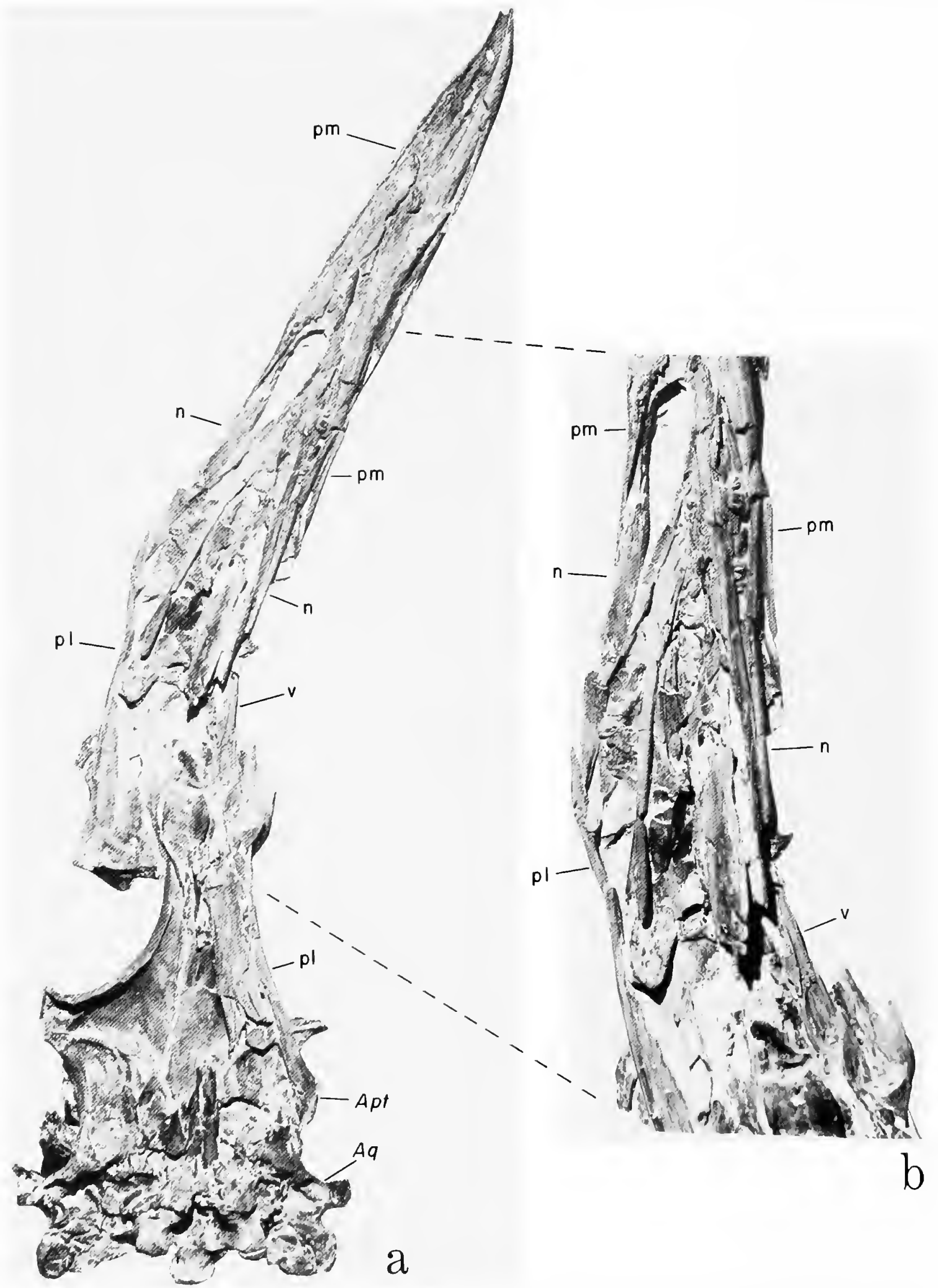

F1GURE 2.-The Kansas skull of Hesperornis (KU 2287), ventral view as preserved, articulated on a slab of Niobrara Chalk. Note particularly the little-disturbed contact between the premaxillae and nasals, while the maxillae arc completely missing. (Apt $=$ pterygoid articulation of palatine, $\mathrm{Aq}=$ quadrate articulation of squamosal, $\mathrm{n}=$ nasal, $\mathrm{pl}=$ palatine, $\mathrm{pm}=$ premaxilla, $\mathrm{v}=$ vomer; approximately two-thirds natural size.) 


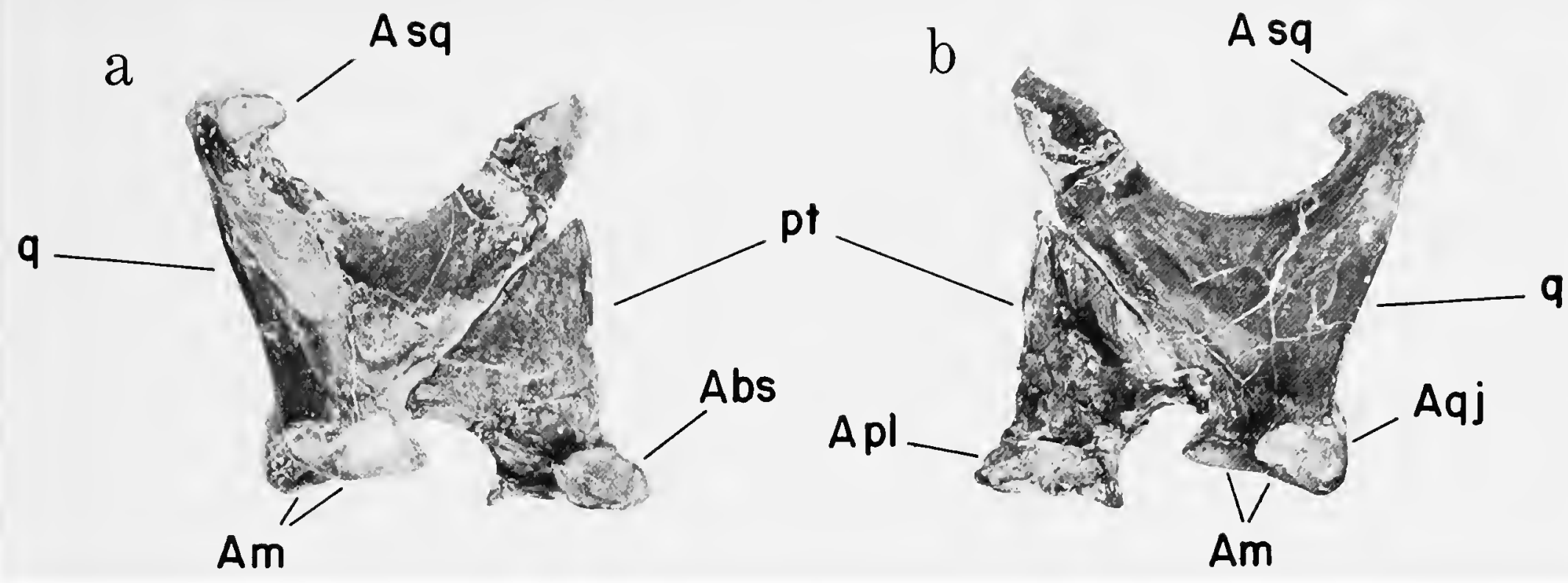

Figure 3.--Articulated left pterygoid (pt) and quadrate (q) of Kansas specimen of Hesperornis (KU 2287): $a$, medial view; $b$, lateral view. Note particularly the complicated articulation between quadrate and pterygoid, the broad basisphenoid articulation of the pterygoid, and the complicated S-shaped articulation of the pterygoid with the palatine. (Abs = basisphenoid articulation of pterygoid, $\mathrm{Am}=$ mandibular articulation of quadrate, $\mathrm{Apl}=$ palatine articulation of pterygoid, Aqj = quadratojugal articulation of quadrate, Asq = squamosal articulation of quadrate; twice natural size.)

proper. The lower jaw bore teeth throughout the length of the dentary. Secondly, in both the Yale and Kansas specimens, the maxillae have clearly separated from the nasal-premaxillary subnarial bars while, at least in the Kansas specimen, the subnarial bars were little disturbed by crushing. It should be noted also that the anterior end of each maxilla was grooved to fit over anteroposteriorly aligned keys or ridges of bone on the ventral surface of the premaxilla. This system of locking would keep the anterior ends of the maxillae from dropping away from the subnarial bars, while permitting anteroposterior motion of the maxillae relative to the subnarial bars. Finally, it now seems unlikely that the left and right vomers were fused to each other at their anterior ends. Such fusion would have prevented independent motion of the left and right maxillary segments of the palate relative to each other. The only possible functional advantage of having the kind of maxillary kinesis postulated here would be in moving each side independently. As evidenced by the unfused mandibular symphysis, such independent movement of the lower jaws was clearly possible. Independent movement of the maxillae would further expand the range of possible movements used in ingesting prey, which in this case was almost certainly fish.

A new specimen of Archaeopteryx, described recently by Wellnhofer (1974), fortunately has a relatively well-preserved skull. Wellnhofer (1974: 185) interprets the skull as being definitely kinetic, but in Archaeopteryx, as in Hesperornis, it is difficult to see where bending that would lift a significant portion of the rostrum could have taken place. Wellnhofer favors bending in the dorsal processes of the premaxillae, but at most this would lift only the tip of the upper jaw. Kinesis approaching that of modern birds seems not to have been present in either Archaeopteryx or Hesperornis.

The present evidence bearing on Huxley's and Marsh's conclusions regarding the evolutionary position of the ratites, the relationship of Hesperornis to the ratites, and the presence of teeth in Hesperornis and Ichthyornis can now be considered. The skeleton of Archaeopteryx is more reptilian than avian, and the uncontested fact that its jaws bear teeth is easy to believe. The skeletons of Hesperornis and Ichthyornis, on the other hand, are more typically avian. That a bird with an avian postcranial skeleton should have jaws with 
teeth has proved more difficult for some ornithologists to accept. The quadrate is not preserved in the original specimen of Ichthyornis and the toothed jaws that Marsh found associated with this skeleton thus cannot be articulated with the remainder of the cranium. The articular regions of the original jaws are also badly distorted. Gregory (1952) made a careful study of the lower jaws of Ichthyornis and concluded that they belonged to a small mosasaur. Therefore Hesperornis alone was left with the combination of toothed jaws and a nearly typically avian skeleton. Inevitably, the association of teeth with the skull of Hesperornis was also questioned. Bock (1969) claimed that the teeth found with Hesperornis were not in place in the jaws, but scattered and cemented with matrix onto the skull. However, one need only examine the Yale specimen to see that teeth are preserved in the jaws as well as being scattered through the matrix (Figure 1). Discovery of a new, uncrushed posterior portion of a mandible of Ichthyornis (Gingerich, 1972), and its comparison with the mandibles of the original specimen and with those of Hesperornis and modern birds, leaves little doubt that Marsh was correct in associating toothed jaws with Ichthyornis.

Interpretation of the structure of the palate in Hesperornis has had an interesting history. Marsh (1880:6) originally determined that the palate resembled most closely that of "Struthious" birds, but he confused the vomers with the palatines of his specimen of Hesperornis and gave no figure or reconstruction of the palate. Thompson (1890), followed by Lucas (1903), Shufeldt (1915), and Heilmann (1926), challenged Marsh's interpretation of Hesperornis as indicating any relationship to the ratites. In the course of the 36 years from 1890 to 1926, the palatal structure of Hesperornis "evolved" rapidly in the literature, ultimately "converging" toward the neognathous palatal type of the modern loon (Gavia), a fish-eating, diving bird with certain similar locomotor adaptations.

Fortunately, the Yale and Kansas specimens of Hesperornis (Figures 1-3) preserve virtually intact at least one example of each of the palatal bones. The quadrate and pterygoid are complete in the Kansas specimen, portions of both vomers are present in the Yale specimen (Figure I), a crushed left vomer remains in the Kansas specimen (Figure 2), and virtually complete palatines are preserved in both. About midway along their length, a rounded surface is present on the medial side of the vomers, which apparently articulated with the parasphenoid rostrum. The left maxilla is preserved in the Yale specimen (Figure 1) and it fits together with, and is overlapped by, the left vomer, as shown in Figure 4. There appears to be an articular facet on a ventrolateral expansion of the vomer for the narrow anterior end of the palatine (Figure 4). It is possible, but unlikely, that the palatines articulated directly with posterior projections of the maxillae (not preserved) rather than with the vomers. As noted above, the maxillae articulated with the subnarial bars formed by the premaxillae and nasals. Returning to the pterygoidquadrate complex, it should be noted that each pterygoid bears a large, round, flat surface that articulates with a "basipterygoid" process of the basisphenoid (Figure 3, "Abs").

The entire reassembled palate is illustrated in Figure $4 c$. Compared with that of living ratites, the palate of Hesperornis is obviously different from an emu or an ostrich in being much longerand narrower. This lengthening has clearly been accomplished by elongation of the premaxillae, maxillae, vomers, and palatines relative to the more posterior elements of the skull. Although having adaptations quite different from those of any living palaeognathous bird, Hesperornis shares with palaeognathous birds all essential palatal characters that distinguish them from neognathous birds: (1) a relatively large vomer, (2) a firm pterygoidpalatine connection, (3) palatines widely separated from the sphenoid rostrum by the pterygoids, (4) strong basipterygoid processes of the sphenoid articulating with the pterygoids, and (5) a complex pterygoid-quadrate articulation including portions of the orbital process of the quadrate (Figure 3).

The structure of the palate is still unknown in Archaeopteryx, but the presence of a palaeognathous palate in Hesperornis would appear to be strong evidence favoring the view that the palaeognathous conformation is primitive in birds. Additional evidence bearing on the primitive structure of the palate of birds is offered by this structure in theropod dinosaurs. Ostrom (1973) has compared the skeleton of Archaeopteryx with that of reptiles and concluded that birds originated from theropod dinosaurs, more specifically, from a coelurosaurian stock of theropods. The palatal 


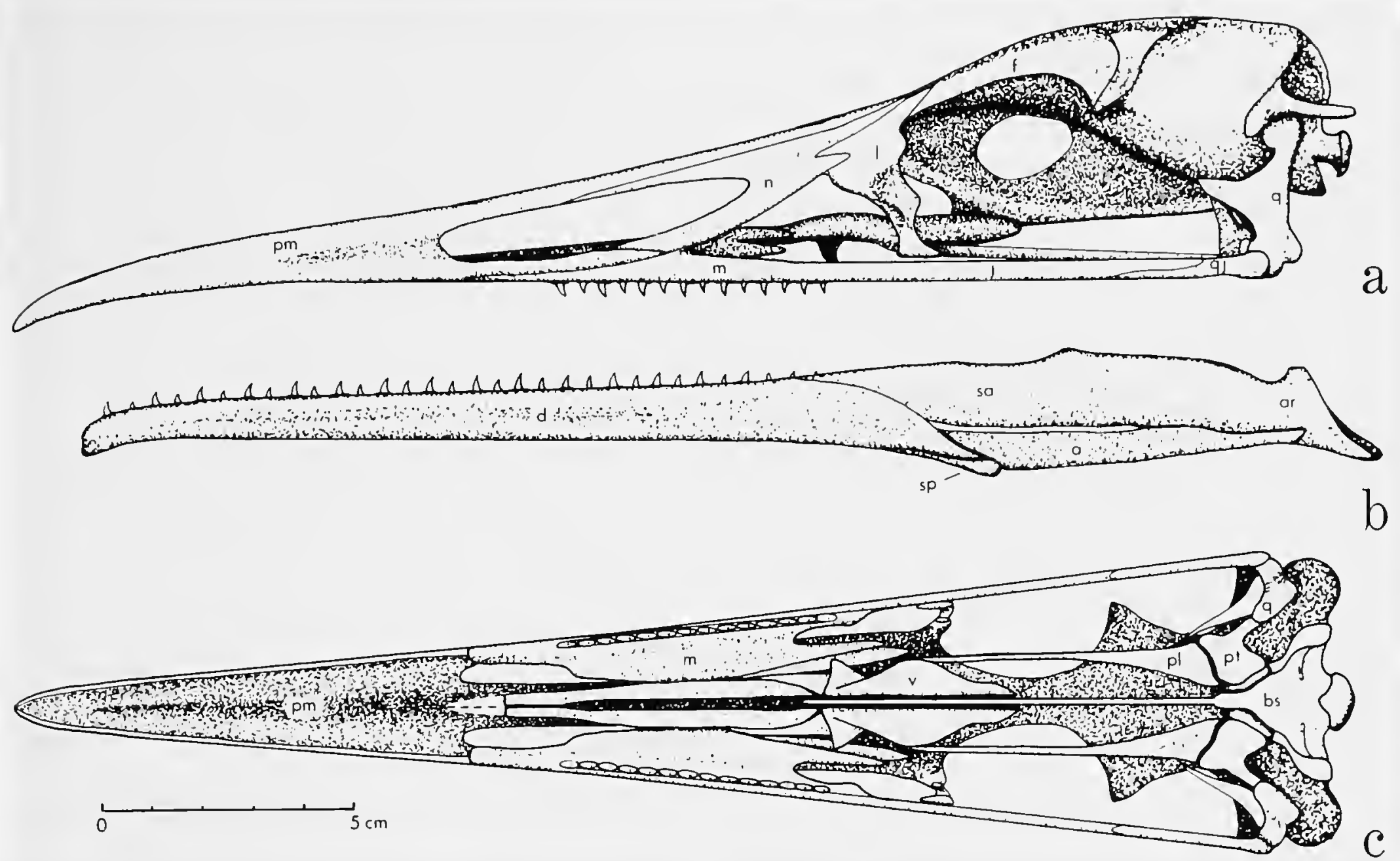

FicURE 4.-Reconstructed skull $(a)$ and mandible $(b)$ of Hesperornis regalis in lateral view; $c$, reconstructed palate in ventral view. (a = angular, ar $=$ articular, bs $=$ basisphenoid, $\mathrm{d}=$ dentary, $\mathrm{f}=$ frontal, $\mathrm{j}=$ jugal, $\mathrm{l}=$ lacrimal, $\mathrm{m}=$ maxilla, $\mathrm{n}=$ nasal, $\mathrm{pl}=$ palatine, $\mathrm{pm}$ $=$ premaxilla, $\mathrm{pt}=$ pterygoid, $\mathrm{q}=$ quadrate, $\mathrm{sa}=$ surangular, $\mathrm{sp}=$ splenial, $\mathrm{v}=$ vomer) (From Gingerich, 1973.)

structure is not known in any coelurosaur, but it is completely preserved in the large carnosaur Tyrannosaurus (Osborn, 1912) and less well preserved in the smaller Dromaeosaurus (Colbert and Russell, 1969) and Deinonychus (Ostrom, 1969). The structure of each of these skulls appears to meet all of the criteria listed above for the palaeognathous palate. Osborn (1912:11) noted this "analogy" implicitly in comparing the palate of Tyrannosaurus with that of a cassowary. The presence of a palaeognathous palate in Mesozoic theropods, the "sister group" of birds, together with the palaeognathous palate of the Cretaceous bird Hesperornis, should leave little doubt that this palatal conformation is truly primitive in birds.

I emphasize the strength of the evidence in this case because Cracraft (1974) has proposed that the living ratite birds are cladistically a "strictly monophyletic" group on the basis of their "de- rived" palaeognathous palate, their unique rhamphothecal structure, and their large ilioischiatic fenestra. Cracraft asserts that the palaeognathous palate is a derived state in birds, not a primitive one, because "it is restricted to a small number of species within this large class" (Cracraft, 1974:497). This specious reasoning would lead one to assume that teeth in Mesozoic birds are a derived condition also, an unlikely hypothesis.

The unique rhamphothecal structure and other resemblances of ratites and tinamous were interpreted by Parkes and Clark (1966) rather less stringently than Cracraft now proposes. They (1966:469) noted that "resemblances are to be attributed to parallel evolution from a common stock . . rather than to convergence from unrelated stocks, and thus, employing Simpson's concepts, the group may be considered monophyletic." The resemblance in rhamphothecal structure of 
ratites and tinamous provides no evidence that this group is strictly monophyletic in Cracraft's sense rather than monophyletic in G. G. Simpson's sense (i.e., possibly paraphyletic, if indeed the unique rhamphothecal structure is a derived state at allit may very well be primitive).

The third character Cracraft (1974:505) cites as evidence that ratites and tinamous are "each other's closest relatives" is their possession of a large ilioischiatic fenestra. Archaeopteryx has long been known to have a large ilioischiatic fenestra (see for example Petronievics and Smith Woodward, 1917), and Cracraft (1974:503) himself notes that this is the condition in Hesperornis and Ichthyornis. In short, of the three "derived" characters cited by Cracraft (1974), the first and third are almost certainly primitive and the second may be primitive as well.

Evidence that ratites are strictly monophyletic remains to be discovered and it is possible, even probable, that the groups of living ratites and the tinamous are paraphyletic. Huxley (1867:419) envisioned the living palaeognathous ratites as "waifs and strays" of an early radiation of birds, the neognathous types representing a subsequent radiation. Judging from the fossil record, successive adaptive radiations replacing older stocks by newer ones are common in vertebrate evolution, and the class Aves is no exception. Although they are sometimes highly modified from the ancestral stock, we are fortunate to have in many groups of vertebrates surviving "waifs and strays," and still more fortunate to have well-preserved archaic fossil forms. In the absence of a more complete fossil record, some question must remain as to whether the modern ratites and tinamous are in fact survivors of a primitive radiation of birds, or whether their primitive characteristics are neotenic solutions to particular adaptive problems, since both the palaeognathous palate and the open ilioischiatic fenestra appear to be present in the developmental stages of modern nonratite birds (Jollie, 1958; Olson, 1973:35-36). To explain away the primitive morphology of Hesperornis and ally it with modern loons and grebes (Cracraft, 1974:497, 503), however, illustrates on the one hand the arbitrary nature of the cladistic method of reconstructing a phylogeny, and on the other hand exemplifies another typological attempt to force an archaic bird into a modern morphological category. To paraphrase von Meyer (1861), if Hesperornis does not fit our philosophical wisdom and if we are not able to include this fossil in our system, our shortsightedness is alone to blame.

\section{Literature Cited}

Bock, W. J.

1969. The Origin and Radiation of Birds. New York Academy of Sciences Annals, 167:147-155.

Colbert, E. H., and D. A. Russell

1969. The Small Cretaceous Dinosaur Dromaeosaurus. American Museum Novitates, 2380:1-49, 15 figures.

Cracraft, J.

1974. Phylogeny and Evolution of the Ratite Birds. Ibis, 116:494-521, 10 figures.

Evans, J.

1865. On Portions of a Cranium and of a Jaw, in the Slab Containing the Fossil Remains of the Ar. chacopteryx. Natural History Review, new series, 5:415-421, 1 figure.

Gingerich, P. D.

1972. A New Partial Mandible of Ichthyornis. Condor, $74: 471-479,2$ figures.

1973. Skull of Hesperornis and the Early Evolution of Birds. Nature, 243:70-73, 2 figures.

Gregory, J. T.

1952. The Jaws of the Cretaceous Toothed Birds, Ichthyornis and Hesperornis. Condor, 54:73-88, 9 figures.
Heilmann, G.

1926. The Origin of Birds. 208 pages. London: H. F. and G. Witherby.

Huxley, T. H.

1867. On the Classification of the Birds; and on the Taxonomic Value of the Modifications of Certain of the Cranial Bones Observable in that Class. Proceedings of the Zoological Society of London, 1867:415-472, 36 figures.

1868. On the Animals Which Are Most Nearly Intermediate between Birds and Reptiles. Annals and Magazine of Natural History, 4th series, 2:66-75.

Jollie, M.

1958. Comments on the Phylogeny and Skull of the Passeriformes. Auk, 75:26-35.

Lucas, F. A.

1903. Notes on the Osteology and Relationship of the Fossil Birds of the Genera Hesperornis, Hargeria, Baptornis, and Diatryma. Proceedings of the United States National Musenm, 26:545-556, 8 figures.

Marsh, O. C.

1872a. Notice of a New and Remarkable Fossil Bird. American Journal of Science, 3rd series, 4:344. 
1872b. Notice of a New Reptile from the Cretaceous. American Journal of Science, 3rd series, 4:406.

1873. On a New Subclass of Fossil Birds (Odontornithes). American Journal of Science, 3rd series, 5:161-162.

1875. On the Odontornithes, or Birds with Teeth. American Journal of Science, 3rd series, 10:402-408, plates 9-10.

1877. Introduction and Succession of Vertebrate Life in America. American Journal of Science, 3rd series, 14:337-378

1880. Odontornithes: A Monograph on the Extinct Toothed Birds of North America. Volume 7 of Report of the Geological Exploration of the 40th Parallel. xv + 201 pages, 34 plates, 40 figures. Washington: Government Printing Office.

von Meyer, $\mathbf{H}$.

1861. Archaeopteryx lithographica (Vogel-Feder) und Pterodactylus von Solenhofen. Neues Jahrbuch für Mineralogie, Geologie, und Palaeontologie, 1861: 678-679.

Olson, S. L.

1973. Evolution of the Rails of the South Atlantic Islands (Aves: Rallidae). Smithsonian Contributions to Zoology, 152:1-53, 11 plates, 8 figures.

Osborn, H. F.

1912. Crania of Tyrannosaurus and Allosaurus. Memoirs of the American Museum of Natural History, new series, 1:1-30, plates 1-4, 27 figures.

Ostrom, J. H.

1969. Osteology of Deinonychus antirrhopus, an Unusual
Theropod from the Lower Cretaceous of Montana. Yale University, Peabody Museum of Natural History Bulletin, 30:1-165, 83 figures.

1973. The Ancestry of Birds. Nature, 242:136.

Parkes, K. C., and G. A. Clark

1966. An Additional Character Linking Ratites and Tinamous, and an Interpretation of their Monophyly. Condor, 68:459-471, 7 figures.

Petronievics, B., and A. Smith Woodward

1917. On the Pectoral and Pelvic Arches of the British Museum Specimen of Archaeopteryx. Proceedings of the Zoological Society of London, 1917:1-6, 1 plate.

Shufeldt, R. W.

1915. On a Restoration of the Base of the Cranium of Hesperornis regalis. Bulletins of American Paleontology, 5:73-85, plates 1-2.

Thompson, D'A. W.

1890. On the Systematic Position of Hesperornis. University College, Dundee, Studies from the Museum of Zoology, 10:1-15, 17 figures.

Wagner, J. A.

1861. Neue Beiträge zur Kenntnis der urweltlichen Fauna des lithographischen Schiefers, II: Schildkröten und Saurier. Abhandlungen der Bayerischen Akademie der Wissenschaften, München, 9:65-124, plates $1-6$.

Wellnhofer, $\mathbf{P}$.

1974. Das Fünfte Skelettexemplar von Archaeopteryx. Palaeontographica, Abteilung A, 147:169-216, plates 20-23, 13 figures. 



\title{
The Skeleton of Baptornis advenus (Aves: Hesperornithiformes)
}

\author{
Larry D. Martin and James Tate, Jr.
}

\begin{abstract}
Baptornis advenus is a foot-propelled diving bird from the Late Cretaceous of Kansas. It was slightly larger than the largest living loon and had an unusually long neck. The feet were large, with only slight modifications for toe-rotation. In this and many other respects, Baptornis was a less specialized diving bird than the contemporaneous Hesperornis. However, examination of almost the entire skeleton shows that Baptornis is more closely related to Hesperornis than to any living diving bird and should be included in the order Hesperornithiformes. It should not be regarded as the earliest record of the Podicipediformes. We maintain Baptornis in a family Baptornithidae separate from Hesperornithidae. Both Hesperornis and Baptornis are in many respects very primitive birds, which in some characters appear to be little modified from Archaeopteryx.
\end{abstract}

\section{Introduction}

In 1964 we discovered a previously unrecognized partial skeleton of Baptornis advenus in the collections of the University of Nebraska State Museum. This specimen was more complete and better preserved than any other known example of the species and it encouraged us to review all known specimens of the form. In other institutions we found numerous examples of Baptornis. We were able to study all of these except a tarsometatarsus reported by Lambrecht (1933) to be in

Larry D. Martin, Museum of Natural History and Department of Systematics and Ecology, University of Kansas, Lawrence, Kansas 66045. James Tate, Jr., P.O. Box 2043, Denver, Colorado 80201.
Germany. We thus were able to reconstruct the skeleton of Baptornis advenus, apart from most of the skull and jaws.

After Hesperornis and Ichthyornis, Baptornis is now the best known Cretaceous bird. It was first described by Marsh (1877) as a new swimming bird allied to Hesperornis, but readily separable from that genus in having the third and fourth trochleae of the tarsometatarsus of about equal size. He did not illustrate the type, but did give detailed measurements and commented that the bird was about the size of a loon and may have had similar habits. In 1880, Marsh illustrated the holotype tarsometatarsus and mentioned a referred femur and tibiotarsus. Lucas (1903:553-555) described a partial skeleton housed at the University of Kansas, and illustrated the coracoid, humerus, radius, ulna, and patella. Shufeldt (1915:9-11, figs. I-6) published photographs of the holotype and discussed it in great detail. Finally, Lambrecht (1933:258-260) summarized what was then known about the anatomy of Baptornis.

After Lambrecht, relatively little has been published on Baptornis, although Swinton (1965) mentioned the genus briefly in his semipopular book Fossil Birds, and suggested that the Cretaceous diving bird Lonchodytes might be related. Storer (1958), in his discussion of evolution in diving birds, made some remarks concerning the evolutionary position of Baptornis, although he mistakenly spelled Baptornis and Baptornithidae as "Bathornis" and "Bathornithidae". Walker (1967) reviewed some of the material and previous work, but erroneously assigned an alleged large humerus to Baptornis. Other than the aforementioned works, the published references to $B a p$ tornis are restricted to checklists and catalogs 
(Wetmore, 1956; Brodkorb, 1963b), and discussion of these (Storer, 1965).

A close relationship between Baptornis and Hesperornis was first suggested by Marsh (1877) and went essentially unquestioned until Brodkorb (1963b) placed the former in the Podicipediformes. Brodkorb's arrangement has been challenged by Storer (1971) and by Martin and Tate (1969) on the basis of the new material discussed in detail below. Relationships also have been suggested between Baptornis and numerous other Mesozoic and Tertiary foot-propelled diving birds including Enaliornis, Lonchodytes, Hesperornis, Neogaeornis, and Eupterornis. Those with Enaliornis and Hesperornis seem best established, as Baptornis seems to differ from these two genera only at the familial level, whereas it seems to have no affinities with the Podicipediformes.

Distribution.-Baptornis is known only from Kansas (Gove, Logan, and Wallace counties) and only from the Smoky Hill (upper) Member of the Niobrara Chalk Formation (Coniacian). Other North American Cretaceous birds (Ichthyornis and Hesperornis) are known from the present Gulf of Mexico to above the Arctic Circle in Canada (Russell, 1966), and range in age from the Turonian, Greenhorn Formation, to the Campanian, Pierre Shale (Walker, 1967; Martin and Tate, 1967). Baptornis is known only from marine deposits. A specimen from Logan County (KUVP 16112) and one from Wallace County (YPM 5768) are from very immature individuals, suggesting that Baptornis may have bred in the vicinity. Young specimens of Hesperornis are uncommon, although Russell (1967) reported several examples of subadult Hesperornis from a bituminous marine shale along the Anderson River in Canada (latitude $69^{\circ} \mathrm{N}$ ) and suggested that a nesting colony might have existed nearby.

The Niobrara Chalk is a carbonate deposit with no evidence of associated continental sediments. The absence of a shoreline would imply that Pteranodon, Ichthyornis, Hesperornis, and Baptornis were accustomed to venturing many hundreds of miles into open sea. Evidence for a nearby shoreline in Kansas in the Coniacian is somewhat sketchy and not completely convincing. The Niobrara deposits do seem to thin, in an easterly direction, toward areas that are known to have been continental in the Early Cretaceous. It also has produced a few examples of dinosaurs which are presumed to have floated out to sea after death. How far these dinosaurs may have floated is presently unknown, but one wonders if it could have been hundreds of miles in such a scavenger-rich sea.

MATERIAL EXAMINED.-All available specimens were studied. These included partial skeletons at the University of Nebraska State Museum, UNSM 20030; Field Museum of Natural History, FMNH 395; American Museum of Natural History, AMNH 5101; University of Kansas Museum of Natural History, KUVP 2290 and 16112; Yale Peabody Museum, YPM 1465 and 5768. We were also permitted to examine some additional material at the Fick Fossil Museum, Oakley, Kansas. Most of the available hesperornithid specimens were also examined, and the extensive skeletal collection of recent birds at the University of Kansas Museum of Natural History was used for comparisons.

ACKNOWLEDGMENTS. - The authors are deeply indebted to the following persons for permission to use specimens in their care: C. B. Schultz, University of Nebraska State Museum; R. Zangerl, Field Museum of Natural History; E. Simons and J. Ostrom, Peabody Museum of Natural History, Yale University; M. Walker, Sternberg Memorial Museum; R. Shaeffer, American Museum of Natural History. We have also benefitted from conversations with P. Brodkorb, R. W. Storer, and J. Cracraft. M. A. Jenkinson read the manuscript and offered many helpful suggestions. The skeletal restoration was prepared by $M$. Tanner, the life restoration by $\mathrm{B}$. Dalzell, and the other drawings by M. Tanner, D. K. Bennett, and D. Brennfoerder.

\section{Class AVES}

\section{Subclass ODONTOHOLCAE Stejneger, 1885}

\section{Order HESPERORNITHIFORMES}

(Fürbringer), 1888

Amended Diagnosis.-Foot-propelled diving birds with teeth; skull paleognathous (at least in Hesperornis); mandibular symphysis not fused; reduced wings; coracoid with glenoid facet on tip of scapular end; clavicles unfused; sternum flat; patella large and perforated for tendon of ambiens muscle; posterior extremities of ilium, ischium, and 
pubis separate; tibiotarsus lacking supratendinal bridge; tarsometatarsus lacking hypotarsal grooves and proximal foramina.

\section{Family BAPTORNITHIDAE American Ornithologist's Union, 1910}

InCLUded Genera.-Baptornis and Neogaeornis. Amended Diagnosis.-Foot-propelled diving birds with fully heterocoelous vertebrae; uncinate processes turned dorsally (straight in Hesperornis); coracoid more slender than in hesperornithids; pelvis with the preacetabular portion of the ilium relatively longer than in hesperornithids; patella pyramidal in shape (much more laterally compressed in Hesperornis); intracentral bones not fused to caudal vertebrae; pygostyle long and laterally compressed; outer trochlea of tarsometatarsus not enlarged; distal foramen on tarsometatarsus an open groove; toe-rotation not well developed.

\section{Genus Baptornis Marsh, 1877}

TyPe-SPeCIEs.-Baptornis advenus.

INCLUded SPECIES. - Type-species only.

Amended Diagnosis.-Foot-propelled diving bird about the size of a Yellow-billed Loon (Gavia adamsii); neck elongate; wing greatly reduced, but radius and ulna present; tarsometatarsus not as compressed as in Neogaeornis.

\section{Baptornis advenus Marsh, 1877}

LECTOTYPE.-Distal end of tarsometatarsus, YPM 1465.

HoRizon.-Smoky Hill Member of Niobrara Chalk, Late Cretaceous.

Type-Locality.-Wallace County, Kansas.

Diagnosis.-Same as for genus.

\section{MORPHOLOGY}

Skull.- The skull of Baptornis is known from only a few fragments. If teeth were present they were restricted to the maxillae and dentaries, as in Hesperornis. KUVP 16112 includes a fragment of the bill just anterior to the nasal openings. There are fairly large, distinct, triangular grooves on the lateral sides of the fragment, extending towards the tip. The sides of the bill are quite thick and vaulted. There is no evidence that the bill came to a point to form a spear as in the grebe Aechmophorus. A fragment of the left side of the bill (AMNH 5101) is probably from a position just posterior to that of KUVP 16112. This fragment shows a single large, elongate, longitudinal nutrient foramen. In KUVP 16112 a large number of smaller foramina extend over the dorsal surface of the bill as in the top of the bill in loons. Apparently the tip of the bill was relatively short and broad, being shaped like that of Hesperornis (Marsh, 1880, pl. 1). It was probably covered by a horny sheath.

AMNH 5101 includes a fragment of the frontal bone which is very difficult to orient (Figure $1 a$ ). The dorsal surface bears a faint scroll-like pattern similar to that on the frontal bone of grebes. However, the frontal-parietal suture is present and the sagittal groove extends up to it, thus extending further posteriorly than in the grebes and indicating that the top of the skull was more similar to that of loons. The cerebral hemispheres of the brain seem to have been expanded, as in modern birds, but better material is needed to confirm this.

The ventral half of a right quadrate (Figure $1 c-e)$ is preserved with AMNH 5101. The shaft is broad but not as massive as in Gavia. The orbital process has been broken off, but it had a triangular base and originated very low on the quadrate. A prominent pit is present on the dorsomedial margin of the base of the orbital foramen, but the quadrate was not pneumatic. There is a small, rectangular facet for the articulation of the pterygoid. This facet is elongated dorsoventrally. Lateral to the pterygoid articulation is a shallow, rectangular depression from the middle of which a low ridge connects to the socket for the quadratojugal. The socket for the quadratojugal is large, shallow, and somewhat triangular in shape (rounded and very deep in loons and grebes). In loons and grebes, the mandibular articulation is divided into two parts by a groove, and the medial facet runs anteroposteriorly. Baptornis resembles Hesperornis in having a single comma-shaped facet running from the pterygoid articulation.

The few fragments preserved are suggestive of a skull close to that of Hesperornis. Hesperornis and Baptornis have very similar quadrates, and both differ from loons and grebes in most details of that bone. 


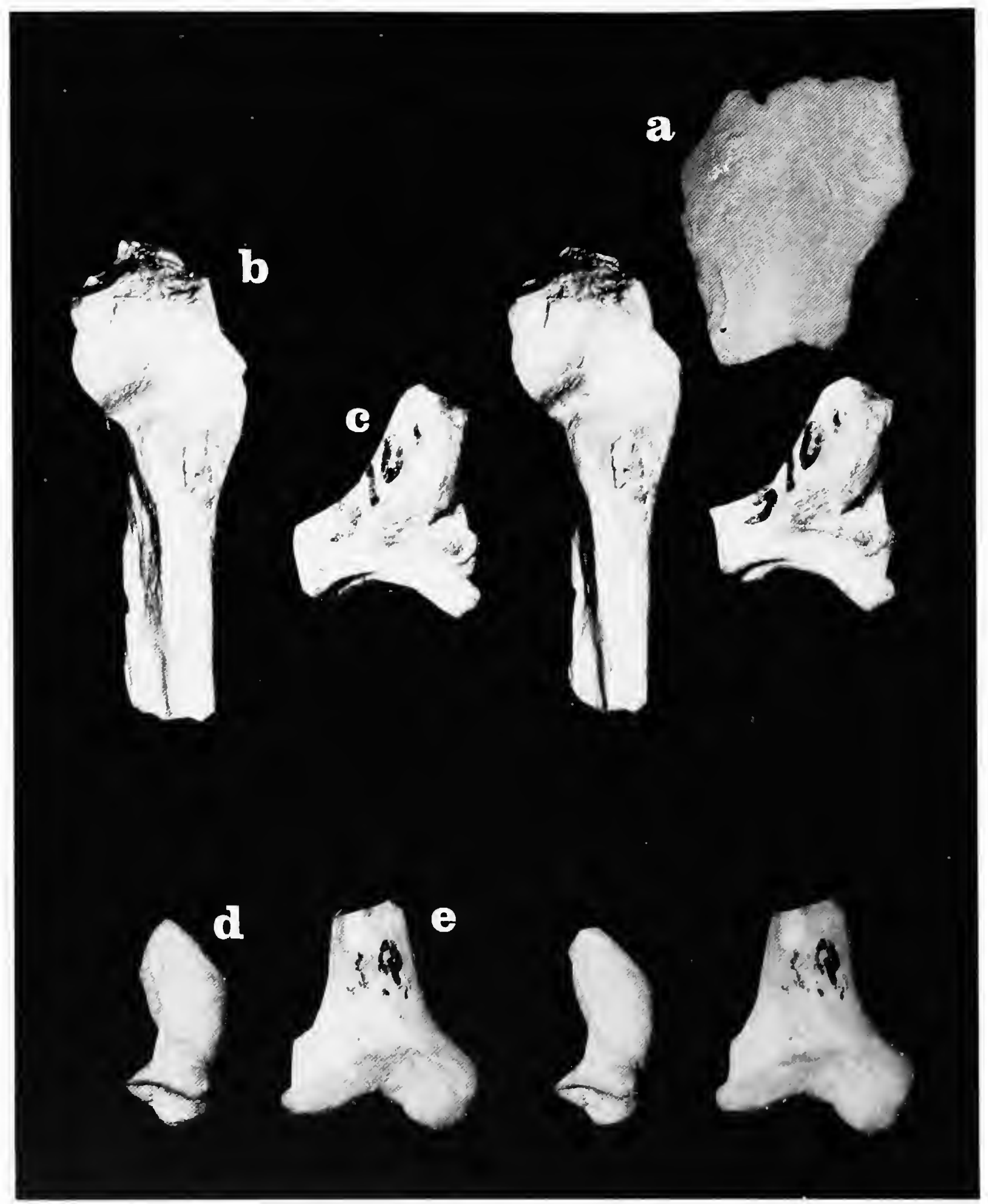

FIGURE 1.-Skull elements of Baptornis advenus: $a$, fragment of the frontal (AMNH 5101), dorsal view; $b$, stercophotographs of posterior fragment of the left ramus (FMNH 395), dorsal view; $c$, stereophotographs of ventral half of the right quadrate (AMNH 5101), anterior view; $d$, same, ventral view; $c$, posterior view. (All $\times 4$.)

Mandibular Ramus.-FMnH 395 includes the posterior portion of the left mandibular ramus with the articular cotyla (Figure 1b). It is slightly crushed dorsoventrally. The only other Cretaceous birds for which any part of the jaw is known are
Hesperornis and Ichthyornis (excluding Caenagnathus, which is not a bird).

In Baptornis, the surangular is tightly fused to the articular, with a groove near the ventrolateral border of the specimen along the suture between 
these two bones. The articular cotyla is divided into anterolateral and posteromedial sections, which are separated by a low ridge. A groove, which includes the articular foramen, lies on the margin of the posterior cotyla and runs under the internal articular process. Anterior to the posterior articular surface is a small depression and a wide, deep groove, which forms at the junction of the surangular and the articular.

The articular surfaces are of about the same shape and occupy approximately the same position as those on the ramus of Hesperornis (Gregory, 1952, fig. 7). They differ from the articular cotylae of the mosasaurs Clidastes and Platycarpus in having a concave, oblique, and elongate posterior articular surface and in the fusion of the jaw elements. Like Hesperornis, Baptornis lacks a depression for the condyle of the quadrate. This depression is present on the jaws of modern diving birds. In the Double-crested Cormorant (Phalacrocorax auritus), for example, it is centrally located and occupies nearly the entire posterior articulation. A posterior articular foramen is similarly located in Hesperornis and modern species of birds, but is absent in the mosasaurs. The posterior portion of the ramus of Baptornis is remarkably similar to that illustrated for Ichthyornis (Gingerich, 1973; fig. 2).

The mandibular articulation of Baptornis is very similar to that of both Hesperornis and Ichthyornis (Figure 2.) The jaws of Cretaceous toothed birds are more similar to one another than is generally supposed. Hesperornis shares with Ichthyornis the following features: teeth flattened from side to side, with expanded bases; anterior end of dentary blunt and symphysis not fused; teeth restricted to dentaries and maxillae; quadrate articulation double. Gingerich (1972:472) lists several additional features shared by Ichthyornis and Hesperornis in the posterior portion of the ramus. In so far as we can tell, Baptornis also shares these characters, and although it cannot yet be proven, we suspect that it was toothed.

Presacral Vertebrae (Table 1).-AMNH 5101 contains the most complete vertebral series of $B a p$ tornis, with at least 22 presacral vertebrae present. UNSM 20030 includes the first eight vertebrae anterior to the sacrum, and at least one of these is absent from AMNH 5101 suggesting that the total number of presacral vertebrae in Baptornis may
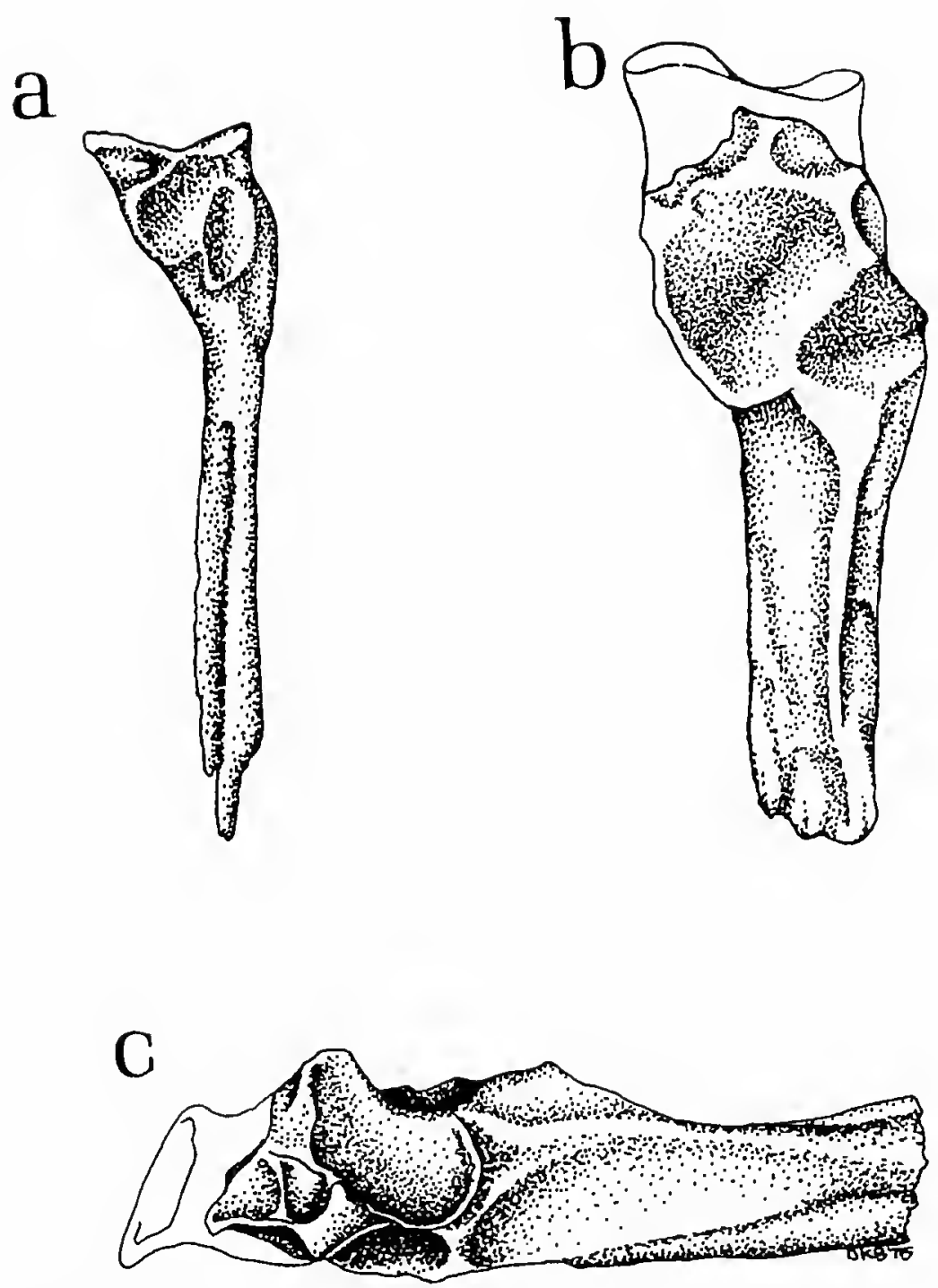

FIGURE 2.-Posterior portions of left rami: a, Ichthyornis (from Gingerich, 1972), dorsal view, $\times 2.8 ; b$, Baptornis advenus (FMNH 395), dorsal view, $\times 4 ; c$, same, medial view, $\times 4$.

have been 23, the same as in Hesperornis. Most of the vertebrae with AMNH 5101 are fragmentary, however, which may cause errors in interpreting their number and position. It is possible that Baptornis may have had 24 or 25 vertebrae, but the number could not have been less than 23 . There are four thoracic and parts of six cervical vertebrae with KUVP 16112. KUVP 2290 also contains four thoracic and six cervical vertebrae. FMNH 395 includes the last unfused thoracic vertebra. Three thoracic and two cervical vertebrae in AMNH 5101 and three cervicals with KUVP 2290 are preserved in articulation. These are the only natural associations available. The relative positions of the other vertebrae have been determined by comparisons with Hesperornis.

Only the cervicals reported on by Lucas (1903: 553) have previously been described. He pointed 
TABLE 1.-Measurements ( $\mathrm{mm}$ ) of the thoracic vertebrae of Baptornis numbered from the synsacrum foreward

\begin{tabular}{|c|c|c|c|c|c|c|c|c|c|c|c|}
\hline \multirow[b]{2}{*}{ Character } & \multicolumn{2}{|c|}{ FIRST } & \multicolumn{2}{|c|}{ SECOND } & \multicolumn{2}{|c|}{ THIRD } & \multicolumn{2}{|c|}{ FOURTH } & \multicolumn{2}{|c|}{ FIFTH } & \multirow{2}{*}{$\begin{array}{l}\text { SIXTH } \\
\text { UNSM } \\
20030\end{array}$} \\
\hline & $\begin{array}{c}\text { UNSM } \\
20030\end{array}$ & $\begin{array}{c}\overline{\text { FMNH }} \\
395\end{array}$ & $\begin{array}{l}\text { UNSM } \\
20030\end{array}$ & $\begin{array}{c}\text { KUVP } \\
2290\end{array}$ & $\begin{array}{l}\overline{\text { UNSM }} \\
20030\end{array}$ & $\begin{array}{c}\text { KUVP } \\
2290\end{array}$ & $\begin{array}{l}\overline{\text { UNSM }} \\
20030\end{array}$ & $\begin{array}{c}\text { KUVP } \\
2290\end{array}$ & $\begin{array}{l}\text { UNSM } \\
20030\end{array}$ & $\begin{array}{c}\text { KUVP } \\
2290\end{array}$ & \\
\hline Length centrum & 19.5 & 18.7 & 22 & 22 & 22 & (22) & 21.5 & 21 & 21.5 & (20) & 21 \\
\hline Width anterior articulation $\ldots \ldots \ldots \ldots$ & 18.3 & 17.6 & - & 18 & $(14.5)$ & 16 & - & 15 & 13 & 14 & 13.5 \\
\hline Height anterior articulation & 9 & 8.8 & 9 & 8.5 & 9 & 8.5 & 8.7 & 9 & 7.7 & 10 & 8 \\
\hline Width posterior articulation & 14 & 12.8 & 15 & - & 13 & 15.5 & 12 & 14 & 10.5 & - & 11 \\
\hline Height posterior articulation & 9.5 & 8.5 & 9.5 & 10.5 & 9.5 & 9 & 9.5 & 9 & 9 & - & 9 \\
\hline Diameter of rib articulations & & & & & & & & & & & \\
\hline Head $\quad \ldots \ldots \ldots \ldots . . . . .1 \ldots$ & * & * & - & - & 4.7 & - & 4.7 & - & 5.5 & 5 & 4.5 \\
\hline Tuberculum & * & * & - & - & - & -. & - & - & - & - & 3.5 \\
\hline Height neural spine $\ldots \ldots \ldots \ldots$. & 14 & - & - & - & - & - & - & - & 11 & - & 8.5 \\
\hline Length base neural spine .......... & 12 & 12 & - & - & 12 & - & 13 & - & 13 & - & 13 \\
\hline Width across transverse process & 23 & 23.5 & - & - & - & - & - & - & - & - & 36 \\
\hline
\end{tabular}

* Ribs do not occur on first vertebra; ()$=$ measurements from crushed specimen.

out that these were somewhat more elongate than the comparable vertebrae in Hesperornis.

The atlas (lacking the dorsal arch) and the crushed anterior portion of the axis (Figure 3a) are present in AMNH 5101. The atlas is similar to the atlas of Hesperornis illustrated by Marsh (1880:196, fig. 40). In Hesperornis, loons, and grebes, however, the ventral border of the atlas is directed posteriorly to form a shelf. In Baptornis the ventral border of the centrum is directed anteriorly and does not form a shelf. The hypapophysis is short and broad so that it is not well separated from the rest of the centrum. On either side of the hypapophysis is a short posteriorly directed process. These are very small in Hesperor$n$ is and absent in the loons and grebes. Short, blunt, transverse processes are also present. The odontoid process of the axis is short and broad. The axis has a large, deep, anteriorly directed pit on its anterolateral side and a pair of small pits on each side of the midline on the anteroventral surface. Its centrum is very narrow, with a thin bladelike hypapophysis. The anterior cervicals are all narrow and elongate (Figure $3 c-c$ ). They become much shorter and more massive posteriorly. The first eight vertebrae after the axis seem modified for downward flexion (Figure 3) and the articular facets of the prezygapophyses curve ventrally. The anapophyses are short and somewhat dorsally directed. The sublateral crests form a triangle with the anteroventral margin of the centrum on most of these vertebrae. In Hesperornis, the sublateral crests on the anterior cervicals are nearly parallel and the centra are much broader ventrally. What appears to be the tenth vertebra is very narrow posteroventrally, with its posteroventral border directed downward. Articulating posteriorly with this vertebra is a short, broad eleventh cervical with the zygapophyses tilted laterally and not directed downwards. The ventral surfaces of this and the four following vertebrae are broad and short and bear low parallel sublateral processes that do not join each other ventrally as they do in similar vertebrae in grebes (Zusi and Storer, 1969, fig. 10). Vertebrae 14-16 bear very large, deep, lateral depressions in their centra. The ventral border of the centrum of the 16th vertebra is directed ventrally and forms a distinct, thick, ventral process. In Baptornis there is no evidence that large vertebrarterial canals were present in as many vertebrae as they are in Hesperornis, loons, and grebes; however, the vertebrae which should show these canals are all badly damaged in the material of Baptornis.

The eighth vertebra anterior to the synsacrum (Figure $4 a-d$ ) corresponds to the 16 th cervical vertebra of Hesperornis. Its dorsal spine is short, thick, and broad at its base. The tubercle is not bifurcated; the post- and prezygapophyses are set at a low angle and are widely spaced; the neural canal is circular in outline; the anterior articulation of the centrum is short dorsoventrally, but very wide; the transverse processes are wide, swing slightly upwards, and are directed posteriorly; the posterior border is thickened while the anterior portion nearest the centrum is slightly concave; and there is no vertebrarterial canal. On this ver- 


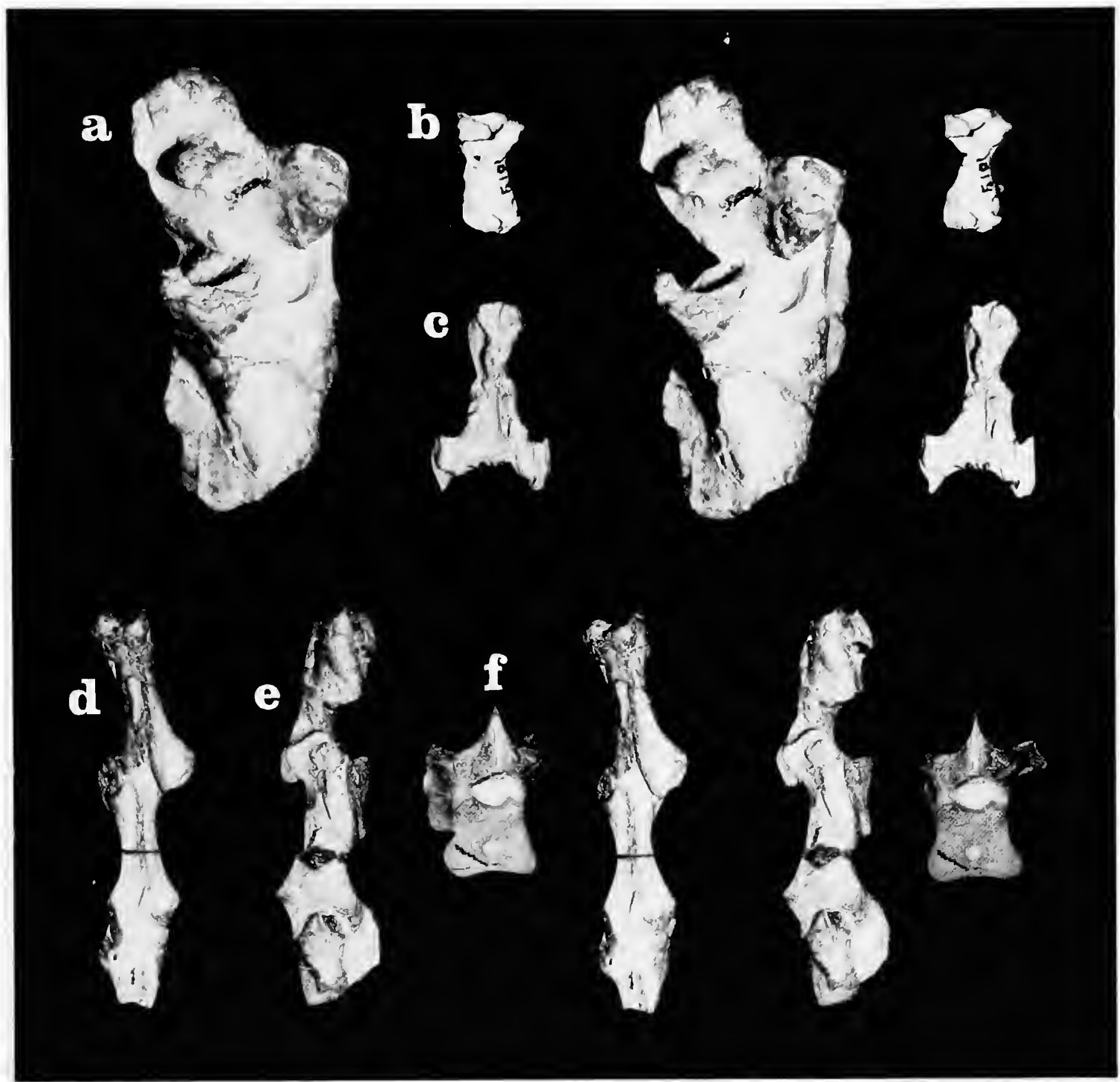

Figure 3.-Stereophotographs of vertebrae of Baptornis advenus: $a$, atlas and axis vertebrae (AMNH 5101), $\times 4 ; b$, cervical vertebra (AMNH 5101), anterior view, $\times 1$; $c$, same, ventral view, $\times 1$; $d$, three partial cervical vertebrae (KUVP 2290), dorsal view, $\times 1$; $e$, same, lateral view, $\times 1$; $f$, thoracic vertebra (KUVP 2290), posterior view, $\times 1$.

tebra the articulation for the tuberculum of the rib is shallow, circular in outline, and slightly recessed from the outermost margin of the diapophyses. The articulation for the head of the rib is deep, circular, and placed anteriorly on the centrum. The centrum itself is short and thick, with a strong indentation on either side. The hypapophysis is extremely short, stout, and directed posteriorly, practically merging in with the rest of the centrum. The distal hypapophysis is terminated by two stubby horizontal wings.
The seventh vertebra anterior to the sacrum corresponds to the last cervical of Hesperornis and resembles the previous vertebra. However, the anterior articulation is not as wide and is higher dorsoventrally; the neural canal is not as rounded; the prezygapophyses are closer together and at a more acute angle; the dorsal spine is wider and thicker; there is a concavity on the anteroventral margin of the transverse process above the articulation for the head of the rib; and the transverse processes are shorter and do not swing back pos- 


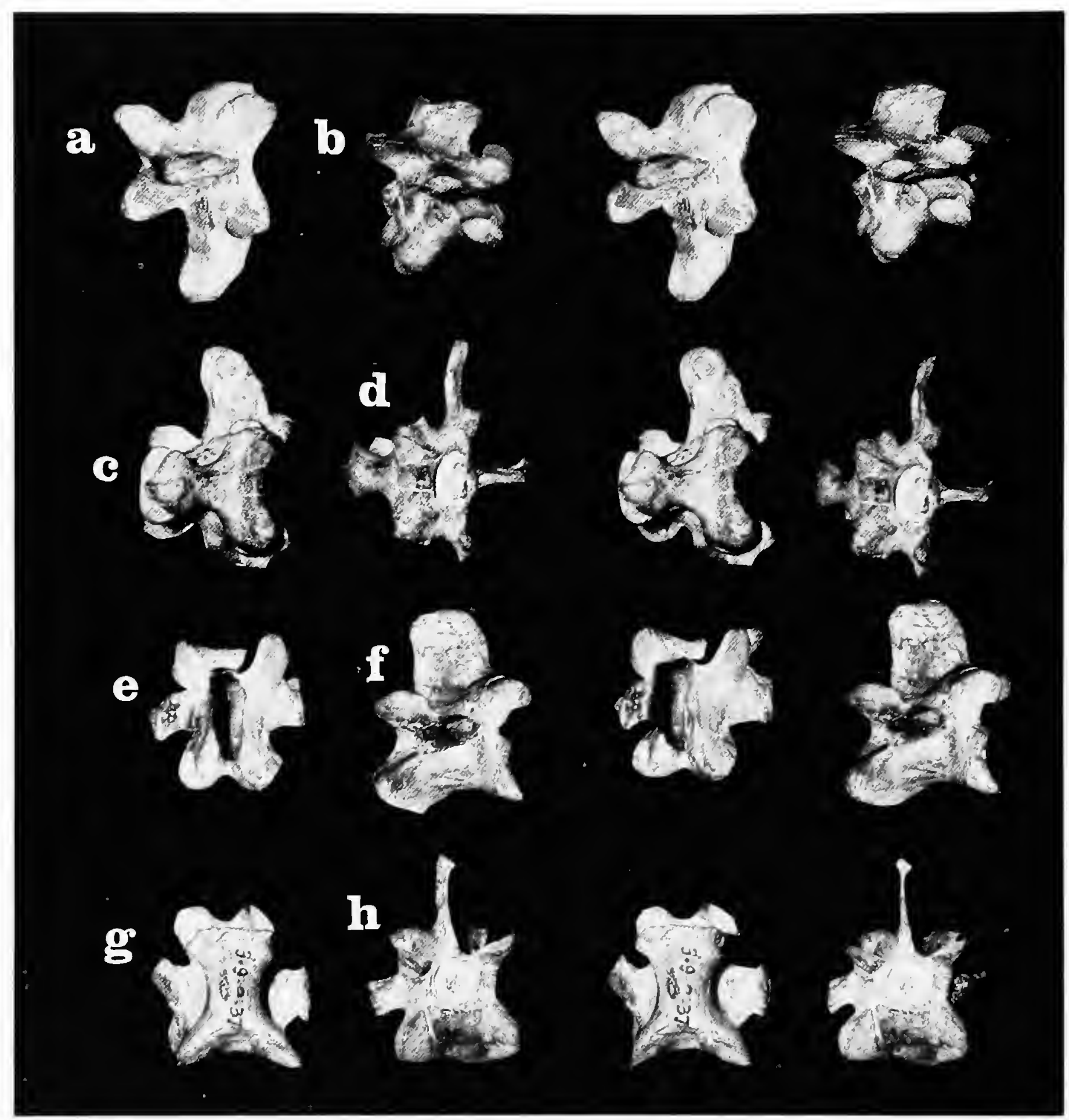

FIGURE 4,-Stereophotographs of vertebrae of Baptornis advenus: $a-d$, dorsal, lateral, ventral, and anterior views of eighth vertebra anterior to the synsacrum (UNSM 20030); $e-h$, dorsal, lateral, ventral, and anterior views of first vertebra anterior to the synsacrum (USNM 20030). (All $\times 1$.)

teriorly. The articulation for the tuberculum of the rib is nearer the lateral edge of the diapophysis than in the 16 th vertebra. The hypapophysis is thin and posteriorly directed.

The sixth vertebra anterior to the sacrum resembles the seventh except that the anterior articulation is not quite as wide and is higher dorsoventrally; the dorsal spine is of about the same height but is thinner; the transverse processes curve posteriorly; the pit above the articulation for the rib is deeper, and the hypapophysis is thin and directed anteriorly.

The fifth vertebra anterior to the sacrum has a narrow, higher anterior articulation than the sixth; the centrum itself is not as indented and the prezygapophyses are closer together and at a more acute angle; the dorsal spine is thin, high, and directed anteriorly; the pit above the articulation for the head of the rib is deep, as in the preceeding vertebrae; the diapophysis and hypapophysis are 
missing, but enough remains of the hypapophysis to show that it was thin and large.

The fourth vertebra anterior to the sacrum similarly has a high, narrow anterior articulation; however, the centrum is less deeply indented; a small pit forms on the dorsal anterior margin of both of the postzygapophyses; the pit above the articulation for the head of the rib has become shallow and elongate. The dorsal spine, transverse processes, right prezygapophysis, and most of the hypapophysis are broken off, but enough remains to show that the hypapophysis was thin, posteriorly directed, and probably short.

The third vertebra anterior to the sacrum has a lower, but wider, anterior articulation; the centrum is less indented; the pit above the articulation for the head of the rib is absent; and the hypapophysis is very short, thin, and triangular. The dorsal spine and diapophysis are missing from the available specimens.

The second vertebra anterior to the sacrum has a wider anterior articulation than the preceding vertebra. The top of the vertebra and the transverse processes are missing in the one available specimen. The articulation for the head of the rib is shallower than in the preceding vertebra, and there is a shallow pit just above it. The hypapophysis is represented by a small knob on the ventral border of the vertebra. The centrum of this specimen had been broken through the middle and repaired with glue. We separated the two halves with acetone but found no medullary cavity.

The first vertebra anterior to the synsacrum (Figure $4 e-h$ ) is distinctive. The anterior articulation is wider than in the preceding vertebra. The dorsal spine is high and thin, and the posterior margin is bordered by two small grooves lying on top of the postzygapophyses. The diapophyses are short, thick, and directed posteriorly, their ends being flattened to buttress against the inner sides of the ilia. There is a small pit lying directly anterior to the diapophysis. The centrum is slightly indented, the ventral border is flat, and there are no rib articulations.

The vertebrae of Baptornis are nonpneumatic and heterocoelous (amphicoelous vertebrae occur in Archaeopteryx, Ichthyornis, and Enaliornis). Compared to Hesperornis, the cervical vertebrae are more elongate and not as deep, the anapo- physes are less developed, and the sublateral processes tend to converge more posteriorly. At least the first five postaxial vertebrae are modified for downward flexion, as are the presumed 14th and 15 th vertebrae. The specimens of intervening vertebrae (7-13) are too fragmentary to be certain of their adaptations but some must have been modified for upward flexion.

The description of the thoracic vertebrae is based almost entirely on the beautifully preserved series with UNSM 20030. These all have good heterocoelous articular surfaces, although circular pits (Figure 3f) occur in the centra of some specimens. They are not fused as in cormorants, or fused and further immobilized by ossified dorsal tendons, as in grebes. They also lack the very deep lateral excavations found in the thoracic vertebrae of Ichthyornis and can best be compared to the thoracic vertebrae of Hesperornis. As Lucas (1903) indicated, the hypapophyses are more anteriorly situated, not as well developed as in Hesperornis, and not bifurcated as in most modern diving birds.

Synsacrum.-The synsacrum (Figure $5 b-d$ ) is represented in KUVP 2290, FMNH 395, AMNH 5101, and a few fragments from KUVP 16112. It is nonpneumatic and extremely narrow. Lucas (1903) reported that the synsacrum of KUVP 2290 contains 10 fused vertebrae and that the first bore a rib. Although he was correct in the number of vertebrae ( 10 also being the number found in FMNH 395) he was mistaken about the presence of a rib with the first fused sacral. Rib facets do not occur on any of the synsacra available nor even on the last unfused thoracic vertebra.

The anterior sacral vertebra has a high, posteriorly sloping neural spine. The transverse processes are tilted and flattened laterally to form a broad contact with the ilium. The second sacral is sutured dorsally to the first. It has a large, laterally flattened, pointed transverse process projecting anteriorly (Figure $5 b$ ) that also abuts the ilium. There are three vertebrae from the acetabulum forward, and these may represent fused lumbars with the rest of the sacrum being composed of seven fused caudals (urosacrals). The neural spines of the synsacral vertebrae are low and form a median ridge bounded by projections on either side. The posterior urosacrals lack the ventral keel found in Gavia, and the posterior central articulations of the last two urosacral vertebrae are divided 

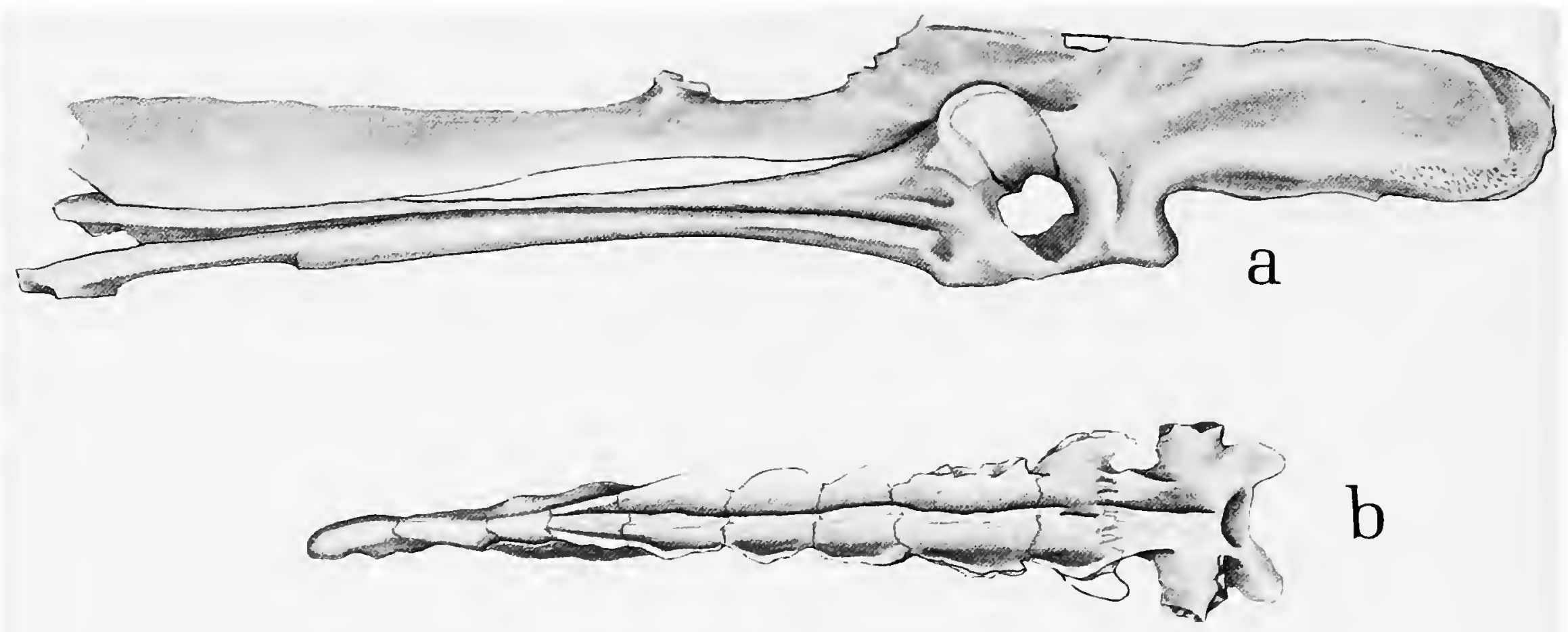

$\mathrm{b}$
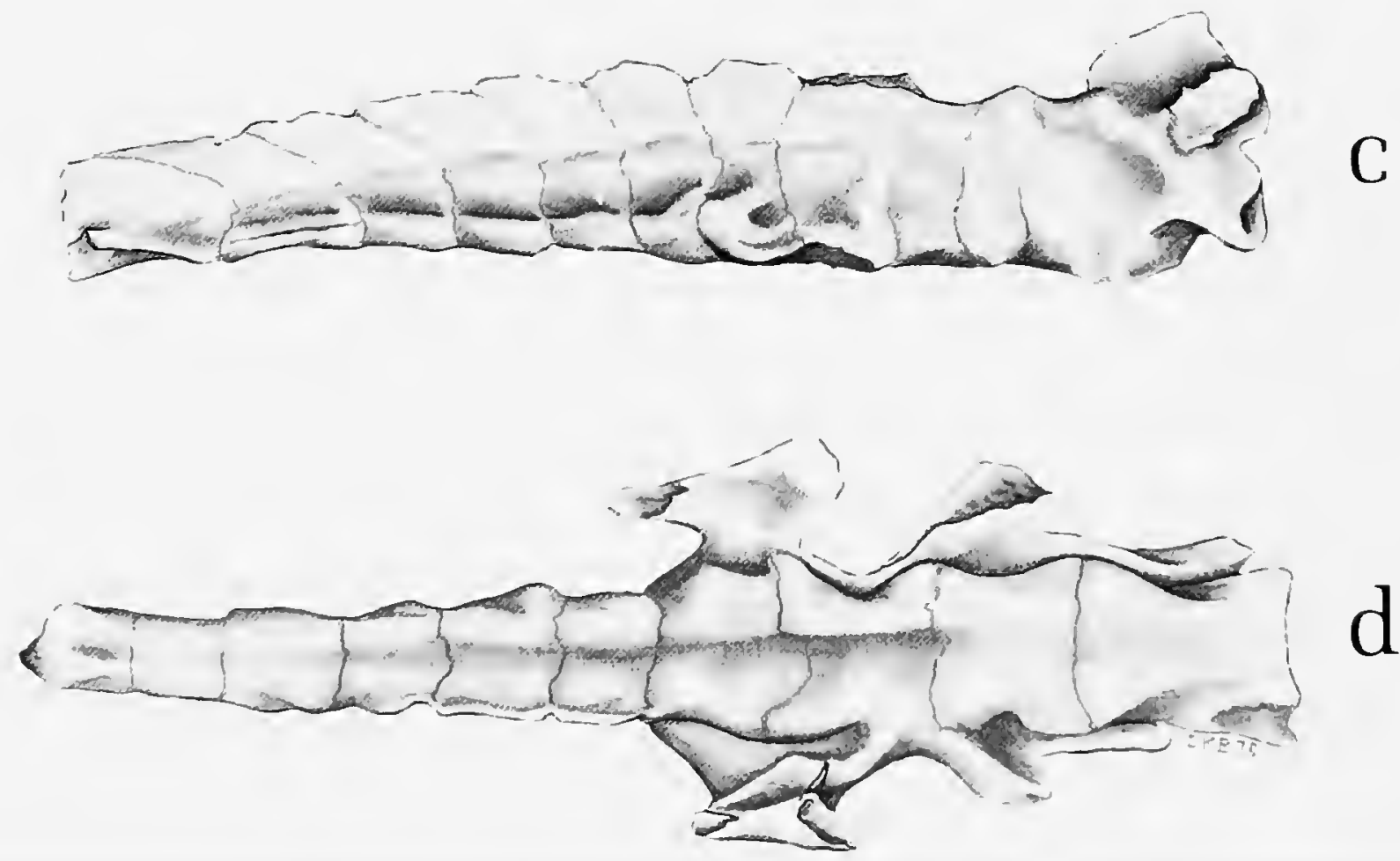

FIGURE 5.-Pelvis of Baptornis advenus: a, right innominate bone (UNSM 20030), lateral view. Synsacra of B. advenus: $b$, dorsal view (KUVP 2290); $c$, lateral view (FMNH 395); $d$, ventral view (AMNH 5101). All $\times 1$.)

medially by a ventral groove.

Caudal Vertebrae.-UNSM 20030 has five caudal vertebrae and a pygostyle, as does FMNH 395. AMNH 5101 also contains five caudals but includes four anterior ones that are not represented in either UNSM 20030 or FMNH 395. The first caudal has already been discussed in the section on the sacrum. The following three vertebrae have low neural spines, flat ventral borders and widen posteriorly, assuming a triangular shape. All of these vertebrae are flanked by the pelvis and their transverse processes abut the ilia. The vertebrae posterior to the pelvis have high, straight, triangular neural spines with rounded tips that become 


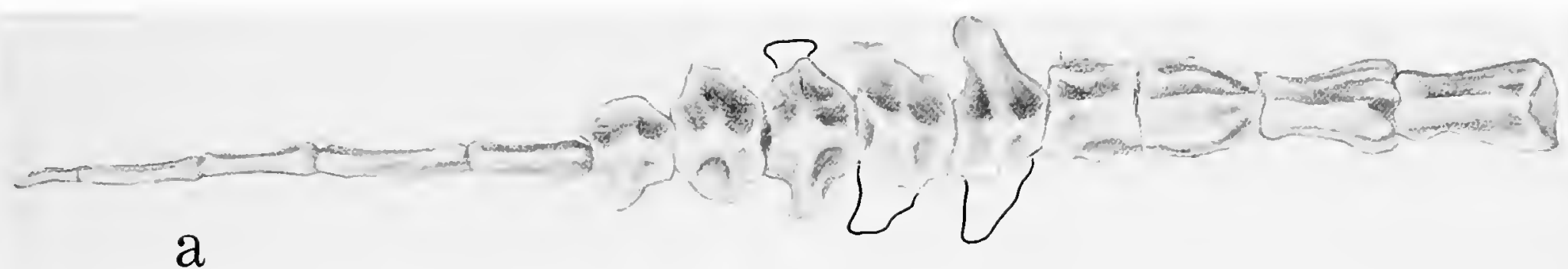

a

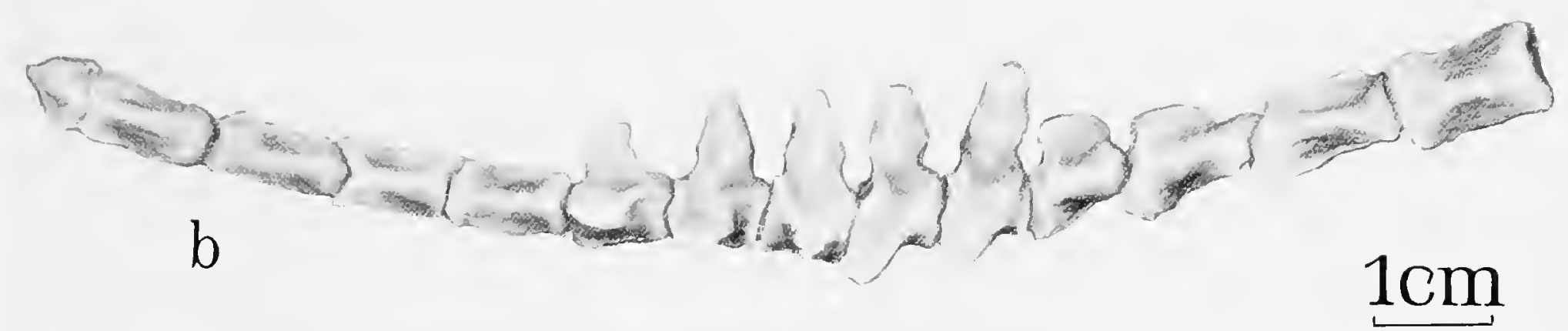

Figure 6.-Caudal vertebrae and pygostyle of Baptornis advenus: a, dorsal view; $b$, lateral view. ( $\times 1$.)

progressively lower posteriorly. The caudals also have large, posteriorly directed and ventrally depressed transverse processes that, along with the centra, become smaller posteriorly. The vertebral centra are either amphicoelous or amphiplatyan and the centra themselves are rounded ventrally and bear ventrolateral depressions or pits. The pygostyle is elongate and laterally flattened. It includes five fused centra. The general configuration of the posterior two-thirds of the tail (Figure 6 ) is roughly similar to that in Gavia and quite different from Hesperornis, which has dorsoventrally flattened caudals with wide, flat transverse processes and shelf-like, fused intracentral bones. Hesperornis has only two fused centra in its pygostyle. Intracentral bones are present in many living diving birds, but they have not been found in Baptornis. In Baptornis, the posteroventral margin of the second fused centrum of the pygostyle bears a distinct projection, which probably served as a muscle insertion.

Ribs and Uncinate Processes.-Some fragments of ribs are present with all of the specimens of Baptornis. The best material (Figure 7) is pre- served in situ on slabs of matrix with UNSM 20030. This material includes at least four different dorsal ribs and four different sternal ribs. These are flattened and shaped about as in Hesperornis, suggesting a narrow rib cage. Six uncinate processes representing five pairs are present in UNSM 20030. The uncinate processes of Hesperornis and Baptornis do not fuse to the ribs-a condition similar to that seen in grebes and loons, as well as certain other modern birds. In Hesperornis, the uncinate

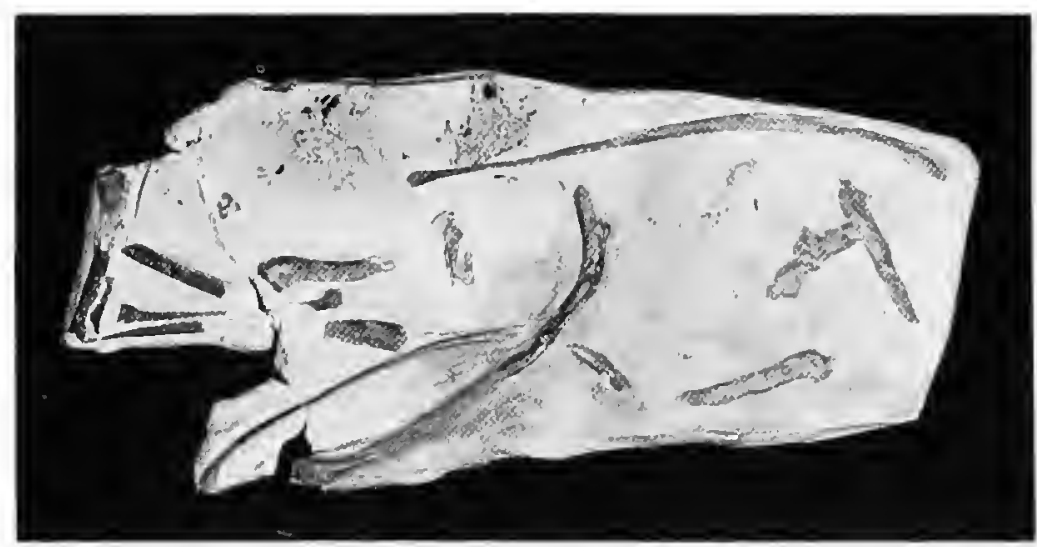

FIGURE 7.-Slab with ribs and uncinate processes of Baptornis advenus (UNSM 20030). 
processes are broad and straight. In Baptornis, they are narrow, and bend upward at an acute angle, thus resembling the uncinate processes of grebes (Figure 8). Because there is no association between ribs and uncinate processes on the slab, none can be placed in order with certainty. The ribs of Baptornis are heavier than those of grebes and loons and do not expand as much ventrally. The tuberculum is not separated as far from the head as it is in Hesperornis or in the modern footpropelled divers.

STERNUM.-The anterior and lateral margins of the sternum (Figure 9a) are preserved with UNSM 20030 , the entire central portion and the posterior margin having been destroyed.

In the area of the dorsal manubrial spine there is only a smooth, thickened border from which a shallow sulcus flares ventrally into a flattened, rounded ventral manubrial spine. The coracoidal sulci are deep, closely spaced, and lie at an angle of $22^{\circ}$ from a line perpendicular to the midline of the sternum. The sternocoracoidal processes are large, rounded, flare laterally, and are not strongly curved. The costal margins are short, and bear five costal ridges.

The sternum is most similar to that found in Hesperornis. It appears to bear a shallow rectangular depression on its anteroventral surface which does not occur in Hesperornis. The sternum also

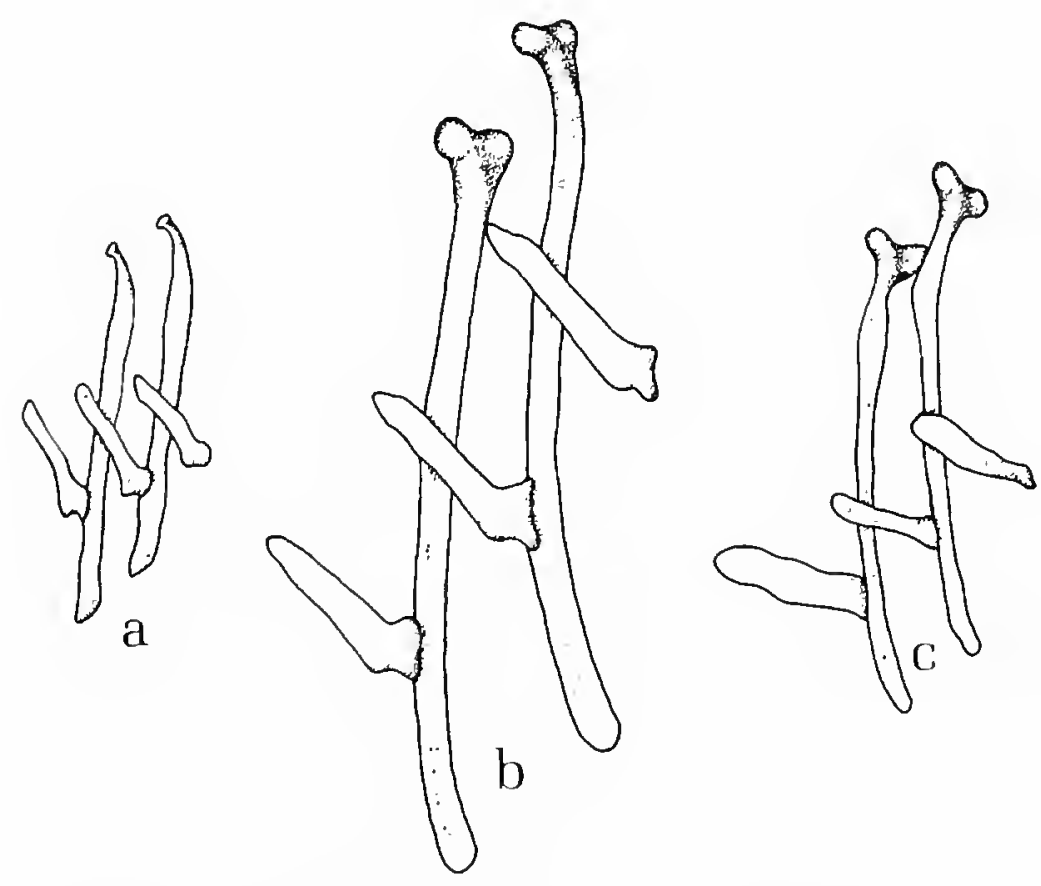

Figure 8.-Ribs and uncinate processes: a, grebe, Aechmophorus occidentalis; $b$, Baptornis advenus; $c$, Hesperornis regalis. (Not to scale.)
TABLE 2.-Measurements ( $\mathrm{mm}$ ) of the coracoid of Baptornis

\begin{tabular}{|c|c|c|}
\hline Character & $\begin{array}{l}\text { UNSM } \\
20030\end{array}$ & $\begin{array}{c}\text { KUVP } \\
2290\end{array}$ \\
\hline Approximate length & - & 53 \\
\hline Width glenoid facet & 4 & 3.5 \\
\hline Length glenoid facet & 7.6 & 8 \\
\hline Width scapular facet & 4.5 & 4.5 \\
\hline Length scapular facet & 7 & 7.5 \\
\hline Width sternal end $\ldots \ldots \ldots \ldots \ldots \ldots \ldots$ & - & 23 \\
\hline
\end{tabular}

appears relatively smaller than in Hesperornis and consequently the body of Baptornis may have been somewhat narrower. The width of the anterior end of the sternum is $53 \mathrm{~mm}$ and the length of the costal margin is $27 \mathrm{~mm}$.

Coracoid (Table 2).-UNSM 20030 includes the scapular end and a fragment of the sternal end of the left coracoid. KUVP 2290 includes most of the right coracoid (Figure 9c). This specimen was illustrated by Lucas (1903, fig. 6).

The head of the coracoid is small and turned towards the procoracoid. The glenoid facet is large, elliptical, and shallow. The furcular facet is low, narrow, not undercut, and set almost directly on the scapular end of the shaft so that it is completely visible when the scapular end of the coracoid is viewed from above (Figure $10 a, 11 a$ ). The surface of the scapular facet is rough and bears two or more distinct pits on its anterior end. The procoracoid is short and recurved towards the shaft to form part of the triosseal canal. Just below the procoracoid is a foramen leading into the shaft of the bone, which is probably the procoracoid foramen. In KUVP 2290 this foramen penetrates from the anterior to the posterior surface, as well as branching into the shaft. Lucas (1903:553) incorrectly states that the procoracoid process and foramen are absent. The shaft is long and narrow. The posterior surface is slightly concave, while the anterior surface is curved and convex. This gives the coracoid the appearance of a shallow spoon with a square end. The sternal end is wide, thin, and lacks definite facets.

The coracoid of Hesperomis is fundamentally

FIgURE 9.-Pectoral and wing elements of Baptornis advenus: $a$ (top to bottom), anterior, ventral, and left lateral views of sternum (UNSM 20030) $\times 1 ; b$, external and internal views of left humerus, $\times 1$; $c$, ventral, dorsal, and external views of right coracoid (KUVP 2290), $\times 1$; d, distal end of right humerus, external view, $\times 5$. 

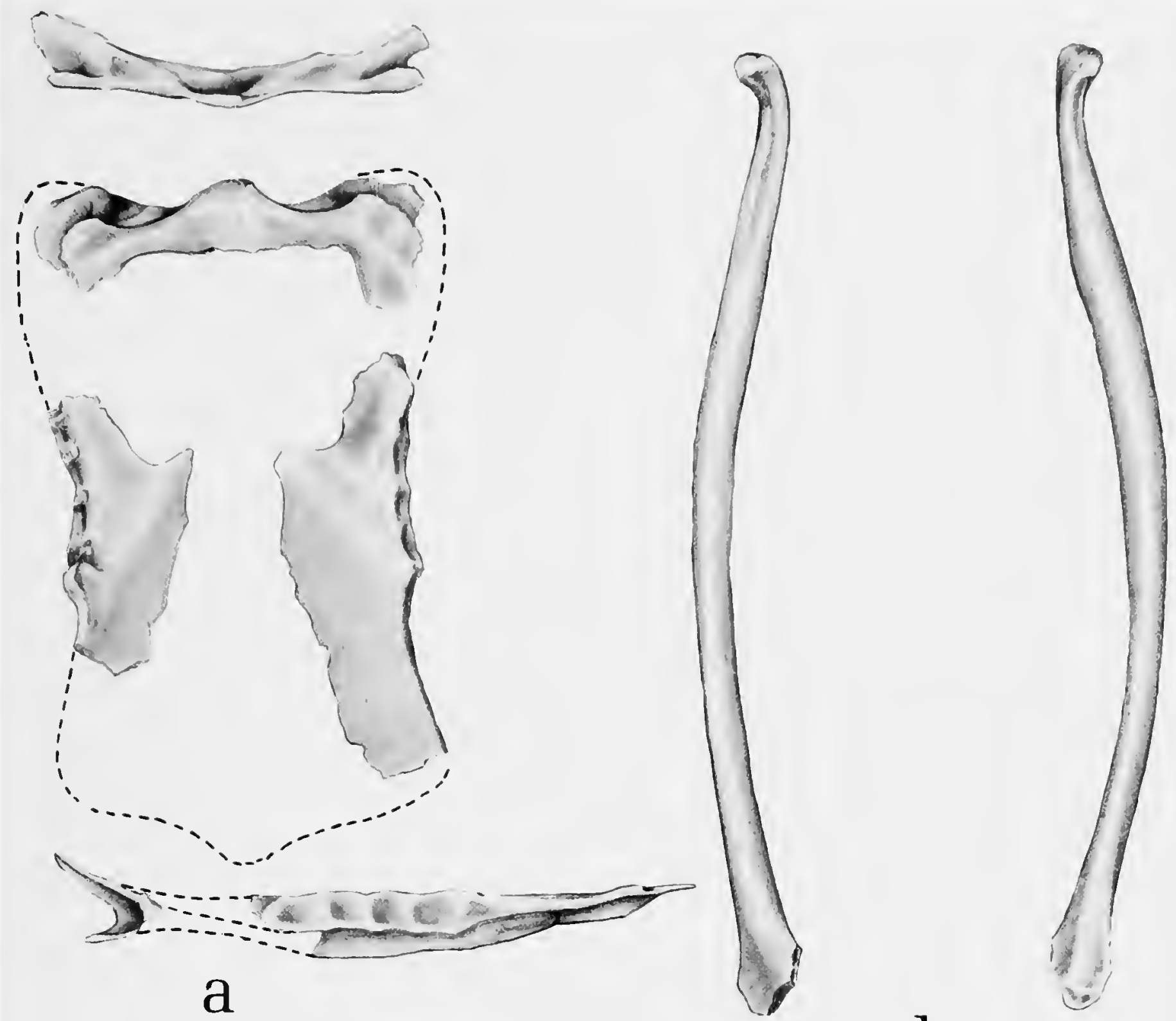

b
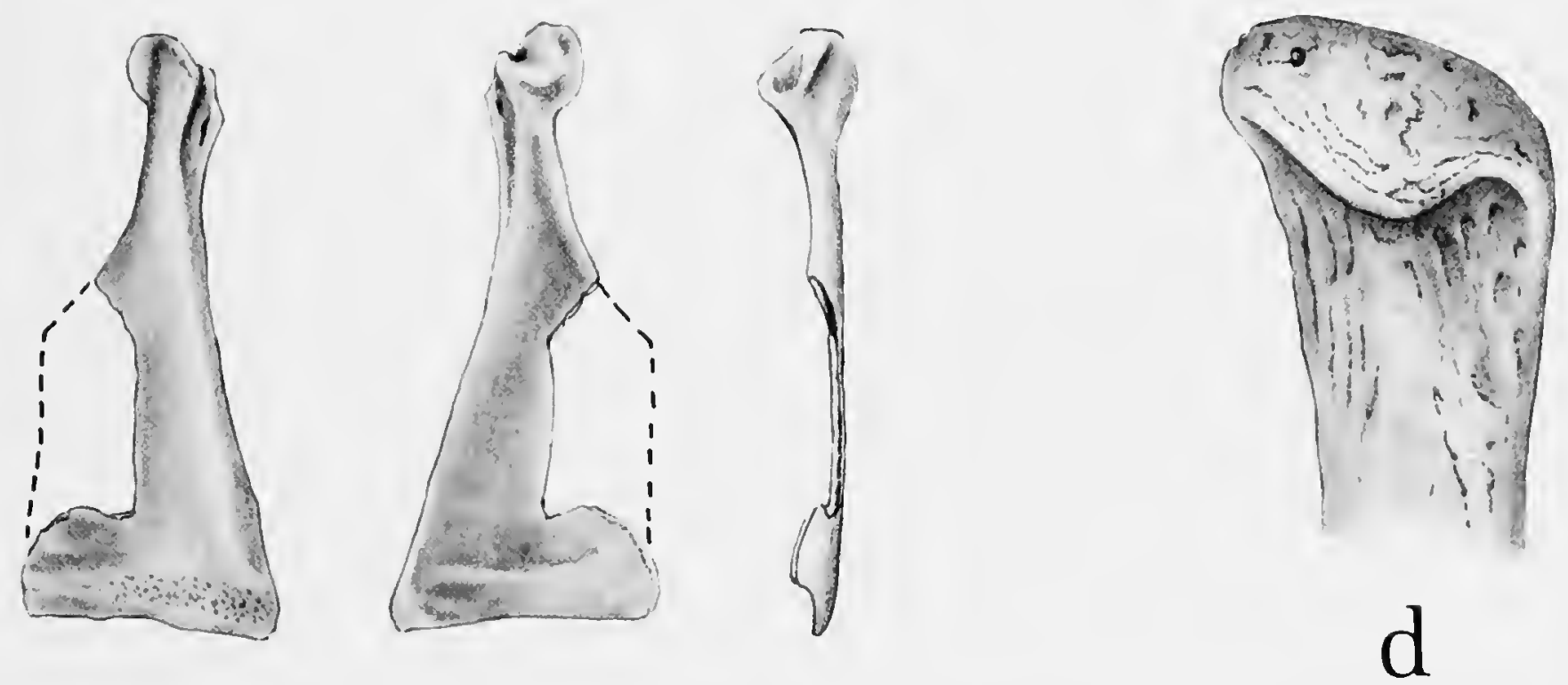

C 

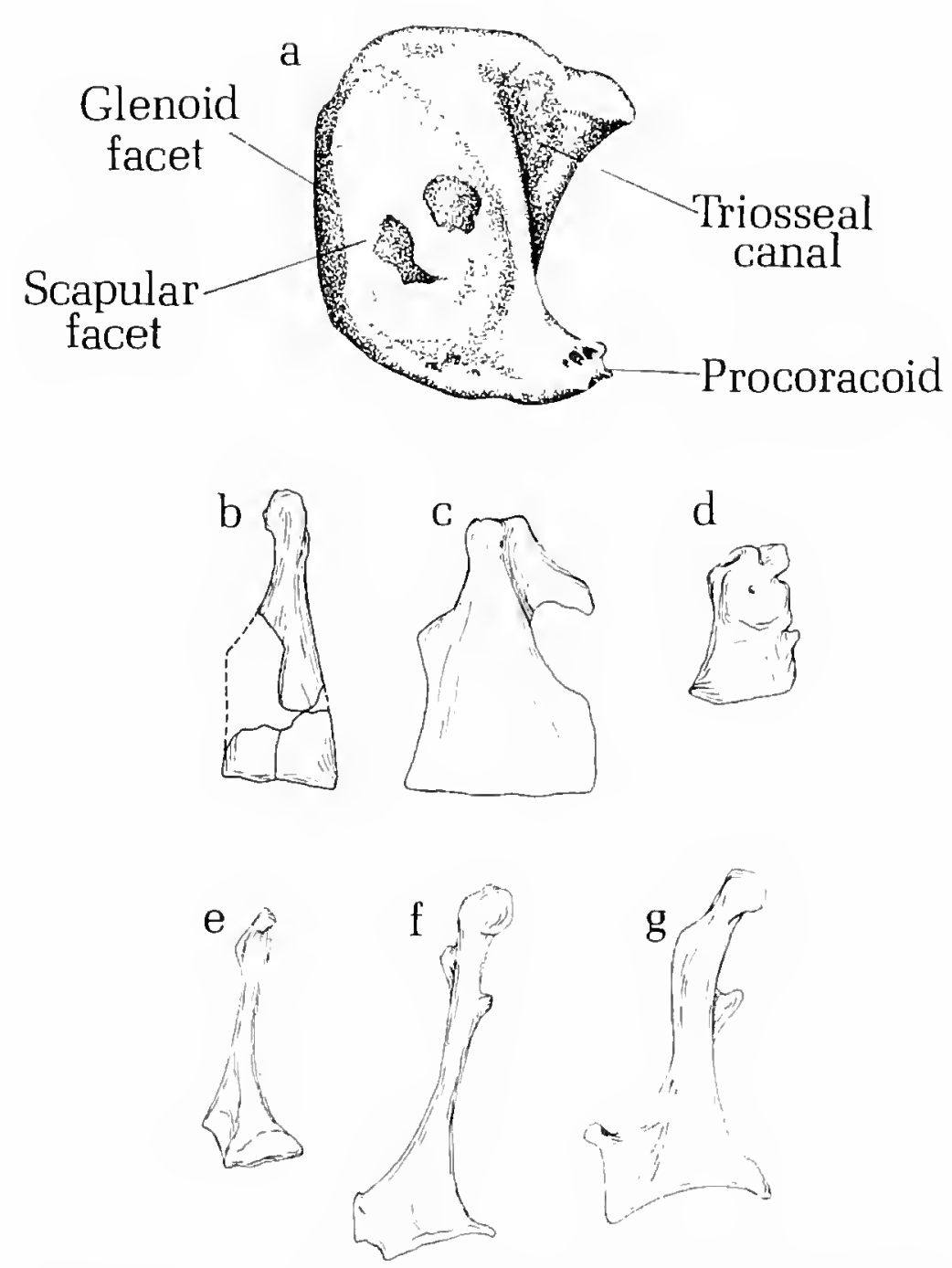

Figure 10.-Coracoids: $a$, tip of the scapular end of the left coracoid of Baptornis advenus; $b-g$, ventral views of the right coracoid: b, Baptornis advenus; $c$, Hesperornis regalis; $d$, Archaeopteryx lithographica; e, Aechmophorus occidentalis; $f$, Phalacrocorax auritus; $g$, Gavia immer. (Not to scale.)

similar to that of Archaeopteryx. In both genera the coracoid is short and broad and the scapula and humerus have articulations on the tip of the scapular end. The coracoid of Baptornis resembles Hesperornis in these features, as well as in having the sternocoracoidal process above the midpoint of the bone. The main longitudinal axis of the shaft of the coracoid is perpendicular to the edge of the sternal facet in the Hesperornithiformes and inclined in all other foot-propelled diving birds for which the coracoid is known (Figure 10). The coracoid of Baptornis is more elongate than in Hesperornis and the procoracoid process is smaller and differently shaped. In Baptornis, the internal edge of the coracoid is nearly straight, while in Hesperornis there is a large, square, internal projection (Figure 10c). It should be noted that Lucas (1903, fig. 6) has illustrated the posterior view of the sternal fragment of the coracoid with the anterior view of the scapular portion (compare his figure 6 with figure 10 of this paper).

A small area for the attachment of the clavicle seems to be present although no clavicles are known.

ScapUla.-KUVP 2290 includes the articular end of the left scapula (Figure 11b-d), which was described and figured by Lucas (1903:553-554). The coracoidal articulation is long, narrow, and slightly curved to fit the contour of the scapular facet on the coracoid. It bears two large pits similar to those found on that facet. The anterodorsal margin of the proximal end does not show any articulation for the furcula. This margin slopes at about 47 degrees to the main axis of the shaft, and is terminated dorsally by a small projection. The ventral border bears a long, shallow groove. The measurements (in $\mathrm{mm}$ ) of the scapula are: width of neck, 7.5; depth of neck, 4.0; width of proximal end, 10.5; length of glenoid facet, 9.4.

The neck of the scapula is wide and thick, which led Lucas to suggest that it may have been expanded posteriorly as in penguins. The scapula of Hesperornis is similarly thickened, but does not expand posteriorly (Marsh, 1880:58). Therefore, the posterior portion of the scapula of Baptornis probably did not differ much from that of Hesperornis.

Humerus.-KUVP 2290 includes the distal end and a portion of the shaft of the right humerus. This specimen was described by Lucas (1903:554), who reported it as being a left humerus, but the curvature of the shaft matches that of Marsh's illustration of the right humerus of Hesperornis regalis (Marsh, 1880, pl. 8: fig. 1). UNSM 20030 includes a slightly abraded proximal end and the greater portion of the shaft of the left humerus. We have examined the large alleged humeri of Baptornis reported by Walker (1967) and have determined that they are fragmentary shafts of the tibiotarsus.

The proximal end of the humerus is simplified as compared with that of modern birds (Figure $9 b)$. The shaft curves downward, then expands noticeably and is twisted posteromedially $75 \mathrm{~mm}$ from its proximal end. There is a nutrient foramen situated in a groove $48.5 \mathrm{~mm}$ from the proximal end in UNSM 20030. This foramen is likewise present in KUVP 2290, which also has a 


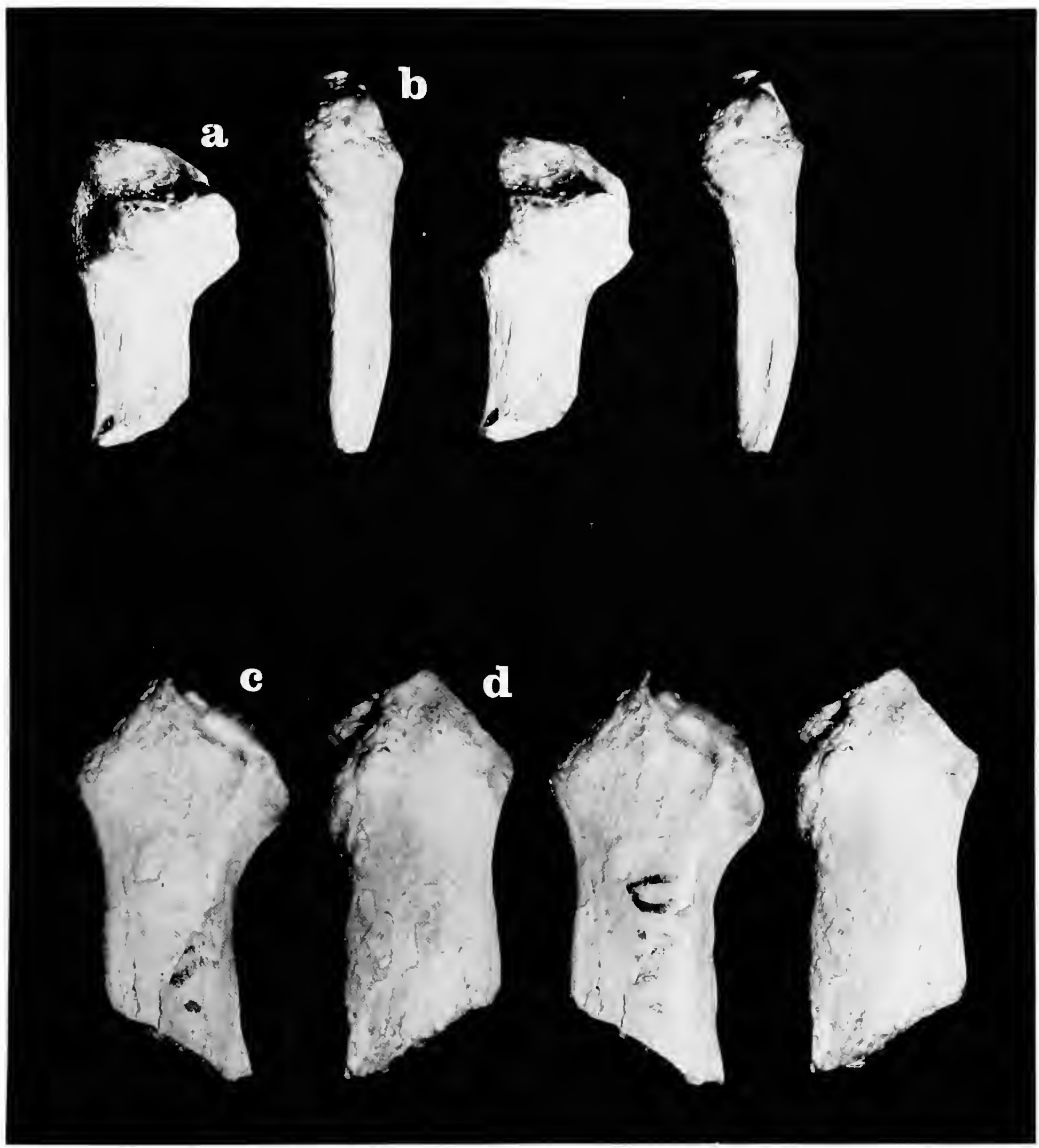

FIGURE 11.-Stereophotographs of pectoral girdle elements of Baptornis advenus: $u$, scapular end of left coracoid (USNM 20030), internal view; $b-d$, ventral, internal, and external views of articular end of left scapula (KUVP 2290). (All $\times 4$ ).

second groove and a foramen $17.5 \mathrm{~mm}$ distal to the previously mentioned one.

A small, rounded prominence set off from the internal condyle by a shallow groove may represent the distal external condyle. The internal condyle is not of the form usually found in birds and is only slightly delineated from the rest of the distal end. It bears a small foramen on its articular surface. There is no distinct olecranal fossa or prominent grooving. The shaft of the University of Nebraska 
specimen was $\mathrm{x}$-rayed and the broken ends of KUVP 2290 and UNSM 20030 were examined. Neither are pneumatic. By transposing the humerus of UNSM 20030 over that of KUVP 2290 so that the curvatures and foramina are in alignment (Figure 9b), a reconstructed length of 118 $\mathrm{mm}$ is obtained. This is only $18 \mathrm{~mm}$ more than Lucas's (1903:553) estimate of $100 \mathrm{~mm}$ based on KUVP 2290 alone. The width of the proximal end is $8.9 \mathrm{~mm}$ and of the distal end $6.8 \mathrm{~mm}$. The greatest diameter of the shaft is $6.5 \mathrm{~mm}$.

The humerus of Baptornis is relatively long, curved, and rounded. It is not flattened and straight as in the wing-propelled auks and penguins. Lucas (1903:554) suggests that the wing may have been used in conjunction with the feet for locomotion. This seems unlikely, although we have shown it as having a stabilizing function (Figure 20). The humerus is larger than that of Hesperornis, which is a much bigger bird. In Hesperornis, the distal end is also much more reduced and the radius and ulna may not have been present.

RADIUS.-A description of the left radius (Figure 12b) KUVP 2290, appears in Lucas (1903: $554)$. The humeral cotyla is large and oval, with the bicipital tuberosity situated along its rim. The shaft expands markedly at about the midpoint. In this area there is a nutrient foramen on the palmar side and also a faint intermuscular line. The lunar depression is shallow. The scapholunar facet is long and narrow and the distal ligamental process is relatively large. The radius is $20.5 \mathrm{~mm}$ long, the proximal end is $3.0 \mathrm{~mm}$ wide, and the distal end is $3.5 \mathrm{~mm}$ wide.

Ulna.-Lucas (1903:554) briefly describes the short, robust, left ulna, KUVP 2290 (Figure 12a). The olecranon process is short, massive, and not noticeably twisted as in many flying birds. The internal and external cotylae on the proximal end are only slightly separated by an intercotyla area and almost form a single articular surface. The proximal radial depression is slightly discernable. The impression of the brachialis anticus is large and oblong, and crosses the palmar surface of the bone diagonally. A faint intermuscular line stretches for 2-3 $\mathrm{mm}$ below the distal end of the impression for the brachialis anticus. No nutrient foramen can be discerned. The distal radial depression is small and quite shallow. The internal con- dyle on the distal end is a small projection. The external condyle is not a distinct ridge but bears a large, flat articular surface which tilts toward the anconal and ventral margins. Although we examined the bone carefully, we could see no scars for feather attachment, Lucas' (1903:554) assertion of their presence notwithstanding. Measurements (in $\mathrm{mm}$ ) of the ulna are: length, 21.6; width proximal end, 4.2; width distal end, 2.9; depth distal end, 3.5 .

The radius and ulna of Baptornis are short, stout bones resembling in general form their counterparts in the extinct diving goose Chendytes milleri (Howard, 1955). The reduction is much greater in Baptornis, however. In C. milleri the ulna is 43 percent as long as the humerus (Howard, 1955:142), while in Baptornis it is only about 19 percent of the restored length $(118 \mathrm{~mm})$ of the humerus. The general form of the ulna is similar to that found in theropod dinosaurs (Figure 13) and it seems possible that the Hesperornithiformes may have split off from the line leading to modern flying birds before the wing had developed the adaptations seen in modern birds. The presence of well-formed articulations on the distal ends of the radius and ulna show that some sort of carpals were present, although these may not have been fused into a true carpometacarpus.

Pelvis.-All the specimens of Baptornis we studied included at least some fragments of the pelvis. Most of the right side is preserved with UNSM 20030, and our description of the pelvis is based on this specimen (Figure $5 a$ ). The synsacrum is in place only in AMNH 5101, in which the acetabulum is opposite the third fused sacral.

The pelvis is similar to that of Hesperornis, but differs in having a much longer preacetabular portion of the ilium. The postacetabular part of the ilium is quite long, as it is in all of the footpropelled diving birds. The middorsal and the posteriormost portions of the ilium are not known, but were probably similar in shape to the same region in Hesperornis, although the whole pelvis is somewhat narrower proportionally. The pectinal process is broad and blunt, as it is in Hesperornis, and the acetabulum is partially closed. The acetabula of the loons and grebes have vertical sides and are completely open. The antitrochanter of Baptornis is large and rectangular, resembling that of Hesperornis. As in Hesperornis, the ante- 


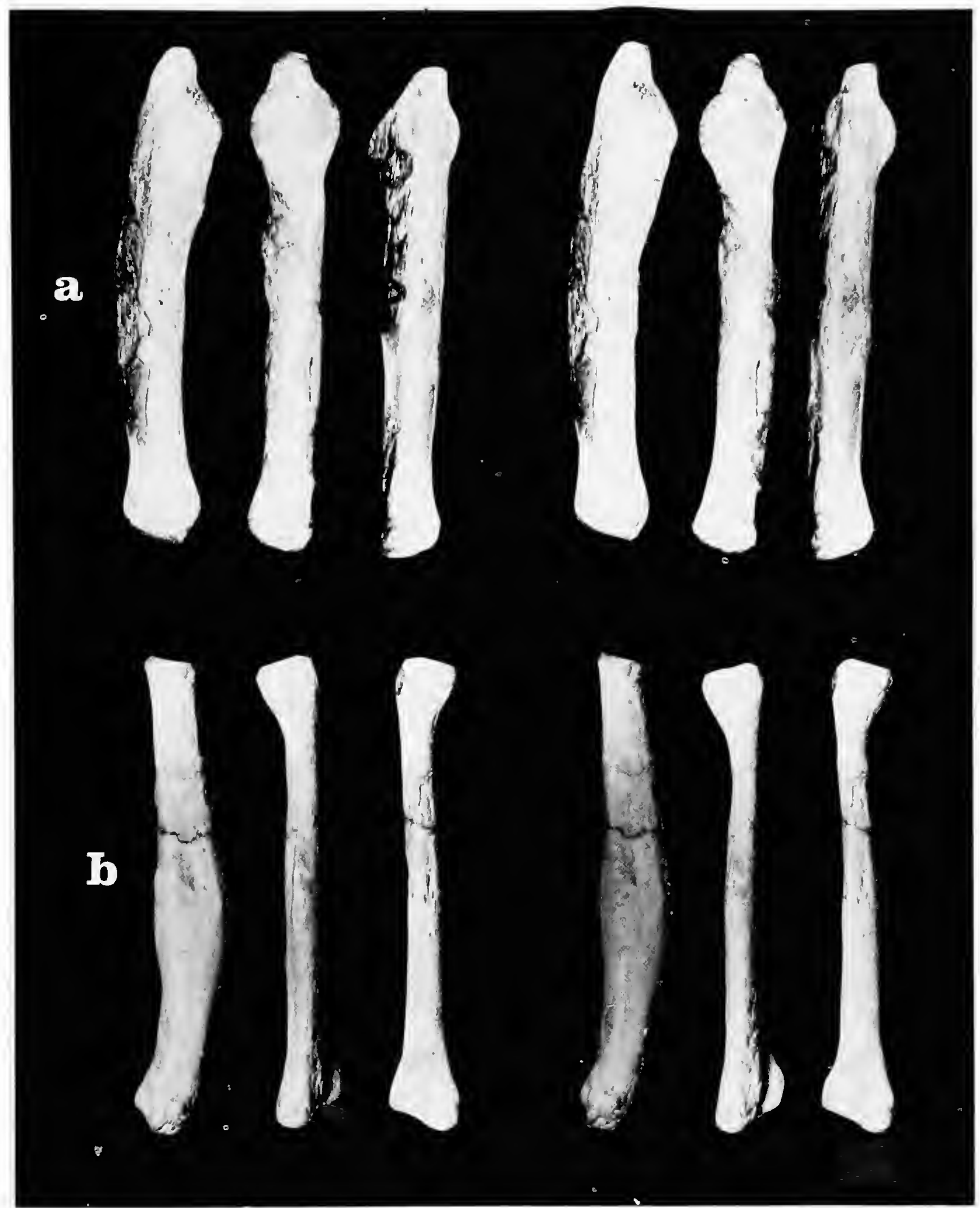

FIGURE 12.--Stereophotographs of wing elements of Baptornis advenus: $a$, medial, palmar, and anconal views of left ulna (KUVP 2290), $\times 4 ; b$, medial, palmar, and anconal views of left radius (KUVP 2290), $\times 4$.

rior end of the ischium sweeps up to form the posteroventral border of the antitrochanter, and there is a prominent suture here in both Baptornis and Hesperornis. On the pelvis of the Common Loon, Gavia immer, just anterior to the antitro- chanter, there is a small scar for the gluteus medius and minimus muscles. This scar is absent in the pelvis of grebes, Baptornis, and Hesperornis. The ilium and ischium of Baptornis are separate throughout their length, as they are in Hesperor- 


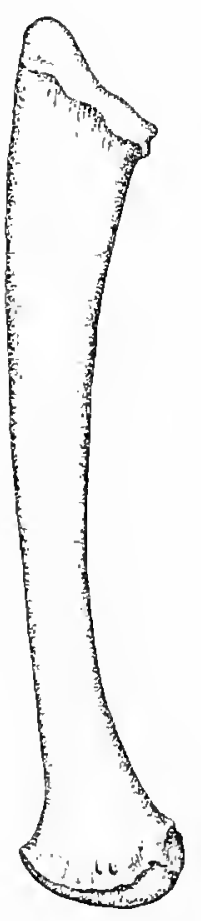

a

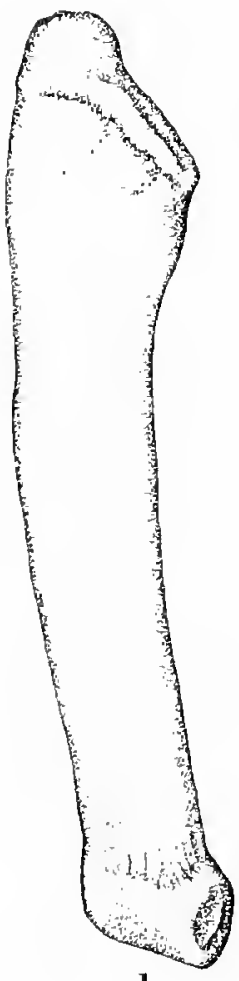

$\mathrm{b}$

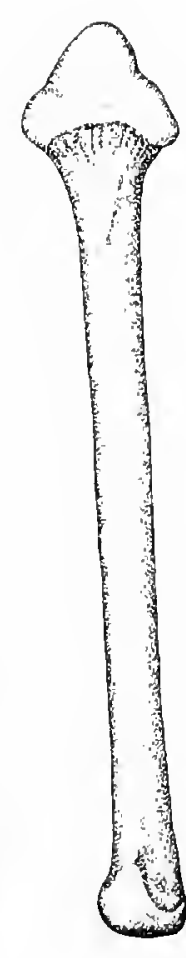

$\mathrm{C}$

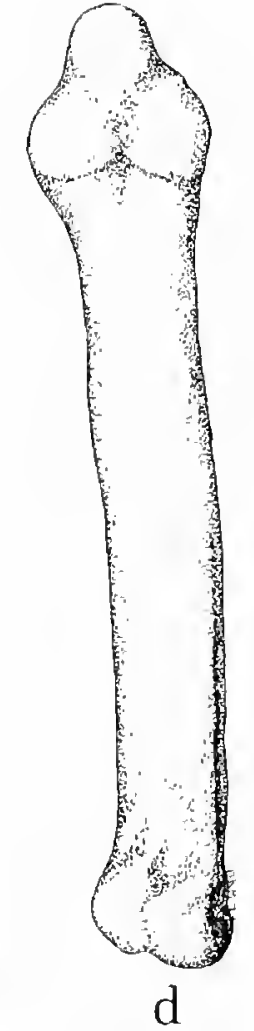

d
Figure 13.-Left ulnae: $a, c$, medial and palmar views of the theropod dinosaur Deinonychus antirrhopus (from Ostrom, 1969, fig. 58); $b, d$, same views of Baptornis advenus. (Not to scale.)

nis. The ischium is long, thin, flattened internally, and rounded externally, so that in cross-section it appears bell-shaped. The pubis is long, heavy, and flattened dorsoventrally. It bears a shallow groove along the anterior quarter of its dorsal surface.

The measurements (in $\mathrm{mm}$ ) of the pelvis are: total length (estimated), 179; length of preacetabular ilium, 54; depth of ilium anterior to pectinal process, 19; depth of ilium at pectinal process 27; greatest diameter of acetabulum, 14; height of antitrochanter, 13; width of antitrochanter, 11; length of free ischium, 103; length of free pubis, 109.

Loons and grebes resemble each other and differ from Baptornis and Hesperornis in having the preacetabular portion of the pelvis narrower, twisted laterally, and spread apart anteriorly. Baptornis also differs from the modern footpropelled diving birds in having the ventral margin of the ilium turned medially (Figure 5). The origins of the iliotrochantericus medius and anticus muscles are ventral in Baptornis, but are dorsal in loons and grebes. The dorsal surface of the preacetabular ilium is turned medially in loons and grebes and laterally in Baptornis. The postacetabular portion of the pelvis of Baptornis is, on a whole, narrower than in other diving birds except Hesperornis.

Femur (Table 3).-Both femora are represented in FMNH 395 and KUVP 2290. UNSM 20030 has the right femur present (Figure 14b) and KUVP 16112 includes fragments of both femora.

The femur of Baptornis is proportionately more elongate than that of Hesperornis; the neck is more constricted; the insertion of the round ligament is smaller; and the trochanter rises slightly above the head, whercas both are of about the same height in Hesperornis. When the femur is articulated with the pelvis its position is more inclined than in Hesperornis, but the difference is probably not as great as Lucas (1903:554) suggested. The iliac facet occupies about the same shape and area as it does in Hesperornis, and the obturator ridge is very similar in form. Baptornis resembles loons in having the lateral margin of the trochanter close to and parallel with the axis of the shaft, whereas the lateral margin of the trochanter extends a considerable distance away from the axis of the shaft in Hesperornis. The anterior intermuscular line sweeps down in a low arc from the trochanteric ridge to the external condyle. The posterior intermuscular line is not well defined, but runs down the medial surface of the bone from just below the head to the internal condyle. The trochanteric ridge is proportionately larger and heavier than it is in Hesperornis. There are no large nutrient foramina evident on the shaft. The popliteal area is broad and shallow. The fibular condyle sends off a distinct wing in Baptornis and Hesperornis and there is a thick connection between the internal and external condyles (this connection is thick in cormorants and grebes and thin in loons). The fibular groove is broad and shallow in Baptornis and Hesperornis. The internal condyles are at about the same level in Hes-

TABle 3.-Measurements ( $\mathrm{mm}$ ) of the femur of Baptornis

\begin{tabular}{|c|c|c|c|}
\hline Character & $\begin{array}{c}\text { UNSM } \\
20030\end{array}$ & $\begin{array}{c}\text { FMNH } \\
395\end{array}$ & $\begin{array}{c}\text { KUVP } \\
2290\end{array}$ \\
\hline Length & 71 & 72 & 75 \\
\hline Diameter head.................. & 10 & 10 & 11.5 \\
\hline Diameter distal articulation & 25 & 24 & 26 \\
\hline 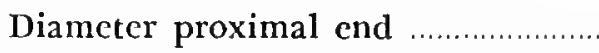 & 24.5 & 24.5 & 28 \\
\hline Antero-posterior diameter midshaft & 11.5 & 12 & 12.5 \\
\hline Transverse diameter midshaft ........... & 10 & 10.5 & 11 \\
\hline
\end{tabular}




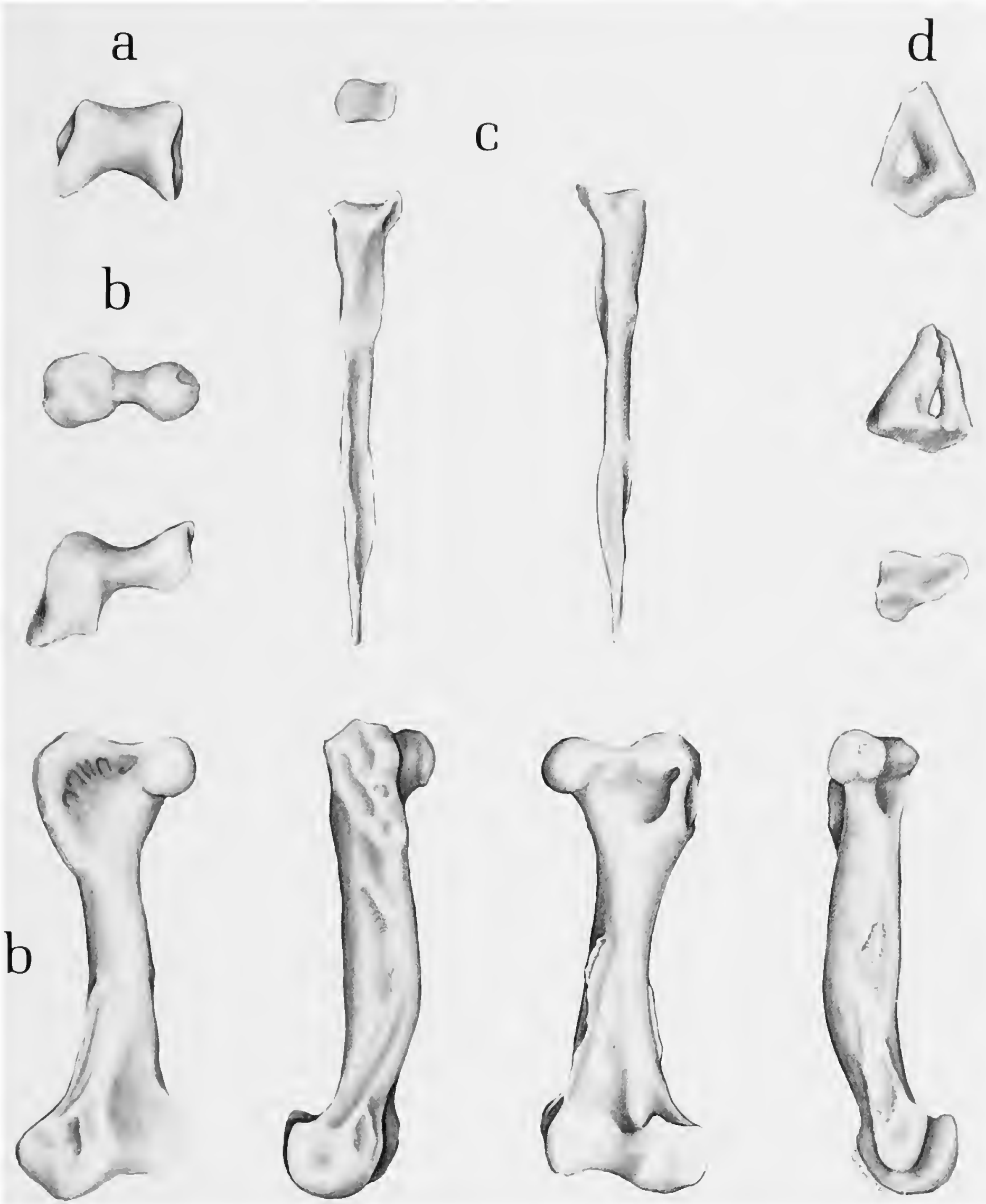

FIgURE 14.-Hindlimb clements of Baptomis advenus: a, distal end of left tibiotarsus (UNSM 20030); $b$ (top to bottom and left to right), proximal, distal, anterior, lateral, posterior, and medial views of right femur (L NSM 20030); c (top to bottom and left to right), proximal, posterior, and anterior views of right fibula (I XS.M 20030); $d$ (top to bottom), anterior, posterior, and distal views of right patella (UNSM 20030). (All $\times$ 1.) 
perornis while the external condyle is much more distal than the internal condyle in Baptornis.

A discussion of the muscle scars on the femur would be valuable but the homologies are difficult to ascertain. Those of the following scars seem fairly certain. Along the posterior intermuscular line, just below the head, is a small raised triangular area which may correspond to the insertion of the $M$. iliacus. On the lateral surface of the femur, along the trochanteric ridge, is a complex region of muscle attachments resembling the same area in Hesperornis. The tubercle for M. piriformis is not as prominent as it is in Hesperornis and is situated about half way up the shaft.

The proportions of the femur of Baptornis suggest that the legs were not bound so closely to the pelvis as in Hesperornis and may have had slightly greater freedom of movement. In Hesperornis, the femora may have been permanently held in the extended position illustrated by Heilmann (1927, fig. 34), while Baptornis may have been able to rotate the legs ventrally for paddling and then $a b$ duct them for diving as do some diving ducks (Raikow, 1970:6).

Patella (Table 4).-The patella of KUVP 2290 was described and illustrated by Lucas (1903). There is also an excellently preserved patella with UNSM 20030 (Figure 14d). This is a short trihedral bone resembling in some respects the patella of a cormorant. The foramen for the tendon of the ambiens muscle is large and perforate. The articular surface on the base of the bone is double, indicating that it probably articulated with both the internal and external condyles of the femur. In Hesperornis there is a single concave surface, which articulated with the external condyle of the femur. Therefore, the patella of Hesperornis would have been lateral to the main axis of the tibiotarsus, while that of Baptornis would almost have been centered on it (contrary to Lucas, 1903:554). Cormorants have the patella

TaBLE 4.-Measurements (mm) of the patella of Baptornis

\begin{tabular}{|c|c|c|}
\hline Character & $\begin{array}{l}\text { UNSM } \\
20030\end{array}$ & $\begin{array}{c}\text { KUVP } \\
2290\end{array}$ \\
\hline Length & 19 & 20.5 \\
\hline Distal antero-posterior diameter $\ldots \ldots \ldots \ldots \ldots$ & 10.5 & 13.5 \\
\hline Distal transverse diameter $\ldots \ldots \ldots \ldots . . .$. & 16 & 16.5 \\
\hline Diameter ambiens foramen........ & 6 & 7 \\
\hline
\end{tabular}

TABLE 5.-Measurements $(\mathrm{mm})$ of the tibiotarsus of Baptornis

\begin{tabular}{|c|c|c|c|}
\hline Character & $\begin{array}{c}\text { UNSM } \\
20030\end{array}$ & $\begin{array}{c}\text { FMNH } \\
395\end{array}$ & $\begin{array}{c}\text { KUVP } \\
2290\end{array}$ \\
\hline Length $\ldots . . . . .$. & 195 & 194 & - \\
\hline Elevation cnemial process ............ & 14 & 13 & 14 \\
\hline Diameter proximal articulation ...... & 18 & 17 & 18.5 \\
\hline Antero-posterior diameter shaft* .... & 9 & 8.5 & - \\
\hline Transverse diameter shaft ${ }^{*} \ldots \ldots \ldots \ldots$ & 12 & 11.5 & - \\
\hline Diameter distal end ................. & 19 & 18 & - \\
\hline
\end{tabular}

* Below fibular ridge.

placed as in Baptornis. The patella in grebes is shaped as in Hesperornis and articulates on the external condyle of the femur. However, grebes lack the ambiens muscle and therefore no foramen is present in the patella.

Tibiotarsus (Table 5).-Both right and left tibiotarsi occur in UNSM 20030 and in FMNH 395 and parts of both are present in KUVP 2290 and 16112 .

The tibiotarsus (Figure 15) is like that of Hesperornis in being elongate and nonpneumatic (like Hesperornis, it has a large medullary cavity). The proximal end flares out as in Hesperornis due to the lateral expansion of the outer cnemial crest. This region is not as expanded in loons and grebes. As in Hesperornis, the inner cnemial crest is low, so that the groove between the two crests is broad and shallow. In loons and grebes, the inner cnemial crest is high and the surface between the two crests is narrow and deeply excavated. The rotular process is lower than in loons or grebes and is similar to Hesperornis. The external articular surface is small and slopes ventrally. It is not as rounded as in loons or grebes, nor is it set apart anteriorly and posteriorly from the inner articular facet by grooves (Figure 16a) as in Hesperornis. The inner and outer articular facets are about equal in size and are separated by a groove in the interarticular area in grebes. The inner articular facet is flat, oval, and directed posteromedially in Baptornis, and just below the inner articular facet is a deep roughened pit for the origin of M. plantaris which appears to be divided into dorsal and ventral parts. The fibular crest extends about half way down the shaft and is deeply grooved along its

Figure 15.-Left tibiotarsus of Baplornis advenus: $u$, posterior, $b$, lateral, $c$, anterior, and $d$, medial views, $(\times 1)$. 

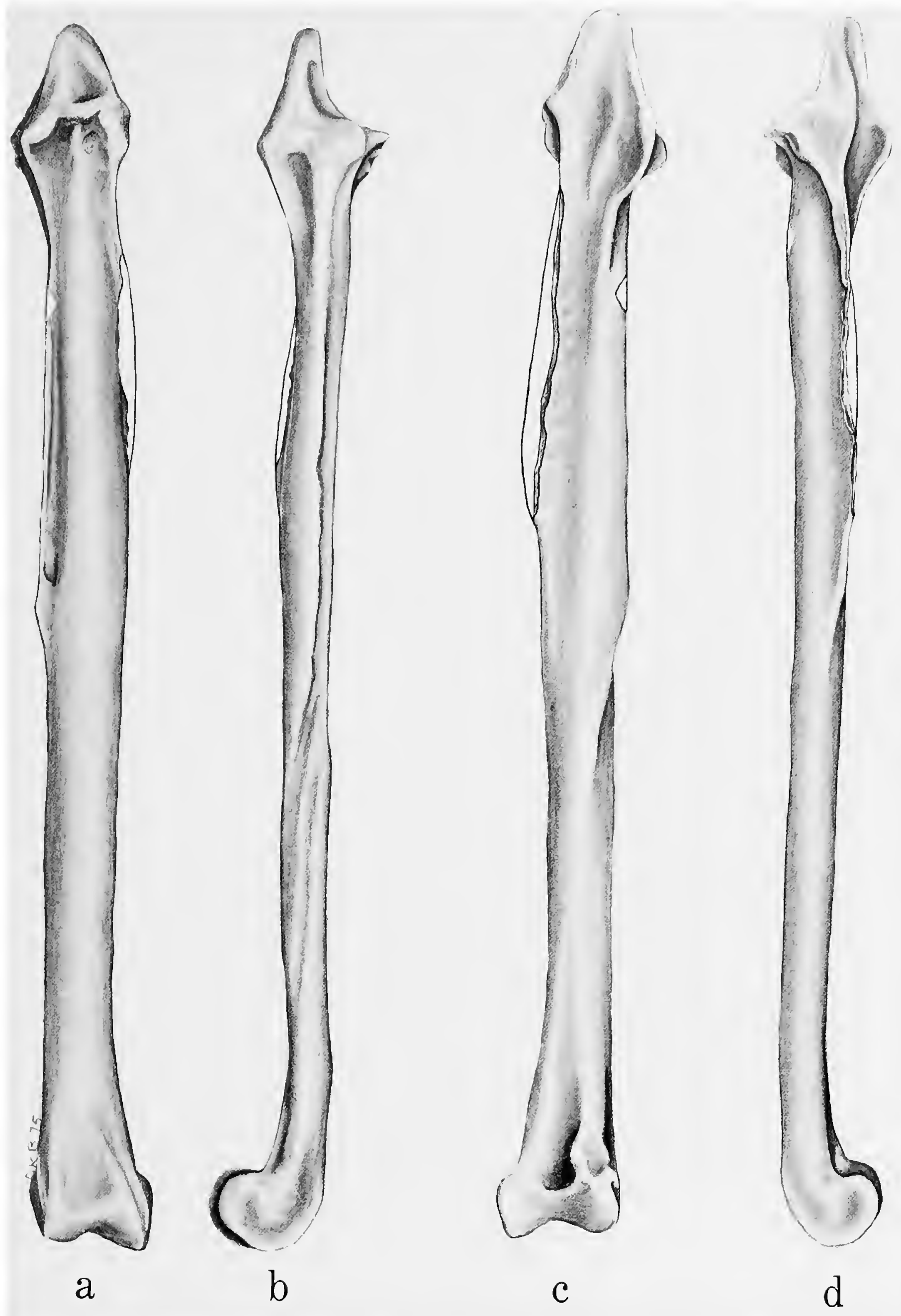
posterior margin, said groove crossing the outer border of the shaft just below the fibular crest. The foramen for the medullary artery lies in this groove. The distal attachment for the spine of the fibula is much smaller than in Hesperornis.

The distal end of the tibiotarsus (Figures 14a, 15, $16 b$ ) is slightly inflected medially, but not as much as in Gavia. In Hesperornis regalis and the grebes, the distal end is almost centered on the shaft. The internal and external condyles of the tibiotarsus are spread farther apart than in Hesperornis and the posterior crests are not as high. The tendinal groove is broad and terminates in a deep lateral pocket. The internal and external condyles are roughly parallel to each other and the anterior intercondylar sulcus is shallow (more so than in Hesperornis). Both the external and internal ligamental prominences are very low. There is no supratendinal bridge, although a large ligamental attachment occurs above the medial side of the external condyle. In FMNH 395 the high ascending process of the astragulus is still clearly discernable and the fusion of this tarsal element to the tibia evidently took place later in otogeny than in modern birds.

Fibula (Table 6).-The fibula of Baptornis (Figure 14c) is most similar to that of Hesperornis. The head is large and rectangular. The shaft has two distinct ridges on its posterior proximal surface and the bicipital tubercle is large and elongate. The head is as in Hesperornis and is not undercut posteriorly as much as in loons. There is no tubercle for $M$. flexor perforatus digiti III as there is in loons, but instead there is a large triangular roughened area as in Hesperornis and grebes.

Tarsometatarsus and Toes (Tables 7,8).-As Shufeldt (1915:9) noted, the holotype tarsometatarsus designated by Marsh consists of two portions that are quite probably from different individuals,

Table 6.-Measurements ( $\mathrm{mm}$ ) of the fibula of Baptornis

\begin{tabular}{l|ccc}
\hline \multicolumn{1}{c|}{ Character } & UNSM & FMNH & KUVP \\
& 20030 & 395 & 2290 \\
\hline $\begin{array}{l}\text { Antero-posterior diameter } \\
\text { proximal end .................................. }\end{array}$ & 7 & 6 & 8.5 \\
Transverse diameter proximal end & 11 & 9 & 11 \\
Greatest transverse shaft diameter .... & 7.5 & 7 & - \\
Antero-posterior diameter & & & \\
at this point ............................. & 5 & 4 & - \\
\hline
\end{tabular}

TABLE 7.-Measurements (mm) of the tarsometatarsus of Baptornis

\begin{tabular}{|c|c|c|c|}
\hline Character & $\begin{array}{l}\text { UNSM } \\
20030\end{array}$ & $\begin{array}{c}\text { FMNH } \\
395\end{array}$ & $\begin{array}{c}\text { KUVP } \\
2290\end{array}$ \\
\hline Length & 84 & 83 & $83^{\mathrm{R}}$ \\
\hline Proximal antero-posterior diameter & $(10)$ & 13.8 & 13.5 \\
\hline Proximal width & $(17)$ & 17.6 & 18 \\
\hline Distal antero-posterior diameter ...... & & & \\
\hline Distal width & 15 & 15.1 & 16 \\
\hline Tip trochlea II to distal end ................ & 11.5 & 11.5 & 12 \\
\hline
\end{tabular}

$\mathrm{R}=$ restored length; ()$=$ measurements from crushed specimens.

as indicated by the facts that the fracture lines of the two halves do not coincide and the proximal portion is from a juvenile, while the distal portion appears to be from an adult. If the two pieces had been from one individual, Shufeldt estimated that as much as a third of the shaft must be missing. At our request, the curators of the Division of Vertebrate Paleontology of the Yale Peabody Museum have agreed to retain YPM 1465 for the distal portion of this specimen, which we here designate as the lectotype. The proximal portion has been renumbered as YPM 5768.

KUVP 2290 represents a well-ossified individual in which the proximal and distal ends of a left tarsometatarsus are uncrushed, but in which the middle of the shaft is missing. YPM 5768 is from a young bird, and along with FMNH 395 (Figure $16 f, g)$ and KUVP 16112 shows the lines of fusion between the metatarsal bones. The tarsometatarsus of UNSM 20030 is mature, but crushed.

The tarsometatarsus of Baptornis is compressed laterally. The external cotyla is slightly larger than the internal one (Figure 16e) and both tilt slightly anteriorly; the intercotylar prominence is low and blunt as compared to Hesperornis; calcaneal ridges are absent, and there are no proximal foramina; the tubercle for tibialis anticus is situated high on the shaft; the anteroproximal face of the shaft is deeply excavated; the attachment for the external ligament is not clearly developed; the outer extensor groove is long and shallow and leads to the region of the distal foramen, with the anterior metatarsal groove running parallel to it; the inner metatarsal groove crosses the medial side about one-third the way down the shaft; the intertrochlear notch between the third and fourth trochleae narrows and then widens so that the dis- 


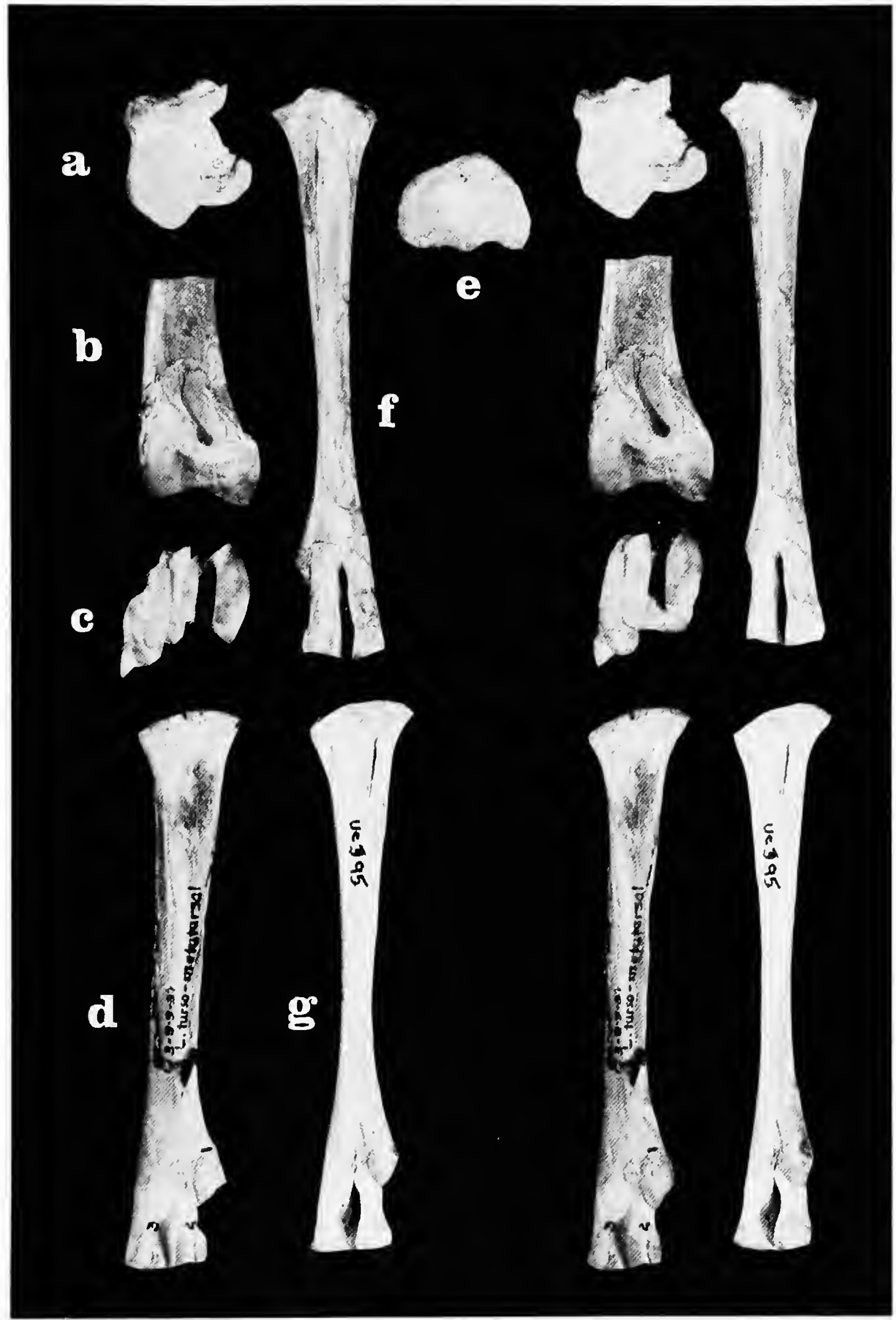

FigURE 16.-Stereophotographs of hindlimb elements of Baptornis advenus: $u$, proximal end of right tibiotarsus (UNSM 20030); $b$, distal end of right tibiotarsus (UNSM 20030); $c$, distal end of left tarsometatarsus (KUVP 2290); $d$, left tarsometatarsus (UNSM 20030), posterior view; $e$, proximal end of left tarsometatarsus (KUVP 2290) (not stereo); $f$, left tarsometatarsus (FMNH 395), anterior view; $g$, same, posterior view. (All $\times 1$, except $c$ and $e$, which are slightly enlarged.) 
tal foramen communicates with the notch and the metatarsal facet is high and posterior. In UNSM 20030 (Figure 16d) the inner trochlea is set about $7 \mathrm{~mm}$ proximal to the middle trochlea. The outer trochlea is in line with the major longitudinal axis of the bone and is approximately equal to the middle trochlea in size. In mature specimens the medial rim of the inner trochlea develops a prominent posterior flange.

There is some ontogenetic variation in the trochleae. Those of YPM 1465 and FMNH 395 have shallow tendinal grooves, are less expanded, and lack the small flange on the inner trochlea that is present in UNSM 20030 and KUVP 2290. The lateral rim of this trochlea extends farther distally than the medial rim.

The outer trochlea extends only slightly farther distally than the middle trochlea and both are about equal in size. In both, the tendinal groove is shallow and continuous along both the plantar and the acrotarsal faces of the middle trochlea, but it is missing from the acrotarsal face of the outer trochlea. The medial rim of the outer trochlea is slightly larger than the lateral rim. The lateral rim extends into a posterior flange in mature specimens. The trochleae are compressed laterally and the extensor grooves run up onto the anterior face as in loons and Hesperornis. In grebes the trochleae are less compressed and tend to be almost smooth on their anterior face. In both grebes and Hesperornis, the inner trochlea has rotated posteriorly, while in loons and Baptornis it is more nearly parallel to the main axis of the shaft.
The tarsometatarsus of Baptornis is like that of Hesperornis in that it is laterally compressed, lacks calcaneal ridges on the hypotarsus, lacks proximal foramina, and the outer trochlea is in line with the longitudinal axis of the bone. Baptornis differs from Hesperornis in that the necks of the trochleae are longer and more delicate.

In Hesperornis the outer extensor groove is very large and deep, and the anterior metatarsal groove is quite prominent, although it is only about onethird the width of the outer extensor groove. There is a distinct groove originating near the distal foramen and extending from the medial rim of the outer trochlea over the trochlea to its lateral rim. This groove is much fainter in Baptornis. In both Baptornis and Hesperornis the distal foramen is well within the intertrochlear notch, between the middle and outer trochleae. Its position in Baptor$n i s$ is delineated by indentations in the necks of the trochleae, but the distal margin is not closed off to form a real foramen. In Hesperornis extensions of the sides of the trochleae meet to form the distal margin of the foramen, and a suture line is usually visible where they meet.

FMNH 395 includes metatarsal I. It is not as short and flat as in Hesperornis. The bone diverges from the shaft of the tarsometatarsus at a fairly steep angle and terminates in a rounded knob. The phalanx of the first digit is a thin, elongate, highly curved bone. None of the toe bones were articulated, so their identification is somewhat subjective. Fourteen phalanges, counting 2 unguals, are preserved with FMNH 395, 6 with

TABLE 8.-Measurements (mm) of the pedal phalanges (arabic numbers in boxhead) of Baptornis

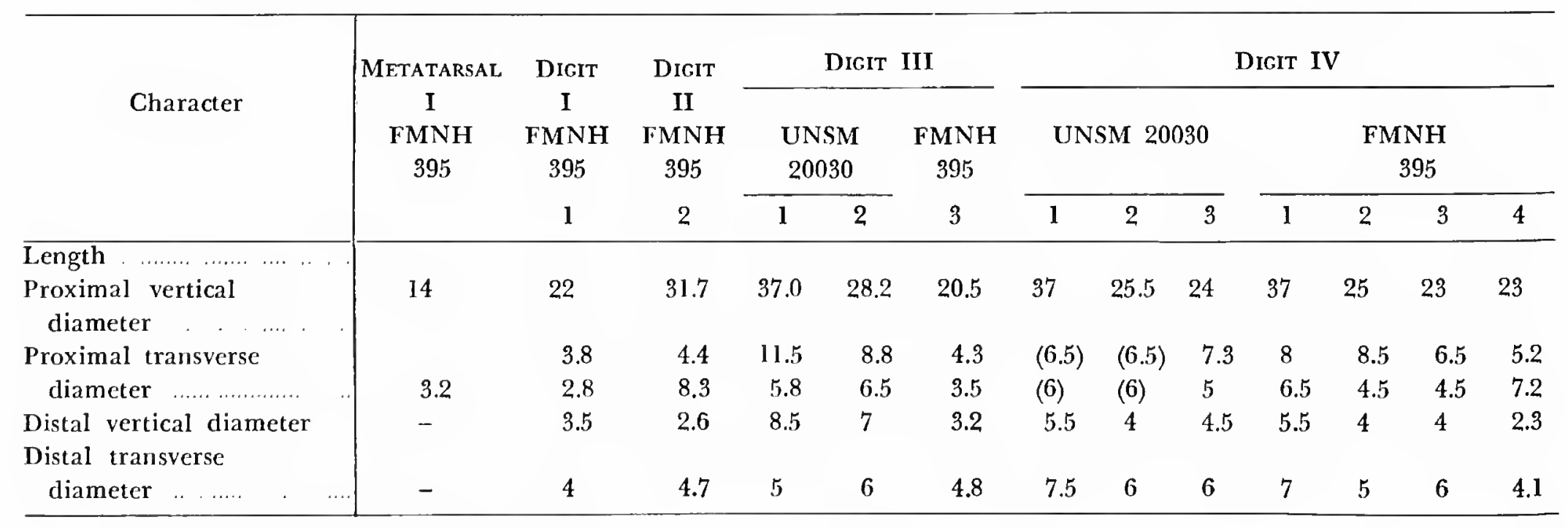

()$=$ Measurements from crushed specimens. 

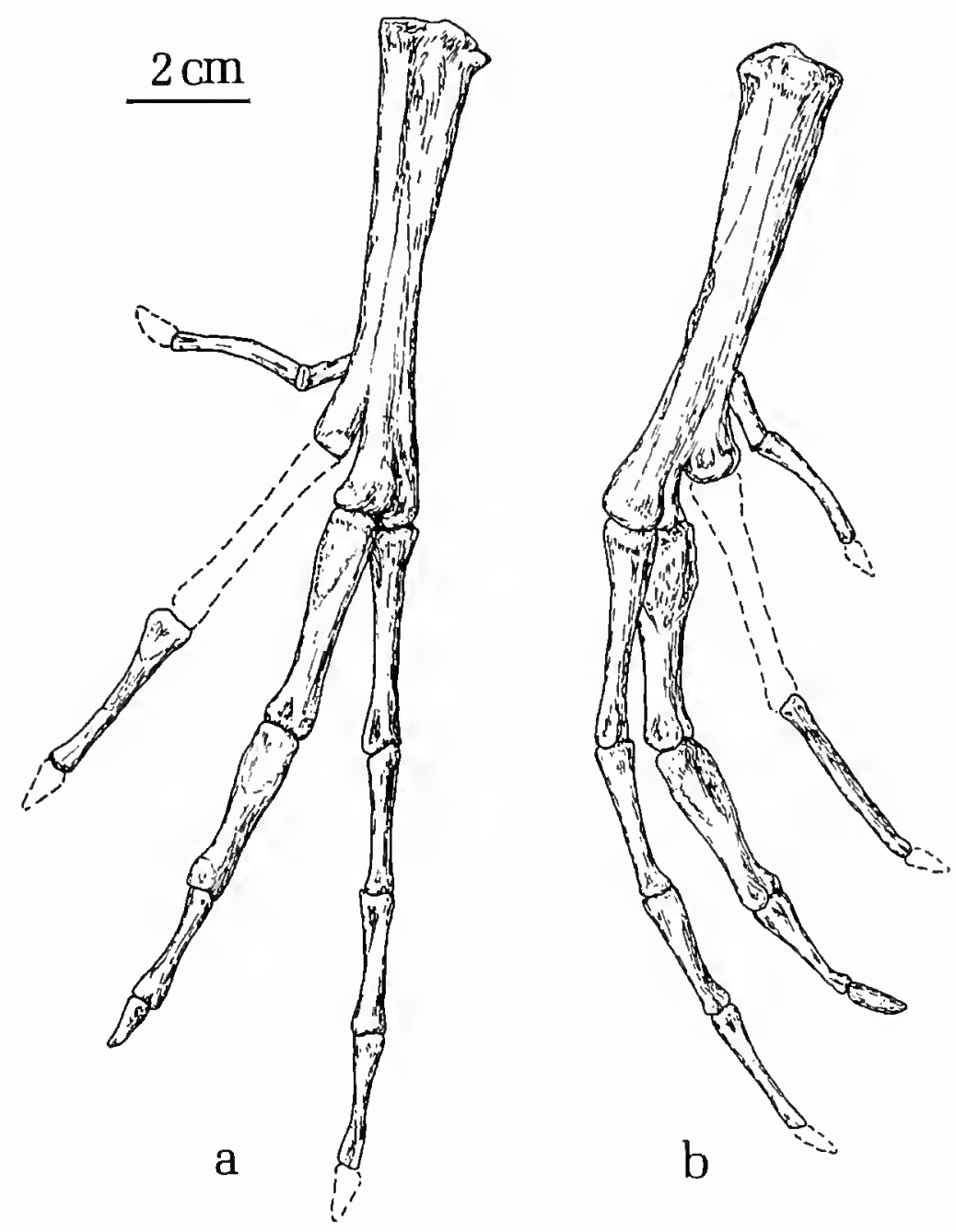

FIGURE 17.-Left foot of Baptornis advenus: $a$, anterior view; $b$, lateral view.

UNSM 20030, and 3 fragments with KUVP 16112. Phalanx 1 of digit II appeared to be absent from our sample. Phalanx 2 of digit II is flattened dorsoventrally, with a broad proximal end, which rapidly narrows anteriorly. It has a simple distal articulation for the claw. Phalanx 1 of digit III is the largest of the foot. It is flattened laterally, with a deep proximal articulation. The distal articulation consists of two parallel ridges, which would
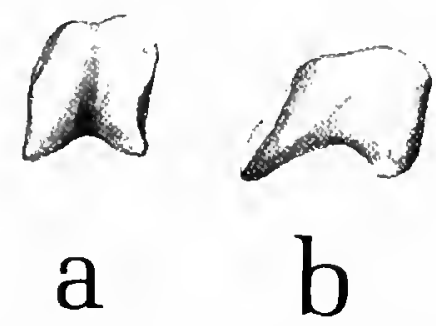
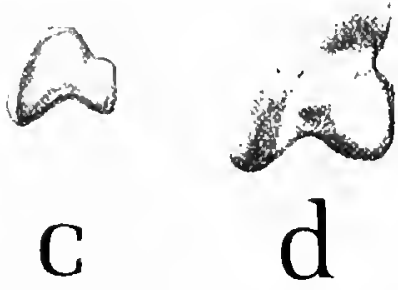

Figure 18.-Distal end of left phalanx 1 of digit IV showing increasing modification for toe rotation from left to right: a, loon, Gavia immer; b, Baptornis advenus; $c$, grebe, Aechmophorus occidentalis; $d$, Hesperornis regalis. (Not to scale.) permit mainly anterior or posterior movements. Phalanx 2 of digit III is a smaller version of the first. Phalanx 3 of digit IV is about the same length as that of digit III but neither articulates as in loons or grebes. That of digit IV is narrower and rounder than in the other toes, and the distal end has the medial ridge of the articulation inclined, suggesting that some degree of toe-rotation was possible. Phalanges 2 and 3 of digit IV are much shorter and deeper than the first phalanx, while the fourth is elongate, laterally compressed, and terminates in an articulation for the claw.

Although phalanx 1 of digit $\mathrm{IV}$ is more elongate than in Hesperornis, nevertheless the third and fourth toes of Baptornis are of about the same size and length (Figure 17), whereas in Hesperornis the fourth toe is much the longest. The phalanges of the fourth toe also lack the deep ventral grooving found in Hesperornis. The claws of Baptornis are somewhat flattened, gently curved and pointed. They are not the broad nail-like structures that grebes have.

Grebes have lobed feet while loons have webbed feet. When swimming, both loons and grebes have their toes spread for the power stroke. On the recovery stroke, loons fold their toes posteriorly while grebes rotate their foot $90^{\circ}$ (Storer, 1958) so that the edges of the lobes cut through the water. These actions are reflected in the morphology of the phalanges of digit IV. In loons the distal articular ridges are parallel to each other and are about the same size. This is the condition found in most birds. In grebes the medial ridge is enlarged and the lateral ridge is small and rounded (Figure 18c). In Hesperornis the distal articulations of the phalanges for digit IV are even more specialized, with the medial ridge extending over the small, rounded lateral ridge (Figure 18d) suggesting highly developed toe-rotation and lobed feet. Baptornis differs from the loons in having the medial ridges enlarged and inclined on the distal articulations of the phalanges for digit IV. However, it is not nearly as specialized as either grebes or hesperornithids (Figure 18b).

\section{Habits of Baptornis}

From the skeletal remains now available, it appears that adults of Baptornis were about one meter long from the tip of the tail to the tip of the 


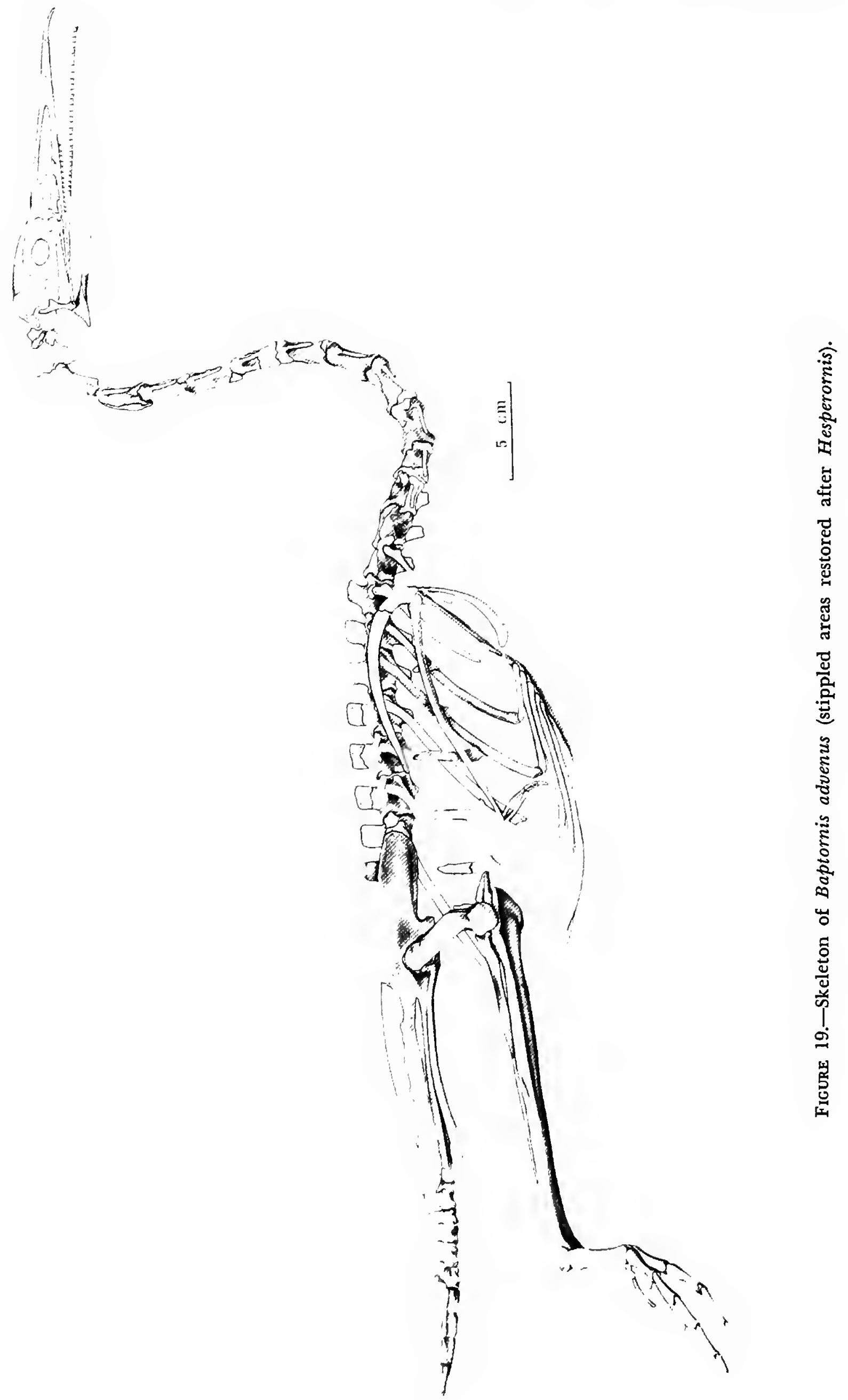




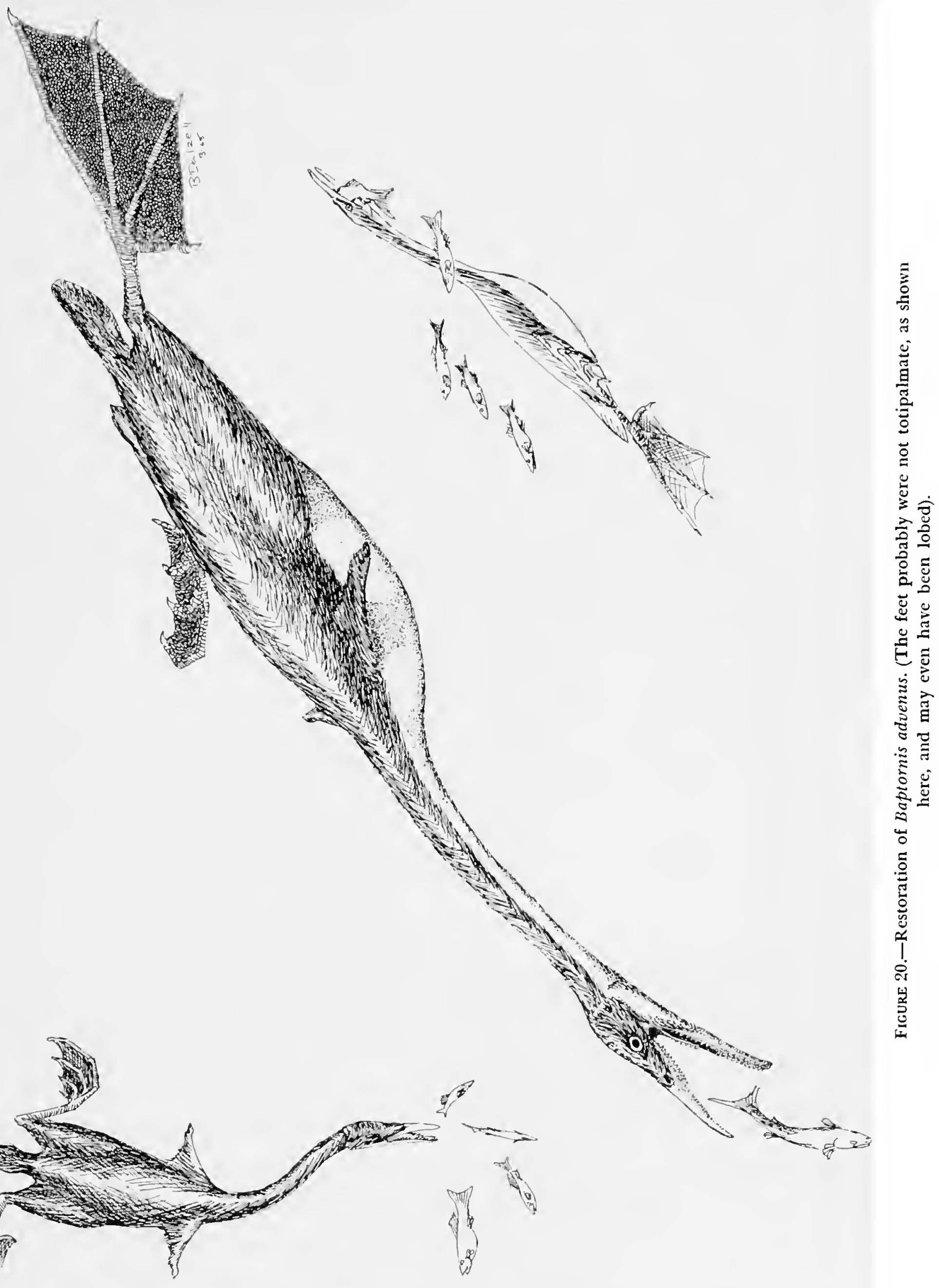


bill. We have restored the bird with teeth (Figures $19,20)$ because of its relationship to the toothed bird Hesperornis. All Mesozoic birds for which dentaries are known (Archaeopteryx, Hesperornis, and Ichthyornis) had teeth.

The skeletons of both Hesperornis and Baptornis are nonpneumatic and are composed of relatively heavy, compact bone. Bones of Hesperornis are often recognized in the field because they appear more solid than most of the other small bones in the Niobrara Chalk. This is hardly surprising, for additional weight is actually of an advantage for a diving animal. The added weight, along with the long necks and fusiform bodies of the Cretaceous divers, suggest that they might have swum partially submerged, like modern anhingas. However, neither Baptornis nor Hesperornis appears to have had the neck modified for stabbing. This is further

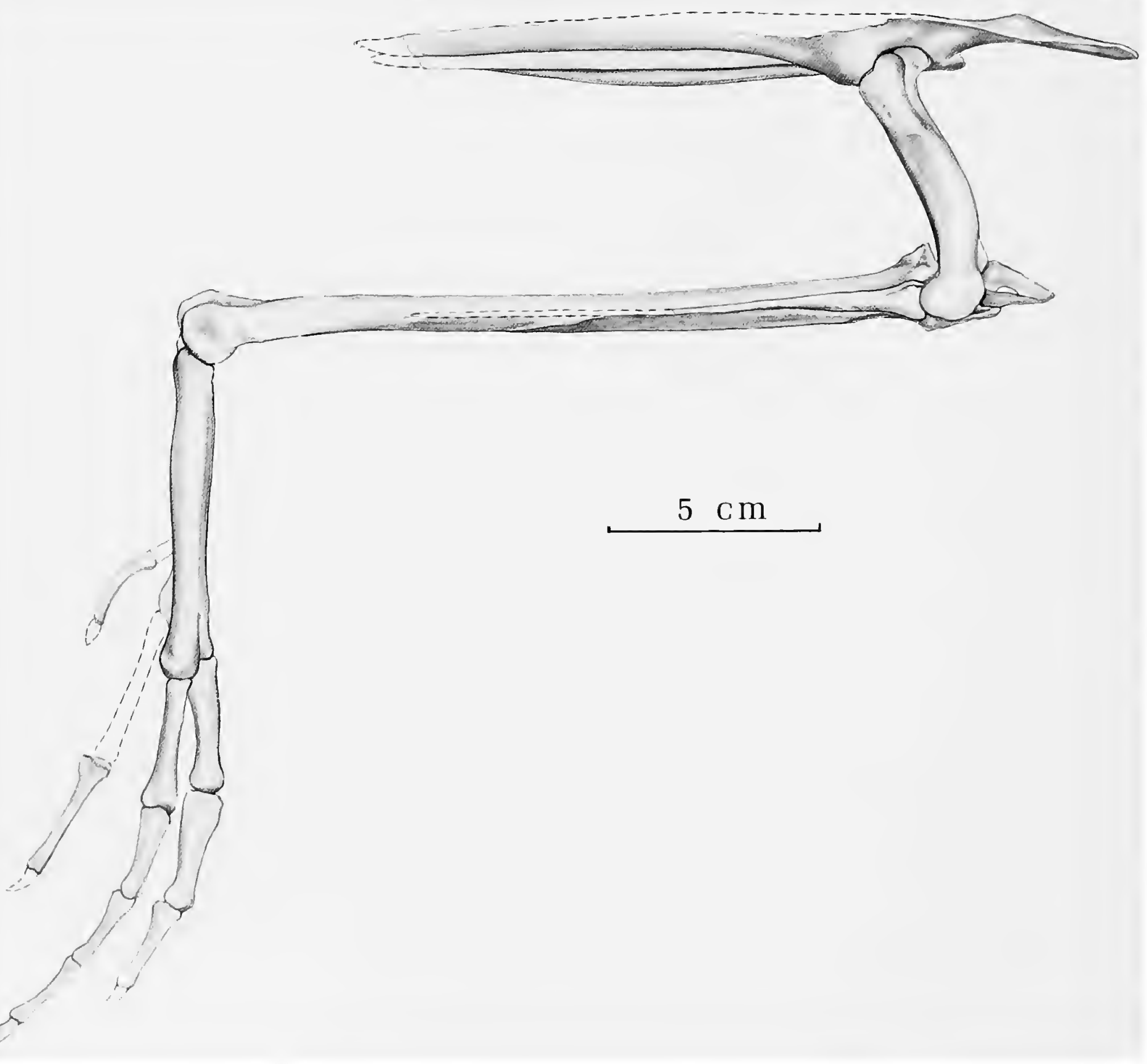

Figure 21.-Pelvis and right hindlimb of Baptornis advenus, dorsal view. 
emphasized by their relatively broad, blunt bills. In both Baptornis and Hesperornis the wing is greatly reduced. This is often the case in marine foot-propelled divers; various adaptations for flight would make them too bouyant for efficient diving, while the loss of flight is not too serious a hardship for them. On the other hand, footpropelled divers that occupy disjunct bodies of fresh water need to be able to fly in order to disperse. Lonchodytes is the only known nonmarine foot-propelled diver from the Mesozoic. It is from freshwater river deposits, and appears to have been volant (Brodkorb, 1963a). The tiny wing of Baptornis could scarcely have been used for locomotion, but it may have had a stabilizing and steering function, much like the pectoral fins in fishes. The sternum in Baptornis is unusually small, even for a flightless bird, and the body must have been very long and narrow. The tibiotarsus was bound to the pelvis as it is in loons, but it was probably not as closely appressed to the postacetabular region as it was in Hesperornis, and the bone itself extended somewhat past the posterior margin of the pelvis (Figures 19, 21). In Hesperornis the distal end of the tibiotarsus is about even with the posterior margin of the pelvis. The above features, along with characters of the acetabulum and femur, suggest that Baptornis had some capacity to rotate its feet under its body, probably for swimming on the surface. When diving, the feet were certainly held out to the side. It seems almost certain that Baptornis could not walk upright on land and in fact must have pushed itself along on its stomach like a seal or a loon. The feet could have been webbed or lobed. They do show some evidence of inefficient toe-rotation and might well have been lobed, although our restoration shows them webbed. Hesperornis almost certainly had lobed feet. The feet of Baptornis are exceptionally large for the size of the bird. The tail is quite long, with a long, laterally compressed pygostyle that probably acted as a rudder. Loons appear to have similar, but shorter tails, while in Hesperornis the tail is long but is dorsoventrally compressed and has a short pygostyle.

Included with UNSM 20030 are eight coprolites, two of which show small fish jaw and other bones. Most are round or elliptical in cross-section and are elongate, except for the two containing the fish material. None shows spiral grooving or surface impressions. George Sternberg, the collector, in a 1937 communication preserved in the records of the University of Nebraska State Museum, makes the following reference to the association of these coprolites with the Baptornis skeleton: "There are 7 or 8 coprolites; . . . 2 show small fish bones. These are small compared to other coprolites I have seen and were found mingled with the bones." It seems likely that these coprolites are correctly associated with the Baptornis skeleton; if so, they are the only ones known for a Cretaceous bird. However, several of them fit together to form a long rounded structure that might be better interpreted as an intestinal cast (Figure 22a). A fish jaw in one coprolite was identified by Orville W. Bonner of the University of Kansas (pers. comm., 1972) as Enchodus cf. parvus Stewart. Enchodus was a very common genus of fish in the Niobrara seas. It included some very small species, which probably formed a significant item in the diet of the Late Cretaceous toothed birds. Hesperornis had scutellate-reticulate tarsi (Williston, 1898). We have a fragment of matrix associated with UNSM 20030 showing what may possibly be the impression of scutes (Figure 22b), suggesting that the tarsometatarsus of Baptornis might also have been scutellate-reticulate (grebes have reticulate tarsi and loons have scutellate-reticulate tarsi).

Hesperornis and Baptornis form a natural group of specialized divers, separate from, and more specialized than any of the other footpropelled divers. Their advanced degree of specialization is not surprising, as the Mesozoic birds occupied a fairly stable environment for the entire Cretaceous and must have been well adapted to it.

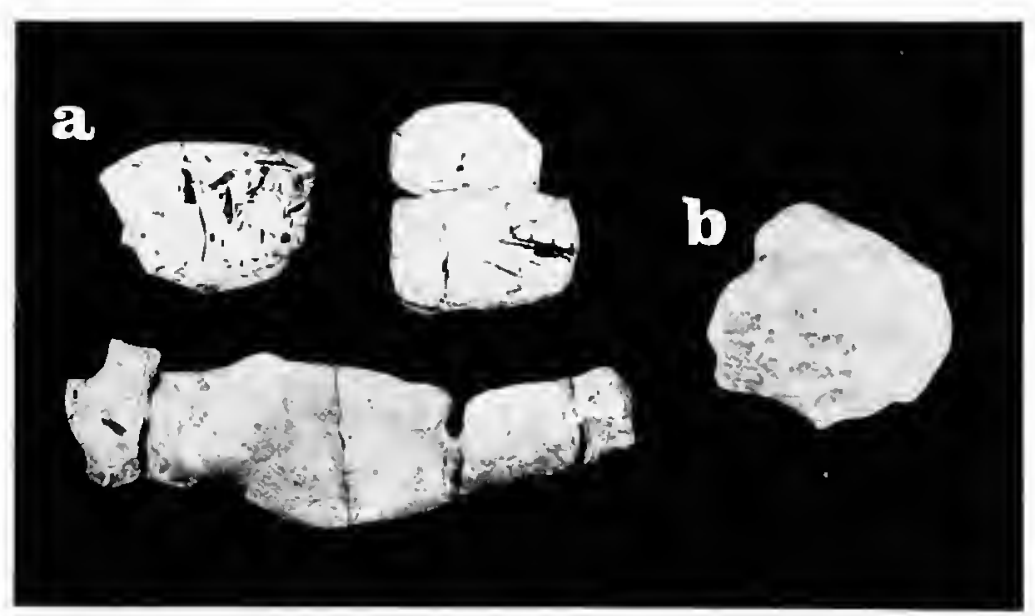

FIgURE 22.-Coprolites (a) and possible scute impressions from the foot (b) of Baptornis advenus (UNSM 20030). (Reduced.) 
Baptornis was probably able to range far from shore, as most of the finds indicate. At the present, all of the known records of Baptornis are from the Smoky Hill Member of the Niobrara Chalk Formation, Upper Cretaceous of Central Kansas. The immature specimens suggest that Baptornis may have nested in this region.

\section{Affinities of Baptornis}

Baptornis and Hesperornis share a number of primitive features with Archaeopteryx. These include: (1) the nature of shoulder girdle, and in particular the shape of the coracoid, with the glenoid and scapular facets near the tip of the scapular end; (2) the character of the distal articulation of the ulna in Baptornis (the ulna of Hesperornis is unknown), which makes the presence of a fused carptometacarpus doubtful; (3) the separation of the distal segments of the ilium, ischium, and pubis; (4) the absence of a supratendinal bridge on the tibiotarsus; (5) the prominence and fusion late in ontogeny of the ascending process of the astragalus on the tibiotarsus; (6) the absence of hypotarsal canals, a closed distal foramen, or proximal foramina in the tarsometatarsus (proximal foramina are present in all modern birds we have examined). To the above we can probably add the various primitive features of the skull, including the shape of the quadrate and the presence of teeth.

The absence of a supratendinal bridge, hypotarsus, and proximal foramina indicates that these are not necessary for foot-propelled diving. Further, the presence of these characters in modern foot-propelled divers suggests that these birds may have been derived from ancestors that were not foot-propelled divers.

The supratendinal bridge is well developed in loons and cormorants, and this may be related to the fact that the distal end of the tibiotarsus in these forms is inflected medially. The supratendinal bridge is not well developed in some grebes which have (as do hesperornithiform birds) a straight articulation between the tarsometatarsus and tibia, causing the foot to be brought more directly out to the side of the body.

Baptornis and Hesperornis also share a large suite of derived characters. Many of these are di- rectly related to foot-propelled diving and can be found in one state or another in all birds that share this form of locomotion. Some of the characters that tend to unite Baptornis and Hesperor$n i s$, in addition to the shape and reduction of the shoulder girdle and the wing, are: (1) the broad shallow fibular groove on the femur; (2) the large trihedral patella with a foramen for the tendon of the ambiens muscle; (3) the broad, triangular procnemial crest on the tibiotarsus; and (4) the compressed tarsometatarsus with the anterolateral edge developed as a high thin ridge. No particular relationship is indicated between Baptornis and any living group of foot-propelled divers. The foot is more similar to that of loons than of grebes, but the coracoid is totally unlike that of any living bird. Throughout, the skeleton is most similar to that of the Hesperornithidae.

Marsh did not attempt to classify Baptornis, but clearly regarded it as a member of his order Odontolcae, which included Hesperornis. His student Williston (1898) included it in this order when he listed the Cretaceous birds of Kansas. Lucas (1903) later suggested that it was separable from Hesperornis at the familial and perhaps the ordinal level. Lambrecht (1933) thought Baptornis was related to the loons and grebes and placed it in the family Enaliornithidae, in which he also included Enaliornis, Neogaeornis, and possibly Eupterornis of the French Paleocene. Romer, in earlier editions of his text Vertebrate Paleontology, placed Eupterornis questionably in the Baptornithidae, but later (1966) followed Brodkorb (1963b) in placing Eupterornis in the Gaviiformes and Baptornis in the Podicipediformes. Wetmore (1956) used the superorder Odontognathae for the New World toothed birds and placed the Baptornithidae in the order Hesperornithiformes. Brodkorb (1963b) treated the Baptornithidae as an ancient family of grebes, which included two genera, Baptornis and Neogaeornis. At the same time, he put Enaliornis and Eupterornis in the Gaviiformes (loons), along with the volant Mesozoic foot-propelled divers of the family Lonchodytidae. Brodkorb (1971:39) has since reaffirmed his opinion regarding Baptor$n i s$ in stating that "the proper position of the family Baptornithidae is surely in the order Podicipediformes." This position follows closely a statement by Lucas (1903:555): "In the slender cervicals, arrangement of the tibia and patella, and 
general structures of the leg, Baptornis is more like a grebe than is the contemporary Hesperornis, and if, with the small amount of material available, it is deemed essential to establish any connection between groups of existing and fossil birds, it is suggested that the ancestors of Baptornis are much more likely to have been also the progenitors of the Colymbine group [ $=$ grebes] than are those of Hesperornis." However, examination of much better material of both Hesperornis and Baptornis than was available to Lucas has failed to substantiate his statement. Actually, Hesperornis is more grebe-like than is Baptornis, which tends more to resemble the loons. Our studies here confirm that Baptornis and Hesperornis resemble each other more than they do any modern birds and that both are far removed from, and unrelated to, either loons or grebes. This removes the Podicipediformes from the Cretaceous record, their next earliest occurrence being in the lower Miocene (Arikareean) of Oregon (Brodkorb, 1963b:227).

Other than Baptornis the only genus we presently include in the Baptornithidae is Neogaeornis from the Late Cretaceous of Chile. We have not examined specimens of Neogaeornis, but the highly compressed tarsometatarsus with the outer trochlea slightly more distal than the middle one (Lambrecht, 1933, fig. 100) suggests affiliation with the Hesperornithiformes. The fact that the outer and middle trochleae are of about equal size supports an allocation to the Baptornithidae rather than the Hesperornithidae.

Enaliornis, from the Lower Cretaceous of Britain, shares many features with the Hesperornithiformes, including a broad shallow fibular groove on the femur, a broad triangular procnemial process and the absence of the supratendinal bridge of the tibiotarsus, and the outer trochlea of the tarsometatarsus slightly more distal than the middle trochlea. Enaliornis shares many features with Baptornis, from which it differs in having amphicoelous dorsal vertebrae. We presently maintain the Baptornithidae as a family separate from the Enaliornithidae. Brodkorb (1963a:60) placed Enaliornis in the Gaviiformes stating that "although currently placed in the order Hesperornithiformes, these birds are slightly less specialized than modern loons of the family Gaviidae and should be transferred to the order Gaviiformes." However, we think Enaliornis is more similar to Baptornis than to any other known bird and regard it as the primitive basal stalk of the Hesperornithiformes. This leaves Lonchodytes as the only Mesozoic bird with any possible affinities with loons.

We agree with Baird's (1967) suggestion that the order Hesperornithiformes probably represents an archaic group that became extinct along with the great sea-lizards at the close of the Cretaceous.

\section{Literature Cited}

Baird, D.

1967. Age of Fossil Birds from the Greensands of New Jersey. $A u k, 84: 260-262$.

Brodkorb, P.

1963a. Birds from the Upper Cretaceous of Wyoming. Proceedings of the 13th International Ornithological Congress, 1:55-70, 10 figures, 1 table.

1963b. Catalogue of Fossil Birds. Bulletin of the Florida State Museum, Biological Sciences, 7:179-293.

1971. Origin and Evolution of Birds. Pages 19-55 in volume 1 of D. S. Farner and J. R. King, editors, Avian Biology. 2 figures, 7 tables. New York and London: Academic Press.

Gingerich, $P$.

1972. A New Partial Mandible of Ichthyornis. Condor, 74(4):471-473, 2 figures.

1973. Skull of Hesperornis and Early Evolution of Birds. Nature, 23:70-73, 2 figures.
Gregory, J. T.

1952. The Jaws of the Cretaceous Toothed Birds Ichthyornis and Hesperornis. Condor, 54:73-89, 9 figures.

Heilman, G.

1927. The Origin of Birds. 210 pages, 142 figures. New York: D. Appleton.

Howard, $\mathrm{H}$.

1955. New Records and a New Species of Chendytes, an Extinct Genus of Diving Geese. Condor, 57:135143, I figure.

Lambrecht, $\mathrm{K}$.

1933. Handbuch der Palaeornithologie. 1022 pages, 209 figures. Berlin: Gebruder Borntraeger.

Lucas, F. A.

1903. Notes on the Osteology and Relationships of the Fossil Birds of the Genera Hesperornis, Hargeria, Baptornis, and Diatryma. Proceedings of the United States National Museum, 26:545-556, 8 figures. 
Marsh, O. C.

1877. Characters of the Odontornithes, with Notice of a New Allied Genus. American Journal of Science, 14:85-87, 1 figure.

1880. Odontornithes, a Monograph of the Extinct Toothed Birds of North America. Report of the United States Geological Exploration of the Fortieth Parallel, 7:1-201, 40 figures, 34 plates.

Martin, L. D., and J. Tate, Jr.

1967. A Hesperornis from the Pierre Shale. Proceedings of the Nebraska Academy of Sciences (77th Annual Meeting): 40.

1969. New Information on Baptornis advenus. Proceedings of the Nebraska Academy of Sciences (79th Annual Meeting): 49-50.

Ostrom, J. H.

1969. Osteology of Deinonychus antirrhopus, an Unusual Theropod from the Lower Cretaceous of Montana. Bulletin of the Peabody Museum of Natural History, Yale University, 30:1-165, 83 figures.

Raikow, R. J.

1970. Evolution of Diving Adaptations in the Stifftail Ducks. University of California Publications in Zoology, 94:1-52, 32 figures, 16 tables.

Romer, A. S.

1966. Vertebrate Paleontology. Third edition, 468 pages, 4 tables, 443 figures. Chicago: University of Chicago Press.

Russell, D. A.

1967. Cretaceous Vertebrates from the Anderson River, N.W.T. Canadian Journal of Earth Sciences, 4:2138,12 figures.

Shufeldt, R. W.

1915. Fossil Birds in the Marsh Collection of Yale Uni- versity. Transactions of the Connecticut Academy of Arts and Sciences, 19:1-110, 15 plates.

Storer, R. W.

1956. The Fossil Loon, Colymboides minutus. Condor, 58:413-426, 4 figures.

1958. Evolution in the Diving Birds. Proceedings of the 12th International Ornithological Congress, 2:694 707, 9 figures.

1965. [Review of] P. Brodkorb, Catalogue of Fossil Birds, Part 1. $A u k, 82: 657-658$.

1971. Classification of Birds. Pages 1-18 in volume 1 of D. S. Farner and J. R. King, editors, Avian Biology. 21 figures, 2 tables. New York and London: Academic Press.

Swinton, W. E.

1965. Fossil Birds. 65 pages, 25 figures, 12 plates. London: British Museum.

Walker, M. V.

1967. Revival of Interest in the Toothed Birds of Kansas. Transactions of the Kansas Academy of Sciences, $70(1): 60-66$.

Wetmore, A.

1956. A Check-List of the Fossil and Prehistoric Birds of North America and the West Indies. Smithsonian Miscellaneous Collections, 131(5):1-105.

Williston, S. W.

1898. Birds. The University Geological Survey of Kansas, 4(2):43-64, 1 figure, 4 plates.

Zusi, R. L., and R. W. Storer

1969. Osteology and Myology of the Head and Neck of the Pied-billed Grebes (Podilymbus). Miscellaneous Publications of the Museum of Zoology, University of Michigan, 139:1-49, 19 figures, 4 tables. 


\title{
Discovery of a Cretaceous Bird, Apparently Ancestral to the Orders Coraciiformes and Piciformes \\ (Aves: Carinatae)
}

\author{
Pierce Brodkorb
}

\begin{abstract}
Alexornis antecedens, new genus and species, is described from the Bocana Roja Formation, Upper Cretaceous (Campanian age), near El Rosario, Baja California, Mexico. The humerus, ulna, scapula, coracoid, femur, and tibiotarsus are represented. The fossil is referred to a new family, Alexornithidae, and a new order, Alexornithiformes, thought to be ancestral to the Tertiary and Recent orders Coraciiformes and Piciformes. Since Caenagnathus collinsi Sternberg and C. sternbergi Cracraft are reptiles, and Gobipteryx minuta Elzanowski appears to be reptilian also, Alexornis is the only certain land bird known from the Cretaceous.
\end{abstract}

\section{Introduction}

The major deficiency in our knowledge of the history of birds is their inadequate Mesozoic record. The only known Jurassic genus is Archaeopteryx, which was certainly a land bird, whether it was arboreal (Brodkorb, 1971b) or a grounddweller (Ostrom, 1974). In the Cretaceous period we have records of about 37 species of water birds, distributed among 18 genera, 12 families, and 7 orders. Because many groups of land birds occur early in the Tertiary, they must also have been present and undergoing radiation during the Cretaceous. However, none of the hitherto known

Pierce Brodkorb, Department of Zoology, University of Florida, Gainesville, Florida 32611. alleged birds from terrestrial Cretaceous deposits is certainly referable to the class Aves.

Three species of supposed land birds have been described from the late Cretaceous. These are: Caenagnathus collinsi Sternberg (1940), Caenagnathus sternbergi Cracraft (1971), and Gobipteryx minuta Elżanowski (1974). Each was described from a single specimen of jaw or skull. Although not comparable with any living or fossil bird, the describers of Caenagnathus and Gobipteryx made them the types of new families and orders of Aves.

Sternberg (1940) based Caenagnathus collinsi on a mandible from the Belly River Series of Alberta, and regarded it as representing a new order of birds. Wetmore (1960) transferred it to the theropod dinosaurs, near Ornithomimidae, an assignment in which Romer (1966) concurred. Cracraft (1971) returned the genus to Aves and founded a second species, C. sternbergi, on a scrap of a lower jaw from the same formation as C. collinsi. White (1973) included Caenognathus [sic] and Caenognathidae [sic] as a valid genus and family of coelurosaurian theropods. Dale A. Russell of the National Museum of Canada (pers. comm.) informs me that new material of Caenagnathus, plus specimens of related forms from Mongolia, confirms that the Caenagnathidae are theropod dinosaurs having affinities with Oviraptor of the Ornithomimidae, thus vindicating Wetmore.

Gobipteryx minuta was described on a small, poorly preserved, flattened skull and mandible from the Barun Goyot Formation in Mongolia. Neither the specimen, which I have seen, nor the published illustrations, are convincingly avian. 
Elizanowski (1974) placed Gobipteryx in the "Superorder Palaeognathae" (i.e., Ratitae), but this is certainly wrong. The specimen is quite small, and the palate is unlike that of ratites or any other bird. Better material is needed before it can be assigned confidently to either Aves or Reptilia.

With the relegation of the above forms to Reptilia or taxa incertae sedis, there are no land birds known from the 72-million-year span of the Cretaceous period. It was therefore with great interest that I agreed to study some possibly avian remains from a terrestrial deposit of Late Cretaceous age in Baja California, Mexico. The best preserved specimens so far recovered are from a small land bird-represented by elements of the pectoral girdle, wings, and legs-the subject of the present paper.

STRATIGRAPHY.-The Rosario Group is composed of three formations, each separated by an unconformity. In descending order these are the Rosario, "El Gallo," and "La Bocana Roja." According to Morris (1972) the last two formations were defined by Kilmer in his doctoral dissertation (1963).

The Rosario Formation is a marine deposit whose invertebrate fauna was assigned an early Maestrichtian or late Campanian age by Durham and Allison (1960). The nannofossils indicate that it is situated close to the Maestrichtian-Campanian boundary (Morris, 1973).

The Gallo Formation has a thickness of more than $150 \mathrm{~m}$. A potassium/argon (K/Ar) date of $73 \pm 2$ million years is available for the middle third of the formation (Morris, 1972, 1973). This would make it of late Campanian age. It contains the remains of hadrosaurian dinosaurs (cf. Lambeosaurus), smaller reptiles, amphibians, mammals, and large tree trunks with well-developed root systems. This assemblage is the only extensive Late Cretaceous terrestrial vertebrate fauna from the Pacific margin of North or Middle America.

The Bocana Roja Formation contained the remains of the bird described here. The typespecimen of the theropod dinosaur Labocania anomala Molnar (1974) also came from this formation, along with hadrosaur ribs and numerous small vertebrate fossils, as yet unstudied. The age of the formation is Campanian or earlier.

During the Cretaceous period the arrangement of the continents was different from that of today, Mexico being in proximity to North Africa and bordering the western part of the Tethys Sea (Deitz and Holden, 1970).

ACKNOWLEDGMENTS.-Field work was supported by the National Geographic Society through grants to Dr. William J. Morris of Occidental College and was sponsored by the Instituto de Geología of the Universidad Nacional Autónoma de México and by the Natural History Museum of Los Angeles County. Over several years the field parties included, in addition to Dr. Morris, Dr. Ismael Ferrusquia $\mathrm{V}$. of the Instituto de Geología and Harley Garbani, J. Loewe, and Robert $M$. McKenzie of the Natural History Museum of Los Angeles County (LACM). I am greatly indebted to Dr. Hildegarde Howard for suggesting that the fossils be sent to me for study. The beautiful photographs of the tiny specimens are by Victor $\mathrm{E}$. Krantz of the Smithsonian Institution. Donald Baird, Nicholas Hotton III, John H. Ostrom, and Dale A. Russell made suggestions or furnished information about Caenagnathus and Gobipteryx.

\section{Alexornis, new genus}

Type of Genus.-Alexornis antecedens, new species.

Diagnosis.-As for the type and only known species.

ETyMology.-From Greek aléxō (I defend) and órnis (common gender, masculine selected here) bird. On the occasion of his ninetieth birthday this genus is dedicated to my friend Alexander Wetmore, who, in addition to his many other accomplishments, has done more to foster paleornithology and has described more species of fossil birds than any other author.

\section{Alexornis antecedens, new species}

Figure 1

HolotyPE.-Distal $10 \mathrm{~mm}$ of right humerus, LACM 33213 (Figure la,b). From LACM locality 7256, 6 miles southwest of El Rosario, Baja California del Norte, Mexico. Bocana Roja Formation, Upper Cretaceous, Campanian age. Collected by H. Garbani and J. Loewe, 16 July 1971.

PARATYPE.-Distal $10 \mathrm{~mm}$ of left humerus, collected in association with the holotype and cataloged with the same number. 


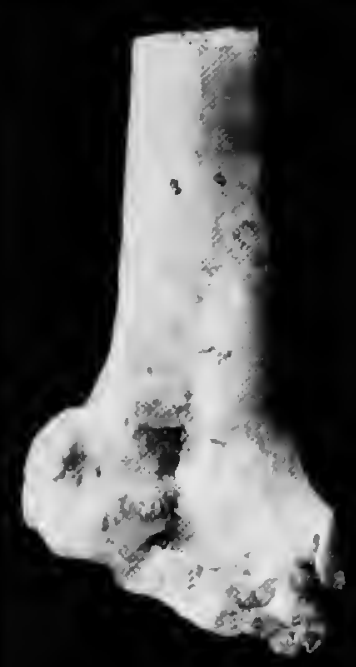

A

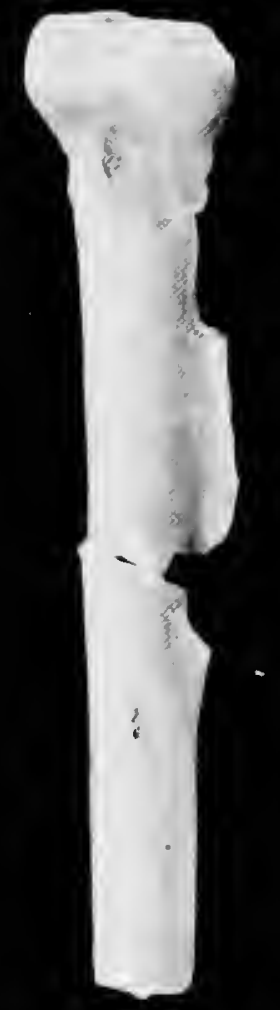

I

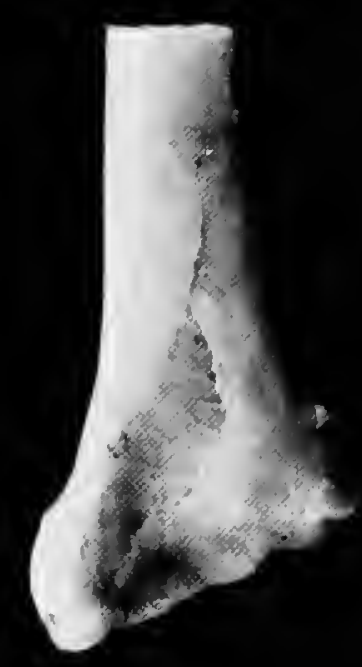

B

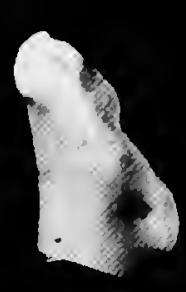

C
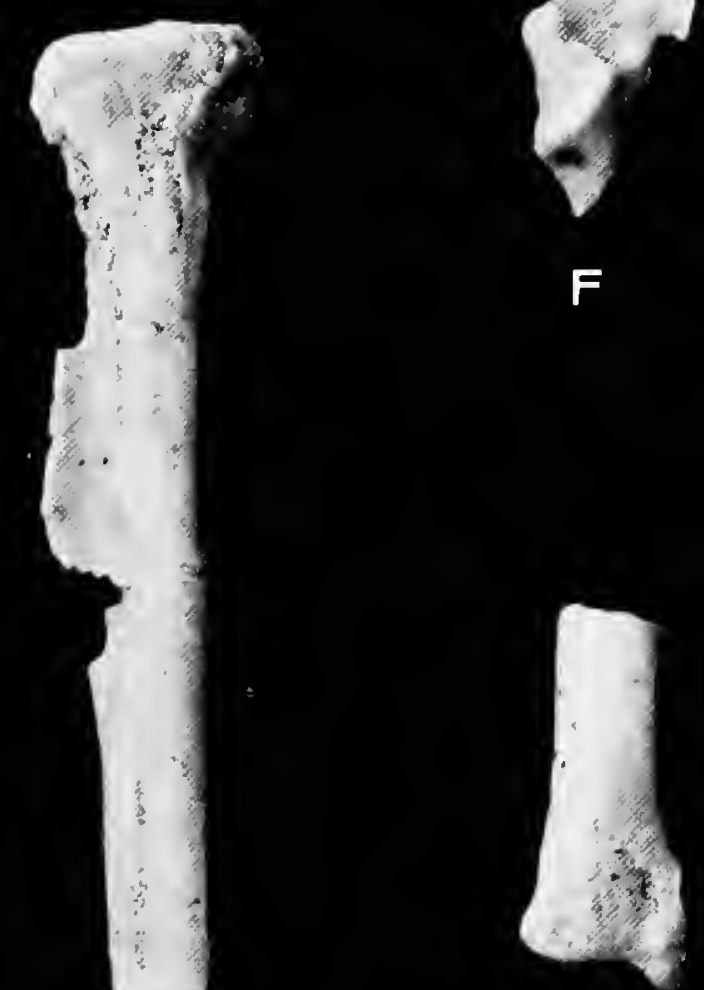

J

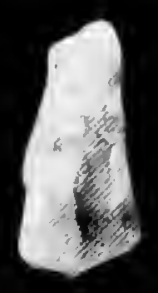

D
E

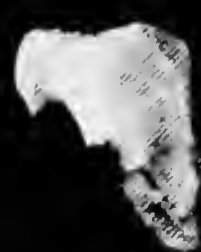

F

K

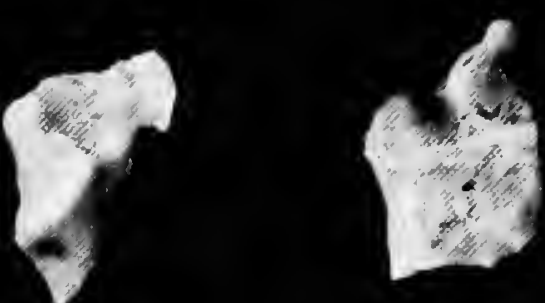

G

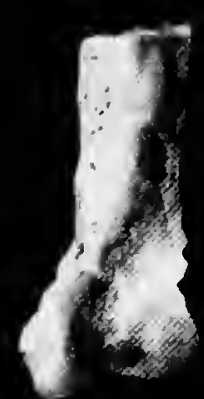

L

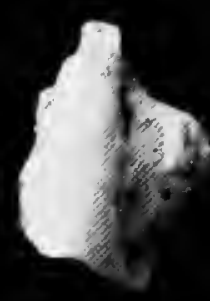

H

Figure 1.-Alexornis antecedens, new genus and species, Bocana Roja Formation, Campanian age, near Rosario, Baja California, Mexico (LACM 33212): $a$, holotype right humerus, palmar view; $b$, same, anconal view; $c$, left scapula, ventral view; $d$, same, dorsal view; $e$, left coracoid, anterior view; $f$, same, posterior view; $g$, right ulna, internal view; $h$, same, external view; $i$, right tibiotarsus, anterior view; $j$, same, posterior view; $k$, left femur, anterior view; $l$, same, posterior view; $m$, same, lateral view. (All $\times 5$.) 
Hypodigm.-The holotype, paratype, and the following referred material, collected in association with the types and cataloged under the same number: proximal $4 \mathrm{~mm}$ of left scapula (Figure $1 c, d$ ), upper $4.4 \mathrm{~mm}$ of left coracoid (Figure le,f), proximal $3.5 \mathrm{~mm}$ of right ulna (Figure $1 \mathrm{~g}, h$ ), distal 6 $\mathrm{mm}$ of left femur (Figure $1 k-m$ ), and proximal $16.3 \mathrm{~mm}$ of right tibiotarsus (Figure $1 i, j$ ). More than 20 other fragments were also collected with the types and cataloged under the same number, but they are left unidentified at this time.

Diagnosis.-Comparison of the hypodigm with the homologous skeletal elements of the known orders of birds shows that the resemblances of Alexornis are closest to certain members of the Piciformes and Coraciiformes. Within those two orders the piciform family Bucconidae and the coraciiform family Momotidae have the most similarity to the fossil. The fossil shares certain characters with both Bucconidae and Momotidae, some with Bucconidae alone, and some with Momotidae alone; but more of its characters are unique. In size the fossil falls between the bucconid Malacoptila panamensis and the motmot Hylomanes momotula (Table 1).

ETYMology.-Latin antecedens, going before in rank or time, ancestral, in reference to the supposed ancestry of this bird to the orders Piciformes and Coraciiformes.

Description.-Humerus: (1) Olecranal fossa deep (shallow in Bucconidae and Momotidae), and (2) wide, extending toward entepicondylar area (as in Momotidae; in Bucconidae less extended toward entepicondyle). (3) Entepicondyle produced distally, resembling Bucconidae (in Momotidae less produced; in Passeriformes much more produced). (4) External condyle bulbous as in both Bucconidae and Momotidae, but (5) oriented transversely at an angle of about 60 degrees to shaft (in Momotidae angle to shaft is about 45 degrees; in Bucconidae condyle is more upright at angle of 30 degrees to shaft). (6) Internal condyle lies inclined toward entepicondyle, resembling condition in Momotidae (in Bucconidae condyle is more transverse), (7) with a strong facet for medial cotyla of ulna, resembling both Momotidae and Bucconidae. (8) Ectepicondylar prominence large and rounded, resembling Bucconidae (less developed in Momotidae), (9) with a transverse ridge across anconal surface proximal
TABLE 1.-Measurements (mm) of skeletal elements

\begin{tabular}{|c|c|c|c|}
\hline Character & $\begin{array}{l}\text { Alexornis } \\
\text { antecedens* }\end{array}$ & $\begin{array}{l}\text { Hylomanes } \\
\text { momotula }\end{array}$ & $\begin{array}{l}\text { Malacoptila } \\
\text { panamensis }\end{array}$ \\
\hline \multicolumn{4}{|l|}{ Humerus } \\
\hline Distal width ..... & $5.6,-$ & 4.4 & 4.8 \\
\hline Shaft width ........ & $2.2,2.3$ & 1.7 & 2.4 \\
\hline Shaft depth ...................... & $1.8,1.8$ & 1.6 & 1.8 \\
\hline $\begin{array}{l}\text { Least depth through } \\
\text { brachial depression }\end{array}$ & $1.1,1.3$ & 1.1 & 1.7 \\
\hline SCAPULA & & & \\
\hline $\begin{array}{l}\text { Diagonal width across } \\
\text { acromion and } \\
\text { glenoid } \ldots \ldots \ldots \ldots \ldots \ldots\end{array}$ & 4.2 & 3.5 & 4.6 \\
\hline $\begin{array}{l}\text { Shaft width } \ldots \ldots \ldots \ldots \\
\text { FEMUR }\end{array}$ & 1.7 & 1.6 & 1.5 \\
\hline Distal width & {$[3.1]$} & 3.4 & 3.7 \\
\hline Shaft width $\ldots \ldots \ldots \ldots \ldots$ & 2 & 1.7 & 2 \\
\hline External condyle depth & 2.35 & 2.5 & 2.5 \\
\hline Fibular condyle depth & 1.6 & 2.2 & 2.2 \\
\hline Internal condyle depth & 2.6 & 2.0 & 2.1 \\
\hline $\begin{array}{c}\text { External condyle } \\
\text { height }\end{array}$ & 2.5 & 1.5 & 1.6 \\
\hline Fibular condyle height & 1.6 & 1.3 & 1.4 \\
\hline $\begin{array}{c}\text { Internal condyle } \\
\text { height }\end{array}$ & 2 & 1.7 & 1.3 \\
\hline $\begin{array}{l}\text { Shaft depth } \\
\text { Tibiotarsus }\end{array}$ & 1.8 & 1.4 & 1.7 \\
\hline Proximal width ........... & 3.7 & 2.6 & 2.9 \\
\hline 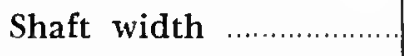 & 1.9 & 1.3 & 1.6 \\
\hline 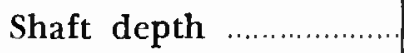 & 1.6 & 1.2 & 1.6 \\
\hline $\begin{array}{l}\text { Width through internal } \\
\text { cnemial crest }\end{array}$ & 4.1 & 3.1 & 4 \\
\hline $\begin{array}{l}\text { Length through fibular } \\
\quad \text { ridge }\end{array}$ & 10.5 & 6.7 & 8.1 \\
\hline
\end{tabular}

* The first measurement of the humerus of Alexornis is of the holotype, the second of the paratype.

Measurement in brackets estimated.

to its base (ridge absent in Bucconidae and Momotidae).

Insofar as preserved, the humerus of Alexornis has three unique characteristics (numbers 1, 5, and 9 above), shares two with Bucconidae alone (3 and 8), shares two with Momotidae alone (2 and 6), and is similar to both Bucconidae and Momotidae in two others ( 4 and 7).

Ulna: (1) Olecranon straight, short, stout (as in Bucconidae and Momotidae), (2) with a pit in the tip (no pit in Bucconidae and Momotidae). (3) External cotyla large and (4) strongly convex (of moderate size and moderately convex in Bucconi- 
dae; small and concave in Momotidae), (5) separated from olecranon by a deep groove (groove absent in Bucconidae and Momotidae); (6) medial rim of external cotyla thick [lateral portion of cotyla missing] (resembling Bucconidae; edge very thin in Momotidae). (7) Internal cotyla small (as in Bucconidae; large in Momotidae), (8) with surface flat (moderately concave in Bucconidae; strongly concave in Momotidae). (9) Proximal radial depression deeply undercuts entire width of rim of internal cotyla (in Bucconidae the depression falls far short of rim of cotyla; in Momotidae the depression extends to the medial edge of cotyla but fails to undercut it).

Insofar as preserved, the ulna of Alexornis has six unique characteristics (numbers 2, 3, 4, 5, 8, and 9 above), shares two with Bucconidae alone (6 and 7), shares none with Momotidae alone, and is similar to both Bucconidae and Momotidae in one characteristic (1).

Scapula: (1) Acromion rather short (long in Bucconidae and Momotidae), with tip slightly damaged, but (2) apparently blunt (as in Bucconidae; tip forms a recurved hook in Momotidae and Passeriformes). (3) Glenoid facet flat (cuplike in Bucconidae and Momotidae).

Thus the scapula, so far as preserved, has two unique characteristics (numbers 1 and 3), shares one with Bucconidae (2), and none with Momotidae.

Coracoid: (1) Brachial tuberosity with a recurved hook directed toward area where procoracoid process would be if preserved (slightly hooked in Bucconidae; hook absent in Momotidae). (2) Triosseal canal very deep (very shallow in Bucconidae; flat in Momotidae). (3) Scapular facet convex (as in Bucconidae and Momotidae), but (4) very broad (very narrow in Bucconidae and Momotidae).

The coracoid has three unique features (numbers 1, 2, and 4), none is shared with Bucconidae alone or with Momotidae alone, and one is shared with both Bucconidae and Momotidae (3).

Femur: The specimen shows evidence of some postmortem compression and distortion. (1) Shaft stout (resembling Bucconidae and Eurylaimidae; slender in Momotidae). (2) External condyle very long, extending both proximally and (3) distally far beyond both internal and fibular condyles (external and internal condyles of about equal extent in Bucconidae and Momotidae; in Eurylaimidae external condyle lengthened distally only). (4) Internal condyle with only very slight indication of a transverse shelf on posterior surface (resembling Bucconidae and Eurylaimidae; shelf very prominent in Momotidae). (5) Fibular condyle small (resembling Momotidae and Eurylaimidae; very stout in Bucconidae). (6) Popliteal area deeply excavated (resembling Momotidae; area nearly flat in Bucconidae and Eurylaimidae). (7) Rotular groove shallow (well developed in Bucconidae and Momotidae).

The femur has three unique features (numbers 2, 3, and 7), three are shared with Bucconidae alone ( 1,4 , and 5), one with Momotidae alone (6), and none are held in common with both Bucconidae and Momotidae.

Tibiotarsus: The cnemial crests are broken off, but their bases are preserved. (1) Shaft stout (resembling Bucconidae; slender in Momotidae). (2) Fibular crest wide (rudimentary in Bucconidae and Momotidae), (3) extending proximally all the way up shaft (as in Momotidae; in Bucconidae falling far short of proximal end of shaft). (4) Distal end of fibular crest merges gently with shaft (as in Momotidae; in Bucconidae distal end joins shaft at a rather abrupt angle). (5) Anterior and posterior surfaces of fibular crest concave, with an anterior and a posterior groove running along junction with shaft (a slight anterior and posterior groove in Bucconidae; in Momotidae anterior and posterior surfaces of crest flat and ungrooved). (6) Proximal internal articular surface swollen and convex (in Momotidae slightly swollen; surface more concave in Bucconidae), (7) without posterior overhang (with slight overhang in Bucconidae; in Momotidae a lip overhangs shaft posteriorly). (8) Outer cnemial crest short (as in Bucconidae and Momotidae). (9) Inner cnemial crest short, although considerably longer than outer crest (resembling Bucconidae and Momotidae).

The tibiotarsus has three unique characteristics (numbers 2, 5, and 7), shares one with Bucconidae alone (1), shares three with Momotidae alone (3, 4 , and 6), and agrees with both Bucconidae and Momotidae in two features (8 and 9).

\section{Familial Position of Alexornis}

The characteristics described above for Alexor- 
nis are grouped in Table 2 to show the number of features confined to a single taxon, those shared by two taxa, and those common to all three taxa. By far the strongest grouping of characteristics is of those confined to a single taxon- 49 percent in Alexornis, 44 percent in Momotidae, and 37 percent in Bucconidae. I interpret this as indicating that the three taxa are of equal taxonomic rank and, therefore, propose Alexornis as the type of a new family.

TABLE 2.- Summary of shared characteristics of Alexornis, Momotidae, and Bucconidae $(+=$ similar to; $-=$ different from)

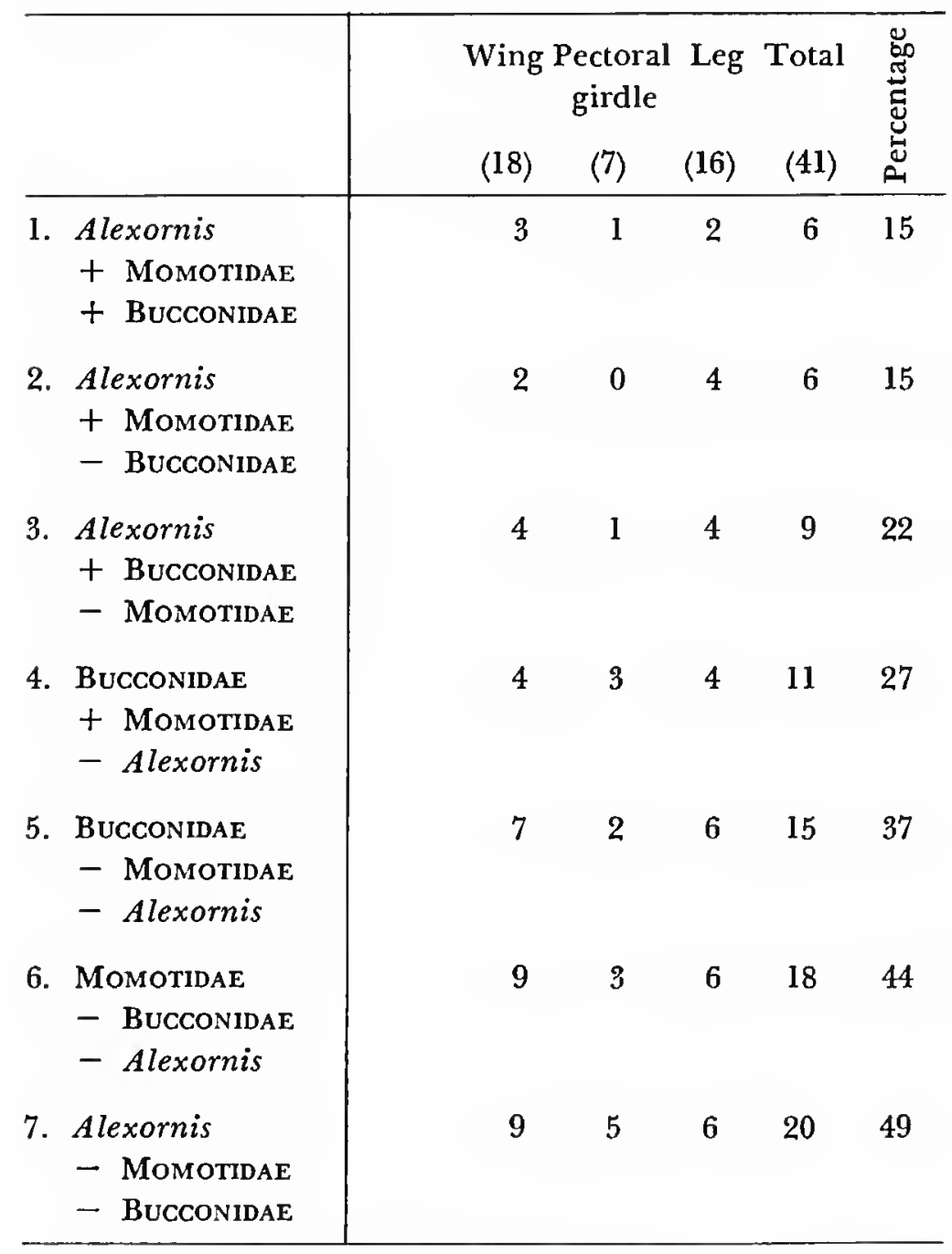

Numbers in parentheses represent number of characters considered.

\section{ALEXORNITHIDAE, new family}

Diagnosis.-Humerus with olecranal fossa deep; entepicondylar area much produced distally; external condyle oriented transversely at an angle of about 60 degrees to shaft; ectepicondylar promi- nence with a transverse ridge across anconal surface proximal to its base. Ulna with a pit at the tip of olecranon; external cotyla large, strongly convex, and separated from olecranon by a deep groove; surface of internal cotyla flat; proximal radial depression deeply undercutting the entire width of lip of internal cotyla. Scapula with acromion rather short and glenoid facet flat. Coracoid with brachial tuberosity hooked; triosseal canal very deep; scapular facet very broad. Femur with external condyle very long, extending both proximally and distally far beyond both internal and fibular condyles; rotular groove obsolete. Tibiotarsus with its proximal articular surface not overhanging shaft posteriorly; fibular crest wide, with both its surfaces concave and separated from shaft by an anterior and a posterior groove.

\section{Ordinal Position of Alexornis}

Although possessing a large number of unique features, Alexornithidae shares some characters with the order Coraciiformes as exemplified by the Momotidae, others with the order Piciformes as exemplified by the Bucconidae, and still others with both of those orders. These similarities are summarized in Table 2, and several different hypotheses at the ordinal level could be formed from these data.

The three taxa might be combined in a single order, for which the name Piciformes would have priority (for order-group synonymies see Brodkorb, 1971a:248, 256). But of the 41 characters analyzed, only 6 are shared by the 3 families (Table 2, line 1). Such a small proportion of common characteristics militates against merging the taxa in a single order.

Alexornithidae might be referred to Coraciiformes, but such an arrangement is also supported by 6 characters only (Table 2, line 2), and this hypothesis is likewise discarded.

Alexornithidae might be placed in Piciformes, as the order is currently understood. Nine characters support this combination (Table 2, line 3), but line 4 of Table 2 argues against it, as Piciformes and Coraciiformes share more characters than any other combination of the taxa under consideration.

The conclusion thus derived from Table 2 is that the three taxa represent separate but related 
orders. I therefore propose Alexornis as the typegenus of a new order.

\section{ALEXORNITHIFORMES, new order}

Diagnosis.-Same as for the only known family, Alexornithidae.

REMARKs.-The age of Alexornis is about 81 million years BP, much earlier than the earliest known occurrence of either the Coraciiformes and Piciformes. The earliest record of the Piciformes is early Eocene, about 51 million years BP, when bucconid-like forms appear in Wyoming (Brodkorb, 1970; Feduccia and Martin, herein). If Harrison and Walker (1972) are correct in assigning the British Halcyornis to the Coraciiformes, the earliest record of that order is also early Eocene. Undoubted members of the Coraciiformes occur in European deposits of middle and late Eocene age (Brodkorb, 1971a). Both morphology and the temporal sequence thus suggest Alexornis as the presumptive ancestor of the orders Coraciiformes and Piciformes.

\section{Literature Cited}

Brodkorb, P.

1970. An Eocene Puffbird from Wyoming. Contributions to Geology, University of Wyoming, 9(1):13-15, 1 figure.

1971a. Catalogue of Fossil Birds, Part 4 (Columbiformes through Piciformes). Bulletin of the Florida State Museum, Biological Sciences, 15(4):163-266, 1 figure.

1971b. Origin and Evolution of Birds. Pages 19-55 in volume 1 of D. S. Farner and J. R. King, editors, Avian Biology. 2 figures, 7 tables. New York and London: Academic Press.

Cracraft, J.

1971. Caenagnathiformes: Cretaceous Birds Convergent in Jaw Mechanism to Dicynodont Reptiles. Journal of Paleontology, 45(5): 805-809, 2 figures, plate 92.

Deitz, R. S., and J. C. Holden

1970. Reconstruction of Pangaea: Breakup and Dispersion of Continents, Permian to Present. Journal of Geophysical Research, 75:4939-4956.

Durham, J. W., and E. C. Allison

1960. Geologic History of Baja California and its Marine Faunas. Systematic Zoology, 9:47-91.

Elianowski, A.

1974. Preliminiary Note on the Palaeognathous Bird from the Upper Cretaceous of Mongolia. Part 5 in Results of the Polish-Mongolian Palaeontological Expeditions. Palaeontologia Polonica, 30:103-109, 2 figures, plates 32-33.

Harrison, C. J. O., and C. A. Walker

1972. The Affinities of Halcyornis from the Lower Eocene. Bulletin of the British Museum (Natural History), Geology, 21(4):151-169, 9 figures, 3 plates.
Kilmer, F. $\mathrm{H}$.

1963. Cretaceous and Cenozoic Stratigraphy, El Rosario Area, Baja California. Ph.D. dissertation, University of California, Berkeley.

Molnar, R. E.

1974. A Distinctive Theropod Dinosaur from the Upper Cretaceous of Baja California (Mexico). Journal of Paleontology, 48(5): 1009-1017, 4 figures.

Morris, W. J.

1972. A Giant Hadrosaurian Dinosaur from Baja California. Journal of Paleontology, 46(5):777-779, 1 figure.

1973. A Review of Pacific Coast Hadrosaurs. Journal of Paleontology, 47(3):551-561, 5 figures.

Ostrom, J. H.

1974. Archaeopteryx and the Origin of Flight. Quarterly Review of Biology, 49:27-47, 10 figures.

Romer, A. S.

1966. Vertebrate Paleontology. Third edition, ix +468 pages, 443 figures. Chicago: The University of Chicago Press.

Sternberg, R. M.

1940. A Toothless Bird from the Cretaceous of Alberta. Journal of Paleontology, 14(1):81-85, 6 figures.

Wetmore, A.

1960. A Classification for the Birds of the World. Smithsonian Miscellaneous Collections, 139(11):1-37.

White, T. E.

1973. Catalogue of the Genera of Dinosaurs. Annals of Carnegie Museum, 44(9):117-155. 



\title{
A Survey of the Paleogene Birds of Asia
}

\author{
E. N. Kurochkin
}

\begin{abstract}
In the past few years, much new material of Paleogene birds has been collected in Mongolia and Kazakhstan, the fossil collections now comprising 350 satisfactory specimens of postcranial elements. The first Paleocene birds known from Asia were obtained in Mongolia, where remains referable to several avian orders were recovered. Fossils from a new middle Eocene site at Khaichin Ula 2, also situated in the South Gobi of Mongolia, were identified as various waterbirds and galliforms. A variety of birds is represented in early Oligocene material from Mongolia and a wealth of new avian material of middle Oligocene age has been obtained from the so-called Indricotherium beds of Central Kazakhstan. Paleoecological conditions in the Asian Paleogene are assessed on the basis of avian fossils, and the sketchy picture of the possible interrelationships of Paleogene birds from Asia, Europe, and North America is outlined.

Abundant new fossil material has made possible a deeper insight into the composition, characteristics, and relationships of the gruiform families Eogruidae and Ergilornithidae, and proves the existence of a phylogenetic continuity between the Eocene genus Eogrus, the Oligocene genera Ergilornis and Proergilornis, and the Pliocene genus Urmiornis. A fragment of humerus assigned to the Ergilornithidae shows that these birds were flightless.
\end{abstract}

\section{Introduction}

Until recently, knowledge of the Paleogene birds of Asia has been derived mainly from casual discoveries, with few attempts at a purposeful gather-

E. N. Kurochkin, Paleontological Institute of the USSR Academy of Sciences, Leninsky Prospect, 33, Moscow, 117071, U.S.S.R. ing of avian remains and their subsequent study being made. Publications on the subject have generally been concerned with systematic descriptions of individual specimens collected in association with Paleogene mammals from isolated Asian localities. The list of these publications is deplorably short, consisting of 15 titles, in which 21 forms of birds are described.

Discoveries of Paleogene birds in Asia have been confined largely to the following three territories: Central Kazakhstan east of the Aral Sea; East Kazakhstan east of Lake Zaisan; and the southern part of Mongolia together with adjoining provinces of China (Figure 1). Avian fossils from outside this area consist of individual specimens from the early middle Eocene of Fergana in Kirgizia (Eobalearica tugarinovi Gureev, 1949), the middle Eocene of Sumatra (Protoplotus beauforti Lambrecht, 1931), and Gruidae genus indet. from the Oligocene of Ordos, China (Teilhard de Chardin, 1926).

Three upper Eocene birds, two of which were described as new, were reported by Wetmore (1934) from China. Lower Oligocene ergilornithids from East Gobi, Mongolia, were studied by Kozlova (1960). Several species of birds of prey, Anseriformes and rails were described by Kurochkin (1968a, 1968b) from the Oligocene of Kazakhstan and Mongolia. Other specimens of Paleogene birds from Asia were discussed by Tugarinov (1940) and Bendukidze (1971). A record of Aquila sp. from middle Oligocene deposits at Min Eske Suek, Kazakhstan (Aubekerova, 1965) has not been confirmed. Surveys of the Tertiary birds from the U.S.S.R, including several Paleogene discoveries, were published by Burchak-Abramovich (1958) and the present writer (Kurochkin, 1974).

In the past few years, great quantities of new avian material have been obtained from the Oligo- 


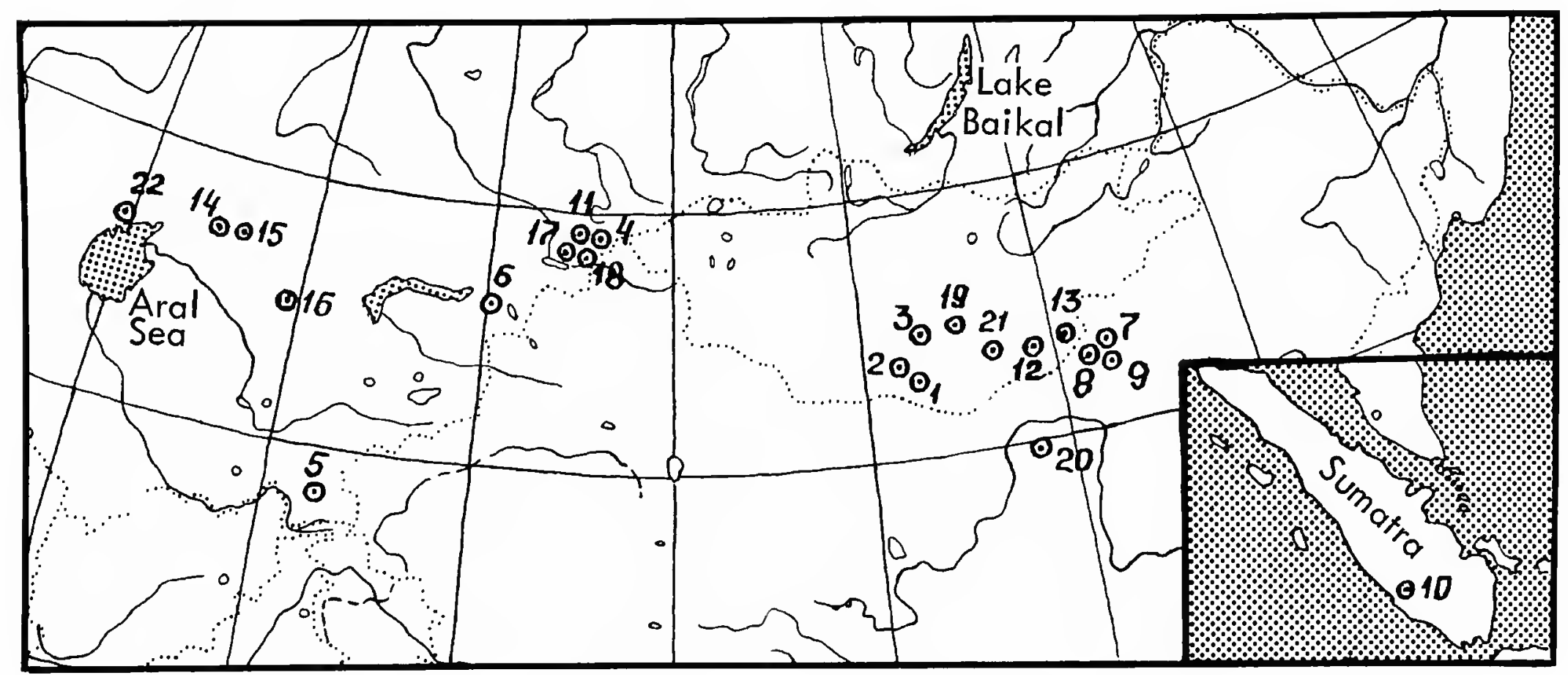

Figure 1.-Schematic map showing collection localities for Paleogene birds in Asia. Paleocene: 1, Naran Bulak and Tsagan Khushu. Midde Eocene: 2, Khaichin Ula 2; 3, Kolobolchi; 4, Kalmakpai; 5, Andarak (in Fergana). LATE EOCENE: 6, Andreevka; 7, Irdin Manha and Ulan Shireh; 8, Iren Dabasu; 9, Tung Gur (Miocene); 10, (inset) Sipang, Sumatra. Early Oligocene: 11, Zhongiz Shoki; 12, Ergelyeen Dzo (Ardyn Obo, Ergil Obo); 13, Khoer Dzan. Middle OligoCENE: 14, Kur Sai and Min Sai (Tchelkar Nura); 15, Donguz Tau; 16, Kyzyl Kak; 17, Kusto; 18. Kusto Kysylkain; 19, Tatal Gol (Shand Gol, Loh, Tatshin Gol); 20, Sen Zhak (Ordos, China); 21. Shunkht. Late Oligocene: 22. Agispe.

cene of Kazakhstan and in various other Paleogene localities. This material was gathered by expeditions of the Paleontological Institute of the U.S.S.R. Academy of Sciences, and also by a joint Soviet-Mongolian paleontological expedition. The tentative studies made so far have shown that a small part of this material belongs to previously known taxa, whereas the greater part represents completely new forms.

In all, about 240 fossils of Paleogene birds have been found in Mongolia. These include the first Asian Paleocene birds known, found in deposits at Naran Bulak and Tsagan Khushu, as well as interesting discoveries made in the Eocene deposits at Khaichin Ula 2 and Kolobolchi, and a large collection from the Oligocene localities at Ergelyeen Dzo, Khoer Dzan, Tatsin Gol, Tatal Gol, and others. New material from the Oligocene sites at Kur Sai and Min Sai, Donguz Tau and Kyzyl Kak in Central Kazakhstan and several Oligocene localities in the Zaisan basin, East Kazakhstan, in- cludes 80 fragments of avian bones, most of which can be identified to the species level.

ACKNowLEDGMENTS.-I want to thank many persons for their valuable assistance in preparing this survey and in gathering the fossil birds reported in this work: Dr. N. Shevyreva, Paleontological Institute of the U.S.S.R. Academy of Sciences (PIN), who provided me with avian material from Zaisan basin; V. Y. Reshetov, also of the Paleontological Institute, for his valuable contributions to the discovery of fossil birds in Naran Bulak, Tsagan Khushu, and Khaichin Ula 2; Dr. D. Dashzeveg, Geological Institute of the Mongolian Academy of Sciences, who provided me with avian remains from Tsagan Khushu and Khoer Dzan; Dr. Malcolm C. McKenna, American Museum of Natural History, for his help in obtaining casts of the original material of Eogrus and for editorial assistance; Dr. K. Yudin and Dr. B. Nekrasov, Zoological Institute of the U.S.S.R. Academy of Science, for permitting me to study a skeleton of Strigops; 
Dr. A. Sudilovskaya and S. V. Lutskaya, Ornithological Department of Moscow University, for their kind permission and assistance in using the osteological collection of the Zoological Museum of Moscow University; Prof. K. K. Flerov, Institute of Evolutionary Morphology and Ecology of Animals of the U.S.S.R. Academy of Sciences; Dr. B. Trofimov, Paleontological Institute of the U.S.S.R. Academy of Sciences, for valuable comments on the manuscript; T. D. Rakova for preparing the illustrations accompanying this survey; and N. N. Sukhareva for technical editing.

\section{The Paleocene}

Birds have not previously been known from the Paleocene of Asia. As a result of field work by the Soviet-Mongolian paleontological expedition, the first such avian fossils were obtained from Naran Bulak and Tsagan Khushu in South Gobi, in the western part of the Nemeget basin. The geology of these localities, which are situated about $6 \mathrm{~km}$ from one another, has been described by Novozhilov (1954), Gradzińsky, et al. (1968), and Shishkin (1975). The mammalian assemblage from these sites is generally referred to as the Naran Bulak fauna (Belaeva, et al., 1974). Although immediately after its discovery this fauna was believed to be early Eocene in age (Efremov, 1954; Novizhilov, 1954), it is presently placed in the late Paleocene (Gradzińsky, et al., 1968; Szalay and McKenna, 1971; Belaeva, et al., 1974). The Naran Bulak mammalian fauna consists of insectivores, multituberculates, lagomorphs, condylarths, dinoceratids, pantodontids, and notoungulates. It has many species in common with the Gashato fauna collected by the Central Asiatic expedition of the American Museum of Natural History (Belaeva, et al., 1974).

In contrast to the early Oligocene avian material from Asia, which appears to consist exclusively of genera and families more or less directly related to Recent birds, a preliminary acquaintance with the avian remains from Naran Bulak produces the distinct impression that these birds are fundamentally different from Recent families in their structure, although they may be assigned quite unambiguously to Recent orders. A pelecaniform humerus is interesting in that it bears certain similarities to both the Sulidae and the Phalacrocoraci- dae. A coracoid and a carpometacarpus referable to the extinct anatid subfamily Romainvilliinae exhibit obvious primitive traits, particularly as compared to the relatively homogeneous skeletal structure of Recent, Neogene, and Oligocene anatids.

In washing thousands of mammalian bones at Tsagan Khushu, only 12 avian bones were found. Half of these were coracoids and scapulae belonging to small anseriforms possessing specific structural details not found in Recent ducks. Also included were remains of a peculiar new type of heron similar to the Ardeidae, and shorebirds having definite affinities with the Scolopacidae.

\section{The Eocene}

Gureev (1949) described Eobalearica tugarinovi from a distal end of tibiotarsus from Andarak in the Fergana valley, a site which was then considered to be late Eocene. New stratigraphic correlations have shown it to belong to the early middle Eocene (Hekker, et al., 1962): Recently, bird remains have been reported from the Zaisan basin, where sediments bearing the so-called Obailin fauna are rather common. Various authors date this fauna as middle to late Eocene. Bendukidze (1971) described Progrus turanicus from a distal end of tibiotarsus from the Kalmakpai River, without giving an exact indication of locality. $\mathrm{He}$ placed this bird in the family Geranoididae, but this allocation would appear to require further scrutiny. P. A. Aubekerova of the Institute of Zoology of the Kazakh S.S.R. Academy of Sciences obtained unidentifiable fragmentary avian remains from the late Eocene localities near Andreevka on the Chinzhili River in Southeast Kazakhstan. Another isolated discovery was that of Protoplotus beauforti Lambrecht (1931), an upper Eocene anhinga from Sipang, in the western part of Sumatra, which was described from an almost complete skeletal impression.

Wetmore (1934) examined the paleornithological material collected by the Central Asiatic expedition at Ulan Shireh (upper Eocene of Irdin Manha) in China. He referred a coracoid to the Falconiformes and also described a femur as a new genus and species of Rallidae, Telecrex grangeri. Recently, Olson (1974) has provided convincing evidence that Telecrex grangeri is a representative 
of the family Numididae, showing some similarities to the modern genus Phasidus. This is the earliest evidence of the presence of this group in Asia. From the same locality, Wetmore (1934) described numerous specimens of a crane as a new genus and species, Eogrus aeola, and reported specimens thought to be of the same species from another upper Eocene locality in Inner Mongolia in the vicinity of Iren Dabasu. Material referable to Eogrus aeola was obtained in 1959 by the SovietChinese paleontological expedition at the same locality, Irdin Manha, in the Shara Murun region of China. This includes 10 distal ends of tibiotarsi and tarsometatarsi (PIN 2197-185-194), which confirm the original characterization of Eogrus and provide a solid basis for a comparative study of new specimens of Eogruidae and Ergilornithidae from the lower Oligocene.

Of interest are recent discoveries from Khaichin Ula 2 on the southern slope of Bugin Tsav in southern Gobi. In 1971-1973, 27 avian postcranial bones were found in these sediments, which are middle upper Eocene in age (Shuvalov, et al., 1974). Most of the bones are well preserved and can be studied in detail. Tentative identifications of this material have shown that the majority of the bones belong to shorebirds of two groups. The lesser part of these are clearly referable to the Scolopacidae, whereas the remainder may be attributed to small birds of the suborder Charadrioidea having no parallel among the recent families of this group and represented by species of different sizes. Coracoids and scapulae were especially numerous and a radius and tarsometatarsus were also found. From the same locality are remains belonging to the Ardeidae, Rallidae, and Threskiornithidae, as well as to unidentified peculiar types of Galliformes, including synsacral fragments belonging to a bird of the family Numididae. Several bones were found by us in 1972 in another middle upper Eocene locality at Kolobolchi, in the Lake Valley near Somon Bogd, Mongolia.

\section{The Early Oligocene}

Information on the early Oligocene of Asia, especially of birds, is, in general, extremely scanty (Flerov, et al., 1974). Cygnavus formosus was described from the Aksiirskaya site in East Kazakh- stan (Kurochkin, 1968b). Kozlova (1960) described two peculiar, almost didactylous species of Gruiformes, Proergilornis minor and Ergilornis rapidus, from Ergelyeen Dzo in Mongolia. Wetmore (1934) referred to a specimen from the same locality as "Eogrus sp." In 1970-1971, large scale paleontological field work was conducted at Ergelyeen Dzo (Ardyn Obo, Ergil Obo) and in other lower Oligocene localities in East Gobi, Mongolia, by Mongolian and Soviet paleontologists. Numerous avian remains were found, especially at Khoer Dzan, situated $70 \mathrm{~km}$ northwest of the railway station at Zamin Ud, at a locality that we called Shuvalov's Hills, after a student from Saratov State University who first discovered them in 1971. In all, about 200 avian bones were found at Khoer Dzan, 150 of which were in good or satisfactory condition and can be studied in detail. Several avian bones were also found in the eastern part of the classical locality at Ergelyeen Dzo.

The fossil material from Khoer Dzan contains specimens referable to the Accipitridae, Anatidae (including Cygninae), Rallidae, Ardeidae, and the suborder Lari. Diurnal birds of prey are represented by several rather large femora resembling the recent Aegypiinae but differing from Gyps, Aegypius, and Gypaetus in a number of important characteristics. A tarsometatarsus of a smaller species of Accipitridae was also found. Ducks, swans, rails, and herons from this locality are fairly comparable to recent families, although a fragment of skull belonging to a large representative of the suborder Lari has no exact parallels among the Recent families of that group.

Most of the avian bones from Khoer Dzan belong to the two gruiform families Eogruidae and Ergilornithidae. Remains of both groups were also found at Ergelyeen Dzo, and the more diagnostic material of the former confirms Wetmore's (1934) assertion that Eogrus may be traced to deposits of lower Oligocene age. These two families are discussed in greater detail in a following section.

\section{The Middle Oligocene}

Information on birds from the middle Oligocene of Asia is relatively rich. In Central Kazakhstan avian remains were found in the classical Indricotherium localities in the vicinity of the solonchak Tchelkar Tengiz. Agnopterus turgaiensis 
was described from this region by Tugarinov (1940), and Cygnopterus lambrechti, Somateria sp., Limicorallus saiensis, and Megagallinula harundinea were later described by the present author (Kurochkin, 1968b). Much new material was also collected in this region in 1968. Among the fossils from the sites at Kur Sai and Min Sai in Tchelkar Nura, north of Tchelkar Tengiz, were remains identified as belonging to the Pelecaniformes, Anatidae (including Cygninae), Accipitridae, Galliformes, Gruidae, Rallidae, and Otididae. Collections made at Donguz Tau, another locality situated on the northeastern part of Tchelkar Tengiz, included avian remains referable to the Gaviiformes, Podicipediformes, Ciconiiformes (including the Threskiornithidae), Anatidae (including members of the Cygninae and Anserinae), Rallidae, Otididae, and Charadriiformes.

The fossil site at Kyzyl Kak, on the northern slope of the basin of the same name in Central Kazakhstan, south of the town of Dzhezkazgan, was discovered and excavated in the past few years. This locality was thought to be middle Oligocene in age (Klebanova, 1965), but the mammalian material obtained there in 1968 casts doubt on this dating and most probably indicates a greater age. Several scraps of avian bones were reported from Kyzyl Kak, and were determined as belonging to the Podicipediformes, Aquilavus sp., Gruidae, and Otididae.

In East Kazakhstan, $60 \mathrm{~km}$ south of Lake Zaisan, new avian material was obtained from Kusto and Kusto Kysylkain, the sediments of which were dated by comparison with the mammalian fauna found at the middle Oligocene site at Kustovskaya. Flamingos, ducks, swans, Cygnopterus sp. and Eogrus sp. were identified from here. In the past few years several different birds were also reported from Bulkair, Tchaibulak, Akzhar, and Bobrovaya Struya, located $90 \mathrm{~km}$ north of Lake Zaisan. All the material was collected by Dr. N. Shevyreva of the Paleontological Institute of the U.S.S.R. Academy of Sciences.

Middle Oligocene sediments are very common on the northern slope of the Lakes Valley at the foot of the highest peaks of the Mongolian Altai, Ikhe Bogdo and Baga Bogdo. The first of these localities, Hsanda Gol and Loh (sediments of the Hsanda Gol Formation), were discovered by the Central Asiatic expedition in the 1920s. Small birds of prey and rails were described from the avian material collected in Tatal Gol in 1947 by the Mongolian paleontological expedition of the U.S.S.R. Academy of Sciences (Kurochkin, 1968a; 1969). Two of these birds of prey belong to the new genera Gobihierax and Venerator. The third species was placed in the recent genus Buteo, the fossil record of which extends back to the middle Oligocene of North America. This material was not included in Mellett's survey of the fauna of the Hsanda Gol Formation (Mellett, 1968). New material from the middle Oligocene sediments of the Lakes Valley was obtained in 1972. The complete tarsometatarsus of a small owl, differing markedly from all recent forms of Strigidae, is the most interesting of these discoveries. In another region of Mongolia, an unidentifiable bird bone was recovered from the middle Oligocene site at Shunkht, in Middle Gobi Aimak, east of Manlai Somon.

\section{The Late Oligocene}

Birds in the late Oligocene deposits at Agispe, on the northwest shore of the Aral Sea, are represented so far only by Anas oligocaena and several other species of Anatidae (Tugarinov, 1940, and more recent unpublished data). A specimen from this locality was identified by the present author as being galliform.

\section{Paleoecology and Paleozoogeography of Asian Paleogene Birds}

We can make some judgment of the life and environment of fossil birds by analogy with Recent birds belonging to allied groups, for in many cases, such as with cormorants, ducks, or bustards, there is no reason to suspect that there would have been significant differences in the habits of the Paleogene forms. However, in studying Paleogene birds with no analogs among the recent fauna, we can only make certain assumptions from their osteology as to their way of life.

The birds from Naran Bulak and Tsagan Khushu provide but scanty evidence of the environment of this region in the Paleocene. The discovery here of Anseriformes, Charadrii, and Ardeidae tells us no more than that there were moist areas present. The distinctive morphology of these birds as compared to Recent forms, makes 
us otherwise very cautious in evaluating their ecological preferences. The same is true of the Eocene birds from Khaichin Ula 2.

Along with Eogrus, the lower Oligocene localities at Ergelyeen Dzo and Khoer Dzan in southeastern Mongolia contain the remains of two gruiform birds, Proergilornis minor and Ergilornis rapidus. In the Paleogene ergilornithids, and in their Pliocene descendent, Urmiornis, the inner toe was vestigial or absent, and the birds had lost the ability to fly, indicating that they were adapted for running in open areas. In this respect their ecological niche was probably perfectly analogous to that of the modern African ostrich (Struthio) and of the Asian ostrich of the Pliocene (Kurochkin and Lungu, 1970). The presence of ergilornithids and Eogrus in the faunas of Ergelyeen Dzo and Khoer Dzan is strong evidence that sparsely vegetated open spaces were present in this area in the early Oligocene.

The middle Oligocene avian material from Tatal Gol in central Mongolia does little to illuminate our knowledge of the ecological conditions that existed at that time. The three birds of prey (Accipitridae) found there could have lived either in forests or in open areas, since Recent species of raptors can live in extremely varied environments. Fossil remains of an owl are similarly uninformative, as this species might well have lived under any of several ecological conditions. The rail described from Tatal Gol appears to have been more terrestrially than aquatically adapted.

We can hypothesize with much more confidence about the habitat found in the middle Oligocene of Central Kazakhstan, near the present solonchak of Tchelkar Tengiz. The specimens from the sites at Tchelkar Nura and those from Donguz Tau may be treated together, as these sites are separated by a mere $30 \mathrm{~km}$ and no great difference in their past contemporaneous environments is likely. It is possible, however, that certain taphonomic factors could have affected the species composition of the birds collected from these two localities. Waterbirds are numerous and diverse at both sites, particularly various anatids and loons. In addition, birds intimately associated with shoals and with marshes overgrown with vegetation are also abundantly represented. These include various rails, grebes, ciconiiforms, pelecaniforms, flamingos, shorebirds, and probably cranes. Certain of these, such as the Limicolae and ciconiiforms, would have required shorelines as feeding sites, while others, such as loons, swans, and other anatids, indicate the former presence of large areas of open water. Although aquatic species constitute a large proportion of the birds found at Donguz Tau and Tchelkar Nura, this does not necessarily reflect the actual situation that existed, as waterbirds are more likely to have been preserved than terrestrial ones. Birds of open dry habitats are also represented here, viz. Galliformes and Otididae. There is much evidence to suggest that in the middle Oligocene in the area of the northern coast of the present Tchalkar Tengiz there were vast basins with stretches of open water, alternating with shoals and marshes and open drier savannas.

The birds of the Kyzyl Kak locality are not numerous but are distinctive in their ecological preferences. The presence of small forms of bustards and cranes suggests open country, perhaps with low dense vegetation, while grebes indicate the presence of some nearby water. The birds from the middle Oligocene deposits of East Kazakhstan at Kusto and Kyzylkain are almost all waterbirds, such as ducks, swans, and flamingos, which certainly indicate the existence of aquatic habitats.

The paleornithological data from the early Oligocene of East Gobi (Ergelyeen Dzo and Khoer Dzan), and the middle Oligocene of Central Kazakhstan (Donguz Tau, Tchelkar Nura, and Kyzyl Kak) and Mongolia in the Lakes Valley (Tatal Gol) confirms the environmental picture derived from an analysis of the mammalian fauna of the same age (Flerov, 1961). On the whole, this suggests a more arid environment for Mongolia as compared with Kazakhstan. This is evidenced not only by the predominance of predatory and cranelike birds in Mongolia, but also by the absence of Anseriformes, which are customarily encountered in localities of this type in other areas. A variety of aquatic and marsh birds prevails in the middle Oligocene of Kazakhstan, whereas terrestrial birds are almost lacking, the few bustard-like birds probably being associated with watering places.

It is appropriate here to consider the possible role of the Turgai area in the evolution of Palearctic waterbirds in the latter half of the Paleogene. Notwithstanding the general paucity of material, the discoveries made so far seem to suggest that in the late Paleogene a number of groups of waterfowl may have originated on the coasts of the Turgai strait and later spread from there to 
other areas. Further studies are needed to confirm or refute this surmise.

For a number of reasons it is difficult to determine the relationships of the Paleogene birds of Kazakhstan and Mongolia to those species from other areas. In the first place, the material thus far described and studied in detail is limited. As can be seen from the preceding discussion, most of it was obtained very recently and so far has been studied but tentatively. The character of much of the paleornithological material also impedes comparisons, since fossil forms of the same systematic group from different geographical areas may be represented by different parts of the skeleton and cannot be compared directly. Generally, the Paleogene birds of Western Europe and North America are incomparably better known than those of Asia. We can cite here only a few examples of Asian Paleogene birds with apparent relatives from other areas.

Eogrus, from the upper Eocene and lower Oligocene of Asia, appears to bear some resemblance to the genus Palaeogrus from the middle Eocene to early Miocene of Europe. Cygnavus formosus from the lower Oligocene of eastern Kazakhstan is comparable to $C$. senckenbergi Lambrecht from the lower Miocene of West Germany. The middle Oligocene forms of Cygnopterus from central and eastern Kazakhstan are close to Cygnopterus affinis (Van Beneden) from the middle Oligocene of Belgium. The genus Agnopterus, known from the middle Oligocene of Central Kazakhstan (Tugarinov, 1940) is represented in the upper Eocene of England and France by two other species. Aquilavus, represented by new material from the middle Oligocene of Kazakhstan, is widely represented by several species in Western Europe that range from upper Eocene to lower Miocene. An undescribed middle Oligocene loon from Central Kazakhstan may prove to be referable to the genus Colymboides, the two other species of which are known in the upper Eocene of England and the lower Miocene of France.

\section{The Families Eogruidae and Ergilornithidae in Asia}

Of special interest is the evolutionary history of the gruiform families Eogruidae and Ergilornithidae in the Tertiary of Asia. The collections

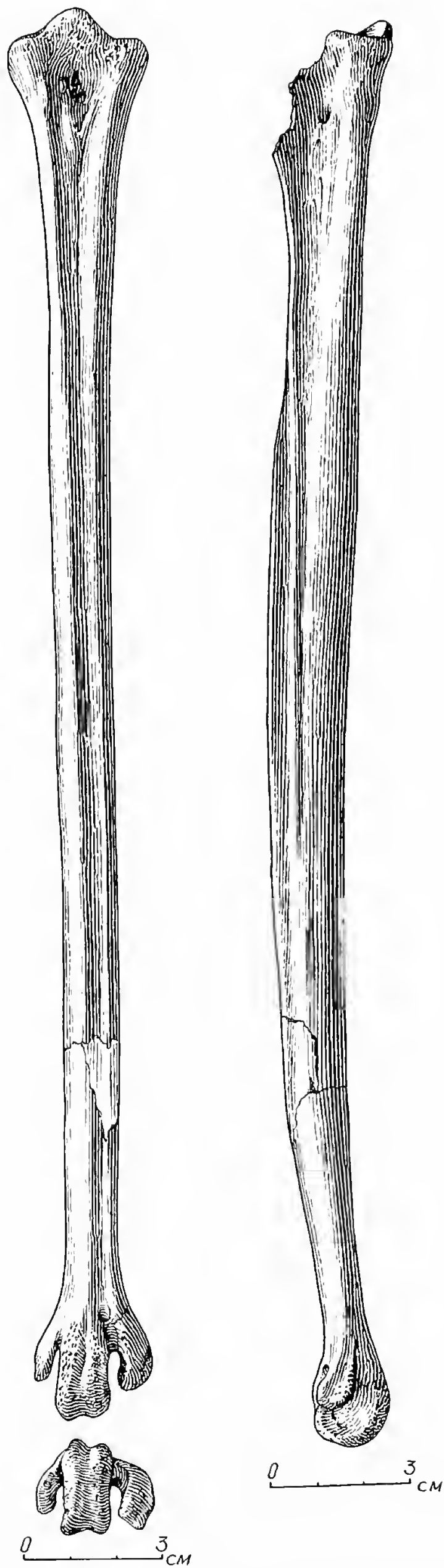

FIgURE 2.-Left tarsometatarsus (PIN 3109-125) of Proergilornis minor Kozlova, 1960; lower Oligocene, Ergelyeen Dzo: anterior, medial, and distal views. (Reduced.) 
from the early Oligocene site at Khoer Dzan are of particular importance in this regard.

A complete tarsometatarsus of Proergilornis minor Kozlova (1960) from Ergelyeen Dzo (Figure 2) was used for comparison with 15 fragments of tarsometatarsi of Eogruidae (PIN 3110-59, 3110-101-113, 3110-172) and 22 fragments of tarsometatarsi of Ergilornithidae (PIN 3110-54, 3110-55, 3110-70-76, 3110-88-100) from Khoer Dzan. These collections also include 9 distal ends of tibiotarsi of Eogruidae (PIN 3110-77-85) and 9 of Ergilornithidae (PIN 3110-64-67) (Figure 3). Unfortunately, no proximal ends of this bone were recovered.

All of the eogruid hindlimb elements from Khoer Dzan are readily attributable to the genus Eogrus, although they exhibit several characters distinguishing them from Eogrus aeola of the late Eocene of Inner Mongolia and E. wetmorei from the Miocene deposits of Tung Gur. It should be noted that the remains of Eogrus from Khoer Dzan are easily separable into two size groups. Quite arbitrarily, we identified several other bones (phalanges 1 and 2 of pedal digit III and a fragment of femur) as belonging to Eogrus.

The remains of both Proergilornis minor and Ergilornis sp. from Khoer Dzan also fall readily into two groups differing in size. As with Eogrus, these differences are detectable in the tibiotatarsi, tarsometatarsi, and phalanges. In the absence of any structural differences between the corresponding bones of the two size groups, we have every reason to believe that there were significant sexual differences in size in the species of Ergilornithidae.

In examining numerous limb bones belonging to Ergilornithidae and Eogruidae we experienced considerable difficulty in distinguishing specimens of one family from those of the other. It seems desirable therefore to detail here the structural differences in the distal end of the tibiotarsus and in the tarsometatarsus that separate the two families (Table 1). In making our comparisons we used Kozlova's original specimens of Proergilornis and Ergilornis in the collection of the Paleontological Institute of the U.S.S.R. Academy of Sciences, casts of the type-material of Eogrus aeola Wetmore (1934) and E. wetmorei Brodkorb (1967), obtained from the American Museum of Natural History, and the referred material of Eogrus aeola from Irdin Manha, also in the collection of the Paleontological Institute.
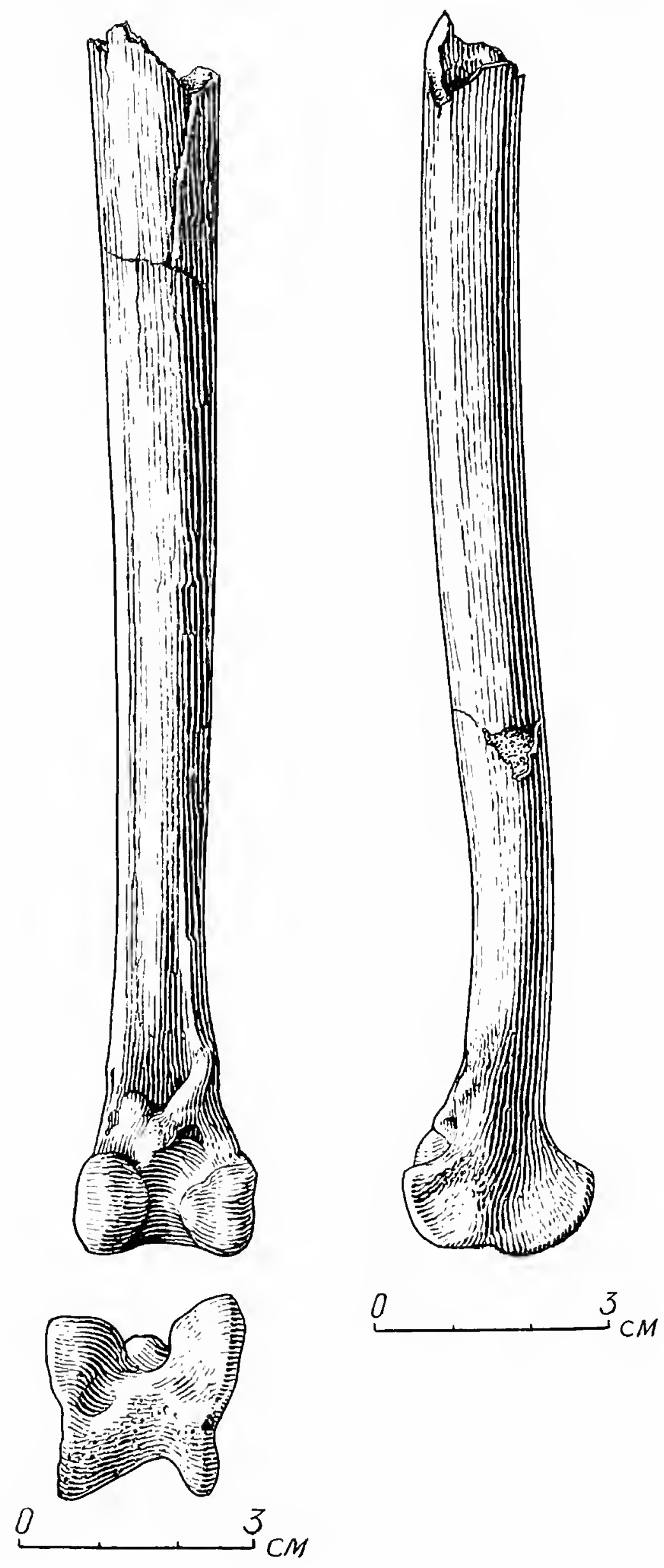

FIGURE 3.-Distal portion of right tibiotarsus (PIN 3110-64) of Ergilornithidae genus indet.; lower Oligocene, Khoer Dzan: anterior, medial, and distal views. (Natural size.) 
Table 1.-Comparisons of the hindlimb of the Eogruidae and Ergilornithidae

\begin{tabular}{|c|c|}
\hline EOGRUIDAE & ERGILORNITHIDAE \\
\hline \multicolumn{2}{|c|}{ DISTAL END OF TIBIOTARSUS } \\
\hline $\begin{array}{l}\text { Posterior edge of internal condyle on the } \\
\text { same level with anterior edge } \\
\text { Inner tuberculum fixatum closer to outer } \\
\text { edge }\end{array}$ & $\begin{array}{l}\text { Posterior edge of internal condyle slopes } \\
\text { distally } \\
\text { Inner tuberculum fixatum on mid-line }\end{array}$ \\
\hline $\begin{array}{l}\text { Anterior part of external condyle flattened } \\
\text { laterally }\end{array}$ & $\begin{array}{l}\text { Anterior part of external condyle with lat- } \\
\text { eral swelling }\end{array}$ \\
\hline Internal ligamental prominence small & Internal ligamental prominence large \\
\hline Distal end narrow relative to shaft & Distal end wide relative to shaft \\
\hline \multicolumn{2}{|c|}{ PROXIMAL END OF TARSOMETATARSUS } \\
\hline External cotyla round & External cotyla oval \\
\hline $\begin{array}{l}\text { Hypotarsus with broad plantar surface and } \\
\text { three tendinal grooves }\end{array}$ & $\begin{array}{l}\text { Hypotarsus with narrow plantar surface and } \\
\text { no traces of tendinal grooves }\end{array}$ \\
\hline \multicolumn{2}{|c|}{ DISTAL END OF TARSOMETATARSUS } \\
\hline $\begin{array}{l}\text { Middle trochlea relatively large, with parallel } \\
\text { lateral surfaces }\end{array}$ & $\begin{array}{l}\text { Middle trochlea relatively small with lateral } \\
\text { surfaces widening distally }\end{array}$ \\
\hline Outer trochlea closer to middle trochlea & Outer trochlea set farther laterally \\
\hline $\begin{array}{l}\text { In posterior view, groove between inner and } \\
\text { outer trochleae located more proximally } \\
\text { in relation to groove between middle and } \\
\text { outer trochleae }\end{array}$ & $\begin{array}{l}\text { Groove between inner and middle trochleae } \\
\text { on same level or ending farther distally in } \\
\text { relation to groove between middle and } \\
\text { outer trochleae }\end{array}$ \\
\hline
\end{tabular}

In the development of the plantar crest on the shaft of the tarsometatarsus, the specimens of Eogrus from Khoer Dzan are intermediate between Eogrus aeola and the Ergilornithidae, thus tending to bridge the differences between the two groups.

Apart from tibiotarsi and tarsometatarsi, the collections from Khoer Dzan include 28 pedal phalanges belonging to the Ergilornithidae, although it has not been possible to assign these phalanges to a particular genus. These phalanges are short and flat and are virtually identical to those found in association with a tarsometatarsus of the Pliocene genus Urmiornis. Figure 4 shows the basal phalanges of digit III as reconstructed from elements belonging to different individuals. The phalanges of digit IV are also present and are easily distinguishable by their shorter length, while certain others we have rather arbitrarily identified as those of digit II. It appears that digit I had been completely lost in the Ergilornithidae. Because the ergilornithids were large and had massive hindlimbs with reduced toes and flattened phalanges well adapted for running, it was natural to suggest that they might have been flightless. This supposition was borne out when a proximal end of humerus (PIN 3110-60) of a bird in which the locomotor function of the wing had obviously been lost (Figure 5) was found at Khoer Dzan. This specimen represents the second fragment of
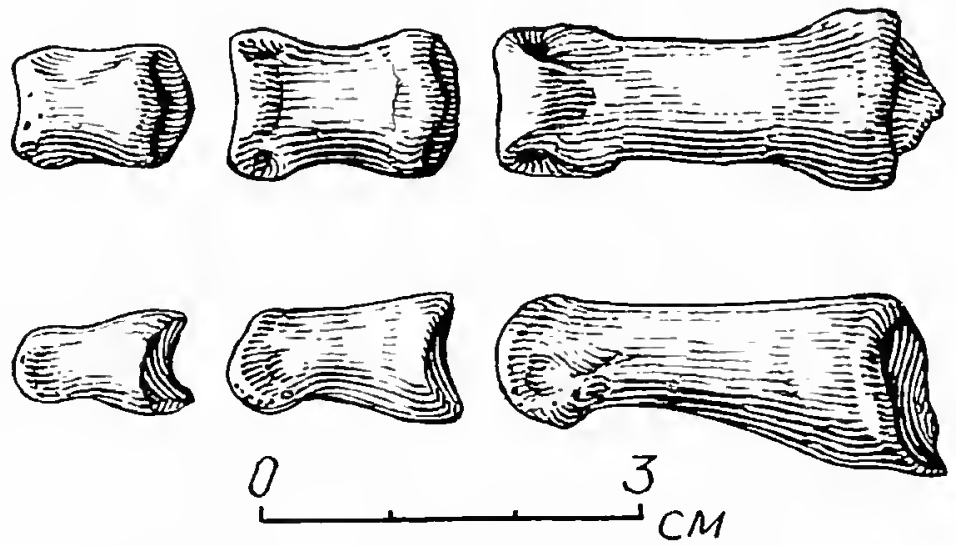

Figure 4.-Basal phalanges of pedal digit III (PIN 3110-61, 62, 63) of Ergilornithidae genus indet.; lower Oligocene, Khoer Dzan: dorsal and lateral views. (Natural size.) 

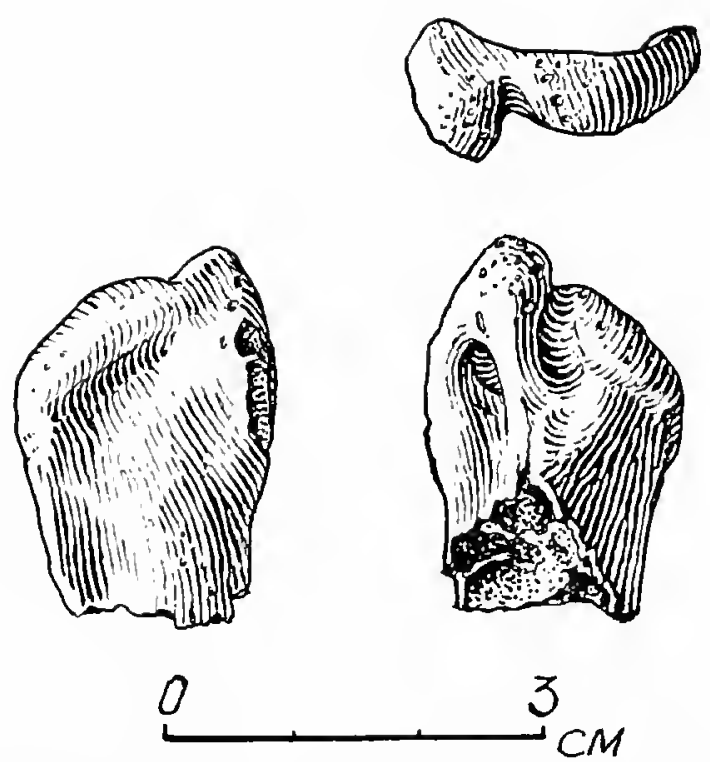

FIGURE 5.-Proximal end of right humerus (PIN 3110-60) of Ergilornithidae genus indet.; lower Oligocene, Khoer Dzan: palmar, anconal, and proximal views. (Natural size.)

its kind, the first, which was found a day earlier, being lost soon after its discovery. This humerus has been so modified through structural degeneration that there is little basis for comparing it with Recent Gruiformes. Nevertheless, we suggest that this fragment is referrable to the Ergilornithidae. It is characterized by general dorsoventral flattening, a markedly reduced and distally sloping head, the complete absence of a deltoid crest and ligamental furrow, and a weakly developed bicipital surface.

We can compare this humeral fragment with the humerus of Strigops habroptilus (Psittacidae), a completely unrelated bird whose ability to fly has been completely lost. Parallelism in the process of reduction is quite evident in both. The humerus of Strigops is similarly characterized by the elongated and flattened proximal end and reduced head and ligamental groove. In the ergilornithid humerus from Khoer Dzan the process of reduction was much farther advanced, however.

The collection from Khoer Dzan also contains a phalanx 1 of digit I of the wing (PIN 3110-163) which is characterized by its swollen structure and its shortened and rounded distal apex. We suggest that it also belongs to the Ergilornithidae.

The question of the nature of the relationship between Proergilornis and Ergilornis naturally arises. The present author is inclined to share Kozlova's (1960) assertion that there is considerable reason to regard these two genera as independent. The complete tarsometatarsus from
Ergelyeen Dzo (PIN 3109-125) belongs to Proergilornis minor (Figure 2). The tarsometatarsi from Khoer Dzan also belong to this species, the only exception being PIN 3110-55, which belongs to Ergilornis rapidus. The fossils were obtained from sediments belonging to two different levels formed at different periods of time, though their accumulation took place within the framework of one and the same sedimentary cycle of the early Oligocene. Presently these two levels are separated by a section 10-15 $\mathrm{m}$ thick. In Shuvalov's Hills, most of the fossils were collected from the lower level, which was composed of a white mass of oligomict sand and clay. Only the tarsometatarsi of Proergilornis minor were represented in this layer. The upper level, an ocherous mass of sands and gravels of polymict composition, contained only five avian bones: a tarsometatarsus of Ergilornis rapidus, a tarsometatarsus of Proergilornis minor, two phalanges referable to the Ergilornithidae and Eogruidae, and a gruiform cervical vertebra. No definite inferences could be made from this material. Nevertheless, it ought to be kept in mind that the numerous bones from the lower level represented a single genus only, whereas the few specimens from the upper level represent two genera.

The question of the possible ancestor of the Ergilornithidae now arises. Our comparative studies suggest that this ancestor may be found in the Eocene forms of the Eogruidae. The structure of the hindlimb elements of the early Oligocene representatives of the two groups exhibit a rather close resemblance, both in overall appearance and in details. If we take into consideration that in the Eocene the Eogruidae exhibit a tendency toward reduction of the inner toe (first noted by Wetmore, 1934), as well as toward development of a sagittal crest on the tarsometatarsus and a medial fixing nodule on the distal end of tibiotarsus, we may suggest that the Eocene Eogruidae were the original members of the lineage leading to the Ergilornithidae. At a later stage these two families were developing in parallel, as is evident from their mutual occurrence in the lower Oligocene of Khoer Dzan, as well as from the presence of Eogrus wetmorei in the Miocene at Tung Gur (Brodkorb, 1967).

The appearance of the flightless didactylous Ergilornithidae in early Oligocene time correlates well with the general trends observed in the to- 
pography, climate, and vertebrate fauna in the transition from the late Eocene to the early Oligocene (Flerov, et al., 1974). This period was characterized by a complete disappearance of contacts between the faunas of Asia and America, an intensive development of open landscapes, and the advent of various groups of Artiodactyla and Perissodactyla that later underwent further development on the vast arid open areas of Asia, Europe, and Africa. Under such circumstances the appearance of the flightless cursorial Ergilornithidae may be considered as a natural product of gruiform evolution.

The Neogene descendant of the Paleogene ergilornithids is Urmiornis, which was described for the first time from a lower Pliocene site at Maragha, Iran (Mecquenem, 1925). Later, remains of representatives of this genus were found in the U.S.S.R. in the southern part of the Ukraine and Moldavia (Burchak-Abramovich, 1951). Additional specimens have been reported from other localities in the Ukraine and Caucasus and also from middle Pliocene deposits (Bendukidze, 1972; Umanskaja, 1973). The collections of the Palento- logical Institute of the U.S.S.R. Academy of Science also contain representative material of Urmiornis from the middle Pliocene at Kalmakpai in the Zaisan basin, East Kazakhstan, and several fragments from the middle Pliocene locality at Khirgis Nur in the Great Lakes Valley, Mongolia. Evidently, Urmiornis was very common in both the lower and middle Pliocene, throughout the entire range of the Hipparion Fauna. Comparisons of the original material of the Ergilornithidae with Urmiornis leaves no doubt as to the affinity between these didactylous gruiform birds, as the structure of their limb bones is very similar. Brodkorb (1967) was quite correct in placing Urmiornis in the family Ergilornithidae. A direct phylogenetic link between the Oligocene ergilornithids and the Pliocene Urmiornis can no longer be doubted.

Thus, a distinct phylogenetic line of Asian gruiforms that survived at least up to the middle Pliocene may be traced through the Tertiary as follows: Eogrus (Late Eocene), Ergilornis and Proergilornis (early Oligocene), Urmiornis (lower and middle Pliocene).

\section{Literature Cited}

Aubekerova, P. A.

1965. Novye dannye ob iskopaemykh ptitsach Kazakhstana. In Novosti ornitologii, Alma-Ata, 18-19. [In Russian.]

Belaeva, E. I., B. A. Trofimov, and V. J. Reshetov

1974. Osnovnye etapy evolutsii mlekopitajutshikh v pozdnem mezozoe-paleogene Tsentralnoj Asii. In Sovmestnaja Sovetsko-Mongolskaja paleontologicheskaja ekspeditsija, trudy, I:19-45 [In Russian.]

Bendukidze, O. G.

1971. Novyj predstavitel' semeistva Geranoididae (Aves, Gruiformes) iz eotsenovykh otlozhenij Zaisan. Soobtzhenija Akademii nauk Gruzinskoj SSR, 63 (3):749-751, 1 figure. [In Russian.]

1972. O nakhodke Urmiornis maraghanus Mecq. na Severnom Kavkaze. Soobtzhenija Akademii nauk Gruzinskoj SSR, 66(3):741-743, 1 figure. [In Russian.]

Brodkorb, $\mathbf{P}$.

1967. Catalogue of Fossil Birds, Part 3 (Ralliformes, Ichthyornithiformes, Charadriiformes). Bulletin of the Florida State Museum, Biological Sciences, $11(3): 99-220$.

Burchak-Abramovich, N. I.

1951. Urmiornis (Urmiornis maraghanus Mecq.) strausopodobnaja ptitsa gipparionovoj fauny Zakavkasja i
Juzhonoj Ukrainy. Izvestija Akademii nauk Azerbajdzhanskoj SSR, 6:83-94, 1 figure. [In Russian.]

1958. Tretichnye ptitsi SSSR. Uchenye zapiski Azerbajd. zhanskogo Gosudarstvennogo Universiteta imeni Kirova, Serija Biologija, 1:81-88, 3 figures. [In Russian.]

Efremov, I. A.

1954. Paleontologischeskie issledovanija v Mongolskoj Narodonoj Respublike (predvaritelnye resultaty ekspeditsii 1946, 1948 i 1949 gg.). Trudy Mongolskoj komissii, 50:3-32. [In Russian.]

Flerov, K. K.

1961. K voprosu o biologicheskoj i paleozoogeograficheskoj kharakteristike indricoterievoi fauny. Paleontologicheskij zhurnal, 1:12-22. [In Russian.]

Flerov, K. K., E. I. Belaeva, N. M. Janovskaja, A. A. Gureev, I. M. Novodvorskaja, V. S. Kornilova, N. S. Schevyreva, E. N. Kurochkin, V. V. Zherichin, V. M. Tchikvadze,

G. G. Martinson, N. V. Tolstikova, A. L. Chepalyga, and L. I. Fotjanova

1974. Zoogeografija paleogena Asii. Volume 146 in Trudy paleontologicheskogo instituta Akademii Nauk SSSR. 302 pages, 162 figures, 4 plates. Moscow: Izdatel'stvo Nauka. [In Russian.] 
Gradzińsky, R., J. Kazmierczak, and J. Lefeld

1968. Geological Data from the Polish-Mongolian Palaeontological Expeditions. Palaeontologica Polonica, 19:33-82.

Gureev, A. A.

1949. Pervaja nakhodka ptitsy v nizhnem paleogene SSSR. Doklady Akademii nauk SSSR, 64(2):249-251, 1 figure. [In Russian.]

Hekker, R. F., A. I. Osipova, and T. N. Belskaja

1962. Ferganskij zaliv paleogenovogo morja Srednej Asii, Kniga I. 332 pages, 89 figures, 22 plates. Moscow: Izdatel'stovo Akademii nauk SSSR. [In Russian.]

Klebanova, I. M.

1965. Novoe mestonakhozhdenie sredneoligotsenovikh mlekopitajutshchikh $\mathrm{v}$ urochishche Kyzyl-Kak. Paleontologicheskij Zhurnal, 4:99-102. [In Russian.]

Kozlova, E. V.

1960. Novye iskopaemye ptitsy iz jugo-vostochnoj Gobi. Trudy Problemnykh $i$ Tematicheskikh Soveshchanii Akademija Nauk SSSR, Zoologicheskij Institut 9: 323-329. [In Russian.]

Kurochkin, E. N.

1968a. Iskopaemye ostatki ptits iz Mongolii. Ornitologija, 9:323-330, 4 figures. [In Russian.]

1968b. Novye oligotsenovye ptitsi Kazakhstana. Paleontologicheskij Zhurnal, 1:92-101, 5 figures. [In Russian].

1969. Novoe nazvanie dlja roda Tutor Kurochkin, 1968. Paleontologicheskij Zhurnal, 2:122. [In Russian.]

1974. Obzor paleogenovykh ptits Azii. Ornitologija, 11: 317-328, 1 figure. [In Russian].

Kurochkin, E. N., and A. N. Lungu

1970. Novyj straus iz srednego sarmata Moldavii. Paleontologicheskij Zhurnal, 1:118-126, 2 figures, 1 plate. [In Russian.]

Lambrecht, K.

1931. Protoplotus beauforti n.g. n.sp., ein Schlangenhalsvogel aus Tertiär von W.-Sumatra. Dienst van den Mijnbouw in Nederlandsch-Indië, Wetenschappelijke Mededeelingen, 17:15-24, 3 plates.

Mecquenem, $\mathbf{R}$.

1925. Contribution a l'étude des fossiles de Maragha [continuation from 1924]. Annales de Paléontologie, 15(1):26-36.
Mellett, J. S.

1968. The Oligocene Hsanda Gol Formation, Mongolia: A Revised Faunal List. American Museum Novitates, 2318:1-16.

Novozhilov, N. I.

1954. Mestonakhozhdenie mlekopitajuschchikh nizhnego eotsena i verkhnego Paleotsena Mongolii. Trudy Mongol'skoj komissii, 59:33-46. [In Russian.]

Olson, S. L.

1974. Telecrex Restudied: A Small Eocene Guineafowl. Wilson Bulletin, 86(3):246-250, 3 figures.

Shishkin, M. A.

1975. Stratigrafija i tafonomija verkhnepaleotsenovogo mestonakhozhdenija pozvonochnikh Naran-Bulak (Juzhnaja Gobi, MNR). Sovmestnaja SovetskoMongolskaja paleontologicheskaja ekspeditsija, trudy, 2:225-244. [In Russian.]

Shuvalov, V. F., V. J. Reshetov, and R. Barsbold

1974. O stratotipicheskom razreze nizhnego paleogena na jugo-zapade MNR. Soumestnaja Sovetsko-Mongolskaja paleontologicheskaja ekspeditsija, 1:60-71. [In Russian.]

Szalay, F. S., and M. C. McKenna

1971. Beginning of the Age of Mammals in Asia: The Late Paleocene Gashato Fauna, Mongolia. Bulletin of the American Museum of Natural History, 144(4):269-318.

Teilhard de Chardin, $\mathbf{P}$.

1926. Description des Mammiferes Tertiares de Chine et de Mongolie. Annales de Paléontologie, 15:1-52.

Tugarinov, A. J.

1940. Novye dannye dlja tretichnoj ornitofauny SSSR. Doklady Akademii nauk SSSR, 23(3):314-316, 2 figures. [In Russian].

Umanskaja, A. S.

1973. Novaja nakhodka ostatkov urmiornisa iz neogenovikh otlozhenij Ukrainy. Vestnik Zoologii, 4:30-33, 1 figure. [In Russian.]

Wetmore, A.

1934. Fossil Birds from Mongolia and China. American Museum Novitates, 711:1-16, 6 figures. 


\title{
The World's Oldest Owl: A New Strigiform from the Paleocene of Southwestern Colorado
}

\author{
Pat Vickers Rich and David J. Bohaska
}

\begin{abstract}
Among the fossils recovered from a small, midPaleocene fissure filling in southwestern Colorado is the oldest known owl, Ogygoptynx wetmorei, new genus and species. This form, represented by a single tarsometatarsus, does not clearly belong in any of the known families of Strigiformes and may represent a new higher category of owls that provides a link between the Strigidae and the Tytonidae.
\end{abstract}

\section{Introduction}

In 1916, Walter Granger, following up the exploratory work of J. W. Gidley, examined sediments around Tiffany in southwestern Colorado and located several fossil-bearing areas that produced a moderately diverse mammalian fauna (Simpson, 1935). This assemblage became important in the definition of a North American land mammal age, the Tiffanian (Wood, et al., 1941). Among the bones found by Granger was a small avian tarsometatarsus. The following paper describes this fossil and considers its relationships.

Acknowledgments.-Thanks are due Mr. Earl Manning, who first recognized the avian affinities of Ogygoptynx, to Dr. Malcolm C. McKenna, American Museum of Natural History (AMNH), for allowing us to borrow the specimen for study, and Ms. Charlotte Holton for arranging the loan. Comparative material of the living genus Phodilus was kindly furnished by Dr. Ned K. Johnson, Mu-

Pat Vickers Rich and David J. Bohaska, Geosciences Department, Texas Tech University, Lubbock, Texas 79409. seum of Vertebrate Zoology, University of California, Berkeley. The photographs and chart were prepared by Lloyd Logan and Robert Suddartha. Sincere thanks are also due Dr. Don E. Russell, Institut de Paléontologie, Museum National d'Histoire Naturelle, Paris (PM) for lending the European Paleogene owls briefly surveyed in this paper and presently under more extensive study. The manuscript was read by Hildegarde Howard and typed by Carol Baldwin.

\section{Order STRIGIFORMES}

\section{Family incertae sedis}

\section{Ogygoptynx, new genus}

Type-Species.-Ogygoptynx wetmorei, new species.

Distribution.-Known only from the Tiffanian (mid-Paleocene) of Colorado.

Diagnosis.-See Table 1.

Characters differing from the Strigidae but similar to the Tytonidae (including the Phodilinae): tarsometatarsus lacking a supratendinal bridge on the proximal end (three strigids also lack this bridge; Ford, 1967); posterior metatarsal groove not separated from the proximal articular surface by a marked bony ledge; anterior metatarsal groove deep across the entire width of the shaft at the proximal end.

Characters differing from the Phodilinae and Strigidae but resembling the Tytoninae: tarsometatarsus elongate and slender; posterior metatarsal groove only slightly excavated, lacking a lateral wall near the proximal end.

Characters resembling the Phodilinae and inter- 
TABLE 1.-Comparison of the tarsometatarsus in Ogygoptynx with several families and subfamilies of owls

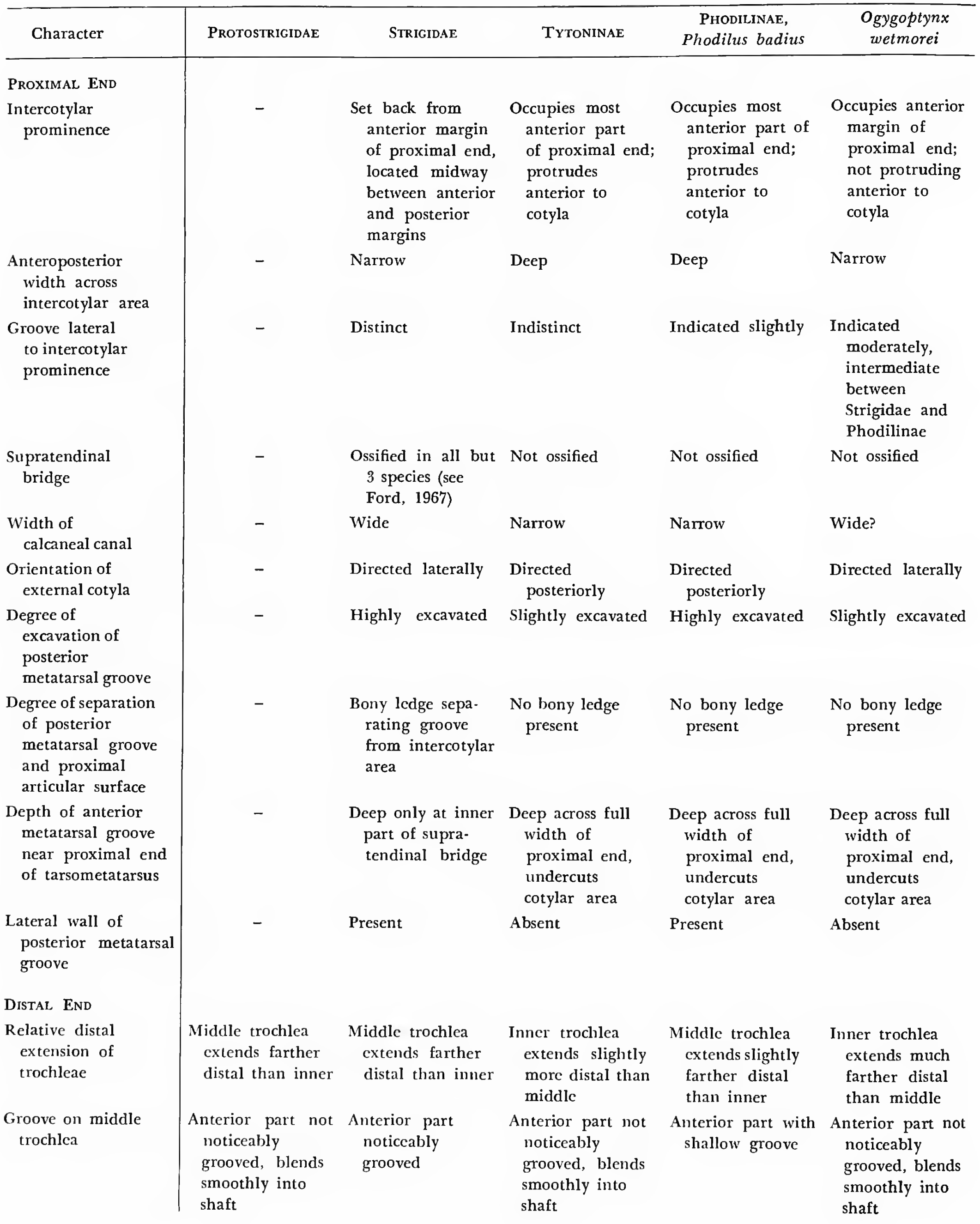


TABLE 1.-Continued

\begin{tabular}{|c|c|c|c|c|c|}
\hline Character & ProtostrigIDAE & StrigidaE & TytoninaE & $\begin{array}{c}\text { Phodilinae, } \\
\text { Phodilus badius }\end{array}$ & $\begin{array}{l}\text { Ogygoptynx } \\
\text { wetmorei }\end{array}$ \\
\hline $\begin{array}{l}\text { Shape of outer } \\
\text { trochlea in } \\
\text { lateral view }\end{array}$ & $\begin{array}{l}\text { Distal margin } \\
\text { highly rounded }\end{array}$ & $\begin{array}{l}\text { Distal margin } \\
\text { flattened or } \\
\text { slightly grooved }\end{array}$ & $\begin{array}{l}\text { Distal margin } \\
\text { strongly grooved }\end{array}$ & $\begin{array}{l}\text { Distal margin } \\
\text { strongly grooved }\end{array}$ & $\begin{array}{l}\text { Distal margin } \\
\text { moderately } \\
\text { rounded }\end{array}$ \\
\hline $\begin{array}{l}\text { Curvature across } \\
\text { trochleae in } \\
\text { distal view }\end{array}$ & $\begin{array}{l}\text { Highly curved; } \\
\text { channel created } \\
\text { by such } \\
\text { curvature deep; } \\
\text { outer trochlea } \\
\text { only slightly } \\
\text { curved (medially } \\
\text { concave) }\end{array}$ & $\begin{array}{l}\text { Moderately } \\
\text { curved; channel } \\
\text { created by such } \\
\text { curvature } \\
\text { shallow; outer } \\
\text { trochlea moder- } \\
\text { ately curved }\end{array}$ & $\begin{array}{l}\text { Highly curved; } \\
\text { channel created } \\
\text { by such } \\
\text { curvature deep; } \\
\text { outer trochlea } \\
\text { highly curved }\end{array}$ & $\begin{array}{l}\text { Moderately } \\
\text { curved; channel } \\
\text { created by such } \\
\text { curvature deep; } \\
\text { outer trochlea } \\
\text { highly curved }\end{array}$ & $\begin{array}{l}\text { Highly curved; } \\
\text { channel created } \\
\text { by such } \\
\text { curvature deep; } \\
\text { outer trochlea } \\
\text { only slightly } \\
\text { curved }\end{array}$ \\
\hline \multicolumn{6}{|l|}{ GENERAL } \\
\hline $\begin{array}{l}\text { Proportions of } \\
\text { tarsometarsus }\end{array}$ & - & $\begin{array}{l}\text { Variable, generally } \\
\text { short, stout }\end{array}$ & Elongate, slender & Short, stout & Elongate, slender \\
\hline
\end{tabular}

mediate between the Strigidae and Tytoninae: shallow groove slightly lateral to the intercotylar prominence.

Characters differing from the Tytonidae but resembling the Strigidae: intercotylar area shallow anteroposteriorly, due in part to the intercotylar prominence not protruding anterior to cotylar margins; distal margin of outer trochlea in lateral view flattened and only slightly rounded, not grooved; outer trochlea in lateral view only slightly curved.

Characters differing from the Protostrigidae: distal margin of outer trochlea in lateral view flattened and only slightly, rather than greatly, rounded.

Characters within the Strigiformes unique to Ogygoptynx: proximal end in lateral view shaped like a parallelogram with unequal angles, not rectangular; outer trochlea in distal view not smoothly rounded but slightly grooved laterally, not tapering to a point but broadened posteriorly; anterior portion of shaft just proximal to middle trochlea elevated farther anteriorly than the remainder of the shaft, but distal portion of shaft medial to this region markedly planar and not rounded; inner trochlea decidedly more elongate than middle trochlea.

ETymology.-From Greek, Ogyges, mythical king of Thebes, suggesting ancient or primeval, and ptynx, an owl.

\section{Ogygoptynx wetmorei, new species}

\section{F1GURES 1, 2}

HoLotype.-Nearly complete right tarsometatarsus, AMNH 2653, missing only a small part of the calcaneal ridge and possibly some of the midshaft.

Type-Locality and Stratigraphic Position.Mason Pocket near old Mason schoolhouse, northern drainage slope of the San Juan River, 6.5 to 8 $\mathrm{km}$ north of Tiffany, Section 20, T33N, R6W, La Plata County, southwestern Colorado. Found in "a small pocket of gray shale imbedded in a stratum of mottled purplish and brownish clay," which has been thought by some workers to be a fissure filling of some type. "Tiffany Beds," Tiffanian, midPaleocene in age (Simpson, 1935).

Diagnosis.-As for the genus.

MeAsurements.-Maximum width of proximal end, $9.0 \mathrm{~mm}$; maximum depth of external cotyla, 4.9 ; maximum depth of internal cotyla, 5.1; maximum length from intercotylar prominence to distal end of attachment of tibialis anticus, 13.8; maximum width of distal end, 9.4; maximum width of inner trochlea, 4.2; maximum width of middle trochlea, 3.7; depth of internal border of inner trochlea, 3.2; depth of external border of inner trochlea, 3.6; depth of internal border of middle trochlea, 3.5; depth of external border of middle 

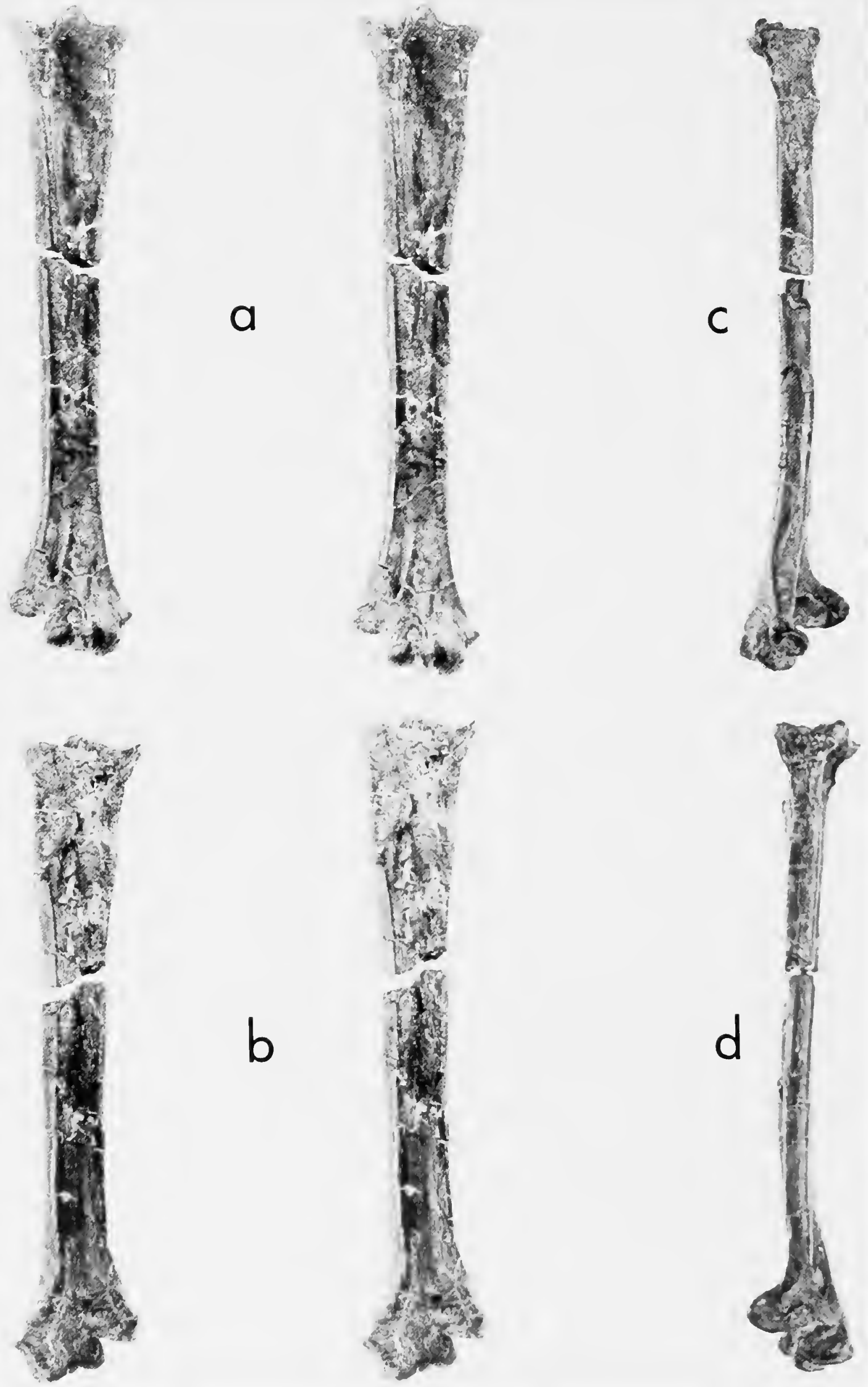

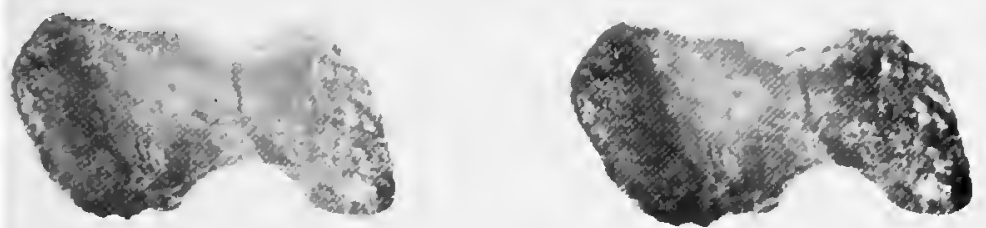

a
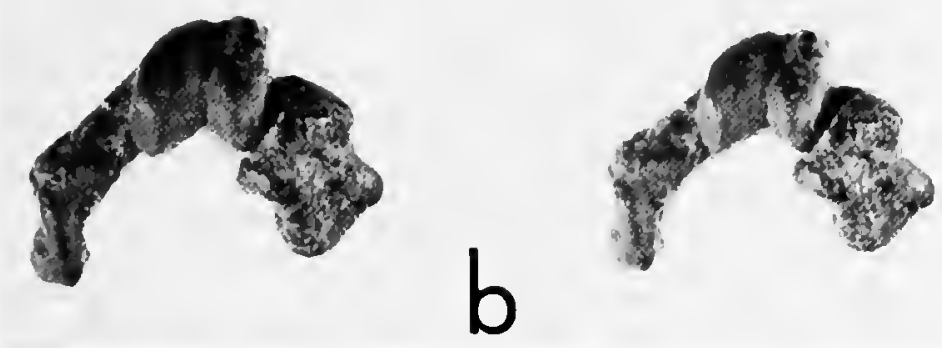

FIGURE 2.-Ogygoptynx wetmorei, new genus and species, stereo pairs of holotype right tarsometatarsus (AMNH 2653): $a$, proximal view; $b$, distal view. ( $\times 3$.)

trochlea, 3.9; depth of external border of outer trochlea, 4.0; overall length from intercotylar prominence to distal end of inner trochlea, at least 48.2.

ETYMOLOGY.-Named in honor of Dr. Alexander Wetmore, who has done much to further the knowledge of fossil owls as well as other birds.

\section{COMPARISON With MOdern Strigiformes}

Ogygoptynx, known only from a tarsometatarsus, clearly belongs in the order Strigiformes as indicated by the broadly and deeply excavated anterior metatarsal groove; the single, slender calcaneal ridge; the shallow, narrow middle trochlea relative to the inner and outer trochleae; and the inner trochlea extending distally nearly as far as, or farther than, the middle trochlea.

Within the order, Ogygoptynx appears to be intermediate between the Tytonidae (including the Phodilinae; Ford, 1967) and the Strigidae, since it possesses a mosaic of character states of each of these families (Table 1).

One modern owl, Phodilus (subfamily Phodilinae), presently allocated to the Tytonidae (Ford, 1967), is to some degree a strigid-tytonid mosaic,

FIGURE 1.-Ogygoptynx wetmorei, new genus and species, holotype right tarsometatarsus (AMNH 2653): $a$, anterior view (stereo pair); $b$, posterior view (stereo pair); $c$, medial view; $d$, lateral view. ( $\times 2$.) but unlike Ogygoptynx, it is clearly most closely related to the Tytonidae. Strigid features seen in Phodilus include the deep proximal excavation of the posterior metatarsal groove, development of a lateral wall on the metatarsal groove near the proximal end, the moderately arched distal end, and the overall short, stout configuration of the tarsometatarsus. In most of its characters, however, Phodilus resembles the Tytonidae (Table 1), and thus, at least as evidenced by the tarsometatarsus, the allocation of Phodilus to the Tytonidae appears to be correct.

Because the tarsometatarsus of Ogygoptynx has such a mingling of strigid and tytonid character states, it cannot clearly be referred to any of the higher categories of modern Strigiformes.

\section{CoMPARISON WITH FossiL STRIGIFORMES}

The mid-Paleocene Ogygoptynx is the earliest known owl (Figure 3) and it is certain that by the early Eocene a number of other strigiforms had made their appearance in North America. Protostrix and Eostrix, in the family Protostrigidae, are known from a number of localities in the American West (Wetmore, 1938; Brodkorb, 1971; Martin and Black, 1972; Rich, unpublished data). The distal end of the tarsometatarsus is known for both genera and thus they may be compared directly with Ogygoptynx. Unfortunately, the proximal end of the tarsometatarsus is not known in any of the protostrigids. The smallest genus, Eostrix, closely approximates Ogygoptynx in size, but along with Protostrix it differs in the relative distal extension of the inner and middle trochleae, in the shape of the outer trochlea, and in lacking those character states unique to Ogygoptynx (see "Diagnosis"). It is difficult to assess the value of many of these unique character states due to the partial crushing of the type of $O$. wetmorei, as well as to our incomplete knowledge of the tarsometatarsus in the Protostrigidae.

A number of other fossil owls, previously classified in the Strigidae (Brodkorb, 1971), show a mixture of strigid and tytonid character states suggesting that they may bear some relationship to Phodilus and Ogygoptynx. Brodkorb (1970) erected the genus Paratyto for Bubo arvernensis Milne-Edwards, from the lower Miocene of France, placing it in the "Phodilidae" on the basis of its 


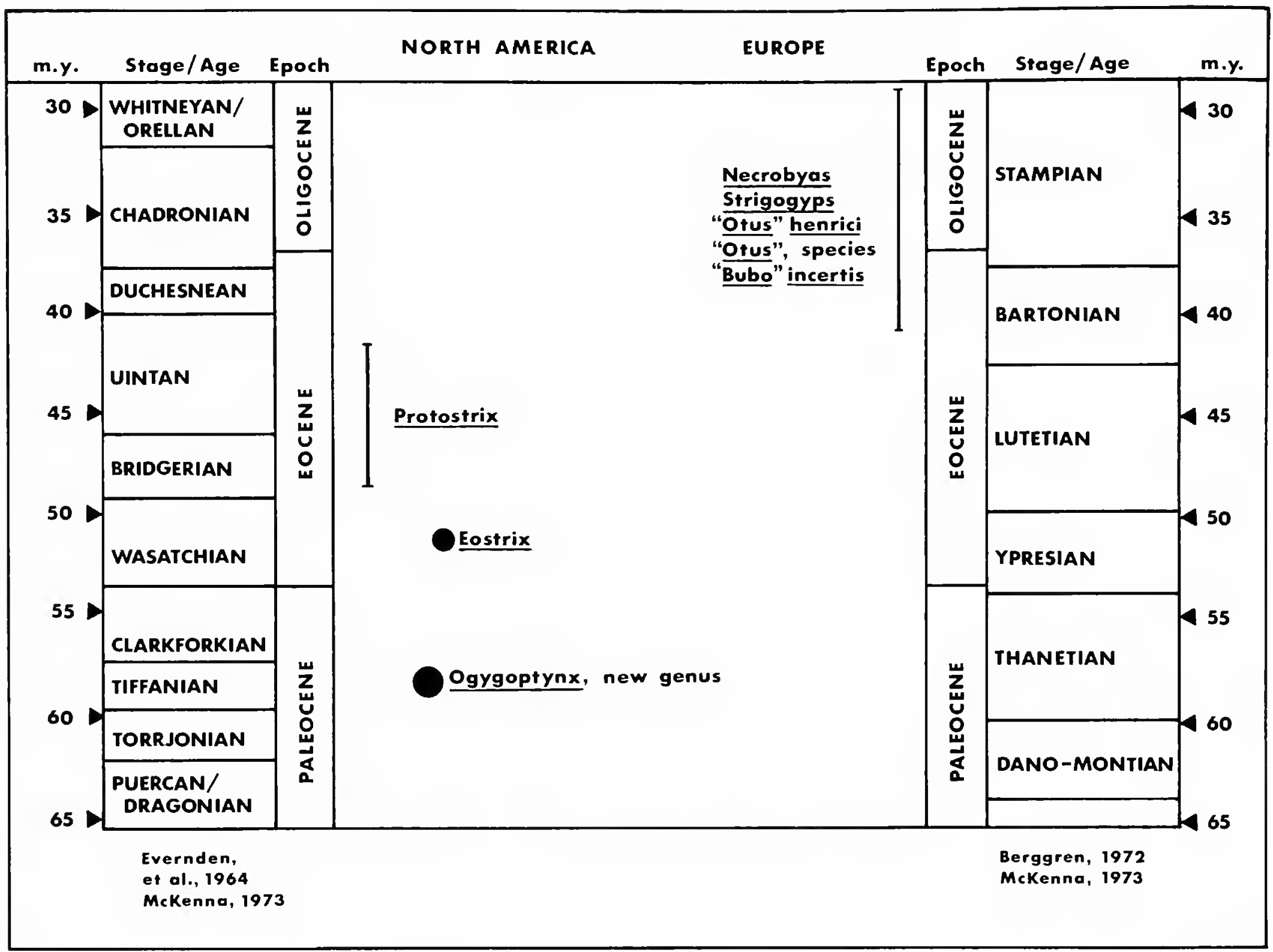

FIGURE 3.-Temporal distribution of early Tertiary owls.

lacking an ossified supratendinal bridge on the tarsometatarsus (as in the Tytoninae and Phodilinae) and on the stoutness of the tarsometatarsus (as in the Strigidae and Phodilinae). He did not mention, however, that three species of strigids also lack an ossified supratendinal bridge, nor did he discuss other characters useful in separating the Strigidae from the Tytonidae (including the Phodilinae). Thus, reexamination of Paratyto would be useful for determining whether it is a strigid or a phodiline.

At least four other European Tertiary owls (Figure 3), Necrobyas harpax, N. rossignoli, "Otus" henrici, and "Otus" sp. (PM 3120) (MilneEdwards, 1892), are based entirely or in part on tarsometatarsi that are stout and also lack an ossified supratendinal bridge. The tarsometatarsus of Ogygoptynx is narrower than in these owls, with $N$. harpax exhibiting proportions most similar to those of the new Paleocene form. Another tytonid character seen in the four European owls and Ogygoptynx is the lack of a ledge proximal to the posterior metatarsal groove on the tarsometatarsus. The calcaneal groove is narrow in the four $\mathrm{Eu}$ ropean owls, as in the tytonids, but is probably wide in Ogygoptynx, as in the strigids. In all of the above four species, the external cotyla points posteriorly, as in the Tytonidae, except in two specimens assigned to "Otus" henrici (PM 3117 and PM 3118) in which the cotyla points laterally as in the Strigidae and Ogygoptynx. The position of the intercotylar prominence in all four species is intermediate between that in the tytonids and strigids and very similar to that in Ogygoptynx. A fifth 
owl, Necrobyas edwardsi Gaillard (1908, 1939), from the Tertiary of France, also based on a tarsometatarsus, was unavailable for study.

Other possibly intermediate genera of owls include Prosybris Brodkorb (1970) and Lechusa Miller (1956). Prosybris, from the lower Miocene of France, is placed with the Tytonidae but has a somewhat stouter tarsometatarsus than Tyto; like Ogygoptynx, its external trochlea is elongate. Lechusa stirtoni, based on a coracoid from the Pliocene of San Diego, California, was classified by Miller (1956) as a tytonid, although both he and Wetmore (in Miller, 1956:620) noted several strigid characters in this form. Miller stated, however, that Lechusa was definitely not a phodiline. Direct comparison between Lechusa and Ogygo- ptynx is impossible because of the lack of corresponding elements.

An extensive review of the above-mentioned fossil forms and some other European fossil owls is needed before the interrelationships of these, as well as modern forms, can be interpreted.

Ogygoptynx, the oldest known owl, does not clearly belong in any of the presently established families within the order Strigiformes (Protostrigidae, Tytonidae, Strigidae) and may well be distinct enough to rate separate familial rank. Until a thorough revision of the early Tertiary European owls is completed, however, we will refrain from making any such designation and only point out the mosaic nature of this early owl.

\section{Literature Cited}

Berggren, W. A.

1972. A Cenozoic Time Scale-Some Implications for Regional Geology and Paleobiogeography. Lethaia, 5:195-215.

Brodkorb, $\mathbf{P}$.

1970. Two Fossil Owls from the Aquitanian of France. Quarterly Journal of the Florida Academy of Science, 32(2):159-160.

1971. Catalogue of Fossil Birds, Part 4 (Columbiformes through Piciformes). Bulletin of the Florida State Museum, Biological Sciences, 15(4):163-266.

Evernden, J. F., D. E. Savage, G. H. Curtis, and G. T. James

1964. Potassium-Argon Dates and the Cenozoic Mammalian Chronology of North America. American Journal of Science, 262:145-198.

Ford, N. L.

1967. A Systematic Study of the Owls Based on Comparative Osteology. Ph.D. dissertation, The University of Michigan, Ann Arbor. [University Microfilms $68-7595,128$ pages.]

Gaillard, C.

1908. Les oiseaux des phosphorites du Quercy. Annales de l'Université de Lyon, new series, l(23):1-178, 37 figures, 8 plates.

1939. Contribution à l'étude des oiseaux fossiles. Archives du Musee d'Histoire Naturelle de Lyon, 15(Mémoire 2):1-100, 34 figures.

Martin, L. D., and C. C. Black

1972. A New Owl from the Eocene of Wyoming. Auk, 89(4):887-888, 1 figure.
McKenna, M. C.

1973. K/Ar Recalibration of Eocene North American Land-Mammal "Ages" and European Ages. Geological Society of America Abstracts, 5(7):733.

Miller, L.

1956. A Collection of Bird Remains from the Pliocene of San Diego, California. Proceedings of the California Academy of Sciences, 28(16):615-621, 1 figure.

Milne-Edwards, A.

1892. Sur les oiseaux fossiles des dépots Eocénes du phosphate de chaux du sud de la France. Pages 60-80 in volume 2 of $2^{m e}$ Congrès Ornithologique International, Budapest, 1891, Partie Scientifique.

Simpson, G. G.

1935. The Tiffany Fauna, Upper Paleocene, I: Multituberculata, Marsupialia, Insectivora, and ?Chiroptera. American Museum Novitates, 795:1-19, 6 figures.

Wetmore, A.

1938. Another Fossil Owl from the Eocene of Wyoming. Proceedings of The United States National Museum, 85(3031):27-29, 2 figures.

Wood, H. E., 2nd, R. W. Chaney, J. Clark, E. H. Colbert, G. L. Jepsen, J. B. Reeside, Jr., and C. Stock

1941. Nomenclature and Correlation of the North American Continental Tertiary. Bulletin of the Geological Society of America, 52:1-48, 1 chart. 



\title{
Neanis schucherti Restudied: Another Eocene Piciform Bird
}

\author{
Alan Feduccia
}

\begin{abstract}
Neanis schucherti, an avian fossil from the lower Eocene Green River Formation of Wyoming, was described in 1913 under the genus Hebe by Shufeldt as the earliest representative of the order Passeriformes. The name Neanis has since been substituted for Hebe for reasons of priority. The specimen is here restudied and is found to be of piciform, not passeriform, affinity. It is assigned to the extinct Eocene family Primobucconidae. Of the two other previously described lower Eocene Piciformes, Primobucco kistneri Feduccia 1973 is reassigned to Neanis, while $P$. mcgrewi Brodkorb 1970 is retained in Primobucco, which genus is recognized by its larger size.
\end{abstract}

\section{Introduction}

The oldest North American avian fossil referred to the order Passeriformes and the only one assigned to the Neotropical family Rhinocryptidae (tapaculos) is Neanis schucherti (Shufeldt, 1913) from the lower Eocene Green River Formation of Wyoming. This fossil was first described under the generic name Hebe. Brodkorb (1965) substituted Neanis for Shufeldt's genus, which was preoccupied by Hebe Risso 1826 (Crustacea). The type of Neanis schucherti consists of a small slab and counterslab (YPM 1233) containing impressions of bone and feathers and some poorly preserved pieces of bone (Figures 1, 2). These were collected in 1874 by F. A. C. Richardson of the Powell Ex-

Alan Feduccia, Department of Zoology, University of North Carolina, Chapel Hill, North Carolina 27514. pedition. The original label reads: "Found five miles west of Green River City, Wyoming. In the fish cut of the R.R. . . Associated with insects described by Scudder." On the back of the label is the following inscription: "Compare Pteroptochidae; see Ibis, 1874, p. 191 (July), for sternum with 2 emarginations in sternum." The citation is to Sclater's (1874) paper on the tapaculos and it was no doubt the above inscription that led Shufeldt to place the fossil in the family Pteroptochidae (= Rhinocryptidae). He based this conclusion almost entirely on the presence of a four-notched sternum (i.e., with "2 emarginations" on each side), and on an alleged "large manubrium which is bifurcated anteriorly" (Shufeldt, 1913:647). I have recently had the opportunity to examine the type of Neanis schucherti, and I present here my conclusion that the affinities of Neanis are with the Piciformes rather than the Passeriformes.

Acknowledgments.-The loan of the type of Neanis schucherti was arranged through the kindness of Drs. Charles G. Sibley and John H. Ostrom of the Yale University Peabody Museum of Natural History (YPM). Dr. Paul O. McGrew of the University of Wyoming Department of Geology kindly lent the types of Primobucco mcgrewi and Primobucco kistneri. Skeletons of modern species were made available through the courtesy of Dr. Pierce Brodkorb (collection of Pierce Brodkorb), Dr. R. L. Storer (University of Michigan Museum of Zoology), and Dr. R. L. Zusi (National Museum of Natural History, Smithsonian Institution). I wish to thank Drs. Pierce Brodkorb, Larry D. Martin, and Helmut C. Mueller for their critical review of the manuscript. This work was supported by a grant from the University of North Carolina Research Council. 


\section{Description and Comparisons}

Two facts render the assignment of Neanis to the Rhinocryptidae questionable or suspect. First, the characters used in the identification, namely the presence of a four-notched sternum and a bifurcate manubrium (= forked spina externa of the sternum), are unique neither to the Rhinocryptidae nor the Passeriformes. Second, in recent years several primitive piciform birds have been described from the lower Eocene Green River Formation of Wyoming, the same horizon and locality from which Neanis was recovered. Piciform birds typically have a four-notched sternum and a forked spina externa. The Green River species Primobucco mcgrewi Brodkorb (1970) and Primobucco kistneri Feduccia $(1973)^{*}$ provide the earliest records of the order Piciformes. Among the structurally primitive piciform families, the Bucconidae has been used in the past to accommodate these lower Eocene zygodactyl birds, but they are now considered to merit their own family, the Primobucconidae, which also includes three middle Eocene genera (Feduccia and Martin, p. 101, herein).

The presence of a four-notched sternum is an unreliable taxonomic character even at the ordinal level. Both two- and four-notched sterna occur in many orders not related to the passerines and their allies (e.g., Ciconiiformes and Charadriiformes), and four-notched sterna are commonly found in certain coraciiform birds (e.g., rollers and kingfishers). All members of the Piciformes possess a four-notched sternum (Feduccia, 1972), and within the Passeriformes the four-notched sternum is found within the Formicariidae and Rhinocryptidae (Heimerdinger and Ames, 1967). I am able to confirm that Neanis schucherti does indeed possess a four-notched sternum although to determine this requires "very close and careful examination with a high-power lens" (Shufeldt, 1913:646). Shufeldt (1913:646) goes on to point out that "the sternum of [Neanis] differed in this particular from all typical existing passerines as they now occur in North America, at least north of Costa Rica."

In birds, the spina externa of the sternum may

\footnotetext{
* Misspelled "kisterni" in two places in the original ref ence.
}

be forked (as in most passerines) or a simple rod (as in most nonpasserines). Olson (1971) has examined the spina externa of the sternum and found it to be highly variable. It is typically forked (bifurcate) in the Passeriformes (exclusively so in the suborder Passeres) but within the "suboscines" an unforked spina externa occurs within the Eurylaimidae, Cotingidae, Philepittidae (Ames, 1971), and Dendrocolaptidae (Xiphocolaptes promeropirhynchus, (personal observation). However, Smithornis of the Eurylaimidae has a forked spina externa and within the Cotingidae the character is intragenerically variable in Procnias (Olson, 1971). Olson (1971:509) also points out that, "the forked versus simple spina externa is variable in other orders as well. In the Piciformes either conformation may be found in the Picidae, Capitonidae, Bucconidae and Galbulidae. The character is also variable in the Coraciiformes and Trogoniformes." Thus, perhaps the only taxonomic use of the nature of the spina externa would be to exclude forms with the simple, unforked spina externa from the suborder Passeres. In any case, I am unable to confirm the presence of a forked spina externa in Neanis schucherti. I have found the structure Shufeldt evidently intended (Figure 1), but the area is so crushed that some imagination is necessary to envision it as a bifurcate spina externa.

The two slabs containing the type of Neanis schucherti are illustrated in Figures 1 and 2. Figure 1 depicts the slab containing the actual bones; Figure 2 shows the counterslab with bone and feather impressions. The bones present on the slab are as follows: sternum (left side: ventral aspect); both coracoids (left, $10.8 \mathrm{~mm}$ ); furcula (12.1 mm from furcular process to scapular tuberosity); left scapula; left humerus (proximal portion as preserved, $13.3 \mathrm{~mm}$; width of proximal end, $5.4 \mathrm{~mm}$; least width of shaft, $1.8 \mathrm{~mm})$; right ulna $(19.1 \mathrm{~mm})$; right radius (approximately $18.4 \mathrm{~mm}$ ); bones of manus (very faint). Unfortunately, no useful ratios could be obtained. Furthermore, few useful osteological characters are exhibited in the bones exposed, except for the form of the proximal end of the humerus, which is preserved in palmar view. It is in the humerus that one finds characters that ally Neanis with the structurally primitive families of the Piciformes, such as the modern family Bucconidae. Neanis conforms with the characters 


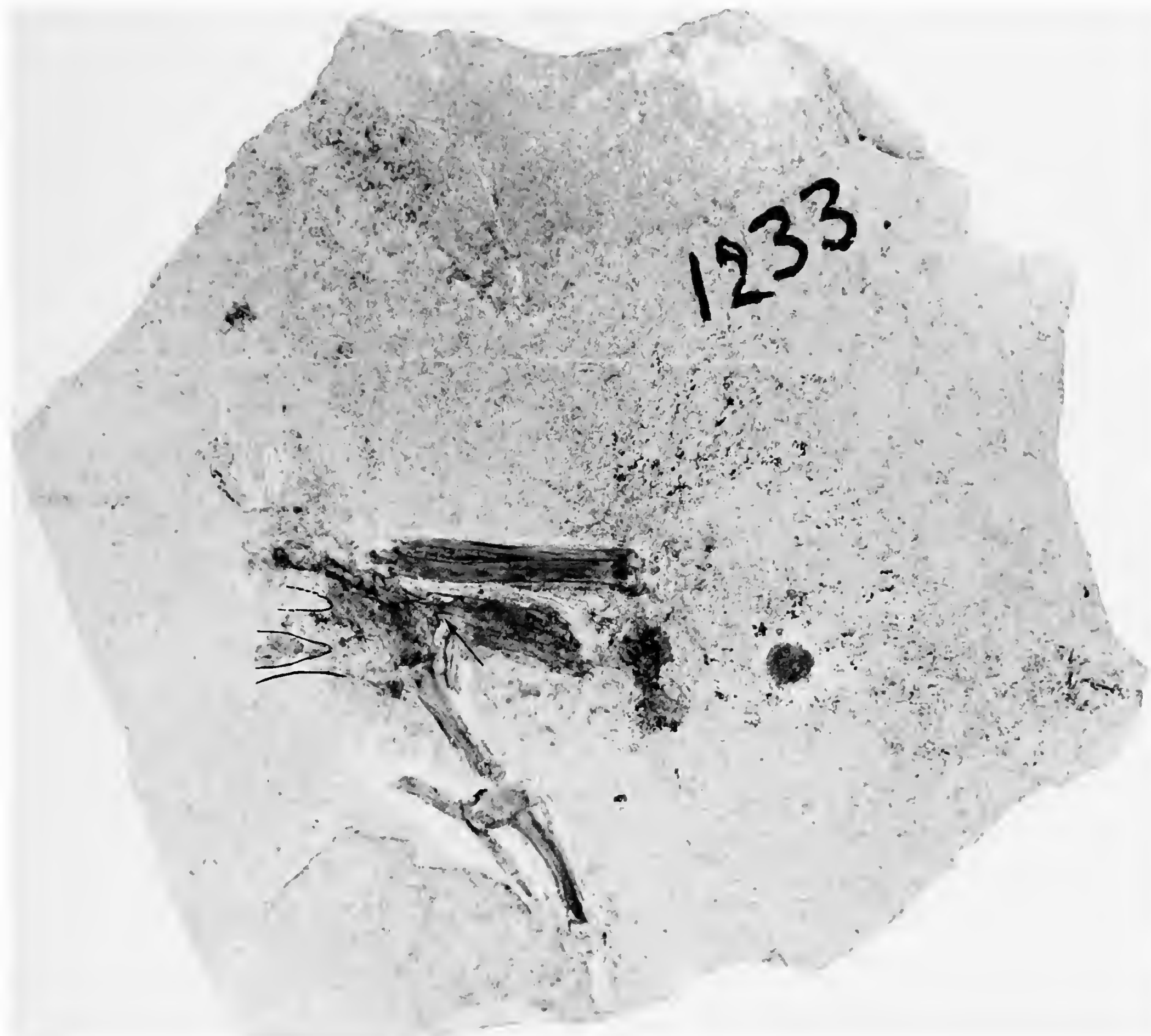

Figure 1.-Holotype of Neanis schucherti (YPM 1233). The slab containing the actual bones, top to bottom: right radius, right ulna, right coracoid, furcula, left coracoid, and left humerus (actual length of proximal portion, $13.3 \mathrm{~mm}$ ), left scapula. The sternum is to the left, and the approximate boundaries of the posterior notches of the left side of the sternum are outlined in ink. The position of the supposed spina externa is indicated by an arrow.

that Brodkorb (1970:13) used to place Primobucco mcgrewi in the Piciformes and Bucconidae: "(1) proximal end inflected, so that entire caput humeri is medial to inner border of shaft (head of humerus more nearly in line with shaft in other families of Piciformes); (2) shaft more curved than in other piciform families; (3) deltoid crest long, bent near its mid-length at an angle of about 150 degrees (deltoid crest nearly parallel with shaft in other piciform families)." The other characters outlined by Brodkorb are not clearly visible in Neanis; however, it is clear from the palmar view of the hu- 


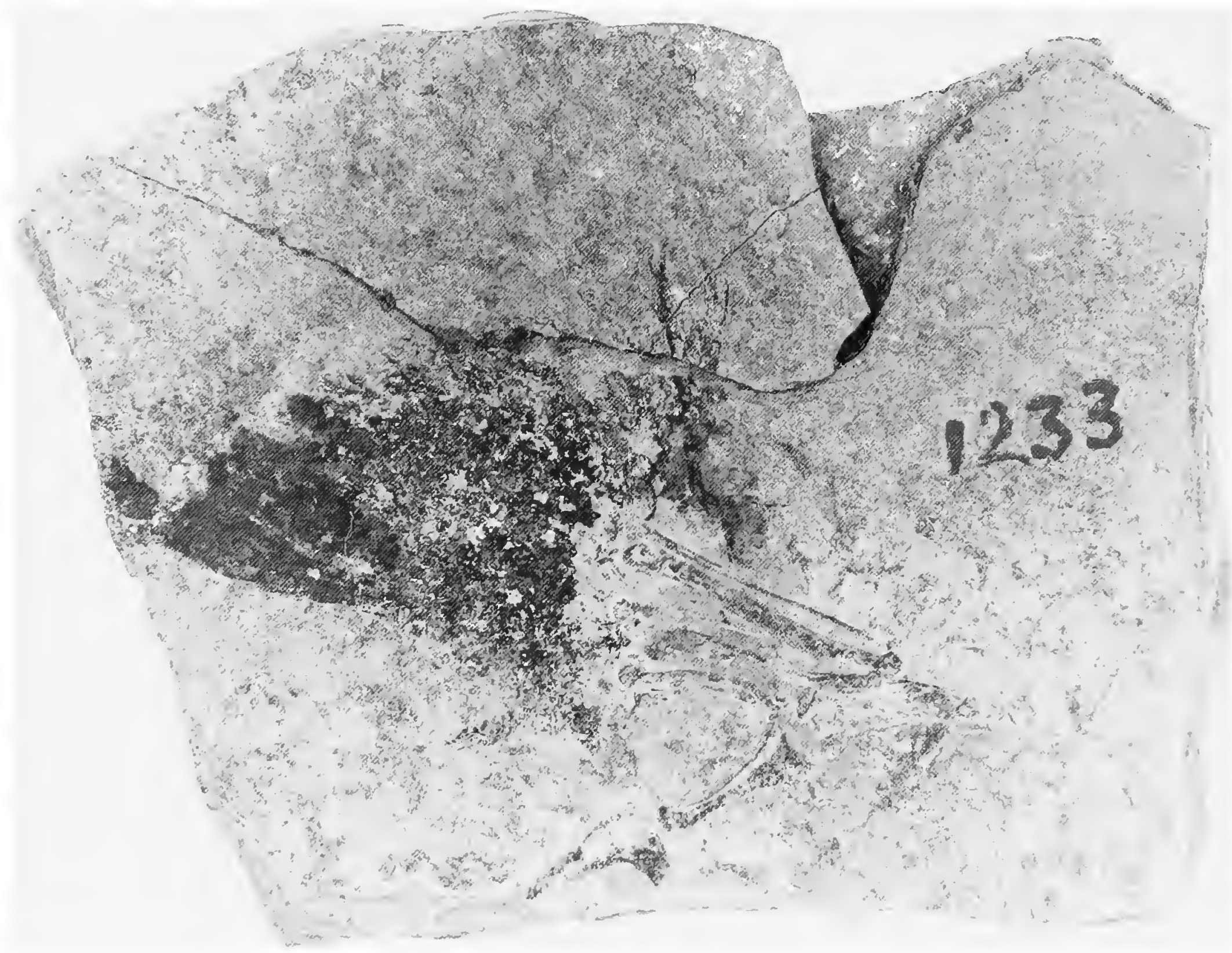

Figure 2-The counterslab of the holotype of Neanis schucherti, containing the impressions of the bones of the slab in Figure 1 and some feather impressions.

merus (Figure 1) that Neanis is not passerine, but piciform, and of living families is most similar to the Bucconidae, as are the two other species of Piciformes from the lower Eocene Green River Formation.

The length of the humerus of Primobucco mcgrewi is $26.7 \mathrm{~mm}$, and that of Primobucco kistneri was accurately estimated at $18-19 \mathrm{~mm}$, as the entire outline of the bone was extant. In outline, the humerus of Neanis schucherti is somewhat similar to that of Primobucco kistneri, but the bones of the latter are so crushed that the comparison is unsatisfactory; however, the two forms were of the same general size, which, as I stated of Primobucco kistneri (Feduccia, 1973:503), "would probably best approximate ... some of the modern African barbets (Capitonidae) of the genus Pogoniulus (including Viridobucco), which are approximately $4-5$ inches in total length." In the $a b$ sence of the evidence to the contrary, it seems best for the present to regard Neanis schucherti and Primobucco kistneri as distinct species; however, because of their general similarity in size, I recommend that $P$. kistneri be included in the genus Neanis, which has priority over Primobucco. Because Primobucco mcgrewi is considerably larger than either Neanis schucherti or Neanis kistneri, I strongly recommend the retention of the genus Primobucco to represent the large lower Eocene piciform birds from the Green River Formation. 


\section{Literature Cited}

Ames, P. L.

1971. The Morphology of the Syrinx in Passerine Birds. Bulletin of the Peabody Museum of Natural History. 37:1-194.

Brodkorb, P.

1965. New Taxa of Fossil Birds. Quarterly Journal of the Florida Academy of Sciences, 28(2):197-198.

1970. An Eocene Puffbird from Wyoming. University of Wyoming Contributions to Geology, 9(1):13-15.

Feduccia, A.

1972. Variation in the Posterior Border of the Sternum in Some Tree-trunk Foraging Birds. Wilson Bulletin, 84(3):315-328.

1973. A New Eocene Zygodactyl Bird. Journal of Paleontology, 47(3):501-503, 1 figure, 1 plate.
Heimerdinger, M. A., and P. L. Ames

1967. Variation in the Sternal Notches of Suboscine Passerine Birds. Postilla, 105:1-44.

Olson, S. L.

1971. Taxonomic Comments on the Eurylaimidae. Ibis, $113(4): 507-516$.

Sclater, P. H.

1874. On the Neotropical Species of the Family Pteroptochidae. Ibis, series 3, 4:189-206.

Shufeldt, R. W.

1913. Fossil Feathers and Some Heretofore Undescribed Fossil Birds. Journal of Geology, 21(7):628-652. 



\title{
The Eocene Zygodactyl Birds of North America (Aves: Piciformes)
}

\author{
Alan Feduccia and Larry D. Martin
}

\begin{abstract}
Recent discoveries of zygodactyl birds in the Eocene of Wyoming, along with reinterpretation of previously described taxa, show that these forms belong to an extinct family, affiliated with the Bucconidae, for which we here propose the name Primobucconidae. The genera Primobucco, $\mathrm{Ne}$ anis, Uintornis, Botauroides, and a new genus, Eobucco, are assigned to this family, and three new species, Primobucco olsoni, Uintornis marionae, and Eobucco brodkorbi are described. Primobucconids appear to have been the dominant small perching birds of the Eocene of North America.
\end{abstract}

\section{Introduction}

Recent discoveries of piciform zygodactyl birds from the lower Eocene Green River Formation of Wyoming brought to light an entirely new element in the avifauna of the North American Tertiary. Brodkorb (1970a) described the first of these forms as a new genus and species of the Bucconidae, which is structurally the most primitive family of the Piciformes. This species, Primobucco mcgrewi, provided the earliest record of the order Piciformes and the only fossil record of the Bucconidae. In addition to describing Primobucco mcgrewi, Brodkorb (1970a) suggested that Uintornis lucaris Marsh (1872), from a much higher level in the Eocene than $P$. mcgrewi, might also be referable to

Alan Feduccia, Department of Zoology, University of North Carolina, Chapel Hill, North Carolina, 27514. Larry D. Martin, Museum of Natural History and Department of Systematics and Ecology, University of Kansas, Lawrence, Kansas, 66045. the Bucconidae. Later, Feduccia (1973) described a new zygodactyl bird, Primobucco kistneri, from the same formation as $P$. mcgrewi. While $P$. mcgrewi was based on a right wing, the type of $P$. kistneri included much of the skeleton on a slab. Although the bones were poorly preserved, the zygodactyl condition of the toes could be clearly discerned for the first time in any known fossil. Few useful osteological characters were present in this fossil, but by using ratios of the hindlimb elements it was at least possible to show that $P$. kistneri was a "perching" piciform bird, closely resembling the Bucconidae and Capitonidae in proportions. Being from the same approximate horizon and locality as $P$. mcgrewi, it seemed reasonable to assume that the two were related, although $P$. mcgrewi was larger than the modern bucconids Notharchus tectus or Malacoptila panamensis (Brodkorb, 1970a:14), whereas P. kistneri was much smaller, being approximately the size of some of the modern African capitonids of the genus Pogoniulus, which are about 100-130 mm long.

Feduccia (pp. 95-99, herein) examined the type of Neanis schucherti (Shufeldt, 1913), also from the lower Eocene of Wyoming, which was originally described as belonging to the Rhinocryptidae, thus supposedly representing the earliest record of the order Passeriformes. He found, however, that this species is not a passerine, but a piciform, probably congeneric with $P$. kistneri. Because both these species are much smaller than $P$. mcgrewi, $P$. kistneri was removed to the genus Neanis, and the genus Primobucco was reserved for larger lower Eocene forms the size of $P$. mcgrewi.

The problematical genus Uintornis was originally affiliated with the woodpeckers (Picidae) by Marsh (1872). Shufeldt (1915:51) stated emphat- 
ically that this assignment was erroneous, but left the question of the true affinities of the genus unsettled. Cracraft examined the type and agreed with Shufeldt that it was not from a woodpecker, suggesting instead that it belonged with the Cuculiformes (Cracraft and Morony, 1969:6). On Cracraft's suggestion, Brodkorb (1970b; 1971) placed Uintornis in the Cuculidae. Our present studies of the type of Uintornis lucaris show that it is not a cuculid and that Brodkorb's (1970a) original assignment of it to the Bucconidae was more nearly correct. We found three other tarsometatarsi, also from middle Eocene deposits in North America, to be affiliated with Uintornis at the family level. One of these was originally described by Shufeldt (1915) as a new genus and species of heron, Botauroides parvus; the second represents an undescribed species of Uintornis; while the last represents a new genus.

Two species of piciform birds from the Miocene of Europe have been placed in an extinct family Zygodactylidae (Brodkorb, 1971), based on the genus Zygodactylus (Ballman, 1969a; 1969b). These forms are distinctly different from the above species and further study of them will be necessary in order to clarify their affinities with other groups of modern and Tertiary zygodactyl birds. Meanwhile, the morphology of the Eocene forms precludes their assignment to any known family of the Piciformes and the erection of a new family is therefore made necessary.

ACKNOWLEDGMENTS.-We are greatly indebted to S. W. Shannon of the Geological Survey of Alabama for bringing to our attention the type of Primobucco olsoni and placing it at our disposal for study. P. O. McGrew of the University of Wyoming, Department of Geology, kindly lent the types of Primobucco mcgrewi and Neanis kistneri. Skeletons of modern species were made available through the courtesy of Pierce Brodkorb (University of Florida), R. W. Storer (University of Michigan Museum of Zoology), and R. L. Zusi (National Museum of Natural History, Smithsonian Institution). C. B. Schultz made the University of Nebraska specimen available. D. Adlams and D. Bennett rendered the illustrations. Abbreviations are as follows: Geological Survey of Alabama Type Collection (GSATC), University of Kansas Museum of Natural History (KUVP), University of Nebraska State Museum (UNSM), University of
Wyoming Geological Museum (UWGM), and Yale Peabody Museum (YPM).

\section{Order PICIFORMES}

\section{Suborder GALBULAE}

\section{PRIMOBUCCONIDAE, new family}

Included Genera.-Primobucco, Neanis, Uintornis, Botauroides, Eobucco.

Diagnosis.-Small perching birds with the following combination of characters: (1) humerus (Figure la) with shaft curved, the head inflected medially, and the deltoid crest low, slightly rounded and proximally located; (2) radius and ulna (Figure Ia) slender and elongate; (3) metacarpals II
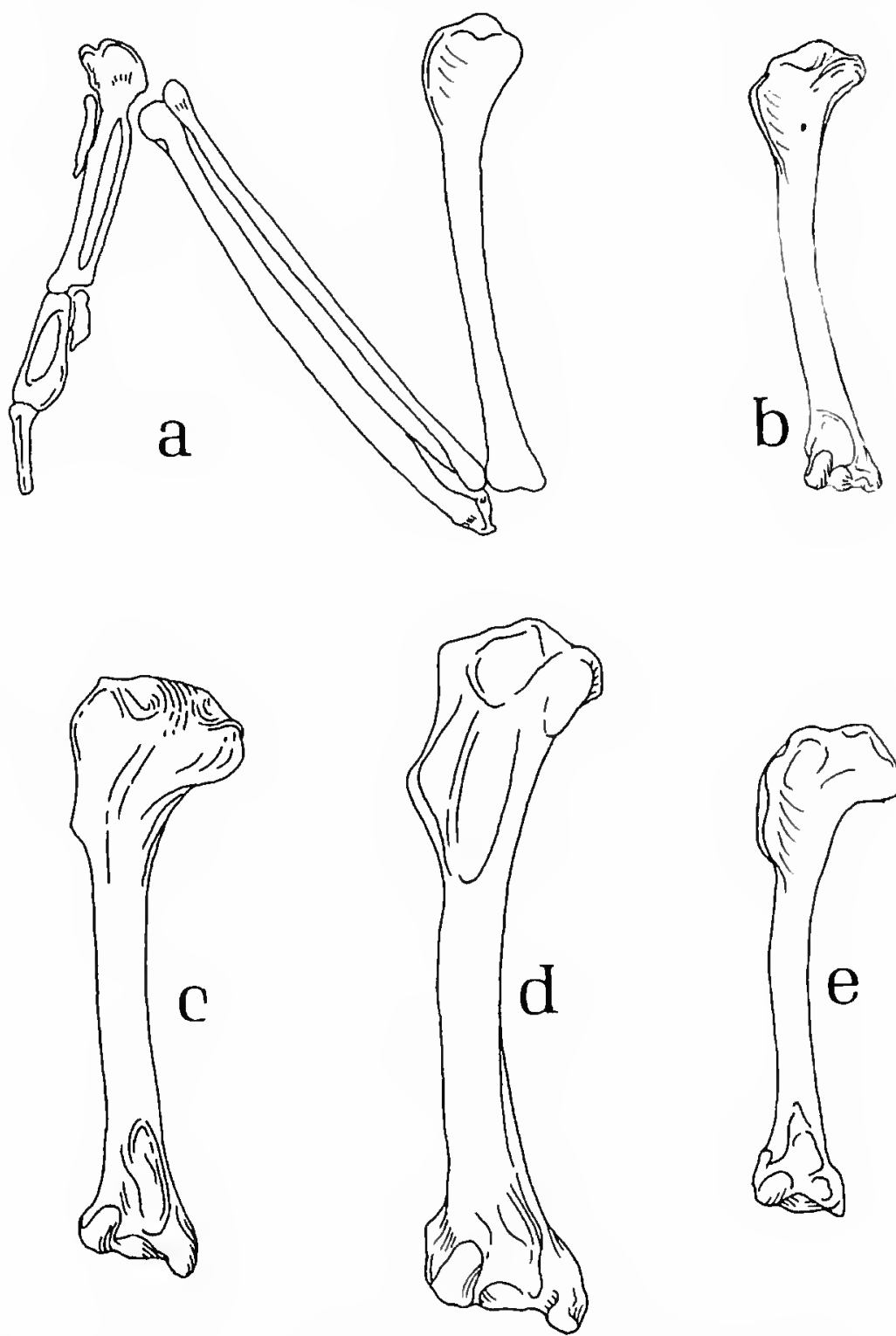

Figure 1.-a, Restoration of the right wing of Primobucco olsoni, palmar vicw. Palmar views of right humeri: $b$, Chelidoptera tenebrosa (Bucconidae); c, Megalaima lineata (Capitonidac); $d$, Tauraco sp. (Musophagidae); $e$, Tapera naevia (Cuculidae). 
and III (Figure 1a) nearly parallel to each other, with only a narrow intermetacarpal space; (4) phalanx 1 digit II of manus (Figure la) broader proximally than in most other Piciformes; (5) tarsometatarsus (Figure 2e, f) relatively short, broad, and flat; (6) hypotarsus with a square lateral block of bone and a low ridge leading distally from it (Figure 6), probably with only a single tendinal canal (not clearly determinable in any known specimen); (7) papilla for tibialis anticus on the extreme internal margin of the tarsometa- tarsus (Figure 2e, f); (8) tarsometatarsus with a single proximal foramen (Figure 6); (9) distal end of tarsometatarsus flared, with large intertrochlear spaces and trochleae lying in the same anteriorposterior plane (Figures $2 e, f, k ; 5 ; 6$ ); (10) middle trochlea the most distad, with the inner and outer trochleae about subequal (Figures $2 e, f ; 5 ; 6) ;(11)$ facet for metatarsal I entirely medial (Figures 5, 6); (12) inner trochlea grooved distally and posteriorly, middle trochlea deeply grooved (Figures $5,6)$; (13) outer trochlea inflected inwards, with-
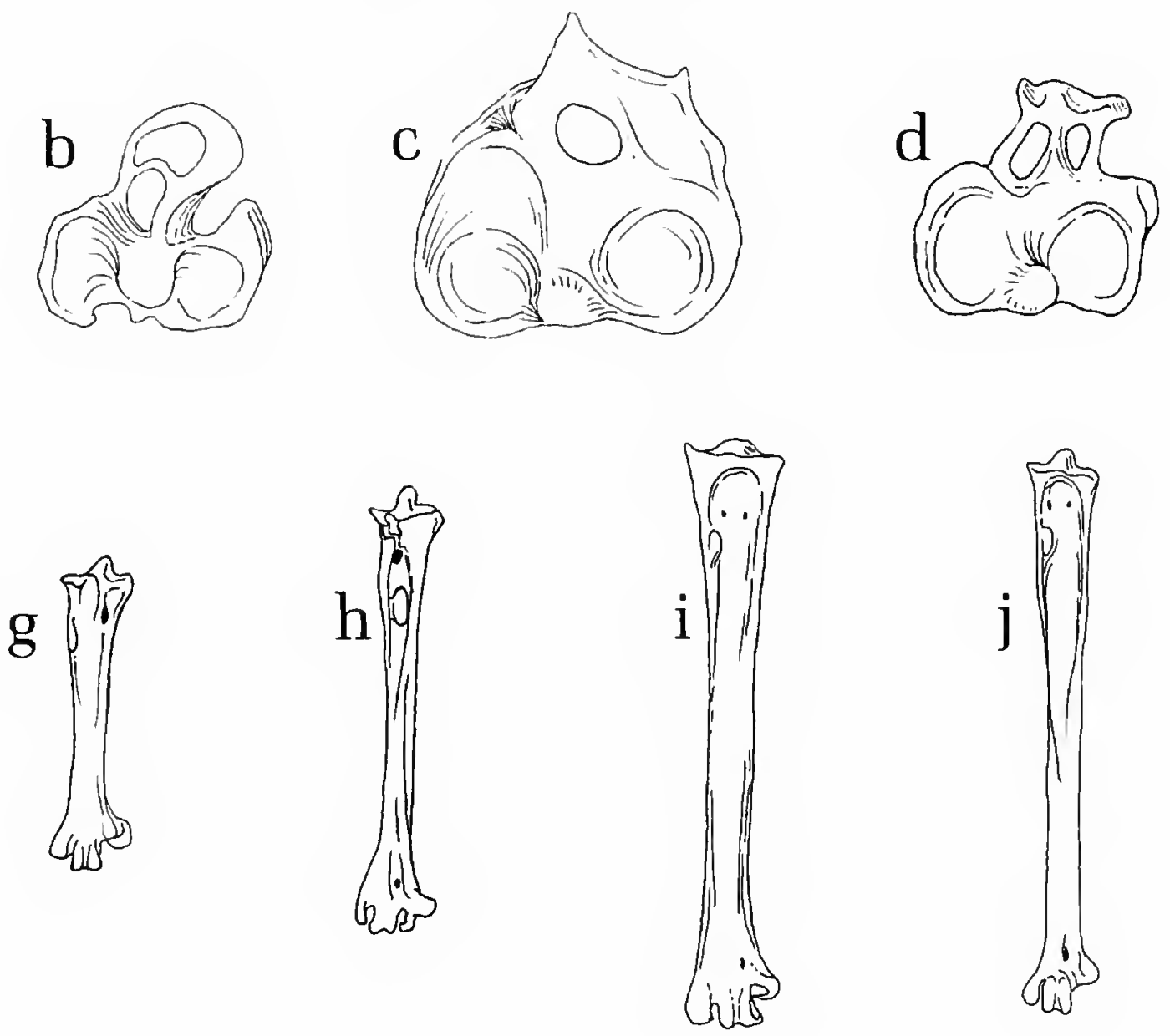
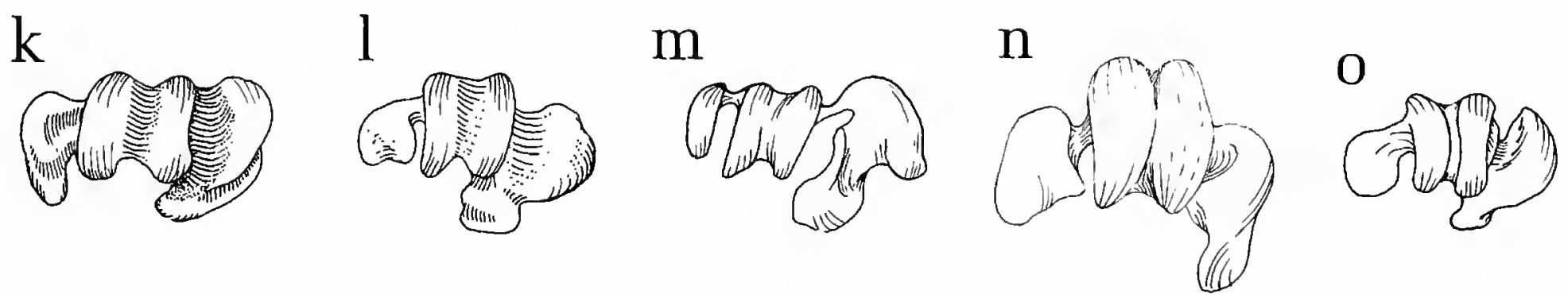

Figure 2.-Proximal views of left tarsometatarsi: $a$, Notharcus macrorhynchos (Bucconidae); $b$, Megalaima lineata (Capitonidae); c, Tauraco sp. (Musophagidae); d, Piaya cayana (Cuculidae). Restoration of the distal end of the left tibiotarsus and tarsometatarsus: $e$, Primobucco olsoni. Anterior $(f-j)$ and distal $(k-o)$ views of left tarsometatarsi: $f, k$, Eobucco brodkorbi (Primobucconidae); $g, l$, Notharcus macrorhynchos (Bucconidae); $h, m$, Megalaima lineata (Capitonidae); $i, n$, Tauraco sp. (Musophagidae); $j$, o, Piaya cayana (Cuculidae). 
out a well-developed sehnenhalter, but with a distinct groove separating the posterior portion of the trochlea from the remainder.

REMARKs.-Characters 1, 6, and 13 of the diagnosis eliminate all families of the Piciformes except the Bucconidae. In the other piciformes, the bill is long (except in indicatorids and capitonids), the shaft of the humerus tends to be straight with the deltoid crest parallel to it (Figure $1 c$ ), there are two or more hypotarsal canals arranged one behind the other (Figure 2b), and the sehnenhalter is well developed (Figure $2 \mathrm{~m}$ ). The fossils tend to be bucconid-like in characters $1,2,3,5,6,7,8$, and 13. They differ from the Bucconidae, however, in having a shorter mandibular symphysis, and in characters 4 , and 9 through 12 . The bucconids and the other piciforms differ from the Primobucconidae in that phalanx 1 digit II of the manus is narrower, especially at its proximal end; the inner and middle trochleae of the tarsometatarsus are placed closer together and the outer trochlea is elevated; the anterior face of the middle trochlea is not deeply grooved; and the facet for the first metatarsal is posteriorly situated.

Because Uintornis was suggested as being culculiform (Cracraft and Morony, 1969), we have compared all members of the Primobucconidae with nine genera of Cuculidae and three genera of Musophagidae. The Primbucconidae differ from both of these families in all but character 10 in the above diagnosis. The musophagids and cuculids differ from the Primobucconidae in that the ulna is short, strongly curved, and has large feather papillae; metacarpal III is strongly curved so that there is a large intermetacarpal space; the supratendinal bridge is much above the proximal margin of the condyles of the tibiotarsus; the tarsometatarsus is elongate (Figure 2i,j); the inner and middle trochleae are close to each other, and the outer trochlea is elevated and inflected inwards, with no separation of the posterior portion from the rest of the trochlea (Figure 2n,o); the facet for metatarsal I is located posteriorly and the inner trochlea is not prominently grooved. The anterior face of the tarsometatarsus is often deeply excavated in cuculiforms and there are usually two proximal foramina. The cuculids always have two large enclosed hypotarsal canals (Figure 2d), a feature that is certainly absent in the only primobucconid in which it can be checked. Also, musophagids have a very triangu- lar and distally situated deltoid crest (Figure $1 d$ ).

Clearly the Primobucconidae belong in the Piciformes and are most closely related to the Bucconidae. We can find no substantive evidence for a relationship between Uintornis (or any of the other forms of Primobucconidae) and any group of the Cuculiformes.

The family Primobucconidae includes five genera. The species of two of these genera, Primobucco and Neanis, are preserved as crushed specimens on slabs and represent medium-sized and small forms, respectively, of lower Eocene age. Three genera, Uintornis, Botauroides, and Eobucco, are medium to large in size and are middle Eocene in age; all are represented by fairly well-preserved tarsometatarsi only. Obviously, distinguishing the lower from the middle Eocene forms is difficult because the material is not strictly comparable. Nevertheless, size differences and such characters of the tarsometatarsus as can be discerned in the lower Eocene genera will permit them to be distinguished from most, if not all, of the middle Eocene forms. For this reason, and because of the time element involved, we believe it is best to recognize five genera in the Primobucconidae.

\section{Primobucco Brodkorb, 1970a}

Type-SPecies.-Primobucco mcgrewi Brodkorb, 1970a.

Included Species.-P. mcgrewi, $P$. olsoni.

Amended Diagnosis.-Medium-sized primobucconids, larger than Neanis and probably smaller than Uintornis, Botauroides, or Eobucco.

\section{Primobucco mcgrewi Brodkorb, 1970a}

HolotyPe.-Right wing, UWGM 3255.

TyPE-Locality AND HoRizon.-From fish quarries in SE 1/4 of Sec 18, T21N, R117W, near Fossil, Lincoln County, Wyoming; lower beds of Green River Formation, lower Eocene (Late Wasatchian) (Brodkorb, 1970a).

\section{Primobucco olsoni, new species}

Figures $1 a, 3,4$

HolotYPE.-Two slabs containing a nearly complete skeletal impression and counterimpression, 
Geological Survey of Alabama Type Collection, GSATC 217 (Figures 3, 4).

Type-Locality and Horizon.-The "first bluff" north of US Highway 30 north, across from Nugget, Lincoln County, Wyoming; Green River Formation, lower Eocene. Collected by Mr. George Moravec.

Diagnosis.-Smaller than Primobucco mcgrewi but larger than Neanis. Wing more slender and humerus longer than in Primobucco mcgrewi. Middle trochlea of tarsometatarsus extending farther distally than the other trochleae.

Description.-Skeleton preserved on two slabs with numerous feather impressions; mandible broad with a short symphysis; humerus with a low, gently curved deltoid crest almost parallel to shaft (Figure la); head of humerus inflected medially; radius and ulna slender, straight, and elongate, the ulna with no evidence of feather papillae; carpometacarpus long and slender with a large, straight process for metacarpal I and a narrow intermetcarpal space; phalanx 1 digit II of the manus broad (narrower proximally in most bucconids); tibiotarsus short and robust with the supratendinal bridge straight, lying just above the condyles; tarsometatarsus broad, short, and flat with a high intercotylar prominence, anterior face of shaft with a low medial ridge, a single medial

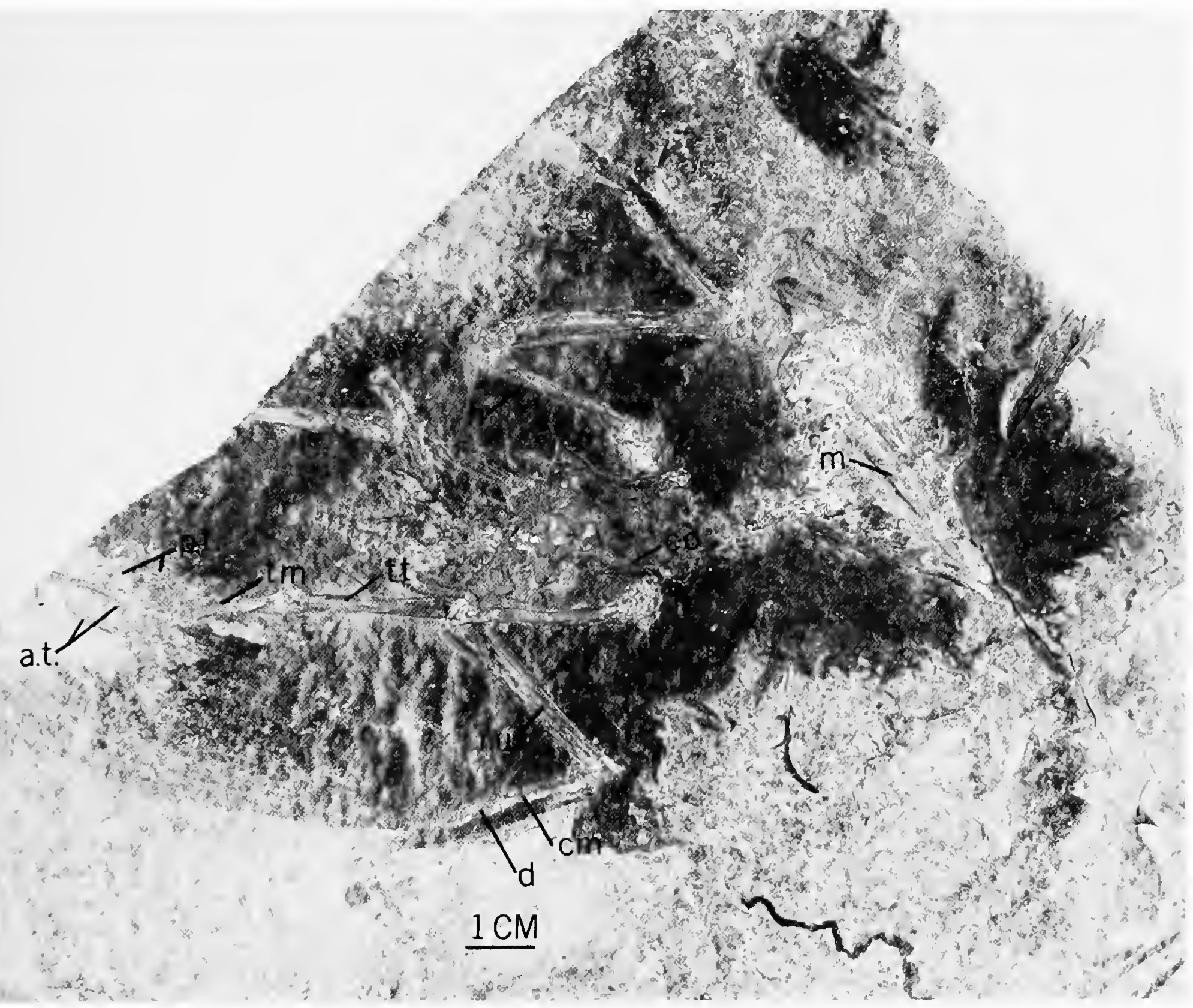

FigURE 3.-Holotype slab of Primobucco olsoni, new species (GSATC 217), viewed ventrally. (a.t. $=$ anterior toes, $\mathrm{co}=$ coracoid, $\mathrm{cm}=$ carpometacarpus, $\mathrm{d}=$ digit $\mathrm{II}, \mathrm{h}=$ humerus, $\mathrm{m}=$ mandibular ramus, p.t. $=$ posterior toes, r.u. $=$ radius and $\mathrm{ulna}, \mathrm{tm}=$ tarsometatarsus, $\mathrm{tt}=$ tibiotarsus) 


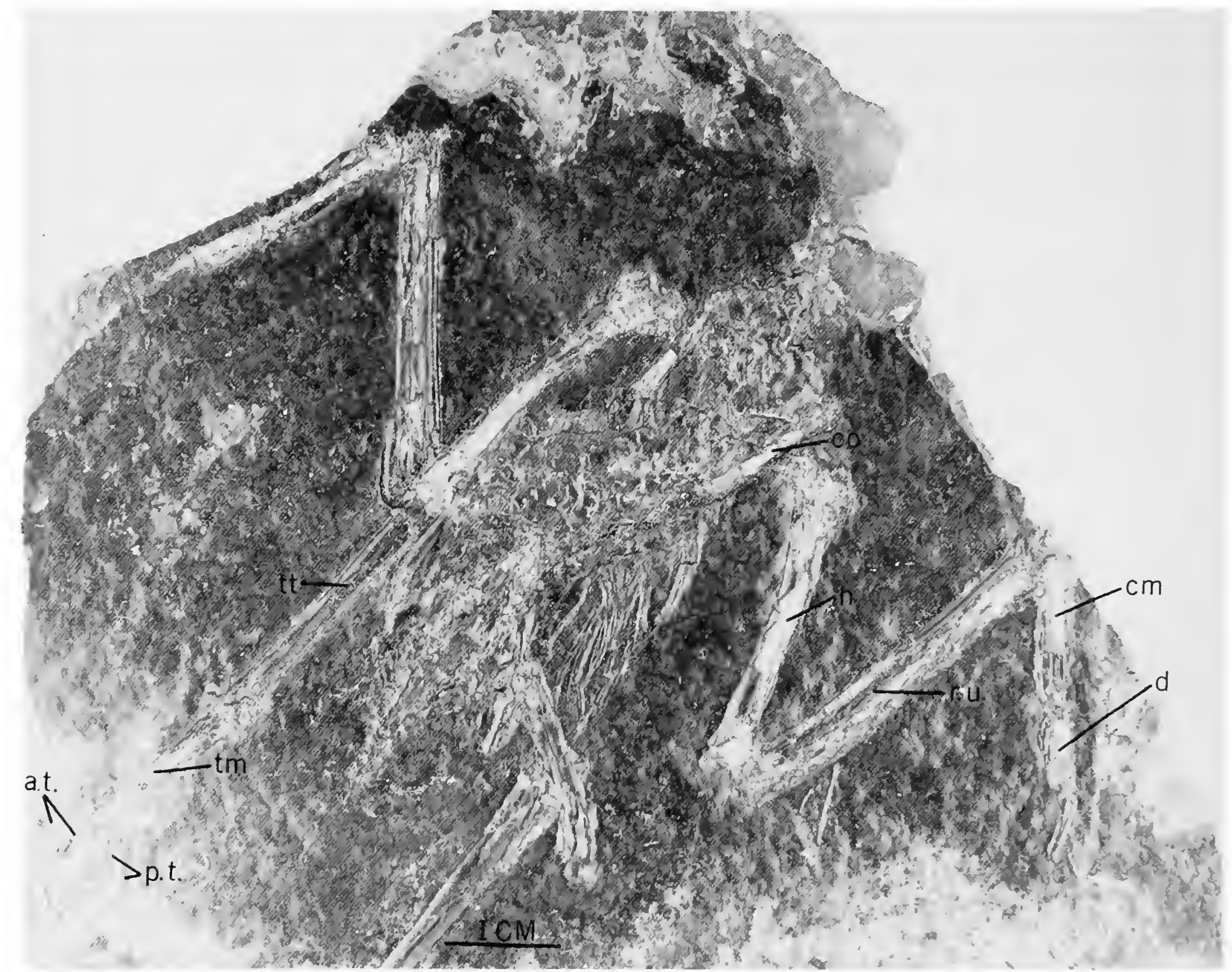

Figure 4.-Holotype counterslab of Primobucco olsoni, new species, viewed dorsally.

(Abbreviations as in Figure 3.)

proximal foramen, the papilla for tibialis anticus along the medial edge, the facet for metatarsal I situated medially, the middle trochlea situated distally, and the trochleae deeply grooved. Compared to Primobucco magrewi the humerus of $P$. olsoni is longer ( 28.8 vs. $26.7 \mathrm{~mm}$ ), the shaft more slender (least width c. 2.2 vs. $3.0 \mathrm{~mm}$ ), the proximal width greater (c. 7.5 vs. $6.7 \mathrm{~mm}$ ), the ulna shorter (c. 32.0 vs. $34.2 \mathrm{~mm}$ ), and phalanx 1 digit II of manus shorter (c 6.7 vs. $7.0 \mathrm{~mm}$ ). The approximate length of the coracoid is c. $15.0 \mathrm{~mm}$ and that of the mandibular ramus c. $34.5 \mathrm{~mm}$. The estimated toe lengths measured (in $\mathrm{mm}$ ) through the arc are: digit I, 11.0; digit II, 16.4; digit III, 18.8; and digit IV, 13.3. Equivalent estimates of the toe arcs for Neanis kistneri are 6.8, 7.4, 8.6, and 8.2, respectively. The chord of the left wing of $P$. olsoni is estimated at $92 \mathrm{~mm}$; of the species of Bucconidae listed in Ridgway (1914), the Barred Puffbird, Nystalus radiatus, is the nearest in size, with the wing chord of males averaging about 92 mm.

Etymology.-The specific name is in honor of Storrs L. Olson for his contributions to avian paleontology.

Remarks.-No accurate measurements of the tibiotarsus were possible but by comparing the two sides we were able to estimate the total length of the tibiotarsus very roughly as $28.5( \pm 3) \mathrm{mm}$. The tarsometatarsus measures c. $15.5 \mathrm{~mm}$, giving a ratio of tarsometatarsus to tibiotarsus of approximately 0.54 . This rules out an affinity with the 
Picidae (average ratio of 8 species, 0.67 ) or the Cuculidae (average of 7 species, 0.69). The same ratio for Neanis kistneri is 0.56 ; the average for 6 species of Bucconidae, 0.58; 3 species of Galbulidae, 0.51 ; five species of Capitonidae, 0.58 ; and 2 species of Indicatoridae, 0.59 (Feduccia, 1973). These ratios indicate only that the fossil does not belong to either the Cuculidae or the Picidae, but is a "perching" piciform bird. In woodpeckers, the different ratio results from the tibiotarsus being proportionately reduced. Comparative measurements of bucconids are given in Brodkorb (1970a).

The holotype of Primobucco olsoni is especially important because it permits us to associate the skeleton of Primobucco with those primobucconids known only from the tarsometatarsus. Features in which Primobucco resembles Eobucco and Uintornis are the short, broad tarsometatarsus with a high intercotylar prominence, the single lateral proximal foramen, the small and very medially situated tubercle for the tibialis anticus, and the medially situated facet for metatarsal I.

\section{Neanis Brodkorb, 1965}

SYNoNYM.-Hebe Shufeldt, 1913 (preoccupied). TYPE-SPECIES.-Hebe schucherti Shufeldt, 1913. INCLUDED SPECIES.-N. schucherti, $N$. kistneri.

AMENDED Diagnosis.-Wing relatively shorter than in Primobucco; tarsometatarsus with large hypotarsus.

REMARKs.-Better preserved material is needed for a full diagnosis of the very small zygodactyl birds referred to Neanis.

\section{Neanis schucherti (Shufeldt, 1913)}

HolotyPE.-YPM 1233, partial skeleton on a slab and impression on counterslab.

TyPe-Locality and HoRizon.-Fish cut of the railroad, $8 \mathrm{~km}$ west of Green River City, Wyoming; Green River Formation, lower Eocene.

\section{Neanis kistneri (Feduccia, 1973)}

HolotyPE.-UWGM 3196, partial skeleton on a slab.

Type-Locality and HoRizon.-N 1/2, NW 1/4, Sec 6, T23N, R104W, Sweetwater County, Wyom- ing; Tipton Tongue Member of the Green River Formation, lower Eocene (Wasatchian).

Amended Diagnosis.-Smaller than N. schucherti or any of the other primobucconids.

\section{Uintornis Marsh, 1872}

TYPE-SPECIES.-Uintornis lucaris Marsh, 1872.

INCLUdED SPECIES.-U. lucaris, U. marionae.

Amended Diagnosis. - Zygodactyl birds with the outer trochlea of the tarsometatarsus not as strongly rotated as in other primobucconids; middle trochlea situated distally; distal foramen located above the outer trochlea.

\section{Uintornis lucaris Marsh, 1872}

Holotype.-YPM 617, distal end of right tarsometatarsus (Figure 5f,g).
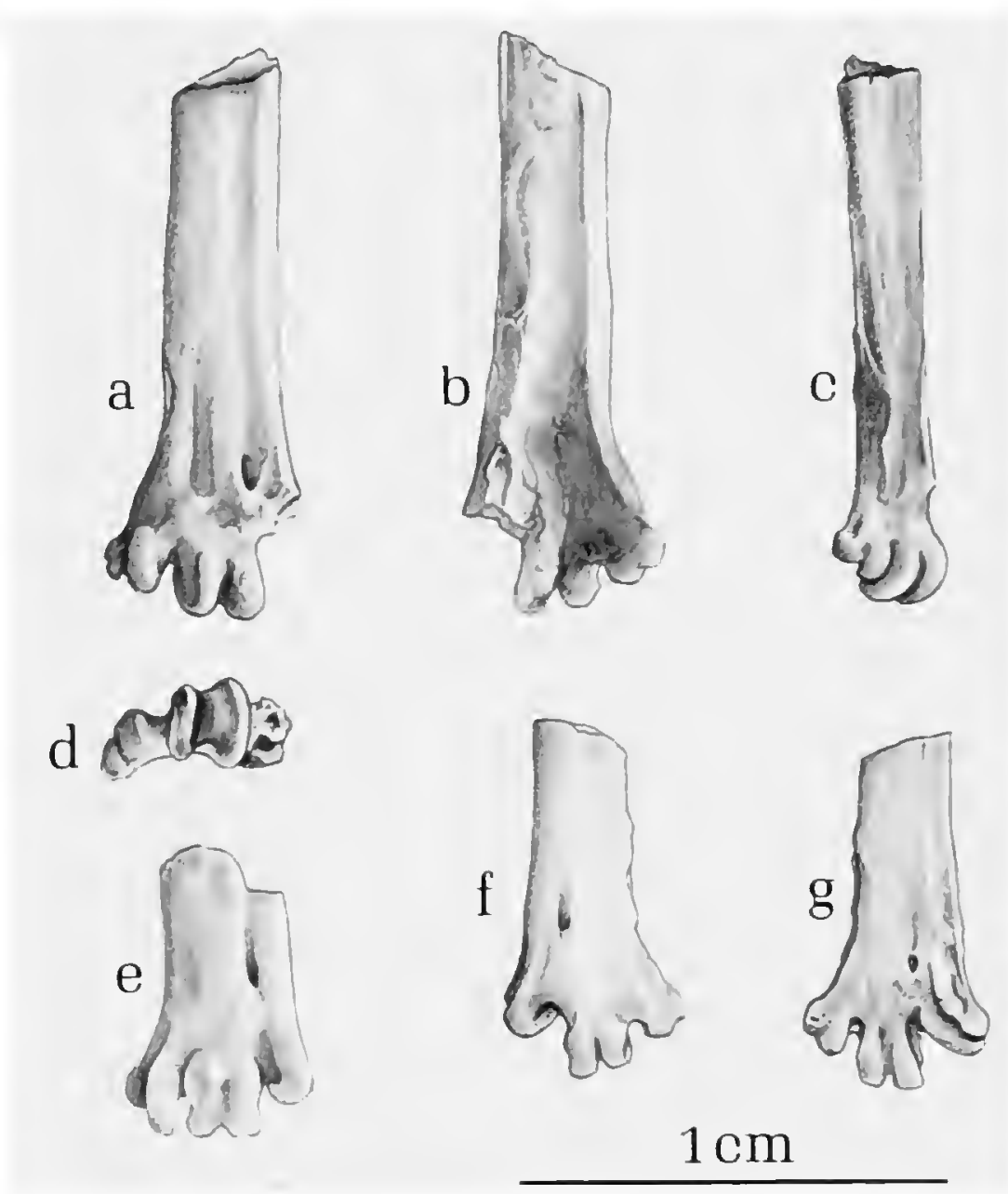

Figure 5.-Tarsometatarsi of Uintornis and Botauroides: a-d, holotype partial left tarsometatarsus of Uintornis marionae, new species (KUVP 26906), anterior, posterior, medial, and distal views; $e$, holotype, partial left tarsometatarsus of Botauroides parous (YPM 1030), anterior view; $f-g$, holotype partial right tarsometatarsus of Uintornis lucaris (YPM 617), anterior and posterior views. 
Type-Locality and Horizon.-Henry's Fork, Sweetwater County, Wyoming; Bridger Formation, middle Eocene.

Amended Diagnosis.-Outer trochlea of tarsometatarsus inflected inwards but with inner and outer trochlear ridges not widely separated; middle trochlea located much farther distally than the others and distal foramen located more proximad.

DESCRIPTION.-Shaft of tarsometatarsus broad and flat; inner extensor grooves deep; distal foramen more proximal than the outer trochlea; distal end expanded with wide intertrochlear notches; trochleae deeply grooved; inner trochlea small, smooth anteriorly and grooved posteriorly, with a small medially directed posterior flange; middle trochlea deeply grooved, with high, thick, trochlear ridges, the inner trochlear ridge distal to the outer and with a short, thick neck; outer trochlea large, at the same level as the inner trochlea and inflected medially; outer trochlea grooved, with the outer ridge produced posteriorly as a flange or incipient sehnenhalter; facet for metatarsal I medially situated. Measurements (in $\mathrm{mm}$ ) of type: width of distal end, 4.77; width of shaft at distal foramen, 3.3; depth and width of inner trochlea, 1.36 and 1.27; depth and width of middle trochlea, 2.00 and 1.90; depth of outer trochlea 2.90 .

\section{Uintornis marionae, new species}

\section{FIGURE $5 a-d$}

HoLotyPe.-KUVP 26906, distal end of right tarsometatarsus lacking outer trochlea (Figure $5 a-d)$.

Type-Locality and Horizon.-Sage Creek, Sweetwater County, Wyoming; Bridger Formation, middle Eocene.

Diagnosis.-Resembles Uintornis and differs from Botauroides in having a more slender shaft, a small inner trochlea, and a distinct groove proximal to the outer trochlea. Differs from Uintornis lucaris in being about 25 percent larger, and in having the facet for metatarsal I less deeply impressed and the outer ridge of the outer trochlea more medially inclined and elongated.

DESCRIPTION.-Tarsometatarsus broad and flat; distal foramen lying proximal to outer trochlea in anterior view and not visible in posterior view; facet for metatarsal I situated laterally; inner trochlea grooved posteriorly and smooth anteriorly; intertrochlear spaces wide; middle trochlea deeply grooved and situated distally; trochleae not arched. Measurements (in $\mathrm{mm}$ ) of type: width of shaft at distal foramen, 4.18; depth and width of inner trochlea, 1.83 and 1.34; depth and width of middle trochlea, 2.25 and 2.02 .

ETYMology.-Named for Marion A. Jenkinson, who has often assisted us in our work on fossil birds.

REMARKs.-The size difference and various qualitative features of the specimen separate it from Uintornis lucaris. After Eobucco, described later in this paper, it is the largest known member of the Primobucconidae. Uintornis seems to be the least specialized genus of the family in terms of toe rotation.

\section{Botauroides Shufeldt, 1915}

Type-Species.-Botauroides parvus Shufeldt, 1915.

InCLUded SPEGIES.-B. paruus.

AMENDED Diagnosis.-Botauroides differs from Uintornis in having a proportionately wider shaft, the notch for the facet of metatarsal 1 shallower and slightly more posterior, the inner trochlea at about the same level as the middle trochlea, and outer trochlea not as elevated. The inner ridge of the outer trochlea is slightly more rotated and does not project as far anteriorly as it does in Uintornis. The outer trochlea is proportionately smaller and the medial ridge of the middle trochlea swings farther medially. Uintornis has a shallow groove just proximal to the outer trochlea, and the inner trochlea is relatively smaller than in Botauroides.

\section{Botauroides parvus Shufeldt, 1915}

Holotype.-YPM 1030, distal end of left tarsometatarsus (Figure $5 e$ ).

TYPE-LOCALITY AND HoRIzON.-Spanish John Meadow, Wyoming; Bridger Formation, middle Eocene.

Diagnosis.-As for the genus.

Description.-Shaft very broad and flat, not expanded distally; distal foramen situated far proximally; inner trochlea larger and grooved posteriorly; inner and middle trochleae at same level; 
outer trochlea relatively small, rotated medially and not very elevated; trochleae not arched.

Remarks.-Cracraft (pers. comm.) directed our attention to the similarities between Botauroides and Uintornis. Shufeldt (1915), with his uncanny ability to err, had referred it to the Ardeidae, where it appears in Brodkorb's (1963) catalog.

\section{Eobucco, new genus}

Type-Species.-Eobucco brodkorbi, new species. Diagnosis.-Largest known primobucconid; resembles Uintornis and differs from Botauroides in having the facet for metatarsal I deeply impressed and the middle trochlea located farther distally. Differs from Uintornis in having the ridges of the middle trochlea not extending as far proximally on the anterior side; in having the outer ridge of the outer trochlea inclined more medially and elongated until it extends past the outer ridge of the middle trochlea (it does not reach this trochlea in Uintornis); in having the outer ridge of the inner trochlea extending posteriorly as a distinct flange; and in the far distal position of the distal foramen.

\section{Eobucco brodkorbi, new species}

FIGURE 6

Holotype.-UNSM 20046 (Figure 6), left tarsometatarsus.

TYPE-Locality and HoRIzon.-56 km north of Green River, Sweetwater County, Wyoming; Bridger Formation, middle Eocene.

Diagnosis.-As for the genus.

DESCRIPTION.-Shaft of tarsometatarsus short, broad, and flattened; intercotylar prominence high and large; hypotarsus damaged but with a large lateral square of bone, which may have included a closed canal (the two closed canals, such as found in cuculids, could not have been present); a shallow groove rather than a ridge leads distally from the hypotarsus; anterior face of shaft grooved, with a high lateral ridge present; medial edge of shaft thin; a single large proximal foramen present near the midline; tubercle for tibialis anticus very small and distally situated along the medial edge of the shaft; facet for metatarsal I high and deeply impressed into the medial side of the shaft; distal foramen small, level with the outer trochlea; trochleae widely spread, not arched; inner trochlea relatively large, anterior face smooth, posterior face grooved; proximal part of the outer rim of the outer trochlea produced into a large posterior flange; middle trochlea large with high trochlear ridges diverging posteriorly; middle trochlea more distal than other trochleae; large outer trochlea at the same level as the inner trochlea; outer trochlea rotated medially with its elongate outer ridge extending medially past the outer rim of the middle trochlea; outer trochlea grooved. Measurements (in $\mathrm{mm}$ ) of type: total length, 26.95; width of proximal end, 6.75; width of distal end, 6.00; depth and width of the inner trochlea, 1.36 and 1.27; depth and width of middle trochlea, 2.00 and 1.90; depth and width of outer trochlea, 2.90 and 1.80 .

ETYMology.-Named for Pierce Brodkorb, who

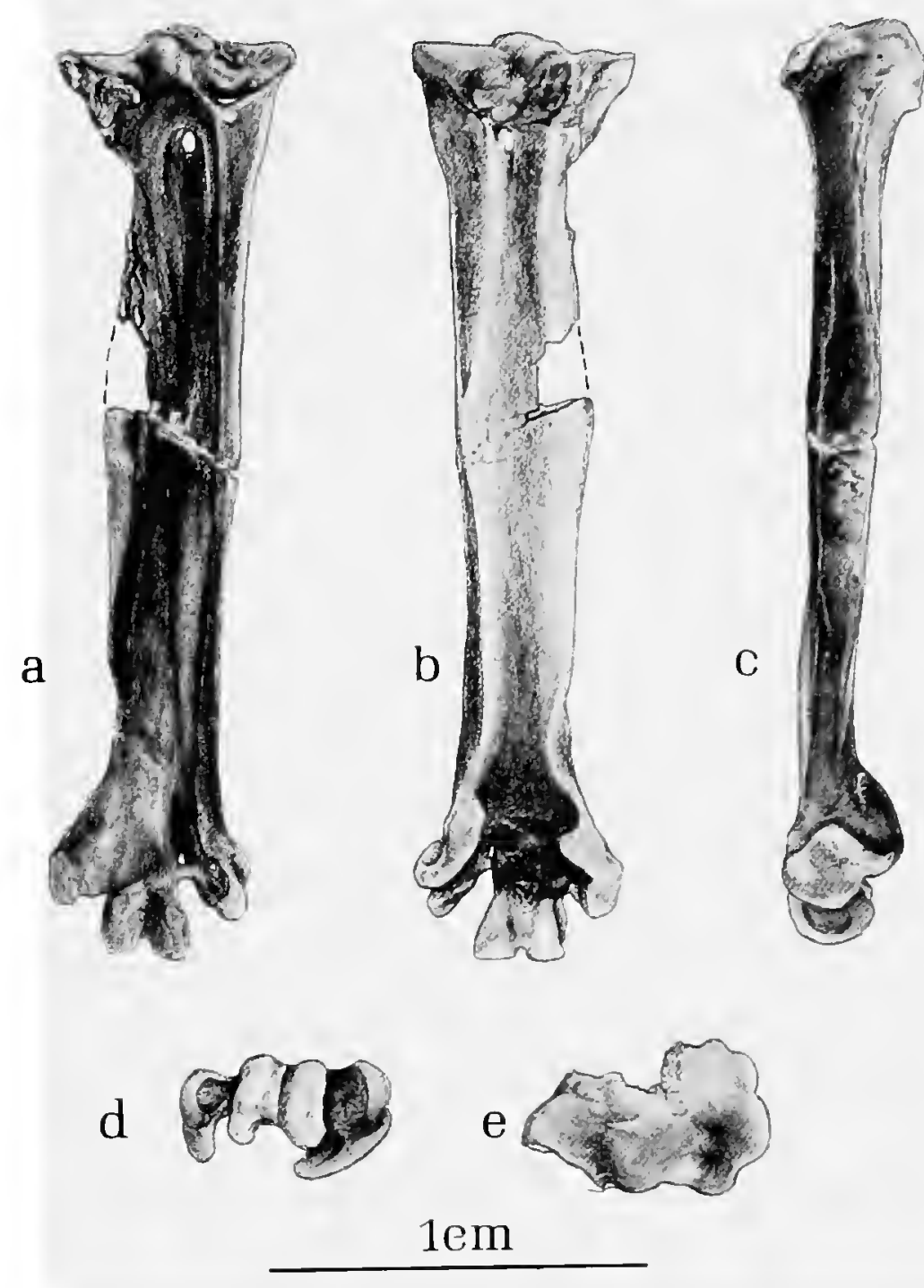

Figure 6.-Holotype left tarsometatarsus of Eobucco brodkorbi, new genus and species (UNSM 20046): $a$, anterior view; $b$, posterior view; $c$, lateral view; $d$, distal view; $e$, proximal view. 
was the first to recognize the true affinity of the primobucconids.

REMARKs.- This is the largest and most advanced of the known primobucconids. It shares with Uintornis the distal position of the middle trochlea but has the outer trochlea much larger and more medially rotated. The single proximal foramen is remarkable for its large size and central position, thereby resembling the proximal foramen in Galbula. The medial side of the shaft is deeply indented under the internal cotyla where it is reduced to a thin blade. The tubercle for the tibialis anticus is extremely reduced. Eobucco possesses a combination of primitive and specialized characters that probably preclude its having given rise to any modern group of piciforms.

\section{Conclusion}

The allocation of Neanis schucherti, Uintornis lucaris, and Botauroides parous to the Piciformes, and the description of the new forms Primobucco olsoni, Uintornis marionae, and Eobucco brodkorbi, brings the total number of species of North American Eocene zygodactyl birds to eight: two very small forms, Neanis schucherti and Neanis kistneri; two medium-size forms, Primobucco mcgrewi and Primobucco olsoni; two large forms,
Eobucco brodkorbi and Uintornis marionae, and two others, Uintornis lucaris and Botauroides parvus, slightly smaller than the last two.

The order Piciformes probably arose in the New World and its forms occupied the "perching" arboreal adaptive zone in the early Tertiary of North America when tropical and subtropical climates predominated. Later, the order spread to the Old World where the Miocene Zygodactylidae and the modern families Picidae, Capitonidae, and Indicatoridae are represented, the last named being the only modern piciform family not found in the New World. Probably through climatic change and competition with more advanced land birds, e.g., passerines, the piciforms retreated mainly to tropical zones of the New and Old Worlds. The most primitive living piciform families, the Bucconidae and Galbulidae, are presently confined to the New World tropics. The Bucconidae are structurally closest to the Eocene family Primobucconidae.

The preponderance of evidence now indicates that the typical "perching" birds of the early Tertiary of North America were primitive piciforms, rather than passerine birds. Thus, it was probably not until the mid-Tertiary that the passerines took over in North America as the predominant "perching" group.

\section{Literature Cited}

Ballmann, P.

1969a. Les oiseaux miocènes de La Grive-Saint-Alban (Isère). Geobios 2:157-204.

1969b. Die Vögel aus der altburdigalen Spaltenfüllung von Wintershof (West) bei Eichstätt in Bayern. Zitteliana 1:5-60.

Brodkorb, P.

1963. Catalogue of Fossil Birds, Part 1 (Archaeopterygiformes through Ardeiformes). Bulletin of the Florida State Museum, Biological Sciences, 7(4):180-293.

1965. New Taxa of Fossil Birds. Quarterly Journal of the Florida Academy of Science, 28:197-198.

1970a. An Eocene Puffbird from Wyoming. University of Wyoming Contributions to Geology, 9(1):13-15, 1 figure.

1970b. The Paleospecies of Woodpeckers. Quarterly Journal of the Florida Academy of Sciences, 33(2):132136, 1 figure.

1971. Catalogue of Fossil Birds, Part 4 (Columbiformes through Piciformes). Bulletin of the Florida State Museum, Biological Sciences, 15(4):163-226.
Cracraft, J., and J. J. Morony, Jr.

1969. A New Pliocene Woodpecker, with Comments on the Fossil Picidae. American Museum Novitates, 2400:1-8, 1 figure.

Feduccia, A.

1973. A New Eocene Zygodactyl Bird. Journal of Paleontology, 47(3):501-503, 1 figure, 1 plate.

Marsh, O. G.

1872. Notice of Some New Tertiary and Post-Tertiary Birds. American Journal of Science, 4(3):256-262.

Ridgway, $\mathbf{R}$.

1914. The Birds of North and Middle America. Bulletin of the United States National Museum, $50(6)$ : 1-882.

Shufeldt, R. W.

1913. Fossil Feathers and Some Heretofore Undescribed Fossil Birds. Journal of Geology, 21:628-652, 12 figures.

1915. Fossil Birds in the Marsh Collection of Yale University. Transactions of the Connecticut Academy of Arts and Sciences, 19:1-110, 15 plates. 


\title{
Oligocene Fossils Bearing on the Origins of the Todidae and the Momotidae (Aves: Coraciiformes)
}

\author{
Storrs L. Olson
}

\begin{abstract}
A new genus and species of tody, Palaeotodus emryi, is described from the "middle" Oligocene (Orellan land mammal stage) of Wyoming, providing the first record of the modern family Todidae outside the West Indies. The fossil bird Protornis glarniensis from the lower Oligocene of Switzerland is removed from the Alcedinidae to the Momotidae to provide the first occurrence of the latter family outside the New World. The Todidae and Momotidae appear to be more closely related to each other than either is to any other family of Coraciiformes. The Momotidae were evidently derived from the Old World. The Todidae appear to have been derived from a momotid-like ancestor in the Oligocene or earlier. The present distribution of these two families in the New World tropics is relictual. The Coraciiformes appear to have been one of the prevalent groups of small land birds in the Oligocene.
\end{abstract}

\section{Introduction}

The five modern species of todies (Todidae), endemic to the Greater Antilles, are among the most intriguing birds of the West Indies. The Momotidae of Central and South America and the Todidae are the only families of Coraciiformes confined to the New World. Apart from late Pleistocene remains of modern species, there has hitherto been no fossil record of either family.

Storrs L. Olson, Department of Vertebrate Zoology, National Museum of Natural History, Smithsonian Institution, Washington, D.C. 20560.
Now, a recently discovered fossil and a new interpretation of one of the first fossil birds to be described, provide us with increased information bearing on the evolution and geographic origins of both the Todidae and the Momotidae.

ACKNowledgments.- I am indebted to Robert J. Emry for calling the Wyoming specimen to my attention, permitting me to work on it, and providing much information and assistance. The manuscript has had the benefit of his comments and those of John Farrand, Jr., Alan Feduccia, and Pierce Brodkorb. Robert W. Storer (University of Michigan Museum of Zoology) kindly lent me a skeleton of Hylomanes for study, and casts of Swiss fossils were generously lent by Malcolm C. McKenna (American Museum of Natural History). I am grateful to L. B. Isham for his skillful illustrations accompanying this paper and to Anne Curtis for rendering Figure 3.

\section{An Oligocene Tody from Wyoming}

In June of 1972, Dr. Robert J. Emry of the Smithsonian Institution collected several blocks of matrix containing great concentrations of bones of small vertebrates from a deposit of Orellan age ("middle" Oligocene) in east-central Wyoming. Present in these samples are the abundant remains of at least two species of squirrels, various smaller rodents, small marsupials, and insectivores. That this great concentration of bone may be attributed to the work of owls is virtually certain since the blocks also contain the beautifully preserved skeletons of at least four small owls, possibly of two species. 
On the surface of one of these blocks, Dr. Emry noticed the bill of a small bird and later found a crushed avian cranium that fit perfectly with the bill. After the two portions had been reunited, an incomplete avian humerus was found attached to the lower surface of the skull. There is no reason to believe that the humerus and skull are not from the same individual. Were they not, the owl that cast the pellet containing these remains would have had to eat two different birds at the same time, since it is rare for elements from a single prey item to be found in two successive pellets (Raczyński and Ruprecht, 1974). This would seem unlikely, particularly in view of the absence of birds other than owls in the remainder of the samples.

The distinctively shaped, flattened bill of the fossil was immediately reminiscent of the Todidae, but since bills of similar shape have evolved independently in several groups of birds, many of them passerines, identification was made cautiously. After careful comparisons, I concluded that this specimen is indeed referable to the family Todidae.

\section{Palaeotodus, new genus}

TYPE.-Palaeotodus emryi, new species.

Diagnosis. - Similar to modern Todus but with different proportions, the wing apparently being better developed. Bill proportionately shorter and broader, not as pointed as in Todus. Mandibular rami not as flattened, the anterior portions grooved, so as to form a distinct dorsal shelf. Three ridges on the ventral side of the interorbital bridge separate, rather than coalesced as in Todus.

ETYMoLoGY.-Greek, palaeos, ancient, plus Todus, the genus of modern todies. See Newton (1896:970, footnote) for the etymology of Todus.

\section{Palaeotodus emryi, new species}

Figure 1

Holotype.-Incomplete and partially crushed skull with most of the anterior portions of the rostrum intact, including the mandibular symphysis and parts of both rami; crushed posterior portion of cranium with ventral surface of interorbital bridge well preserved; much of the rest of the skull crushed, jumbled, and displaced ventroanteriorly. Vertebrate Paleontological Collections of the Na- tional Museum of Natural History, Smithsonian Institution, USNM 205608. Collected in NW $1 / 4$, SE $1 / 4$, Sec. 27, T32N, R71W, about 5.6 $\mathrm{km}$ SSE of Douglas, Converse County, Wyoming $\left(42^{\circ} 42^{\prime} 55^{\prime \prime} \mathrm{N} ; 105^{\circ} 21^{\prime} 15^{\prime \prime} \mathrm{W}\right)$ on 12 June 1972 by Robert J. Emry (Field No. WYO. 72-246) and Leroy Glenn.

Horizon.-Brule Formation, Orellan landmammal stage, "middle" Oligocene.

PARATYPE.-Somewhat distorted right humerus with the shaft crushed and lacking the distal end; same number and data as the holotype.

MeAsurements.-Overall length of skull as preserved $34.5 \mathrm{~mm}$, length of bill from anterior of nostril 10.0, length of mandibular symphysis 7.8 , width of mandible at beginning of symphysis 5.6, width of mandibular ramus 1.7, proximal width of humerus 6.7.

Etymology.-After Dr. Robert J. Emry, the collector, in recognition of his significant contributions to our knowledge of the Oligocene fauna of North America.

DESCRIPTION.-Bill flat, broad, nearly spatulate, with a broader more rounded tip than in Todus. Internarial bar long, slender, terete, and somewhat heavier than in Todus, continued out the rostrum as a slightly elevated ridge. Mandible flattened, the symphysis shorter and broader than in Todus; mandibular rami deeper than in Todus, grooved anteriorly to form a dorsal shelf. Ventral surface of interorbital bridge with three ridges, the middle one terminating in a pointed process (tip broken off in the type), the outer ones flaring laterally to form the edges of the huge anterior cranial fenestra. The condition in Todus is essentially similar, but the three ridges are not as distinct anteriorly and coalesce to form a narrower, deeper interorbital bridge. The middle process in Todus is a

Figure 1.-Skull (holotype) and humerus (paratype) of Palaeotodus emryi, new genus and species (USNM 205608), compared with the same elements of Todus subulatus (USNM 292589): $a$, dorsal view of skull of $P$. emryi; $b$, dorsal view of skull of $T$. subulatus; $c$, lateral view of skull of $P$. emryi; $d$, ventral view of mandible of $P$. emryi; $e, f$, cutaway views of ventral side of interorbital bridge and dorsal part of anterior cranial fenestra of $T$. subulatus; $g, h$, same views of $P$. emryi; $i$, anconal view of humerus of $P$. emryi; $j$, proximal end of humerus of $P$. emryi, viewed with distal portion tilted further upward; $k$, proximal view of same; $i$, anconal view of humerus of $T$. subulatus. (All figures approximately $\times 3$.) 

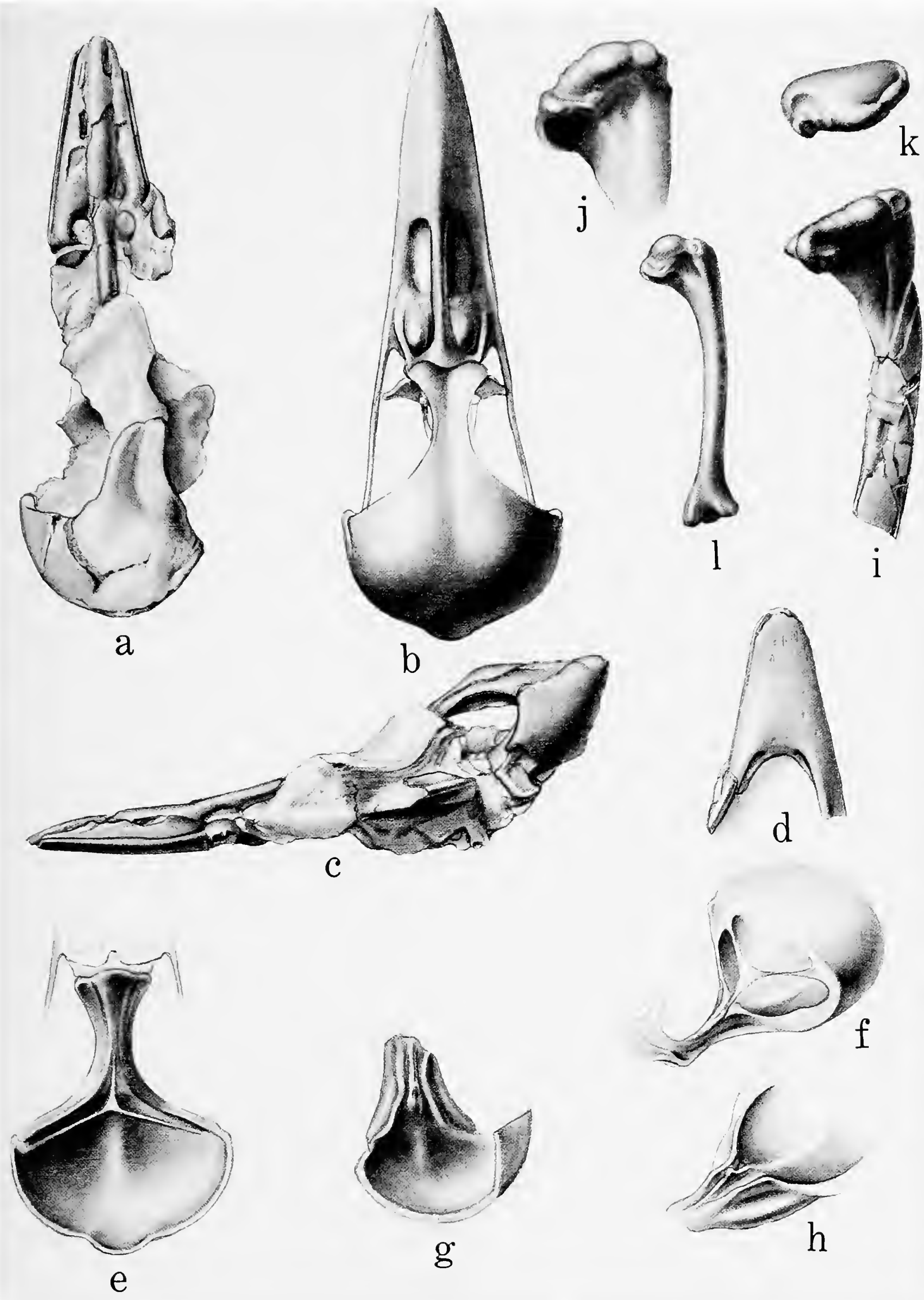
point of attachment for a narrow ligament that joins with similar ligaments from the parasphenoid rostrum and the lateral edges of the cranial fenestra to form a tenuous cross holding the anterior part of the brain in place. The humerus of Palaeotodus is similar to that of Todus, but is much larger; the internal tuberosity is heavier and much less lateromedially elongate; and the ligamental furrow and the scar on the external tuberosity are both considerably deeper.

REMARKs.-Few nonpasserine landbirds have the bill anywhere near as flattened as in Todus and Paleotodus. Those with the most flattened bills are Electron, Hylomanes, and Aspatha (Momotidae), Jacamarops (Galbulidae), and Myioceyx (Alcedinidae). In all of these forms the bill is deeper and the internarial bar broader and shorter than in either of the two genera of Todidae. The bony structure of the bill in passerines, as for example in Todirostrum (Tyrannidae), is quite different from that of Todus and Palaeotodus, being deeper and more arched, with a more troughlike mandible and a shorter, wider, and less terete internarial bar.

Palaeotodus agrees with Todus and differs conspicuously from the Momotidae, Alcedinidae, Galbulidae, and indeed from all of the rest of the Coraciiformes and Piciformes, in having the anterior wall of the cranium and the interorbital septum unossified. In the Momotidae, Alcedinidae, and Galbulidae the interorbital septum is partially or very heavily ossified. The anterior wall of the cranium is ossified in all of these families, whereas in Todus and Palaeotodus there is a great, open fenestra.

The humerus of Palaeotodus is broken and distorted, with the head crushed down distally relative to the internal and external tuberosities. Although in Todus there is slightly more of a depression beneath the head than in other Coraciiformes, the humerus can in no sense be regarded as having a double fossa, as stated by Bock (1962), and has a single pneumatic opening beneath the internal tuberosity. Palaeotodus is similar to Todus in this respect. The humerus of Palaeotodus differs from that of the Passeriformes in the less bulbous head, the much lesser development of the bicipital crest, the higher and more pronounced external tuberosity, and the narrower, more ventrally projecting internal tuberosity. In the Piciformes the deltoid crest is much more expanded, the head more bulbous, the capital groove much deeper, and the internal tuberosity less perpendicular to the shaft than in Palaeotodus, although these differences are considerably less pronounced in the Galbulidae and Bucconidae. Within the Coraciiformes the humeri of the Upupidae, Phoeniculidae, and Meropidae have larger, more triangular deltoid crests than in Palaeotodus, while in the Coraciidae the bicipital crest is more extensive. The humerus in the Alcedinidae has the head more bulbous and situated much higher above the external tuberosity, the shaft straighter, the internal tuberosity much heavier, and the bicipital surface much less produced than in Palaeotodus. The humerus of Palaeotodus is most similar to that of the Todidae and the Momotidae. In the conformation of the internal tuberosity it is more similar to the Momotidae, whereas in the greater excavation of the external tuberosity and ligamental furrow it more closely resembles the Todidae.

The manner in which the skull was crushed in the type of Palaeotodus makes it appear smaller, while the distortion of the humerus is such as to make it appear wider and thus larger. Nevertheless, it is quite evident that the proportions of Palaeotodus are different from those of Todus, the wing being much larger in relation to the head.

This difference in proportions may be due at least in part to the small size of Todus being secondarily derived, since the species of this genus are the smallest members of the order Coraciiformes. In the evolution of vertebrates, body size usually changes at a more rapid rate than head size, so that small forms derived from larger ones tend to have proportionately larger heads, and vice versa. Many authors have remarked on the large-headed appearance of Todus in life. In the Oligocene, the Todidac were possibly more diverse than at present and probably included larger, more actively flying forms with better developed wings than the strictly sedentary modern todies.

\section{An Oligocene Motmot from Switzerland}

In 1839, von Meyer called attention to the remains of what he thought to be a passerine bird from slate deposits (Glarner Fischschiefer) in Switzerland, then considered to be of Cretaceous age. In a subsequent publication he named this specimen Protornis glarniensis (von Meyer, 1844). 
Later (von Meyer, 1856), he emended the name to $P$. glaronensis and this spelling was in general use until Brodkorb (1971), whom I have followed, revived the original orthography. Lambrecht (1933) maintained Protornis as a genus incertae sedis in the Passeriformes. At that time the deposits from which the type of $P$. glarniensis was derived were regarded as upper Eocene in age. Subsequent studies have shown them to be of lower Oligocene age (Peyer, 1957).

The type of $P$. glarniensis consists of a slab containing the bones of all four limbs, the pectoral girdle, a complete mandible, the quadrates, and a few vertebrae and ribs. These were insufficiently exposed when von Meyer studied them, but Peyer (1957) undertook further preparation of the type, illustrating his results with numerous photographs and x-radiographs. The fossil is slightly distorted from stresses imposed on the rock after deposition; Stüssi (1958) and Baumann (1958) have offered mathematical and optical corrections, respectively, for this distortion. Another less complete specimen was referred to Protornis, possibly glarniensis, by Peyer (1957). I have had access to casts of both these specimens, as well as to Peyer's excellent illustrations. The casts were made by a copper electroplate process and appear to be very accurate representations of the original specimens.

After his study of the type of $P$. glarniensis, Peyer (1957) concluded that it belonged with the Alcedinidae (kingfishers) and more particularly that it was nearest to Dacelo. I agree with the assignment of this form to the Coraciiformes, but numerous characters of its skeleton show conclusively that Protornis cannot be a kingfisher.

Protornis glarniensis is a small bird, slightly smaller than the modern motmot Hylomanes momotula. As detailed by Peyer, many aspects of its structure demonstrate that it does not belong with the Passeriformes and the clearly anisodactyl feet eliminate the Piciformes from consideration. The mandibular symphysis is broad, flattened and somewhat spatulate, differing from most nonpasserine landbirds except the Momotidae and Todidae. The overall conformation of the mandible is in fact, markedly similar to that of the motmot genera Electron and Hylomanes and is quite distinct from that of the kingfishers, including the flat-billed genus Myioceyx (Figure 2). The symphysis is broader than in the Todidae and somewhat shorter than in the modern genera of Momotidae, being most similar in this respect to Hylomanes, which genus is generally conceded to be the most primitive of living motmots.

In the mandibular articulation of Protornis the internal process is a long, thin splint set off from a well-developed retroarticular process by a distinct notch, with the actual articulating surface for the quadrate much reduced. This is exactly the condition seen in the Momotidae and Todidae. In the Alcedinidae the articular cup for the quadrate is large and deep, the retroarticular process virtually absent, and the internal process wide, heavy, and triangular, quite unlike Protornis or the motmots and todies. Bee-eaters, Meropidae, have a fairly long, slender internal process, but it is not set off from the retroarticular by a notch, and the articular cup is deep, as in kingfishers. Furthermore, the bill shape of Protornis is not at all like that of the Meropidae.

The shape of the hypotarsus in Protornis is exactly as in motmots and differs from that of the kingfishers, in which it projects above the cotylae in a distinct point. The tarsometatarsus of Protornis is only slightly shorter than the middle toe with claw, as in the motmots. In todies the tarsus is longer than the middle toe with claw, whereas in the kingfishers and bee-eaters the tarsus is squat and much shorter than the middle toe. The procoracoid process appears to be nearly absent in Protornis, as in motmots and todies, whereas it is better developed in kingfishers.

From the evidence detailed above it is clear that Protornis does not belong with the Alcedinidae, where Peyer (1957) placed it. The proportions of the bill and of the hindlimb and toes preclude its assignment to the Todidae. In all of its important features it agrees with the Momotidae. It differs from the modern forms of the family mainly in the shorter mandibular symphysis and the higher, more expanded sternocoracoidal process of the coracoid. Protornis glarniensis should, therefore, be assigned to the family Momotidae.

A second fossil from the Glarner Fischschiefer, consisting of a slab with both hindlimbs, the right wing, some ribs, and portions of the pelvis superimposed on the sternum, was assigned to the genus Protornis by Peyer (1957), who suggested that it might, be referable to the species $P$ glarniensis. This is plainly impossible, for the second specimen 

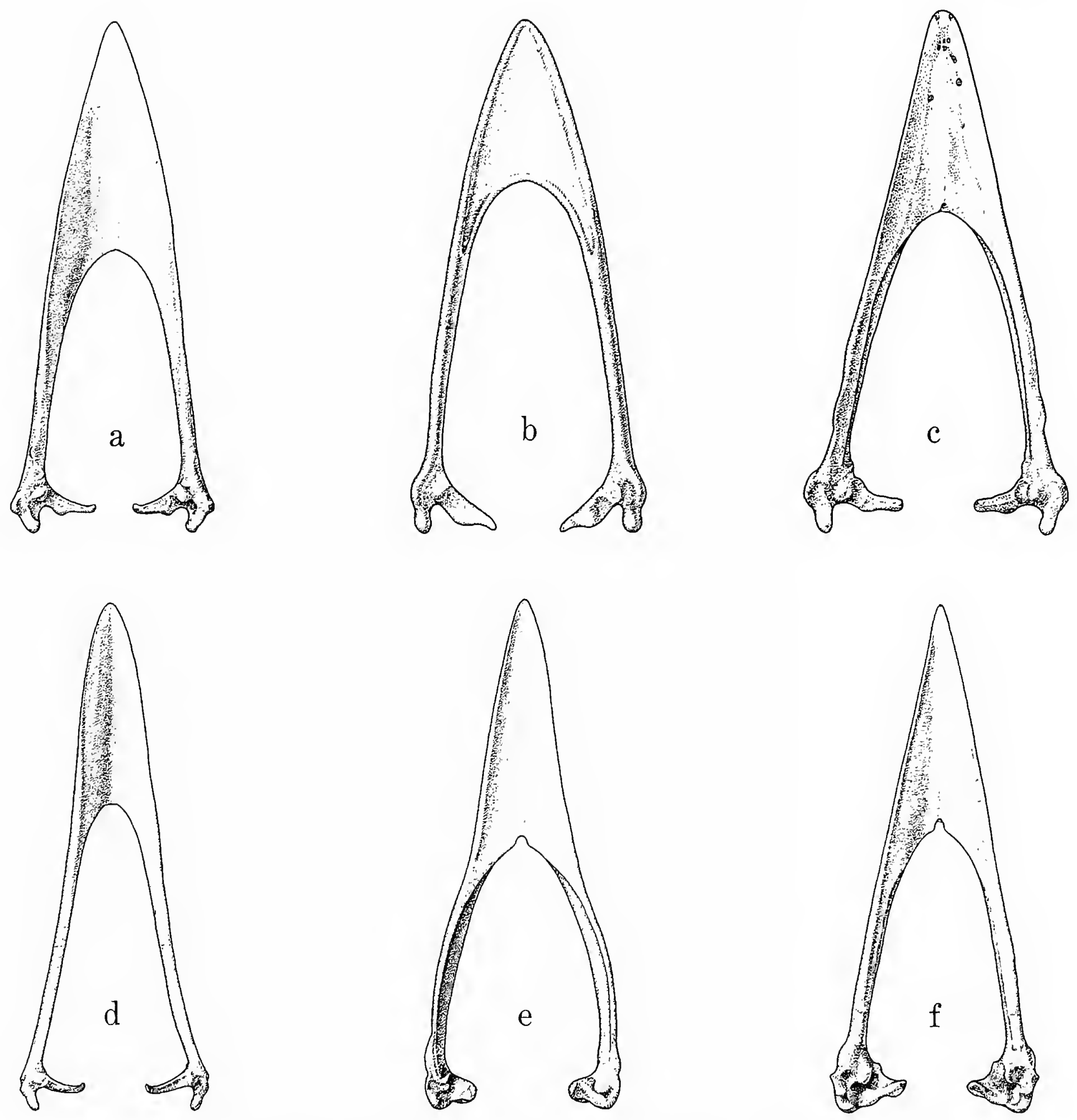

Figure 2.-Dorsal views of mandibles: $u$, Electron platyrhynchum; b, Protornis glarniensis (adapted from Peyer, 1957); $c$, Hylomanes momotula; d, Todus subulatus; e, Myioceyx lecontei; f, Dacelo novaeguineae. (Not to scale.)

is much too large to belong to the same species as $P$. glarniensis; the carpometacarpus, for example, is twice as long. Furthermore, in the right foot of this specimen it can be clearly seen that both digits I and II are reversed (Figure 3)-a condition found only in the Trogonidae among modern birds. The rest of the skeleton of this specimen is generally similar to that of modern trogons, although differing in some details. This specimen deserves a great deal more attention since it provides the 


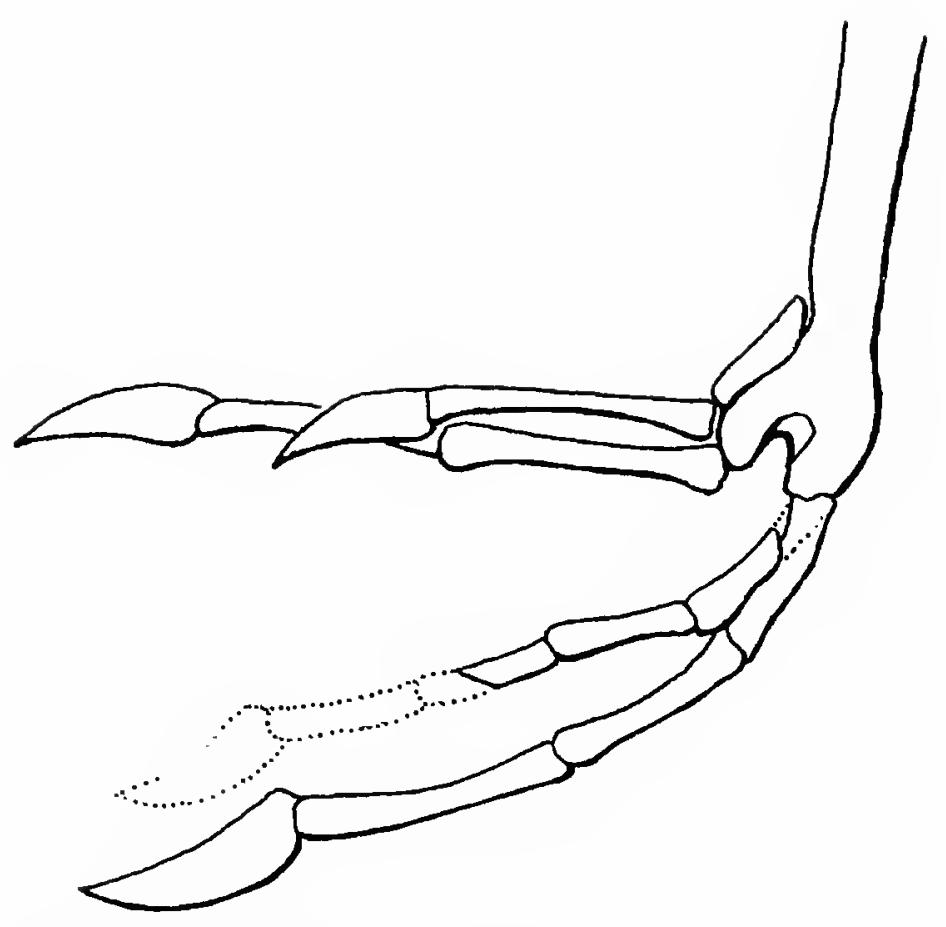

Figure 3.-Diagram of right foot of the so-called second specimen of Protornis showing the heterodactyl condition typical of the Trogonidae. (Adapted from Peyer, 1957, and a cast of the specimen; the distal portion of the fourth toe is present as an impression in the matrix.)

earliest evidence of the occurrence of the heterodactyl foot. It obviously cannot be assigned to Protornis or the Momotidae and for the present should be regarded as belonging to the Trogonidae. Four fossil species of trogons are known-all from France (Brodkorb, 1971). Three of these, in the genus Archaeotrogon, are from the Phosphorites du Quercy, which range in age from upper Eocene to lower Oligocene, and are thus possibly contemporaneous with the Swiss specimen. The fourth species, Paratrogon gallicus, is from lower Miocene (Aquitanian) deposits at Langy.

A second species of Protornis, P. blumeri, was described from the Glarner Fischschiefer in 1865 by Heer (1876). The type appears to have been poorly preserved and has not been restudied, its whereabouts being unknown. Brodkorb (1971) placed this species, along with $P$. glarniensis, in the Alcedinidae, but considered its position uncertain. From the original illustration one cannot even ascertain that the specimen was avian. In view of this, and since more than one family of birds occurs in the Glarner deposits, $P$. blumeri should be relegated to the category of Aves incertae sedis.

\section{Discussion}

The ten families of the order Coraciiformes fall into several diverse groups whose relationships within and without the order are as yet uncertain. Sibley and Ahlquist (1972:230) maintained that, "no compelling evidence exists to ally any group of the Coraciiformes more closely to a noncoraciiform than to other members of the Coraciiformes." On the basis of biochemical analysis of egg-white proteins, Sibley and Ahlquist concluded, as have other taxonomists in the past, that within the Coraciiformes, the Alcedinidae, Todidae, Momotidae, and Meropidae appear to form a natural but distantly interrelated group. Feduccia (1975) discovered that these families possess a highly derived stapes, which is shared only with the Trogonidae, and concluded that all five families are closely related. Contrary to most earlier opinions, Sibley and Ahlquist (1972:230) suggested that the Todidae are more closely allied to the Alcedinidae than to the Momotidae. The osteology of these families does not support this contention, and along with their distributional history strongly indicates that a fairly close affinity exists between todies and motmots and that these families differ considerably from the kingfishers.

Seven of the ten families of Coraciiformes are confined to the Old World. Of approximately 89 Recent species of Alcedinidae, only six, in two genera, are found in the New World. Of these, two are in the genus Ceryle, which also contains two Old World species, while the genus Chloroceryle, which is only weakly differentiated from Ceryle, contains four species endemic to the New World. Clearly the kingfishers are an Old World family that has only recently invaded the Americas. Thus, the Todidae and Momotidae are the only truly New World families of modern Coraciiformes.

Recent motmots are neotropical in distribution, ranging from southern Mexico south through Brazil. In a classical exercise in zoogeography, Chapman (1923) analyzed the distribution of the genera, species, and subspecies of motmots, concluding that they had originated in Central America, the few South American forms having been derived from the north. Lönnberg (1927), noting that Central and North America probably presented a more or less continuous tropical environment in the Tertiary, felt that the motmots could as easily be con- 
sidered North American in origin. A North or Central American origin of the modern members of the family, as opposed to a South American one, has properly gained general acceptance. Nevertheless, this leaves unanswered the question of the origins of ancestral motmots.

The modern todies, confined to the West Indies, are also thought of as being North American in origin. This is due in part to their presumed relationship with the motmots and in part to the North American derivation of most of the rest of the Antillean avifauna (Bond, 1966). It might then be asked whether the todies evolved their distinctive characteristics from some momotid-like ancestor after arriving in the Greater Antilles, or had already assumed these characteristics before colonizing the islands.

Because of the small size and feeble flight of modern todies, Bond (1966) expressed reservations about their ability to cross even narrow water gaps and suggested that they might have been rafted to the West Indies from Central America. However, because the five species of modern todies are very similar in plumage and morphology, one must assume that members of the genus Todus have been able to cross the water barriers between the Greater Antilles within relatively recent geologic time. Moreover, since there are two species of Todus on Hispaniola, one must either assume sympatric speciation or a double invasion of the island. Bond's own remarks (1974) on the greater similarity of the voice of Hispaniolan T. angustirostris to that of Cuban $T$ multicolor than to that of the other Hispaniolan species, T. subulatus, suggest a double invasion. Thus, if todies were able to cross the water barriers between the islands of the Greater Antilles they might as easily have crossed from the mainland. Furthermore, the evidence provided by Palaeotodus shows that in the Oligocene, todies were larger and had proportions suggestive of greater powers of flight. It therefore seems possible that todies might have colonized the West Indies over water as easily as, say, kingfishers, and it is not necessary to invoke rafting to explain their present distribution.

Without doubt, the order Coraciiformes, as traditionally conceived, arose in the Old World. The existence of Protornis in the lower Oligocene of Switzerland now provides evidence that the family
Momotidae, presently confined to the New World, actually had its origins in the Old World. The place and time of origin of the Todidae are uncertain. The Orellan land-mammal stage represents a geologically very short span of time following the much longer Chadronian stage and preceeding the Whitneyan stage, the latter also representing a very short span of time. The deposits from which Palaeotodus was recovered are about 30 million years old and have traditionally been regarded as middle Oligocene, although there is as yet no paleontological correlation between the North American terrestrial deposits of so-called Oligocene age and those of Europe. By the reduced ossification of the skull, Palaeotodus certainly seems to be referable to the Todidae rather than the Momotidae, but perhaps with material from earlier in the Oligocene it would not be possible to distinguish the two families, the family Todidae having assumed its characteristics since that time.

Probably through a combination of climatic change and competition with more advanced land birds, the motmot-tody group was entirely supplanted in the Old World. The deterioration of tropical conditions in North America in the late Tertiary left motmots only in Central America, from whence they have spread into South America since the closing of the Panamanian seaway in the late Pliocene. Similar factors affected the North American todies and only the isolated West Indian relicts of the genus Todus have survived up to the present.

Feduccia and Martin (p. 110, herein) have shown that the predominant order of small land birds of the Eocene in North America was the Piciformes. It is now becoming evident that the Oligocene was similarly important in the evolution of the Coraciiformes. Although the evidence is far from conclusive, if the Coraciiformes (including the Trogonidae) were not the predominant perching land birds of the Oligocene, they were certainly much more prevalent than today. Recently I have examined a number of fragments of small land birds of Chadronian and Orellan age from the western United States. All of these appear to be referable either to the Coraciiformes or Piciformes and definitely are not passerine. Thus, it would appear that the Passeriformes may not have gained a strong foothold in North America until the Miocene. 


\section{Literature Cited}

Baumann, E.

1958. Affine Entzerrug mit einfachen optischen Mitteln. Schweizerische Paläeontologische Abhandlungen, 73:17-21, 4 figures. [Separate.]

Bock, W. J.

1962. The Pneumatic Fossa of the Humerus in the Passeres. $A u k, 79(3): 425-443,2$ figures.

Bond, J.

1966. Affinities of the Antillean Avifauna. Caribbean Journal of Science, 6:173-176.

1974. Nineteenth Supplement to the Check-list of Birds of the West Indies (1956). 12 pages. Philadelphia: Academy of Natural Sciences of Philadelphia.

Brodkorb, $\mathbf{P}$.

1971. Catalogue of Fossil Birds, Part 4 (Columbiformes through Piciformes). Bulletin of the Florida State Museum, Biological Sciences, 15(4):163-266.

Chapman, F. M.

1923. The Distribution of the Motmots of the Genus Momota. Bulletin of the American Museum of Natural History, 48:27-59, 4 figures.

Feduccia, A.

1975. Morphology of the Bony Stapes (Columella) in the Passeriformes and Related Groups: Evolutionary Implications. The University of Kansas Museum of Natural History Miscellaneous Publication, 3:1-34, 7 figures, 16 plates.

Heer, 0 .

1876. The Primaeval World of Switzerland. Volume 1. London: Longmans, Green and Co. [English translation of Die Urwelt der Schweiz, Volume 1. Zürich, 1856 (not seen).]

Lambrecht, $\mathrm{K}$.

1933. Handbuch der Palaeornithologie. xix + 1024 pages. Berlin: Gebrüder Bornträger.
Lönnberg, E.

1927. Some Speculations on the Origin of the North American Ornithic Fauna. Kungliga Suenska Ventenskapakademiens Handlingar, series 3, 4(6):1-24. von Meyer, $\mathrm{H}$.

1839. Ein Vogel im Kreideschiefer des Kantons Glaris. Neues Jahrbuch für Mineralogie, Geognosie, Geologie und Petrefaktenkunde, 1:683-685.

1844. [Letter.] Neues Jahrbuch für Mineralogie, Geognosie, Geologie und Petrefaktenkunde, 6:329-340.

1856. Schildkröte und Vogel aus dem Fischschiefer von Glarus. Palaeontographica, 4(3):83-95, 2 plates.

Newton, A.

1896. A Dictionary of Birds. 1088 pages. London: Adam and Charles Black.

Peyer, B.

1957. Protornis glaronensis H. v. Meyer Neubeschreibung des Typusexemplares und eines weiteren Fundes. Schweizerischen Paläontologischen Abhandlungen, 73:1-47, 26 figures, 11 plates.

Raczyński, J., and A. L. Ruprecht

1974. The Effect of Digestion on the Osteological Com position of Owl Pellets. Acta Ornithologica, 14(2): $1-36$.

Sibley, C. G., and J. E. Ahlquist

1972. A Comparative Study of the Egg White Proteins of Non-Passerine Birds. Peabody Museum of Natural History Yale University Bulletin, 39:1-276, 37 figures.

Stüssi, F.

1958. Die Entzerrung von Fossilien am Beispiel des Protornis glaronensis. Schweizerischen Paläontologischen Abhandlungen, 73:1-16, 13 figures. [Separate.] 



\title{
Two New Species of Aegialornis from France, with Comments on the Ordinal Affinities of the Aegialornithidae
}

\author{
Charles T. Collins
}

\begin{abstract}
Collections from the upper Eocene-lower Oligocene phosphorite deposits of Quercy, France, include numerous fossil elements attributed to two species of Aegialornis. An examination of the humeri in this series disclosed the presence of two unrecgonized species, which are newly described here as Aegialornis wetmorei and $A$. broweri. Preliminary study of the other skeletal elements previously assigned to Aegialornis indicates that at least some of them are probably referable to the Charadriiformes and the Coraciiformes. The humeri of Aegialornis show closer similarity to Chordeiles than to any members of the Hemiprocnidae or Apodidae, and, therefore, the Aegialornithidae is removed from the Apodiformes and placed in the Caprimulgiformes near the Caprimulgidae.
\end{abstract}

\section{Introduction}

In the Museum National D'Histoire Naturelle, Paris, and the British Museum (Natural History), are extensive collections of bird fossils from the upper Eocene to lower Oligocene phosphorite deposits of Quercy, France. These include numerous distinctive humeri and some additional material referred to two species in the genus Aegialornis: $A$. gallicus Lydekker and $A$. leenhardti Gaillard. An additional form, Primapus lacki, was later described from the lower Eocene London Clay of Britain (Harrison and Walker, 1975). Further study of the Quercy material indicates the presence of two additional species of Aegialornis. This ge-

Charles T. Collins, Department of Biology, California State University, Long Beach, California 90840. nus has been placed in a distinct family, the Aegialornithidae, the taxonomic history of which has been summarized by Harrison (1975). The family was first proposed by Lydekker (1891) who treated it as incertae sedis near the Laridae. The subsequent view of Milne-Edwards (1892) and Gaillard (1908) that Aegialornis is more properly included in the Apodiformes has been widely, though seemingly uncritically, accepted. Brodkorb (1971), on the basis of the evidence now presented here, included the Aegialornithidae in the Caprimulgiformes, a placement recently disputed by Harrison (1975). It is the purpose of this paper to review the species of Aegialornis and to comment on the possible affinities of the Aegialornithidae.

A wide array of fossil and recent material was examined in this study. Included were the types of Aegialornis gallicus, A. leenhardti, and Tachyornis hirundo, and much of the additional material referred to these species. Recent skeletons examined included many genera of Caprimulgiformes, particularly Chordeiles, Caprimulgus, and Phalaenoptilus, and from one to several species of swifts and crested swifts in the genera Hemiprocne, Cypseloides, Streptoprocne, Apus, Aeronautes, Reinarda, Hirundapus, and Chaetura.

AcKNowledgments.-The study of these fossils, part of a wider study of the biology and evolution of swifts, has been generously supported by research grants and a postdoctoral fellowship from the Frank M. Chapman Memorial Fund of the American Museum of Natural History. Fossil material was obtained on loan from the Institut de Paléontologie, Museum National D'Histoire Naturelle, Paris (PM); the Department of Paleontology, British Museum (Natural History) (BMNH); and the Musée D'Histoire Naturelle de Montauban. 
Recent comparative material of Hemiprocne was obtained from the National Museum of Natural History, Smithsonian Institution. I am indebted to the curators of these institutions for their kindnesses. C. J. O. Harrison and C. A. Walker generously provided advance copies of their papers and photographs of Primapus. John Auth provided essential photographic assistance.

AEGIALORNITHIDAE Lydekker, 1891

Aegialornis Lydekker, 1891

Synonyms.-Tachyornis Milne-Edwards, 1892; Belornis Milne-Edwards, 1893.

\section{Aegialornis gallicus Lydekker, 1891}

Figures $1,4 b$

Type-Locality.-Departement de Lot, Bach near Lalbenque, France.

SYNONYM.-Tachyornis hirundo Milne-Edwards, 1892. France, Phosphate de Chaux (= Phosphorites du Quercy, fide Gaillard, 1908).

This species is represented by at least $20 \mathrm{hu}-$ meri: the type-series of 13 and 2 additional specimens in the British Museum, and 5 specimens, including the type of Tachyornis hirundo, in the Paris Museum. Referred material includes 2 coracoids, 3 ulnae, 11 carpometacarpi, and 3 proximal phalanges of digit II (BMNH); and 26 tarsometatarsi (PM). As noted by Lydekker (1891) and Harrison and Walker (1975), the humerus is short and stout with a long, prominent, angular deltoid crest; deep ligamental furrow; large, flattened ectepicondylar process; laterally compressed head; broad bicipital surface and bicipital crest; and deep brachial depression. The humeri of $A$. gallicus are

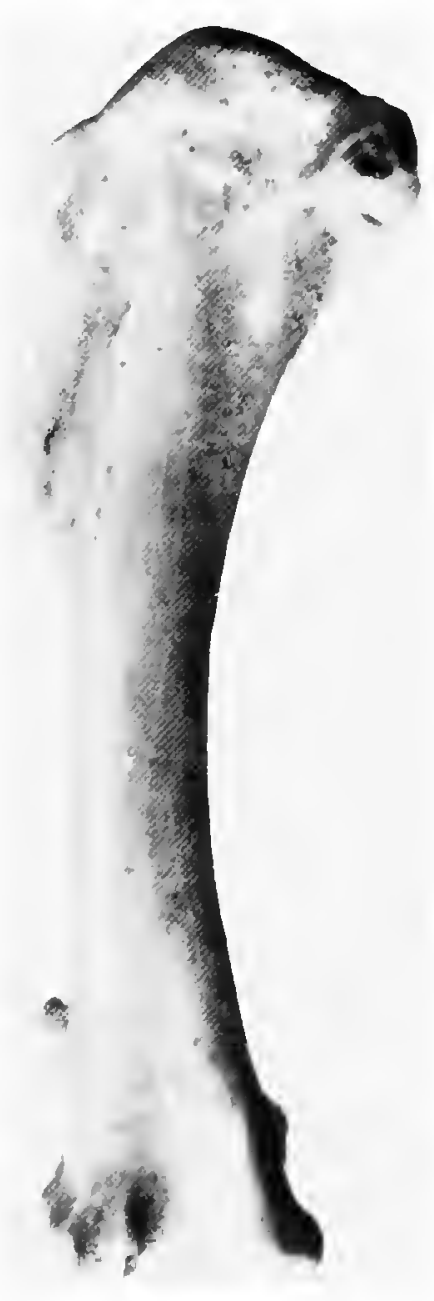

$\mathbf{a}$

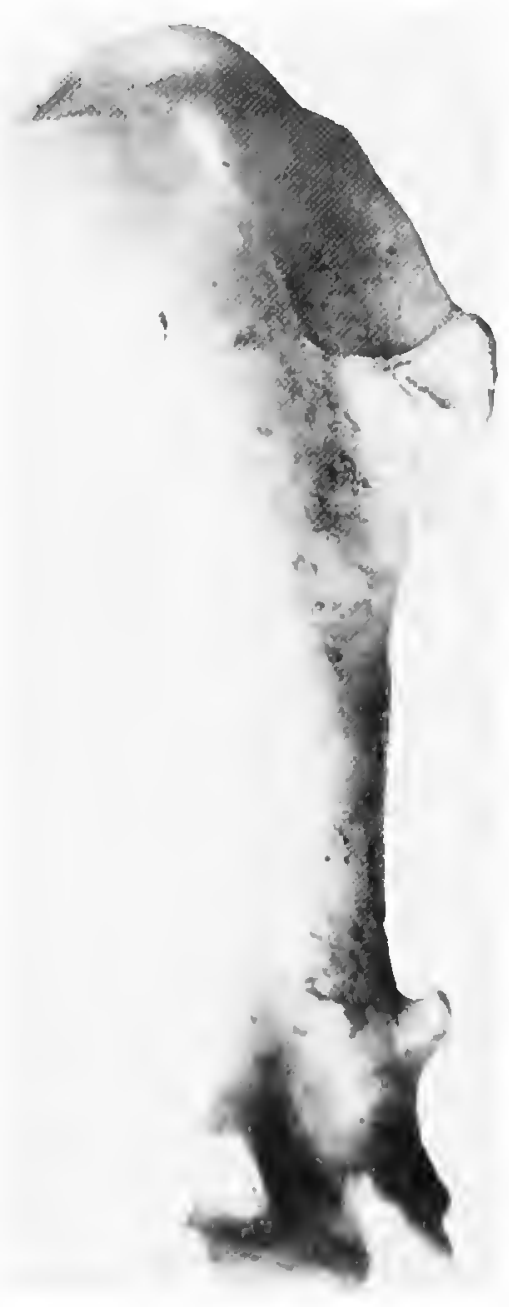

b

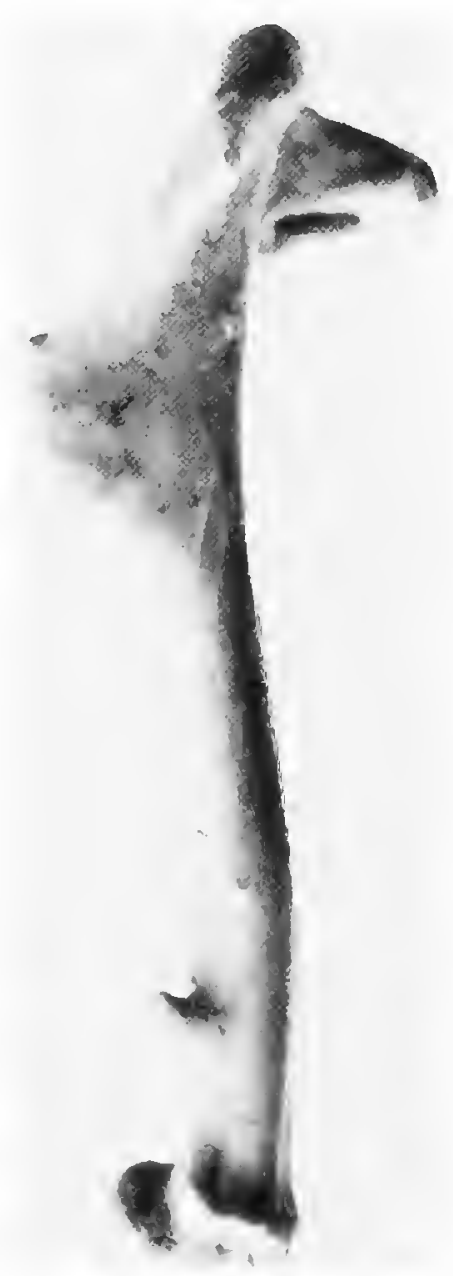

C

FIgURE 1.-Left humerus of Aegialornis gallicus: $a$, anconal view; $b$, palmar view;

$c$, external view. ( $\times$ 4.) 
TABle 1.-Ranges and means (in parentheses) of measurements (mm) of humeri in Aegialornis

\begin{tabular}{|c|c|c|c|c|}
\hline Character & $\begin{array}{c}\text { A. leenhardti } \\
n=2\end{array}$ & $\begin{array}{c}\text { A. gallicus } \\
n=20\end{array}$ & $\begin{array}{l}\text { A. wetmorei } \\
n=3\end{array}$ & $\begin{array}{c}\text { A. broweri } \\
n=1\end{array}$ \\
\hline Overall length ....... & $29.2-29.8(29.5)$ & $24.3-27.4 \quad(25.9)$ & $21.8-22.4(22.0)$ & 19.1 \\
\hline Shaft width $\ldots \ldots \ldots \ldots$ & $3.7-3.7 \quad(3.7)$ & $2.5-3.3 \quad(3.1)$ & $2.6-2.8 \quad(2.7)$ & 2.3 \\
\hline Shaft depth & $2.7-2.8 \quad(2.8)$ & $2.2-2.5 \quad(2.4)$ & $2.0-2.1 \quad(2.1)$ & 1.7 \\
\hline $\begin{array}{l}\text { Width of } \\
\text { distal end }\end{array}$ & $7.0-7.3 \quad(7.2)$ & $5.6-6.3 \quad(5.9)$ & $4.9-5.0 \quad(5.0)$ & 4.2 \\
\hline $\begin{array}{l}\text { Depth of } \\
\text { distal end }\end{array}$ & $3.9-4.1 \quad(4.0)$ & $3.6-4.0 \quad(3.7)$ & $3.2-3.4 \quad(3.3)$ & 2.7 \\
\hline $\begin{array}{l}\text { Height of } \\
\text { ectepicondylar } \\
\text { process }\end{array}$ & $5.9-6.1 \quad(6.0)$ & $5.5-6.3 \quad(6.0)$ & $6.1-6.2 \quad(6.2)$ & 4.8 \\
\hline $\begin{array}{l}\text { Height of } \\
\text { ectepicondylar } \\
\text { process as } \% \text { of } \\
\text { total length }\end{array}$ & 20.33 & 23.04 & 28.03 & 25.1 \\
\hline
\end{tabular}

smaller than those of $A$. leenhardti (Table 1), but larger than those of other species of Aegialornis or Primapus. The referred elements, not all of which appear to be properly assigned to Aegialornis, are discussed below.

\section{Aegialornis leenhardti Gaillard, 1908}

Figures 2, $4 a$

SYNONYM.-Originally proposed as Aegialornis leehnardti Gaillard, 1908; spelling emended to leenhardti by Brodkorb, 1971:233.

Type-Locality.-Phosphorites du Quercy, France.

The holotype right humerus (Musee D'Histoire Naturelle de Montauban) and a previously unrecognized left humerus (PM) agree in being larger than $A$. gallicus and in having a larger and more distally located ectepicondylar process (Table 1). Additional material of this species (not examined in this study) is present in other museum collections (Gaillard, 1908; P. Ballmann, pers. comm.). A left tarsometatarsus from Caylux (Museum de Lyon) figured by Gaillard (1908) appears similar to the numerous tarsometatarsi he referred to $A$. gallicus and which were examined in this study. These specimens are, in my opinion, from an undescribed species possibly belonging in the Coraciiformes.

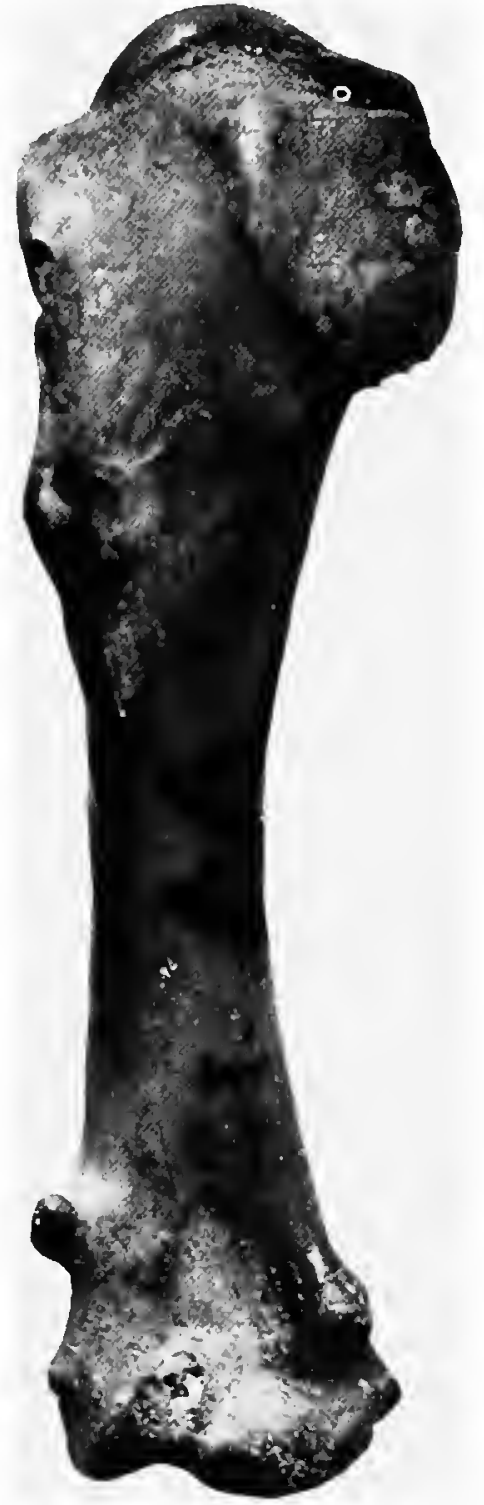

FIGURE 2.- -Holotype right humerus of Aegialornis leenhardti, palmar view. $(\times 4$.) 


\section{Aegialornis wetmorei, new species}

Figures $3 a, 4 c$

Holotype.-Complete right humerus (PM 15478) from the upper Eocene-lower Oligocene Phosphorites du Quercy, France.

Measurements of Holotype.-Overall length from head to internal condyle $21.8 \mathrm{~mm}$, width and thickness of shaft at midpoint $2.8 \times 2.1 \mathrm{~mm}$, greatest width of distal end $5.0 \mathrm{~mm}$, thickness through internal condyle $3.4 \mathrm{~mm}$, height of proximal edge of ectepicondylar process above distal edge of ectepicondyle $6.3 \mathrm{~mm}$.

Paratypes.-Two nearly complete left humeri (PM 15479 and 15480) slightly abraded on deltoid crest, bicipital crest, and internal tuberosity; from the same deposits as the type.

ETYMoLogy.-This species is named after Dr. Alexander Wetmore on the occasion of his ninetieth birthday, in recognition of his many contributions to the field of paleornithology.

DiAgnosis AND DESCRIPTION.-These humeri are appreciably smaller and more slender than the

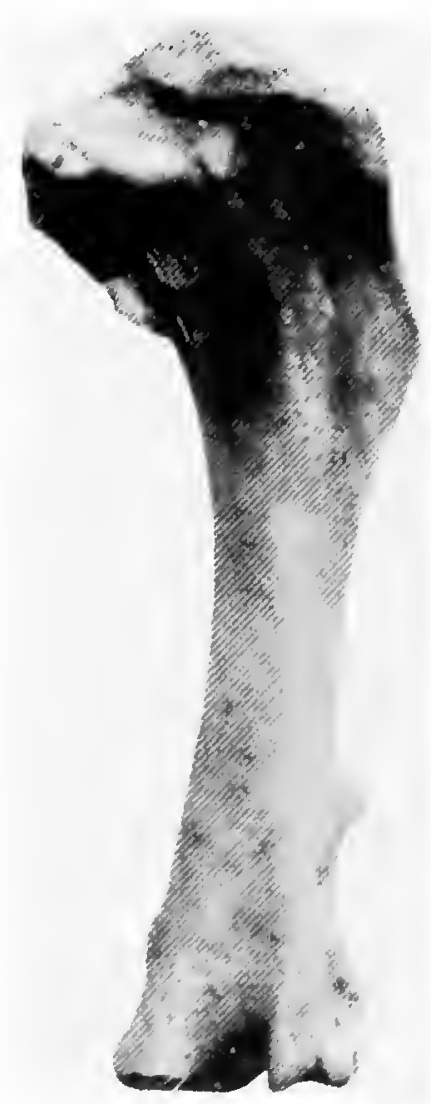

a

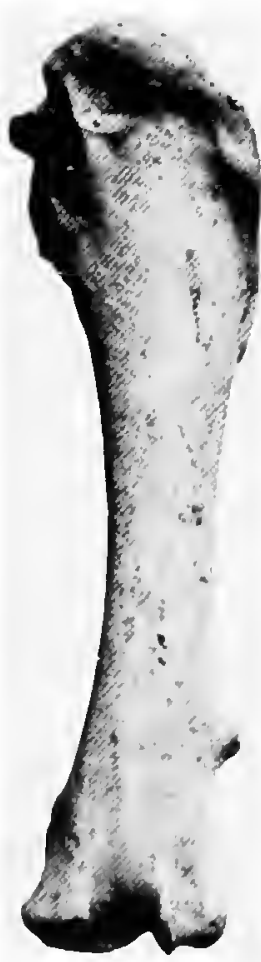

b
FICURE 3.-Holotype right humeri of Aegialornis, anconal views: $a, A$. wetmorei, new species; $b, A$. broweri, new species. $(\times 4$. smallest humerus of $A$. gallicus (the type of Tachyornis hirundo) or that of the still larger species $A$. leenhardti. The ectepicondylar process is less robust than in $A$. leenhardti or A. gallicus and is located farther proximally, being well above the proximal edge of the brachial depression, whereas the ectepicondylar process is located at the level of the proximal end of the brachial depression in $A$. gallicus and $A$. broweri and is somewhat more distal in $A$. leenhardti (Table 1).

\section{Aegialornis broweri, new species}

Figures $3 b, 4 d$

HoLotype.-Nearly complete right humerus (PM 15481) from the upper Eocene-lower Oligocene Phosphorites du Quercy, France.

Measurements of Holotype.-Overall length from head to internal condyle $19.1 \mathrm{~mm}$, width and thickness of shaft at midpoint $2.3 \times 1.7 \mathrm{~mm}$, greatest width of distal end $4.3 \mathrm{~mm}$, thickness of distal end through external condyle $2.6 \mathrm{~mm}$, thickness through internal condyle $2.7 \mathrm{~mm}$, height of proximal edge of ectepicondylar process above distal edge of ectepicondyle $4.8 \mathrm{~mm}$.

ETYMology.-This species is named after Dr. Lincoln P. Brower in recognition of his contributions to other fields of biology and also for instilling in me a way of thinking I have tried to follow throughout my career.

Diagnosis and Description.-The single known humerus of $A$. broweri differs from $A$. leenhardti, $A$. gallicus, and $A$. wetmorei in being smaller, with a proportionately more slender shaft. The ectepicondylar process is more proximally located than in either $A$. leenhardti or $A$. gallicus, but is not as far proximal as in $A$. wetmorei. The brachial depression is less excavated and the muscle attachments of the proximal end are less well defined than in the other species of the genus. The type shows no signs of immaturity and must therefore pertain to an additional small species of Aegialornis in this fauna. The lower Eocene species Primapus lacki is still smaller, the humerus being little more than two-thirds the length of that of $A$. broweri.

\section{Discussion}

It is perhaps surprising that there should be four 
such closely related species of Aegialornis (Figure 4) in the same fauna. The differences in the position of the ectepicondylar process in these forms, however, make it unlikely that the apparent species limits are simply breaks in a continuum of one or two highly variable or sexually dimorphic species. Primapus lacki from the lower Eocene of Britain differs from the four species of Aegialornis in being much smaller and in having a slightly bilobed appearance to the bicipital crest and the entepicondyle projecting distally beyond the internal condyle (Harrison and Walker, 1975). The putative swift, Cypselayus gallicus Gaillard, from the upper Eocene-lower Oligocene Phosphorites du Quercy, was not examined in this study, but as noted elsewhere (p. 131, herein), it appears from the published illustrations that it may be a small member of the Aegialornithidae, about the same size as Primapus lacki. The earliest known modern swift (Apodidae) is Cypseloides ignotus (MilneEdwards) from the lower Miocene (Aquitanian) of France.
The affinity of the Aegialornithidae to the Apodidae and Hemiprocnidae of the suborder Apodi, has been accepted, largely uncritically, since the early suggestions of Milne-Edwards (1892) and Gaillard (1908). This action has recently been endorsed by Harrison (1975) on the basis of a review of the humeri and other referred elements of Aegialornis gallicus and Primapus lacki. From my study of the referred material of $A$. gallicus I am convinced that the coracoids, the proximal phalanges of digit 2, and the tarsometatarsi belong to species in the orders Charadriiformes and Coraciiformes, and thus cannot be used to elucidate the ordinal affinities of Acgialornis. The similarity of some of these elements to those of the Laridae was noted by Lydekker (1891) in the original description of Aegialornis. Until it is possible to restudy all of the referred material, it seems wisest to confine discussion of the possible affinities of Aegialor$n i s$ to characters of the humerus, the type-element in all the species of the Aegialornithidae.

The original allocation of Aegialornis to a fam-

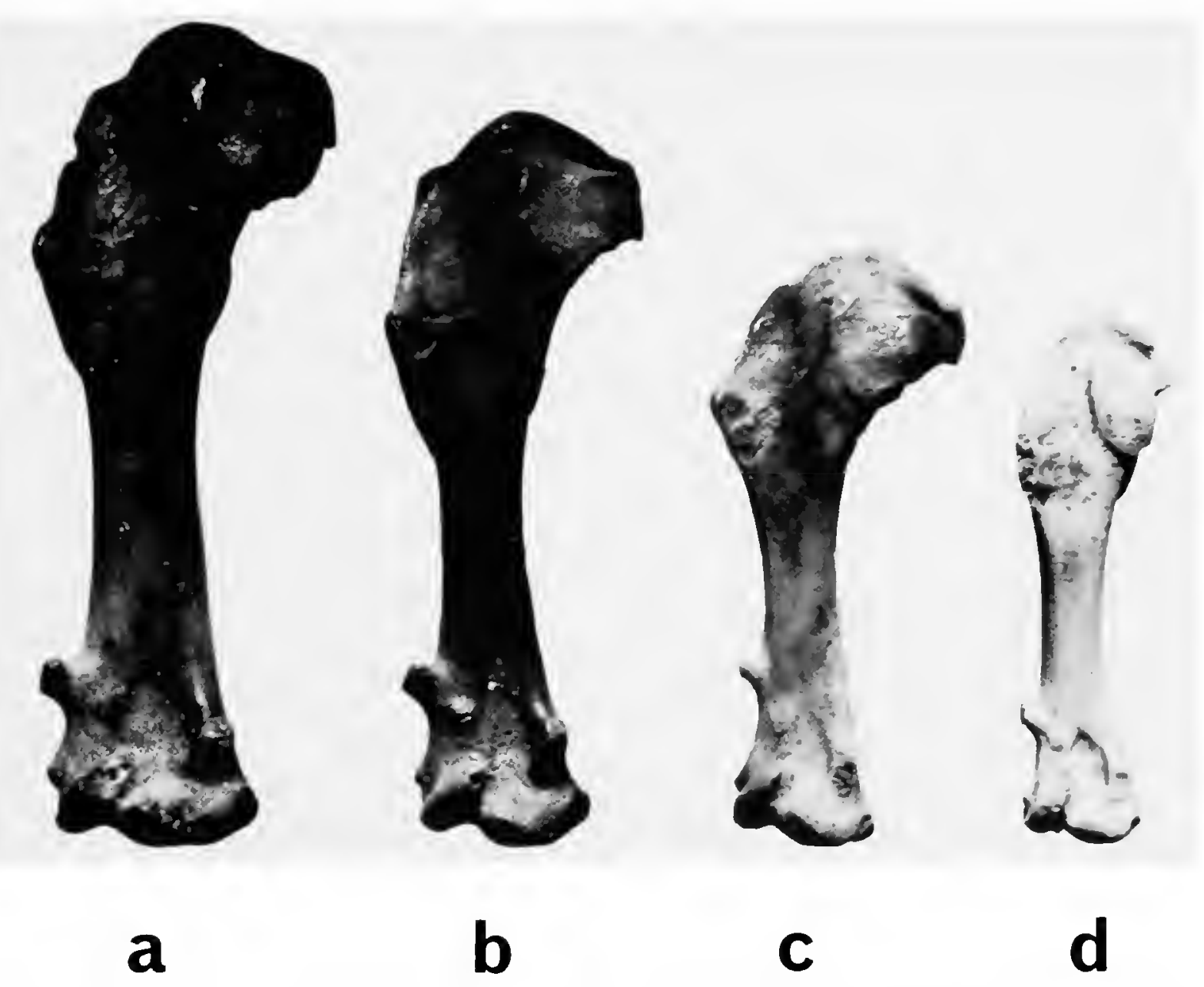

FIGURE 4.-Size comparison of palmar views of right humeri of the four species of Aegialornis: $a, A$. leenhardti, holotype; $b, A$. gallicus; $c, A$. wetmorei, new species, holotype; $d, A$. broweri, new species, holotype. ( $\times 3$.) 
ily within the Apodi seems to have been based principally on the superficial resemblance of the short and stout humeri to those of the Hemiprocnidae and Apodidae. Harrison (1975) also cites the prominent ectepicondylar process, shorter and more abruptly projecting deltoid crest, less proximally deflected internal tuberosity, and the presence of the distinct flange on the bicipital crest as characteristics shared with the Apodi. Although there are some definite similarities between the humeri of Aegialornis and those of the Apodi, particularly Hemiprocne, I feel there is a greater resemblance between Aegialornis and some members of the Caprimulgidae, particularly Chordeiles and related genera (the Chordeilidae of Oberholser, 1914).

In Aegialornis the head is deflected anconally and the distal end is directed palmarly. This condition, somewhat accentuated by the longer shaft, is also found in Chordeiles. The humerus is notably straight in Hemiprocne and the primative swifts of the subfamily Cypseloidinae; only a slight anconal deflection of the head is present in the Apodinae and Chaeturinae. The deep ligamental furrow in Aegialornis and Chordeiles extends well out onto the internal tuberosity, where it curves to approach the distal margin. In the Apodi the ligamental furrow is shorter and straighter, ending near the proximal base of the internal tuberosity. In Chordeiles the internal tuberosity is deffected slightly more proximally at the tip than in Aegialornis, and the pnenumatic fossa is more exposed. In the Apodi the internal tuberosity projects laterally or is deflected clistally and bears little resemblance to that of Aegialornis. A distinct similarity exists between Aegialornis and Chordeiles in the thickened median crest and broadly excavated capital groove proximal to it. A slight projecting flange on the bicipital crest of Aegialornis can also be noted in some specimens of Chordeiles. Although this flange is usually much more highly developed in Aegialornis, considerable variation is shown in the specimens examined in this study, with some individuals showing only slight development of this feature. The shape of the deltoid crest is very similar in Chordeiles and Aegialornis and lacks the more abrupt taper and concave proximal edge of the Apodi. The deltoid crest is appreciably different in other genera of the Caprimulgidae (e.g., Caprimulgus and Phalaenoptilus), which have a more flattened lateral edge and a longer, more gradual slope to the distal edge. Thus, only some of the genera of Caprimulgidae have the "longer and more smoothly rounded" profile of the deltoid crest incorrectly attributed to the entire family by Harrison (1975).

The distal end of the humerus shows many similarities between Aegialornis, Hemiprocne, and to a lesser extent Streptoprocne, in the flared external tricipital groove and medially expanded entepicondyle. Aegialornis and Chordeiles are alike in having a broader and more protruding attachment for the anterior articular ligament and a deeper intercondylar groove. A large peglike ectepicondylar process, the single most distinctive characteristic of the humeri of swifts and Aegialornis, is accompanied by a distinct, raised lateral muscle scar at its base in Aegialornis which is lacking in the Apodi. A small ectepicondylar process and associated muscle scar is also present in Chordeiles and, as noted by Harrison (1975), in Podager. In the Apodi the ectepicondylar process is never as thickened as in Aegialornis and is always substantially more proximally located. In some of the Apodi there is also a secondary process located distal to the ectepicondylar process. This is particularly well developed in the Hemiprocnidae and Cypseloidinae but completely absent in Aegialornis. Within the Caprimulgidae there is considerable difference in the appearance of the distal portion of the humerus, as well as in the development of the ectepicondylar process. A strong resemblance to Aegialornis can be found in Ghordeiles and related genera, but not in Caprimulgus, Phalaenoptilus, and Eurostopodus.

Although the Aegialornithidae show some similarities to the Hemiprocnidae, I feel that the majority of the characters of the humeri indicate a closer relationship with the Chordeiles group of the Caprimulgidae. I therefore place the Aegialornithidae as a family within the Caprimulgiformes, possibly allied to the Caprimulgidae.

With the tentative removal of Cypselavus gallicus from the Apodidae to the Aegialornithidae, the earliest fossil swifts appear in the lower and middle Miocene deposits of France (p. 131, herein). There is thus no longer any evidence to support the earlier notion that the Apodidae and Aegialornithidae were contemporaneous during the late Eocene or early Oligocene. Therefore, the possi- 
bility exists that the Aegialornithidae are representatives of a caprimulgiform lineage that later gave rise to the swifts and crested swifts. Although a close relationship between the Caprimulgiformes and the Apodi is not supported by presently available biochemical information (Sibley and Ahl- quist, 1972), neither does this information provide any conclusive evidence of the affinities of swifts to other groups. A caprimulgiformapodiform relationship should be reviewed further when additional fossil elements are found that can definitely be assigned to the Aegialornithidae.

\section{Literature Cited}

Brodkorb, P.

1971. Catalogue of Fossil Birds, Part 4 (Columbiformes through Piciformes). Bulletin of the Florida State Museum, Biological Sciences, 15(4):163-266.

Gaillard, C.

1908. Les oiseaux des phosphorites du Quercy. Annales de l'Université de Lyon, new series, 1(23):1-178, 37 figures, 8 plates.

Harrison, C. J. 0.

1975. Ordinal Affinities of the Aegialornithidae. Ibis, $117(2): 164-170,5$ figures.

Harrison, C. J. O., and C. A. Walker

1975. A New Swift from the Lower Eocene of Britain. Ibis, 117(2): 162-164, plates 14-15.

Lydekker, $\mathbf{R}$.

1891. Catalogue of the Fossil Birds in the British Museum (Natural History). 368 pages. London: Taylor and Francis.
Milne-Edwards, A.

1892. Sur les oiseaux des dépots Eocénes des phosphates de chaux du sud de la France. Pages 60-80 in volume 2 of $C . R .2^{m \theta}$ International Ornithological Congress, Budapest 1891.

1893. [Letter.] Bulletin of the British Ornithologists' Club, 1:53-54.

Oberholser, H. C.

1914. A Monograph of the Genus Chordeiles Swainson, Type of a New Family of Goatsuckers. Bulletin of the United States National Museum, 86(1):1-123, 6 plates.

Sibley, C. G., and J. E. Ahlquist

1972. A Comparative Study of the Egg White Proteins of Non-passerine Birds. Peabody Museum of Natural History, Yale University, Bulletin, 39:1-276, 37 figures. 



\title{
A Review of the Lower Miocene Swifts (Aves: Apodidae)
}

\author{
Charles T. Collins
}

\begin{abstract}
Three nominal species of swifts have been described from lower Miocene (Aquitanian) deposits of France. Re-examination of these forms, Cypselus [=Apus] ignotus Milne-Edwards, Collocalia incerta Milne-Edwards, and Cypselavus intermedius Gaillard, indicates that they are attributable to a single species, ignotus, referable to the modern genus Cypseloides. This provides the first occurrence of the Cypseloidinae in the fossil record and indicates a possible origin in the Old World for this primitive group of swifts, presently restricted to the New World.
\end{abstract}

\section{Introduction}

Up to now, five species of fossil swifts have been described, all coming from Tertiary deposits in France. The present paper is aimed at reviewing the three nominal species from deposits of early Miocene age, with comparisons being made with a much wider array of skeletal material of modern swifts than were available to the original describers of the fossil forms. Recent swifts examined in this study included Cypseloides rutilus, C. cherriei, C. niger, and Streptoprocne zonaris in the Cypseloidinae; from one to several species in the genera Apus, Aeronautes, Cypsiurus, Tachornis, Reinarda, and Panyptila in the Apodinae; and Chaetura, Collocalia, and Hirundapus in the Chaeturinae.

Acknowledgments.-I thank the Frank M. Chapman Memorial Fund of the American Museum of

Charles T. Collins, Department of Biology, California State University, Long Beach, California 90840.
Natural History for support and I am also indebted to Dr. J. P. Lehman of the Institut de Paléontologie, Museum National D'Histoire Naturelle, Paris, for lending the types of Cypselus ignotus and Collocalia incerta.

\section{Family APODIDAE}

\section{Subfamily CYPSELOIDINAE}

\section{Cypseloides ignotus (Milne-Edwards, 1871)}

Cypselus ignotus Milne-Edwards, 1871:394, pl. 177: figs. 9-13. Apus ignotus.-Paris, 1912:286.

Collocalia incerta Milne-Edwards, 1871:394, pl. 177: figs. 1-8. Cypselavus intermedius Gaillard, 1939:42, fig. 20.

From the Aquitanian deposits at St.-Gerand-lePuy, Departement de Allier, France, MilneEdwards (1871) described a new species of swift, Cypselus [=Apus] ignotus. This was based on a complete right carpometacarpus and a left ulna with the proximal end badly chipped. When I examined these specimens, a second left ulna, excellently preserved, had somehow been associated with the two syntypes. This is identical to the first ulna and I therefore refer it to the species ignotus also. From the same deposits, Milne-Edwards (1871) named a second species of swift, Collocalia incerta, based on a single well-preserved left tibiotarsus. This was characterized as being much too small to have come from the same species as the wing elements assigned to Apus ignotus. Considerably later, Gaillard (1939) reported a left humerus of a swift from Aquitanian deposits at Chavroches, also in the Departement de Allier, which he described as a new species, intermedius, in the 
Eocene-Oligocene genus Cypselavus (Gaillard, 1908).

I have studied the original material of Apus ignotus and Collocalia incerta as well as Gaillard's (1939) description and illustrations of Cypselavus intermedius. While all these fossils clearly belong to the Apodidae, it is equally apparent that none is referable either to Apus or to Collocalia.

In size and conformation, the two ulnae of ignotus (Figure 1a) are very similar to those of some of the smaller species of the genus Cypseloides. They lack the well-developed olecranal process found in the subfamilies Apodinae and Chaeturinae. This condition is typical of the Cypseloidinae. The fossil ulnae are slightly longer and stockier than the ulnae of Cypseloides rutilus or C. cherriei, and the prominence for the anterior articular ligament is more shelf-like. Also, the ex-

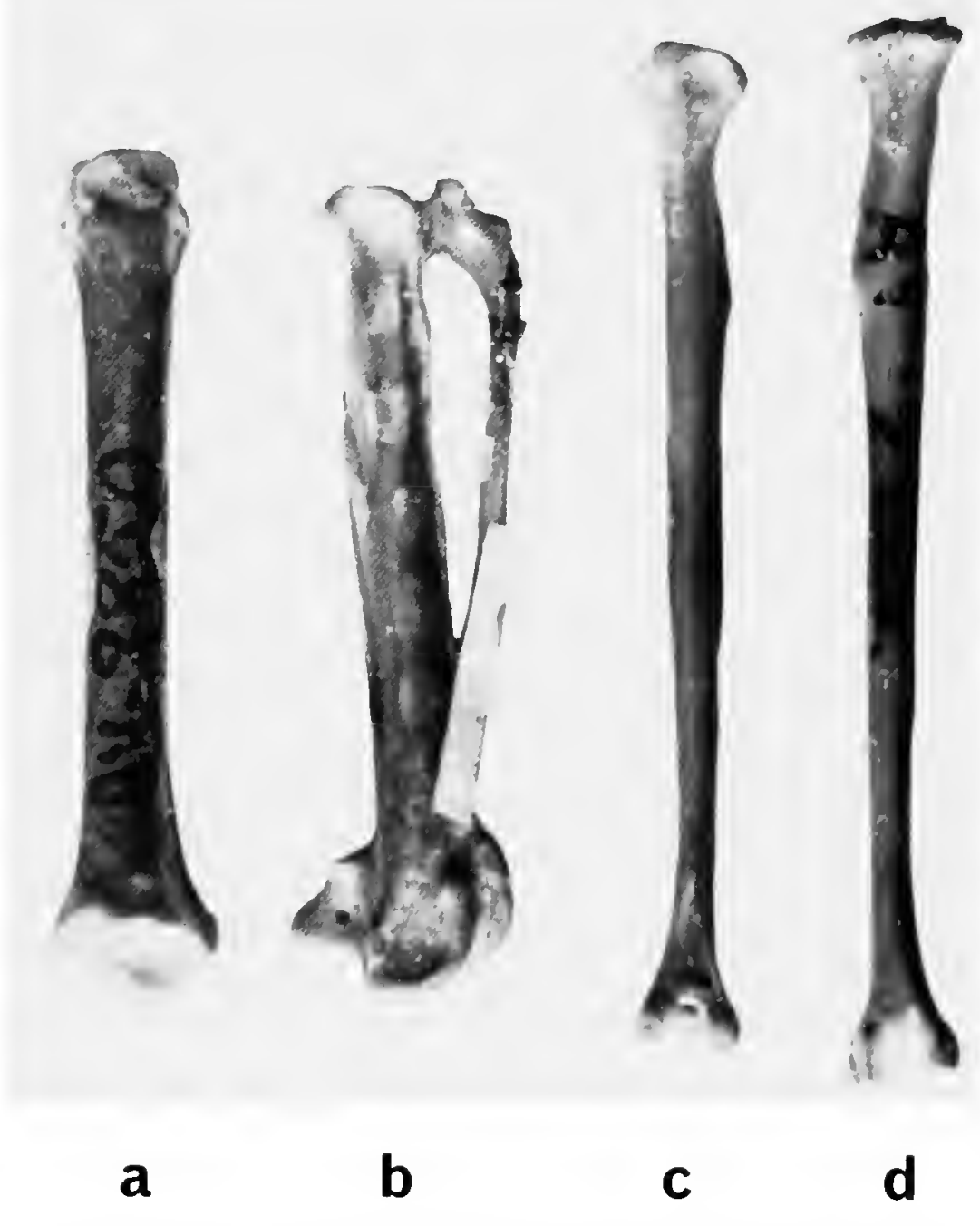

Figure 1.-Bones of Cypseloides ignotus (Milne-Edwards): $a$, referred left ulna; $b$, syntype right carpometacarpus; $c$, left tibiotarsus (holotype of Collocalia incerta), anterior vicw; $d$, same, posterior view. (Approximately $\times 3.5, c$ and $d$ at slightly different magnifications.) ternal cotyla appears slightly more undercut at its palmar edge and the distal ligamental attachment of the carpal tuberosity is less laterally flared.

The carpometacarpus of swifts shows less marked distinctions between the subfamilies than does the ulna. That of ignotus (Figure $1 b$ ) is somewhat longer and stockier than in Cypseloides rutilus or C. cherriei, but it does have the more widely flared pollical facet of metacarpal I and the more pronounced tendinal groove on metacarpal II typical of the Cypseloidinae. The fossil also has a broader and more flared tuberosity of metacarpal II, providing a wider articular facet for digit II, which is typical of the two smaller species of Cypseloides studied, but not of swifts of other subfamilies.

As noted by Milne-Edwards (1871) the tibiotarsus of Collocalia incerta (Figure $1 c, d$ ) is indeed more delicate than would be expected for any member of the Apodinae or Chaeturinae of the size of Apus ignotus. However, the tibiotarsus in the Cypseloidinae is proportionately more slender than in the other subfamilies of swifts, particularly the Apodinae. There is, in fact, a very close agreement in overall size and morphology between the type of Collocalia incerta and Recent specimens of cypseloides rutilus. The posterior intercondylar groove of incerta is not deeply excavated as it is in members of the Apodinae and Chaeturinae, in cluding Apus and Collocalia. The proximal portion of the shaft is straight, as in Cypseloides, and not distinctly bent laterally as typical of many other swifts. The fossil element is slightly smaller and stockier than in $C$. rutilus ( $C$. cherriei has a much longer tibiotarsus than $C$. rutilus in spite of its having wing elements similar in size to both $C$. rutilus and $A$. ignotus), and the internal ligamental prominence is less developed but more excavated under the lip of the rotular crest.

The wing elements of ignotus are clearly those of a small swift belonging to the genus Cypseloides. The tibiotarsus of incerta similarly shows affinities to Cypseloides particularly to C. rutilus. Contrary to Milne-Edwards (1871), it is entirely probable that these fossils, which are from the same locality and horizon, come from the same species. This species should now be known as Cypseloides ignotus (Milne-Edwards) with incerta becoming a junior synonym, ignotus being chosen on the basis of line priority.

In the referred ulna of Cypseloides ignotus, the 
maximum length is $17.9 \mathrm{~mm}$, distal width $3.2 \mathrm{~mm}$, proximal width $3.7 \mathrm{~mm}$, and shaft width $1.6 \mathrm{~mm}$. No accurate length could be determined for the chipped ulna in which the distal width is $3.2 \mathrm{~mm}$, proximal width $3.7 \mathrm{~mm}$, and shaft width $1.8 \mathrm{~mm}$. The single carpometacarpus measures $16.4 \mathrm{~mm}$ in total length, proximal height $5.2 \mathrm{~mm}$, proximal width $2.35 \mathrm{~mm}$, and distal width $3.95 \mathrm{~mm}$. The tibiotarsus has a total length of $21.1 \mathrm{~mm}$, width across condyles $2.2 \mathrm{~mm}$, width across proximal articular surfaces $2.5 \mathrm{~mm}$, and shaft dimensions of $0.9 \times 1.0 \mathrm{~mm}$ at the narrowest point and $1.0 \times 1.5$ $\mathrm{mm}$ at the middle of the fibular crest.

The type-humerus of Cypselavus intermedius Gaillard (1939) was not examined in this study, but from the original figures it appears to have the distinctively longer and narrow proportions characteristic of the species of Cypseloides. As was noted by Lowe (1939:324), the ectepicondylar process of intermedius is much more distally positioned than in any of the modern forms of the Apodinae or Chaeturinae but is only slightly more distal than in Cypseloides, a genus that was not compared by earlier workers. The measurements of the type of $C$. intermedius as given by Gaillard (1939:43) are: total length $11 \mathrm{~mm}$, proximal width $4.5 \mathrm{~mm}$, distal width $3 \mathrm{~mm}$. Thus, this specimen agrees closely in size with specimens of modern Cypseloides rutilus and $C$. cherriei, and it would therefore also be of the same approximate size as C. ignotus. The type of Cypselawus intermedius comes from the same horizon and from a locality close to that of Cypseloides ignotus. Since it also appears to belong to the genus Cypseloides and is of the same size as C. ignotus, I feel that Cypselavus intermedius should also be synonymized with Cypseloides ignotus. As a result, the genus Cypselavus Gaillard is reduced to a single species, $C$. gallicus, from the upper Eocene or lower Oligocene (Phosphorites du Quercy) of France; the genus Collocalia is deleted from the fossil record; and the earliest fossil possibly attributable to $A$ pus now becomes Apus gaillardi (Ennouchi) from the upper middle Miocene (Tortonian) of France (Brodkorb, 1971).

Although the specimens of Cypselavus gallicus and Apus gaillardi were not examined in this study, the published illustrations are sufficient to determine that neither species shows any similarities to Cypseloides ignotus or the modern Cypseloidinae. In fact, Cypselavus gallicus shows a distinctly closer resemblance to the Aegialornithidae, the humerus agreeing in size with the newly described small aegialornithid Primapus lacki, from the lower Eocene of Britain (Harrison and Walker, 1975). In the published illustrations (Gaillard, 1908), the humerus of Cypselavus gallicus appears to lack the prominant ectepicondylar process seen in the Aegialornithidae, but this could well be the result of damage. The illustrations of the humerus of Apus gaillardi (Ennouchi, 1930 ) show it to have the general proportions of the modern Apodidae and Chaeturinae. This species, and an additional swift from the upper Miocene of Italy, are currently under review elsewhere (P. Ballmann, pers. comm.).

The Cypseloidinae (see Brooke, 1970:14-15 for use of this term) appears to be the most primitive subfamily of the Apodidae. It is therefore not unexpected that an extinct species of Cypseloides be among the earliest known swifts. Like the vultures of the family Cathartidae [= Vulturidae], the modern species of Cypseloidinae are confined to the New World; but also like the Cathartidae (Cracraft and Rich, 1972), they can now be shown to have had a past distribution and possible origin in the Old World. Further elucidation of the origin and evolution of the Apodidae will have to await a review of additional modern forms and the remaining fossil swifts, as well as the swift-like members of the Aegialornithidae (see Harrison and Walker, 1975; Harrison, 1975, Collins, pp. 121-127, herein).

\section{Literature Cited}

Brodkorb, P.

1971. Catalogue of Fossil Birds, Part 4 (Columbiformes through Piciformes). Bulletin of the Florida State Museum, Biological Sciences, 15(4):163-266.

Brooke, R. K.

1970. Taxonomic and Evolutionary Notes on the Sub- families, Tribes, Genera and Subgenera of the Swifts (Aves: Apodidae). Durban Museum Novitates, $9(2): 13-24$.

Cracraft, J., and P. V. Rich

1972. The Systematics and Evolution of the Cathartidae in the Old World Tertiary. Condor, 74(3):272-283, 10 figures. 
Ennouchi, E.

1930. Contribution à l'étude de la faune du Tortonien de La Grive-St-Alban (Isère). 135 pages, 6 plates. Paris: Les Presses Modernes.

Gaillard, C.

1908. Les oiseaux des phosphorites du Quercy. Annales $d u$ Université de Lyon, new series, 1(23):1-178, 37 figures, 8 plates.

1939. Contributions à l'étude des oiseaux fossiles. Archives du Museum d'Histoire Naturelle de Lyon, 15(mémoire 2):1-100, 34 figures.

Harrison, C. J. O.

1975. Ordinal Affinites of the Aegialornithidae. Ibis, 117(2):164-170, 5 figures.
Harrison, C. J. O., and C. A. Walker

1975. A New Swift from the Lower Eocene of Britain. Ibis, 117(2):162-164, 2 plates.

Lowe, P. R.

1938. On the Systematic Position of the Swifts (Suborder Cypseli) and Hummingbirds (Suborder Trochili), with Special Reference to their Relation to the Order Passeriformes. Transactions of the Zoological Society of London, 25(4):307-348, 4 plates.

Milne-Edwards, A.

1871. Recherches anatomiques et paléontologiques pour servir à l'histoire des oiseaux fossiles de la France. 4 volumes (1869-1871). Paris: Victor Masson et Fils.

Paris, $\mathbf{P}$.

1912. Oiseaux fossiles de France. Revue Française d'Ornithologie, 4(37):283-298. 


\title{
A New Osprey from the Miocene of California (Falconiformes: Pandionidae)
}

\author{
Stuart L. Warter
}

\begin{abstract}
Two nearly complete humeri and two partial ulnae from Barstovian age Miocene deposits at Sharktooth Hill, near Bakersfield, Kern County, California, are described as the first known extinct species of the modern genus Pandion. Possible functional implications of the morphological differences observed between the fossil species and modern $P$. haliaetus are discussed and the fossil record of the Pandionidae is reviewed.
\end{abstract}

\section{Introduction}

In 1973 an avian fossil owned by a private collector was brought for identification to the Natural History Museum of Los Angeles County (LACM) by Mr. Raj Guruswami-Naidu. The specimen, from the Miocene Sharktooth Hill beds, was identified by Dr. Hildegarde Howard and me as a right humerus closely resembling that of a modern osprey, Pandion haliaetus. The specimen was cast and returned, subsequently to be obtained anew by the collector and original owner, Mr. William Hawes, who donated it to the LACM, along with portions of a left humerus and parts of right and left ulnae that were found associated with it. Through the courtesy of Dr. Howard, Dr. Lawrence Barnes and Dr. David Whistler, all of the Department of Vertebrate Paleontology, LACM, the specimens were made available to me for study.

Upon detailed comparison, the bones, which

Stuart L. Warter, Department of Biology, California State University, Long Beach, California 90840, and Research Associate, Natural History Museum of Los Angeles County, Los Angeles, California 90007. bear a remarkable resemblance to those of modern Pandion haliaetus, were found to differ from that species in a number of subtle, but apparently significant features. These were considered sufficiently important to warrant recognition of a new species, thus extending the history of the genus Pandion back as far as the Miocene.

The terminology used follows that of Howard (1929) and Fisher (1946). Twelve specimens of modern $P$. haliaetus were examined, four at the LACM and eight at the University of California, Los Angeles. Appreciation is expressed to the curators of these collections for their cooperation. Detailed comparisons are based on skeleton LACM Bi 268, which is typical of larger specimens of $P$. haliaetus.

\section{Pandion homalopteron, new species}

Figures 1-3

Holotype.-Nearly complete left and right humeri and proximal portions of left and right ulnae, all associated; LACM 42815; collected by Mr. William Hawes of Bakersfield, California. Right humerus entire, but shattered and filled in two places with plaster; surfaces of head and internal tuberosity sufficiently intact to permit reasonably accurate total measurement $(151 \mathrm{~mm})$, but other contours of both ends badly eroded; deltoid crest missing. Left humerus consisting of three pieces, plus fragments; shaft and distal end joined by actual contact along external surface, proximal portion joined by comparison with companion right humerus and with left humerus of recent Pandion. Head of left humerus entire, but other contours of proximal end severely eroded; all articular surfaces of distal end intact; only a small portion of 


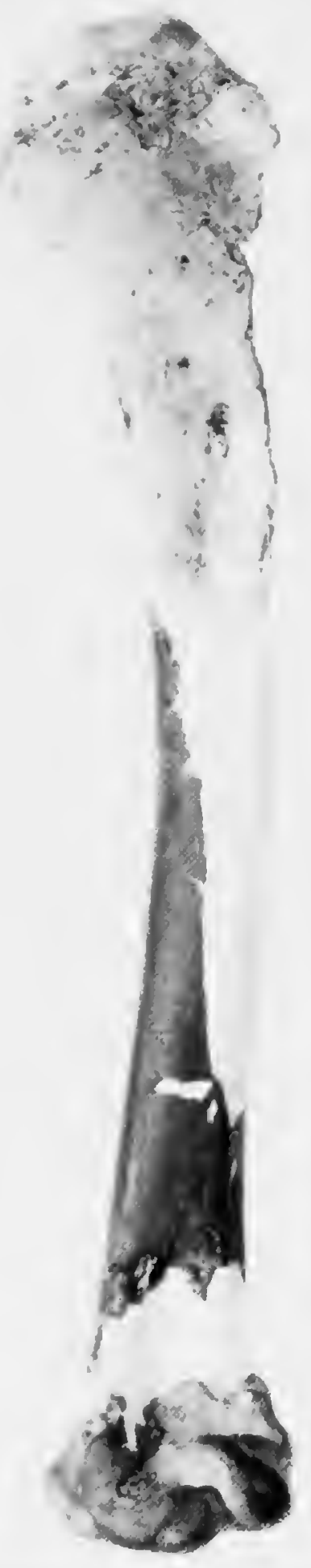

a
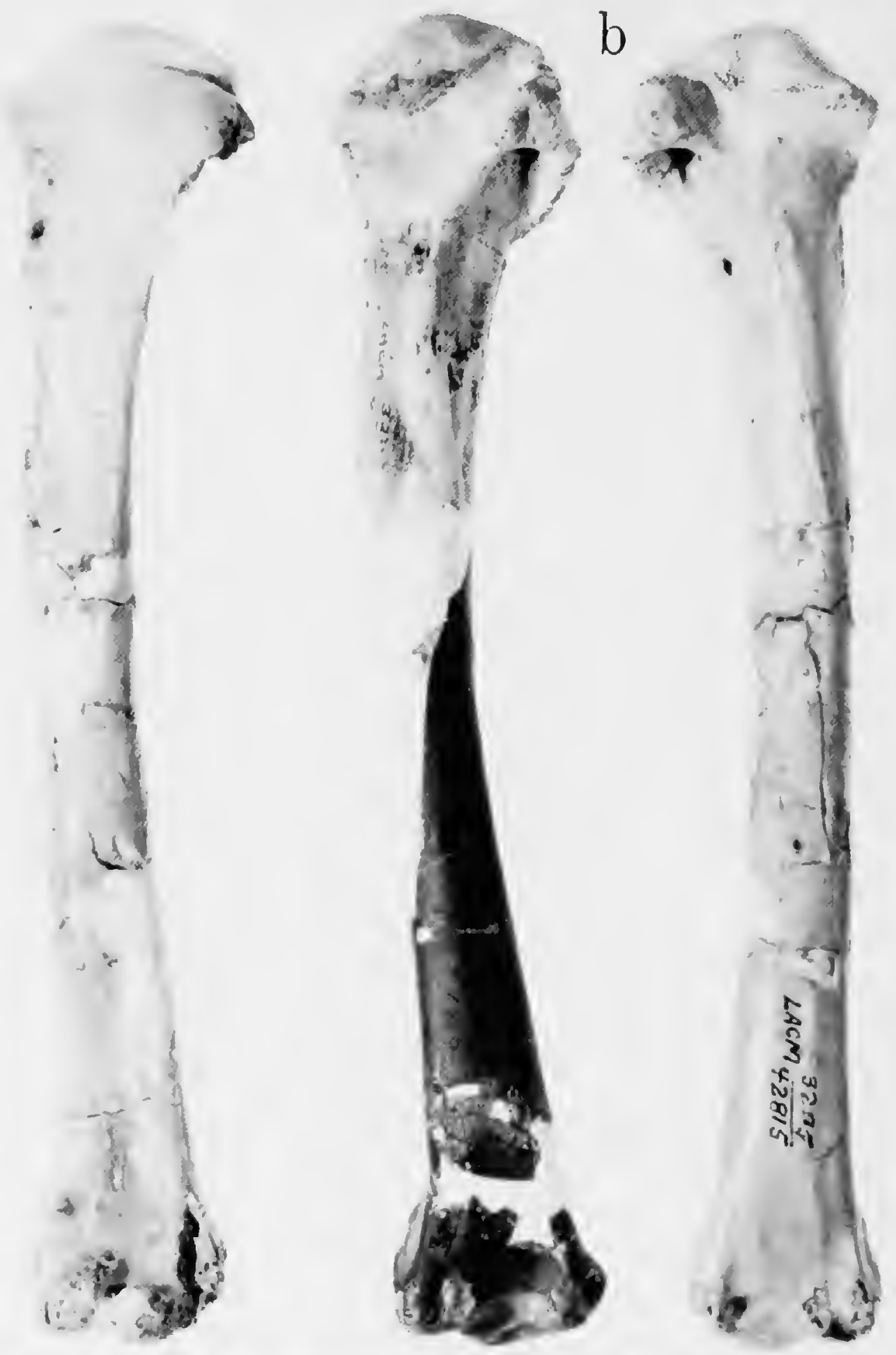

Figure 1.-Holotype humeri of Pandion homalopteron, new species (LACM 42815): a, palmar view and, $b$, anconal view of Jeft and right elements. Natural size. (Courtesy of Natural History Museum of Los Angeles County)

basce of cleltoid crest remaining. Left ulna badly shattered, but nearly complete $(180 \mathrm{~mm})$, lacking approximately $20 \mathrm{~mm}$ or less of the distal end; proximal articular surfaces largely intact, tip of olecranon and tip of external cotyla broken. Right ulna less complete $(120 \mathrm{~mm})$ with proximal articu- lar surface largely intact, but olecranon, tip of internal cotyla, and edge of external cotylit missing; distal $18 \mathrm{~mm}$ of shaft lacking the anconal surface, litst $32 \mathrm{~mm}$ displaced to the palmar side and joined only by matrix. Colors variable: right humerus light tan; right ulnar fragment brown: left hu- 

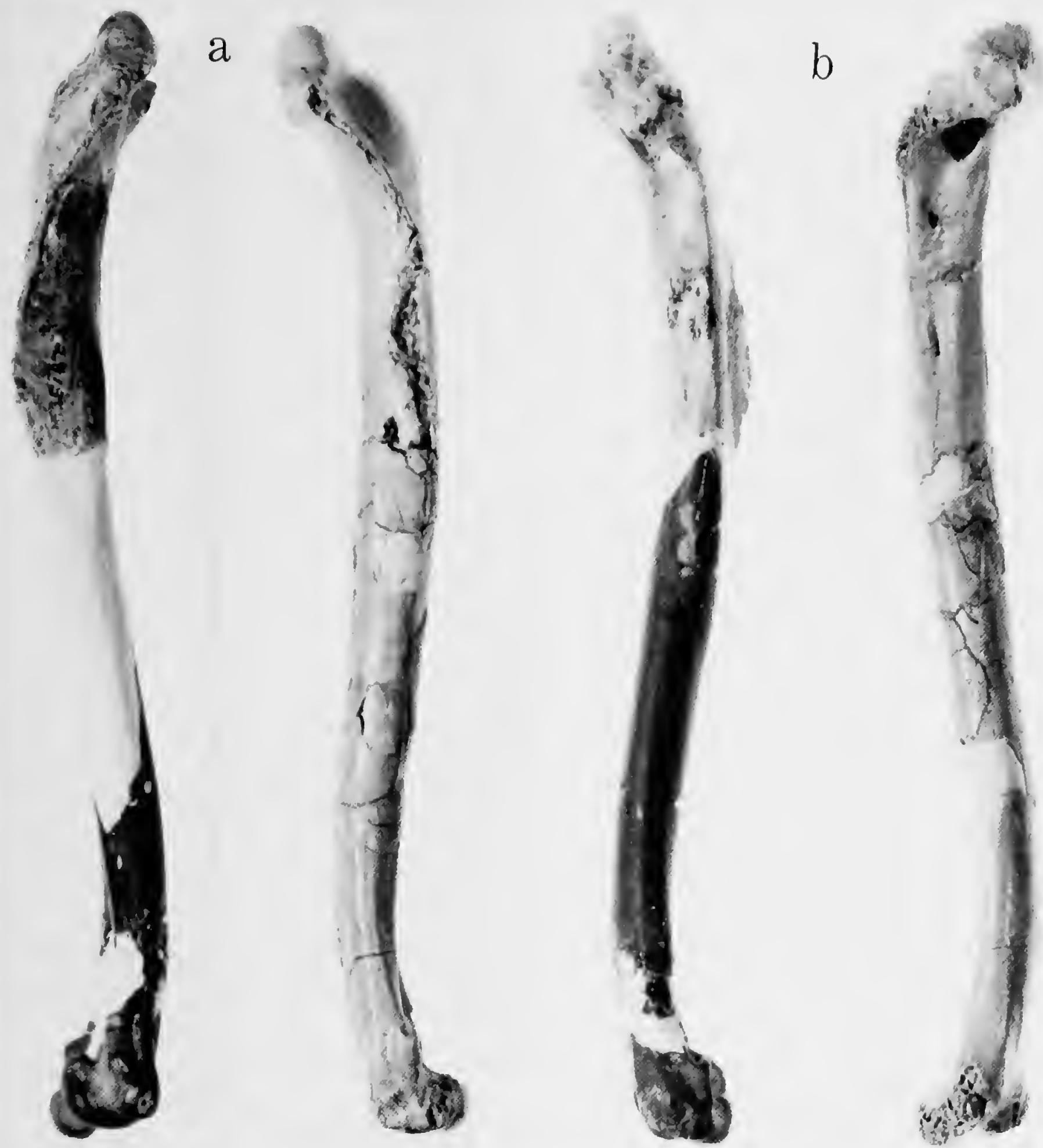

Figure 2.-Holotype humeri of Pandion homalopteron, new species (LACM 42815): $a$, external view and $b$, internal view of left and right elements. Natural size. (Courtesy of Natural History Museum of Los Angeles County)

merus with proximal segment light tan, shaft and distal segment brown; left ulna brown proximally, fading to light tan distally.

Locality and Age.--From the Sharktooth Hill bone bed, middle Miocene (Barstovian age, Savage and Barnes, 1972:133). Round Mountain Silt,
Sharktooth Hill, near Bakersfield, Kern County, California; LACM locality 3205.

Measurements of Holotype.-See Table 1. The brachialis scar of the right humerus is $13 \pm 2.5$ $\mathrm{mm}$ long by $6 \pm 1 \mathrm{~mm}$ wide (margin indistinct) and the'length of the brachialis scar of the right 
TABLE 1.-Measurements (mm) of the holotype humeri ( $R$ $=$ right; $\mathrm{L}=$ left) of Pandion homalopteron, new species, compared with modern $P$. haliaetus

\begin{tabular}{|c|c|c|c|c|}
\hline \multirow{2}{*}{ Character } & \multirow{2}{*}{ P. homalopteron } & \multicolumn{3}{|c|}{$P$. haliaetus } \\
\hline & & mean & range & $n$ \\
\hline Total length & $151(\mathrm{R})$ & 145.9 & $135-154$ & 8 \\
\hline $\begin{array}{l}\text { Width of head from } \\
\text { the external to the }\end{array}$ & & & & \\
\hline internal tuberosity & $27.5(\mathrm{R})$ & 27.1 & $25-28.5$ & 9 \\
\hline $\begin{array}{l}\text { Length from head to } \\
\text { distal margin of }\end{array}$ & & & & \\
\hline deltoid crest & $63(\mathrm{R} \& \mathrm{~L})$ & 63.3 & $58-69$ & 8 \\
\hline $\begin{array}{l}\text { Ratio of above } \\
\text { measurement to } \\
\text { total length }(=\%\end{array}$ & & & & \\
\hline of total length) & 41 & 42.9 & $40-44$ & 8 \\
\hline $\begin{array}{l}\text { Width of shaft at } \\
\text { distal end of }\end{array}$ & & & & \\
\hline deltoid crest & $12(\mathrm{R} \& \mathrm{~L})$ & 11.5 & $11-12$ & 8 \\
\hline $\begin{array}{l}\text { Length of } \\
\text { ectepicondyle from } \\
\text { proximal margin } \\
\text { of extensor } \\
\text { metacarpi radialis } \\
\text { to distal margin of } \\
\text { flexor metacarpi }\end{array}$ & & & & \\
\hline radialis scar .......... & $14.5(\mathrm{R} \& \mathrm{~L})$ & 15.8 & $14.5-16.5$ & 8 \\
\hline $\begin{array}{l}\text { Length of } \\
\text { entepicondyle } \\
\text { from proximal } \\
\text { margin of } \\
\text { pronator brevis } \\
\text { scar to distal } \\
\text { margin of flexor }\end{array}$ & & & & \\
\hline carpi ulnaris scar & $12.5(\mathrm{~L})$ & 14.6 & $13-16$ & 8 \\
\hline Width of distal end & $24.5(\mathrm{~L})$ & 23.8 & $21.5-24.5$ & 10 \\
\hline
\end{tabular}

ulna is $30 \mathrm{~mm}$. These measurements in $P$. haliaetus are variable and may differ between the right and left sides of the same individual: the brachialis scar of the humerus ranges from 15 to $17.5 \mathrm{~mm}$ in length and 7 to $8.5 \mathrm{~mm}$ in width $(\mathrm{n}=10)$; that of the ulna ranges from 28 to $36 \mathrm{~mm}$ in length $(\mathrm{n}=10)$.

DIAGNOSIs.-Pandion with humerus and ulna resembling those of large individuals of modern $P$. haliaetus, but showing evidence of weaker musculature and other osteological features that probably permitted less extension at the elbow and less rotation at the shoulder.

ETYMOLOGY.-Greek homalos, even, level; and pteron, wing; referring to the more level configuration of the wing that would result from a reduced ability to raise the wrist during soaring, thereby reducing or eliminating the "kinked-wing" appearance often presented in flight by members of the modern species.

DesCRIPTION.-Humerus with head more triangular, less rounded than in the modern form; capital groove and ligamental furrow shallower, less deeply excavated; anconal surface of internal tuberosity in internal view less tapering, more nearly perpendicular to main axis of shaft; capital groove and median crest not extending below pneumatic foramen as they do in P. haliaetus.

Distal end of humerus with internal condyle higher, more rounded than in $P$. haliaetus; olecranal fossa in palmar-distal view shallower and wider; border of fossa in anconal-distal view less rounded, more triangular; brachial depression noticeably smaller and less excavated, its external margin situated more externally; external condyle in palmar view rotated, its long axis at a greater angle from the axis of the shaft; viewed from the external side the external condyle rounder, less squared, and less deep than in the modern form. Ectepicondylar and entepicondylar prominences shorter, the scars for $M$. extensor metacarpi radialis and M. pronator brevis closer to the distal end of the bone; facet of anterior articular ligament wider and shorter, its surface flat to concave, this facet in $P$. haliaetus being longer, narrower, and convex.

Proximal end of ulna with surface of internal cotyla shallower, its lip (palmar surface) more extensively flared; palmar lip of radial depression less enlarged; surface of external cotyla less angled from the axis of the shaft, more steeply inclined from the surface of the internal cotyla; scar for the insertion of $\mathrm{M}$. brachialis (= M. brachialis anticus) shorter than in most modern specimens of equivalent size; prominence for anterior articular ligament with shorter, wider facet; proximal half of radial surface of ulna convex in cross-section, whereas flattened or concave in the modern form; olecranon apparently less robust.

\section{Discussion}

The modern Osprey, Pandion haliaetus, is a highly specialized fish hunter. It is capable of hovering over one spot with rapidly beating wings held high over the back. Also, it is capable of increasing 


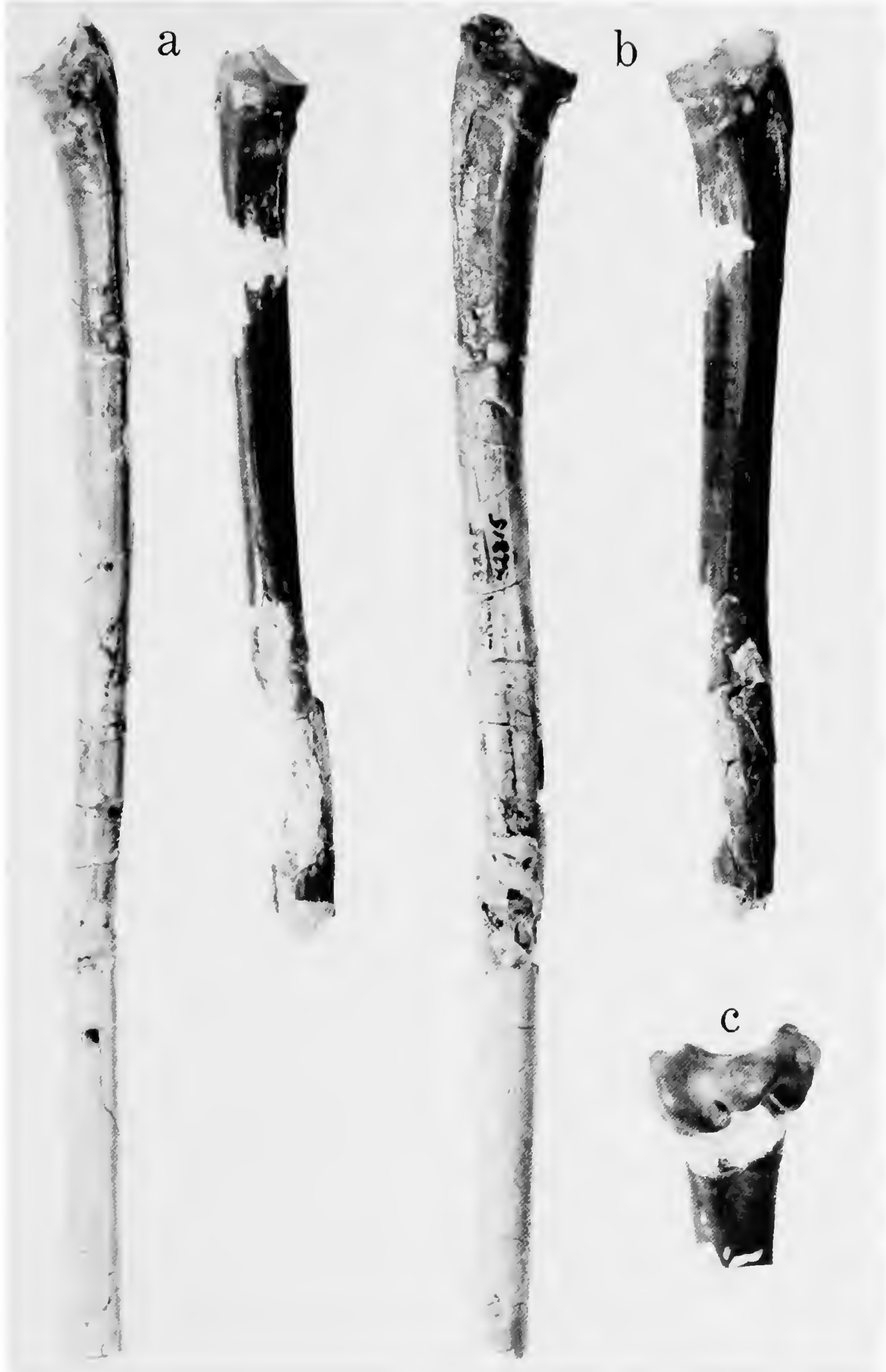

Figure 3.- Holotype ulnae and humerus of Pandion homalopteron, new species (LACM 42815): $a$, dorsal view and $b$, palmar view of left and right ulnae; $c$, distal end of left humerus in distopalmar view. Natural size. (Courtesy of Natural History Museum of Los Angeles County) 
the angle of attack of the wings in level soaring flight by raising the wrists through rotation of the long outstretched forelimbs. In this position the wings present the "kinked" or "crooked" appearance for which it is so well known.

The distinctive shape of the deltoid crest of $P$. haliaetus is undoubtedly related to the aforementioned abilities. It is a large, triangular plate, deflexed from the external surface in a palmar direction and beginning abruptly at a point more distad than in other falconiforms. While the deltoid crest is missing from both humeri of $P$ homalopteron, enough remains of the base of the crest of the left humerus to tell that the entire process was similarly positioned, enlarged and deflexed (Figure 1).

A large deltoid crest usually is indicative of strong pectoral musculature and well-developed powers of flight. Perhaps paradoxically, such a crest occurs in Pandion along with a rounded sternal carina, a feature that in soaring birds like cathartid vultures often is associated with a small deltoid crest and a relatively weak flight mechanism. In Coragyps (Fisher, 1946:603), the palmar surface of the deltoid crest provides the area of insertion of the superficial layer of $\mathrm{M}$. pectoralis (= pectoralis superficialis), and on the anconal surface of the crest, M. deltoideus minor and M. deltoideus major originate on the crest and on extensive areas of the shaft of the humerus proximál, distal, and posterior to the deltoid crest. Judging from muscle scars on the humerus of $P$. haliaetus, however, the enlarged deltoid crest serves as the area of insertion for much, if not all, of the large M. del toideus major, whereas $M$. deltoideus minor is small and inserts anconally along the shaft anterior to the crest.

In Coragyps, the anterior portion of M. deltoideus major "is more important in elevating the leading edge of the wing since the anterior extension of the deltoid crest provides a longer lever arm" (Fisher, 1946:590). An important function of the expanded, deflexed, deltoid crest in Pandion, then, is to provide a lever arm for increasing the upward rotational ability of the humerus through the action of $M$. deltoideus major. A similar increase in downward rotational ability would probably be conferred to the humerus by M. pectoralis.

The humerus of Pandion also has an enlarged internal tuberosity, the function of which is to increase the lever arm for several small muscles in- serting upon it which, in vultures (Fisher, 1946: $603)$, serve to depress the trailing edge of the wing, thereby raising the leading edge. The described differences in the humeral head, capital groove, ligamental furrow, and internal tuberosity of $P$. homalopteron may indicate a lesser degree of muscular development and rotational ability in the shoulder than in $P$. haliaetus.

The differences in the morphology of the elbow joint provide additional evidence of some degree of functional dissimilarity between the two species of Pandion. The configuration of the joint surfaces would seem to indicate a lesser degree of extension at the elbow in $P$ homalopteron. This appears to be borne out by mechanical manipulation of the bones. The forearm of $P$. haliaetus exhibits a much greater degree of extension at the elbow than does that of Buteo. The robust olecranon of $P$. haliaetus fits closely into its corresponding depression on the humerus, possibly serving as a bony stop against further extension. The degree of this extension in $P$. homalopteron is also greater than in Buteo, but less than in $P$. haliaetus. In spite of the olecranon being incomplete, the ulna of $P$ homalopteron could not be extended to the same degree as that of $P$. haliaetus without partially disarticulating the joint. The observed differences in the size and configuration of the attachment for the anterior articular ligament also might be related to the decreased ability to extend the elbow.

In the fossil form, the convex radial surface of the ulna, the smaller $M$. brachialis scars, and possibly the more distal origins of $\mathrm{Mm}$. pronator brevis and extensor metacarpi radialis, may indicate weaker intrinsic musculature. All three of the above muscles are involved in flexion of the forearm, while $\mathrm{Mm}$. brachialis and pronator brevis also are involved in supination and pronation, respectively, of the manus (Fisher, 1946:591-594).

Intrinsic rotational movements of the hand and forearm in birds are limited (Bellairs and Jenkin, 1960:258), and the degree to which they occur has not been determined (George and Berger, 1966: 14). However, P. haliaetus may have greater abilities to raise the wrist through intrinsic rotation, as well as by rotation at the shoulder of an entire, more extended wing, than did $P$. homalopteron.

There is no reason to assume that $P$. homalopteron was any less variable in its dimensions than is modern $P$. haliaetus. To the extent that the 
single available specimen can be considered typical of the Miocene population, the species P. homalopteron appears to have been larger in absolute gross skeletal dimensions than an average-sized modern Osprey, but was smaller than average in other measurable features. Several of these features may indicate a lighter wing musculature relative to bone size than is found in $P$. haliaetus. This, along with the seemingly lesser powers of extension and rotation of the wing, presents a picture of a bird similar to the modern Osprey in size, but one with a more level wing and less refined powers of soaring and hovering. Such a bird could be ancestral to $P$. haliaetus.

\section{The Fossil Record of the Pandionidae}

Pandion homalopteron provides the only Tertiary record of the family Pandionidae founded on adequate and diagnostic material. Brunet (1970) has placed the species Palaeocircus cuvieri MilneEdwards, based primarily on an incomplete carpometacarpus from the upper Eocene of France, in the Pandionidae, stating that the type, while specifically distinct, is scarcely separable from Pandion at the generic level. Storrs Olson (pers. comm.) believes that Brunet's illustrations of the specimen indicate to the contrary, however, since both the proximal and distal symphyses between metacarpals II and III are longer than in Pandion. The assignment of Palaeocircus to the Pandionidae should be regarded with caution, particularly since the family is at present monotypic and the addition of another genus would require redefinition of the family.

A record of Pandion from the middle Pliocene Bone Valley Formation in Central Florida (Brodkorb, 1972) is based on a single claw (Storrs Olson, pers. comm.). Another claw, kindly lent to me by the National Museum of Natural History, Smithsonian Institution, (USNM 192193), comes from the Lee Creek phosphate mine near Aurora, Beaufort County, North Carolina. Middle Miocene and Pliocene fossiliferous deposits are exposed there, and in this case it is not certain from which level the specimen was derived (Storrs Olson, pers. comm.). This claw is from digit III of the right foot, but has the tip broken so that an accurate measurement of the chord is not possible. It is referable to the genus Pandion and is of a size appropriate for either $P$. homalopteron or $P$. haliaetus, but since this element is not diagnostic and its age is uncertain, no specific identification can be made.

The only other fossil records for the Pandionidae are Pleistocene remains of the modern species Pandion haliaetus. To the various localities listed in Brodkorb (1964:260) may be added a previously unreported left tarsometatarsus (LACM 27082) from Pleistocene deposits at Kelly Springs, Kelly Park, Orange County, Florida (LACM locality 7119).

\section{Literature Cited}

Bellairs, A. D'A., and C. R. Jenkin

1960. The Skeleton of Birds. Pages 241-300 in Volume 1 of A. J. Marshall, editor, The Biology and Comparative Physiology of Birds. New York: Academic Press.

Brodkorb, P.

1964. Catalogue of Fossil Birds, Part 2 (Anseriformes through Galliformes). Bulletin of the Florida State Museum, Biological Sciences, 8(3):195-335.

1972. New Discoveries of Pliocene Birds in Florida [Abstract]. Page 64 in Proceedings of the XVth International Ornithological Congress. Leiden: E. J. Brill.

Brunet, J.

1970. Oiseaux de l'Éocène Supérieur du Bassin de Paris. Annales de Paléontologie (Vertébrés), 56(1):1-57, 4 plates.

Fisher, H. I.

1946. Adaptations and Comparative Anatomy of the
Locomotor Apparatus of New World Vultures. American Midland Naturalist, 35(3):545-727, 28 figures, 13 plates.

George, J. C., and A. J. Berger

1966. Avian Myology. xii +500 pages. New York: Academic Press.

Howard, $\mathbf{H}$.

1929. Avifauna of the Emeryville Shellmound. University of California Publications in Zoology, 32(2):301394, 54 figures.

Savage, D. E., and L. G. Barnes

1972. Miocene Vertebrate Geochronology of the West Coast of North America. Pages 124-145 in E. H. Stinemeyer, editor, Proceedings of the Pacific Coast Miocene Biostratigraphic Symposium. 364 pages. Bakersfield, Cal.: Society of Economic Paleontologists and Mineralogists. 



\title{
A New Species of Flightless Auk from the Miocene of California (Alcidae: Mancallinae)
}

\author{
Hildegarde Howard
}

\begin{abstract}
Praemancalla wetmorei is described from the late Miocene of Orange County, California, with humerus and ulna as holotype and paratype, and radius, carpometacarpus, and coracoid referred. The species, although less specialized as a flightless diver than the geologically younger genus Mancalla, appears to be more advanced then Praeman. calla lagunensis, which is believed to be derived from slightly older deposits.
\end{abstract}

\section{Introduction}

Since Lucas (1901) described the first humerus of Mancalla, knowledge of the flightless mancalline alcids (Mancallinae) has increased to include nearly all skeletal elements and to involve five species and two genera.

The type-genus, Mancalla, is known from four species-M. californiensis Lucas (1901), M. diegense (Miller, 1937), M. milleri Howard (1970) and $M$. cedrosensis Howard (1971)-and is recorded from Humboldt County in northern California to Cedros Island, Mexico. The Humboldt County site, with a single humerus assigned to $M$. diegense (Howard, 1970), is believed by Kohl (1974:217) to be Pleistocene in age. The other records are middle to late Pliocene. Praemancalla is known from the single species, $P$. lagunensis Howard (1966), de-

Hildegarde Howard, Chief Curator Emeritus, Natural History Museum of Los Angeles County, 900 Exposition Blvd., Los Angeles, California 90007. scribed from a late Miocene deposit in Leisure World, Laguna Hills, Orange County, California.

Recently, three other Miocene sites in Orange County have yielded mancalline bones. These sites are in Laguna Niguel, approximately $5 \mathrm{~km}$ south of the Laguna Hills locality. The specimens from these sites are in the collections of the Natural History Museum of Los Angeles County. The catalog and locality numbers are listed under Los Angeles County Museum (LACM).

The associated avifauna from these sites includes the same families recorded at the type-locality of Praemancalla lagunensis (LACM Loc. 1945), but the species represented are not identical. None of the species described as new from locality 1945 has appeared in the Laguna Niguel localities. On the basis of associated marine mammals, it is suggested that these sites may represent a later subdivision of the late Miocene than locality 1945 (Barnes, et al., in prep.).

The mancalline skeletal elements from Laguna Niguel include humerus, ulna, radius, carpometacarpus, and coracoid, all of which have been previously described for Mancalla. Only for the carpometacarpus, coracoid, and distal end of the humerus is there comparable material of Praemancalla. The newly found specimens suggest a generally larger form than any previously described mancalline species. Qualitative characters show distinction from comparable elements of all species of Mancalla. Distinctions are also apparent with respect to Praemancalla lagunensis, but the degree of adaptation towards restriction of the wings for swimming is closer to Praemancalla than to Mancalla. Possibly a third genus is indicated. At the 
present state of knowledge, however, it seems wiser to assign the specimens to the genus Praemancalla under a new species name.

Acknowledgments. - I am grateful to the Earth Sciences Division of the Natural History Museum of Los Angeles County for placing the museum's collections at my disposal and for the many courtesies of the staff members. I particularly appreciate the assistance of Dr. Lawrence Barnes in discussion of matters pertaining to the field work in Orange County. The photographs were taken by Lawrence Reynolds, museum photographer. Special thanks go to my husband, Henry Anson Wylde, for the art work in connection with the preparation of the plate.

\section{Praemancalla Howard}

In describing Praemancalla lagunensis, the specific diagnosis of the holotype humerus and paratype carpometacarpus served also as the generic diagnosis. In the specimens from Laguna Niguel now at hand, the following characters are in agreement with that diagnosis:

Humerus with groove separating base of ectepicondyle from external condyle, brachial impression faint and running diagonally from ectepicondylar prominence to a point slightly proximal to attachment of articular ligament, with no papilla present above condyles. The tricipital grooves and ridges are broken in the humerus from Laguna Niguel, so the characters of this area set forth in the original diagnosis cannot be assessed.

Carpometacarpus with distinct, blunt pisiform process, trochlear area having narrow, deep groove between internal and external crests posteriorly, metacarpal II relatively broad with more rounded anterior contour and more angular internal contour than in Mancalla, and process of metacarpal I relatively shorter.

The following additional characters observed in the specimens now at hand are considered to be of generic value when compared with Mancalla: humerus with head only slightly extended over capital groove, deltoid crest weakly developed, area of anterior articular ligament slightly swollen; ulna with prominent olecranon process; radius lacking prominent crest on convex contour; coracoid with scapular facet facing dorsally, coracohumeral attachment flat and angular in outline.

\section{Praemancalla wetmorei, new species}

\author{
Figure $1 a, b, e-g, i-k$
}

Holotype.-Humerus, LACM 42653, complete except for tricipital area of distal end (Figure $1 i, j)$.

TyPe-Locality.-LACM Loc. 6906, site of excavation for North American Rockwell building (now U.S. General Services Administration building) on El Lazo Road, Laguna Niguel, Orange County, California; $914 \mathrm{~m}$ north of junction of Aliso Creek and Sulfur Creek, in yellow sands and laminated gray shale. Latitude $33^{\circ} 33^{\prime} 43^{\prime \prime} \mathrm{N}$, longitude $117^{\circ} 42^{\prime} 44^{\prime \prime} \mathrm{W}$. In the NE $1 / 4 \mathrm{NE} 1 / 4 \mathrm{SE}$ 1/4 of unsurveyed Sec 16, T7S, R8W, San Juan Capistrano quadrangle, USGS 1948, 1:24000.

Formation and Age.-Monterey Formation, late Miocene.

PARATYPe.-Proximal end of ulna LACM 32429 from type-locality (Figure $1 e$ ).

Diagnosis.-Humerus broad proximally; medial profile of capital groove a wide open curve; depth through deltoid crest only 5 percent greater than depth of shaft above distal end; ectepicondylar prominence notably protuberant at its proximal tip and slightly lateral in position with respect to palmar surface of shaft; groove between external condyle and base of ectepicondyle more constricted and less distal in extent than in $P$. lagunensis; shaft breadth above ectepicondylar prominence 53 percent of shaft depth at same point; shaft depth 113 percent of breadth of distal end.

Ulna laterally compressed, with short brachial impression partially palmad in position and bordered palmad by heavy ridge; olecranon blunt but protruding proximally beyond cotylae and distinctly set off from cotylae by lateral depression both externally and internally.

Measurements.-Humerus: length to external condyle $82.7 \mathrm{~mm}$, greatest proximal breadth from pectoral to bicipital crests $22.2 \mathrm{~mm}$, breadth across head $19.6 \mathrm{~mm}$, breadth through distal condyles $8.5 \mathrm{~mm}$, breadth and depth of shaft above ectepicondylar prominence $5.1 \mathrm{~mm}$ and $9.6 \mathrm{~mm}$, respectively, height of ectepicondylar prominence above distal end $16.9 \mathrm{~mm}$, greatest depth through deltoid crest $10.1 \mathrm{~mm}$, breadth of shaft at same point 5.5 mm. Ulna: proximal breadth across cotylae 7.5 $\mathrm{mm}$, proximal depth through olecranon $11.3 \mathrm{~mm}$, 

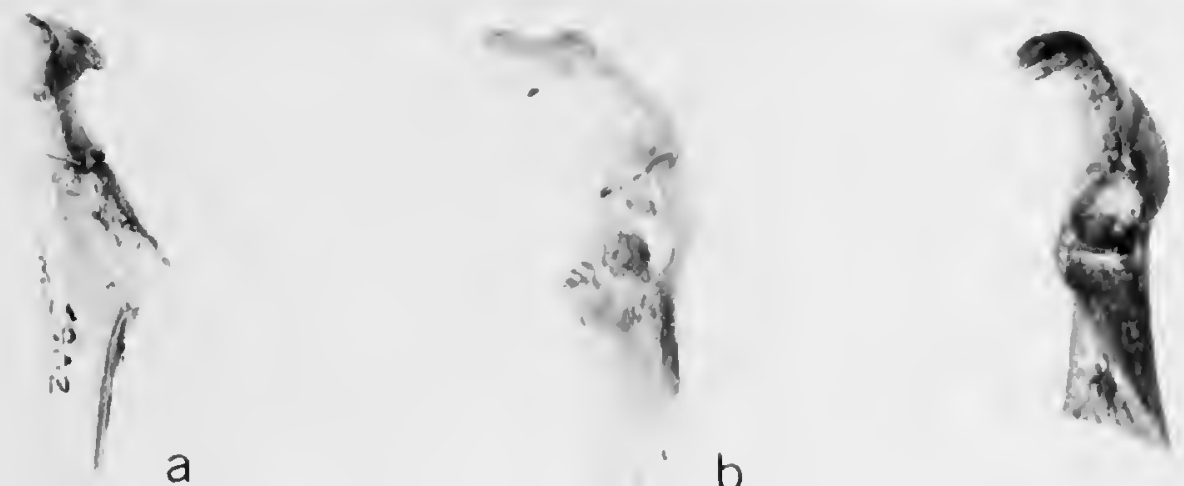

a

b

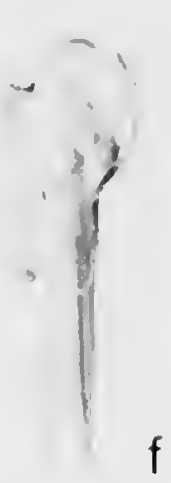

C

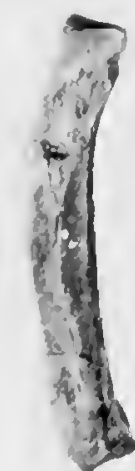

g

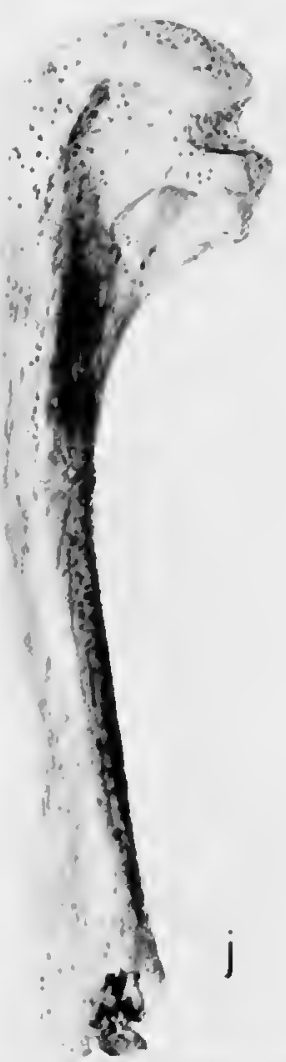

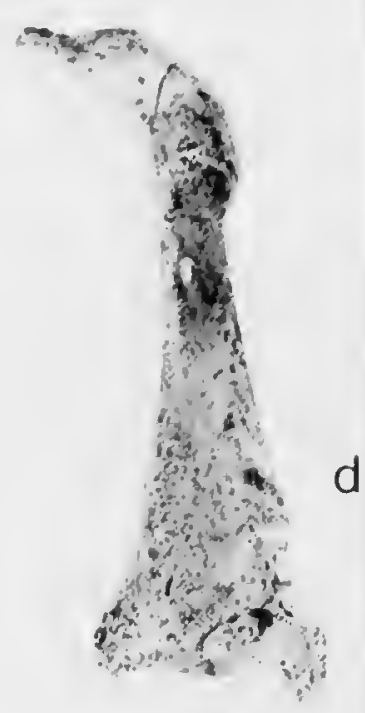
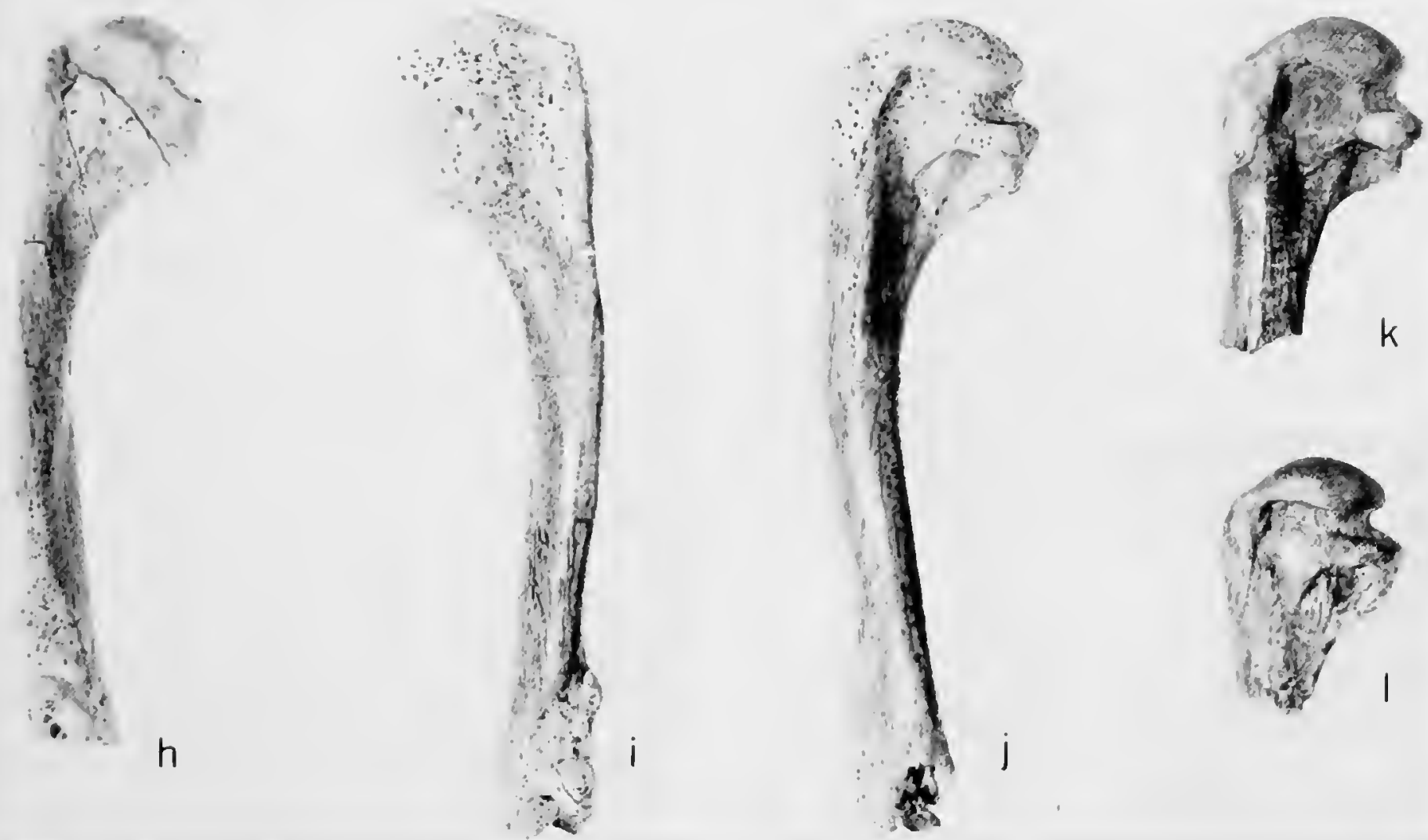

Figure 1.-Skeletal elements of Praemancalla and Mancalla: $a$, b, coracoid (LACM 37637) of $P$. wetmorei, new species, medial and dorsal views; $c$, coracoid (LACM 15289) of P. lagunensis, dorsal view; $d$, coracoid (LACM 2310) of $M$. diegense, dorsal view; $e$, paratype ulna (LACM 32429) of $P$. wetmorei, internal view; $f$, referred carpometacarpus (LACM 52216) of P. wetmorei, internal view; g, radius (LACM 53907) of $P$. wetmorei, palmar view, $h$, humerus (LACM 15367) of $M$. cedrosensis, palmar view; $i, j$, holotype humerus (LACM 42653) of $P$. wetmorei, palmar and anconal views; $k$, referred humerus (LACM 32432) of $P$. wetmorei, anconal view; $l$, humerus (LACM 2331) of $M$. diegense, anconal view. (Approximately natural size.) 
breadth and depth at middle of shaft $4.2 \mathrm{~mm}$ and $6.2 \mathrm{~mm}$ respectively.

RefERRED MATERIAL.-From Laguna Niguel, Orange County, California, late Miocene, Monterey Formation. Proximal end of humerus LACM 32432 (Figure $1 k$ ) from type-locality (LACM Loc. 6906). Complete radius LACM 53907 (Figure $1 g$ ) and scapular end of coracoid LACM 37637 (Figure $l a, b)$ from LACM locality 6902 at northwest end of El Lazo Road, $365 \mathrm{~m}$ northwest of type-locality and $244 \mathrm{~m}$ east of Aliso Creek, in basal $0.5-1.5 \mathrm{~m}$ of coarse yellow sand directly overlying laminated gray shale. Proximal $3 / 4$ of carpometacarpus LACM 52216 (Figure 1f) from LACM locality 3185 , in tributary gully west of Aliso Creek in coarse yellow sand.

ETYMOLOGY.-I take pleasure in naming this new species in honor of Dr. Alexander Wetmore, who has done so much to further the science of paleornithology and who has generously given advice and counsel to me throughout my years of study in this field.

Description.- Compared with Mancalla, the humerus of $P$. wetmorei is relatively, as well as actually, broader both proximally and distally (ratio of greatest proximal breadth to length 26.8 percent in $P$. wetmorei, $23-25$ percent in Mancalla; ratio of distal breadth to length 10.2 percent in $P$. wetmorei, 8.2-9.6 percent in Mancalla) and exceeds in length all but one specimen of Mancalla (the maximum of $M$. diegense). It is, however, 8 percent longer than the average for $M$. diegense and 12 percent longer than the average for $M$. cedrosensis (Table 1), and 32 percent longer than the much smaller $M$. milleri.

The lesser protrusion of the head over the capital groove is reflected in the wide, open curve between the head and internal tuberosity as seen in palmar and anconal views; this condition contrasts with the narrow, U-shaped curve found in Mancalla (Figure $1 h-l$ ). Further distinction from Mancalla is seen in the deltoid crest which, in $P$. wetmorei, describes a low, even arc and is not expanded towards its distal termination. Distally, the greater breadth of the humerus is observed not only in the width through the condyles but also in a slight expansion in the region of the attachment of the anterior ligament. In this character, as well as in the lateral slant of the brachial impression and absence of a prominent papilla above the condyles, $P$. wetmorei resembles Praemancalla lagunensis. It is distinguished from that species in the greater projection of the ectepicondylar prominence from the shaft, narrower groove between the base of the ectepicondyle and external condyle, and relatively narrower and deeper shaft (relative breadth to depth of shaft 53 percent in $P$. wetmorei, 66 percent in $P$. laguensis). In depth of shaft relative to breadth of distal end, $P$. wetmore $i$ is intermediate between Praemancalla lagunensis and the several species of Mancalla (99 percent in P. lagunensis, 113 percent in $P$. wetmorei, 126-140 percent in Mancalla).

The prominence of the olecranon immediately distinguishes the ulna of $P$. wetmorei from all species of Mancalla, but the palmad position of the brachial impression and the shortened lip of the external cotyla assign the element to the subfamily Mancallinae rather than the typical alcids.

The radius (LACM 53907), although short and laterally compressed as in Mancalla, is less bladelike and lacks the prominent crest on its convex contour. The ulnar depression is broader and deeper than in Mancalla. Neither the ulna nor the radius is known for Praemancalla lagunensis. Those assigned to $P$. wetmore $i$ both show less modification towards a flipper-like wing than in Mancalla, and in this regard are in keeping with the character of the other elements known for Praemancalla.

The radius is 12 percent longer than the maximum known for any species of Mancalla (Table 1). Using the radius as a guide, and comparing the relative size of ulna to radius in the type of $\mathrm{Man}$ calla cedrosensis (associated skeletal elements of one individual), it is suggested that the ulna of $P$. wetmorei attained a length of $36.5 \mathrm{~mm}$.

Carpometacarpus LACM 52216 differs from that of Mancalla and resembles Praemancalla in the presence of a distinct, blunt pisiform process, rounded anterior contour of shaft of metacarpal II and deep narrow groove between the internal and external crests of the trochlea posteriorly. It is distinguished from $P$. lagunensis by the narrower shaft and the relatively longer process of metacarpal I, with more than half its length distal to the level of the metacarpal symphysis; also, the trochlea extends higher above that process and the lateral surface of the internal crest of the trochlea is more broadly and less deeply depressed.

In coracoid LACM 37637 the furcular facet is 
TABLE 1.-Skeletal measurements (mm) of Praemancalla wetmorei compared with $P$. lagunensis, Mancalla diegense, $M$. cedrosensis, $M$. californiensis

\begin{tabular}{|c|c|c|c|c|c|c|c|c|c|}
\hline \multirow{2}{*}{ Character } & \multirow{2}{*}{ P. wetmorei } & \multirow{2}{*}{$\begin{array}{l}\text { P. lagun- } \\
\text { ensis }\end{array}$} & \multicolumn{3}{|c|}{ M. diegense } & \multicolumn{3}{|c|}{ M. cedrosensis } & \multirow{2}{*}{$\begin{array}{c}\text { M. cali- } \\
\text { forniensis }\end{array}$} \\
\hline & & & $\min$. & mean & $\max$. & $\min$. & mean & $\max$. & \\
\hline \multicolumn{10}{|l|}{ Humerus } \\
\hline 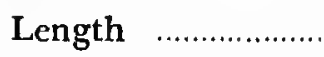 & 82.7 & - & 71 & 76.5 & 85.2 & 69.5 & 73.5 & 80 & - \\
\hline Greatest proximal & & & & & & & & & \\
\hline breadth & 22.2 & - & 17.3 & 18.7 & 20.3 & 17 & 17.9 & 20.1 & 19.4 \\
\hline Distal breadth ..... & 8.5 & 7.8 & 6.4 & 6.7 & 8 & 6.9 & 7 & 7.2 & - \\
\hline ULNA & & & & & & & & & \\
\hline Proximal depth ... & 11.3 & - & $9+$ & & 9.3 & 8.8 & 9.7 & 10.2 & 9.9 \\
\hline Proximal breadth . & 7.5 & - & 5.9 & 6.4 & 6.6 & 6.2 & 6.6 & 7.2 & 6.5 \\
\hline \multicolumn{10}{|l|}{ Radius } \\
\hline Greatest length ..... & 35.8 & - & 29.6 & 30.9 & 31.8 & 27.3 & 29.3 & 31.1 & 29.7 \\
\hline $\begin{array}{l}\text { Greatest shaft } \\
\text { depth }\end{array}$ & 5.8 & & 6.3 & 6.35 & 6.4 & 5.4 & 5.6 & 6.1 & 6.8 \\
\hline Shaft breadth ........... & 3 & - & 2.3 & 2.5 & 2.7 & 2.5 & 2.6 & 2.8 & 2.3 \\
\hline \multicolumn{10}{|l|}{ CARPoMETACARPUS } \\
\hline \multicolumn{10}{|l|}{ Length process } \\
\hline Metacarpal I .... & 15.7 & 14 & 15.2 & 15.3 & 15.5 & 15.4 & 15.6 & 16 & 17.1 \\
\hline Proximal depth & 12.1 & 11.9 & 9.7 & 10.3 & 11 & 10.2 & 10.5 & 11.1 & 11.2 \\
\hline Shaft breadth ........ & 4.3 & 4.5 & 3.1 & 3.4 & 3.7 & 3.4 & 3.5 & 3.8 & 3.4 \\
\hline \multicolumn{10}{|l|}{ CoRACOID } \\
\hline \multicolumn{10}{|l|}{$\begin{array}{l}\text { Length from below } \\
\text { scapular facet } \\
\text { to head }\end{array}$} \\
\hline Breadth below & & & & & & & & & \\
\hline furcular facet & 5.8 & 6 & 5.4 & 5.8 & 6.3 & 5.2 & 5.5 & 6 & 5.9 \\
\hline Breadth furcular & & & & & & & & & \\
\hline facet & 10.3 & - & 7.3 & 7.8 & 8.6 & $7.1 \dagger$ & & 7.3 & 8.7 \\
\hline
\end{tabular}

* Only one specimen of each element of $M$. californiensis, except carpometacarpus (average of four).

† Only two specimens measurable for this dimension.

broad and deep; it extends ventrally well beyond the triosseal canal, is strongly thrust mediad above the canal, and is markedly undercut. Below the facet the bone narrows and the ventral border of the triosseal canal is sharply angular. The species of Mancalla vary in development of the furcular facet and the bordering of the triosseal canal. The greatest overhang of the facet and the least angular border of the triosseal canal are found in $M$. cedrosensis; the least overhang and most angular border of the canal occur in $M$. californiensis. In no specimen of Mancalla is the furcular facet as ventrally extended as in $P$. wetmorei. This facet is broken ventrally in the single known coracoid of $P$. lagunensis, but the portion that remains is deep and has a strong overhang; below the facet, however, the area is broader and more rounded than in $P$. wetmorei. In direct dorsal view (with dorsal surface of shaft held horizontally) the scapular facet in $P$. wetmorei is more dorsally and less laterally directed than in Mancalla, and the triosseal canal faces more mediad. Resemblance is closer to Praemancalla lagunensis, although the canal is even more medially directed in the latter species. The attachment of the coracohumeral muscle in $P$. wetmore $i$ is broad, flat, and angular in outline at its anterior end, as in P. lagunensis, but is relatively longer, and narrows near the glenoid facet. In Mancalla the attachment is narrow and rounded. 


\section{Conclusions}

Four wing elements and a coracoid from three correlative localities of late Miocene age in Laguna Niguel, Orange County, California, represent a new species, Praemancalla wetmorei, in the alcid subfamily Mancallinae. The degree of specialization towards a flipper-like wing is less than in the Pliocene genus Mancalla, and reflects a stage of development closer to the Miocene genus Praemancalla. Differences noted with respect to Prae- mancalla lagunensis, however, suggest a slight advance towards the more specialized wing of Mancalla. The humerus is more compressed, the triosseal canal of the coracoid more dorsally rotated and narrower, and the process of metacarpal I of the carpometacarpus longer.

This suggested evolutionary trend is in keeping with the evidence presented by the associated faunas of the localities involved, which indicates a slightly greater age for the type-locality of $P$. lagunensis than for the Laguna Niguel sites.

\section{Literature Cited}

Barnes, L. G., D. P. Domming, H. Howard, R. W. Huddleston, and C. A. Repenning

In prep. Correlation and Characterization of Late Miocene (Clarendonian Correlative) Marine Vertebrate Assemblages in California.

Howard, Hildegarde

1966. A Possible Ancestor of the Lucas Auk (Family Mancallidae) from the Tertiary of Orange County, California. Los Angeles County Museum Contributions in Science, 101:1-9, 1 figure, 2 tables.

1970. A Review of the Extinct Avian Genus Mancalla. Los Angeles County Museum Contributions in Science, 203:1-12, 1 figure, 4 tables.

1971. Pliocene Avian Remains from Baja California. Los
Angeles County Museum Contributions in Science, 217:1-17, 2 figures, 1 table.

Kohl, Roy F.

1974. A New Late Pleistocene Fauna from Humboldt County, California. Veliger, 17(2):211-219, 2 maps, 1 table.

Lucas, Frederic A.

1901. A Flightless Auk, Mancalla californiensis, from the Miocene of California. Proceedings of the United States National Museum, 24(1245):113-134, 3 figures.

Miller, Loye

1937. An Extinct Puffin from the Pliocene of San Diego, California. Transactions of the San Diego Society of Natural History, 8(29): 375-378, 2 figures. 


\title{
The Pleistocene Pied-billed Grebes (Aves: Podicipedidae)
}

\author{
Robert W. Storer
}

\begin{abstract}
Pleistocene specimens of pied-billed grebes (Podilymbus) were compared with a series of skeletons of the modern North American form, Podilymbus podiceps podiceps. Most of the fossils agreed closely with this form and are allocated to it. The co-types of Podilymbus magnus Shufeldt also fall within the range of variation of this form, hence $P$. magnus becomes a synonym of $P$. podiceps. A new species, Podilymbus wetmorei, characterized by a wide tarsometatarsus and a heavy femur, is described from the Pleistocene of Florida.
\end{abstract}

\section{Introduction}

The Pied-billed Grebe (Podilymbus podiceps) is widely distributed in the New World from Canada to southern South America. The only other living species of the genus, the Atitlán or Giant Piedbilled Grebe ( $P$ gigas), is confined to Lake Atitlán, Guatemala. The genus is represented in upper Pliocene deposits of Idaho by a large species, $P$. majusculus (Murray, 1967), and in numerous Pleistocene deposits. Most of the Pleistocene specimens have been assigned to the living species, $P$. podiceps, but a few have been referred to an allegedly larger extinct species, $P$. magnus. The latter was first described by Shufeldt (1913:136137) on the basis of two tarsometatarsi and a coracoid from Fossil Lake, Oregon. Later, Wetmore (1937:198-199) synonymized $P$. magnus with $P$. podiceps, pointing out that there is considerable

Robert W. Storer, Museum of Zoology, The University of Michigan, Ann Arbor, Michigan, 48104. sexual dimorphism in the genus and that Shufeldt had only one skeleton (a female) of the living species with which to compare his fossil material. Wetmore found that the larger of the tarsometatarsi described by Shufeldt was only slightly larger than those of two males of the living North American subspecies ( $P$. p. podiceps) and was matched by an example of the slightly larger South American race (P. p. antarcticus). More recently, Brodkorb (1959: 273-274) revived the name $P$. magnus for twelve bones from Arredondo, Florida, using eight skeletons of the living North American form for comparison. He (1963a:113) also referred material from the Santa Fe River, Florida, to P. magnus. McCoy (1963:337) in his report on the fossil avifauna of the Itchtucknee River, a tributary of the Santa $\mathrm{Fe}$, referred two tarsometatarsi to $P$. magnus and 47 other bones (including two other tarsometatarsi) to $P$. podiceps. Subsequently, Brodkorb (1963b:230) wrote that "specimens from Fossil Lake and some of the Floridian localities average large and are perhaps recognizable as a temporal subspecies, Podilymbus podiceps magnus Shufeldt."

The availability of a series of 39 skeletons of the modern North American form (Podilymbus $p$. podiceps) from Michigan and Wisconsin has permitted a better estimate of variation within a living population of this species than was heretofore possible, as well as providing a comparison of skeletal elements of this population with a large number of fossil elements from late Pleistocene deposits. The following fossil material has been examined:California: McKittrick, 1 tarsometatarsus; Rancho La Brea, I femur; Florida: Reddick, 3 coracoids, 1 humerus, 1 tibiotarsus, 2 tarsometatarsi; Haile, 1 coracoid, 1 ulna, 1 tibiotarsus; Arredondo, 2 coracoids, 3 humeri, 1 ulna, 3 carpometacarpi, 1 femur, 
Table 1.-Measurements $(\mathrm{mm})$ of modern and late Pleistocene Pied-billed Grebe bones

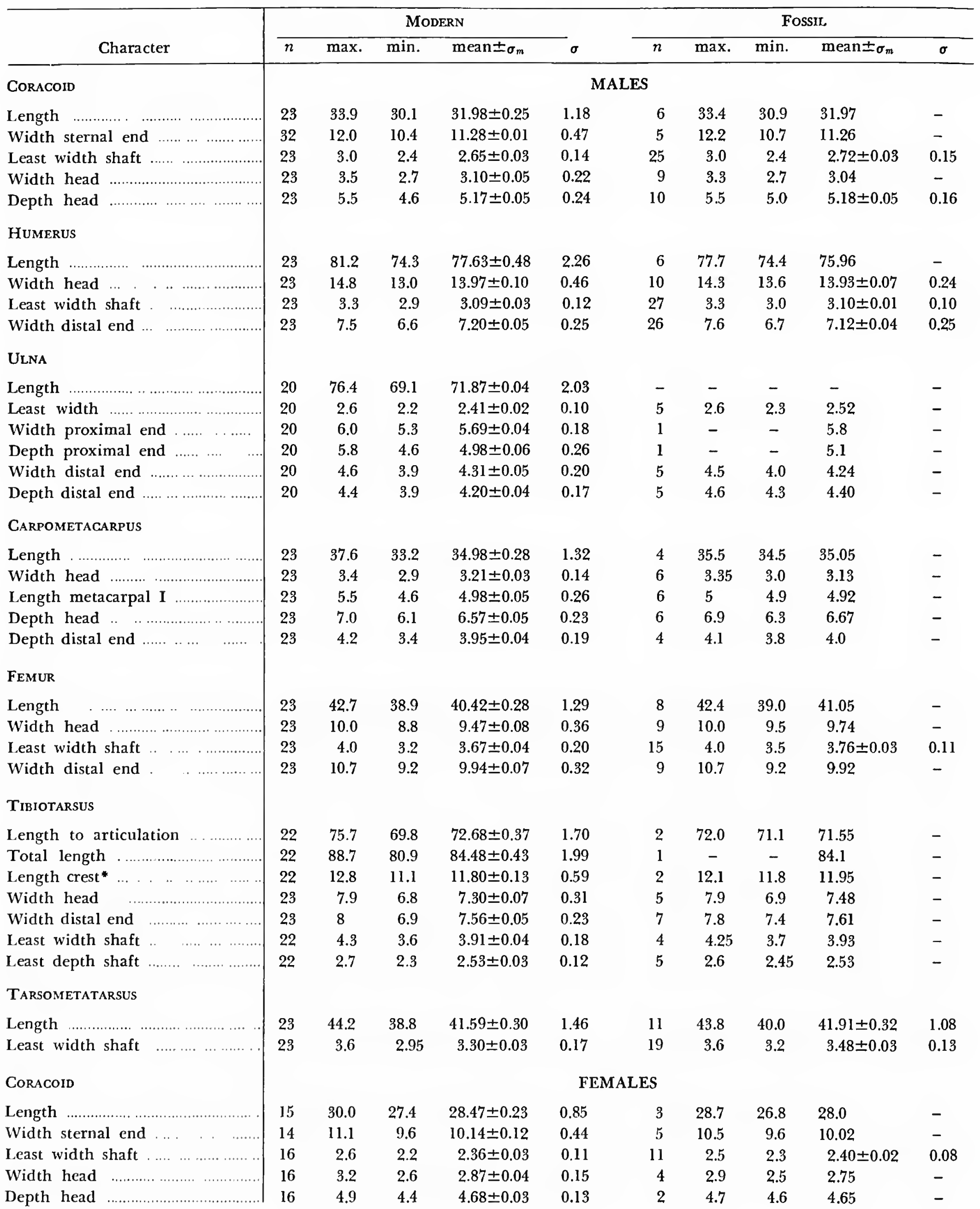


TABLE 1.-Continued

\begin{tabular}{|c|c|c|c|c|c|c|c|c|c|c|}
\hline \multirow[b]{2}{*}{ Character } & \multicolumn{5}{|c|}{ MODERN } & \multicolumn{5}{|c|}{ Fossle } \\
\hline & $n$ & $\max$. & $\min$. & $\operatorname{mean} \pm \sigma_{m}$ & $\boldsymbol{\sigma}$ & $n$ & $\max$ & $\min$. & $\operatorname{mean} \pm \sigma_{m}$ & $\sigma$ \\
\hline \multicolumn{11}{|l|}{ HUMERUS } \\
\hline Length & 15 & 74.3 & 65.6 & $69.17 \pm 0.63$ & 2.34 & 8 & 70.9 & 66.5 & 69.62 & - \\
\hline Width head & 15 & 13.0 & 11.8 & $12.28 \pm 0.09$ & 0.35 & 7 & 12.6 & 11.9 & 12.44 & - \\
\hline Least width shaft & 15 & 3.0 & 2.6 & $2.75 \pm 0.03$ & 0.12 & 21 & 3.0 & 2.4 & $2.76 \pm 0.03$ & 0.15 \\
\hline Width distal end & 15 & 6.9 & 6.3 & $6.48 \pm 0.05$ & 0.18 & 19 & 7.2 & 6.1 & $6.50 \pm 0.07$ & 0.30 \\
\hline \multicolumn{11}{|l|}{ ULNA } \\
\hline Length & 16 & 67.2 & 61.6 & $64.61 \pm 0.04$ & 1.72 & 1 & - & - & 62.7 & - \\
\hline Least width …............... & 16 & 2.3 & 1.9 & $2.20 \pm 0.03$ & 0.10 & 4 & 2.4 & 2.1 & 2.26 & - \\
\hline Width proximal end .... & 16 & 5.4 & 4.8 & $5.08 \pm 0.05$ & 0.18 & 1 & - & - & 5.3 & - \\
\hline Depth proximal end & 16 & 4.8 & 4.2 & $4.43 \pm 0.05$ & 0.18 & 1 & - & - & 4.5 & - \\
\hline Width distal end & 16 & 4.1 & 3.7 & $3.90 \pm 0.04$ & 0.15 & 1 & - & - & 3.6 & - \\
\hline 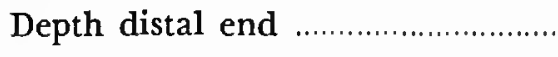 & 16 & 4.1 & 3.5 & $3.80 \pm 0.04$ & 0.17 & 3 & 4.0 & 3.6 & 3.82 & - \\
\hline \multicolumn{11}{|l|}{ CARPOMETACARPUS } \\
\hline Length & 16 & 32.8 & 29.2 & $31.13 \pm 0.27$ & 1.05 & 1 & - & - & 33.2 & - \\
\hline Width head & 16 & 3.0 & 2.7 & $2.87 \pm 0.03$ & 0.10 & 1 & - & - & 2.9 & - \\
\hline Length metacarpal I …......... & 16 & 4.9 & 4.0 & $4.47 \pm 0.06$ & 0.24 & 1 & - & - & 4.5 & - \\
\hline Depth head … ........... & 16 & 6.1 & 5.7 & $5.99 \pm 0.04$ & 0.15 & 1 & - & - & 6.2 & - \\
\hline Depth distal end . & 16 & 3.7 & 3.3 & $3.57 \pm 0.03$ & 0.13 & 1 & - & - & 3.7 & - \\
\hline \multicolumn{11}{|l|}{ FeMur } \\
\hline Length ........... & 15 & 39.2 & 35.2 & $36.56 \pm 0.30$ & 1.08 & 5 & 37.3 & $35.9^{-}$ & 36.8 & - \\
\hline Width head & 15 & 9.0 & 8.1 & $8.54 \pm 0.07$ & 0.27 & 5 & 8.9 & 8.3 & 8.64 & - \\
\hline Least width shaft & 15 & 3.4 & 3.0 & $3.25 \pm 0.04$ & 0.15 & 6 & 3.5 & 3.1 & 3.33 & - \\
\hline Width distal end & 15 & 9.1 & 8.3 & $8.68 \pm 0.06$ & 0.23 & 5 & 9.0 & 8.5 & 8.82 & - \\
\hline \multicolumn{11}{|l|}{ Tibiotarsus } \\
\hline Length to articulation & 14 & 68.2 & 62.1 & $64.81 \pm 0.49$ & 1.85 & 4 & 63.9 & 63.0 & 63.50 & - \\
\hline Total length & 14 & 79 & 72.2 & $75.18 \pm 0.52$ & 1.96 & 2 & 73.4 & 73.2 & 73.3 & - \\
\hline Length crest ${ }^{*}$ & 15 & 10.8 & 9.7 & $10.25 \pm 0.09$ & 0.33 & 3 & 10.4 & 9.6 & 100.33 & - \\
\hline 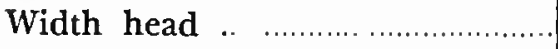 & 15 & 6.8 & 6.2 & $6.56 \pm 0.05$ & 0.18 & 3 & 6.9 & 6.55 & 6.78 & - \\
\hline Width distal end & 15 & 7.3 & 6.3 & $6.83 \pm 0.07$ & 0.28 & 4 & 7.1 & 6.7 & 6.90 & - \\
\hline Least width shaft & 14 & 3.8 & 3.3 & $3.49 \pm 0.04$ & 0.16 & 5 & 3.6 & 3.3 & 3.44 & - \\
\hline Least depth shaft & 14 & 2.3 & 2.1 & $2.19 \pm 0.02$ & 0.08 & 5 & 2.25 & 2.1 & 2.19 & - \\
\hline \multicolumn{11}{|l|}{ TARSOMETATARSUS } \\
\hline Length & 15 & 39.0 & 35.8 & $37.43 \pm 0.27$ & 1.05 & 5 & 37.5 & 36.0 & 36.98 & - \\
\hline Least width shaft & 15 & 3.2 & 2.7 & $2.92 \pm 0.03$ & 0.13 & 9 & 3.05 & 2.85 & 2.98 & - \\
\hline
\end{tabular}

* Calculated by subtracting the length measured from the articulation from the total length.

3 tarsometatarsi; Catalina Lake, I coracoid; Hornsby Spring, I femur, I tibiotarsus; Itchtucknee River, 28 coracoids, 58 humeri, 7 ulnae, 7 carpometacarpi, 18 femora, 23 tibiotarsi, 20 tarsometatarsi; Jenny Spring, I humerus; Lake Monroe, 2 humeri, I femur, I tibiotarsus; Rock Spring, 2 coracoids, 5 humeri, 1 ulna, 6 tibiotarsi; St. John's Lock, 3 humeri, I ulna, I tibiotarsus, I tarsometatarsus; Vero Beach, 1 humerus. Nevada: Smith
Creek Cave, I coracoid. Oregon: Fossil Lake, 4 tarsometatarsi (including the types of $P$. magnus). Total: 220 bones.

Using dial calipers reading to one tenth of a millimeter, 33 measurements were taken from the fossil and modern bones (Table 1). Each fossil specimen was "sexed" by comparing it with the largest, and smallest element for each sex in the modern sample. There is very little or no overlap 
between the sexes in the total lengths of the elements measured, males being larger. In instances in which a fossil was within a zone of overlap in length, it was almost always outside a zone of overlap in another measurement. Therefore, I believe that few, if any, of the fossils were assigned to the wrong sex and only a few fragmentary specimens could not be "sexed" in the above manner. Variability within the sexes of the modern material and the fossils "sexed" in this way proved similar, a further indication that most, if not all of the fossils were assigned to the correct sex.

The means and, where practical, the standard errors of the means and standard deviations of the measurements for these bones were calculated and compared with those of the modern material (Table 1).

Acknowledgments.-I am indebted to Pierce Brodkorb of the University of Florida $(\mathrm{PB})$ and to the curators of the American Museum of Natural History (AMNH), the Natural History Museum of Los Angeles County (LACM), the Museum of Comparative Zoology (MCZ), the University of Florida (UF), and the University of Michigan Museum of Paleontology for permission to use material under their care. The figure was prepared by Mark Orsen. Part of this work was subsidized by the National Science Foundation through Grant GB-8269.

\section{Discussion}

The late Pleistocene material is discussed below by skeletal element. Unless otherwise indicated, all specimens in the following sections are from the Itchtucknee River.

Coracoid.-In both sexes, the means of all measurements of the modern and Pleistocene coracoids are very close. One specimen (PB1209 " $q ")$ falls outside the expected range (i.e., mean $\pm 2 \sigma$ ) of the modern sample in the width of the head $(2.5$ $\mathrm{mm}$ as opposed to $2.6 \mathrm{~mm}$ in the smallest modern specimen).

Humerus.-With five exceptions, the fossil humeri agree with the modern series in size. A distal portion (UF 15309) measures $3.0 \mathrm{~mm}$ in shaft width and $6.5 \mathrm{~mm}$ in distal width, the former measurement being near the mean for males and the latter near the mean for females in the modern series. (This bone was not included in the calculations of the fossil sample because it could not be assigned with confidence to either sex.) Humerus PB 8005 has a shaft width of $3.4 \mathrm{~mm}$, which is approximately 2.5 standard deviations above the mean for males, whereas its other measurements are well within the range of modern males. (It was not included in the calculations of the fossil sample because its identification was not certain; it might belong to the new species described herein.) UF 15297 has a shaft width of $2.4 \mathrm{~mm}$, three standard deviations below the mean for modern females, and a distal width of $6.3 \mathrm{~mm}$, which is within the range of modern females. UF 15280 and UF 15307 have distal widths of 7.2 and $7.0 \mathrm{~mm}$, respectively, which are somewhat outside the expected range of the modern sample.

Ulna.-One partial ulna (PB 7687 from Rock Spring) has a distal width of $4.6 \mathrm{~mm}$ or 2.35 standard deviations above the mean for modern males. In other measurements, it is within the expected range of modern specimens, as are the other fossil ulnae examined.

Carpometacarpus.-The fossil carpometacarpi are all within the expected range of variation of the modern sample.

FEMUR.-With two exceptions (UF 15214 and UF 15220), all the fossil femora fall within the expected range of modern specimens. The two exceptions are referred to the new species and are not included in the calculations of the fossil sample.

Tibiotarsus.-Four fossils are outside the range of the modern sample. UF 15251 " 8 " is more than 2 standard deviations above the means for males in distal width $(8.2 \mathrm{~mm})$ and least width of shaft $(4.4 \mathrm{~mm})$. Two modern specimens are $8.0 \mathrm{~mm}$ in distal width and one is $4.3 \mathrm{~mm}$ in shaft width.) UF 15254 is $68.7 \mathrm{~mm}$ in length, measured from the articulation, which is between the ranges of the two sexes but slightly nearer the mean of females, $3.7 \mathrm{~mm}$ in width of shaft, within the range of either sex, and $2.4 \mathrm{~mm}$ in depth of shaft, within the range of modern males. MCZ 2606 “ of " and PB 1851 " $\$$ " have cnemial crests well below the range expected for their assigned sexes. In other measurements, they are within the range of modern specimens or differ by only a tenth of a millimeter. These four fossils were not included in the calculations of means for the fossil samples.

Tarsometatarsus.-All but three fossils of this element fall within the expected range of the mod- 
ern sample. Two of these (UF 15223 and PB 1762 from Reddick) are very broad and are referred to the new species. The third (PB 1854) measures $44.8 \mathrm{~mm}$ in length and 3.5 in least width of shaft. The former measurement is 2.2 and the latter 1.2 standard deviations above the mean for the modern series. These three fossils are not included in the calculations of the fossil sample.

Thus, most of the Pleistocene fossils agree well with the sample of modern specimens. These fossils include the type tarsometatarsi of $P$. magnus, which measure 43.6 and $42.9 \mathrm{~mm}$ in length and 3.5 and $3.2 \mathrm{~mm}$ in least width. I have not examined the coracoid Shufeldt (1913, pl. 38:fig. 449) tentatively assigned to $P$. magnus, but his photograph of it agrees better with the modern form than two other coracoids (his figures 461, 462) he did assign to $P$. podiceps. Wetmore (1937:199) referred this specimen to the modern form. The 12 fossils from Arredondo referred to $P$. magnus by Brodkorb (1959:273-274) fall within the expected range of variation of the modern form. I have not seen the fossil (or fossils) from the Santa Fe River referred without comment to $P$. magnus by Brodkorb (1963a:115). The tarsometatarsi from the Itchtucknee River referred to $P$. magnus by McCoy (1963:337) also fall within the expected range of the modern form, although one (PB 1854) is 0.6 $\mathrm{mm}$ longer than the longest modern specimen measured. Both measure $3.5 \mathrm{~mm}$ in least width and are equaled or surpassed by both fossil and modern specimens in this dimension. Thus, I can find no evidence that the late Pleistocene birds were significantly larger than the modern ones. Because the types of $P$. magnus are indistinguishable from the modern form, Podilymbus magnus Shufeldt must be considered a synonym of Podilymbus podiceps (Linnaeus).

Of the few fossils falling outside the range of the modern series, several are heavier than the corresponding elements of $P p$. podiceps and are established here as a new species.

\section{Podilymbus wetmorei, new species}

\section{FIGURE $1 b, d$}

Holotype.-Nearly complete left tarsometatarsus in the collection of Pierce. Brodkorb (PB 1762) from the Dixie Lime Products quarry, locality IA,
Table 2.-Measurements ( $\mathrm{mm}$ ) of Podilymbus wetmorei

\begin{tabular}{|c|c|c|}
\hline Character & "Male" & "Female" \\
\hline Tarsometatarsus & UF 15223 & PB 1762 (type) \\
\hline 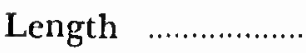 & 42.0 & 36.8 \\
\hline Least width shaft & 3.75 & 3.5 \\
\hline FEMUR & UF 15214 & UF 15220 \\
\hline Length .................. & 42.4 & 36.8 \\
\hline Width head ......... & 10.2 & 8.4 \\
\hline Least width shaft & 42.0 & 3.7 \\
\hline Width distal end & 10.8 & 9.0 \\
\hline
\end{tabular}

$1.6 \mathrm{~km}$ south of Reddick, Marion County, Florida. Collected by Pierce Brodkorb, 2 March 1957.

Agr.-Late Pleistocene (Rancholabrean) fide Webb (1974:13).

RANGE.-Known so far only from two localities in peninsular Florida.

Diagnosis.- Similar in length and general configuration to the tarsometatarsus of Podilymbus podiceps, the shaft much heavier (Figure 1; Table 2). Differs from Podilymbus majusculus Murray (1967), from the upper Pliocene of Idaho, in being shorter, comparatively wider in the shaft, and in having the ridge along the external side of the anterior surface of the bone much reduced for its distal third. Shorter and relatively heavier than the tarsometatarsus of $P$. gigas.

Referred Material.-One tarsometatarsus (UF 15223) and two femora (UF 15214 and UF 15220) all from the Itchtucknee River, Columbia County, Florida. Like the type, the second tarsometatarsus has a notably heavy shaft; the femora have thick shafts and wider heads and distal ends than $P$. podiceps (Table 2). Two exceptional humeri mentioned above (UF 15309 and PB 8005 from the Itchtucknee River) have wide shafts and may likewise represent $P$. wetmorei. Two tibiotarsi (MCZ 2606 and PB 1851 from the Itchtucknee River) have short cnemial crests. The former is wide at both articulations and has a thick (deep) shaft, suggesting that it may also belong to the new form. However, the second bone is small in all these dimensions and probably is an aberrant or worn example of $P$. podiceps. The placement of the other fossils that fall outside the range of the modern form is uncertain, and will probably remain so until more material becomes available.

REMARKs.- - Having both a thick tarsometatarsus 

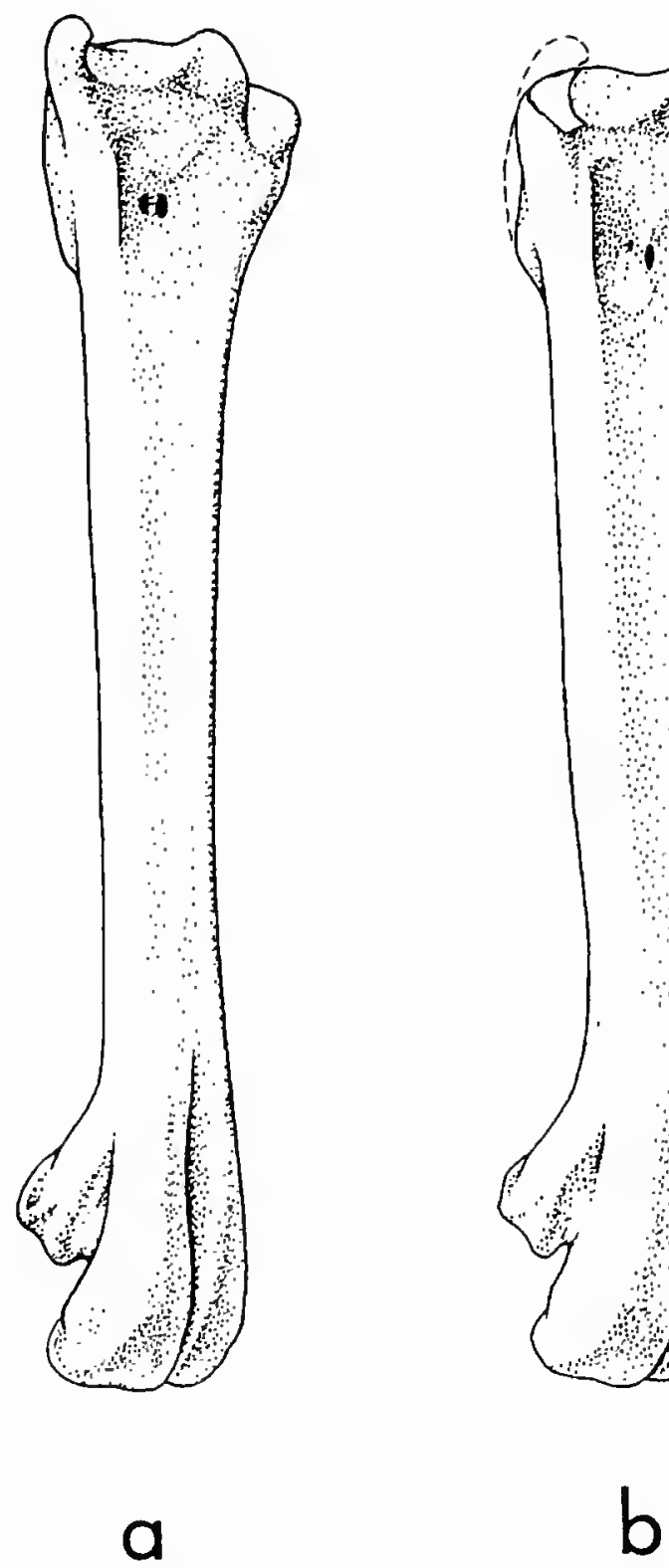
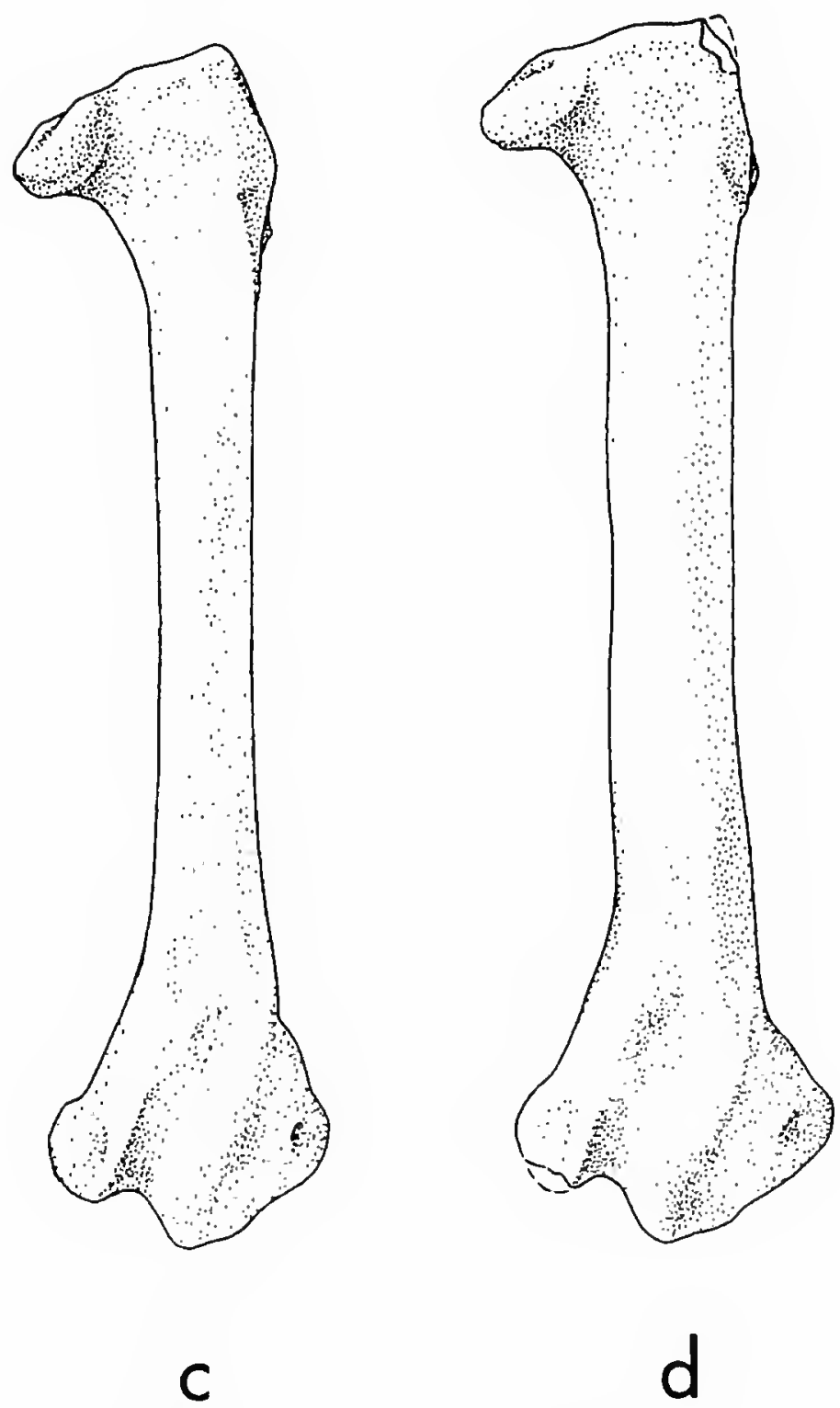

Figure 1.-Left tarsometatarsi and left femora of species of Podilymbus: $u, c$, $P$. podiceps (UMMZ 151328); b, P. wetmorei, new species (holotype, PB I762); d, P. wetmorei (UF 15220). $($ Scale $=10 \mathrm{~mm}$.)

and a heavy femur is paradoxical in a footpropelled diving bird, because the complex of structural modifications which appear adaptive for rapid locomotion under water includes a short, heavy femur, a long cnemial crest, and a narrow tarsometatarsus. In the case of $P$. wetmore $i$, a thickened but not shortened femur might have provided a greater area for the attachment of muscles used in swimming (notably the gastrocnemius), which could compensate for the area lost through the shorter cnemial crest. Modern pied-billed grebes inhabit bodies of water with considerable emergent vegetation and have wider tarsometatarsi than grebes inhabiting more open water. Presumably this is an adaptation for diving almost directly downward, breast first, rather than springing forward like most other grebes. The even wider tarsometatarsi of $P$. wetmorei probably represent a further extension of this adaptive trend already evident in modern species of Podilymbus.

The presence of two species of Podilymbus in the same Rancholabrean deposits in Florida suggests that one ( $P$. wetmore $i$ ) may have been a resident form that differentiated from the widespread $P$. podiceps, which latter may only have wintered there. The situation between the fossil form known as Gallinula brodkorbi, also from the Itchtucknee, and G. chloropus (Olson, 1974:174) suggests an interesting parallel and might be accounted for similarly.

ETYMOLOGY.-I take great pleasure in naming this species in honor of Alexander Wetmore. 


\section{Literature Cited}

Brodkorb, $\mathrm{P}$.

1959. The Pleistocene Avifauna of Arredondo, Florida. Bulletin of the Florida State Museum, Biological Sciences, 4(9):269-291.

1963a. A Giant Flightless Bird from the Pleistocene of Florida. $A u k, 80(2): 111-115$.

1963b. Catalogue of Fossil Birds, Part 1 (Archacopterygiformes through Ardeiformes). Bulletin of the Florida State Museum, Biological Sciences, 7(4):179-293.

McCoy, J. J.

1963. The Fossil Avifauna of Itchtucknee River, Florida. Auk, 80(3):335-351.

Murray, B. G., Jr.

1967. Grebes from the Late Pliocene of North America. Condor, 69(3):277-288.
Olson, S. L.

1974. The Pleistocene Rails of North America. Condor, $76(2): 169-175$.

Shufeldt, R. W.

1913. Review of the Fossil Fauna of the Desert Region of Oregon, with a Description of Additional Material Collected There. Bulletin of the American Museum of Natural History, 32(6):123-178, 35 plates.

Webb, S. D.

1974. Pleistocene Mammals of Florida. $\mathrm{x}+270$ pages. Gainesville: University Presses of Florida.

Wetmore, A.

1937. A Record of the Fossil Grebe, Colymbus parous, from the Pliocene of California, with Remarks on Other American Fossils of This Family. Proceedings of the California Academy of Sciences, series 4, 23(13):195-201, 15 figures. 



\title{
The Late Pleistocene Avifauna of La Carolina, Southwestern Ecuador
}

\author{
Kenneth E. Campbell, Jr.
}

\begin{abstract}
A collection of fossils from the late Pleistocene site known as La Carolina, located on the arid Santa Elena Peninsula of southwestern Ecuador, contains 53 species of birds, representing 16 families and 42 genera, including 7 extinct species previously recorded only from the Talara Tar Seeps of northwestern Peru. New species of Buteo and Oreopholus are described. The genus Protoconurus Spillman is synonymized with Aratinga.

Seventy-two percent of the species recorded from La Carolina were also recorded from the Talara Tar Seeps. The resemblance between the two avifaunas suggests a similarity in age, habitat, and climatological conditions at the two sites at the time of deposition. Evidence suggests that during glacial periods the currently arid Santa Elena Peninsula was part of a broad, forested coastal savanna extending from central Ecuador south to northern Peru.
\end{abstract}

\section{Introduction}

While on a visit to Quito, Ecuador, in early 1970, in connection with my research on the late Pleistocene avifauna of the Talara Tar Seeps of northwestern Peru (Campbell, in press), I had the pleasure of meeting and talking with Professor Gustav Orcés V. of the Escuela Politécnica Nacional. During the course of our conversations I learned that he had in storage at the Escuela a collection of fossil birds from a site known as La Carolina, located on the Santa Elena Peninsula. The collection

Kenneth E. Campbell, Jr., Department of Zoology, University of Florida, Gainesville, Florida 32611. was made by Dr. Robert Hoffstetter in the course of his work on the Pleistocene mammals of Ecuador (Hoffstetter, 1952). I was most graciously granted permission to take the fossil birds back to the University of Florida where I could work on them in conjunction with the Talara avifauna.

The La Carolina site is located on the north side of the Santa Elena Peninsula near the town of La Libertad (Figure 1). Hoffstetter (1952) and Edmund (1965) have described the location and geological history of this and othèr nearby sites. Spillman (1942) also contributed to our knowledge of the paleontology and geological history of the Santa Elena Peninsula, including descriptions of what he regarded as two extinct genera and species of birds.

I have not visited the site personally and must therefore refer the reader to the description published by Hoffstetter (1952). The fossil beds consist of fine-grained aeolian and fluviatile sands that were deposited in a broad, shallow estuarine environment. Certain zones of the deposit are impregnated with pitch and some evidence suggests that this occurred subsequent to the deposition of the sands (Edmund, 1965). Preservation of the fossil material is generally excellent, indicating rapid burial with little disturbance. In addition to the specimens recorded below, there are a large number of small, delicate specimens of various species of Passeriformes that are not sufficiently prepared to include in this report.

Species distributions were taken from Chapman (1926), Marchant (1958), and Meyer de Schauensee (1966). For osteological characters of the various species the reader is referred to a pending paper on the paleoavifauna of the Talara Tar Seeps (Campbell, in press). The La Carolina specimens 
are currently uncataloged and will be returned to Professor Orcés in the near future.

Acknowledgments.-I wish to thank Professor Gustav Orcés V. for his kind permission to study the avian material from La Carolina. Special thanks also go to Pierce Brodkorb for his assistance in the preparation of this manuscript and for access to his skeletal collection. I am very grateful to the Frank M. Chapman Fund of the American Museum of Natural History, the Society of Sigma $\mathrm{Xi}$, and the Organization for Tropical Studies, Inc. (Pilot Research Proposal No. 69-23) for providing the crucial financial assistance that made possible my field studies in Ecuador and Peru. The National Museum of Natural History and the American Museum of Natural History kindly loaned specimens that were critical for identification of some of the fossil material reported on here. A. Gordon Edmund of the Royal Ontario Museum provided numerous useful comments.

\section{ARDEIDAE}

\section{Nycticorax nycticorax (Linnaeus)}

Material-O One complete right coracoid, humeral end of 1 left coracoid, 1 complete left carpometacarpus, proximal ends of 1 right and 1 left femur.

ReMARKs. $-N$. nycticorax is resident in Ecuador.

\section{ANATIDAE}

\section{Dendrocygna autumnalis (Linnaeus)}

Material.-One left scapula, 1 complete right coracoid, proximal end of 1 right ulna, distal end of 1 left tibiotarsus.

REMARKS.-D. autumnalis is resident in Ecuador.

\section{Anatidae genus and species}

Material.-Two complete right and 2 complete left coracoids, humeral end of 1 right coracoid, 1 complete left ulna, l complete left radius, l complete right carpometacarpus, proximal ends of 1 right and 1 left carpometacarpus.

Remarks.-This new genus and species of Anatidae is being described as a form of Tadorninae

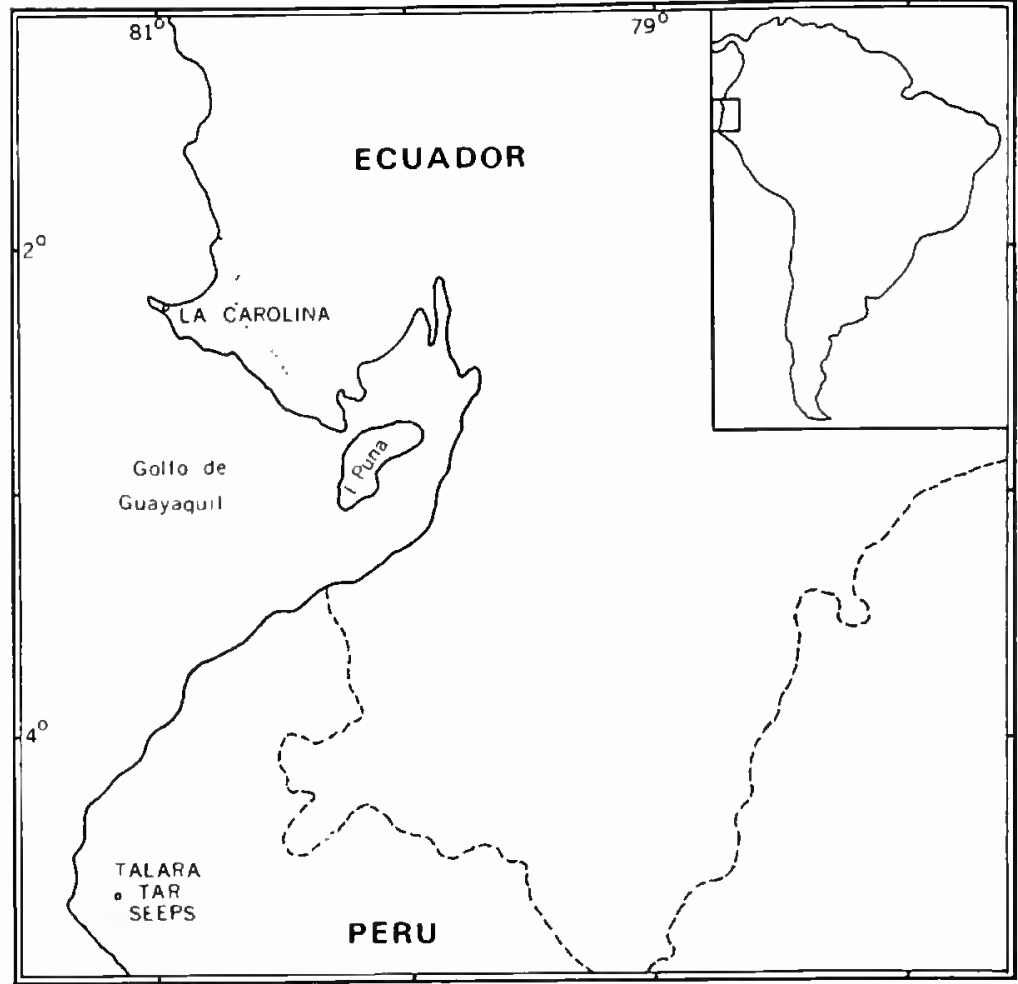

Figure 1.-Location of the La Carolina fossil site, southwestern Ecuador, relative to the Talara Tar Seeps of northwestern Peru. The dotted line marks the approximate eastward limit of the arid zone of the Santa Elena Peninsula.

from the Talara Tar Seeps of northwestern Peru (Campbell, in press). The presence of this and the other entinct species listed below indicate that paleoclimatic conditions at La Carolina were similar to those at the Talara Tar Seeps, much as similar conditions exist at the two sites today.

\section{Anas species 1}

MATER1AL.-One complete right coracoid, proximal end of 1 right radius, distal end of 1 right tibiotarsus, l complete left tarsometatarsus.

REMARKs.-The proximal end of the radius is not included in the description of Anas species 1, from the Taiara Tar Seeps (Campbell, in press). The present specimen is referred to this species on the basis of size (proximal width, $4.4 \mathrm{~mm}$ ), and because it differs from the radius being referred to Anas species 2 (Campbell, in press) by having: (1) ligamental prominence high, (2) ulnar depression deep, (3) scapholunar facet broad and flat.

\section{Anas species 3}

Material.-One left scapula, l complete left humerus (holotype), 2 complete left carpometacarpi. 
REMARKs.--The complete humerus from La Carolina is being used as the holotype in the description of Anas species 3 (Campbell, in press), because it is in better condition than any of the material from the Talara Tar Seeps. Elements of this species not found in the Talara Tar Seeps include the scapula and carpometacarpus. The small size of these specimens indicates that they may be safely referred to Anas species 3 . In addition to its small size, the scapula is characterized by having: (1) acromion of moderate length and width, with anteroventral corner a prominent projection; (3) attachment of Lig. furculoscapulare dorsale oval in shape, located on midline of shaft. Measurements of the scapula are: proximal height, 7.7 $\mathrm{mm}$; proximal width, $2.4 \mathrm{~mm}$.

The carpometacarpus is characterized by having: (1) process of metacarpal I moderately higl and long; (2) proximal edge of metacarpal I sloping slightly proximad; (3) proximal metacarpal symphysis of moderate length, distal symphysis long; (4) internal face of external rim of carpal trochlea angular proximally; (6) area covered by external cuneiform ligament moderately convex; (7) posterior carpal fossa of moderate width for its length; (8) surface of carpal trochlea extending deep into posterior carpal fossa; (9) internal rim of carpal trochlea with posterior edge bowing externally. Measurements (in $\mathrm{mm}$ ) of the two carpometacarpi are as follows: length, 35.0 and 35.2; height through metacarpal I, 8.1 and broken; proximal width, 3.9 and 3.9 ; least width of shaft, 2.5 and 2.7; length of distal fornix, 5.0 and 4.9.

The numbered characters listed above correspond to those being used in the descriptions of Anas species 1, and Anas species 2 (Campbell, in press). The absence of Anas species 2, from La Carolina may be a result of the small sample size, although it was more common at the Talara Tar Seeps than Anas species 3.

\section{Anas bahamensis Linnaeus}

Material.-Portions of 12 crania, 9 right and 4 left scapulae, 23 complete right and 27 complete left coracoids, humeral ends of 5 right and 7 left coracoids, 4 complete right and 2 complete left humeri, proximal ends of 1 right and 2 left humeri, distal ends of 1 right and 4 left humeri, 16 complete right and 18 complete left ulnae, proximal ends of 3 right and 3 left ulnae, distal ends of 2 right and 3 left ulnae, 11 complete right and $3 \mathrm{com}$ plete left radii, proximal ends of 7 right and 4 left radii, distal ends of 3 right and 5 left radii, 28 complete right and 34 complete left carpometacarpi, proximal ends of 3 left carpometacarpi, 5 complete right and 8 complete left femora, proximal ends of 2 left femora, distal ends of 3 left femora, 3 complete right and 1 complete left tibiotarsus, 1 almost complete right and 1 almost complete left tibiotarsus, proximal ends of 1 right and 1 left tibiotarsus, distal ends of 4 right and 3 left tibiotarsi, 19 complete right and 24 complete left tarsometatarsi, proximal ends of 2 right and 4 left tarsometatarsi.

REMARKS.-In terms of numbers of specimens and of individuals, $A$. bahamensis is the second most abundant species in the La Carolina deposits. This species is currently found in large numbers in southwestern Ecuador when standing bodies of fresh water occur (Marchant, 1958).

I am elsewhere (Campbell, in press) expressing my belief that it was material of this species that Spillman (1942) named Archeoquerquedula lambrechti. The absence of any large, extinct duck from the La Carolina deposits upholds the view that Archeoquerquedula lambrechti should be synonymized with Anas bahamensis.

\section{VULTURIDAE}

\section{Vulturidae genus and species indeterminate}

MATERIAL.-Proximal end of 1 right tarsometatarsus.

REMARKs.-This specimen is too broken to be identified further. It represents a condor the size of a large individual of Vultur gryphus Linnaeus. The intercotylar prominence is very broad and low, unlike that found in either Vultur Linnaeus, Gymnogyps Lesson, or the new genus of condor being described from the Talara Tar Seeps (Campbell, in press). I am convinced the specimen represents a new genus and species, but consider the specimen too fragmentary to describe.

\section{Coragyps cf. atratus (Bechstein)}

MATERLAL.-Distal ends of 1 right and 1 left carpometacarpus. 
REMARKs.-These specimens resemble those from the Talara Tar Seeps in differing slightly from the subspecies of $C$. atratus currently resident in southwestern Ecuador and northwestern Peru.

\section{Cathartes aura (Linnaeus)}

Material.-One right scapula, proximal end of I left radius, I complete left tarsometatarsus, distal ends of 2 left tarsometatarsi.

REMARKS.-C. aura is resident in southwestern Ecuador.

\section{ACCIPITRIDAE}

\section{Accipitridae genus and species}

MATERIAL.-Proximal end of 1 left femur.

REMARKs.-This extinct new genus and species of large eagle is being described from the Talara Tar Seeps (Campbell, in press). Hoffstetter (1952: 40) mentioned an enormous eagle from La Carolina. The specimens he was referring to probably belong to this species.

\section{Geranoaetus melanoleucus (Vieillot)}

Material.-Proximal end of 1 right carpometacarpus, distal end of 1 left tibiotarsus.

REMARKs.-G. melanoleucus is resident in western Ecuador today.

\section{Buteo polyosoma (Quoy and Gaimard)}

Material.-Proximal ends of 1 right and 1 left humerus, proximal end of 1 right radius, 1 complete left carpometacarpus, distal end of 1 right tibiotarsus, 2 complete left tarsometatarsi.

REMARKS. $-B$. polyosoma is a common resident in southwestern Ecuador.

\section{Buteo hoffstetteri, new species}

Figure 2

Holotype.-Right tarsometatarsus lacking medial portion of proximal end. Uncataloged.

PARATYPE.-Almost complete left tarsometatarsus. Diagnosis.-Tarsometatarsus agrees with that of
Buteo Lacépède and differs from that of all other South American genera of Accipitridae by having those characters of the genus Buteo as listed by Campbell (in press).

Tarsometatarsus characterized by having: (1) internal cotyla very concave (moderately concave in $B$. lineatus, very concave in $B$. polyosoma); (2) anterior metatarsal groove very deep immediately distal to intercotylar prominence and distal to tubercle for tibialis anticus (moderately deep in both areas in $B$. lineatus and $B$. polyosoma); (3) shaft narrow abruptly distal to tubercle for tibialis anticus (narrows gradually in $B$. lineatus, abruptly in $B$. polyosoma); (4) shaft with posterior metatarsal groove moderately deep (very deep in $B$. lineatus, moderately deep in $B$. polyosoma); (5) intertrochlear notches wide (narrow in $B$. lineatus and $B$. polyosoma); (6) internal trochlea with very prominent angular proximolateral projection (not as prominent in $B$. lineatus, very prominent in B. polyosoma); (7) external trochlea narrow, short, and projecting posterodistad at approximately $45^{\circ}$ to axis of shaft (wide, long, and at approximately $85^{\circ}$ to axis of shaft in $B$. lineatus and $B$. polyosoma); (8) shaft very slender (similar in $B$. lineatus, wider in $B$. polyosoma).

Measurements (in $\mathrm{mm}$ ) of the holotype and paratype (in parentheses) are as follows: length, 74.6 (76.3); proximal width, broken (11.1 \pm 1.0 ); distal width, 10.7 (12.2 \pm 0.5$)$; least width of shaft, 4.0 (4.2).

ReFerred Material.-Distal end of 1 left and 1 right tibiotarsus.

Characters.-Tibiotarsus characterized by having: (l) shaft only slightly concave at posteroproximal end of internal condyle (moderately to deeply concave in $B$. lineatus and $B$. polyosoma); (2) internal condyle short (long in B. lineatus, of moderate length in $B$. polyosoma); (3) external condyle merging gradually with shaft anteroproximally, not forming a lip (merges abruptly, forming a lip in $B$. lineatus and $B$. polyosoma). The only measurement that can be taken is the distal width $(10.6 \mathrm{~mm})$ of one specimen.

ETymologY.- This species is named for Dr. Robert Hoffstetter of the Muséum National d'Histoire Naturelle, Paris, France, in recognition of his paleontological work in Ecuador and his role in the preservation of the La Carolina fossils.

Remarks.-Although Buteo lineatus does not oc- 


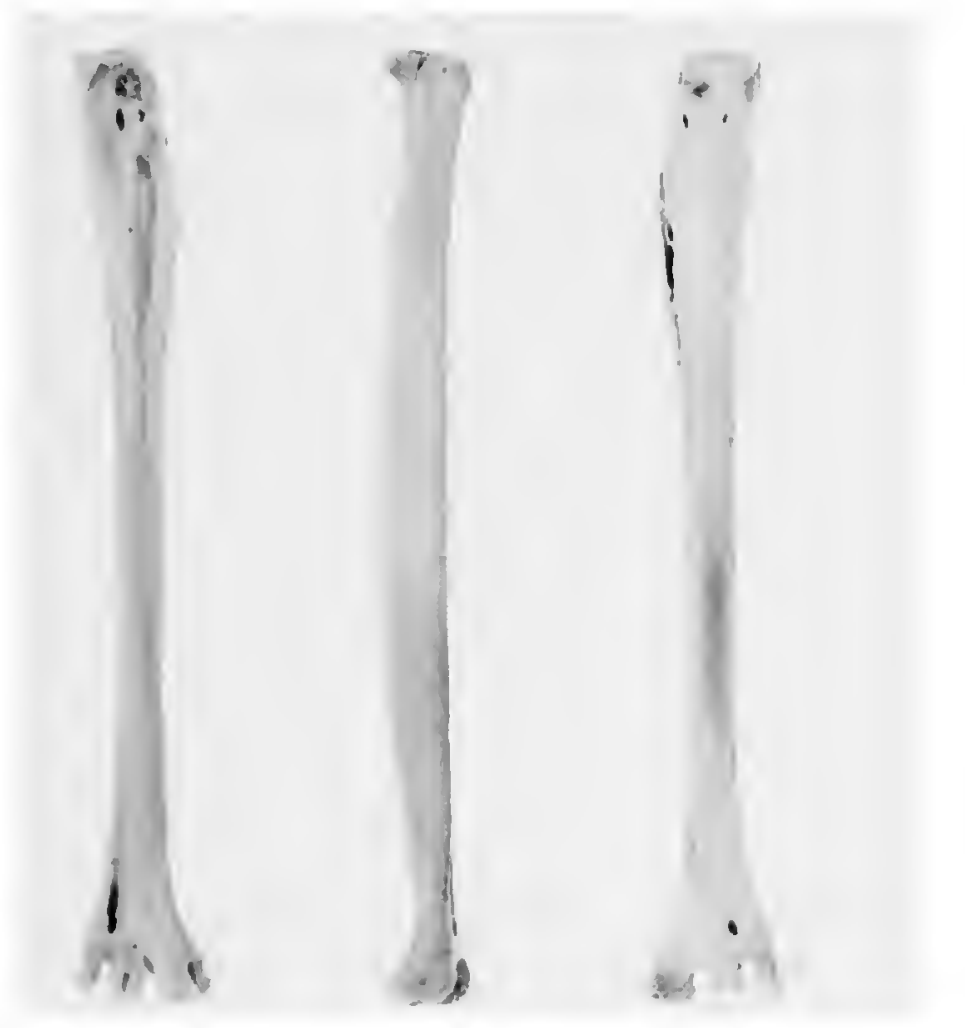

FIgure 2.-Holotype right tarsometatarsus of Buteo hoffstet. teri, new species (uncataloged), in anterior, external, and posterior view, $\times 1$.

cur in South America, it was used in the diagnosis because its tarsometatarsus resembles that of $B$. hoffstetteri in being long and slender rather than short and stout. While the tarsometatarsus of $B$. polyosoma is the same length as that of $B$. lineatus, it is much more robust. In all other species of Buteo with tarsometatarsi of similar length, the bone is even more robust than in $B$. polyosoma and these species must therefore also differ from $B$. hoffstetteri.

\section{Circus cinereus Vieillot}

MATERIAL.-Proximal end of 1 left carpometacarpus, 1 complete right femur, distal end of 1 left tibiotarsus.

REMARKs. $-C$. cinereus is resident in western Ecuador, but has not been recorded from the Santa Elena Peninsula.

\section{FALCONIDAE}

\section{Falco peregrinus Tunstall}

Material.-Two left scapulae, sternal end of 1 right coracoid, proximal end of 2 left humeri, distal end of 1 right humerus, 1 complete left ulna, proximal end of 1 right ulna, distal ends of 2 left ulnae, proximal end of 1 right radius, 2 complete right carpometacarpi, proximal ends of 1 right and 1 left carpometacarpus, distal end of 1 right carpometacarpus, 1 complete left femur, distal end of 1 right tibiotarsus, 1 complete right tarsometatarsus, proximal ends of 2 left tarsometatarsi.

REMARKs.-F. peregrinus occurs in Ecuador both as a northern and a southern migrant.

\section{Falco femoralis Temminck}

Material.-One complete left coracoid, proximal end of 1 left tibiotarsus.

REMARKs. $-F$. femoralis is resident in western Ecuador.

\section{Polyborus plancus (Miller)}

Material.-Five right and 4 left scapulae, 2 complete right and 2 complete left coracoids, humeral ends of 4 right and 1 left coracoid, proximal ends of 3 right and 1 left humerus, distal ends of 1 right and 1 left humerus, 1 complete right ulna, proximal ends of 2 left ulnae, distal ends of 3 right and 2 left ulnae, 1 complete right and 3 complete left carpometacarpi, proximal ends of 2 left carpometacarpi, proximal ends of 2 left femora, distal end of 1 right femur, distal ends of 2 right and 1 left tibiotarsus, proximal end of 1 left tarsometatarsus, distal ends of 3 right and 4 left tarsometatarsi.

REMARKs.-These specimens differ from the subspecies presently found in southwestern Ecuador and northwestern Peru in the same way as do the specimens from the Talara Tar Seeps. The complete right carpometacarpus is considerably lighter in build than the rest of the carpometacarpi from this site as well as those from the Talara Tar Seeps and is perhaps sufficiently different to warrant consideration as a distinct species. However, the great variation found in Polyborus makes it unwise to describe a new species without a larger sample. $P$. plancus is common in southwestern Ecuador.

\section{Milvago species}

Material.-Two left scapulae, 1 complete left carpometacarpus.

REMARKs.-This species is being described from 
the Talara Tar Seeps (Campbell, in press). No species of Milvago presently occurs west of the Andes Mountains in Peru or Ecuador.

\section{CHARADRIIDAE}

\section{Pluvialis dominica (Statius Müller)}

MATERIAL.-One complete right and 3 complete left coracoids, 8 complete right and 4 complete left humeri, distal ends of 1 right and 2 left humeri, 5 complete right and 5 complete left carpometacarpi, 2 complete left femora, proximal ends of 2 right tibiotarsi, distal ends of 3 right and 1 left tibiotarsus, 1 complete right and 5 complete left tarsometatarsi, proximal ends of 1 right and 1 left tarsometatarsus, distal ends of 2 right tarsometatarsi.

Remarks.-As North American migrants, $P$. dominica and the following 3 species of plovers occur as seasonal visitors or residents along the coast of Ecuador.

\section{Pluvialis squatarola (Linnaeus)}

MATERIAL.-Proximal end of 1 right humerus.

\section{Charadrius vociferus Linnaeus}

Material.-Proximal end of 1 left tibiotarsus.

\section{Charadrius semipalmatus Bonaparte}

Material.-One complete left humerus, distal end of 1 left tibiotarsus.

\section{Oreopholus orcesi, new species}

\section{Figure 3}

Holotype.-Complete left femur. Uncataloged.

Diagnosis.-Femur agrees with that of Oreopholus and differs from that of all other genera of South American plovers (with possible exception of Zonibyx Reichenbach, Pluvianellus Gray, and Phegornis Gray, which were not available for comparison) by having: (1) head disc-shaped, projecting mediad, perpendicular to shaft, without protruding dorsad above level of flat iliac facet; (2)
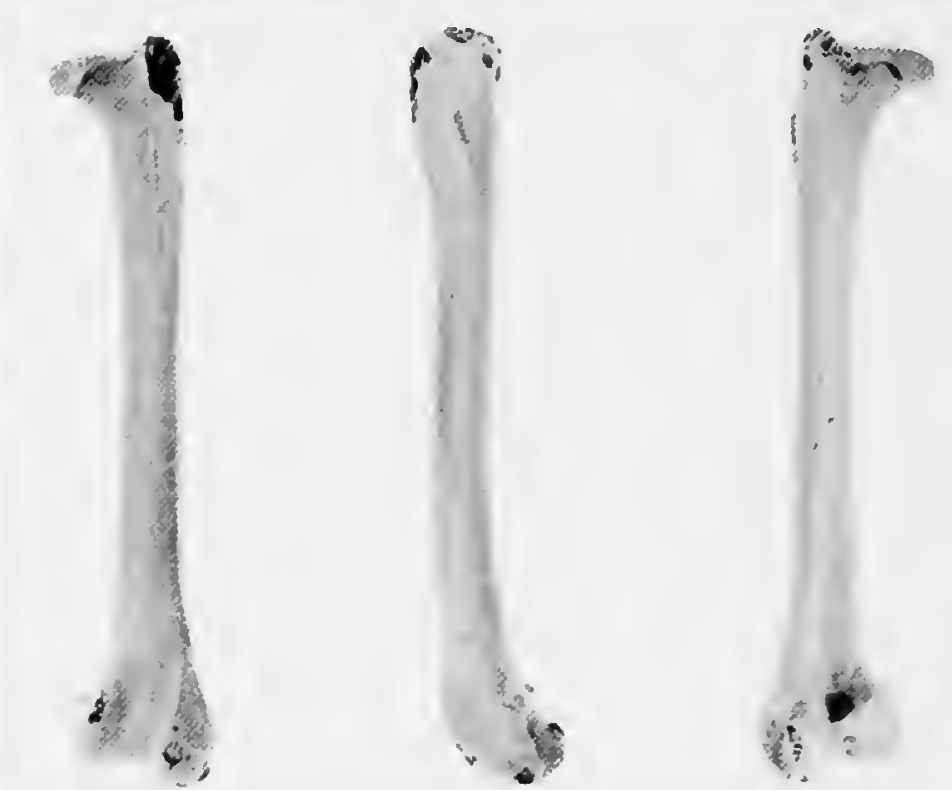

Figure 3.-Holotype left femur of Oreopholus orcesi, new species (uncataloged), in anterior, external, and posterior views, $\times 2$.

attachment of M. flexor ischiofemoralis elevated along anterior edge; (3) shaft with proximal twothirds straight, and marked anteroposterior flexure in distal third, in lateral view; (4) shaft with distal end turned sharply mediad posterior to anteroproximal termination of internal condyle, in anterior view; (5) internal condyle with posteroproximal corner projecting proximad more than external condyle; (6) shaft very wide immediately proximal to condyles.

Femur differs from that of Oreopholus ruficollis (Wagler) by having: (1) head much smaller; (2) attachment of $M$. iliacus marked by sharp, high ridge along corner of shaft (ridge absent and attachment much larger in area in O. ruficollis); (3) shaft with greater anteroposterior flexure; (4) shaft with marked concavity at point of flexure medial to internal condyle, resulting in internal condyle terminating proximally in high, narrow ridge (not as excavated in $O$. ruficollis, but with internal condyle more rounded); (5) internal condyle deeper anteroposteriad, with posterior articular surface flat (convexity present on surface in O. ruficollis); (6) external condyle projecting less proximad, and at a greater angle to axis of shaft, in posterior view; (7) attachment of $M$. gastrocnemius, pars externa, smaller in area, more elevated, and positioned more posteriad; (8) rotular groove narrower and deeper.

Measurements (in $\mathrm{mm}$ ) of the holotype, with 
those of one specimen of $O$. ruficollis (in parentheses), are as follows: length from external condyle to iliac facet, 29.7 (30.0); width of proximal end, 5.9 (6.2); width of distal end, 6.0 (6.1); least width of shaft, 2.5 (2.4).

Etymology.-This species is named for Professor Gustav Orcés V., of the Escuela Politécnica Nacional, Quito, Ecuador, for his pioneering work in the natural history of Ecuador.

REMARKs.-Although only one specimen of $O$. ruficollis was available for comparison, the majority of the characters cited above are considered unlikely to vary with a larger sample. The species of Zonibyx, Pluvianellus, and Phegornis are all much smaller than $O$. orcesi. In the event that the species described here does not belong in Oreopholus, but in one of the three genera listed above, it would still represent a new species, if based solely on size.

\section{SCOLOPACIDAE}

\section{Tringa solitaria Wilson}

Material.-Proximal end of I left tibiotarsus, proximal end of 1 left tarsometatarsus, distal end of 1 left tarsometatarsus.

Remarks.-As North American migrants, $T$. solitaria and the following 12 species of the family Scolopacidae occur as seasonal visitors or residents along the coast of Ecuador.

\section{Totanus flavipes (Gmelin)}

MATERIAL.-One complete right coracoid, l complete right and 2 complete left humeri, l complete right and 1 complete left carpometacarpus, shaft and proximal end of 1 right femur, distal ends of 3 right and 1 left tarsometatarsus.

REMARKS.-I consider the osteological differences between Tringa and Totanus as sufficient to separate them at the generic level.

\section{Totanus melanoleucus (Gmelin)}

MATERIAL.-Humeral end of 1 right coracoid, l complete left humerus, proximal end of 1 right humerus, distal end of 1 left humerus, 1 complete left carpometacarpus.

\section{Catoptrophorus semipalmatus (Gmelin)}

Material.-Distal ends of 2 right and 1 left humerus, 3 complete right and 3 complete left carpometacarpi, proximal end of 1 left carpometacarpus, shaft and proximal end of 1 right femur, distal end of 1 right tibiotarsus, proximal end of 1 right tarsometatarsus.

\section{Calidris canutus (Linnaeus)}

Material.-One complete left coracoid, 6 complete right and 6 complete left humeri, 5 almost complete right and 5 almost complete left humeri, proximal ends of 2 right and 3 left humeri, distal ends of 4 right and 5 left humeri, 5 complete right and 3 complete left carpometacarpi, proximal ends of 2 right carpometacarpi, distal ends of 7 right and 3 left tibiotarsi.

\section{Erolia melanotos (Vieillot)}

Material.-Three complete right and 8 complete left humeri, 1 almost complete right humerus, proximal ends of 1 right and 1 left humerus, distal end of 1 left humerus, 1 complete right and 2 complete left carpometacarpi, l complete right femur, distal end of 1 left femur, distal end of 1 right tibiotarsus, 1 complete left tarsometatarsus.

REMARKs.-I consider the osteological differences between Calidris, Erolia, and Ereunetes as sufficient to separate them as three distinct genera.

\section{Ereunetes pusillus (Linnaeus)}

Material.-One complete right and l complete left humerus, distal end of 1 right humerus.

\section{Ereunetes mauri (Cabanis)}

Material.-Two complete right and 4 complete left humeri, distal ends of 1 right and 3 left humeri.

\section{Micropalama himantopus (Bonaparte)}

Material.-One complete right femur.

\section{Bartramia longicauda (Bechstein)}

Material.-One complete right humerus, distal 
end of 1 right humerus, 1 complete right and 1 complete left carpometacarpus, distal ends of 2 left tibiotarsi, proximal end of 1 left tarsometatarsus, distal end of 1 left tarsometatarsus.

\section{Numenius phaeopus (Linnaeus)}

Material.- Two complete left coracoids, I complete right carpometacarpus, distal end of 1 left tibiotarsus.

\section{Limosa fedoa (Linnaeus)}

Material.-One complete right and 1 fragmentary left carpometacarpus.

\section{Arenaria interpres (Linnaeus)}

Material.-Two complete left and 1 complete right coracoid, humeral end of I right coracoid, proximal end of 1 left carpometacarpus, 1 complete left femur, 1 complete left tarsometatarsus.

\section{Scolopacidae genus and species}

Material.-One complete left coracoid, l complete right femur.

REMARKs.-A new genus and species of Scolopacidae is being described from the Talara Tar Seeps (Campbell, in press) on the basis of a coracoid and a tarsometatarsus. The coracoid from La Carolina agrees in all characters with the holotype coracoid, differing only in being more robust. Measurements (in $\mathrm{mm}$ ) of the La Carolina coracoid are as follows: length, 17.3; head to scapular facet, 6.7; depth of proximal end, 4.9; least width of shaft, 2.4; length of sternal facet, 5.8.

The above femur agrees with the other elements assigned to the new genus in superficially resembling Limnodromus more than any other genus of scolopacid. The femur differs from that of $L$. griseus by having: (1) neck longer and much more constricted; (2) head directed more anteriorly; (3) shaft flexed anteriad at level of attachment of M. iliacus, in lateral view (straight in L. griseus); (4) shaft curved gradually posteriad in distal half, in lateral view (curvature more localized in $L$. griseus); (5) attachment of M. gastrocnemius, pars externa, more elevated, facing more posteriad, but lying more on corner of shaft, farther from base of external condyle; (6) external condyle more distinctly set off at base posteriorly. The internal condyle is too broken to yield any characters.

Measurements (in $\mathrm{mm}$ ) of the femur are as follows: length from iliac facet to external condyle, 28.9; width of proximal end, 5.3; width of distal end, 4.8; least width of shaft, 2.2; depth of proximal end, 4.0.

\section{RECURVIROSTRIDAE}

\section{Himantopus mexicanus (Statius Müller)}

MATERIAL.-One complete right coracoid.

REMARKs. - H. mexicanus is generally distributed along the coast of Ecuador.

\section{PHALAROPODIDAE}

\section{Phalaropus fulicarius (Linnaeus)}

Material.-One complete right humerus, shaft and distal ends of 2 right humeri, 2 complete left carpometacarpi.

Remarks.-As North American migrants, $P$. fulicarius and the following two species of phalaropes occur in western Ecuador as seasonal visitors or residents.

\section{Lobipes lobatus (Linnaeus)}

Material.-Two complete right and 6 complete left humeri, 1 almost complete left humerus, I complete right and 4 complete left coracoids, proximal ends of 1 right and 1 left humerus, distal ends of 1 right and 2 left humeri, 2 complete right and 2 complete left carpometacarpi, proximal end of 1 right carpometacarpus, 1 complete right and 3 complete left tarsometatarsi.

\section{Steganopus tricolor Vieillot}

MATERIAL.-Five complete right and 4 complete left coracoids, 19 complete right and 20 complete left humeri, 3 almost complete right and 2 almost complete left humeri, proximal ends of 1 right and 2 left humeri, distal ends of 3 right and 7 left humeri, 5 complete right and 9 complete left carpo- 
metacarpi, 2 complete right and 2 complete left femora, distal ends of 6 right and 5 left tibiotarsi, 2 complete right tarsometatarsi, 1 almost complete right and 1 almost complete left tarsometatarsus, proximal ends of 1 right and I left tarsometatarsus, distal end of 1 right tarsometatarsus.

\section{Steganopus species}

Material.-One complete right and I complete left humerus, distal end of 1 left humerus, 1 complete right tarsometatarsus.

Remarks.-This species is being described from the Talara Tar Seeps on the basis of a complete femur (Campbell, in press). As the above elements differ significantly from $S$. tricolor they are here referred to the new species.

The humerus of the new Steganopus differs from that of $S$. tricolor by having: (1) median crest larger, less excavated; (2) internal tuberosity larger, more rounded, directed less dorsad, and projecting less anconally; (3) head not undercut by capital shaft groove; (4) attachment of $M$. proscapulohumeralis positioned closer to base of median crest; (5) attachment of $M$. triceps, external head, larger dorsoventrad and bordered ventrally by distinct lip of bicipital crest, resulting in a larger bicipital crest; (6) deltoid crest longer, thicker, and higher; (7) impression of M. brachialis anticus shallower, not as deeply inset at the edges; (8) attachment of anterior articular ligament shorter and higher; (9) attachment of $M$. pronator brevis positioned more distad; (10) internal and external condyles longer; (11) shaft much larger.

The tarsometatarsus of the new species differs from that of $S$. tricolor by having: (1) internal trochlea larger, but projecting less posteriad; (2) internal trochlea less excavated adjacent to middle trochlea; (3) middle trochlea more rounded posteriad in medial view; (4) internal trochlea positioned close to, and directed more toward, midline of shaft. The proximal ends of the tarsometatarsi of Steganopus apparently do not ossify completely except in older individuals. Although the present specimen showed only a slight indication of pitting, no reliable characters could be obtained from the proximal end.

For measurements of the humerus and tarso- metatarsus of the two species of Steganopus, see Table 1.

\section{BURHINIDAE}

\section{Burhinus superciliaris (Tschudi)}

MATERIAL.-Proximal end of I left humerus, distal ends of 1 right and 3 left humeri, 1 complete right and 3 complete left coracoids, proximal end of 1 left coracoid, distal end of 1 right scapula, distal end of 1 right ulna, 1 complete right and 2

TABle 1.-Measurements (mm) of the humerus and tarsometatarsus of Steganopus (OR $=$ Observed range, $\mathrm{M}=$ Mean, $\mathrm{N}=$ Number of specimens)

\begin{tabular}{|c|c|c|c|}
\hline $\begin{array}{l}\text { Character and } \\
\text { measurement }\end{array}$ & $\begin{array}{l}\text { Steganopus } \\
\text { species }\end{array}$ & $\begin{array}{c}\text { Steganopus } \\
\text { tricolor } \\
\text { Recent }\end{array}$ & $\begin{array}{l}\text { Steganopus } \\
\text { tricolor } \\
\text { La Carolina }\end{array}$ \\
\hline \multicolumn{4}{|l|}{ HUMERUS } \\
\hline \multicolumn{4}{|l|}{ Length } \\
\hline OR $\quad \ldots \ldots \ldots \ldots \ldots$ & $31.6-32.5$ & $32.1-38$ & $31.6-37.1$ \\
\hline $\mathbf{M}$ & 32 & 34.6 & 34.3 \\
\hline $\mathrm{N}$ & & 8 & 35 \\
\hline \multicolumn{4}{|l|}{ Width of proximal end } \\
\hline OR & $7.1-7.4$ & $6.9-8.2$ & $6.8-8$ \\
\hline $\mathbf{M}$ & 7.3 & 7.4 & 7.3 \\
\hline $\mathbf{N}$ & 2 & 8 & 35 \\
\hline \multicolumn{4}{|l|}{ Width of distal end } \\
\hline OR & $5-5.1$ & $4.5-5.6$ & $4.7-5.6$ \\
\hline $\mathbf{M}$ & 5.1 & 4.9 & 5.1 \\
\hline $\mathrm{N}$ & 2 & 8 & 35 \\
\hline \multicolumn{4}{|l|}{ Least width of shaft } \\
\hline OR & 2.4 & $2-2.3$ & $2-2.6$ \\
\hline $\mathbf{M} \ldots \ldots \ldots \ldots \ldots \ldots \ldots \ldots$ & 2.4 & 2.2 & 2.3 \\
\hline $\mathrm{N}$ & 2 & 8 & 35 \\
\hline \multicolumn{4}{|l|}{ TARSOMETATARSUS } \\
\hline \multicolumn{4}{|l|}{ Length } \\
\hline OR & 30.6 & $31-34.7$ & $32.8-34.5$ \\
\hline $\mathbf{M}$ & - & 32.2 & 33.6 \\
\hline $\mathbf{N} \quad \ldots \quad \ldots \quad \ldots \ldots \ldots \ldots \ldots$ & 1 & 8 & 2 \\
\hline \multicolumn{4}{|l|}{ Width of proximal end } \\
\hline OR & 3.5 & $3.2-3.7$ & $3.5-3.8$ \\
\hline $\mathbf{M}$ & - & 3.4 & 3.6 \\
\hline $\mathrm{N}$ & 1 & 8 & 4 \\
\hline \multicolumn{4}{|l|}{ Width of distal end } \\
\hline OR & 3.2 & $3-3.3$ & $3.3-3.5$ \\
\hline M & - & 3.2 & 3.4 \\
\hline $\mathrm{N}$ & 1 & 8 & 2 \\
\hline \multicolumn{4}{|l|}{ Least width of shaft } \\
\hline OR & 1.2 & $1.2-1.3$ & 1.3 \\
\hline $\mathbf{M}$ & - & 1.2 & 1.3 \\
\hline $\mathbf{N}$ & 1 & 8 & 4 \\
\hline
\end{tabular}


complete left carpometacarpi, l complete left femur, distal end of 1 left tibiotarsus, distal end of 1 right tarsometarsus.

REMARKs. $-B$. superciliaris is common in the semi-arid region of Ecuador.

\section{THINOCORIDAE}

\section{Thinocorus rumicivorus Eschscholtz}

Material.-One complete right and l complete left humerus, 1 complete right and 1 complete left carpometacarpus.

REMARKS.- $T$. rumicivorus is resident in the arid regions of Ecuador.

\section{LARIDAE}

\section{Larus pipixcan Wagler}

Material.-One complete right carpometacarpus, proximal end of 1 right carpometacarpus.

Remarks.-A North American migrant, L. pipixcan is a seasonal resident of Ecuador.

\section{Larosterna inca (Lesson)}

MATERIAL.-Humeral end of 1 left coracoid.

REMARKs.-A small, shallow attachment of Lig. humerocoracoideum anterius superius, located on the anteroventral corner of the head of the coracoid, is characteristic of Larosterna. This is the first fossil record of the genus. L. inca is found along the coast of southern Ecuador.

\section{COLUMBIDAE}

\section{Zenaida auriculata (Des Murs)}

Material.-Two right and 2 left scapulae, 1 complete right and 8 complete left coracoids, humeral ends of 1 right and 1 left coracoid, 1 complete right and 6 complete left humeri, proximal ends of 2 right and 3 left humeri, distal ends of 1 right and 1 left humerus, 4 complete right and 5 complete left ulnae, 2 complete right and 2 complete left radii, 5 complete right and 6 complete left carpometacarpi, 1 complete right and 1 complete left femur, 1 complete right and 1 complete left tibio- tarsus, distal end of 1 right tibiotarsus, 4 complete right and 1 complete left tarsometatarsus, shaft and proximal end of 1 left tarsometatarsus.

REMARKS. $Z$. auriculata is resident in western Ecuador.

\section{Zenaida asiatica (Linnaeus)}

Material.-Proximal end of 1 left carpometacarpus.

REMARKS.- $Z$. asiatica is resident in southwestern Ecuador.

\section{Columbina cruziana (Knip and Prevost)}

Material.-One complete right humerus.

REMARKs. - C. cruziana is common in southwestern Ecuador.

\section{PSITTACIDAE}

\section{Aratinga roosevelti (Spillman)}

MATERIAL.-Portions of 11 crania, 12 premaxillaries, 14 mandibles, 24 right and 17 left scapulae, 35 complete right and 46 complete left coracoids, humeral ends of 2 left coracoids, 25 complete right and 24 complete left humeri, proximal end of 1 right humerus, distal ends of 3 left humeri, $55 \mathrm{com}$ plete right and 56 complete left ulnae, proximal ends of 1 right and 1 left ulna, distal end of 1 left ulna, 30 complete right and 28 complete left radii, proximal ends of 5 right and 1 left radius, distal ends of 2 right and 2 left radii, 85 complete right and 71 complete left carpometacarpi, proximal ends of 3 right and 2 left carpometacarpi, shafts of 2 left carpometacarpi, 29 complete right and 22 complete left femora, distal ends of 1 right and 1 left femur, 36 complete right and 24 complete left tibiotarsi, proximal ends of 1 right and 1 left tibiotarsus, distal ends of 4 right and 1 left tibiotarsus, 21 complete right and 19 complete left tarsometatarsi, proximal ends of 2 left tarsometatarsi, distal ends of 3 left tarsometatarsi.

REMARKs.-Spillman (1942) reported a large collection of parrot fossils from a site on the Santa Elena Peninsula near La Carolina. He placed this material in a new genus and species, Protoconurus roosevelti. From his descriptions and illustrations 
it is reasonably certain that the present material belongs to the same species. I could not detect sufficient differences between this fossil material and Recent specimens of the genus Aratinga to warrant the placement of the former in a different genus. Therefore, I suggest that Protoconurus be synonymized with Aratinga.

It is not possible at this time to say whether the fossil material represents an extinct species, as Spillman believed, or an extant species. This cannot be determined until a satisfactory series of comparative material is available. The fossil material is slightly larger than the one available specimen of $A$. erythrogenys from southwestern Ecuador and differs from that species in many ways.

One coracoid of those listed above is significantly smaller than the others and may represent a different species.

\section{Aratinga species}

MATERIAL.--One complete left coracoid, distal end of 1 right humerus.

Remarks. - These two specimens appear to represent a species of Aratinga, but may possibly represent another genus, as not all genera of Ecuadorian parrots were available for comparison. They are considerably larger than the corresponding elements of $A$. erythrogenys.

\section{TYTONIDAE}

\section{Tyto alba (Scopoli)}

Material.-One complete right coracoid.

REMARKs. $-T$. alba is resident in western Ecuador.

\section{STRIGIDAE}

\section{Speotyto cunicularia Gloger}

Material.-One complete right and 1 complete left carpometacarpus, distal ends of 2 right tibiotarsi, distal end of 1 left tarsometarsus.

REMARKs.-S. cunicularia is resident in western Ecuador.

\section{Discussion}

Ecological Considerations.-La Carolina is located in the most arid region of Ecuador. Vegetation is very sparse, except in the larger dry river valleys. Ecological and climatological conditions at the site are very similar to those found at the Talara Tar Seeps, except that La Carolina is much closer to the coastline and receives slightly more rainfall. The major difference between the arid region of Ecuador and that of coastal Peru is in the greater area of the latter. Whereas the Peruvian coastal desert is thousands of kilometers long, the Ecuadorian desert is essentially limited to the Santa Elena Peninsula (Figure 1). The transition from barren desert to heavy forest is very abrupt, in some places occurring over only a few kilometers.

The principal references concerning the modern avifauna of southwestern Ecuador are the works of Chapman (1926) and Marchant (1958, 1959, 1960 ). A point stressed by both authors is the rapidity with which the arid and semi-arid regions are colonized by birds from the adjacent forests following the rare periods of rainfall. Marchant also documents how large numbers of birds are attracted to standing bodies of fresh water on the peninsula, such as an artificial lake.

The importance of the La Carolina avifauna in interpreting the paleoecology of southwestern Ecuador is difficult to assess. This is because the desert region is so small, the transition to forest so sharp, and the speed of colonization under the proper conditions so rapid, that only a few years of heavy rainfall are needed to change the desert into a lush savanna with seasonally flowing rivers. Such rivers would in turn form wide deltas in the lowlying, flat coastal zone. This type of environment undoubtedly attracts birds from the surrounding areas and provides excellent stop-over points for the North American migrants that make up over 43 percent of the paleoavifauna.

A climatological phenomenon known as El Niño (Chapman, 1926; Murphy, 1926) periodically brings heavy rains to southwestern Ecuador and northern coastal Peru. This supposedly occurs every seven years, but in reality the phenomenon may take place in any year. When rains do come to southwestern Ecuador they occur during the northern hemisphere winter. This increases the probability of migrant species encountering favor- 
able conditions during passage to and from their wintering grounds.

If the avifauna of the Talara Tar Seeps were not known, one would probably interpret the avifauna of La Carolina, and possibly the mammalian fauna as well, as having been deposited during El Niño years. However, the Talara avifauna strongly suggests that the entire climatological regime of northern coastal Peru, and thus by inference that of southwestern Ecuador, was quite different from that found today. Instead of desert, the area was probably a lush savanna or, in the case of the Santa Elena Peninsula, more probably a tropical dry deciduous forest. Archeological work on the Santa Elena Peninsula also indicates a moister climatic regime in the past (Meggers, Evans, and Estrada, 1965; Richardson, 1973). The causes of the present dry climate, as opposed to the wetter climate present during glacial periods, are the subject of another paper currently in preparation.

Comparison with the Avifauna of the Talara TAR Seeps.-Of the 53 species from La Carolina, $38(72 \%)$ were also found at the Talara Tar Seeps (Table 2). This includes 7 extinct species common to both sites that were first recorded from the Talara Tar Seeps. The high degree of similarity between the paleoavifaunas of the two localities, as well as that between the modern avifaunas, confirms that there must have been a great deal of interchange between coastal Ecuador and coastal Peru. A similar situation is observed between the mammalian faunas of the two sites (Lemon and Churcher, 1961).

The straight line distance between La Carolina and the Talara Tar Seeps is approximately 273 kilometers. At the present time the Gulf of Guayaquil separates the arid region of Ecuador from that of northern Peru. During glacial periods, however, the lowered sea level exposed as dry land the area currently covered by the Gulf of Guayaquil, allowing easy movement between the two areas. The formation of the Gulf of Guayaquil at the end of the Pleistocene resulted in the isolation of the avifauna of the arid Santa Elena Peninsula from that of coastal Peru. Consequently, a great deal of subspeciation has occurred between the two areas (Chapman, 1926).

The differences observed in the composition of the two paleoavifaunas can be attributed to two major causes-the means of entrapment and the location relative to the coastline. The active tar seeps at Talara attracted large numbers of scavenger species that came to feed upon other animals, including large mammals, trapped in the tar. The drawing power of La Carolina in this regard must have been weak. As the Talara site is located approximately 32 kilometers inland, it has a higher percentage of terrestrial species and fewer strictly marine species that do not venture inland. The opposite is true of La Carolina which was on, or very near, the coastline.

The similarities between the avian and mammalian faunas of La Carolina and the Talara Tar Seeps, particularly in the extinct species, suggest that material was being deposited at the two sites contemporaneously. The Talara site has been dated at c. 13,900 B.P. (Churcher, 1966). If the age of La Carolina differs significantly from that of the Talara Tar Seeps, I believe it will prove to be younger rather than older, for climatological reasons to be discussed in a later publication.

Entrapment of the Birds at La Carolina.How birds became trapped, or their remains concentrated, at La Carolina is not clear. The undisturbed matrix available with the collection was extremely rich in avian specimens, and contained only a few fragmentary mammalian bones. At other nearby sites, however, Edmund (pers. comm.) found only mammalian and no avian material.

None of the fossil material I studied shows any large concentration of pitch, although there are some indications of its presence in the matrix surrounding some specimens. The absence of heavy pitch concentrations on the bones indicates that the birds were not trapped in active tar seeps, as at the Talara Tar Seeps and Rancho La Brea. It is quite possible, however, that oil seeps may have coated the water with a surface layer of oil and that upon landing in this the feathers of the birds would become oil-soaked, preventing further flight and resulting in their drowning. As the bodies decomposed, the bones would be freed from the oil and drop to settle in the soft mud. Such a film of oil would also help to explain the lack of mammalian specimens in the concentration of avian remains. Mammals are better able to sense and avoid oilcovered water than are birds alighting from flight. For larger mammals, passage through oil covered water would be no more than an unpleasant inconvenience. 
TABle 2.-Fifty-three nonpasserine species from La Carolina, Ecuador

\begin{tabular}{|c|c|c|c|c|c|}
\hline Species & $\begin{array}{c}\text { No. of } \\
\text { Specimens }\end{array}$ & $\begin{array}{l}\text { Minimum } \\
\text { No. of } \\
\text { Individuals }\end{array}$ & Species & $\begin{array}{c}\text { No. of } \\
\text { Specimens }\end{array}$ & $\begin{array}{l}\text { Minimum } \\
\quad \text { No. of } \\
\text { Individuals }\end{array}$ \\
\hline${ }^{*}$ Nycticorax nycticorax ....... & 5 & 1 & *Erolia melanotos. & 22 & 9 \\
\hline "Dendrocygna autumnalis .............. & 4 & 1 & Ereunetes pusillus & 3 & 2 \\
\hline ANATIDAE genus and species ....... & 10 & 3 & ${ }^{*}$ Ereunetes mauri & 10 & 7 \\
\hline${ }^{*}$ Anas species 1 & 4 & 1 & - Micropalama himantopus .............. & 1 & 1 \\
\hline${ }^{*}$ Anas species $3 \ldots \ldots \ldots \ldots \ldots \ldots \ldots \ldots \ldots \ldots \ldots$ & 4 & 2 & Bartramia longicauda & 8 & 2 \\
\hline *Anas bahamensis ................................. & 326 & 37 & Numenius phaeopus …………......... & 4 & 2 \\
\hline Vulturidae gen. et sp. indet. ...... & 1 & 1 & Limosa fedoa & 2 & 1 \\
\hline *Coragyps cf. atratus ........................... & 2 & 1 & *Arenaria interpres & 7 & 2 \\
\hline${ }^{*}$ Cathartes aura ................................. & 5 & 3 & ${ }^{*}$ Scolopacidae genus and species.. & 2 & 1 \\
\hline *ACcipitridar genus and species. & 1 & 1 & Himantopus mexicanus ............... & 1 & 1 \\
\hline *Geranoaetus melanoleucus ........... & 2 & 1 & Phalaropus fulicarius ...................... & 5 & 3 \\
\hline *Buteo polyosoma ……..................... & 7 & 2 & ${ }^{*}$ Lobipes lobatus ............................... & 28 & 8 \\
\hline Buteo hoffstetteri, new species .... & 4 & 1 & 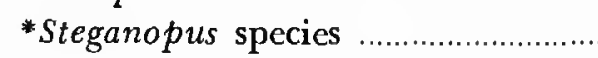 & 4 & 2 \\
\hline 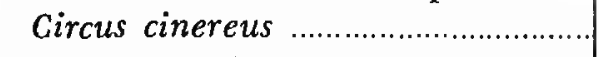 & 3 & 1 & Steganopus tricolor & 102 & 29 \\
\hline •Falco peregrinus .................................. & 22 & 3 & *Burhinus superciliaris ....................... & 18 & 4 \\
\hline${ }^{*}$ Falco femoralis ............................. & 2 & 1 & ${ }^{*}$ Thinocorus rumicivorus ............ & 4 & 1 \\
\hline${ }^{*}$ Polyborus plancus & 52 & 6 & ${ }^{*}$ Larus pipixcan & 2 & 1 \\
\hline 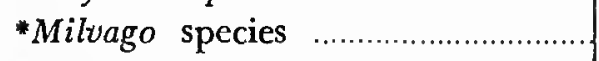 & 3 & 2 & Larosterna inca & 1 & 1 \\
\hline *Pluvialis dominica & 47 & 9 & *Zenaida asiatica & 1 & 1 \\
\hline 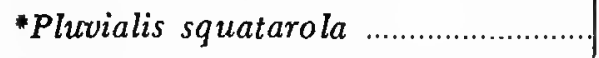 & 1 & 1 & ${ }^{*}$ Zenaida auriculata .......................... & 64 & 9 \\
\hline${ }^{*}$ Charadrius vociferus .............................. & 1 & 1 & ${ }^{*}$ Columbina cruziana & 1 & 1 \\
\hline *Charadrius semipalmatus ................... & 2 & 1 & Aratinga roosevelti & 724 & 88 \\
\hline Oreopholus orcesi, new species .... & 1 & 1 & Arating $a$ species & 2 & 1 \\
\hline *Tringa solitaria .................................... & 3 & 1 & ${ }^{*}$ Tyto alba & 1 & 1 \\
\hline *Totanus flavipes . & 11 & 3 & *Speotyto cunicularia & 5 & 2 \\
\hline${ }^{*}$ Totanus melanoleucus & 5 & 2 & & & \\
\hline${ }^{*}$ Catoptrophorus semipalmatus ...... & 5 & 2 & & & \\
\hline Calidris canutus .................................... & 57 & 15 & Total & 1611 & 284 \\
\hline
\end{tabular}

*Also recorded from the Talara Tar Seeps, Peru.

Perhaps the most remarkable aspect of the avifauna from La Carolina is the tremendous number of specimens of parrots, making up approximately 44 percent of the entire collection. Parrots must have been attracted to the site in large flocks, perhaps for water, and subsequently trapped by the oil. From such large flocks of parrots one could reason either that water was scarce and La Carolina was the only watering site available, the parrots thus having to travel long distances to reach it, or water may have been abundant and La Carolina close to the roosting or feeding areas of the parrots. If the latter were true, it would indicate the presence of forest on the presently barren peninsula.

\section{Literature Cited}

Campbell, K. E., Jr.

In press. The Pleistocene Avifauna of the Talara Tar Seeps, Northwestern Peru. Royal Ontario Museum, Toronto, Life Sciences Division, Contribution.

Chapman, F. M.

1926. The Distribution of Bird-life in Ecuador: A Contribution to a Study of the Origin of Andean Bird-Life. Bulletin of the American Museum of Natural History, 55:1-784.

Churcher, C. S.
1966. The Insect Fauna from the Talara Tar-seeps, Peru. Canadian Journal of Zoology, 44:985-993.

Edmund, A. G.

1965. A Late Pleistocene Fauna from the Santa Elena Peninsula, Ecuador. Royal Ontario Museum, Toronto, Life Sciences Division, Contribution, 63:1-21.

Hoffstetter, R. F.

1952. Les mammifères Pléistocènes de la République de l'Équateur. Mémoires de la Société Géologique de France, new series, 66:1-391. 
Lemon, R. R. H., and C. S. Churcher

1961. Pleistocene Geology and Paleontology of the Talara Region, Northwestern Peru. American Journal of Science, 259:410-429.

Marchant, S.

1958. The Birds of the Santa Elena Peninsula, S. W. Ecuador. Ibis, 100:349-387.

1959. The Breeding Season in S. W. Ecuador. Ibis, 101: 137-152.

1960. The Breeding of Some S. W. Ecuadorian Birds. Ibis, 102:349-382, 584-599.

Meggers, B. J., C. Evans, and E. Estrada

1965. Early Formative Period of Coastal Ecuador: The Valdivia and Machalilla Phases. Smithsonian Contributions to Anthropology, 1:1-234.

Meyer de Schauensee, $\mathbf{R}$.

1966. The Species of Birds of South America with Their
Distribution. 577 pages. Wynnewood, Pennsylvania: Livingston Publishing Company.

Murphy, R. C.

1926. Oceanic and Climatic Phenomena Along the West Coast of South America During 1925. The Geographical Review, 16:26-54.

Richardson, J. B.

1973. The Preceramic Sequence and the Pleistocene and Post-Pleistocene Climate of Northwest Peru. Pages 199-211 in D. W. Lathrap and J. Douglas, editors, Variation in Anthropology: Essays in Honor of John C. McGregor. Urbana Illinois: Illinois Archaeological Survey.

Spillman, F.

1942. Contribución al conocimiento de fósiles nuevos de la avifauna Ecuatoriana en el Pleistoceno de Santa Elena. Proceedings of the Eighth American Scientific Congress, Washington, 4:375-389. 


\title{
The Great Predatory Birds of the Pleistocene of Cuba
}

\author{
Oscar Arredondo
}

translated and amended by Storrs L. Olson

ABSTRACT

\begin{abstract}
Recent paleontological investigations in Cuba have shown that the island was formerly inhabited by large populations of rodents and edentates. Based on discoveries of giant fossil raptorial birds (Strigiformes and Accipitriformes) in Cuba and other Antillean islands, the theory is put forth here that these predators were the principal agents in controlling the abundance of these native mammals. Details are given of the discovery in Cuba of the gigantic owl Ornimegalonyx, two species of giant barn owls (Tyto), a giant species of eagle (Aquila borrasi), and a vulture (Antillovultur) similar in size to the Andean Condor (Vultur gryphus). The relationships and possible origins of gigantism in these birds are discussed. Descriptions, geographic distribution, tables of measurements, and a list of the extinct faunas found in each of the type-localities are offered for each species.
\end{abstract}

\section{Introduction}

Recent studies of fossil material from numerous caves in Cuba have convincingly demonstrated the former extraordinary abundance of endemic mammals there. These include rodents of the genera Heteropsomys, Capromys (including Geocapromys), and Macrocapromys; ground sloths (Edentata) of the genera Cubanocnus, Miocnus, Mesocnus, and Megalocnus; and insectivores of the genera Solenodon and Nesophontes. These genera were represented throughout the island by species very numerous in terms of individuals. From such caves as Paredones and El Túnel in the province of Habana it is no exaggeration to say that tens of

Oscar Arredondo, Grupo Espeleológico, Martel de Cuba, Avenida 43, No. 5847, Apartado 4, Mariano 14, Habana, Cuba.
Se expone la tesis, basada en los últimos descubrimientos realizados en Cuba y otras Antillas sobre aves fósiles gigantes de los órdenes Strigiformes y Accipitriformes, de que dichos táxones constituyeron el elemento faunístico primoridal que controlara con su acción predatora a roedores y desdentados que en estas islas existían, manteniendo asi el equilibrio biológico necesario. Se ofrecen datos concretos probatorios de la extremada abundancia en las Antillas de poblaciones de roedores y desdentados. Se dan detalles del descubrimiento en Cuba del gigantesco buho Ornimegalonyx, de dos especies gigantes de lechuzas del género Tyto, de una especie de águila gigante y de un buitre similar en talla a Vultur gryphus. Se plantea una discusión sobre el motivo que pudo originar el gigantismo en estas aves. Se ofrecen descripciones específicas de todas estas grandes aves predatoras, incluyéndose, distribución geográfica, tablas de medidas y una relación de la fauna extinguida hallada asociada en las localidades típicas.

thousands of mandibles of Capromys pleistocenicus can be extracted from a single small chamber, although most of these specimens are poorly preserved. An examination of only a part of the fossil material taken from a small cave in Cayo Salinas, a few miles east-southeast of Caibarién, Las Villas, yielded the remains of over 200 individuals of the edentate genus Mesocnus (Acevedo, Arredondo, and Gonzalez, 1975). Further confirming the former abundance of native mammals is the widespread occurrence in Cuba of remains of bloodeating vampire bats of the genus Desmodus (Koopman, 1958; Arredondo, 1958b; Woloszyn and Mayo, 1974). These bats would necessarily have required numerous, large, warm-blooded mammals to sustain them. Similar abundant faunas of large' rodents and ground sloths are also known from cave deposits in Hispaniola and Puerto Rico. 
Obviously, some natural regulator must have acted to maintain a biological equilibrium between these prolific herbivorous mammals and the vegetation on which they fed. In the Antilles, however, there are virtually no native carnivorous mammals. Exceptions are Cubacyon transwersidens (Arredondo and Varona, 1974), a canid known from a single fragment of maxilla found in association with extinct vertebrates in a cave in the province of Habana, and the extant populations of Procyon known from the Bahamas, Barbados, and Guadeloupe, some or all of which may have been introduced to these islands by man (Varona, 1974; Arredondo and Varona, 1974). A mandible found in an Indian midden in Camagüey, Cuba, and attributed to Procyon lotor by the naturalist Andrés Poey (Harrington, 1935), may similarly have pertained to an introduced animal; the record is dubious in any case, since the specimen can no longer be found. Regardless, small procyonids could not have been an influential factor in the control of the endemic Antillean rodents and edentates.

The numerous and dense deposits of smaller vertebrates (Table 1) frequently found in Cuban caves abound with remains of the rodents ${ }^{1}$ Capromys pleistocenicus, Capromys nanus, Heteropsomys torrei, and $\mathrm{H}$. offella; the insectivores Nesophontes micrus and $N$. major; several genera of bats; passeriform birds, particularly of the genera Mimocichla, Quiscalus and Dives; as well as nonpasserines such as Crotophaga and Glaucidium. These remains are certainly attributable to the actions of medium-sized owls still existing in the island such as Tyto alba and Asio stygius, and perhaps to others now extinct, such as Pulsatrix arredondoi (Brodkorb, 1969).

The most outstanding accumulations of bones, however, are those of the larger mammals (Table 1) such as Capromys pilorides, C. columbianus, Macrocapromys acevedo, and occasional examples of Cubanocnus gliriformis, as well as large birds of various orders. Such remains suggest that many larger predators were once active in Cuba.

Much of the accumulation of vertebrate remains

\footnotetext{
The mammalian classification used in this paper follows Varona (1974) and in some instances is at variance with Professor Arredondo's preferences.-Ed.
}

in cave deposits in Haiti was attributed to the depredations of the extinct giant barn owl Tyto ostologa, first described by Wetmore (1922). Another giant barn owl, Tyto pollens Wetmore (1937), first reported from Great Exuma and later from New Providence Island (Brodkorb, 1959), must have been an effective predator of Capromys in the Bahamas, as no doubt were the extinct diurnal raptors (Accipitridae) of the genera Calohierax and Titanohierax (Wetmore, 1937). The presence of such large raptors elsewhere in the Antilles suggested that the Cuban cave deposits might be attributable to similar avian predators. This was vividly confirmed by the discovery in Cuba of remains of five species of predatory birds of truly tremendous proportions. These birds occupied the niches which in continental areas are usually filled by various groups of carnivorous mammals. The absence of mammalian competitors, combined with a superabundance of large prey, are no doubt the principal factors contributing to the gigantism observed in these birds. The larger forms may have functioned particularly to keep the populations of edentates in check.

\section{Brief History of Certain Discoveries}

On 2 January 1954, the remains of a gigantic owl, the largest known, were discovered for the first time in the depths of a large cavern known as Pio Domingo Cave, located in the Sierra de Sumidero, opposite Pica-Pica Valley in Pinar del Río. These bones (Figure 5) were found in place, fastened to the calcareous surface of the floor by travertine, just as were those of the various edentates encountered in the immediate vicinity. This owl was described under the name Ornimegalonyx oteroi (Arredondo, 1958a) and was at first erroneously regarded as a member of the Phorusrhacidae, an extinct family of flightless South American carnivorous birds. Dr. Byran Patterson, who studied some of these remains, afterwards informed me (pers. comm.) of his belief that they actually pertained to a great owl, two times larger in linear dimensions than Tyto ostologa of Haiti. Brodkorb (1961), recognizing the validity of the nomenclature proposed in 1958, established that the species belonged in the family Strigidae, where he maintained it in later publications (Brodkorb, 1969, 1971). Addi- 
TABLE 1.-Associated fauna found in the type-localities of the large extinct species of Cuban birds of prey

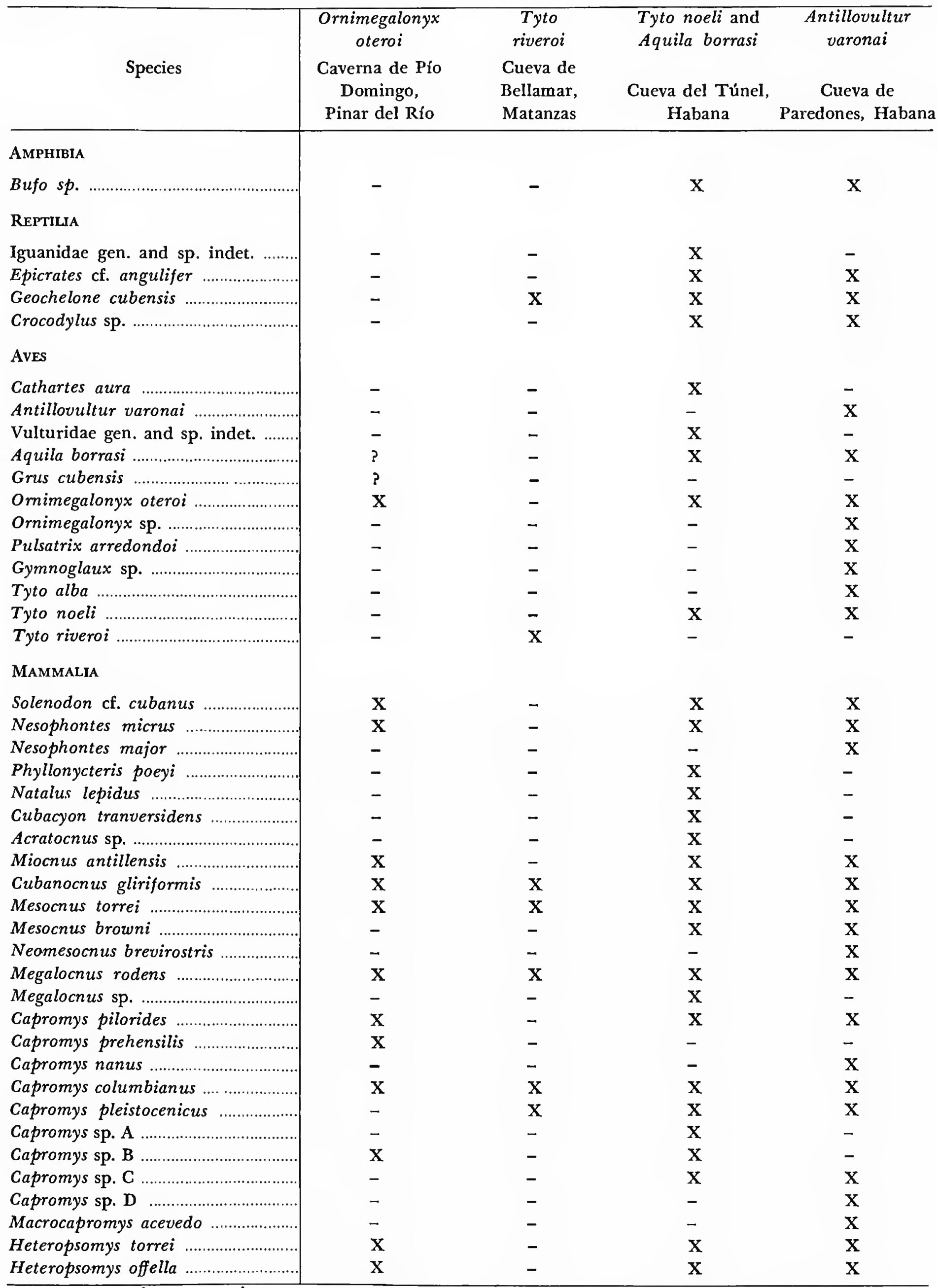

$\mathrm{X}=$ present; ? = uncertain; - = not present. 
tional fossils of this giant owl were later found in various caves in the provinces of Habana, Matanzas, Las Villas, and Camagüey, as well as in the Isle of Pines. It is possible that two unrecognized species of Ornimegalonyx may exist among these remains; one of these seems to be somewhat smaller than $O$. oteroi, while the other is larger. Considering the enormous size of this owl, particularly of its claws, it is quite conceivable that it could have made victims of juvenile edentates, notwithstanding the fact that Ornimegalonyx appears to have been incapable of flight.

In July 1954, explorations in the Cueva de Paredones in San Antonio de los Baños, revealed for the first time the fossil bones of an eagle larger than any of the living species of the family Accipitridae. Other bones of it were found a few years later in the Cueva del Túnel, La Salud, Habana. This eagle was named Aquila borrasi (Arredondo, 1970). According to its tarsometatarsus, it was very similar in size and morphology to the recently described species Garganoaetus freudenthali from the upper Miocene of Italy (Ballmann, 1973).

A fossil vulture from Cueva de Paredones was recently described as a new genus and species, Antillovultur varonai Arredondo (1971), and was the size of an Andean Condor. Various bones found in a cave in Habana and now under study, possibly indicate another large species of vulture.

Two species of giant barn owls of the genus Tyto were discovered a little later (Arredondo, 1972a, $1972 \mathrm{~b})$. One of these, Tyto noeli, founded on abundant bones from two caves in Habana, was similar in size to Tyto ostologa of Haiti. The other species, Tyto riveroi, based on the distal portion of a tarsometatarsus from Cueva de Bellamar, Matanzas, was truly gigantic, being larger than any of the fossil or living species of the genus. It is the one strigiform that most closely approaches the size of Ornimegalonyx oteroi, and like that species could also have captured small edentates. The eminent paleornithologist Alexander Wetmore (1959) was the first to report fossil remains of large barn owls from Cuba, but these were not named.2

\footnotetext{
'These specimens, a humerus and a femur, are still at the National Museum of Natural History. They are very much larger than $T$. ostologa or $T$. noeli and most probably pertain to the distinctive species $T$. riveroi. At a later date I hope to be able to describe these fossils further, along with abundant unpublished material of $T$. oslologa.-Ed.
}

The discovery of three species of tytonids in the upper Miocene of Italy (Ballmann, 1973), one of which, Tyto robusta, is equal in size to $T$. noeli and $T$. ostologa, and the other, Tyto gigantea, being only, slightly smaller than $T$. riveroi, partly contradicts the hypothesis that gigantism in Antillean barn owls is attributable to insular evolution from smaller species that responded to the great abundance of food and the lack of competition from carnivorous mammals. The genus Tyto evidently had already evolved giant species in Europe, millions of years before the beginning of the Pleistocene. The following conclusions could therefore be drawn: (I) either the giant Antillean barn owls evolved in parallel with those of Europe, arriving through convergence at species of approximately the same size, or (2) the Antillean forms are descended from Tertiary European forms that established themselves in North America and colonized the Antilles before or during the Pleistocene. Against this last suggestion is the absence on the American continent of giant species of $T y t o$.

Ornimegalonyx is truly exceptional for its extremely large size. It appears to have evolved its gigantism in Cuba from some remote smaller ancestor. An affinity of Ornimegalonyx with any of the living genera of large continental owls is not clearly evident and its relationships may lie closer to some extinct form rather than with any presently living.

The study of the origins, evolution, and paleoecology of the giant raptorial birds of the Antilles is of great interest and significance to our understanding of the environment and evolution of many of the terrestrial vertebrates of those islands. It is hoped that this summary of what is known of the Cuban birds will aid in that understanding.

Abbreviations used are as follows: Academia de Ciencias de Cuba (ACC), Departamento de Paleontología de la Universidad de la Habana (DPUH), Museo del Grupo de Exploraciones Cientificas "Pedro Borrás Astorga" (GEC), Museum of Comparative Zoology (MCZ), Museo Felipe Poey de la Academia de Ciencias de Cuba (MFP), Museo Montané de la Universidad de la Habana (MMUH), personal collection of Oscar Arredondo (OA), Sociedad Espeleológica de Cuba (SEC). 


\section{Order ACCIPITRIFORMES}

\section{Family VULTURIDAE}

\section{Genus Antillovultur Arredondo, 1971}

\section{Antillovultur varonai Arredondo, 1971}

HoLotYPE.-Proximal portion of left tarsometatarsus, DPUH 1254.

Type-Locality.-Cueva de Paredones, San Antonio de los Baños, Habana, Cuba.

Age.-Late Pleistocene.

Other Material.-GEC (unnumbered), distal portion of left humerus; OA 847, external trochlea of left tarsometatarsus; OA 848 , body of seventh cervical vertebra. All specimens from the typelocality.

DesCRIPTION.-The type (Figure $1 a, b$ ) is a proximal portion of a tarsometatarsus, $42.5 \mathrm{~mm}$ in length, lacking the proximal articulating surface, hypotarsus, and slightly more than half the distal portion of the bone. The estimated total length is $141 \mathrm{~mm}$, or about equal to that of Vultur gryphus and longer and slightly more robust than in Gymnogyps californianus (Figure 2, Table 2). From these two species and Cathartes aura it differs in having the groove in the anterior face of the bone narrower and deeper and the internal tubercle for M. tibialis anticus more expanded. In anterior view, the surface of the shaft between the internal border and the groove is notably thick and rounded, whereas in Vultur, Cathartes, and Teratornis it is narrower and sharp-edged. The surface of the shaft delimited by the external border and the groove is more slender than the internal ridge, contrary to the condition in the other genera mentioned. The shaft in medial view is proportionately more slender than in Vultur or Cathartes. These characters are considered to be of generic value.

The distance between the proximal border of the larger tubercle for $M$. tibialis anticus and the proximal extremity of the anterior groove is greater than in Vultur or Teratornis and equal to that in Gymnogyps. Antillovultur has an additional two proximal foraminae situated above the usual two. Vultur similarly possesses another aperture above the lateral proximal foramen but lacks the medial proximal foramen of Antillovultur.

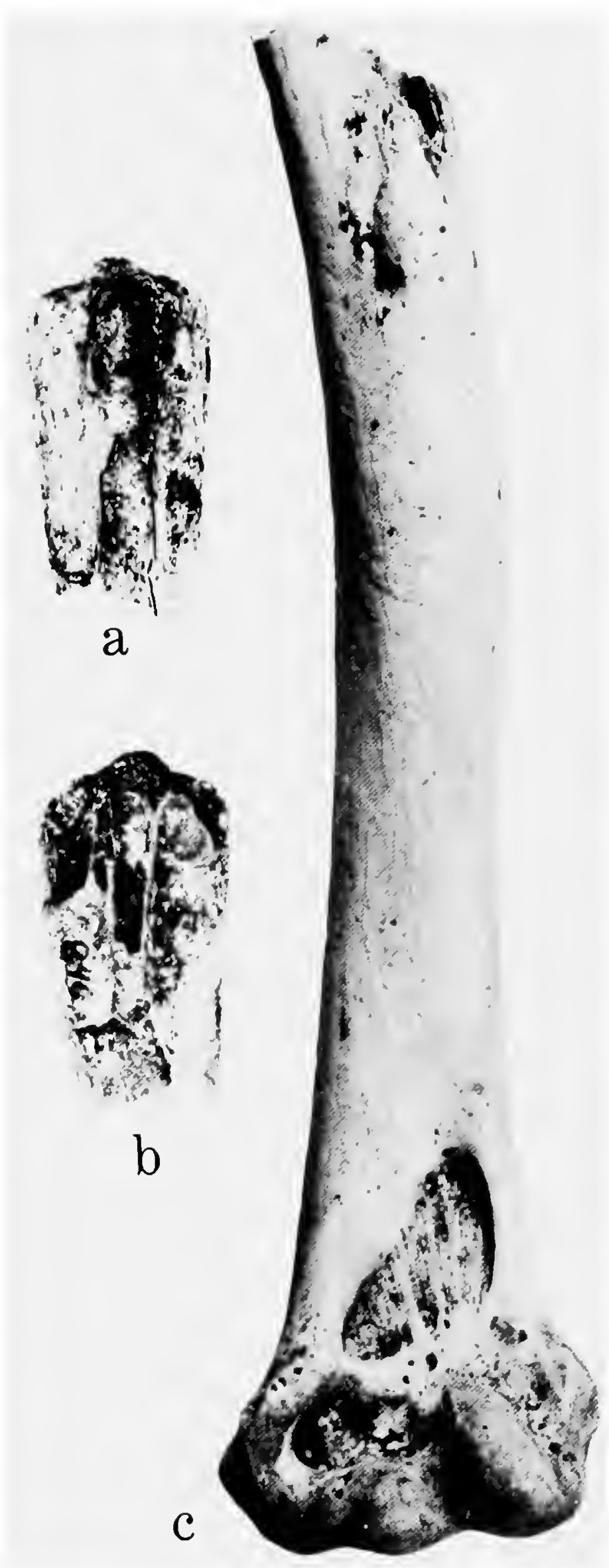

Figure 1.-Specimens of Antillovultur varonai, Cueva de Paredones: $a$, holotype fragmentary proximal end of left tarsometatarsus (DPUH 1254), anterior view; b, same, posterior view; $c$, left humerus lacking proximal end (GEC unnumbered), palmar view. (Natural size.) 
TABLE 2.-Measurements (mm) of the tarsometatarsus of Antillovultur varonai compared with other large New World vultures

\begin{tabular}{|c|c|c|c|c|}
\hline Character & $\begin{array}{c}\text { Antillovultur } \\
\text { varonai } \\
\text { Type, DPUH } 1254\end{array}$ & $\begin{array}{l}\text { Vultur } \\
\text { gryphus }\end{array}$ & $\begin{array}{l}\text { Gymnogyps } \\
\text { californianus }\end{array}$ & $\begin{array}{l}\text { Teratornis } \\
\text { merriami }\end{array}$ \\
\hline 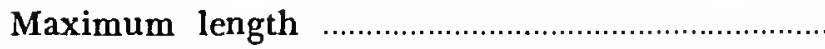 & 141 & 141 & 124.2 & 132 \\
\hline Greatest proximal width & 32.2 & 30.2 & 27 & 28 \\
\hline Least width of shaft (at break) & 17 & 17 & 16.8 & 15 \\
\hline $\begin{array}{l}\text { Length of outer trochlea from the angle of the } \\
\text { middle trochlea }\end{array}$ & 9 & 9.5 & 6 & 9 \\
\hline Greatest width of outer trochlea & 8 & 8 & 8 & 8 \\
\hline Greatest width across trochlea & $35^{*}$ & 35.4 & 30 & 29.5 \\
\hline
\end{tabular}

* Estimated.

Cathartes aura has only two proximal foramina. Teratornis differs in having three great united foramina arranged so as to form a kind of circle. In Antillovultur the medial tubercle for M. tibialis anticus is better developed than in either Vultur, Gymnogyps, or Cathartes, and is situated over a slight protruberance on the internal border of the anterior groove. In posterior view the surface of the bone from the lateral foramen to the external border is flat and does not slope downward as in Vultur. On the opposite side, the surface from the medial foramen to the external border is very depressed compared to that in Vultur. An external trochlea from a left tarsometatarsus of this species is similar in size and shape to that of Vultur.

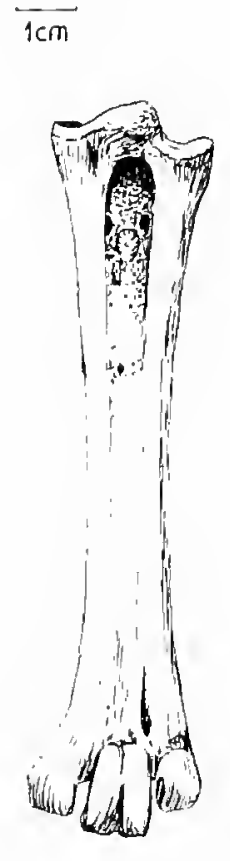

a
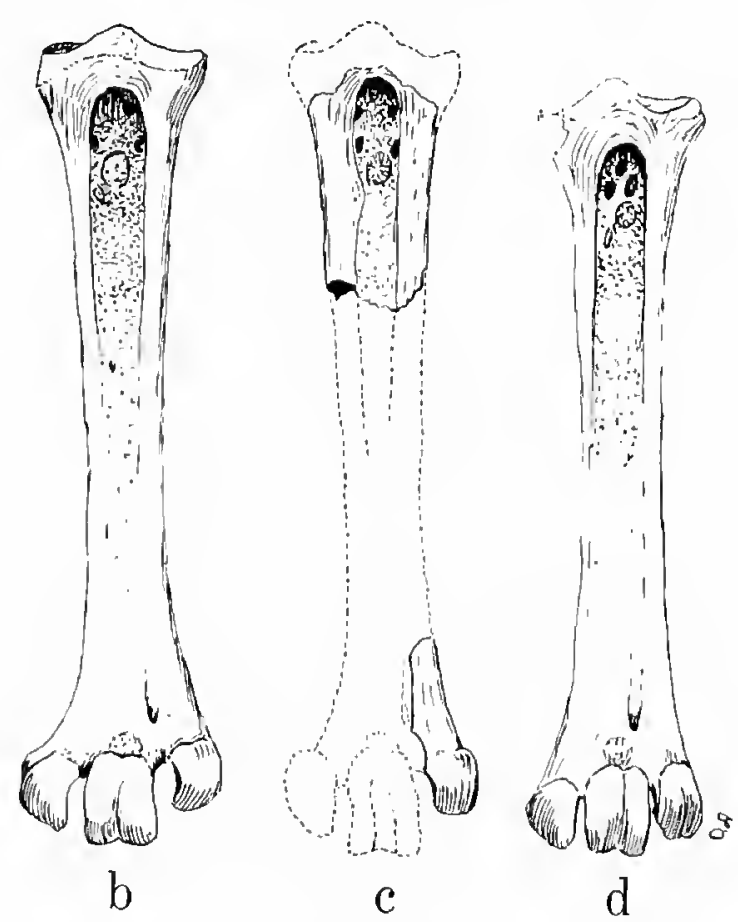

Figure 2.-Comparison of tarsometatarsi of New World vultures: a, Gymnogyps californianus; b, Vultur gryphus; $c$, Antillovultur varonai; $d$, Teratornis merriami (based on Wet more, 1931). (Half natural size.)
A seventh cervical vertebra attributed to Antillovultur consists of the complete body lacking all of the processes. It is similar to vertebrae of Vultur in size and morphology.

A distal portion of a left humerus (Figure 1c) is from a specimen very similar in size to Vultur. This fragment has a length of $184 \mathrm{~mm}$ from the distal end to a point a little beyond the protruberance at the distal extremity of the deltoid crest. Taking this protruberance as a point of reference, the complete length of the bone can be estimated as $265 \mathrm{~mm}$, which is about $20 \mathrm{~mm}$ less than in the specimens of Vultur compared. The least width of the shaft is $20 \mathrm{~mm}$ (21.7 in Vultur); the maximum distal width is $45.8 \mathrm{~mm}$ (54.3 in Vultur). The bone, although almost as large as that of Vultur, is more slender. The distal protruberance of the deltoid crest is at the same level as in Vultur. Antillovultur differs from Vultur in having the ectepicondylar prominence less pronounced, recalling that of Cathartes. The internal and external condyles are slightly smaller than in Vultur but with the distal borders more prominent. The internal condyle has a smooth and extensive depression on the entepicondylar side, which is present in Cathartes but absent in Vultur. The attachment of the anterior articular ligament is as large as in Vultur, but situated closer to the internal condyle, the space between them being less than in Vultur and more similar to Cathartes. The foramen located in this space is isolated from the brachial depression by a ridge that is absent in Vultur but somewhat evident in Cathartes. The brachial depression is deeper and more pronounced than in Vultur, particularly in the proximal region, but is notably less expanded than in either Vultur or Cathartes. The olecranal fossa is similar to that of Vultur and 
less dilated than in Cathartes. The tricipital grooves are similar to those of Vultur but the external one is somewhat deeper and appears like that of Cathartes.

\section{Family ACCIPITRIDAE}

\section{Genus Aquila Brisson}

\section{Aquila borrasi Arredondo, 1970}

HoLOTYPE.-Left tarsometatarsus lacking trochleae, DPUH 1250.

TyPe-Locality.-Cueva del Túnel, La Salud, Habana, Cuba.

Other Localities.-Cueva de Paredones, San Antonio de los Baños, Habana. Cueva de Pío Domingo, Sumidero, Pinar del Rio.

AgE.-Late Pleistocene.

Other Material.-Right femur lacking condyles, SEC P-26; ungual phalanges, SEC P-31, P-32, P-35, P-1147, and ACC 1000a; subterminal phalanx, ACC 1000b; distal end of tarsometatarsus, SEC P-40.

DEsCRIPTION.-Tarsometatarsus (Figure 3) generally similar to that of Aquila chrysaetos but notably longer, since even without the distal end it measures $97.7 \mathrm{~mm}$. The estimated total length of the bone is $130 \mathrm{~mm}$, or $34 \mathrm{~mm}$ longer than that of Aquila chrysaetos and larger than that of any living species of eagle (Table 3). The proximal articular region is similar to that in Aquila but with the proximal foramina located only $5 \mathrm{~mm}$ from the internal cotyla, whereas in $A$. chrysaetos this distance is nearly twice as great. That which remains of the base of the hypotarsus in the type indicates that this process was probably similar to that of $A$. chrysaetos.

The tarsometatarsi of the fossil species Buteo typhoius and $B$. contortus, from the upper Miocene of Nebraska, and of $B$. conterminus, from the upper Pliocene of Nebraska (Wetmore, 1923), are larger than those of Recent species of Aquila and Haliaeetus, but are more slender proximally, the articular region in proximal view being of a different shape than in Aquila and also differing in the form and position of the middle trochlea. The tarsometatarsus of $B$. contortus measures $113 \mathrm{~mm}$ in length, which is $17 \mathrm{~mm}$ less than in Aquila borrasi. Although the Cuban species has certain simi- larities to $B$. contortus in the general structure of the tarsometatarsus, it is larger and more robust than that species and appears more like $A$. chrysaetos. According to the published figures, the recently described species Garganoaetus freudenthali Ballmann (1973), from the upper Miocene of Italy, is similar morphologically to $B$. borrasi, although its tarsometatarsus is slightly more robust. Aquila borrasi was a gigantic form within its genus, the only other known fossil forms of which are Aquila delphinensis and A. pennatoides, described by Gaillard (1939) from tarsometatarsi from the upper Miocene of France.

The femur of Aquila borrasi is larger and more robust than that of any living eagle. Although the one known specimen is incomplete, its maximum length is estimated at about $155 \mathrm{~mm}$, as opposed to $125 \mathrm{~mm}$ in Aquila chrysaetos, $114 \mathrm{~mm}$ in Haliaeetus leucocephalus, and $96 \mathrm{~mm}$ in Spizaetus ornatus. This is even larger than in the two immense living eagles Harpia harpyja (131 mm)

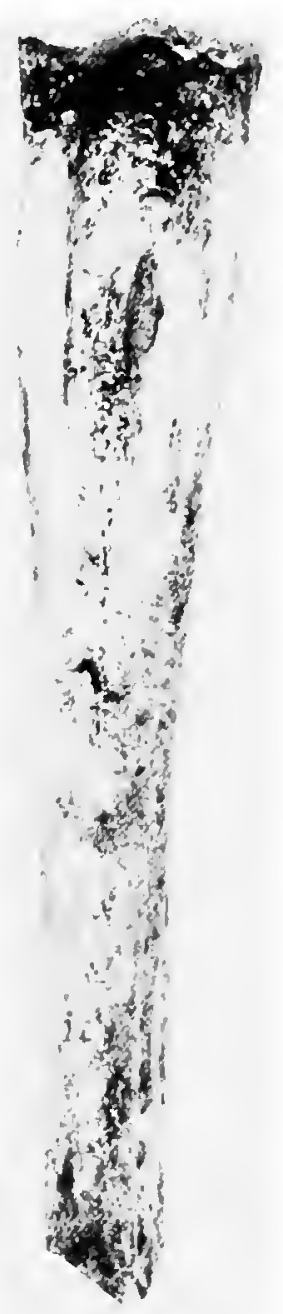

Figure 3.- Holotype left tarsometatarsus of Aquila borrasi (DPUH 1250), Cueva del Túnel. (Anterior view at natural size.) 
TABLE 3.- Measurements (mm) of the tarsometatarsus and claws of Aquila borrasi compared with other species of living eagles

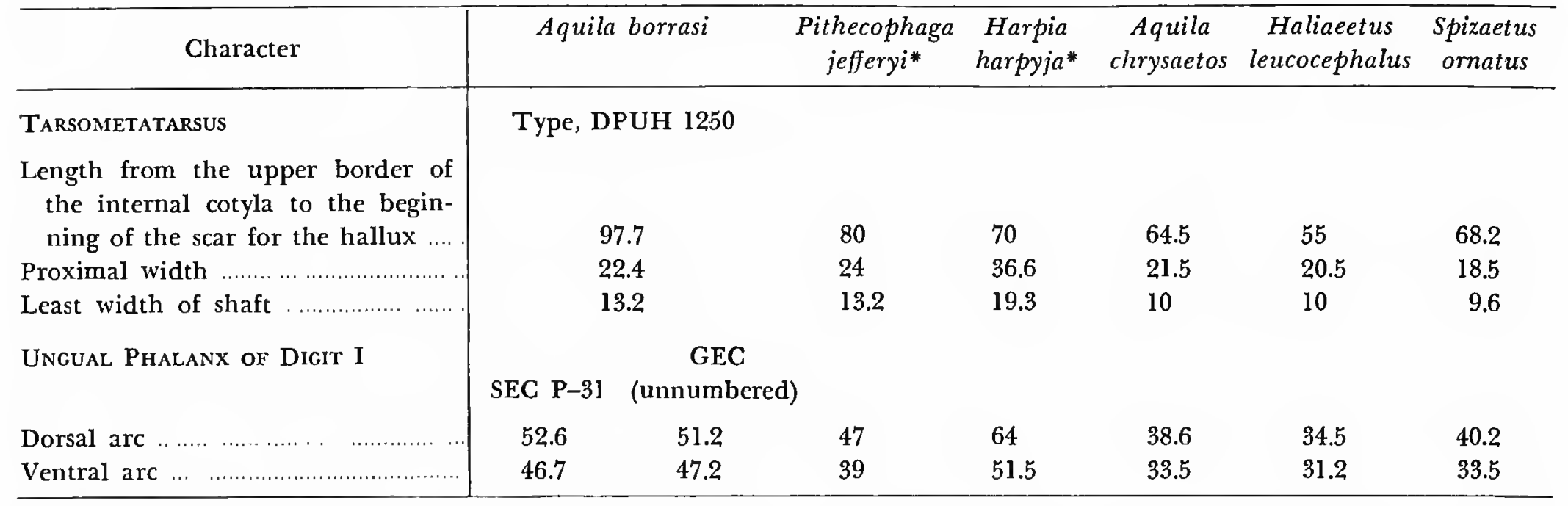

* Measurements from specimens in the USNM collections. It can be seen that the tarsometatarsus of Aquila borrasi, while decidedly longer, is proportionately much more gracile than in either Pithecophaga or Harpia-Ed.

and Pithecophaga jefferyi $(130 \mathrm{~mm}) .^{3}$ Other measurements (in $\mathrm{mm}$ ) of this specimen are as follows: total length as preserved, 140, proximal width 45.4 , vertical diameter of head 16.3 , width of neck 17.2, maximum width of pneumatic foramen 8.0 , length of pneumatic foramen 14.0 , least width of shaft 19.8 .

The femur differs from that of allied genera by the lesser projection of the trochanter above the head and by the greater width between the anterior border of the head and the apex of the trochanter (twice that of Aquila chrysaetos or Haliaeetus leucocephalus). The pneumatic opening is roughly oval in shape but wider distally. It is located at the base of the trochanter as in Aquila but differs in being not perfectly oval and in being oriented semiobliquely towards the external border of the trochanter. The foramina of the upper region of the trochanter are larger and deeper than in the other species compared. The rugose intermuscular line on the anterior face of the bone angles below and near the pneumatic opening along the external border of the shaft almost to its midpoint. In contrast, this line in $A$. chrysaetos originates farther above the upper border of the pneumatic opening and descends straight to the midpoint of the shaft. The head is massive and the neck is thick and oriented slightly upwards.

${ }^{3}$ Measurements supplied from specimens in the collections of the National Museum of Natural History, Smithsonian Institution.-Ed.
The ungual phalanges are very well developed (Figure 4), being almost two times larger than those of $A$. chrysaetos. They resemble those of Harpia harpyja in having the same degree of curvature. The ungual phalanx of digit IV is larger, while that of digit $I$ is smaller than in Harpia (Table 3). The shape of the articular region and the ventral process of the first ungual phalanx of A. borrasi more closely resembles that of Aquila than Haliaeetus, Spizaetus, or Buteo. The ungual phalanges of digits II and IV are likewise similar to those of Aquila and differ from those of the other genera examined. The ungual phalanx of digit IV measures $33 \mathrm{~mm}$ through the ventral arc and $35 \mathrm{~mm}$ through the dorsal arc.

\section{Order STRIGIFORMES}

\section{Family STRIGIDAE}

\section{Genus Ornimegalonyx Arredondo}

\section{Ornimegalonyx oteroi Arredondo, 1958a}

Synonim.-Ornimegalonyx arredondoi Arredondo, 1958.

Lectotype.-Left tarsometatarsus SEG P-383E. Lectotype designated by Brodkorb (1961); deposited in the Museum of Comparative Zoology, Harvard University.

Type-Locality,-Caverna de Pío Domingo, Si- 


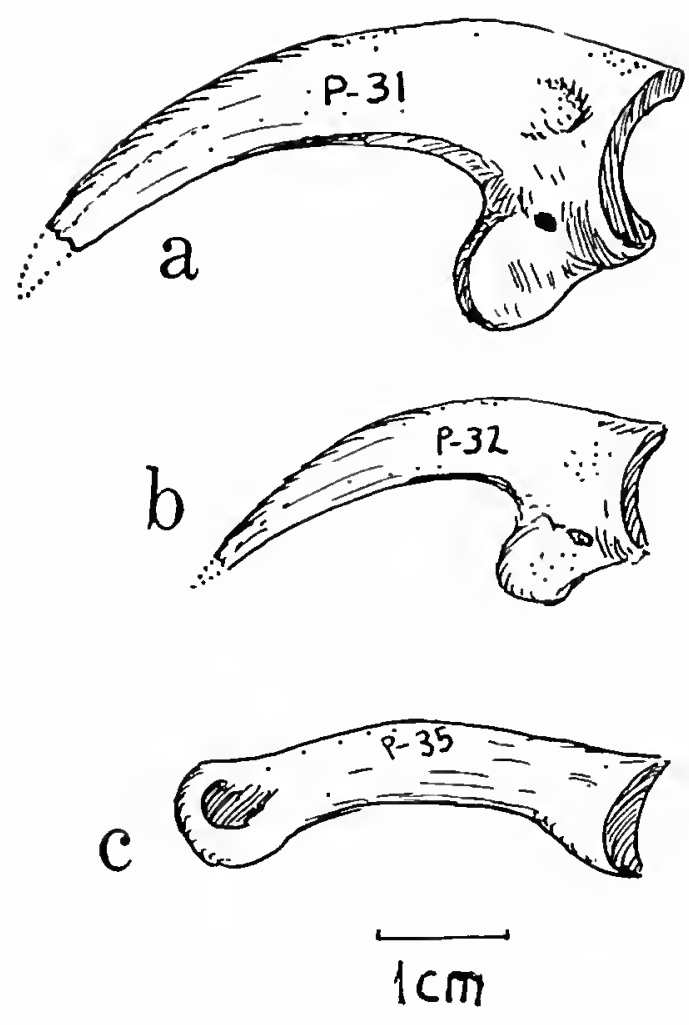

Figure 4.-Phalanges of Aquila borrasi from Cueva de Paredones: $a$, ungual phalanx of digit I (SEC P-31); $b$, ungual phalanx of digit II (SEC P-32); $c$, subterminal phalanx (SEC P-35). (Natural size.)

erra de Sumidero, Ensenada de Pica-Pica, Pinar del Rio, Cuba.

Other Localities.-Sierra de Anafe, Guanajay, Habana; Cueva de Paredones, San Antonio de los Baños, Habana; Cueva del Túnel, La Salud, Habana; Cueva de Isla, Punta del Este, Isla de Pinos; Cueva de Quinto, Boca de Camarioca, Mantanzas; Canteras de los Hornos de Cal, Sancti Spiritus, Las Villas; Sierra de Cubitas, Camagüey.

AgE.-Late Pleistocene.

Other Material.-Caverna de Pío Domingo, SEC P-383E, various pieces from the same individual as the lectotype as follows: left tarsometatarsus and fragments of the right, fragments of both tibiotarsi, left femur and fragments of the right, articular portions of the mandible, fragments of the sternum, scapula, carpometacarpus, and ungual and subterminal phalanges. From Paredones, El Túnel, Quinto, and Isla caves there are unnumbered pieces of tarsometatarsi, tibiotarsi, femora, phalanges, synsacra and other bones, all in private collections. From the collection of the author there are three subterminal phalanges from El Túnel and Paredones (OA 671, 676, 800).

DESCRIPTION.-Eight tarsometatarsi of Ornimega- lonyx have come to light so far: the lectotype from Pío Domingo; one from Cueva de Quinto; two proximal halves from Paredones; a distal half from Cueva del Túnel and a proximal half from the same locality. Ultimately, two complete specimens from the same individual were found in a cave in the Sierra de Cubitas, Camaguiey, along with other elements.

The dimensions of these bones indicate the enormous size that this bird had in relation to all other known Strigiformes, living or fossil (Figures 5-9, Tables 4-6). The tarsometatarsus is almost double the length of that of Bubo bubo, or more than double if one considers the specimen from Cueva de Quinto (GEC unnumbered) (Figure 7a) or that from Paredones. These bones are more than three times the size of the corresponding element of Nyctea scandiaca, more than four times that of Asio otus, and eight and a half times the size of Glaucidium siju.

In spite of its gigantic size, the tarsometatarsus of Ornimegalonyx is proportionately less robust than that of Bubo, Nyctea, or Pulsatrix, the difference being due to the relative lengthening of the shaft in Ornimegalonyx. If the tarsometatarsus of Ornimegalonyx were reduced to the length of that of Asio otus, the two elements would be seen to be very similar in proportion, whereas if one magnified the tarsometatarsi of Bubo, Nyctea, or Pulsatrix to the size of that of Ornimegalonyx, they would appear much stronger, wider, and more robust.

In Ornimegalonyx the internal trochlea is proportionately shorter and wider than in Bubo, Nyctea, or Asio, being more similar to Pulsatrix. The middle trochlea is narrow and placed very close to the outer trochlea. The distal foramen is somewhat lower than in Bubo, Nyctea, or Asio, and the ossified bridge on the anteroproximal region of the bone recalls that of $B u b o$ and differs from Nyctea in that it is stronger and more circular. The internal cotyla is similar to that in $B u b o$ and $A s i o$, but somewhat lower than in Nyctea. The wide, deep groove on the posterior face of the bone is more pronounced than in Bubo, Nyctea, or Asio.

The tibiotarsi of the type individual are fractured into proximal and distal portions and shafts (Figure 5, Table 5). In a complete state they would have measured some $250 \mathrm{~mm}$ in length. The tibio- 
Tarle 4.-Measurements (mm) of the tarsometatarsus of Ornimegalonyx oteroi compared with other owls

\begin{tabular}{|c|c|c|c|c|c|c|}
\hline \multirow[b]{2}{*}{ Character } & \multicolumn{4}{|c|}{ Ornimegalonyx oteroi } & \multirow{2}{*}{$\begin{array}{l}\text { Bubo } \\
\text { bubo }\end{array}$} & \multirow{2}{*}{$\begin{array}{c}\text { Nyctea } \\
\text { scandiaca }\end{array}$} \\
\hline & $\begin{array}{l}\text { SEC P-383.E } \\
\text { Lectotype }\end{array}$ & SEC P-39 & $\begin{array}{l}\text { GEC (un- } \\
\text { numbered) }\end{array}$ & $\begin{array}{l}\text { MFP (un- } \\
\text { numbered) }\end{array}$ & & \\
\hline Total length & $147^{*}$ & 177 & 177 & 178 & 83.7 & 55.7 \\
\hline Proximal width & c. 32 & 36 & 35 & - & 22.6 & 19.9 \\
\hline Distal width across trochleae ...................................... & ci 34 & - & 33 & 32 & 24.4 & 20.8 \\
\hline Least width of shaft & c. 15 & c. 16 & 15 & 18 & 12.2 & 11.5 \\
\hline $\begin{array}{l}\text { Length of middle trochlea from angle with inner } \\
\text { trochlea }\end{array}$ & - & - & 10 & 10 & 6.2 & 5.5 \\
\hline Least width of middle trochlea & - & - & 13 & 13 & 8.9 & 8 \\
\hline $\begin{array}{l}\text { Length of outer trochlea from angle with middle } \\
\text { trochlea }\end{array}$ & c. 6 & - & 6 & 6 & 3 & 2.5 \\
\hline Width of outer trochlea & c. 9 & - & 8 & 9 & 5.4 & 6.8 \\
\hline $\begin{array}{l}\text { Length of inner trochlea from angle with middle } \\
\text { trochlea }\end{array}$ & - & - & 9 & 9 & 6 & 5.5 \\
\hline Width of inner trochlea & - & - & 14 & c. 13 & 6.7 & 6 \\
\hline
\end{tabular}

* Estimated.

tarsus from Cueva de Quinto has a length of 272 $\mathrm{mm}$, which is almost twice that of $B u b o$ bubo or Nyctea scandiaca. Its proximal width of $40 \mathrm{~mm}$ is likewise twice that of those species. The tibiotarsus of the lectotype individual appears to have been straight, while that from Cueva de Quinto is slightly curved and subtly twisted. Compared to the modern genera examined, the tibiotarsus of Ornimegalonyx (Figure $6 a$ ) has the fibular articulation more pronounced, the rotular crest, and the cnemial crest more elevated, and the fossa proximal to the condyles on the anterior face deeper.

Eight femora of Ornimegalonyx have been found so far. The left femur of the type individual is in the MCZ. Of the right, only a part of the proximal end remains in Cuba. The largest femur, represented by the proximal end only (Figure $7 d$ ), was found to the east of Sancti Spiritus and is deposited in the Museo Montané of the University of Havana (MMUH 3072). Two incomplete femora from Paredones (formerly SEC P-37 and SEC $\mathrm{P}-38$, but now in the MCZ) are smaller than those of the type and for now are perhaps best referred to as Ornimegalonyx sp.

The femur of Ornimegalonyx differs principally from that of other owls in being much larger and notably more robust (Table 6). That of the type individual is almost one and a half times larger than the femur of Bubo bubo, while the large femur (MMUH 3072) from Sancti Spiritus is almost double the size of that of Nyctea scandiaca. It is curious that when reduced, the tarsometatarsi of Ornimegalonyx are less robust than in Bubo or Nyctea, while in the femora the opposite occurs.

Fragments of the sternum, as well as parts of the scapulae, ribs, vertebrae and carpometacarpi, were associated with the type individual in Pío Domingo cave. The most important sternal fragments are an anterior portion with the articulations for the coracoids, and another fragment of the left side containing four costal facets (the fifth having been fractured off). The costal facets vary slightly in size, the largest being $6 \times 6 \mathrm{~mm}$. Through these fragments it has been possible to reconstruct the sternum (Figure 8) as being wide, almost flat (both dorsally and ventrally), with a vestigial keel, which indicates that the bird was hardly able to fly. Its estimated length is $120 \mathrm{~mm}$ (vs. $47 \mathrm{~mm}$ in Tyto alba), the estimated width $75 \mathrm{~mm}(30 \mathrm{~mm}$ in $T$. alba); and the height at the keel some $30 \mathrm{~mm}$ (25 $\mathrm{mm}$ in $T$. alba). The similarity of this last measurement in two species which otherwise differ so greatly in size is a further indication of the great extent of the atrophy of the keel in Ornimegalonyx.

The carpometacarpus of Ornimegalonyx is small in proportion to the enormous size of the body. Its total length is estimated at about $90 \mathrm{~mm}$ whereas in $B u b o$ bubo, a smaller volant species, it is $85 \mathrm{~mm}$.

Figure 5.-Tibiotarsus, tarsometatarsus, femur, and phalanges (SEC P-383E) from the same individual as the lectotype of Ornimegalonyx oteroi, Caverna de Pio Domingo. The specimens are covered with calcareous concretions. (Natural size.) 


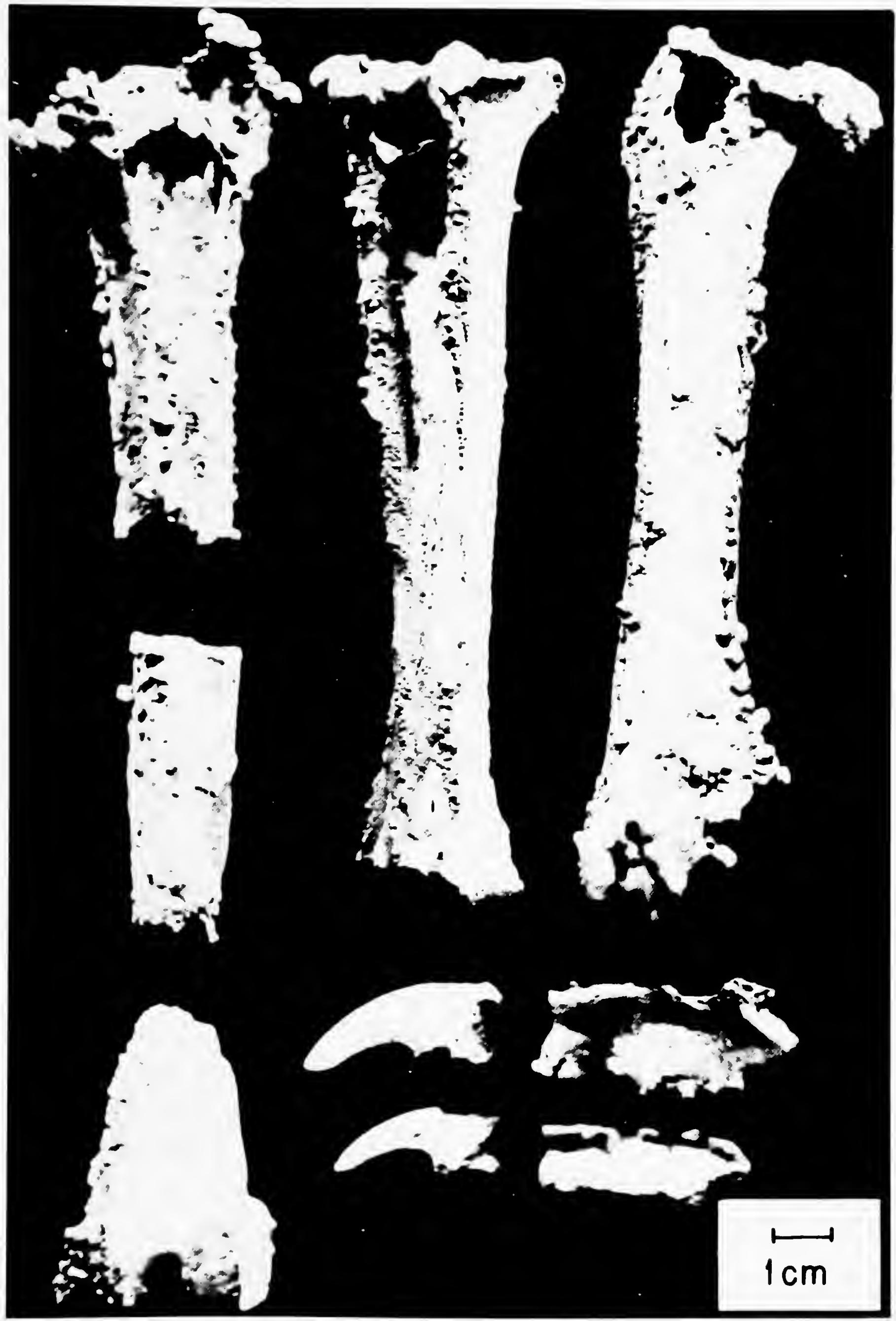


As with the other bones, the phalanges of Ornimegalonyx stand apart from those of other owls by their great size. The length of the ungual phalanges of digits II and III, measured through the dorsal arc, range from 37 to $39 \mathrm{~mm}$, while that of

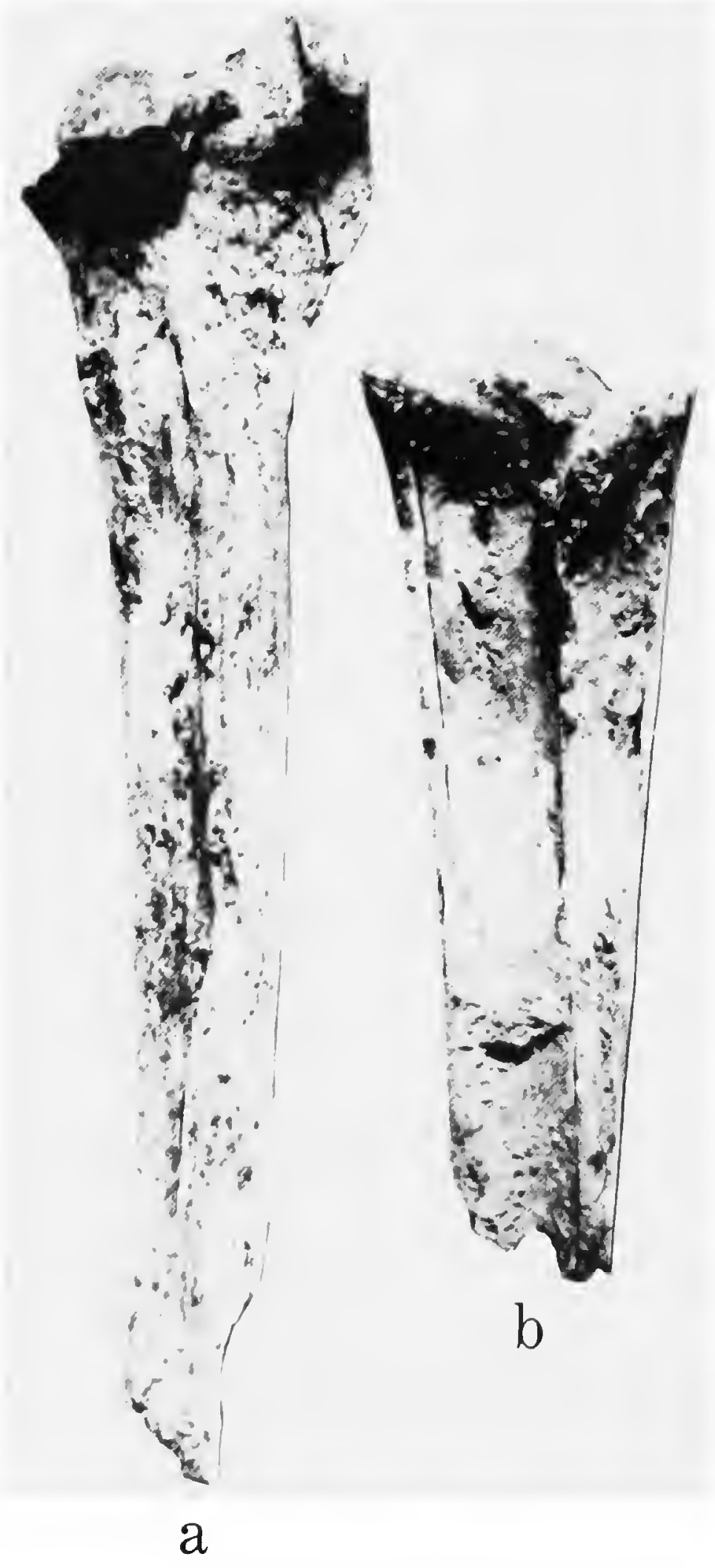

Figure 6.-Hindlimb clements of Omimegalonyx oteroi from Cueva de Paredones: $a$, right tibiotarsus lacking distal cnd (SEC P-28); b, posterior view of left tarsometatarsus lacking distal end (SEC P-39). (Natural size.) digit I measures $40 \mathrm{~mm}$. The proximal height of these phalanges ranges from $15-17 \mathrm{~mm}$.

It was not until the beginning of 1969 that fragments of mandibles were found among the remains of the type individual of Ornimegalonyx oteroi. These consist of the two articular portions of both rami. These fragments permit for the first time a very approximate estimate of the size of the mandible and ultimately of the whole skull (Figure $9 a)$. These mandibles are very similar in overall morphology to those of the diminutive genus Glaucidium. They differ from $B u b o$ bubo in that the internal angular process is greatly lengthened. The posterior angular process, in comparison to that of $B u b o$, is notably more robust, and the portions that remain of the surangular and angular are greatly thickened at the point of the fracture. Judging by comparison with recent owls, the length of the entire mandible of Ornimegalonyx oteroi would have been some $115 \mathrm{~mm}$ and the distance between the external borders of the articulations was approximately $100 \mathrm{~mm}$, or about two times larger than in Bubo bubo.

A portion of a cranium of Ornimegalonyx was

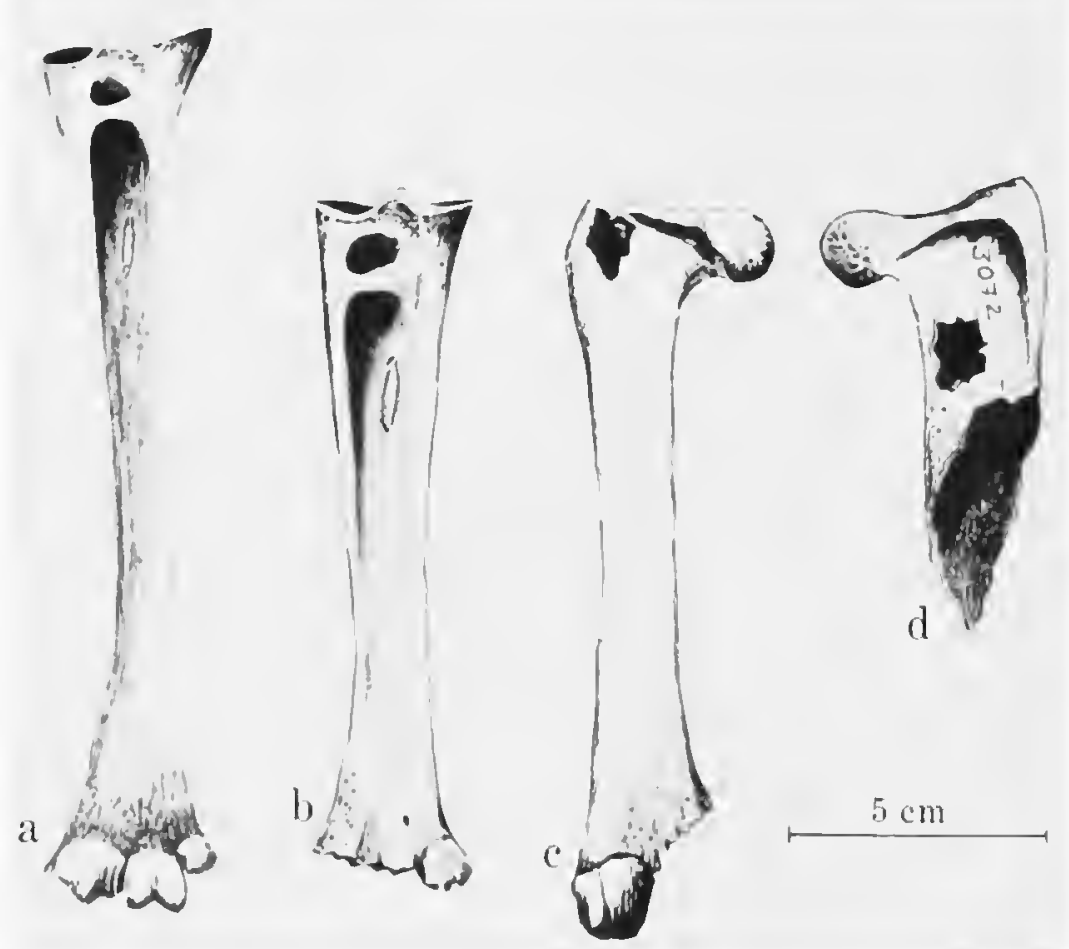

FigURE 7.-Some variation in the hindlimb of Ornimegalonyx: a, Ornimegalonyx cf. oteroi, left tarsometatarsus (GEC unnumbered), Cueva del Quinto; b, c, Ornimegalonyx oteroi, left tarsometatarsus and right femur of the type individual (SEC P-38E), Pío Domingo cave; $d$, Ornimegalonyx sp., proximal end of left femur (MMUH 3072), Cantera de los Hornos de Cal, Sancti Spiritus. 
TABle 5.-Measurements ( $\mathrm{mm})$ of the tibiotarsus of Ornimegalonyx oteroi compared with other owls

\begin{tabular}{|c|c|c|c|c|c|c|c|}
\hline \multirow[b]{2}{*}{ Character } & \multicolumn{5}{|c|}{ Ornimegalonyx oteroi } & \multirow{2}{*}{$\begin{array}{l}\text { Bubo } \\
\text { bubo }\end{array}$} & \multirow{2}{*}{$\begin{array}{c}\text { Nyctea } \\
\text { scandiaca }\end{array}$} \\
\hline & SEC P-383.E & SEC P-28 & SEC P-29 & $\begin{array}{l}\text { MFP (un- } \\
\text { numbered }\end{array}$ & $\begin{array}{l}\text { GEC (un- } \\
\text { numbered }\end{array}$ & & \\
\hline Proximal width $\ldots \ldots \ldots \ldots \ldots \ldots \ldots . . . . . . . . . .$. & c. 36 & 39 & - & - & 37 & 19 & 17.6 \\
\hline Least width of shaft & c. 13 & 14 & $15^{*}$ & $13 *$ & c. 15 & 9.5 & 8 \\
\hline Distal width across trochleae & 30 & - & 31 & c. 30 & c. 30 & 20.8 & 19.2 \\
\hline
\end{tabular}

* Estimated.

TABLE 6.-Measurements (mm) of the femur of Ornimegalonyx oteroi compared with other owls

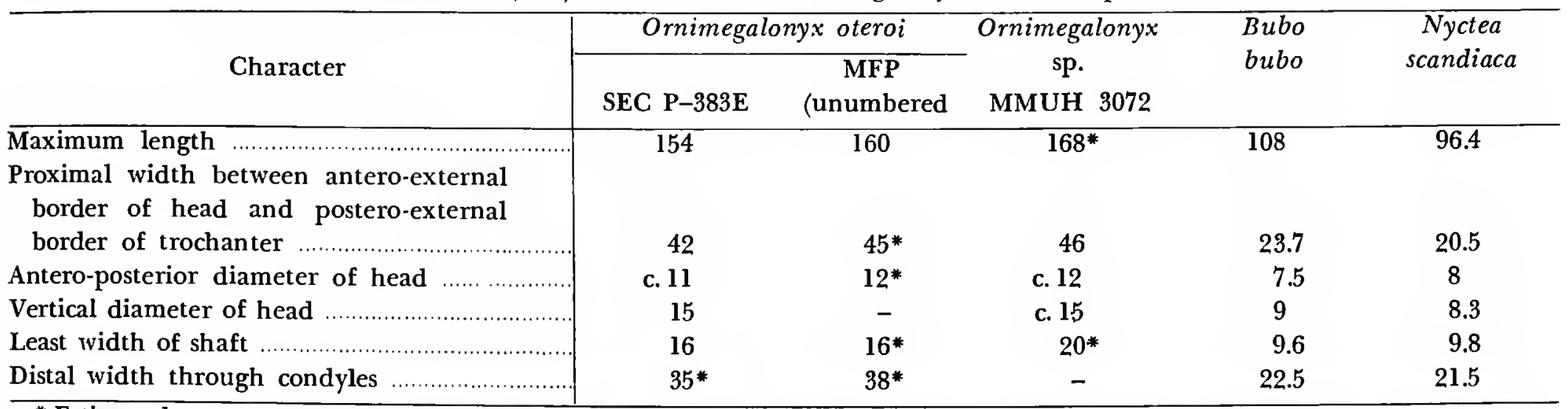

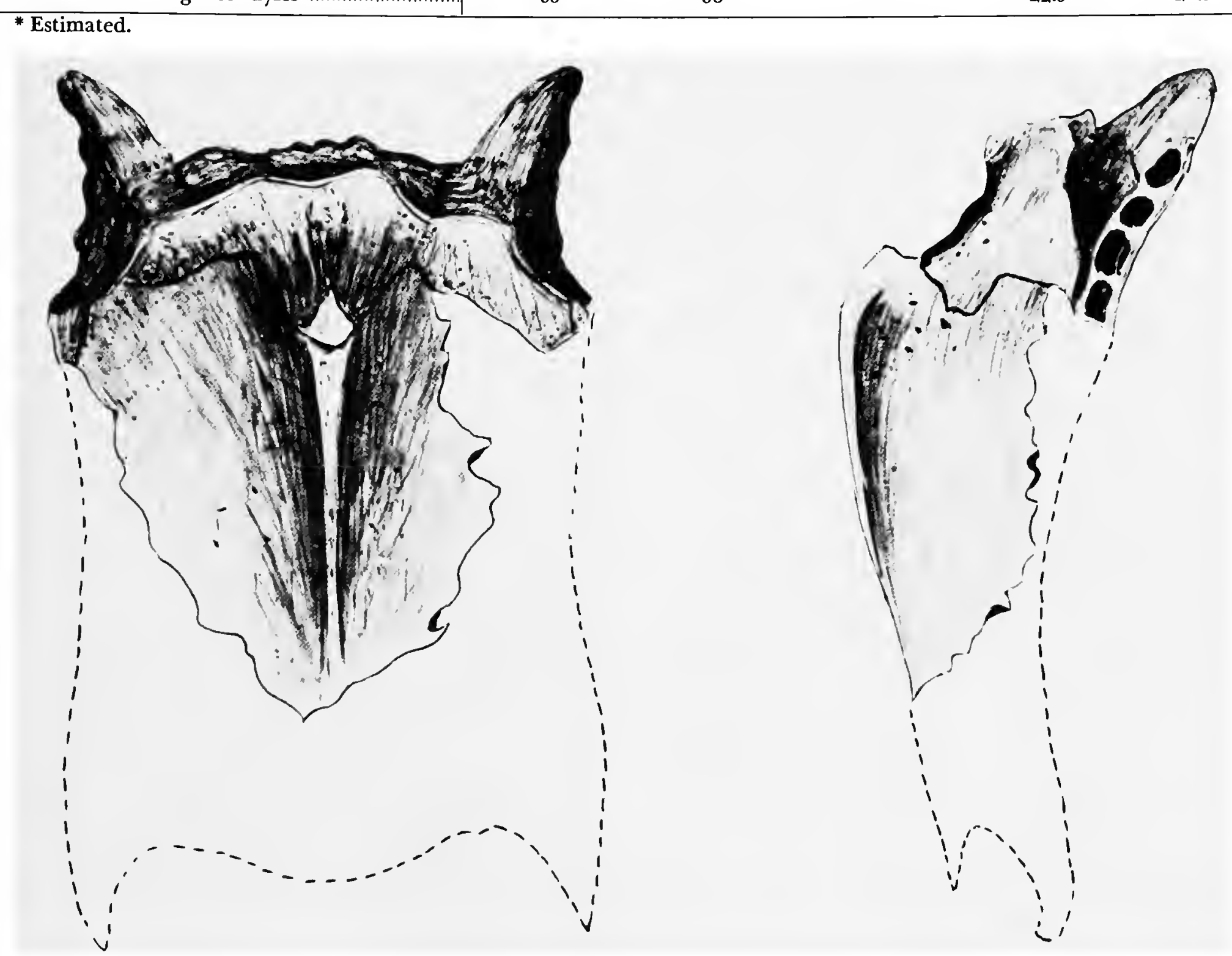

Figure 8.-Ventral and lateral views of the sternum of Ornimegalonyx oteroi, as reconstructed from two fragments from Pío Domingo and Paredones caves. (Natural size.) 


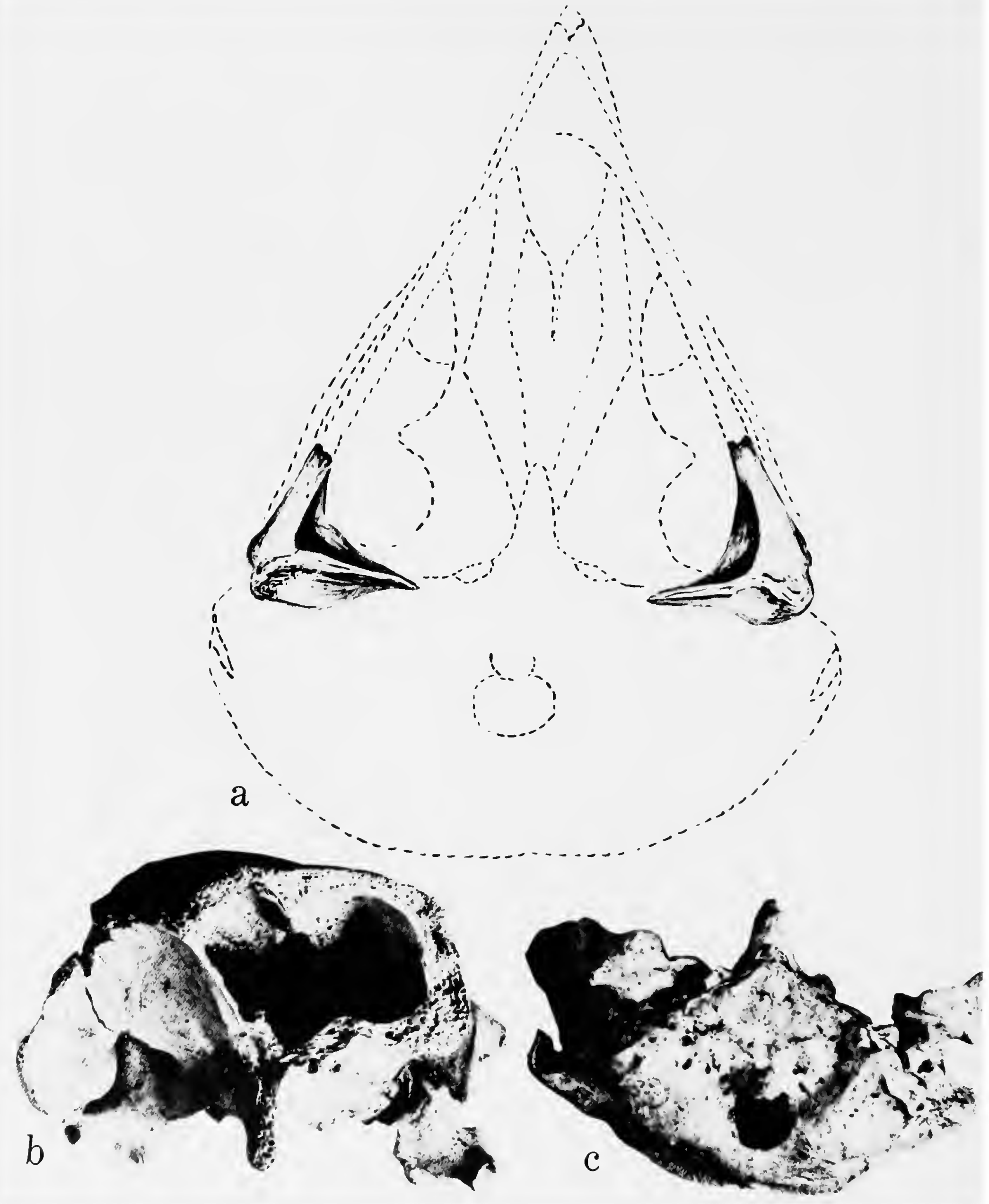


found in Cueva de Paredones in 1959 (Figure $9 b, c)$. For the time being it is best referred to only as Ornimegalonyx sp., for it is apparent that it does not correspond to the species $O$. oteroi. Rather, it appears to belong to a smaller form, as also evidenced by the femora found in the same locality. The specimen consists of the posterior portion of a cranium from the postorbital arc to the occiput and including the basisphenoid, the foramen magnum, and the occipital condyle. Viewed from the front, the great thickness of the walls of the cranium are seen in the region of the break. Compared to Bubo bubo it is larger, and in ventral view it has the postorbital process better developed. The opisthotic process is rather prominent and its extremity bends notably, hanging in the form of an ear. The basipterygoid processes are well developed. The foramen magnum is somewhat higher than wide, as opposed to Glaucidium and Tyto in which it is wider than high. As in Nyctea, the occipital condyle is very well developed in relation to the foramen magnum, whereas it is proportionately much smaller in Glaucidium and Tyto.

From the actual and estimated measurements of the various bones of Ornimegalonyx it can be established that this great owl stood some $1100 \mathrm{~mm}$ high in life. Although the general aspect of its skeleton is similar to that of living owls, it is distinguished from them by the long and robust hindlimbs, provided with long, heavy toes armed with the most powerful claws possessed by any strigiform bird. Although the sternum is larger than in any living owl, it is actually small in proportion to the rest of the bones of the skeleton. Its semiflat structure and reduced keel show that Ornimegalonyx was little or not at all capable of flight. In accordance with this, the bones of the wing are poorly developed, particularly the carpometacarpus.

Some of the differences in morphology and size that are observed between individuals of Ornimegalonyx are probably attributable to sexual dimorphism, since in other owls the females are

FIGURE 9.-Skulls of Ornimegalonyx: a, hypothetical reconstruction of the skull of Ornimegalonyx oteroi to show the size as extrapolated from the two mandibular articulations associated with the type; $b, c$, anterior and ventral views of the cranium (GEC unnumbered) of Ornimegalonyx sp. from Cueva de Paredones (the left quadrate is incorrectly articulated). (All figures natural size.) larger than the males. Nevertheless, other bones that are either larger or smaller than those of the type individual and have distinct differences from it, probably indicate additional species-the cranium and femora from Paredones and the femur from Sancti Spiritus being examples.

Ornimegalonyx had to have been the scourge and terror of most of the larger mammals of the Pleistocene of Cuba and the claws and mandibles of this bird would have constituted a terrible combination of superior destructive power.

\section{Family TYTONIDAE}

\section{Genus Tyto Billberg}

\section{Tyto noeli Arredondo, 1972a}

Holotype.-Right tarsometatarsus, DPUH 1251. Type-Locality.-Cueva del Túnel, La Salud, Habana, Cuba.

Other Localities.-Cueva de Paredones, San Antonio de los Baños, Habana; Cueva del Indio, Reparto El Globo, Calabazar, Habana; quarries near Sancti Spiritus, Las Villas.

Agr.-Late Pleistocene.

Other Material.-Cueva del Túnel: OA 818, right femur; OA 812 , distal portion of left tibiotarsus; OA 804 , distal portion of right humerus; OA 806, proximal fragment of right humerus; OA 822 , shaft of right tibiotarsus; OA 815 , distal portion of right ulna. Cueva de Paredones: OA 828, proximal portion of right tarsometatarsus; OA 827 , proximal portion of right tibiotarsus; OA 839 , right coracoid. Cueva del Indio: OA 1027, right femur.

Descriptron.-Similar to the living species Tyto alba in its general skeletal configuration, but much larger (Figures 10,11, Tables 7 and 8), equaling in size the extinct species Tyto ostologa of Haiti and $T$. pollens of the Bahamas. The tarsometatarsus was between 90 and $100 \mathrm{~mm}$ long and was similar to that of $T$. pollens, but more slender, even in specimens that are longer than in $T$. pollens. The tibiotarsus is likewise similar to that of $T$ pollens but is less robust. This slenderness of the hindlimb is the most notable difference between the two species.

In the femur, humerus, ulna, coracoid, and claws, the only pronounced difference from $T y t o$ 


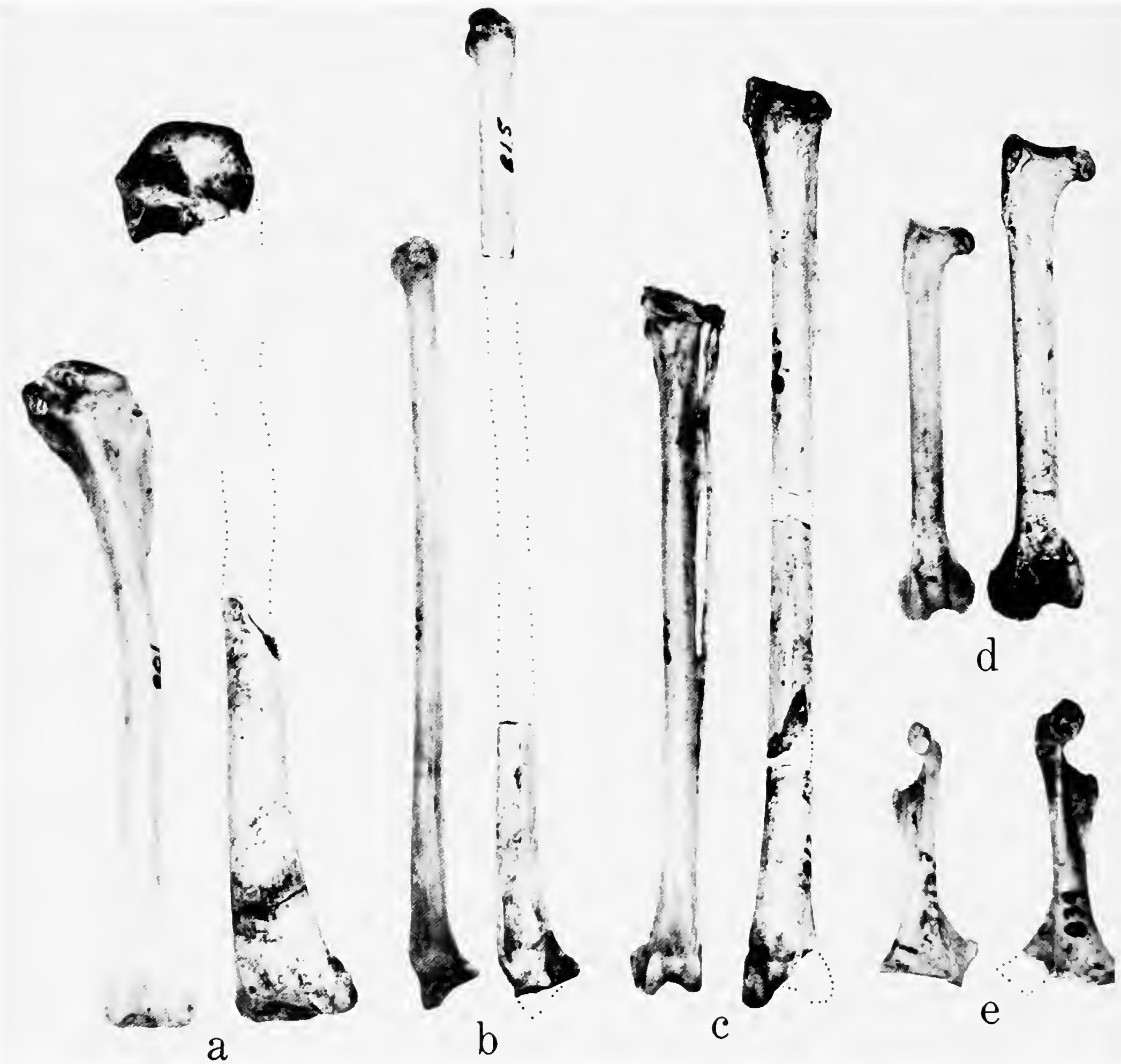

Figure 10.-Paratypes of Tyto noeli from Cueva del Túnel and Cueva de Paradones compared with a Recent specimen of Tyto alba furcata (on the left in each pair): $a$, fragments of right humerus (OA 804 and 826); $b$, fragments of right ulna (OA 806 and 815); $c$, fragments of tibiotarsus (OA 827, 812, and 822); $d$, right femur (OA 818); $e$, right coracoid (OA 839). (Natural size.)

alba is in size. Likewise, a fragment of the anterior portion of a sternum of $T$. noeli from quarries near Sancti Spiritus has the same conformation as that of $T$. alba but is larger. One might expect to find greater distinctions in the skull, but so far only fragments of the skull of $T$. noeli have been found. Brodkorb (1959:357) suggested that $T$. pollens may possibly be differentiated from $T$ ostologa only at the subspecific level. The same could be suggested for $T$. noeli. From the upper Miocene of Italy, a new species of giant barn owl, Tyto robusta Ballmann (1973), has been described that is near the size of $T$. noeli. The Cuban species is somewhat larger and heavier, however. 
Table 7.-Measurements of limb bones of Tyto noeli compared with Tyto alba

\begin{tabular}{|c|c|c|c|c|}
\hline Character & \multicolumn{3}{|c|}{ Tyto noeli } & Tyto alba furcata \\
\hline FEMUR & OA 818 & OA 834 & A 1027 & \\
\hline Total length & 74.3 & $73 *$ & - & 61 \\
\hline Proximal width & 14.4 & 13.1 & 14 & 11.4 \\
\hline Antero-posterior diameter of head ....... & 5 & 5 & 5.5 & 3.2 \\
\hline 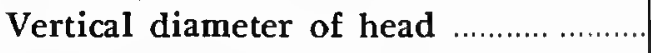 & 5.8 & 5 & 5.7 & 4.6 \\
\hline Breadth through trochanter .............. & 9.2 & 8.2 & 9.2 & 6.8 \\
\hline Least width of shaft $\ldots \ldots \ldots \ldots \ldots$ & 6.4 & 6 & 6.5 & 5 \\
\hline Distal width $\ldots \ldots \ldots \ldots . . . . . .$. & 14.8 & 14 & - & 12.1 \\
\hline Tibiotarsus & OA 827 & OA 831 & & \\
\hline 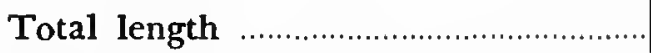 & $147 *$ & - & & 108 \\
\hline Proximal width ............... & 16 & - & & 10.9 \\
\hline Least width of shaft & 6.4 & - & & 5.5 \\
\hline Distal width & - & 15 & & 11.3 \\
\hline HumERuS & OA 804 & OA 826 & & \\
\hline Total length $\ldots \ldots \ldots \ldots \ldots \ldots \ldots$ & $137 *$ & - & & 100.1 \\
\hline Proximal width & - & 23 & & 16.9 \\
\hline Width of shaft & 8.5 & - & & 6.2 \\
\hline 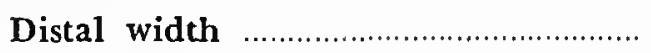 & 20.5 & - & & 15.7 \\
\hline
\end{tabular}

* Estimated.

TABLE 8.-Measurements $(\mathrm{mm})$ of the tarsometatarsi of the three Cuban species of Tyto

\begin{tabular}{|c|c|c|c|c|}
\hline \multirow[b]{2}{*}{ Character } & \multirow{2}{*}{$\begin{array}{c}\text { Tyto riveroi } \\
\text { DPUH } 1252 \\
\text { Type }\end{array}$} & \multicolumn{2}{|c|}{ Tyto noeli } & \multirow[t]{2}{*}{ Tyto alba furcata } \\
\hline & & $\begin{array}{l}\text { DPUH } 1251 \\
\text { Type }\end{array}$ & OA 828 & \\
\hline Maximum length & $125^{*}$ & 91.7 & $100 *$ & 78.4 \\
\hline Proximal width $\ldots \ldots \ldots \ldots \ldots \ldots \ldots$ & $22 *$ & 14.6 & 16 & 11.1 \\
\hline Distal width & 22 & 17.4 & - & 13.7 \\
\hline Least width of shaft $\ldots \ldots \ldots \ldots \ldots \ldots \ldots$ & 9 & 6.7 & 7.3 & 5.2 \\
\hline $\begin{array}{l}\text { Length of middle trochlea from } \\
\text { angle of internal trochlea }\end{array}$ & 6.8 & 5 & - & 2.5 \\
\hline Width of middle trochlea ........... & 8.5 & 6.4 & - & 4.8 \\
\hline $\begin{array}{l}\text { Length of outer trochlea from } \\
\text { angle of middle trochlea }\end{array}$ & 11.5 & c. 4 & - & 3 \\
\hline Width of outer trochlea & 12.3 & 4.8 & - & 3.9 \\
\hline $\begin{array}{l}\text { Length of inner trochlea from } \\
\text { angle of middle trochlea }\end{array}$ & 6.5 & 4.4 & - & 2.8 \\
\hline Width of inner trochlea ................. & 9.8 & 7.5 & - & 5 \\
\hline
\end{tabular}

* Estimated.

\section{Tyto riveroi Arredondo, 1972b}

Holotype--Distal portion of a left tarsometatarsus, DPUH 1252.

TyPe-Locality.-Cueva de Bellamar, Mantanzas, Cuba.

AgE.-Late Pleistocene.

DESCRIPTION.-Tarsometatarsus with the general aspect of that of Tyto alba and still more similar to that of $T$. noeli. Except for size, significant morphological differences from the above species are almost absent; however, the measurements of the type of $T$. riveroi notably exceed the limits of either (Figure 11, Table 8). The estimated total length of this bone would be approximately 125 
$\mathrm{mm}$. The following slight morphological distinctions are also noted: greater separation of the internal and external trochleae from the middle trochlea, the intertrochlear spaces being narrower in $T$ alba and $T$ noeli; shaft proportionately wider and thicker. Compared with $T$. pollens, the same slight differences are apparent.
Tyto gigantea, recently described from the upper Miocene of Gargano, Italy (Ballmann, 1973), was an enormous barn owl, equal in size to $T$. riveroi. According to the published figures, the Italian species has the distal foramen somewhat more elevated and the middle trochlea lower and more elongate than in the Antillean species.

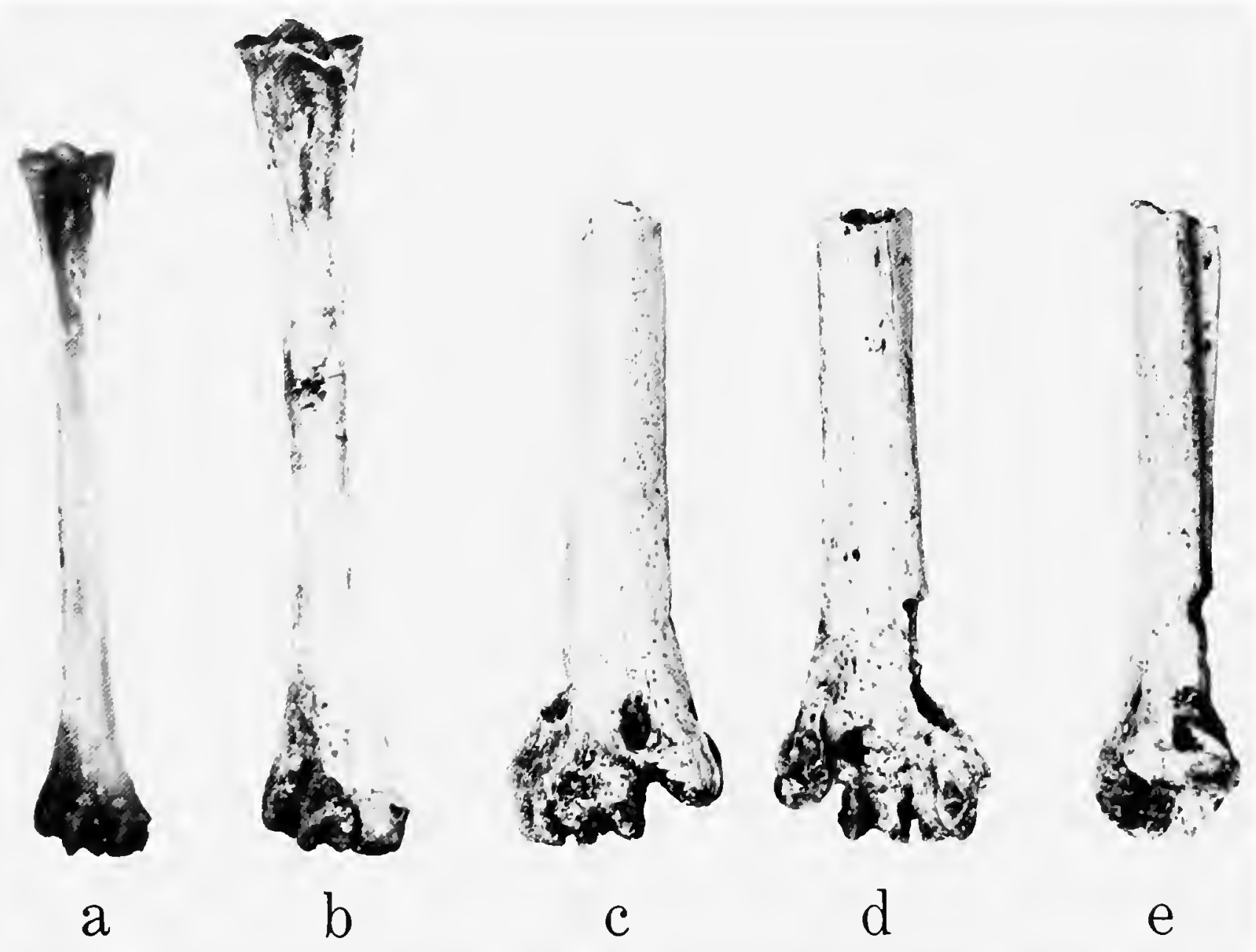

Figure 11.-Comparison of the tarsometatarsi of the three Cuban species of Tyto: $a$, Recent Tyto alba furcata; $b$, Tyto noeli, holotype (DPUH 1251), Cueva del Túnel; c-e, Tyto riveroi, holotype (DPUH 1252), Cueva de Bellamar, anterior, posterior, and lateral views. (Natural size.)

\section{Literature Cited}

Acevedo, M., O. Arredondo, and N. González

1975. La Cueva del Túnel. Volume 1, 74 pages, 17 figures, 2 maps, 6 tables. Havana: Editorial Pueblo y Educación. Instituto del Libro.

Arredondo, $\mathbf{O}$.

1958a. Aves gigantes de nuestro pasado prehistórico. El Cartero Cubano, 17(7):10-12, 6 figures.

1958b. El Vampiro Cubano. Scout (Havana), pages 6-7, 10, 6 figures.

1970. Nueva especie de ave pleistocénica del orden Accipitriformes (Accipitridae) y nuevo género para las Antillas. Ciencias, series 4, Ciencias Biológicas, 8:1-19, 10 figures.
1971. Nuevo género y especie de ave fósil (Accipitriformes: Vulturidae) del Pleistoceno de Cuba. Memoria de la Sociedad de Ciencias Naturales La Salle, 31(90): 309-323, 5 figures.

1972a. Nueva especie de ave fósil (Strigiformes: Tytonidae) del Pleistoceno superior de Cuba. Boletin de la Sociedad Venezolana de Ciencias Naturales, 29(122123):415-431, 5 figures.

1972b. Especie nueva de lechuza (Strigiformes: Tytonidae) del Pleistoceno cubano. Boletin de la Sociedad Venezolana de Ciencias Naturales, 30(124-125): 129-140, 4 figures. 
Arredondo, O., and L. S. Varona

1974. Nuevos género y especic de mamífero (Carnivora: Canidae) del Cuaternario de Cuba. Poeyana, 131: 1-12, 3 figures.

Ballmann, $\mathbf{P}$.

1973. Fossile Vögel aus dem Neogen der Halbinsel Gargano (Italien). Scripta Geologica, 17:1-75, 16 figures, 7 plates.

Brodkorb, P.

1959. Pleistocene Birds from New Providence Island, Bahamas. Bulletin of the Florida State Museum, Biological Sciences, 4(11):349-371.

1961. Recently Described Birds and Mammals from Cuban Caves. Journal of Paleontology, 35(3):633635.

1969. An Extinct Pleistocene Owl from Cuba. Quarterly Journal of the Florida Academy of Sciences, 31(2): 112-114, 1 figure.

1971. Catalogue of Fossil Birds, Part 4 (Columbiformes through Piciformes). Bulletin of the Florida State Museum, Biological Sciences, 15(4):163-266.

Gaillard, C.

1939. Contribution a l'étude des oiseaux fossiles. Archives du Muséum d'Histoire Naturelle de Lyon, 15(mémoire 2):1-100, 34 figures.

Harrington, M. R.

1935. Cuba antes de Colon. 290 pages, 111 figures, 108 plates. Havana: Colección de Libros Cubanos,
XXXII, Cultural.

Koopman, K. F.

1958. A Fossil Vampire Bat from Cuba. Breviora, 90: $1-4$, 1 plate.

Varona, Luis S.

1974. Catálogo de los mamiferos vivientes y extinguidos de las Antillas. 139 pages. Havana: Academia de Ciencias de Cuba.

Wetmore, A.

1922. Remains of Birds from Caves in the Republic of Haiti. Smithsonian Miscellaneous Collections, 74 (41): $1-4,2$ figures.

1923. Avian Fossils from the Miocene and Pliocene of Nebraska. Bulletin of the American Museum of Natural History, 48:483-507, 20 figures.

1931. The Avifauna of the Pleistocene in Florida. Smithsonian Miscellaneous Collections, 85(2):1-41, 16 figures, 6 plates.

1937. Bird Remains from Cave Deposits on Great Exuma Island in the Bahamas. Bulletin of the Museum of Comparative Zoology, 80(12):427-441, 16 figures, 1 plate.

1959. Birds of the Pleistocene in North America. Smithsonian Miscellaneous Collections, 138(4):1-24.

Wołoszyn, B. W., and N. A. Mayo

1974. Postglacial Remains of a Vampire Bat (Chiroptera: Desmodus) from Cuba. Acta Zoologica Cracoviensia, 19(13):253-265, 5 figures, 1 prate. 



\title{
The Species of Moas (Aves: Dinornithidae)
}

\author{
Joel Cracraft
}

\begin{abstract}
In order to provide a basis for future studies on the functional morphology and evolutionary history of the New Zealand moas, the species-level systematics of the family is reviewed. Based on a study of museum collections and an analysis of intraspecific variability, only 13 species are considered to be valid: Anomalopteryx didiformis, $A$. oweni, Megalapteryx didinus, $M$. benhami, Pachyornis elephantopus, P. mappini, Euryapteryx curtus, E. geranoides, Emeus crassus, Dinornis struthoides, $D$. torosus, $D$. novaezealandiae, and $D$. giganteus. The taxa accepted as valid in this paper probably fit the biological species concept more closely than do those of previous classifications, in which as many as 29 species have been recognized. The "species-pairs," Pachyornis mappini-P septentrionalis, Euryapteryx curtus-E. exilis, E. geranoidesE. gravis, and Emeus crassus-E. huttonii probably represent examples of sexual size dimorphism.
\end{abstract}

\section{Introduction}

Birds provide a number of classic examples of insular adaptive radiations, the best known being the Hawaiian honeycreepers (Drepanididae) and the Galapagos finches (Geospizinae). A unique radiation of this sort is also found in the New Zealand moas (Dinornithidae)-unique because a spectacular radiation took place not only in feeding mechanisms, but also in body size and proportions, in contrast to the well-known passerine radiations. This occurred within a group that was completely flightless, and indeed it is probable that being flightless enhanced selective pressures toward divergence in cranial morphology and body size.

Joel Cracraft, Department of Anatomy, University of Illinois at the Medical Center, Chicago, Illinois 60680.
Moas are primitive ratite birds whose closest living relatives are probably the kiwis (Cracraft, 1974). I have postulated elsewhere that the common ancestor of the kiwis and moas probably had a distribution in the Cretaceous that included western Antarctica and parts of South America and that moas and kiwis were isolated on New Zealand following northward continental drift of that landmass beginning in the Late Cretaceous (Cracraft, $1973 \mathrm{a} ; 1974)$. If this is so, then the radiation of moas probably began in the Tertiary, but it is my opinion that the taxonomic and morphological diversity observed in the Holocene assemblages of moas is the result of a relatively recent, probably Pleistocene, episode of speciation (Cracraft, in prep.). Thus, species formation within moas probably involved repeated cycles of isolation and sympatry among populations of the two major islands and among populations that very likely were isolated in forest refugia at glacial maxima. It is within such a model of their evolution that I have considered the species-level systematics of moas.

Despite the fact that hundreds of papers have been written about moas (see summaries in Lambrecht, 1933; Oliver, 1949), there is comparatively little known about their functional morphology or evolutionary history. Upon initiating such studies, it quickly became clear that the complexities and confusion of presently accepted species-level systematics would hinder any advances in morphological or evolutionary investigations. It thus became necessary to review the status of the various species of moas, and this paper presents the results of that study.

The species-level systematics of moas has suffered from a century of typological thinking and a lack of application of modern concepts of population biology. No less than 60 specific names have been applied to a group that almost certainly con- 
tains fewer than 20 biological species (see Brodkorb, 1963, for citations to the taxonomic literature). Each variant, each newly discovered bone in some cases, was frequently given a new specific name. Unfortunately, the taxonomic philosophy of certain influential recent workers, rather than clarifying the systematics of these birds, merely confounded matters further. Oliver (1949:132-134), for example, believed that "it is the work of the systematist . to define the units that make up [a series of continuous sizes between extreme forms]," and that "in dealing with fossil species we should not hesitate to give specific names to forms that differ only slightly from one another . . ." (1949:164). It was this philosophical approach that enabled Oliver as late as 1949 to describe one new genus and six new species of moas, all of which were based on a small number of isolated bones. As will be seen, none of these taxa appears to be valid.

It is my purpose here to propose species-limits within moas which it is hoped will reflect the biological structure of those species. I have attempted to obtain some estimate of intraspecific variability and to apply this to recognizing species-limits. Species based on isolated bones or on inadequate material are critically evaluated for validity; likewise, geographic representatives on separate islands, previously given separate species names, are here considered conspecific unless there is good evidence to the contrary. Species-limits of moas undoubtedly will remain a matter of personal opinion for some time to come, and I make no pretense at having arrived at a definitive picture. There is a need for additional studies, and the systematics of these birds would benefit especially from a comprehensive numerical-multivariate approach. I do believe, however, that the species-limits proposed in this paper considerably clarify moa taxonomy and facilitate more interesting studies of their evolution.

Materials AND METHODs.-I have studied material of moas in the following museums (abbreviations used in the text follow in parentheses): British Museum (Natural History) (BM); American Museum of Natural History; Field Museum of Natural History; Canterbury Museum, Christchurch; Otago Museum, Dunedin; and National Museum of New Zealand (formerly Dominion Museum) (DM), Wellington. During this study the only major collection I was unable to examine was that at the Auckland Museum (AM), Auckland. Fortunately, Archey's (1941) valuable monograph on the moas is based almost entirely on the Auckland collection and I was, therefore, able to incorporate much information on that material into this study.

Of the species recognized by Oliver (1949) I have examined material of all except Pachyornis murihiku, Anomalopteryx antiquus, Megalapteryx hectori, and $M$. benhami. All of these were described from isolated bones and it is probable that none represents a valid species, with the possible exception of $M$. benhami. Thus, I was able to study the majority of taxa in need of critical evaluation.

In addition to using standard univariate statistical procedures, I have employed several multivariate morphometric techniques in order to characterize patterns of intra- and interspecific variability in more detail. The theory and methodology of multivariate approaches and their application to biological problems are discussed by Blackith and Reyment (1971) and Oxnard (1973). Basically, these techniques describe patterns of variation or degrees of similarity (or difference) for many variables taken simultaneously over many taxa. I have used two techniques: (I) principal components analysis (BMDO1M; Dixon, 1970 ) in order to examine the structure of variation within groups, primarily to investigate problems of sexual dimorphism in size and shape within a species; (2) discriminant functioncanonical analysis (BMDO7M; Dixon, 1970), in order to examine the patterns of variation among groups that are defined prior to the analysis. I employed this approach to examine the nature of the separations among the presumed species of a genus to evaluate species distinctness and the presence of sexual dimorphism. Part of the output of RMDO7M is a posterior probability classification which allows one to discover whether individuals assigned to one group prior to the analysis are in fact closer to the means of another group.

In all examples employing multivariate techniques, I undertook the analysis of each hindlimb element based either on my own data or that in Archey (1941) and Oliver (1949) using the follow. ing four variables: bone length, breadth of proximal end, breadth of shaft at midpoint, and breadth of distal end. 
Acknowledgments.- It is with pleasure that I dedicate this paper to Dr. Alexander Wetmore in honor of his ninetieth birthday, his many contributions to avian paleontology and ornithology, and especially for the affection he has shown us all.

I want to thank the following institutions and individuals for making their collections available to me and for making my visits enjoyable and productive: American Museum of Natural History (Wesley Lanyon, Malcolm C. McKenna); British Museum (Natural History) (Alan J. Charig, Cyril A. Walker); Canterbury Museum (Roger S. Duff, Ronald J. Scarlett, Michael Trotter); Field Museum of Natural History (John Bolt, Melvin A. Traylor); National Museum of New Zealand (John C. Yaldwyn, R. K. Dell); and Otago Museum (Roy Forster, J. Darby). I am grateful to Hildegard Howard and Pat V. Rich, John C. Yaldwyn, and Sir Robert Falla for providing helpful comments on an early draft of this paper. My trip to New Zealand and subsequent data analysis were made possible by financial support from the Australian Academy of Science (through H. J. Frith), the Chapman Fund of the American Museum of Natural History, and the National Science Foundation (grant GB-41089).

\section{Intraspecific Variability}

The relative variability of one species of kiwi and four species of moas, all of which are believed to represent "good" biological species, are examined here. By gaining some understanding of the degree of variability within species recognized to be valid by nearly all previous workers, a basis of comparison can thereby be provided for assessing species-limits among the more controversial taxa considered in the following section. For reasons to be discussed below, these assessments of variability within "good" species cannot be used as absolute limits or criteria of species variability, but they can serve as guidelines.

\section{Causes of Variability in Moas}

It has been known for 100 years or more that moas are highly variable. Moreover, some workers have seemed to appreciate the fact-although they seldom stated so explicitly-that this variation is complex in nature and cannot be attributed to any single factor. The main obstacle to understanding this variation is that of dealing with fossil (perhaps more correctly, subfossil) populations and their well-known problems of sampling in space and time. Some workers have sought to solve these problems either by ignoring them or by naming new species for each variant and thereby eliminating the necessity of delimiting or explaining intraspecific variability (note comments by Oliver cited above).

At this time it is not possible to make quantitative estimates of the separate factors contributing to patterns of variability within species of moas. Sample sizes for some species over their entire range, or for local populations of most species, are usually too small; stratigraphic control is lacking for all but a few of the moa specimens collected so far. Consequently, one is forced to estimate intuitively the relative importance of temporal, geographic, and individual components of variation. Within most fossil populations, particularly of moas, the following five factors seem important.

INTRAPOPULATIONAL VARIATION.-This is the variation observed in individuals of the same local interbreeding populations. We might expect the amount of such variation to be relatively low compared to those samples in which the influences of geographic or temporal variation are also present. Most of the samples discussed in this section do not represent single local populations; such samples probably do exist for certain species, but restrictions of time while in New Zealand did not permit me to study this aspect of variation in detail. Certain samples of Apteryx australis and Euryapteryx curtus (including $E$. exilis) might provide examples of this type of variation, and these are discussed below.

Sexual Dimorphism.--Since sexual size dimorphism is common in other ratites (with either males or females being larger), one would expect moas to show sexual size dimorphism also. Unfortunately, sample sizes are usually inadequate to lend support to this, although evidence is presented below of four probable examples of sexual size dimorphism in moas. The question of how much size difference to expect between sexes must be considered when dealing with fossil populations: if there were too great a difference between two particular samples, then we might be inclined to recognize two species rather than two sexes. But 
what is "too great" a difference? Almost no quantitative information has been published about dimorphism in other ratites. In one study of the Emu (Dromiceius novaehollandiae), data gathered by Long (1965) show that coefficients of variation (CV) of combined male-female samples range from 3.5 for bill length to 19.14 for body weight. Coefficients of variation for lengths of a few skeletal elements range from 4.77 for the tarsometatarsus to 5.28 for the tibiotarsus. These GVs for the skeletal elements are generally less than those calculated for the expanded species of moas discussed in the next section.

Geographic Variation.-The major factor in this type of variation in moas is probably interisland differentiation. It has previously been noted that the bones of North Island forms tend to be shorter and less stout than those of comparable taxa from the South Island (Archey, 1941:62, 71; Scarlett, 1972:20; Oliver, 1949:164). In addition, some intra-island differentiation may have occurred, but samples are too limited to confirm this. I believe geographic differentiation contributes greatly to the large variability in the samples of certain species discussed below.

Temporal Variation.-It is difficult to assess the importance of temporal variation in affecting variability within moas. The chronology of natural moa deposits is not well known. One can be reasonably certain that these assemblages are no older than 7000-8000 years, and most are undoubtedly much younger, apparently less than 4000 years old (Fleming, 1962). Hence, it may be that temporal variation contributes relatively little to the variability of the available samples of moas.

VARIATION AND RECENCY OF SYMPATRY.-If speciation in moas has resulted from isolation in forest refugia during glacial maxima, then it is reasonable to assume that variability would have increased as a result of this isolation, thus providing an example of intra-island geographic variation. Many samples of moas probably are composed of different populations that had come in contact following the last glaciation. Thus, we may be sampling birds that had recently diverged morphologically, and some of the variation observed may be the result of recent character displacement in size following this contact.

\section{ANALysis of SPEcies}

Basic statistical data for the femora, tibiotarsi, and tarsometatarsi of Apteryx australis and four species of moas are given in Table 1 . Of particular importance for the discussions that follow are the coefficients of variation (CV), which are measures of relative variability independent of size.

Apteryx australis: This sample (housed in the National Museum of New Zealand) of 24-32 individuals referable to the modern Brown Kiwi, comes from the Castle Rocks cave deposit on the South Island. It is evident from Table 1 that $A$. australis, with CVs ranging from 4.68 to 7.6 , exhibits less variability than any of the moas. I attribute this to the relative lack of geographic and temporal influences since the sample comes from a single locality and was probably deposited over a relatively short span of time. Of the species studied, this sample of $A$. australis possibly comes closest to representing only intrapopulational variation. The degree of variability in this sample is similar to that shown by fossil populations of some species of gruiforms (Cracraft, 1973b). In A. australis, measurements of length are less variable than those of breadth.

Megalapteryx didinus: This sample is taken from many localities in the South Island (data from Archey, 1941; Oliver, 1949). In a later section I synonymize $M$. hectori with $M$. didinus, but specimens assigned to the former are not included in this sample. This species may be one of the more variable of moas in that the lowest $\mathrm{CV}$ is 5.79 while the highest is 12.04. Most of this variability is probably attributable to geographic variation. As with $A$. australis, measurements of length are less variable than those of breadth.

Anomalopteryx didiformis: The analysis of this species is based on a large sample collected from sites on both islands. Included in this series by Archey (1941, table A) are a few specimens that might be assigned to Oliver's (1949) species $A$. parvus. Few workers accept $A$. parvus as a distinct species (see below) and my analysis is based on all the specimens listed by Archey. This species also shows a fairly high degree of variability, with CVs ranging from 6.79 to 9.3. Again, lengths are less variable than other measurements. The variability of this sample is probably influenced substantially by geographic and intrapopulational variation. 
Table 1.-Statistics for Apteryx australis and four species of moas (measurements in mm)

\begin{tabular}{|c|c|c|c|c|c|}
\hline Character & $\begin{array}{l}\text { Apteryx } \\
\text { australis }\end{array}$ & $\begin{array}{l}\text { Megalapteryx } \\
\text { didinus }\end{array}$ & $\begin{array}{c}\text { Anomalopteryx } \\
\text { didiformis }\end{array}$ & $\begin{array}{l}\text { Dinornis } \\
\text { torosus }\end{array}$ & $\begin{array}{l}\text { Pachyornis } \\
\text { elephantopus }\end{array}$ \\
\hline \multicolumn{6}{|l|}{ FEMUR } \\
\hline \multicolumn{6}{|l|}{ Length } \\
\hline n & 24 & 16 & 38 & 16 & 21 \\
\hline$\overline{\mathbf{x}}$ & 89.45 & 245.69 & 238.45 & 295.38 & 308.86 \\
\hline SD & 4.43 & 15.29 & 16.2 & 17.73 & 15.54 \\
\hline CV & 4.96 & 6.22 & 6.79 & 6 & 5.03 \\
\hline \multicolumn{6}{|l|}{ Proximal breadth } \\
\hline $\mathbf{n}$ & 24 & 13 & 37 & 12 & 20 \\
\hline$\overline{\mathbf{x}}$ & 20.1 & 71.62 & 82.27 & 108.83 & 129.55 \\
\hline SD & 1.53 & 6.19 & 7.65 & 10.21 & 12.11 \\
\hline CV & 7.6 & 8.64 & 9.3 & 9.38 & 9.35 \\
\hline \multicolumn{6}{|l|}{ Distal breadth } \\
\hline n & 24 & 15 & 38 & 12 & 21 \\
\hline$\overline{\mathbf{x}}$ & 21.45 & 75.73 & 85.53 & 117.58 & 145.57 \\
\hline SD & 1.13 & 7.72 & 7.89 & 11.75 & 8.84 \\
\hline CV & 5.25 & 10.2 & 9.26 & 9.99 & 6.07 \\
\hline \multicolumn{6}{|l|}{ Tibiotarsus } \\
\hline \multicolumn{6}{|l|}{ Length } \\
\hline n & 32 & 15 & 39 & 14 & 27 \\
\hline$\overline{\mathbf{x}}$ & 129.93 & 385.33 & 377.21 & 588.36 & 542.93 \\
\hline SD & 6.08 & 22.3 & 27.33 & 36.77 & 37.97 \\
\hline CV & 4.68 & 5.79 & 7.25 & 6.25 & 6.99 \\
\hline \multicolumn{6}{|l|}{ Proximal breadth } \\
\hline $\mathbf{n}$ & 32 & 12 & 33 & 10 & 19 \\
\hline$\overline{\mathbf{x}}$ & 17.31 & 85.58 & 101.27 & 139.7 & 167.42 \\
\hline SD & 1.06 & 7.75 & 8.9 & 8.34 & 14.32 \\
\hline CV & 6.11 & 9.06 & 8.79 & 5.97 & 8.56 \\
\hline \multicolumn{6}{|l|}{ Distal breadth } \\
\hline $\mathbf{n}$ & 32 & 15 & 38 & 13 & 27 \\
\hline$\overline{\mathbf{x}}$ & 15.71 & 51.93 & 56.71 & 82.07 & 97.33 \\
\hline SD & 0.88 & 6.25 & 4.89 & 6.86 & 9 \\
\hline CV & 5.59 & 12.04 & 8.62 & 8.36 & 9.25 \\
\hline \multicolumn{6}{|l|}{ TARSOMETATARSUS } \\
\hline \multicolumn{6}{|l|}{ Length } \\
\hline $\mathbf{n}$ & 30 & 18 & 43 & 16 & 29 \\
\hline$\overline{\mathbf{x}}$ & 64.85 & 179.39 & 179.02 & 303.13 & 230.55 \\
\hline SD & 3.3 & 10.9 & 13.96 & 22.75 & 15.75 \\
\hline CV & 5.09 & 6.07 & 7.8 & 7.51 & 6.83 \\
\hline \multicolumn{6}{|l|}{ Proximal breadth } \\
\hline $\mathbf{n}$ & 29 & 16 & 41 & 13 & 27 \\
\hline$\overline{\mathbf{x}}$ & 17.17 & 53.25 & 59.15 & 88.54 & 105.85 \\
\hline SD & 0.98 & 5.04 & 5.34 & 5.08 & 10.25 \\
\hline CV & 5.73 & 9.46 & 9.03 & 5.73 & 9.68 \\
\hline \multicolumn{6}{|l|}{ Distal breadth } \\
\hline $\mathbf{n}$ & 30 & 17 & 42 & 14 & 29 \\
\hline$\overline{\mathbf{x}}$ & 21.05 & 72.41 & 77.43 & 112.71 & 134.52 \\
\hline SD & 1.11 & 7.4 & 6.26 & 7.62 & 12.06 \\
\hline CV & 5.29 & 10.22 & 8.08 & 6.76 & 8.97 \\
\hline
\end{tabular}


Dinornis torosus: The data for this species are based on a small sample collected from many sites in the South Island (Archey, 1941; Oliver, 1949). Variability is fairly high, with CVs ranging from 5.73 to 9.99 . This is the only species in which lengths tend to be more variable than breadths. Variability in this sample is probably affected by geographic and temporal components.

Pachyornis elephantopus: This sample is from various sites on the South Island (Archey, 1941; Oliver, 1949; and measurements by the author). Coefficients of variation are comparable to those of $A$. didiformis and D. torosus, ranging from 5.03 to 9.68. Once again, length measurements are less variable than those of breadth. Intra-island components probably contribute substantially to variability in this species.

\section{SUMMARY}

Variability within individual species of moas appears somewhat higher than is found in most other birds so far studied. For example, in six fossil species of gruiforms, CVs for hindlimb elements averaged 6-7 (Cracraft, 1973b:97-107). Simpson (1946) presented data for the King Penguin (Aptenodytes patagonicus) and Goodge (1951) analyzed variability in the Common Murre (Uria aalge); both workers found low CVs, averaging 2-4, in these extant species.

Data for $A$. didiformis, $D$. torosus, and $P$. elephantopus would seem to suggest that in moas CVS generally fall in the range of $6-10$, but if the sample of $M$. didinus were used as a standard, then CVs as high as 10-12 might be expected within a single species. Indeed, estimates based on the above samples may be conservative in that they possibly include only individuals of a single sex, specimens of the other sex previously having been considered as forming a distinct species.

During growth, the length of long bones apparently reaches its maximum value before maximum body weight is obtained (Cock, 1963). Bone breadths of adults, on the other hand, probably reflect final body weight since they have a mechanical relationship to the amount of weight that can be supported. It can thus be expected that breadth measurements will tend to be more variable than those for length, since the former depend upon variation in body weight at the termination of growth. Estimates of variation in length might be preferred over those for breadth as a more precise, and more conservative, measure of intraspecific variability. For this reason the comparisons in the following section will be based on measurements of length.

\section{Systematics}

In this section I have attempted to formulate species limits based on information from univariate and multivariate analyses of variation, personal examination and comparison of many complete and partial skeletons, and an evaluation of previously published opinions on moa systematics. Detailed discussions of morphology (particularly at the generic level and higher), natural history, and taxonomic synonymies can be found in Archey (1941), Oliver (1949), Brodkorb (1963), or papers cited therein, and are not included here unless they bear directly on the subject of species limits.

\section{Family DINORNITHIDAE}

\section{Subfamily ANOMALOPTERYGINAE}

\section{Anomalopteryx Reichenbach, 1852}

Summary.-Two species of Anomalopteryx are tentatively admitted here-a larger form, $A$. didiformis, found on both North and South islands, and a smaller, less common form, $A$. oweni, found only on the North Island.

\section{Anomalopteryx didiformis (Owen, 1844)}

Synonyms.-Anomalopteryx parvus (Owen, 1883), Anomalopteryx antiquus Hutton, 1892.

Of the two species of the genus recognized here, this was the more common and occurred on both the North and South islands. Archey's (1941:14-29) discussion, although not employing statistical methods, amply demonstrated the great variation present within this species.

Anomalopteryx parvus, based on fairly extensive material from both islands, is included in this species, following Archey (1941), Brodkorb (1963), and Scarlett (1972). This is contrary to Oliver (1949:138), who maintained $A$. parvus as distinct. Oliver (1949:144-145, figs. 115-116) pictured bones 
of the two species for comparative purposes, and indeed these appear quite different in size. Oliver's method of analysis and argumentation, however, was to compare the extremes in size or shape, thus magnifying the differences. There is a continuity in size and morphology in specimens assigned to these two species (Archey, 1941:18); thus, unlike examples to be described below in other genera, it is not possible to recognize two size groups within $A$. didiformis that could represent sexual size dimorphism.

According to Scarlett (1972:22), A. antiquus is now considered to come from lower Pleistocene deposits rather than being Miocene or Pliocene in age as previously thought. Scarlett further indicated that $A$. antiquus is "doubtfully distinct from didiformis" and that there are no significant morphological differences between them. Likewise, Archey (1941:29) noted close similarities between the two species. I did not locate the type during my stay at the Canterbury Museum. At present I believe that compelling evidence is lacking to maintain $A$. antiquus as a separate species.

\section{Anomalopteryx oweni (Haast, 1885)}

There has been some controversy about the generic assignment of this species. As did all other early workers, Haast $(1885,1886)$ placed this species in Dinornis. Shortly thereafter, Lydekker (1891:280) put oweni in Anomalopteryx on the basis of its skull morphology. Archey (1941:44) transferred the species to Pachyornis without comment; Brodkorb (1963:211) followed Archey. Oliver (1949:134-135) returned oweni to Anomalopteryx, claiming that the type cranium illustrated by Haast (1886) shows the diagnostic features of Anomalopteryx, as does the associated premaxilla, and that most of the skeletal material assigned to oweni by Archey belongs to Pachyornis septentrionalis ( $=P$. mappini of this paper).

Although I was unable to examine the typematerial of $A$. oweni in the Auckland Museum, several comments on the species can still be made. The cranium and premaxilla illustrated by Haast do appear to be more similar to Anomalopteryx than to Pachyornis, although the rounded anterior border of the temporal fossa in dorsal view and the markedly sloping nasal region in lateral view do not resemble species of either genus. Some of the hindlimb elements listed by Archey as belonging to oweni are within the size range of Pachyornis mappini (including $P$. septentrionalis), whereas others appear to be too small to be referred to that species. Thus, until the systematics of oweni can be clarified by restudy of the type and comparison with other material, I tentatively include it as a valid species in the genus Anomalopteryx.

\section{Megalapteryx Haast, 1886}

Summary.-Two species of Megalapteryx are accepted here-a small one, $M$. didinus, and a larger one, $M$. benhami. Both are known from the South Island, the alleged presence of $M$. didinus in the North Island being doubtful.

\section{Megalapteryx didinus (Owen, 1883)}

Synonym.-Megalapteryx hectori Haast, 1886.

Megalapteryx didinus is known from a moderate number of bones from the South Island, few of which were found in association. The presence of this species on the North Island is suspect (Oliver, 1949:151-152).

Archey (1941) synonymized $M$. hectori with $M$. didinus without comment, but Oliver (1949:149) maintained the species. Brodkorb (1963) and Scarlett (1972) followed Archey. I also believe there is insufficient evidence to justify recognition of $M$. hectori. Only a few limb bones are presumably applicable to this species (I did not examine the type, which is in the Nelson Museum), and their size, although somewhat smaller than typical bones of $M$. didinus, probably falls within the limits of variability for that species. For example, CVs for the lengths of the hindlimb elements for the combined sample of $M$. didinus and $M$. hectori are comparable to $\mathrm{CVs}$ of the other moas listed in Table I: e.g., femur, 8.45; tibiotarsus, 6.76; and tarsometatarsus, 7.40. I therefore follow the authors cited above in synonymizing hectori with didinus.

\section{Megalapteryx benhami Archey, 1941}

This species was described on the basis of a femur and a tibiotarsus, not positively associated, from the Mt. Arthur region, South Island. Oliver (1949) also lists a femur from Wairanga, South Island. 
The bones were placed in Megalapteryx on the basis of several morphological characters associated with the rotular groove and muscle scars (Archey, 1941:35), and it would be important for future workers to confirm the validity of these characters in distinguishing genera. As many authors have noted, there is great variability in the form of the femur and it is frequently difficult to identify this element to genus unless found in association with more diagnostic bones. As it now stands, the species $M$. benhami can be tentatively accepted, as its larger size (mean femur length of $296.5 \mathrm{~mm}$; length of tibiotarsus, $454 \mathrm{~mm}$ ) is very probably outside the range of variation for $M$. didinus. Future workers need to restudy the material of this species in order to verify its validity and generic assignment.

\section{Pachyornis Lydekker, 1891}

Summary.-Two species of Pachyornis are recognized here. The larger, $P$. elephantopus, is known only from the South Island. A smaller species, $P$. mappini, showing what appears to be pronounced sexual dimorphism in size, was restricted to the North Island.

\section{Pachyornis elephantopus (Owen, 1856)}

Synonyms.-Pachyornis murihiku Oliver, 1949; Pachyornis australis Oliver, 1949.

Pachyornis elephantopus was restricted to the South Island and was the larger of the two species of the genus recognized here. It was also one of the more common species of moas and is represented by a number of complete skeletons from the Pyramid Valley Swamp.

Oliver (1949:67) described P. murihiku for a single skeleton said to be from a "full-grown but not quite mature" individual from Southland, South Island. The type was supposedly in the Southland Museum, Invercargill, but according to Scarlett (1972:21) it cannot now be found. Both Brodkorb (1963) and Scarlett (1972) accepted $P$. murihiku as a distinct species. The measurements of $P$. murihiku indicate that it was only slightly smaller than $P$. elephantopus (Oliver, 1949:59, 86-87); furthermore, if the measurements of the limb bones of $P$. murihiku are included in the sample of $P$. elephantopus in Table 1 , the CVs of bone length are not appreciably increased; viz. femur, 6.52; tibiotarsus, 8.04; and tarsometatarsus, 7.67. Oliver (1949:68-70) listed the following characters as distinguishing $P$. murihiku from $P$. elephantopus: (1) culmen rises at a higher angle, (2) the "front of the body [of the sternum] is not bent upwards so far as to bring it to a right angle with the rest of the body," and (3) the ischia and pubes are widely diverging. It is difficult to evaluate these features in terms of species differences, especially since the type of $P$. murihiku is from an immature individual. In the absence of additional material it may be questioned whether the above differences should be accepted as being consistent between the two species. There is a great deal of variation in skeletons of $P$. elephantopus, and I believe that the above features of $P$. murihiku must be verified by additional specimens before this species is accepted as valid.

Oliver (1949:70) described another species of Pachyornis, $P$. australis, from a single wellpreserved cranium from Takaka River, South Island. Both Brodkorb (1963) and Scarlett (1972) accepted $P$. australis as a distinct species, although Scarlett indicated that it may be a variant of $P$. elephantopus. I have compared the type (DM 26) with a large series of skulls of $P$. elephantopus and can find no significant differences that can be regarded as being of specific value. Even though the skull of $P$. australis is at the lower end of the size range for $P$. elephantopus, several skulls assigned to the latter species by Oliver himself (1949:84) are of comparable size (e.g., DM 95, DM 198, DM 333). Crania of $P$. elephantopus exhibit considerable variability in shape and in the development of processes and muscle scars. For example, within a series of skulls of $P$. elephantopus in the National Museum of New Zealand it was possible to find the following characters attributed to " $P$. australis" by Oliver (1949:70-72): (1) skull wider in proportion to length, (2) evenly rounded cranium, (3) wide space between lambdoidal and temporal ridges, and (4) narrow temporal fossa. Furthermore, there are similarities in rostral shape and considerable variation in the development of the transverse process of the basisphenoid rostrum. Therefore, it does not seem prudent to accept $P$. australis as a valid species. 


\section{Pachyornis mappini Archey, 1941}

SYNONYM.-Pachyornis septentrionalis Oliver, 1949.

Archey (1941:41) proposed this species for a small North Island form of Pachyornis. The type (AM 124) is an almost complete skeleton. Most of the remaining material assigned to $P$. mappini consists of isolated elements and many of those in the National Museum of New Zealand have been acquired recently and are as yet undescribed.

Oliver (1949:61) described a new species, $P$ septentrionalis, for a partial skeleton (DM 129), also from the North Island. He included in this species those bones from the lower end of the series that Archey (1941) placed in P. mappini. Oliver (1949:61) stated that bones of $P$. septentrionalis, in addition to being smaller, are also more slender than those of $P$. mappini. Brodkorb (1963) accepted both species, while Scarlett (1972) suggested that the two might be conspecific.

An analysis of the skeletal measurements of these nominal species (Archey, 1941:139; Oliver, 1949: 86; measurements by the author) indicates that two separable populations do appear to exist, the major difference between them being in size (Table 2). Using principal components analysis of each element of the hindlimb (Figure 1), a moderately well-defined separation between the two forms can be demonstrated along the first principal component, which in this case is a size axis. The second component is a shape axis, mainly defining
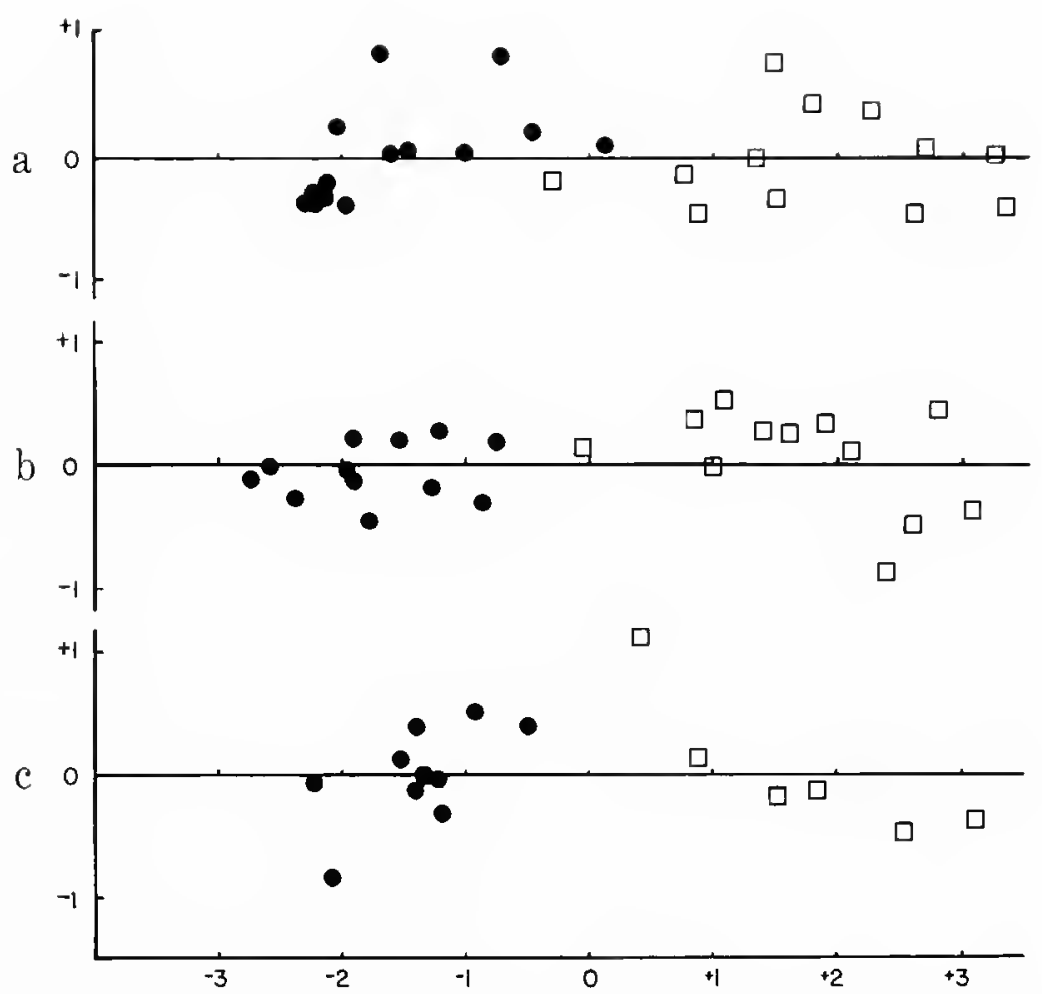

FIGURE 1.-Principal components analyses of logarithmically transformed measurements of the femur $(a)$, tibiotarsus $(b)$, and tarsometatarsus (c) of Pachyornis septentrionalis (dark circles) and $P$. mappini (open squares). The first principal component of each analysis is graphed along the abscissa and is a size axis; the second principal component is graphed along the ordinate and is a shape axis, primarily indicating relative robustness. (Note that the two taxa are separated by size but not by shape. See text for details.)

relative robustness, and it is evident that the two populations do not differ significantly in this respect. Thus, Oliver's (1949:61) claim that bones of $P$. septentrionalis are more slender than those of $P$.

TABle 2.-Statistics for Pachyornis mappini and $P$. septentrionalis (measurements in mm)

\begin{tabular}{|c|c|c|c|}
\hline Character & P. mappini & $P$. septentrionalis & $\begin{array}{l}\text { P. mappini }+ \\
\text { P. septentrionalis }\end{array}$ \\
\hline \multicolumn{4}{|l|}{ Length of femur } \\
\hline $\mathbf{n}$ & 12 & 14 & 26 \\
\hline$\overline{\mathbf{X}}$ & 206.25 & 174.07 & 188.92 \\
\hline SD & 12.88 & 11.63 & 20.27 \\
\hline $\mathbf{C V}$ & 6.24 & 6.68 & 10.73 \\
\hline \multicolumn{4}{|l|}{ Length of tibiotarsus } \\
\hline $\mathbf{n}$ & 12 & 12 & 24 \\
\hline$\overline{\mathbf{x}}$ & 365.5 & 291.67 & 328.58 \\
\hline $\mathrm{SD}$ & 30.44 & 14.79 & 44.38 \\
\hline (n) & 8.33 & 5.07 & 13.51 \\
\hline \multicolumn{4}{|l|}{ Length of tarsometatarsus } \\
\hline $\mathbf{n}$ & 7 & 10 & 17 \\
\hline$\overline{\mathbf{x}}$ & 156.29 & 133 & 142.59 \\
\hline SD & 12.57 & 3.71 & 14.37 \\
\hline CV & 8.04 & 2.79 & 10.08 \\
\hline
\end{tabular}


TABLE 3.-Posterior probability classification of stepwise discriminate function analysis for bones assigned to Pachyornis mappini and $P$. septentrionalis

\begin{tabular}{|c|c|c|c|c|}
\hline Character & $\begin{array}{c}P . \\
\text { mappini }\end{array}$ & $\begin{array}{c}P . \\
\text { septentrionalis }\end{array}$ & $n$ & $\begin{array}{c}\text { Percent } \\
\text { misclassified }\end{array}$ \\
\hline \multicolumn{5}{|l|}{ Femur } \\
\hline P. mappini & 11 & 1 & 12 & 8.3 \\
\hline P. septentrionalis .... & 1 & 13 & 14 & 7.1 \\
\hline \multicolumn{5}{|l|}{ Tibiotarsus } \\
\hline P. mappini .................. & 12 & 0 & 12 & 0 \\
\hline P. septentrionalis ... & 0 & 12 & 12 & 0 \\
\hline \multicolumn{5}{|l|}{ Tarsometatarsus } \\
\hline P. mappini & 7 & 0 & 7 & 0 \\
\hline P. septentrionalis & 0 & 10 & 10 & $\mathbf{0}$ \\
\hline
\end{tabular}

mappini is not substantiated. In order to examine further the distinction between the two forms, I analyzed the data using a step-wise discriminate function-canonical analysis. The distinctness of the two groups was further verified and few of the elements were misclassified (Table 3).

What is the meaning of these differences? If, in fact, the two taxa do not represent distinct species, then very likely we are dealing with sexual size differences. Table 2 presents some basic statistical data for lengths of the hindlimb bones. The combined sample of measurements for the lengths of the femur and tarsometatarsus do not show CVs much higher than those for $P$. mappini alone, or for those of other moas (Table 1). It can be noted also that the CV of 2.79 for the tarsometatarsus length of $P$. septentrionalis (Table 2) is suspiciously low compared to CVs of other moas. It is my belief that these two skeletal populations probably represent different sexes and that Oliver's (1949) description of a new species was unwarranted. I therefore synonymize septentrionalis with mappini until firm evidence can be offered that they are distinct.

\section{Euryapteryx Haast, 1874}

SYNONYM.-Zelornis Oliver, 1949.

Oliver (1949:117-128) created the genus Zelornis for the species Euryapteryx exilis Hutton (the genotype) and Emeus haasti Rothschild. Archey (1941) considered the former to be a valid species in the genus Euryapteryx, while the latter he treated as a synonym of Euryapteryx gravis (p. 54). The diagnostic feature separating Zelornis from Euryapteryx was said to be the high arched culmen.
Oliver (1949:110) admitted that there were no differences in the shape of the postcranial elements. The type-specimen of $Z$. exilis is a skeleton from Wangaehu in the Wanganui Museum. The skull was figured by Oliver (1949, figs. 92-94) where it is readily apparent that the premaxilla is considerably broken and abraded. The premaxilla of $Z$. exilis does not appear to differ in shape from those referred to $Z$. haasti. I have examined nearly all of the cranial material assigned to Zelornis haasti by Oliver (1949:127) and can find no important differences in size or shape that will distinguish it at the generic level from Euryapteryx. To my knowledge Scarlett (1972) is the only recent author to synonymize Zelornis with Euryapteryx, and $\mathrm{I}$ concur with his decision.

Summary.-Two sexually dimorphic species are recognized here-a moderately large form, $E$. geranoides, present on both North and South islands, and a small species, E. curtus, confined to North Island.

\section{Euryapteryx curtus (Owen, 1846)}

Synonyms.-Euryapteryx exilis Hutton, 1897; Euryapteryx tane Oliver, 1949.

Euryapteryx curtus was a small species of moa, apparently confined to the North Island. The only morphological difference between $E$. curtus and $E$. exilis is in size (Archey, 1941:60), E. exilis being slightly larger (Table 4). In order to assess the morphological similarities in size and shape in Euryapteryx, I analyzed the measurements of the femur, tibiotarsus, and tarsometatarsus given by Archey (1941) and Oliver (1949), using principal components and canonical analyses. Figure 2 plots 
Table 4.-Statistics for species of Euryapteryx (measurements in mm)

\begin{tabular}{|c|c|c|c|c|c|c|c|}
\hline Character & E. tane & E. curtus & E. exilis & $\begin{array}{c}\text { E. exilis }+ \\
\text { E.curtus }\end{array}$ & E. geranoides & E. gravis & $\begin{array}{l}\text { E. gravis }+ \\
\text { E. geranoides }\end{array}$ \\
\hline \multicolumn{8}{|l|}{ Length of Femur } \\
\hline n & 3 & 15 & 18 & 33 & 8 & 13 & 21 \\
\hline$\overline{\mathbf{x}}$ & 190.67 & 167.6 & 198.17 & 184.27 & 236.63 & 280.15 & 263.57 \\
\hline SD & 9.29 & 12.82 & 10.89 & 18.24 & 12.53 & 10.89 & 24.4 \\
\hline CV & 4.87 & 7.65 & 5.5 & 9.9 & 5.3 & 3.89 & 9.26 \\
\hline \multicolumn{8}{|l|}{ Length of tibiotarsus } \\
\hline n & 3 & 20 & 17 & 37 & 5 & 12 & 17 \\
\hline$\overline{\mathrm{x}}$ & 328 & 268.8 & 331.65 & 297.68 & 387.6 & 475.17 & 449.41 \\
\hline SD & 9 & 16.5 & 12.67 & 34.97 & 17.99 & 21.57 & 45.74 \\
\hline CV & 2.74 & 6.14 & 3.82 & 11.75 & 4.64 & 4.54 & 10.18 \\
\hline \multicolumn{8}{|l|}{ Length of tarsometatarsus } \\
\hline 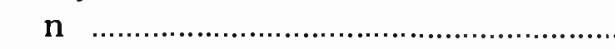 & 3 & 19 & 15 & 34 & 9 & 13 & 22 \\
\hline$\overline{\mathrm{x}}$ & 149 & 124.74 & 148.4 & 135.12 & 174.78 & 209.62 & 195.36 \\
\hline SD & 7.55 & 8.29 & 4.39 & 13.64 & 12.34 & 16.16 & 22.68 \\
\hline CV & 5.07 & 6.65 & 2.96 & 10.09 & 7.06 & 7.71 & 11.61 \\
\hline
\end{tabular}

group centroids for the first two canonical axes. The multivariate analysis substantiates the separation of $E$. exilis and $E$. curtus, but the centroids themselves as projected onto the first axis are only about two and a half SD units from each other (except for the tibiotarsus where they are almost four units apart). If one examines the statistics of the combined sample (Table 4), the population E. exilis $+E$. curtus has CVs of about 10-12 for bone lengths. This variability is comparable to that of Pachyornis mappini, and I believe it is likely that the difference between $E$. exilis and $E$. curtus is one of sexual size dimorphism. Most of the specimens in Archey's series of these two forms (1941, tables H, I) come from Doubtless Bay, North Island.

Oliver (1949:105) described a separate species, $E$. tane, for a small number of specimens that were larger than those of $E$. curtus. He (1949:123) noted that some of the leg bones of $E$. tane possibly belonged to what he called Zelornis exilis. It is readily apparent that the samples of $E$. tane and $E$. exilis are virtually identical (Table 4; Figure 2). There is little question, therefore, that $E$. tane should be synonymized with $E$. curtus as defined here.

\section{Euryapteryx geranoides (Owen, 1848)}

Synonyms.-Euryapteryx gravis (Owen, 1870), Zelornis haasti (Rothschild, 1907).

The type-material of $E$. geranoides consists of a cranium, premaxilla, and mandible collected at $\mathrm{Te}$ Rangatapu, North Island, and housed in the British Museum (Natural History). According to Oliver (1949:106) the mandible belongs to Anomalopteryx didiformis, and the cranium and premaxilla, which may or may not be associated, belong to Euryapteryx. To my knowledge a lectotype has not yet been designated, but the cranium (BM 21687) would be a logical choice. The type cranium and premaxilla are smaller than most of the material attributed to $E$. gravis but larger than in E. curtus. Therefore, $E$. geranoides has been accepted as a distinct species of intermediate size by Archey (1941), Oliver, (1949), and Brodkorb (1963). It should be pointed out that there is apparently no postcranial material directly associated with cranial material attributable to $E$. geranoides (sensu stricto).

Material assigned to the large form known as $E$. gravis is abundant in South Island localities (the type-skeleton in the British Museum is from Kakanui) but very rare on the North Island (Archey, 1941:54-56; Oliver, 1949:108-112). Statistics presented in Table 4 and the results of the canonical analyses shown in Figure 2 confirm the intermediate position of $E$. geranoides between " $E$. exilis" (=E. curtus) and E. gravis. The question is whether $E$. geranoides is a distinct species, and if not, to which species-the larger $E$. gravis or the smaller E. curtus-this skeletal population belongs. Recently, Scarlett (1972:21) suggested that E. gera- 


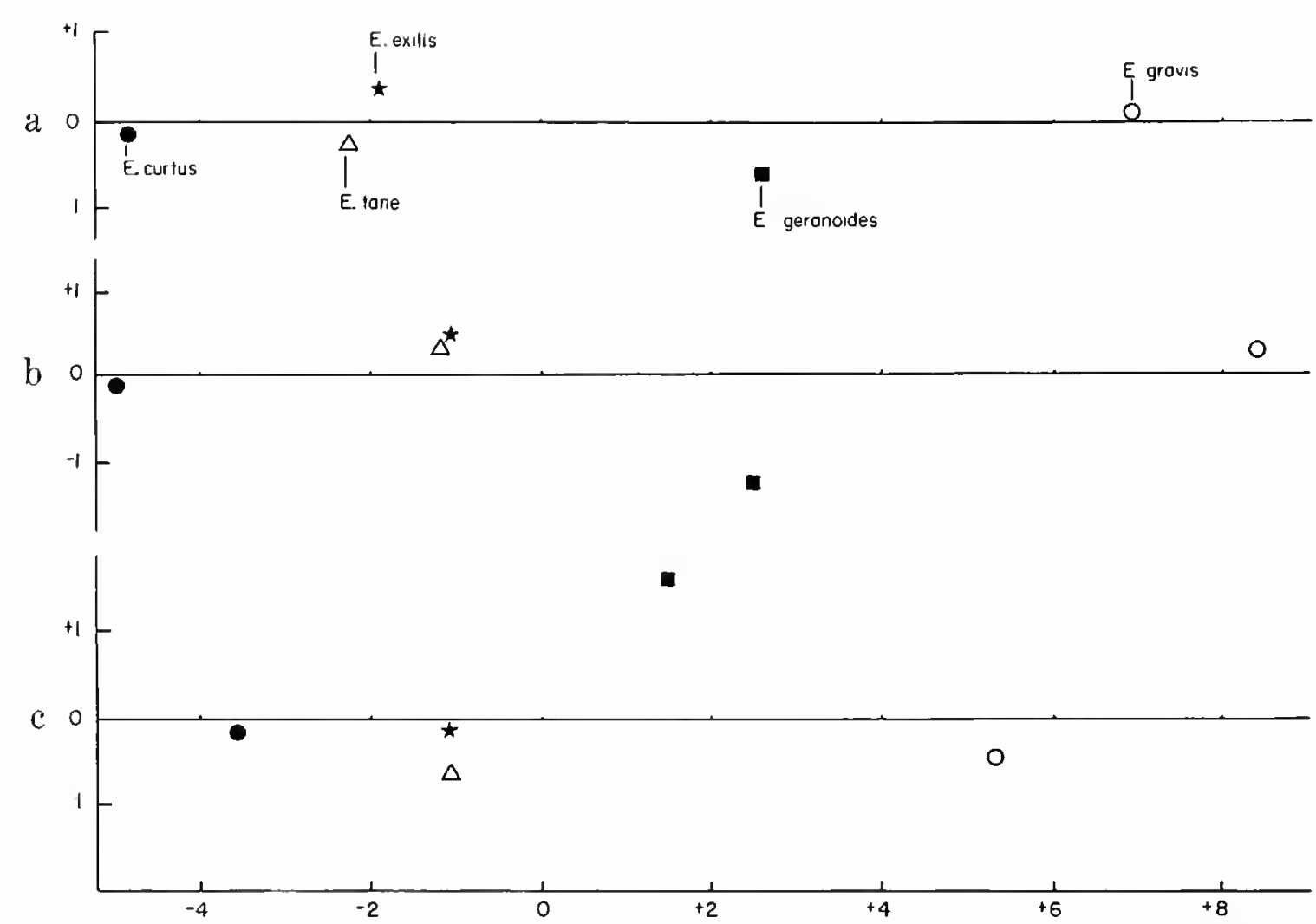

FIGURE 2.-Group centroids of five nominal taxa of Euryapteryx plotted against the first (abscissa) and second (ordinate) canonical axes for logarithmically transformed measurements of the femur $(a)$, tibiotarsus $(b)$, and tarsometatarsus $(c)$. Scales are in standard deviation units. Note the closeness of group centroids of $E$. tane and $E$. exilis, the closeness of $E$. curtus to $E$. tane-E exilis, and the intermediate position of $E$. geranoides between $E$. gravis and the smaller forms. (See text for details.)

noides might be united with $E$. curtus once the gaps were eliminated.

I would like to suggest here that $E$. geranoides is conspecific with $E$. gravis and that these forms represent another case of sexual size dimorphism. The evidence is two-fold. First, measurements of the combined sample exhibit $\mathrm{CVs}$ very similar to those seen in $P$. mappini-P. septentrionalis and $E$. curtus-E. exilis, the two other presumed examples of sexual size dimorphism (Table 4). Secondly, bones attributed to $E$. geranoides and E. gravis occur on both North and South islands. If E. geranoides were conspecific with $E$. curtus (or with $E$. exilis, if this form were distinct from E. curtus), then the absence of E. curtus from the South Island is unexplained. If $E$. geranoides and $E$. exilis represented different sexes, then both should be present on the South Island. Present evidence, therefore, is more consistent with the hypothesis that $E$. curtus-E. exilis constitute one sexually dimorphic species and $E$. geranoides-E. gravis another. In the case of the latter, the older name, geranoides, has priority.
As noted above, the cranial material of Zelornis haasti is very similar to that of $E$. geranoides. The femur and tibiotarsus of the one skeleton of $Z$. haasti are somewhat larger than typical "E. gravis" (Oliver, 1949:128; see also Table 4), but the associated tarsometatarsus is easily within the size range of that form. Hence, it is likely that the few bones assigned to $Z$. haasti are large, perhaps aberrant bones of E. geranoides, and I follow Archey (1941) in synonymizing haasti.

\section{Emeus Reichenbach, 1852}

\section{Emeus crassus (Owen, 1846)}

Synonym.-E. huttonii (Owen, 1879).

There has been little difference of opinion about species-limits within Emeus. Most recent authors (Archey, 1941; Oliver, 1949; Brodkorb, 1963) have accepted two species, the large crassus and the smaller huttonii. Only Scarlett (1972:22) has combined the two species, stating that several specimens from Pyramid Valley are intermediate in 
Table 5.-Statistics for species of Emeus (measurements in $\mathrm{mm}$ )

\begin{tabular}{|c|c|c|c|}
\hline Character & E.crassus & E. huttonii & $\begin{array}{c}\text { E. crassus }+ \\
\text { E. huttonii }\end{array}$ \\
\hline \multicolumn{4}{|l|}{ Length of femur } \\
\hline $\mathrm{n}$ & 21 & 10 & 31 \\
\hline $\bar{x} \ldots \ldots \ldots$ & 272.81 & 238.4 & 261.71 \\
\hline SD & 12.23 & 11.92 & 20.24 \\
\hline CV & 4.48 & 5 & 7.73 \\
\hline \multicolumn{4}{|l|}{ Length of tibiotarsus } \\
\hline n & 21 & 11 & 32 \\
\hline$\overline{\mathrm{x}} \ldots$ & 464.24 & 386.64 & 437.56 \\
\hline SD & 23.08 & 19.01 & 43.16 \\
\hline CV & 4.97 & 4.92 & 9.86 \\
\hline \multicolumn{4}{|l|}{ Length of tarsometatarsus } \\
\hline n & 22 & 10 & 32 \\
\hline$\overline{\mathrm{x}}$ & 213.55 & 184.4 & 204.44 \\
\hline SD & 11.58 & 13.46 & 18.22 \\
\hline CV $\ldots \ldots \ldots \ldots \ldots \ldots \ldots \ldots \ldots \ldots \ldots \ldots$ & 5.42 & 7.3 & 8.91 \\
\hline
\end{tabular}

size. Both forms occurred in the South Island and are known primarily from the Canterbury and Otago districts. Although according to Archey (1941:51) several bones referable to Emeus have allegedly been found at Martinborough and Te Aute on the North Island, Yaldwyn (1956) does not list Emeus from the Martinborough Caves, nor did Oliver (1949) make note of Emeus on the North Island. On the South Island $E$. crassus has been reported as moderately common, whereas $E$. huttonii was apparently less so.

Statistics presented in Table 5 show that the bones assigned to $E$. crassus and $E$. huttonii by Archey (1941) and Oliver (1949) comprise two distinct populations. Multivariate analysis of the hindlimb measurements verifies the univariate re- sults, and in the posterior probability classification of the discriminate function analysis, few bones are misclassified (Table 6).

The two forms of Emeus could represent two species, or alternatively, they might represent sexual dimorphism within a single species. It is my opinion that the latter hypothesis is more probable. First, the combined sample of the two populations does not exhibit variability that could be considered outside the limits for a single species of moa, all CVs being fairly low (Table 5: femur length, 7.73; tibiotarsus length, 9.86; tarsometatarsus length, 8.91). Secondly, the two forms appear to have been broadly sympatric, both occurring together in the larger fossil deposits. To my knowledge there is no good evidence that one had a distribution exclusive of the other. If the two forms represent dimorphic sexes, then the larger form, crassus, would appear to have been the female, as an egg was found preserved in association with a skeleton of this form at Pyramid Valley (Falla, 1941). I therefore follow Scarlett (1972) in tentatively synonymizing $E$. huttonii with $E$. crassus.

\section{Subfamily DINORNITHINAE}

\section{Dinornis Owen, 1843}

Summary.-Four species of Dinornis are recognized here. The smallest, D. struthoides, was confined to the North Island. A second species, $D$. torosus, was only slightly larger than $D$. struthoides and was restricted to the South Island. A larger form, D. novaezealandiae, and the largest species of moa, D. giganteus, were both found on the North and South islands.

TABLE 6.-Posterior probability classification of stepwise discriminate function analysis for bones assigned to Emeus crassus and $E$. huttonii

\begin{tabular}{|c|c|c|c|c|}
\hline & E.crassus & E. huttonii & $n$ & $\begin{array}{c}\text { Percent } \\
\text { misclassified }\end{array}$ \\
\hline \multicolumn{5}{|l|}{ Femur } \\
\hline E. crassus & 18 & 1 & 19 & 5.3 \\
\hline E. huttonii . & $\mathbf{0}$ & 10 & 10 & $\mathbf{0}$ \\
\hline \multicolumn{5}{|l|}{ Tibiotarsus } \\
\hline . & 20 & $\mathbf{0}$ & 20 & $\mathbf{0}$ \\
\hline E. huttonii & $\mathbf{0}$ & 10 & 10 & 0 \\
\hline \multicolumn{5}{|l|}{ Tarsometatarsus } \\
\hline 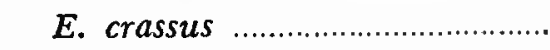 & 21 & 1 & 22 & 4.5 \\
\hline E. huttonii & 1 & 10 & 11 & 9.1 \\
\hline
\end{tabular}




\section{Dinornis struthoides Owen, 1844}

SyNonym.-Dinornis gazella Oliver, 1949.

Because of a decision by the International Commission of Zoological Nomenclature (Hemming, 1954), the name $D$. struthoides refers to all those specimens included under the name $D$. novaezealandiae in Archey (1941), Oliver (1949), and Brodkorb (1963). This species was the smallest of the genus and was found on the North Island. Oliver (1949:170) recorded two bones from the South Island which he assigned to this species, noting that some of these bones were "indistinguishable in size and proportions" from those of the North Island. Neither Archey (1941), Brodkorb (1963), nor Scarlett (1972) listed this species from the South Island and it may be that Oliver's specimens are referable to small individuals of $D$. torosus. Thus, the presence of $D$. struthoides on the South Island needs to be verified (unfortunately, I did not examine the relevant material while in New Zealand). In any case, if D. struthoides were present on the South Island, it was evidently uncommon.

Oliver (1949:166) described a new species from the North Island, D. gazella, based on a pelvis and some referred bones that are smaller than those typical of $D$. struthoides (Table 7). The size differences are slight, however, and the variation exhibited by the combined sample of struthoides and gazella is easily within the range of a single species (Table 8). I compared a series of bones (DM 108: 5 tarsometatarsi, 3 tibiotarsi from $\mathrm{Te}$ Aute) referred by Oliver to $D$. gazella with bones of $D$. struthoides and found that those of the former had thinner shafts although the two samples were nearly equal in length. The differences appear to be entirely related to age, as the bones referred to $D$. gazella are those of immature individuals. Therefore, I suggest that $D$. gazella be merged with $D$. struthoides.

\section{Dinornis torosus Hutton, 1891}

This species is only slightly larger than D. struthoides and has been considered the South Island counterpart of that species (e.g., Archey, 1941:62; Oliver, 1930). Indeed, I would be inclined to merge $D$. torosus with $D$. struthoides if it were not for some significant differences that apparently exist in cranial structure.

As I will detail in subsequent papers on evolutionary relationships and cranial morphology, $D$. torosus appears to be more advanced in cranial structure than $D$. struthoides but in certain other respects is more primitive than the two larger species $D$. novaezealandiae and $D$. giganteus. The skull of $D$. torosus differs from that of $D$. struthoides in having the basisphenoid rostrum moderately inflated, and the mandible stouter and less deflected ventrally. The most important and consistent difference seems to be in the nature of the

Table 7.-Statistics for species of Dinornis (measurements in $\mathrm{mm}$ )

\begin{tabular}{|c|c|c|c|c|c|c|c|c|}
\hline Character & $\begin{array}{c}D . \\
\text { struthoides }\end{array}$ & $\begin{array}{c}D . \\
\text { gazella }\end{array}$ & $\begin{array}{c}D . \\
\text { torosus }\end{array}$ & $\begin{array}{l}\text { D. novae- } \\
\text { zealandiae }\end{array}$ & $\begin{array}{c}D . \\
\text { robustus }\end{array}$ & $\begin{array}{c}D . \\
\text { hercules }\end{array}$ & $\begin{array}{c}\text { D. } \\
\text { maximus }\end{array}$ & $\begin{array}{c}D . \\
\text { giganteus }\end{array}$ \\
\hline \multicolumn{9}{|l|}{ Length of femur } \\
\hline n & 12 & 1 & 15 & 15 & 12 & 1 & 23 & 8 \\
\hline$\overline{\mathbf{x}}$ & 265 & 231 & 295.33 & 340.53 & 354.5 & 353 & 406.13 & 390.88 \\
\hline SD & 17.41 & - & 18.35 & 13.14 & 15.47 & - & 20.73 & 22.2 \\
\hline $\mathrm{CV} \quad \ldots \ldots \ldots \ldots \ldots \ldots \ldots$ & 6.57 & - & 6.21 & 3.86 & 4.36 & - & 5.1 & 5.68 \\
\hline \multicolumn{9}{|l|}{ Length of tibiotarsus } \\
\hline $\mathrm{n}$ & 9 & 3 & 14 & 21 & 15 & 5 & 32 & 10 \\
\hline$\overline{\mathbf{x}}$ & 520.67 & 469.67 & 588.36 & 701.67 & 718.6 & 779.8 & 866.63 & 875.2 \\
\hline SD & 29.08 & - & 36.77 & 40.87 & 22.8 & 37.99 & 46.54 & 71.57 \\
\hline $\mathrm{CV}$ & 5.59 & - & 6.25 & 5.82 & 3.17 & 4.87 & 5.37 & 8.18 \\
\hline \multicolumn{9}{|l|}{$\begin{array}{l}\text { Length of } \\
\quad \text { tarsometatarsus }\end{array}$} \\
\hline $\mathbf{n}$ & 15 & 5 & 16 & 13 & 14 & 3 & 29 & 10 \\
\hline$\overline{\mathbf{x}}$ & 282.2 & 259 & 303.13 & 368.08 & 382.64 & 420.33 & 463.41 & 486.1 \\
\hline SD $\ldots \ldots \ldots \ldots \ldots \ldots \ldots \ldots$ & 19.27 & 12.43 & 22.75 & 30.54 & 17.72 & - & 38.78 & 30.08 \\
\hline $\mathrm{CV}$ & 6.83 & 4.8 & 7.51 & 8.3 & 4.63 & - & 8.37 & 6.19 \\
\hline
\end{tabular}


Table 8.-Statistics for combined species of Dinornis (measurements in mm)

\begin{tabular}{|c|c|c|c|}
\hline Character & $\begin{array}{c}\text { D. struthoides + } \\
\text { D.gazella }\end{array}$ & $\begin{array}{c}\text { D. novaezealandiae }+ \\
\text { D. robustus }+ \\
\text { D. hercules }\end{array}$ & $\begin{array}{c}\text { D. giganteus }+ \\
\text { D. maximus }\end{array}$ \\
\hline \multicolumn{4}{|l|}{ Length of femur. } \\
\hline $\mathbf{n}$ & 13 & 28 & 31 \\
\hline$\overline{\mathbf{x}}$ & 262.38 & 346.96 & 402.19 \\
\hline SD & 19.15 & 15.38 & 21.82 \\
\hline CV & 7.3 & 4.43 & 5.42 \\
\hline \multicolumn{4}{|l|}{ Length of tibiotarsus } \\
\hline $\mathbf{n}$ & 12 & 41 & 43 \\
\hline$\overline{\mathbf{x}}$ & 507.92 & 717.39 & 866.91 \\
\hline (1) & 34.43 & 42.17 & 53.32 \\
\hline 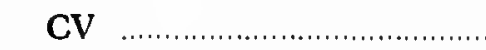 & 6.78 & 5.88 & 6.15 \\
\hline \multicolumn{4}{|l|}{ Length of tarsometatarsus } \\
\hline $\mathbf{n}$ & 20 & 30 & 39 \\
\hline 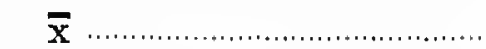 & 276.4 & 380.1 & 469.23 \\
\hline 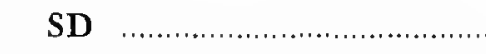 & 20.3 & 27.79 & 37.73 \\
\hline CV & 7.35 & 7.31 & 8.04 \\
\hline
\end{tabular}

basisphenoid rostrum. In $D$. giganteus, and to a lesser extent in $D$. novaezealandiae, there is a marked inflation of the basisphenoid rostrum as compared to the condition seen in $D$. torosus. Based on the comparative series I was able to examine, these differences are consistent between species.

\section{Dinornis novaezealandiae Owen, 1843}

Synonyms.-Dinornis ingens Owen, 1844; D. robustus Owen, 1846; D. hercules Oliver, 1949.

As a result of the above-mentioned decision of the International Commission of Zoological Nomenclature (Hemming, 1954), D. ingens now becomes a synonym of $D$. novaezealandiae. Consequently, the latter name belongs to those forms of Dinornis that were larger than $D$. struthoides and $D$. torosus but smaller than $D$. giganteus. Bones referred to $D$. novaezealandiae $(=D$. ingens of Archey, Oliver, and Brodkorb) are known from both the North and South islands, although they were apparently less common in the latter. I include $D$. robustus in this species because it appears to be little more than the South Island representative of $D$. novaezealandiae. Bones referred to the two species overlap considerably in length (Table 7 ), but those included under the name D. robustus are somewhat stouter than those assigned to $D$. novaezealandiae (Archey, 1941:71, Oliver, 1949: 171).
Oliver (1949:174) described an additional species, $D$. hercules, from a few limb bones from the North Island. The type tibiotarsus (DM 217) is about the same length as some tibiotarsi of $D$. novaezealandiae but has the shaft more curved; in general, bones assigned to $D$. hercules by Oliver are slightly larger than those of $D$. novaezealandiae (Table 7). Scarlett (1972:21) suggested that $D$. hercules may be a "bow-legged variant" of $D$. giganteus, but I believe most of the specimens assigned to $D$. hercules are closer to $D$. novaezealandiae in size and I here include it with that species. I was able to compare the type of $D$. hercules with other species of Dinornis and in my opinion the differences in stoutness and the curvature of the shaft of the type are attributable to individual variation.

The combined sample of bones of $D$. novaezealandiae, $D$. robustus, and $D$. hercules exhibits very little variation, all CVs being less than 7.50 (Table 8). This variability is well within that for a single species of moa.

\section{Dinornis giganteus Owen, 1844}

SyNonym.-Dinornis maximus Owen, 1867.

Dinornis giganteus is the North Island representative of the largest species of moa and $D$. maximus is its South Island form. Bones of the latter are somewhat stouter, but measurements of the two overlap greatly (Table 7). I can see little 
value in considering these minor variations to be indicative of species differences. The combined samples show a relatively small amount of variability, certainly within the limits of a single species (Table 8 ). Judging from the available collections, the North Island form was less common than the South Island form.

\section{Conclusions}

In contrast to the 20 species recognized by Archey (1941) and 29 species recognized by Oliver (1949), I here accept only 13 species as being valid. The present arrangement is actually fairly similar in parts to Archey's, but combines several North and South islands counterparts, while several "species-pairs" are regarded as examples of sexual size dimorphism. Further study may show that Anomalopteryx oweni and Megalapteryx benhami, which are based on somewhat dubious material, perhaps do not deserve recognition. Certainly the acceptance of the large number of species advocated by Oliver is untenable.

The systematic results of this paper can be summarized by the following classification:

Family Dinornithidae

Subfamily AnomalopteryginaE

Genus Anomalopteryx Reichenbach, 1852

A. didiformis (Owen, 1844)

A. oweni (Haast, 1885)

Genus Megalapteryx Haast, 1886

$M$. didinus (Owen, 1883)

M. benhami Archey, 1941
Genus Pachyornis Lydekker, 1891

P. elephantopus (Owen, 1856)

P. mappini Archey, 1941

Genus Euryapteryx Haast, 1874

E. curtus (Owen, 1846)

E. geranoides (Owen, 1848)

Genus Emeus Reichenbach, 1852

E. crassus (Owen, 1846)

Subfamily DinornithinaE

Genus Dinornis Owen, 1843

D. struthoides Owen, 1844

D. torosus Hutton, 1891

D. novaezealandiae Owen, 1843

D. giganteus Owen, 1844

The 13 species recognized here appear to have been distributed as follows:

NorTH IsLAND
Anomalopteryx didiformis
A. oweni
Pachyornis mappini
Euryapteryx geranoides
E. curtus
Emeus crassus (uncertain)
Dinornis struthoides
D. novaezealandiae
D. giganteus

South IsLAND
Anomalopteryx didiformis
Megalapteryx didinus
M. benhami
Pachyornis elephantopus
Euryapteryx geranoides

Emeus crassus

Dinornis struthoides (uncertain)

D. novaezealandiae

D. giganteus

D. torosus

It is of interest to note that the smaller and topographically less diverse North Island had fewer species than the South Island. Also, many of the North Island forms appear to have been smaller than their South Island counterparts.

\section{Literature Cited}

Archey, G.

1941. The Moa: A Study of the Dinornithiformes. Bulletin of the Auckland Institute and Museum, 1:1-145.

Blackith, R. E., and R. A. Reyment

1971. Multivariate Morphometrics. ix +412 pages. New York: Academic Press.

Brodkorb, P.

1963. Catalogue of Fossil Birds, Part 1 (Archaeopterygiformes through Ardeiformes). Bulletin of the Florida State Museum, Biological Sciences, 7(4): 177-293.

Cock, A. G.

1963. Genetical Studies on Growth and Form in the Fowl, 1: Phenotypic Variation in the Relative Growth Pattem of Shank Length and Body Weight. Genetical Research, 4:167-192.
Cracraft, J.

1973a. Continental Drift, Paleoclimatology, and the Evolution and Biogeography of Birds. Journal of Zoology, 169:455-545.

1973b. Systematics and Evolution of the Gruiformes (Class Aves), 3: Phylogeny of the Suborder Grues. Bulletin of the American Museum of Natural History, 151:1-127.

1974. Phylogeny and Evolution of the Ratite Birds. Ibis, 116:494-521.

Dixon, W. J.

1970. BMD Biomedical Computer Programs. Los Angeles: University of California Press.

Falla, R. A.

1941. The Avian Remains. Pages $339-353$ in R. S. Allan, E. Percival, R. S. Duff, and R. H. Falla, Prelimi- 
nary Report of Excavations at Pyramid Valley Swamp, Waikari, North Canterbury. Records of the Canterbury Museum, 6.

Fleming, C. A.

1962. The Extinction of Moas and Other Animals During the Holocene Period. Notornis, 10:113-117.

Goodge, W.

1951. Variation in Skeletal Measurements of the Common Murre. Condor, 53:99-100.

Haast, J. von

1885. Preliminary Notice of Paper on Dinornis oweni Haast. Proceedings of the Zoological Society of London, 1885:482.

1886. On Dinornis oweni, a New Species of the Dinornithidae, with Some Remarks on $D$. curtus. Transactions of the Zoological Society of London, 12: 171-182.

Hemming, F., editor

1954. Opinion 229: Acceptance of the Lectotype Selected by Lydekker (1891) for the Nominal Species Dinornis novaezealandiae Owen, 1843 (Class Aves.) International Commission of Zoological Nomenclature, Opinions and Declarations, 4(19):221:230.

Lambrecht, $\mathbf{K}$.

1933. Handbuch der Palaeornithologie. xix +1024 pages. Berlin: Gebrüder Bornträger.
Long, J. L.

1965. Weights, Measurements and Food of the Emu in the Northern Wheatbelt of Western Australia. Emu, 64:214-219.

Lydekker, $\mathbf{R}$.

1891. Catalogue of the Fossil Birds in the British Museum (Natural History). xxvii + 368 pages. London: British Museum (Natural History).

Oliver, W. R. B.

1930. New Zealand Birds. viii + 541 pages. Wellington: Fine Arts (N.Z.) Limited.

1949. The Moas of New Zealand and Australia. Dominion Museum Bulletin, 15:1-206.

Oxnard, C. E.

1973. Form and Pattern in Human Evolution. ix +218 pages. Chicago: University of Chicago Press.

Scarlett, R. J.

1972. Bones for the New Zealand Archaeologist. Canterbury Museum Bulletin, 4:1-69.

Simpson, G. G.

1946. Fossil Penguins. Bulletin of the American Museum of Natural History, 87:1-99.

Yaldwyn, J. C.

1956. A Preliminary Account of the Sub-fossil Avifauna of the Martinborough Caves. Records of the Dominion Museum, 3(1):1-7. 



\title{
Evidence of the Survival to Recent Times of the Extinct Flightless Duck Chendytes lawi Miller
}

\author{
G. Victor Morejohn
}

\begin{abstract}
Skeletal remains of the extinct late Pleistocene flightless diving duck, Chendytes lawi, were discovered at two northern California Indian midden sites. Carbon 14 dates of midden shell and aspartic acid racemization of the Chendytes bones showed that this species lived into the Holocene and became extinct sometime after 3780 years BP. The remains from these northern California middens and a newly discovered Pleistocene tibiotarsus from the Port Orford Formation of Oregon extend the known range of Chendytes lawi from the Channel Islands of southern California northward some 720 kilometers.
\end{abstract}

\section{Introduction}

Study of avian skeletal remains from an Indian midden on the south shore of Laguna Creek, Santa Cruz County, California, has revealed many elements which unquestionably belong to the extinct, flightless diving duck, Chendytes lawi Miller. Two bones of this species were also found in another midden on Año Nuevo Point, about $29 \mathrm{~km}$ north of the city of Santa Cruz. Previously, all certain records of Chendytes were from Pleistocene deposits. The present account documents its persistence into the Holocene and its contemporaneity with aboriginal man.

ACKNowledgments.-I wish to thank Kenneth R. Lajoie and Edward Helly of the U.S. Geological Survey for providing Carbon 14 dates and assistance in field work. Jeffery L. Bada of Scripps Institution

G. Victor Morejohn, Department of Biological Sciences, San Jose State University, San Jose, California 95192. of Oceanography kindly determined the age of bone fragments through aspartic acid racemization. Burton L. Gordon of San Francisco State University provided many bone fragments found at the Laguna Creek midden, some of which belonged to Chendytes. Hildegarde Howard assisted in the original identifications of bones and supplied useful comments on the study. Eric Anderson, Janice Cross, Howard Hutchison, Diana Matthiesen, and Bruce Welton were helpful in the field or assisted me in the museum collections.

\section{Description and Age of the Sites}

The Laguna Creek midden (State of California Archeological site designation-Santa Cruz 7, hereafter abbreviated as CA-SCr-7) is situated atop a large sand dune (Sandhill Bluff) on a marine terrace some 25 meters above sea level at latitude $36^{\circ} 58^{\prime} 30^{\prime \prime} \mathrm{N}$ and longitude $122^{\circ} 09^{\prime} 10^{\prime \prime} \mathrm{W}$, approximately $12 \mathrm{~km}$ north of Santa Cruz, Santa Cruz County, California, and about 230 meters west of U.S. Highway No. 1. The dune occupies an area of about $915 \mathrm{~m}^{2}$, with the midden capping the highest part and occupying an area of about $120 \mathrm{~m}^{2}$. The windswept seaward side of the midden is greatly eroded, in places to a depth such that the underlying dune substrate is visable. Most of the bones were collected from this exposed face. Bones of Chendytes lawi were found from $15 \mathrm{~cm}$ below the surface to the basal layer of the midden, and several others were found scattered on the surface of the dune below the exposed face.

Most of the midden consists of broken mollusk and barnacle shells tightly packed to a depth varying between 1.5 and $1.75 \mathrm{~m}$. Early reports (Stearns, 1873-1874:157) indicate that this midden was 
originally some $6.5 \mathrm{~m}$ high, but recent local use for shell to feed poultry has greatly reduced the size of the midden and removed the younger upper layers. Samples of mollusk and barnacle shells from the upper and lower midden levels were used for Carbon 14 dating. The uppermost layer was aged at $3780 \pm 95$ years $\mathrm{BP}$ and the basal layer was aged at $5390 \pm 100$ years BP. Two bones of Chendytes from the basal layer were determined by aspartic acid racemization (Bada, et al., 1974) to be approximately 6000 years old, which corresponds closely with the Carbon 14 dates of other material from the same layer. Fragments of a human femur and an incomplete skull lacking the rostrum and lower jaw were also found in the basal layer, but the aspartic acid age of these fragments was approximately 4000 years BP, obviously indicating secondary introduction through burial. The above datings establish CA-SCr-7 as the oldest known site of Indian occupation on the central California coast (M. J. Moratto, in litt., 19 December 1974). The Indian midden on Año Nuevo Point, San Mateo County, California, has not been studied. Archeologists have estimated its age at about 2500 years BP, but it is probably older. Persistent seasonal winds expose part of the midden or cover it with sand. Only a few vertebrate fragments have so far been collected.

The following bones of Chendytes were recovered from the Laguna Creek and Año Nuevo middens: humeri, 1 left, 2 right proximal ends; femora, 8 left, 7 right nearly complete, 4 left, 5 right incomplete; tibiotarsi, 1 left, 5 right proximal ends, 3 left, 3 right distal ends, 10 partial shafts; tarsometatarsus, 1 left incomplete; synsacrum, 1 incomplete; cervical vertebra, 1 incomplete.

\section{Discussion}

Because comparisons were initially made with reference specimens of living taxa, the elements of Chendytes collected at CA-SCr-7 at first proved impossible to identify. Later, while studying anseriform fossils with Dr. Hildegarde Howard at the Natural History Museum of Los Angeles County, I examined specimens of Chendytes that I then recognized as being similar to the unidentified bones from CA-SCr-7. In size (Table 1) and morphology, the midden bones were found to conform with those previously described for Chendytes
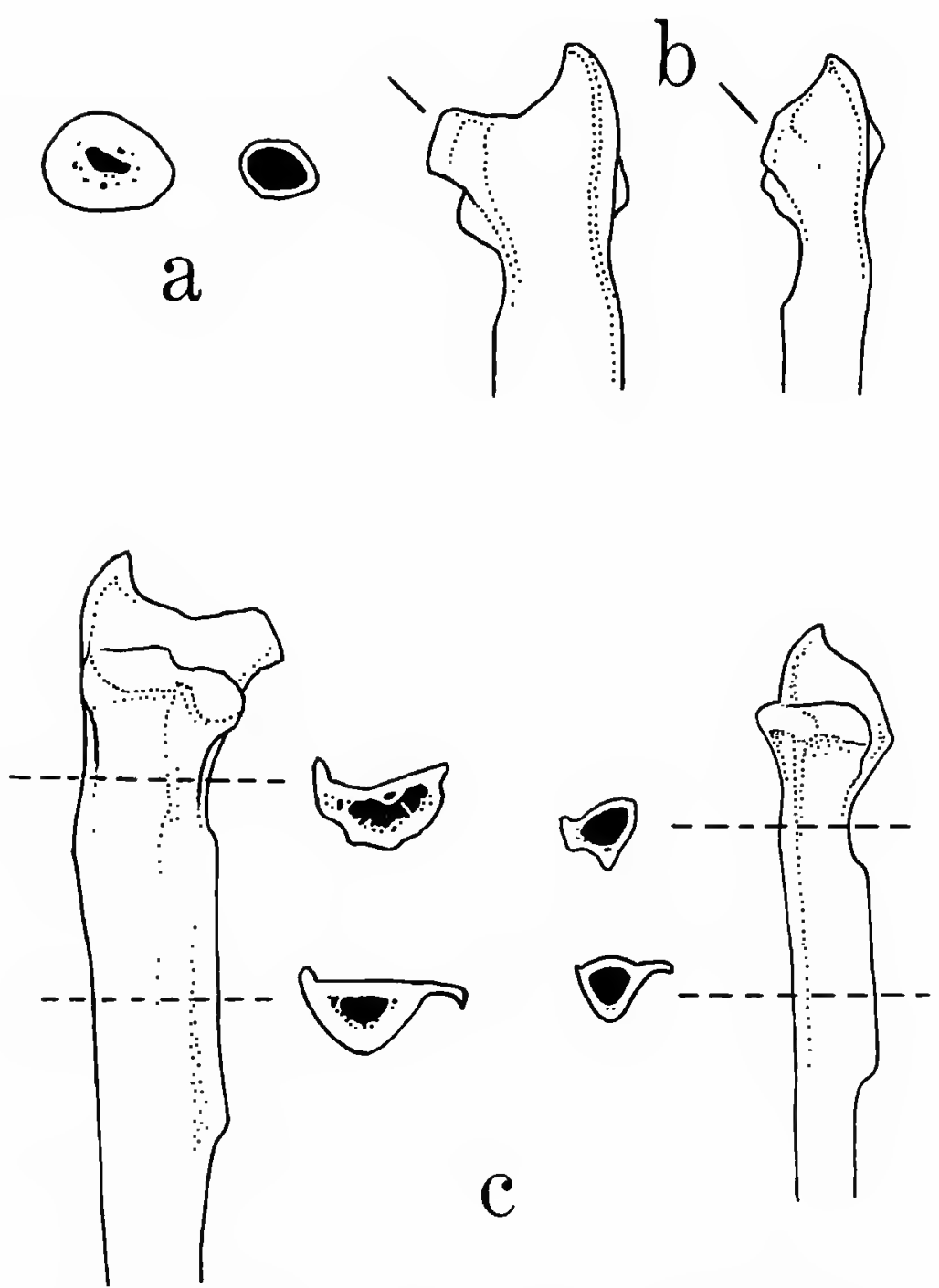

Ficure 1.-Comparisons of femora and tibiotarsi of Chendytes lawi (on the left in each pair) and Melanitta fusca: a, crosssection of femora at midshaft showing cancellous nature of bone and heavy compact peripheral layer present in the flightless $C$. lawi; $b$, anterior view of proximal end of tibiotarsus contrasting the development of the outer cnemial crest; $c$, posterior views of proximal ends of tibiotarsi with cross-sections proximal to and through the fibular crest.

lawi by Miller (1925; 1930), Miller, et al. (1961), and Howard $(1947,1949,1955)$. I later noted several characteristics of the tibiotarsi and femora that had not previously been considered by these authors.

Miller (1925) first recognized the affinities of Chendytes with the diving ducks, particularly the scoters. Compared to Melanitta fusca, the largest of the scoters, I found great reduction in the marrow cavities of the tibiotarsi and femora, with a concomitant increase in the thickness of the peripheral compact bone in $C$. lawi (Figure 1a). In fact, certain cross-sections of the femora of Chendytes bear a similarity to those of mammalian 
femora. The density of the bone in Chendytes is probably an adaptation for diving. Cross-sections of the tibiotarsus proximal to the fibular crest show $M$. fusca to have a pronounced posterior ridge, whereas in Chendytes this ridge is low and rounded (Figure 1c). Cross sections through the fibular crest show $M$. fusca and Chendytes to have a flattened anterior and a ridged posterior surface, but in Chendytes the inner cnemial crest extends distally to about the middle of the fibular crest and angles anteriorly (Figure $1 b$ ). The outer cnemial crest in anterior view is also markedly different in the two species (Figure $1 d$ ).

Howard (1955) reported a total of 156 fossil skeletal remains of Chendytes (C. lawi, 89; C. milleri, 67) from eleven localities in southern California. Since then, another 130 specimens have been recovered from Anacapa Island (Howard, 1964). While most of the bones were clearly from Pleistocene localities, fifteen were reportedly collected from two Indian middens (one at Malaga Cove in the Palos Verdes area of Los Angeles County, the other on San Nicolas Island). However, these bones are well mineralized, unlike those

TABLE 1.-Comparison of measurements (mm) of bones of Chendytes lawi from northern and southern California localities

\begin{tabular}{|c|c|c|c|c|}
\hline \multirow[t]{2}{*}{ Character } & \multicolumn{3}{|c|}{$\begin{array}{l}\text { Northern } \\
\text { California }\end{array}$} & \multirow{2}{*}{$\begin{array}{c}\text { Southern } \\
\text { California* } \\
\text { range }\end{array}$} \\
\hline & $n$ & mean & range & \\
\hline \multicolumn{5}{|l|}{ Humerus } \\
\hline \multicolumn{5}{|l|}{$\begin{array}{l}\text { Breadth of proximal } \\
\text { end from external } \\
\text { to internal } \\
\text { tuberosity }\end{array}$} \\
\hline $\begin{array}{l}\text { Breadth of shaft } \\
\text { below external } \\
\text { tuberosity }\end{array}$ & 3 & 4.3 & $4-4.5$ & 4.8 \\
\hline \multicolumn{5}{|l|}{ FEMUR } \\
\hline Length & 5 & 73.2 & $69.6-77.5$ & $65.7-76.4$ \\
\hline $\begin{array}{l}\text { Breadth of proximal } \\
\text { end }\end{array}$ & 9 & 16.1 & $15.2-17.8$ & $14-17$ \\
\hline $\begin{array}{l}\text { Breadth of distal end } \\
\text { Tibiotarsus }\end{array}$ & 6 & 19 & $17.7-20.4$ & $16.3-18.2$ \\
\hline $\begin{array}{c}\text { Breadth of proximal } \\
\text { end }\end{array}$ & 3 & 15 & $14.4-15.7$ & $14.8-15.5$ \\
\hline Breadth of distal end & 3 & 13.7 & $13.3-14.5$ & $13.3-14.5$ \\
\hline
\end{tabular}

* From Howard, 1955. typically found in middens, and they were considered by Howard (1955) to have been secondarily associated with the Indian midden material. In contrast, bones of $C$. lawi from the Laguna Creek and Año Nuevo Point Indian middens in northern California were not mineralized.

Although bones of a variety of birds have been recovered from other Indian middens along the California coast (Howard, 1929; Howard and Dodson, 1933; and D. M. Howard and Cook, 1971) and demonstrate that a number of avian species were eaten by Indians (Table 2), no other elements of Chendytes have thus far been found. Howard (1929), for lack of comparative anseriform skeletal material, chose not to attempt identification of waterfowl in her study of the avian remains from the Emeryville shellmound. I recently reexamined the anseriform material from this site in an attempt to find elements of Chendytes, but met with no success.

The Emeryville site was estimated to be no younger than $2310 \pm$ years (Hubbs, et al., 1962). Chendytes may have been extinct by this time, or its absence from the Emeryville site may have been due to the lack of appropriate habitat. The site is located on an alluvial plane (Howard, 1929) with-

TABLE 2.--Relative abundance of avian species found associated with remains of Chendytes lawi at the Laguna Creek Indian midden

\begin{tabular}{lc}
\hline \multicolumn{1}{c}{ Species } & Number of specimens \\
\hline Gavia stellata & 1 \\
Puffinus griseus & 6 \\
Fulmarus glacialis & 2 \\
Unidentified albatross & 23 \\
Diomedea albatrus & 10 \\
Unidentified cormorant & 2 \\
Phalacrocorax penicillatus & 3 \\
Phalacrocorax pelagicus & 1 \\
Unidentified anseriform & 12 \\
Unidentified duck & 6 \\
Melanitta fusca & 2 \\
Chendytes lawi & 46 \\
Unidentified falconiform & 1 \\
Buteo jamaicensis & 1 \\
Unidentified galliform & 1 \\
Unidentified charadriiform & 1 \\
Uria aalge & 29 \\
Cepphus columba & 6 \\
Ptychoramphus aleutica & 1 \\
Unidentified gull & 26 \\
Unidentified bird & 99 \\
\hline &
\end{tabular}


out nearby reefs or rocky shorelines such as were probably required by Chendytes (Miller, et al., 1961). The elements of Chendytes lawi from CASCr-7, which may be at least as young as 3780 years, provide the latest known occurrence of the genus. At some time after deposition of these bones, perhaps 2500 to 3000 years ago, Chendytes became extinct.

The known fossil localities of $C$. lawi are concentrated in southern California and the range of the species was formerly considered by Miller, et al. (1961:10) to be "south of Point Conception, from Ventura County to Orange County." Although the material from CA-SCr-7 extends this range some $320 \mathrm{~km}$ farther northward, a hitherto unreported, nearly complete, fossilized tibiotarsus of C. lawi (University of California Museum of Paleontology No. 112026) collected by David Taylor from the lower Pleistocene Port Orford Formation in Curry County, Oregon, near Cape Blanco (UCMP vertebrate locality V-74042) extends the range of this species some $720 \mathrm{~km}$ north of the southern California sites (Figure 2).

Evolution of flightlessness in smaller birds is usually associated with insular distribution (Olson, 1973:31-36). Being flightless, the breeding sites of Chendytes almost certainly had to be restricted to offshore islands, and it may be assumed that the Channel Islands were of particular importance in this regard. There is no geological evidence of former islands in the immediate vicinity of the Laguna Creek area. Therefore, C. lawi was probably present in this area as a nonbreeding migrant.

The frequency of occurrence of bones of Chendytes lawi at CA-SCr-7 may indicate selective predation by Indians there. The bird was flightless, was no doubt relatively easy to capture, and had large goose-sized legs which would have made it a preferred food item. The preponderance of leg bones at CA-SCr-7 supports this contention. Prob-

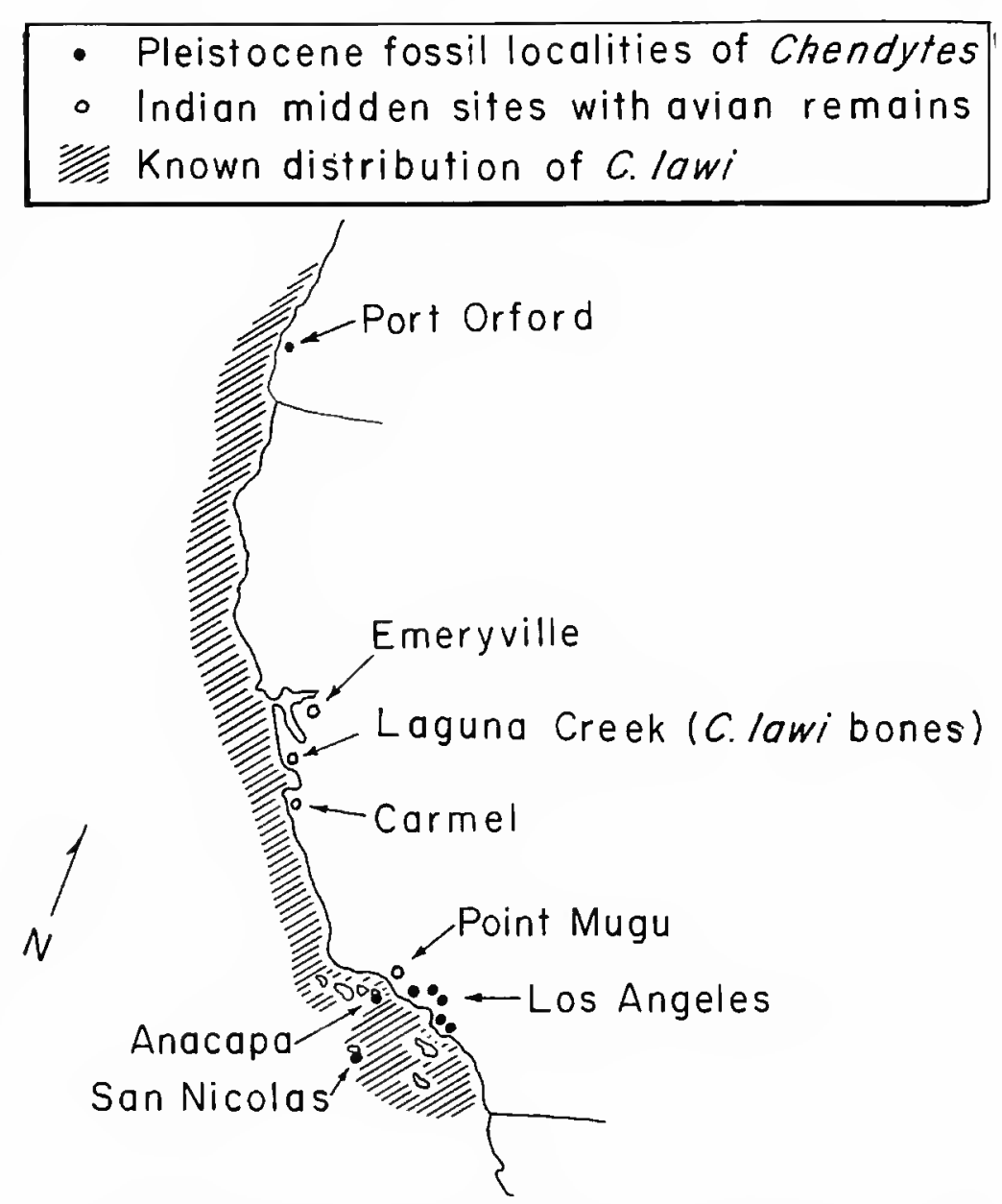

Figure 2.-The known distribution of Chendytes along the Pacific coast of California and southern Oregon.

ably for the preceding reasons, the remains of $C$. lawi were more abundant in this midden than any other species of bird (Table 2). The birds probably were caught in the surf zone, rather than on land, inasmuch as the California Indians were known to have captured waterfowl with nets (Heizer, 1974). The extinction of $C$. lawi prior to the deposition of the other coastal middens thus far studied in California may account for its absence in them. Overharvest by aboriginal man was probably the principal factor contributing to the extinction of this species.

\section{Literature Cited}

Bada, J. L., R. A. Schroeder, and G. F. Carter

1974. New Evidence for the Antiquity of Man in North America Deduced from Aspartic Acid Racemization. Science, 184(4138):791-793, 2 tables.

Heizer, R. F., editor

1974. The Costonoan Indians. Local History Studies, 18: 1-115, 23 figurcs. Cupertino, California: California History Center, De Anza College.
Howard, D. M., and S. F. Cook

1971. The Archeology of the Hudson Mound. Monterey County Archeological Society Quarterly, 1:1-11, 7 figures.

Howard, $\mathrm{H}$.

1929. The Avifauna of Emeryville Shellmound. University of California Publications in Zoology, 32(2): 301-394, 4 plates, 55 figures. 
1947. Wing Elements Assigned to Chendytes. Condor, 49(3):76-77, 1 figure, 1 table.

1949. Avian Fossils from the Marine Pleistocene of Southern California. Condor, 51(1):20-28.

1955. New Records and a New Species of Chendytes, an Extinct Genus of Diving Geese. Condor, 57(5):135143, 3 figures, 2 tables.

1964. Further Discoveries Concerning the Flightless "Diving Geese" of the Genus Chendytes. Condor, 66(9): 372-376.

Howard, H., and L. M. Dodson

1933. Birds Remains from an Indian Shellmound near Point Mugu, California. Condor, 35(11):235.

Hubbs, C. L., G. S. Bren, and H. E. Suess

1962. La Jolla Natural Radiocarbon Measurements II. Radiocarbon, 4:208.

Miller, L.
1925. Chendytes, a Diving Goose from the California Pleistocene. Condor, 27(7):145-149, 1 figure.

1930. Further Bird Remains from the Upper San Pedro Pleistocene. Condor, 32(3):116-118, 1 figure.

Miller, L., E. D. Mitchell, and J. H. Lipps

1961. New Light on the Flightless Goose Chendytes lawi. Los Angeles County Museum Contributions in Science, 43:3-11, 2 plates.

Olson, S. L.

1973. Evolution of the Rails of the South Atlantic Islands (Aves: Rallidae). Sinithsonian Contributions to Zoology, 152:1-53, 8 figures, 11 plates, 4 tables, 2 appendices.

Stearns, R. E. C.

1873-1874. Remarks on the Upper Tuolumne Cañon. Proceedings of the California Academy of Sciences, first series, 5:155-158. 





\section{Publication in Smithsonian Contributions to Paleobiology}

Manuscripts for serial publications are accepted by the Smithsonian Institution Press, subject to substantive review, only through departments of the various Smithsonian museums. Non-Smithsonian authors should address inquiries to the appropriate department. If submission is invited, the following format requirements of the Press will govern the preparation of copy.

Copy must be typewritten, double-spaced, on one side of standard white bond paper, with $11 / 2$ " top and left margin, submitted in ribbon copy with a carbon or duplicate, and accompanied by the original artwork. Duplicate copies of all material, including illustrations, should be retained by the author. There may be several paragraphs to a page, but each page should begin with a new paragraph. Number consecutively all pages, including title page, abstract, text, literature cited, legends, and tables. The minimum length is 30 pages, including typescript and illustrations.

The titls should be complete and clear for easy indexing by abstracting services. Taxonomic titles will carry a final line indicating the higher categories to which the taxon is referable: "(Ammonoidea: Goniatitidae)." Include an abstract as an introductory part of the text. Identify the author on the first page of text with an unnumbered footnote that includes his professional mailing address. A table of contents is optional. An index, if required, may be supplied by the author when he returns page proof.

Two headings are used: (1) text heads (boldface in print) for major sections and chapters and (2) paragraph sideheads (caps and small caps in print) for subdivisions. Further headings may be worked out with the editor.

In taxonomic keys, number only the first item of each couplet; if there is only one couplet, omit the number. For easy reference, number also the taxa and their corresponding headings throughout the text; do not incorporate page references in the key.

In synonymy, use the short form (taxon, author, date:page) with a full reference at the end of the paper under "Literature Cited." Begin each taxon at the left margin with subsequent lines indented about three spaces. Within an entry, use a period-dash (.-) to separate each reference. Enclose with square brackets any annotation in, or at the end of, the entry. For references within the text, use the author-date system: "(Jones, 1910)" and "Jones (1910)." If the reference is expanded, abbreviate the data: "Jones (1910:122, pl. 20: fig. 1)."

Simple tabulations in the text (e.g., columns of data) may carry headings or not, but they should not contain rules. Formal tables must be submitted as pages separate from the text, and each table, no matter how large, should be pasted up as a single sheet of copy.

Use the metric system instead of, or in addition to, the English system.

Illustrations (line drawings, maps, photographs, shaded drawings) can be intermixed throughout the printed text. They will be termed Figures and should be numbered consecutively; however, if a group of figures is treated as a single figure, the components should be indicated by lowercase italic letters on the illustration, in the legend, and in text references: "Figure $9 b$." If illustrations (usually tone photographs) are printed separately from the text as full pages on a different stock of paper, they will be termed Plates, and individual components should be lettered (Plate $9 b$ ) but may be numbered (Plate 9: figure 2). Never combine the numbering system of text illustrations with that of plate illustrations. Submit all legends on pages separate from the text and not attached to the artwork. An instruction booklet for the preparation of illustrations is available from the Press on request.

In the bibliography (usually called "Literature Cited"), spell out book, journal, and article titles, using initial caps with all words except minor terms such as "and, of, the." For capitalization of titles in foreign languages, follow the national practice of each language. Underscore (for italics) book and journal titles. Use the colon-parentheses system for volume, number, and page citations: "10(2):5-9." Spell out such words as "figures," "plates," "pages."

For free copies of his own paper, a Smithsonian author should indicate his requirements on "Form 36" (submitted to the Press with the manuscript). A non-Smithsonian author will receive 50 free copies; order forms for quantities above this amount with instructions for payment will be supplied when page proof is forwarded. 


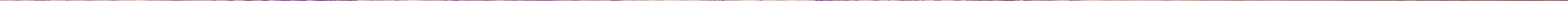

